\title{
Synthesis and Characterization of Pyridine Dipyrrolide Iron Complexes Relevant to Nitrene and Carbene Group Transfer
}

\author{
Brett M. Hakey \\ West Virginia University, bmhakey@mix.wvu.edu
}

Follow this and additional works at: https://researchrepository.wvu.edu/etd

Part of the Inorganic Chemistry Commons

\section{Recommended Citation}

Hakey, Brett M., "Synthesis and Characterization of Pyridine Dipyrrolide Iron Complexes Relevant to Nitrene and Carbene Group Transfer" (2020). Graduate Theses, Dissertations, and Problem Reports. 7939. https://researchrepository.wvu.edu/etd/7939

This Dissertation is protected by copyright and/or related rights. It has been brought to you by the The Research Repository @ WVU with permission from the rights-holder(s). You are free to use this Dissertation in any way that is permitted by the copyright and related rights legislation that applies to your use. For other uses you must obtain permission from the rights-holder(s) directly, unless additional rights are indicated by a Creative Commons license in the record and/ or on the work itself. This Dissertation has been accepted for inclusion in WVU Graduate Theses, Dissertations, and Problem Reports collection by an authorized administrator of The Research Repository @ WVU.

For more information, please contact researchrepository@mail.wvu.edu. 
Brett M. Hakey

\author{
Dissertation submitted to the Eberly College of Arts and Sciences \\ at West Virginia University \\ In Partial Fulfillment of the Requirements for the Degree of \\ Doctor of Philosophy in \\ Chemistry
}

\author{
Carsten Milsmann, PhD, Chair \\ Jeffrey Petersen, PhD \\ Brian Popp, $\mathrm{PhD}$ \\ Brian Dolinar, $\mathrm{PhD}$ \\ Mikel Holcomb, PhD
}

Department of Chemistry

Morgantown, West Virginia

2020

Keywords: Iron, nitrene, carbene, dipyrrolide, group transfer, electronic structure Copyright @ 2020 Brett M. Hakey 


\begin{abstract}
SYNTHESIS AND CHARACTERIZATION OF PYRIDINE DIPYRROLIDE IRON COMPLEXES RELEVANT TO NITRENE AND CARBENE GROUP TRANSFER
\end{abstract}

\author{
Brett M. Hakey
}

The synthesis and electronic structures of the square-planar high-spin $\mathrm{Fe}^{\mathrm{II}}$ complexes $\left({ }^{\mathrm{Mes}} \mathrm{PDP}^{\mathrm{Ph}}\right) \mathrm{Fe}\left(\mathrm{OEt}_{2}\right)$ and $\left({ }^{\mathrm{Mes}} \mathrm{PDP}^{\mathrm{Ph}}\right) \mathrm{Fe}(\mathrm{thf})$ were investigated. Analysis of these compounds using a combination of ${ }^{1} \mathrm{H}$ NMR and ${ }^{57} \mathrm{Fe}$ Mössbauer spectroscopies, in conjunction with computational analysis, has resulted in a rationalization for their unusual electronic structures, which arise from the unique coordination environment enforced by the pyridine dipyrrolide chelate ligand.

The reactivity of $\left({ }^{\mathrm{Mes}} \mathrm{PDP}^{\mathrm{Ph}}\right) \mathrm{Fe}(\mathrm{thf})$ with organic azides has been probed and resulted in the isolation of an array of products that are consistent with the generation of reactive iron nitrene intermediates. Computational analysis has evidenced that the suspected iron nitrene species are intermediate-spin ferric ions engaged in antiferromagnetic coupling to iminyl radical ligands. Increasing the steric bulk of the nitrene source via the use of mesityl azide allowed for the spectroscopic observation of $\left({ }^{\mathrm{Mes}} \mathrm{PDP}{ }^{\mathrm{Ph}}\right) \mathrm{Fe}(\mathrm{NMes})$, which has been identified as a competent intermediate in nitrene transfer to a $\mathrm{C}-\mathrm{H}$ bond of the pyridine dipyrrolide supporting ligand. In attempts to sequester intraligand $\mathrm{C}-\mathrm{H}$ amination and leverage intermolecular reactivity, the new high-spin ferrous species $\left({ }^{2,6-\mathrm{Cl} 2 \mathrm{Ph}} \mathrm{PDP}^{\mathrm{Ph}}\right) \mathrm{Fe}(\mathrm{thf})$ has been synthesized. $\left({ }^{2,6-\mathrm{Cl} 2 \mathrm{Ph}} \mathrm{PDP}{ }^{\mathrm{Ph}}\right) \mathrm{Fe}(\mathrm{thf})$ is also capable of generating nitrene adducts, as demonstrated by the isolation of diamagnetic $\left({ }^{2,6-\mathrm{Cl} 2 \mathrm{Ph} P D P}{ }^{\mathrm{Ph}}\right) \mathrm{Fe}\left(\mathrm{N}^{1} \mathrm{Ad}\right)$ and paramagnetic $\left({ }^{2,6-\mathrm{Cl} 2 \mathrm{Ph}} \mathrm{PDP}{ }^{\mathrm{Ph}}\right) \mathrm{Fe}(\mathrm{NMes})$ from its reaction with 1adamantyl azide and mesityl azide, respectively. It is anticipated that these results will provide a foundation for future investigations of the efficacy of pyridine dipyrrolide iron complexes in nitrene group transfer reactions, which may find application in the construction of new carbonnitrogen bonds from hydrocarbon substrates.

The reaction of $\left({ }^{\mathrm{Mes}} \mathrm{PDP}{ }^{\mathrm{Ph}}\right) \mathrm{Fe}(\mathrm{thf})$ with diphenyldiazomethane has resulted in the isolation of an unprecedented paramagnetic square-planar iron carbene complex, $\left({ }^{\mathrm{Mes}} \mathrm{PDP}{ }^{\mathrm{Ph}}\right) \mathrm{Fe}\left(\mathrm{CPh}_{2}\right)$. Physical characterization and computational analysis of $\left({ }^{\mathrm{Mes}} \mathrm{PDP} \mathrm{Ph}^{\mathrm{P}}\right) \mathrm{Fe}\left(\mathrm{CPh}_{2}\right)$ suggests an $\mathrm{S}=1$ ground state for the compound and an electronic structure which may be described as an intermediate-spin $\mathrm{Fe}^{\mathrm{III}}$ ion engaged in antiferromagnetic coupling with a carbene radical ligand. The reactivity of $\left({ }^{\mathrm{Mes}} \mathrm{PDP}^{\mathrm{Ph}}\right) \mathrm{Fe}\left(\mathrm{CPh}_{2}\right)$ with $\mathrm{CO}$ and isocyanides was explored and yielded the low-spin $\mathrm{Fe}^{\mathrm{II}}$ carbene group transfer products $\left(\mathrm{CPh}_{2}{ }^{\mathrm{Mes}} \mathrm{PDP}{ }^{\mathrm{Ph}}\right) \mathrm{Fe}(\mathrm{CO})_{2}$ and $\left(\mathrm{CPh}_{2}{ }^{\mathrm{Mes}} \mathrm{PDP}{ }^{\mathrm{Ph}}\right) \mathrm{Fe}\left(\mathrm{C} \equiv \mathrm{N}-2,6-\left(\mathrm{CH}_{3}\right)_{2} \mathrm{Ph}\right)_{2}$, arising from carbene insertion into an iron pyrrolide nitrogen bond. 


\section{BIOGRAPHICAL SKETCH}

Brett Michael Hakey, the first of Michael Hakey and Betsy Isham's four children, was born on July $2^{\text {nd }}, 1993$, in Burlington, Vermont, on the shores of Lake Champlain. Owing to the great fortune of having a large extended family in Northeast Vermont, he grew up in the warm company of numerous family members, many with repute as talented athletes, educators, and scientists, alike. He attended grade schools in Georgia, and Milton, Vermont. In 2007, Brett moved to neighboring Fairfax, a quiet farm town nestled in the shadows of Mount Mansfield and the surrounding Green Mountains. There, he attended high-school at Bellows Free Academy.

During this time, Brett, and his younger siblings, Thomas, Jake, and Meghan, had the wonderful experience of living with their paternal grandparents, Mark and Louise Hakey. In 2011, after high-school graduation, Brett leapt at an opportunity to try his hand at college baseball, and headed south to West Virginia. Although baseball didn't quite work out, he studied chemistry while at West Virginia Wesleyan College. There, under the tutelage of Dr. Joanna Webb, he became interested in the application of late $3 \mathrm{~d}$ transition metals in catalysis, and performed undergraduate research, with a focus on synthesizing cobalt pincer ligand complexes. Upon receiving his undergraduate degree in 2015 , he took a graduate research position at West Virginia University, in the laboratory of newly minted Assistant Professor Carsten Milsmann. During his time in Morgantown, Brett had the great pleasure of exploring the synthesis, reactivity, and electronic structures of pyridine dipyrrolide iron compounds. 
This dissertation is dedicated in loving memory of:

Charles, Doris, and Louise Hakey 


\section{ACKNOWLEDGEMENTS}

I'd like to thank the many colleagues, friends, and family members that have offered me support in advance of and during my time at West Virginia University. Foremost, I would like to extend the sincerest of thanks to Professor Carsten Milsmann for offering me the opportunity to pursue graduate study in his laboratory. Interacting with Carsten over the past few years has not only inspired me to challenge myself intellectually, but has also undoubtedly furthered my development as a critical thinker and thorough scientist. I consider myself very fortunate to have him as a mentor.

I would also like to express my thanks to Dr. Jeffrey Petersen, Dr. Brian Popp, Dr. Brian Dolinar, and Dr. Mikel Holcomb for willingly serving on my committee. I was fortunate enough to have had courses with Dr. Petersen and Dr. Popp, both of whom have offered complementary insight into the world of organometallic chemistry. Notably, Dr. Petersen has tirelessly offered his expertise and time in the analysis of innumerable X-ray crystallographic studies, a number of which are presented in this dissertation. I'm glad to have had shared an admiration for college basketball with him, as our discussions of Bob Huggins and his WVU teams helped pass many hours screening samples on the diffractometer in the always chilly X-ray lab. Additionally, I thank Dr. Petersen for his patience with me as a student. There were times during his courses where I did not meet expectations. However, despite my occasional faltering, Dr. P was always supportive and didn't give up on me. For this, I am incredibly grateful. Dr. Brian Dolinar has also offered gracious assistance in a number of recent X-ray crystallographic analyses that are described in this work, for which I am very thankful.

Countless thanks are extended to Dr. Jonathan Darmon. From afar, Jon has been the hero of my Ph.D., having undertaken the characterization of dozens of compounds via ${ }^{57} \mathrm{Fe}$ Mössbauer 
spectroscopy in support of my interest in understanding the electronic structures of the compounds I've synthesized. Without Jon's generous assistance and expertise, this work would not have been possible. With that being said, thanks are also extended to his supervisor, Professor Paul Chirik, who has graciously allowed access to his group's Mössbauer spectrometer.

Thanks are also due to Professor John Berry and Dr. Caleb Harris who have acquired SQUID magnetometry data on compounds presented in this dissertation. Professor Yisong "Alex" Guo and Dr. Jin Xiong at Carnegie Mellon University are also thanked for their interest in our iron chemistry and the acquisition of the applied-field Mössbauer data presented herein. Dr. Novruz Akhmedov is also acknowledged for the endless help that he has offered in aiding the understanding of the solution phase structures of many compounds. I'm very fortunate to have collaborated with Novruz, as his expertise and assistance in NMR characterization has been invaluable.

Thanks are also extended to the WVU Chemistry staff, Allen Burns, Randy Eaglen, Gregory Lusk, and Sherman Adams. I would especially like to thank Sherman for being a great friend during my time at WVU. Many hours were spent with him in his glassblowing shop hearing about his life experiences and discussing all things under the sun, with college football and politics being topics of special foci. I wish him the best in his retirement. I would also like to offer my thanks to Rebecca Secrist and Brenda Prentiss, who were always warm and supportive when logistical or administrative assistance was needed. Albert "JR" Taylor and Crys Povenski are also acknowledged, as they were not only patient and supportive supervisors during my time as a teaching assistant, but were also always willing to find time in their busy schedules to assist me in sending samples to our numerous collaborators. 
To my friends in the Milsmann Group: Minh Do, Jordan Martinez, Dylan Leary, Jose Rodriguez, Nick Vaughan, and most importantly, our honorary group member, and my dearest friend, Notashia Baughman, thank you! What great teammates you are. I'll always look fondly upon memories of our times together on the fourth floor of CRL. And Notashia, our times on the third floor of Christopher Hall at Wesleyan as well!

Lastly, I'd like to thank my entire family for their unwavering support. The love and encouragement I've received from my parents, Michael and Betsy, has been integral in the realization of my educational journey. My siblings, Thomas, Jake, Meghan, Isabella, and Oliver, have offered me constant inspiration through their own personal accomplishments. My grandparents, Mark and Louise, have also played a significant role in encouraging my education. Particularly, over the past few years, even more so than ever, "Grandpa Mark" and "Grandma Lou" have been a constant source of strength. Despite being faced with the grave reality of terminal illness, my grandmother offered the daily reminder that determination is key in any and all endeavors. I'm very grateful for the relationship that we developed, and the completion of this dissertation is in many ways possible because of her. I'd also like to acknowledge my aunts and uncles, most notably, my Aunt Joyce, as well as my Aunt Holly, and Uncle Patrick. Joyce, a prolific educator, has famously reminded me, and many others in Franklin County, Vermont that every day we go to "school not work". I have relied on this positive perspective countless times as a reminder that education isn't a burden, but in fact a great opportunity! Patrick and Holly have both been great role models and have demonstrated to my siblings and I that a chemistry degree can really take you anywhere in the world. I appreciate all of their generosity and encouragement. 
Finally, I'd like to thank my great-grandparents, Charles and Doris. Gram and Gramp were there from the start for all of us Hakeys. I'm so proud to be a part of the amazing family that they've built! 


\section{TABLE OF CONTENTS}

Biographical Sketch iii

Dedication iv

Acknowledgements $\mathrm{V}$

Table of Contents ix

List of Figures xiv

List of Tables xxiv

List of Schemes xxvii

List of Chemical Abbreviations $\mathrm{XxX}$

List of Acronyms, Symbols, and Units $\mathrm{xxxi}$

Chapter I: IRON: THE NATURAL CHOICE FOR GROUP TRANSFER CHEMISTRY

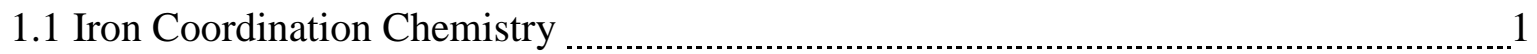

1.2 Biomimetic Iron Chemistry: Atom and Group Transfer Reactivity .............................. 5

1.3 Rhodium and Ruthenium Catalyzed Nitrene Group Transfer

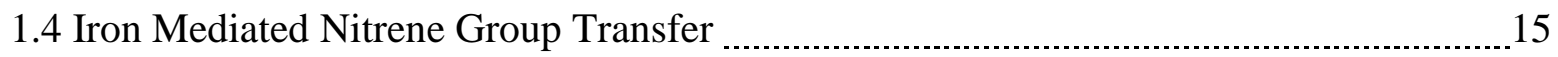

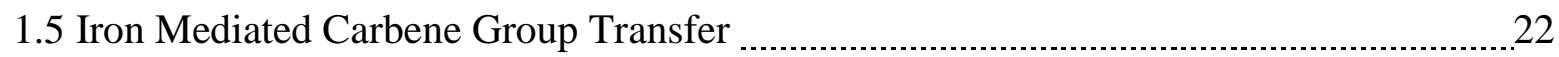

References

Chapter II: SYNTHESIS AND ELECTRONIC STRUCTURE OF SQUARE-PLANAR

HIGH-SPIN IRON(II) PYRIDINE DIPYRROLIDE COMPLEXES

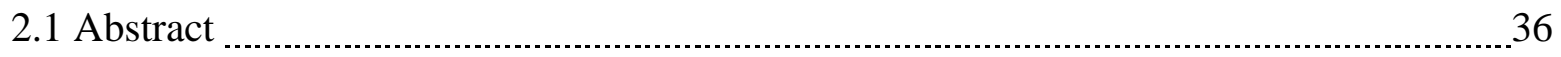

2.2 Introduction $\ldots$

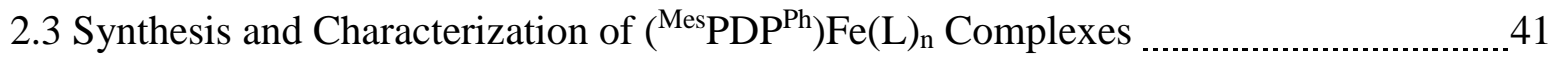


2.5 Experimental Procedures

References

CHAPTER III: REACTIVITY OF HIGH-SPIN IRON(II) PYRIDINE DIPYRROLIDE COMPLEXES WITH ORGANIC AZIDES

3.1 Abstract 93

3.2 Introduction 94

3.3 Reactivity of $\left({ }^{\mathrm{Mes}} \mathrm{PDP}{ }^{\mathrm{Ph}}\right) \mathrm{Fe}(\mathrm{L})\left(\mathrm{L}=\mathrm{Et}_{2} \mathrm{O}\right.$ or thf) with 1-Adamantyl Azide 97

3.4 Reactivity with the Aromatic Azide Paratolyl Azide 104

3.5 Reactivity of $\left({ }^{\mathrm{Mes}} \mathrm{PDP}{ }^{\mathrm{Ph}}\right) \mathrm{Fe}(\mathrm{L})\left(\mathrm{L}=\right.$ thf or $\left.\mathrm{Et}_{2} \mathrm{O}\right)$ with Benzyl Azide 115

3.6 Reactivity of $\left({ }^{\mathrm{Mes}} \mathrm{PDP}{ }^{\mathrm{Ph}}\right) \mathrm{Fe}(\mathrm{thf})$ with Mesityl Azide

3.7 Reactivity of $\left({ }^{\mathrm{Mes}} \mathrm{PDP}{ }^{\mathrm{Ph}}\right) \mathrm{Fe}($ thf $)$ with 4-Azido-4-methylpentylbenzene

3.8 Calculations of Putative $\left({ }^{\mathrm{Mes}} \mathrm{PDP} \mathrm{Ph}^{\mathrm{Ph}} \mathrm{Fe}(\mathrm{NR})\right.$ Intermediates

3.9 Conclusion 141

3.10 Experimental Procedures

References 153

Chapter IV: SYNTHESIS AND CHARACTERIZATION OF HIGH-SPIN IRON(II) COMPLEXES OF VARIOUS PYRIDINE DIPYRROLIDE LIGANDS

4.1 Abstract 165 
4.3 Synthesis and Characterization of $\left({ }^{\mathrm{tBu}} \mathrm{PDP}^{\mathrm{Ph}}\right)$ High-Spin $\mathrm{Fe}^{\mathrm{II}}$ Complexes

4.4 Synthesis and Characterization of ( $\left.{ }^{\mathrm{Ar}} \mathrm{PDP}{ }^{\mathrm{Ph}}\right)$ High-Spin $\mathrm{Fe}^{\mathrm{II}}$ Complexes

4.5 Conclusion

4.6 Experimental Procedures

References

CHAPTER V: REACTIVITY OF A ROBUST HIGH-SPIN IRON(II) PYRIDINE

BISPYRROLIDE COMPLEX WITH ORGANIC AZIDES

5.1 Abstract

5.3 Reactivity of $\left({ }^{2,6-\mathrm{Cl} 2 \mathrm{Ph}} \mathrm{PDP}{ }^{\mathrm{Ph}}\right) \mathrm{Fe}(\mathrm{thf})$ with Adamantyl Azide

5.4 Reactivity of $\left(^{2,6-\mathrm{Cl} 2 \mathrm{Ph}} \mathrm{PDP}{ }^{\mathrm{Ph}}\right) \mathrm{Fe}($ thf $)$ with 4-Substituted Aryl Azides

5.5 Reactivity of $\left({ }^{2,6-\mathrm{Cl} 2 \mathrm{Ph}} \mathrm{PDP}{ }^{\mathrm{Ph}}\right) \mathrm{Fe}($ thf $)$ with Mesityl and Xylyl Azide 236

5.6 Reactivity of $\left(^{2,6-\mathrm{Cl} 2 \mathrm{Ph}} \mathrm{PDP}{ }^{\mathrm{Ph}}\right) \mathrm{Fe}($ thf $)$ with 1-(4-Azidobutyl)benzene 239

5.7 Calculations of Isolated Iron Imides and Iminyl Radical Complexes

5.8 Conclusion 256

5.9 Experimental Procedures 
CHAPTER VI: SYNTHESIS, CHARACTERIZATION, AND REACTIVITY OF A

PYRIDINE DIPYRROLIDE IRON CARBENE COMPLEX

6.1 Abstract 269

6.2 Introduction 270

6.3 Reactivity of ( $\left.{ }^{\mathrm{Ar}} \mathrm{PDP}{ }^{\mathrm{Ph}}\right) \mathrm{Fe}(\mathrm{thf})$ Complexes With Diphenyldiazomethane 278

6.4 Density Functional Theory Study of $\left({ }^{\mathrm{Mes}} \mathrm{PDP}^{\mathrm{Ph}}\right) \mathrm{Fe}\left(\mathrm{CPh}_{2}\right)$ 289

6.5 Reactivity Studies of $\left({ }^{\mathrm{Mes}} \mathrm{PDP}{ }^{\mathrm{Ph}}\right) \mathrm{Fe}\left(\mathrm{CPh}_{2}\right)$ 296

6.6 Reactivity Studies of $\left(\mathrm{CPh}_{2}{ }^{\mathrm{Mes}} \mathrm{PDP}{ }^{\mathrm{Ph}}\right) \mathrm{Fe}\left(\mathrm{C} \equiv \mathrm{N}-2,6-\left(\mathrm{CH}_{3}\right)_{2} \mathrm{Ph}\right)_{2}$ 308

6.7 Synthesis of a Monoisocyanide Carbene Adduct.

6.8 Conclusion 323

6.9 Experimental Procedures 324

References

CHAPTER VII: CONCLUDING REMARKS AND FUTURE OUTLOOKS 348

APPENDIX I: SYNTHESIS AND CHARACTERIZATION OF A REDUCED

PYRIDINE DIPYRROLIDE IRON TETRAZENE COMPLEX

A.1.1 Abstract 353

A.1.2 Introduction 353

A.1.3 Synthesis and Characterization of $\left[\mathrm{CoCp}_{2}\right]\left[\left({ }^{\mathrm{Mes}} \mathrm{PDP}^{\mathrm{Ph}}\right) \mathrm{Fe}\left(\mathrm{N}_{4} \mathrm{Tol}_{2}\right)\right]$ 355 
A.1.4 Experimental Procedures

References

362

APPENDIX II: MISCELLANEOUS STRUCTURES OBTAINED FROM X-RAY CRYSTALLOGRAPHIC ANALYSIS 364 


\section{LIST OF FIGURES}

1.1. Important biological structures containing iron.

1.2. Proposed mechanism of $\mathrm{C}-\mathrm{H}$ hydroxylation facilitated via $\mathrm{P} 450$. 4

1.3. Simplified electronic structure of Compound I. 5

1.4. Proposed mechanism of dirhodium catalyzed C-H amination. 9

1.5. Selectivity for allylic $\mathrm{C}-\mathrm{H}$ amination vs. olefin aziridination in dirhodium and diruthenium catalyst systems.

1.6. Proposed mechanisms of ruthenium porphyrin catalyzed $\mathrm{C}-\mathrm{H}$ amination.

1.7. Proposed mechanism of allylic C-H amination of cyclohexene with dipyrromethene iron iminyl complexes.

2.1. Mononuclear square-planar high-spin $\mathrm{Fe}^{\mathrm{II}}$ complexes featuring bidentate alkoxide or siloxide ligands. 38

2.2. Mononuclear square-planar high-spin $\mathrm{Fe}^{\mathrm{II}}$ complexes featuring tridentate pincer ligands. 40

2.3. ORTEP of $\mathrm{Fe}\left(\mathrm{H}^{\mathrm{Mes}} \mathrm{PDP}{ }^{\mathrm{Ph}}\right)_{2}$ displayed at $30 \%$ probability ellipsoids. 42

2.4. ORTEP of ( $\left.{ }^{\mathrm{Mes}} \mathrm{PDP}{ }^{\mathrm{Ph}}\right) \mathrm{Fe}\left(\mathrm{OEt}_{2}\right)$ displayed at $30 \%$ probability ellipsoids.

2.5. ORTEP of $\left({ }^{\mathrm{Mes}} \mathrm{PDP}{ }^{\mathrm{Ph}}\right) \mathrm{Fe}(\mathrm{thf})(\mu-\mathrm{Cl}) \mathrm{Li}(\mathrm{thf})_{3}$ displayed at $30 \%$ probability ellipsoids. ... 48 2.6. Zero field ${ }^{57} \mathrm{Fe}$ Mössbauer spectra of $\left({ }^{\mathrm{Mes}} \mathrm{PDP}{ }^{\mathrm{Ph}}\right) \mathrm{Fe}\left(\mathrm{OEt}_{2}\right)$ and $\left({ }^{\mathrm{Mes}} \mathrm{PDP}{ }^{\mathrm{Ph}}\right) \mathrm{Fe}($ thf $)(\mu-\mathrm{Cl}) \mathrm{Li}(\text { thf })_{3}$ recorded at $80 \mathrm{~K}$.

2.7. Comparison of the ${ }^{1} \mathrm{H}$ NMR spectra of $\left({ }^{\mathrm{Mes}} \mathrm{PDP}^{\mathrm{Ph}}\right) \mathrm{Fe}(\mathrm{thf})_{2}$ in THF- $d_{8}$ and $\left({ }^{\mathrm{Mes}} \mathrm{PDP}{ }^{\mathrm{Ph}}\right) \mathrm{Fe}($ thf $)$ in benzene- $d_{6}$.

2.8. ORTEP of ( $\left.{ }^{\mathrm{Mes}} \mathrm{PDP} \mathrm{Ph}^{\mathrm{Ph}}\right) \mathrm{Fe}(\mathrm{thf})$ displayed at $30 \%$ probability ellipsoids. 52 
2.9. Variable temperature ${ }^{1} \mathrm{H}$ NMR data from $25{ }^{\circ} \mathrm{C}$ to $-80{ }^{\circ} \mathrm{C}$ for

$\left({ }^{\mathrm{Mes}} \mathrm{PDP}^{\mathrm{Ph}}\right) \mathrm{Fe}($ thf $)$ in toluene- $d 8$.

2.10. Changes in selected chemical shifts of $\left({ }^{\mathrm{Mes}} \mathrm{PDP} \mathrm{Ph}^{\mathrm{Ph}}\right) \mathrm{Fe}(\mathrm{thf})$ with added THF. 56

2.11. ${ }^{1} \mathrm{H}$ NMR spectra of a titration of THF against $\left({ }^{\mathrm{Mes}} \mathrm{PDP}{ }^{\mathrm{Ph}}\right) \mathrm{Fe}(\mathrm{thf})$ in benzene- $d_{6}$ at $298 \mathrm{~K}$.

2.12. ORTEP of $\left({ }^{\mathrm{Mes}} \mathrm{PDP} \mathrm{Ph}^{\mathrm{Ph}}\right) \mathrm{Fe}(\mathrm{py})_{2}$ depicted at $30 \%$ probability ellipsoids. 58

2.13. Zero-field ${ }^{57} \mathrm{Fe}$ Mössbauer spectra of ( $\left.{ }^{\mathrm{Mes}} \mathrm{PDP}{ }^{\mathrm{Ph}}\right) \mathrm{Fe}(\mathrm{thf})$ and $\left({ }^{\mathrm{Mes}} \mathrm{PDP} \mathrm{Ph}^{\mathrm{Ph}} \mathrm{Fe}(\text { thf })_{2}\right.$ recorded at $80 \mathrm{~K}$. 59

2.14. Zero-field ${ }^{57} \mathrm{Fe}$ Mössbauer spectra of $\left({ }^{\mathrm{Mes}} \mathrm{PDP}{ }^{\mathrm{Ph}}\right) \mathrm{Fe}(\mathrm{py})_{2}$ recorded at $80 \mathrm{~K}$.

2.15. Splitting diagram for the iron $3 \mathrm{~d}$ orbitals in $\left({ }^{\mathrm{Mes}} \mathrm{PDP}{ }^{\mathrm{Ph}}\right) \mathrm{Fe}\left(\mathrm{OEt}_{2}\right)$

obtained via DFT calculations at the B3LYP level.

2.16. Molecular orbital diagram depicting the metal d orbitals obtained via unrestricted DFT calculations at the B3LYP level.

2.17. Qualitative d-orbital splitting diagrams for square-planar high-spin $\mathrm{Fe}^{\mathrm{II}}$ complexes showing the effect of $\sigma$ - and $\pi$-interactions for compounds with two bidentate bis(alkoxide) or bis(siloxide) ligands and $\left({ }^{\mathrm{Mes}} \mathrm{PDP}^{\mathrm{Ph}}\right) \mathrm{Fe}\left(\mathrm{OEt}_{2}\right)$. 66

2.18. Qualitative d-orbital diagram for $\left({ }^{\mathrm{Mes}} \mathrm{PDP} \mathrm{Ph}^{\mathrm{Ph}}\right) \mathrm{Fe}(\mathrm{py})_{2}$ obtained from DFT calculations at the B3LYP level. 67

2.19. Mulliken spin populations for selected protons of the ${ }^{\mathrm{Mes}} \mathrm{PDP}^{\mathrm{Ph}}$ ligand in fourand five-coordinate $\left({ }^{\mathrm{Mes}} \mathrm{PDP}{ }^{\mathrm{Ph}}\right) \mathrm{Fe}(\mathrm{L})_{n}$ complexes. 70

3.1. Iron complexes with pyrrole-based ligands employed in nitrene transfer reactions. .....96

3.2. Pyridine dipyrrolide (PDP) iron complexes with distinct coordination geometries investigated for their reactivity with organic azides. 
3.3. Comparison of the ${ }^{1} \mathrm{H}$ NMR spectra of $\mathrm{Fe}\left(\mathrm{NH}^{1} \mathrm{Ad}-{ }^{\mathrm{Mes}} \mathrm{PDP}^{\mathrm{Ph}}\right)$ in benzene- $d_{6}$ and $\left(\mathrm{NH}^{1} \mathrm{Ad}-{ }^{\mathrm{Mes}} \mathrm{PDP} \mathrm{Ph}^{\mathrm{Ph}}\right) \mathrm{Fe}($ thf $)$ in THF- $d_{8}$. 100

3.4. Zero-field Mössbauer spectrum of $\mathrm{Fe}\left(\mathrm{NH}-{ }^{1} \mathrm{Ad}^{\mathrm{Mes}} \mathrm{PDP}^{\mathrm{Ph}}\right)$ acquired at $80 \mathrm{~K}$. 101

3.5. Zero-field Mössbauer spectrum of $\left(\mathrm{NH}^{1} \mathrm{Ad}-{ }^{\mathrm{Mes}} \mathrm{PDP} \mathrm{Ph}^{\mathrm{Ph}}\right) \mathrm{Fe}(\mathrm{thf})$ acquired at $80 \mathrm{~K}$. 103

3.6. ORTEP of $\left(\mathrm{NH}^{1} \mathrm{Ad}-{ }^{\mathrm{Mes}} \mathrm{PDP}{ }^{\mathrm{Ph}}\right) \mathrm{Fe}(\mathrm{thf})$ displayed at $30 \%$ probability ellipsoids. 104

3.7. ORTEP of $\left({ }^{\mathrm{Mes}} \mathrm{PDP}{ }^{\mathrm{Ph}}\right) \mathrm{Fe}\left(\mathrm{N}_{4} \mathrm{Tol}_{2}\right)$ displayed at $30 \%$ probability ellipsoids. 107

3.8. Zero-field Mössbauer spectrum of ( $\left.{ }^{\mathrm{Mes}} \mathrm{PDP}{ }^{\mathrm{Ph}}\right) \mathrm{Fe}\left(\mathrm{N}_{4} \mathrm{pTol}_{2}\right)$ acquired at $80 \mathrm{~K}$. 108

3.9. ${ }^{1} \mathrm{H}$ NMR spectra of $\left({ }^{\mathrm{Mes}} \mathrm{PDP}{ }^{\mathrm{Ph}}\right) \mathrm{Fe}\left(\mathrm{N}_{4} \mathrm{Tol}_{2}\right)$ at $400 \mathrm{MHz}$ in benzene- $d_{6}$. 109

3.10. Variable temperature ${ }^{1} \mathrm{H}$ NMR spectra of $\left({ }^{\mathrm{Mes}} \mathrm{PDP}{ }^{\mathrm{Ph}}\right) \mathrm{Fe}\left(\mathrm{N}_{4} \mathrm{Tol}_{2}\right)$ at $400 \mathrm{MHz}$ in toluene- $d_{8}$. 110

3.11. Spin density distributions obtained via Mulliken population analysis for $\left({ }^{\mathrm{Mes}} \mathrm{PDP}^{\mathrm{Ph}}\right) \mathrm{Fe}\left(\mathrm{N}_{4} \mathrm{Tol}_{2}\right)$ using BS(1,1), BS(3,1), BS(5,1), and UKS5 computational approaches.

3.12. Zero-field Mössbauer spectra of Fe $\left(\{\mathrm{NHBn}\}_{2^{-}}{ }^{\mathrm{Mes}} \mathrm{PDP} \mathrm{Ph}^{\mathrm{Ph}}\right)$ and $\left({ }^{\mathrm{Mes}} \mathrm{PDP}{ }^{\mathrm{Ph}}\right) \mathrm{Fe}\left(\mathrm{N}_{4} \mathrm{Bn}_{2}\right)(\mathrm{HN}=\mathrm{CHPh})$ at $80 \mathrm{~K}$. 116

3.13. ORTEP of $\mathrm{Fe}\left(\{\mathrm{NHBn}\}_{2^{-}}{ }^{\mathrm{Mes}} \mathrm{PDP}^{\mathrm{Ph}}\right)_{2}$ displayed at $30 \%$ probability ellipsoids. 117 3.14. ORTEP of $\left({ }^{\mathrm{Mes}} \mathrm{PDP}{ }^{\mathrm{Ph}}\right) \mathrm{Fe}\left(\mathrm{N}_{4} \mathrm{Bn}_{2}\right)(\mathrm{HN}=\mathrm{CHPh})$ displayed at $30 \%$ probability ellipsoids. 118

3.15. ${ }^{1} \mathrm{H}-{ }^{13} \mathrm{C}$ HSQC spectrum of $\left({ }^{\mathrm{Mes}} \mathrm{PDP}{ }^{\mathrm{Ph}}\right) \mathrm{Fe}\left(\mathrm{N}_{4} \mathrm{Bn}_{2}\right)(\mathrm{HN}=\mathrm{CHPh})$ in benzene- $d_{6}$ indicating aldimine $\mathrm{CH}$ correlation.

3.16. ${ }^{1} \mathrm{H}_{-}{ }^{15} \mathrm{~N}$ HSQC spectrum of $\left({ }^{\mathrm{Mes}} \mathrm{PDP}{ }^{\mathrm{Ph}}\right) \mathrm{Fe}\left(\mathrm{N}_{4} \mathrm{Bn}_{2}\right)(\mathrm{HN}=\mathrm{CHPh})$ in benzene- $d_{6}$ indicating aldimine $\mathrm{NH}$ correlation. 
3.17. ORTEP of Fe(NHMes- $\left.{ }^{\mathrm{Mes}} \mathrm{PDP} \mathrm{Ph}^{\mathrm{Ph}}\right)$ at $30 \%$ probability ellipsoids.

3.18. ORTEP of $\mathrm{Fe}\left(\mathrm{NH}\left(\mathrm{C}\left(\mathrm{CH}_{3}\right)_{2}\left(\mathrm{CH}_{2}\right)_{3} \mathrm{Ph}\right)-{ }^{\mathrm{Mes}} \mathrm{PDP}^{\mathrm{Ph}}\right)$ displayed at

$30 \%$ probability ellipsoids.

3.19. Qualitative molecular orbital diagram visualizing the electronic structure of

$\left.{ }^{\mathrm{Mes}} \mathrm{PDP}{ }^{\mathrm{Ph}}\right) \mathrm{Fe}^{\mathrm{III}}\left(\mathrm{N}^{1} \mathrm{Ad}^{\bullet 1-}\right)$ showing the $\mathrm{d}$ orbital occupation of the intermediate-spin

$\mathrm{Fe}^{\mathrm{III}}$ ion and the singly occupied molecular orbital of the iminyl ligand radical.

135

3.20. Spin density distributions obtained via Mulliken population analysis for

$\left({ }^{\mathrm{Mes}} \mathrm{PDP} \mathrm{Ph}^{\mathrm{Ph}}\right) \mathrm{Fe}\left(\mathrm{N}^{1} \mathrm{Ad}\right),\left({ }^{\mathrm{Mes}} \mathrm{PDP} \mathrm{Ph}^{\mathrm{Ph}}\right) \mathrm{Fe}(\mathrm{NBn}),\left({ }^{\mathrm{Mes}} \mathrm{PDP}^{\mathrm{Ph}}\right) \mathrm{Fe}(\mathrm{NTol})$, and

$\left({ }^{\mathrm{Mes}} \mathrm{PDP} \mathrm{Ph}^{\mathrm{Ph}}\right) \mathrm{Fe}(\mathrm{NMes})$ using a BS$(3,1)$ or $\mathrm{UKS} 3$ computational approach.

3.21. Spin density plot obtained from Mulliken population from BS(3,1)/UKS3

calculation of $\left({ }^{\mathrm{H}} \mathrm{PDP}{ }^{\mathrm{H}}\right) \mathrm{Fe}\left(\mathrm{N}^{1} \mathrm{Ad}\right)$.

4.1. Pyridine dipyrrolide ligands used in this study.

168

4.2. ${ }^{1} \mathrm{H}$ NMR spectra of the mixture of $\left({ }^{\mathrm{tBu}} \mathrm{PDP}^{\mathrm{Ph}}\right) \mathrm{Fe}\left(\mathrm{OEt}_{2}\right)$ and $\mathrm{Fe}_{2}\left(\mu_{2}-\kappa^{2}{ }_{-}{ }^{\mathrm{Bu}}{ } \mathrm{PDP}{ }^{\mathrm{Ph}}\right)_{2}$

and isolated $\mathrm{Fe}_{2}\left(\mu_{2}-\kappa^{2}{ }_{-}{ }^{\mathrm{Bu}}{ }^{\mathrm{PDPP}}\right)_{2}$ at $400 \mathrm{MHz}$ in benzene- $d_{6}$.

4.3. ORTEP of $\left({ }^{\mathrm{tBu}} \mathrm{PDP}{ }^{\mathrm{Ph}}\right) \mathrm{Fe}\left(\mathrm{OEt}_{2}\right)$ and $\mathrm{Fe}_{2}\left(\mu_{2}-\kappa^{2}{ }_{-}{ }^{\mathrm{Bu}} \mathrm{PDP}^{\mathrm{Ph}}\right)_{2}$

at $30 \%$ probability ellipsoids.

172

4.4. Zero-field ${ }^{57} \mathrm{Fe}$ Mössbauer spectra of $\left({ }^{\mathrm{tBu}} \mathrm{PDP}{ }^{\mathrm{Ph}}\right) \mathrm{Fe}\left(\mathrm{OEt}_{2}\right)$ and $\mathrm{Fe}_{2}\left(\mu_{2}-\kappa^{2}{ }_{-}{ }^{\mathrm{Bu}} \mathrm{PDP}^{\mathrm{Ph}}\right)_{2}$

recorded at $80 \mathrm{~K}$.

4.5. Spin-density plot obtained from Mulliken population analysis of BS(4,4)

calculation ofFe $2\left(\mu_{2}-\kappa^{2}{ }_{-}{ }^{\mathrm{Bu}} \mathrm{PDP}^{\mathrm{Ph}}\right)_{2}$.

4.6. ORTEP of $\left({ }^{\mathrm{tBu} P D P}{ }^{\mathrm{Ph}}\right) \mathrm{Fe}(\mathrm{thf})_{2}$ and $\left({ }^{\mathrm{tBu}} \mathrm{PDP} \mathrm{Ph}^{\mathrm{Ph}}\right) \mathrm{Fe}(\mathrm{py})_{2}$

at $30 \%$ probability ellipsoids. 
4.7. Zero-field ${ }^{57} \mathrm{Fe}$ Mössbauer spectra of $\left({ }^{\mathrm{tBu}} \mathrm{PDP} \mathrm{P}^{\mathrm{Ph}}\right) \mathrm{Fe}(\mathrm{thf})_{2}$ and $\left({ }^{\mathrm{tBu}} \mathrm{PDP}^{\mathrm{Ph}}\right) \mathrm{Fe}(\mathrm{py})_{2}$ recorded at $80 \mathrm{~K}$. 180

4.8. ORTEP of $\mathrm{H}_{2}{ }^{2,6-\mathrm{Cl} 2 \mathrm{Ph}} \mathrm{PDP}^{\mathrm{Ph}}$ excluding DMSO solvent and $\mathrm{H}_{2}{ }^{2,6-\mathrm{Cl} 2 \mathrm{Ph}} \mathrm{PDP}^{\mathrm{Ph}}$

depicting the hydrogen bonding interaction between the pyrrole hydrogens and DMSO oxygen atom.

4.9. ORTEP of the hydrogen bonded dimer $\left[\mathrm{H}_{2} 4-\mathrm{MeO}^{2,6-\mathrm{Cl} 2 \mathrm{Ph}} \mathrm{PDP}^{\mathrm{Ph}}\right]_{2}$ and

$\mathrm{H}_{2} 4-\mathrm{MeO}^{2,6-\mathrm{Cl} 2 \mathrm{Ph}} \mathrm{PDP}^{\mathrm{Ph}}$ displayed at $30 \%$ probability ellipsoids.

4.10. ORTEP of $\left({ }^{2,6-C 12 P h} \mathrm{PDP}^{\mathrm{Ph}}\right) \mathrm{Fe}(\mathrm{py})_{2}$ at $30 \%$ probability ellipsoids. 184

4.11. Zero-field ${ }^{57} \mathrm{Fe}$ Mössbauer spectrum of $\left({ }^{\mathrm{C} 6 \mathrm{F5} 5} \mathrm{PDP}^{\mathrm{Ph}}\right) \mathrm{Fe}(\mathrm{py})_{2}$ recorded at $80 \mathrm{~K}$. 185

4.12. ORTEP of ( $\left(^{2,6-\mathrm{Cl} 2 \mathrm{Ph}} \mathrm{PDP}^{\mathrm{Ph}}\right) \mathrm{Fe}$ (thf) and $\left(4-\mathrm{MeO}^{2,6-\mathrm{Cl} 2 \mathrm{Ph}} \mathrm{PDP}^{\mathrm{Ph}}\right) \mathrm{Fe}($ thf $)$ at $30 \%$ probability ellipsoids. 187

4.13. Zero-field ${ }^{57} \mathrm{Fe}$ Mössbauer spectra of (2,6-C12Ph $\left.\mathrm{PDP}^{\mathrm{Ph}}\right) \mathrm{Fe}($ thf $)$ and (4- $\left.\mathrm{MeO}^{2,6-\mathrm{Cl} 2 \mathrm{Ph}} \mathrm{PDP}^{\mathrm{Ph}}\right) \mathrm{Fe}$ (thf) recorded at $80 \mathrm{~K}$.

4.14. Comparison of the ${ }^{1} \mathrm{H}$ NMR spectra of $\left({ }^{2,6-\mathrm{Cl} 2 \mathrm{Ph}} \mathrm{PDP}^{\mathrm{Ph}}\right) \mathrm{Fe}(\text { thf })_{2}$ in THF- $d_{8}$ and $\left.{ }^{2,6-\mathrm{C} 12 \mathrm{Ph}} \mathrm{PDP}^{\mathrm{Ph}}\right) \mathrm{Fe}($ thf $)$ in benzene- $d_{6}$. 190

4.15. Zero-field ${ }^{57} \mathrm{Fe}$ Mössbauer spectra of $\left({ }^{2,6-C l 2 P h} \mathrm{PDP}^{\mathrm{Ph}}\right) \mathrm{Fe}(\text { thf })_{2}$ and (2,6-Cl2Ph $\left.\mathrm{PDP}^{\mathrm{Ph}}\right) \mathrm{Fe}(\mathrm{py})_{2}$ recorded at $80 \mathrm{~K}$.

4.16. ORTEP of $\left({ }^{2,6-\mathrm{Cl} 2 \mathrm{Ph}} \mathrm{PDP}^{\mathrm{Ph}}\right) \mathrm{Fe}(\mathrm{thf})_{2}$ at $30 \%$ probability ellipsoids. 193

5.1. Examples of pyrrole based ligands susceptible to intramolecular $\mathrm{C}-\mathrm{H}$ amination. 221

5.2. Dipyrromethene and pyridine dipyrrolide iron nitrene complexes. 222

5.3. ${ }^{1} \mathrm{H}$ NMR spectrum of $\left({ }^{2,6-\mathrm{Cl} 2 \mathrm{Ph}} \mathrm{PDP}^{\mathrm{Ph}}\right) \mathrm{Fe}\left(\mathrm{N}^{1} \mathrm{Ad}\right)$ at $400 \mathrm{MHz}$ in benzene- $d_{6}$. 226

5.4. ORTEP depictions of $\left({ }^{2,6-C l 2 P h} \mathrm{PDP}^{\mathrm{Ph}}\right) \mathrm{Fe}\left(\mathrm{N}^{1} \mathrm{Ad}\right)$ displayed at $30 \%$ probability ellipsoids. 227 
5.5. Zero-field Mössbauer spectrum of $\left({ }^{2,6-\mathrm{Cl} 2 \mathrm{Ph}} \mathrm{PDP}^{\mathrm{Ph}}\right) \mathrm{Fe}\left(\mathrm{N}_{4}(\mathrm{pFPh})_{2}\right)$

acquired at $80 \mathrm{~K}$.

229

5.6. ORTEP depictions of two perspective views of $\left({ }^{2,6-\mathrm{Cl} 2 \mathrm{Ph}} \mathrm{PDP}^{\mathrm{Ph}}\right) \mathrm{Fe}\left(\mathrm{N}_{4}(\mathrm{pFPh})_{2}\right)$

displayed at $30 \%$ probability ellipsoids.

232

5.7. ${ }^{1} \mathrm{H}$ NMR spectra of $\left({ }^{2,6-\mathrm{Cl} 2 \mathrm{Ph}} \mathrm{PDP}{ }^{\mathrm{Ph}}\right) \mathrm{Fe}\left(\mathrm{N}_{4}(\mathrm{pFPh})_{2}\right)$ and

$\left({ }^{2,6-\mathrm{Cl} 2 \mathrm{Ph}} \mathrm{PDP} \mathrm{Ph}^{\mathrm{Ph}}\right) \mathrm{Fe}\left(\mathrm{N}_{4}\left(\mathrm{p}^{\mathrm{t}} \mathrm{BuPh}\right)_{2}\right)$ at $400 \mathrm{MHz}$ in benzene- $d_{6}$.

5.8. Spin density plot obtained from the Mulliken population analysis of a BS(1,1)

calculation of $\left({ }^{2,6-\mathrm{Cl} 2 \mathrm{Ph}} \mathrm{PDP}{ }^{\mathrm{Ph}}\right) \mathrm{Fe}\left(\mathrm{N}_{4}(\mathrm{pFPh})_{2}\right)$.

236

5.9. ${ }^{1} \mathrm{H}$ NMR spectra of $\left({ }^{2,6-\mathrm{ClPh}} \mathrm{PDP}{ }^{\mathrm{Ph}}\right) \mathrm{Fe}(\mathrm{NMes})$ and $\left({ }^{2,6-\mathrm{Cl} 2 \mathrm{Ph}} \mathrm{PDP}^{\mathrm{Ph}}\right) \mathrm{Fe}(\mathrm{NXyl})$

in benzene- $d_{6}$.

5.10. ORTEP of $\left({ }^{2,6-\mathrm{Cl} 2 \mathrm{Ph}} \mathrm{PDP}{ }^{\mathrm{Ph}}\right) \mathrm{Fe}\left(\mathrm{N}_{4}(\mathrm{nBuPh})_{2}\right)\left(\mathrm{HN}=\mathrm{CH}\left(\mathrm{CH}_{2}\right)_{3} \mathrm{Ph}\right)$

depicted at $30 \%$ probability ellipsoids.

5.11. Spin density plot obtained from the Mulliken population analysis of

$\mathrm{BS}(3,1) / \mathrm{UKS} 3, \mathrm{BS}(2,2)$, and UKS5 calculations of ( $\left.{ }^{2,6-\mathrm{Cl} 2 \mathrm{Ph}} \mathrm{PDP}^{\mathrm{Ph}}\right) \mathrm{Fe}\left(\mathrm{N}^{1} \mathrm{Ad}\right)$.

5.12. $\mathrm{BS}(5,1)$ optimized structure of $\left({ }^{2,6-\mathrm{Cl} 2 \mathrm{Ph}} \mathrm{PDP} \mathrm{Ph}^{\mathrm{Ph}}\right) \mathrm{Fe}(\mathrm{NMes})$ indicating

$\mathrm{Fe}-\mathrm{Cl}$ interaction.

252

5.13. Comparison of bond lengths from the X-ray crystal structure of

$\left({ }^{\mathrm{Ar}} \mathrm{L}\right) \mathrm{FeCl}\left(\mathrm{N}\left(p-{ }^{\mathrm{t}} \mathrm{BuC}_{6} \mathrm{H}_{4}\right)\right)$ and the optimized structures obtained from $\mathrm{UKS} 3 / \mathrm{BS}(3,1)$,

UKS5, and BS(5,1) DFT calculations of (2,6-C12Ph $\left.\mathrm{PDP}{ }^{\mathrm{Ph}}\right) \mathrm{Fe}(\mathrm{NMes})$.

5.14. Spin density plots obtained from the Mulliken population analysis of BS(3,1)/UKS3,

$\mathrm{BS}(5,1)$, and UKS5 calculations of $\left.{ }^{2,6-\mathrm{Cl} 2 \mathrm{Ph}} \mathrm{PDP}^{\mathrm{Ph}}\right) \mathrm{Fe}(\mathrm{NMes})$. 254

6.1. Examples of popular Schrock and Grubbs metathesis catalysts. 271 
6.2. Examples of selected crystallographically characterized mononuclear iron carbene complexes and their corresponding iron carbene bond lengths.

6.3. ${ }^{1} \mathrm{H}$ NMR spectrum of $\left({ }^{\mathrm{Mes}} \mathrm{PDP}^{\mathrm{Ph}}\right) \mathrm{Fe}\left(\mathrm{CPh}_{2}\right)$ at $600 \mathrm{MHz}$ in benzene- $d_{6}$. 279

6.4. IR spectrum of $\left({ }^{\mathrm{Mes}} \mathrm{PDP}^{\mathrm{Ph}}\right) \mathrm{Fe}\left(\mathrm{CPh}_{2}\right)(\mathrm{KBr})$. 280

6.5. ORTEP of ( $\left.{ }^{\mathrm{Mes}} \mathrm{PDP}{ }^{\mathrm{Ph}}\right) \mathrm{Fe}\left(\mathrm{CPh}_{2}\right)$ depicted at $30 \%$ probability ellipsoids. 281

6.6. Zero-field ${ }^{57} \mathrm{Fe}$ Mössbauer spectrum of $\left({ }^{\mathrm{Mes}} \mathrm{PDP}^{\mathrm{Ph}}\right) \mathrm{Fe}\left(\mathrm{CPh}_{2}\right)$ acquired at $80 \mathrm{~K}$. 284

6.7. Zero-field and applied-field ${ }^{57} \mathrm{Fe}$ Mössbauer spectra of $\left({ }^{\mathrm{Mes}} \mathrm{PDP}^{\mathrm{Ph}}\right) \mathrm{Fe}\left(\mathrm{CPh}_{2}\right)$ acquired at temperatures from $4.2 \mathrm{~K}$ to $100 \mathrm{~K}$ and field strengths of 0 to $7 \mathrm{~T}$. 286 6.8. Zero-field and applied-field ${ }^{57} \mathrm{Fe}$ Mössbauer spectra of $\left({ }^{\mathrm{Mes}} \mathrm{PDP}^{\mathrm{Ph}}\right) \mathrm{Fe}\left(\mathrm{CPh}_{2}\right)$ acquired at temperatures from $4.2 \mathrm{~K}$ to $30 \mathrm{~K}$ and fields strengths of 2 to $7 \mathrm{~T}$. 287 6.9. Qualitative molecular orbital diagram derived from the Unrestricted Corresponding Orbitals (UCO) obtained from BS(3,1)/UKS3 DFT calculations. 294 6.10. Spin-density plots obtained from Mulliken population analysis of $\operatorname{UKS} 3 / \mathrm{BS}(3,1)$, BS(5,1), and UKS5 DFT calculations. 295

6.11. IR spectrum of $\left(\mathrm{CPh}_{2}{ }^{\mathrm{Mes}} \mathrm{PDP}^{\mathrm{Ph}}\right) \mathrm{Fe}(\mathrm{CO})_{2}(\mathrm{KBr})$. 297

6.12. ORTEP depictions of two perspectives of $\left(\mathrm{CPh}_{2}{ }^{\mathrm{Mes}} \mathrm{PDP}^{\mathrm{Ph}}\right) \mathrm{Fe}(\mathrm{CO})_{2}$ at $30 \%$ probability ellipsoids.

6.13. IR spectrum of $\left(\mathrm{CPh}_{2}{ }^{\mathrm{Mes}} \mathrm{PDP}^{\mathrm{Ph}}\right) \mathrm{Fe}\left(\mathrm{C} \equiv \mathrm{N}-2,6-\left(\mathrm{CH}_{3}\right)_{2} \mathrm{Ph}\right)_{2}(\mathrm{KBr})$. 301

6.14. ${ }^{1} \mathrm{H}-{ }^{13} \mathrm{C}$ HMBC spectrum of $\left(\mathrm{CPh}_{2}{ }^{\mathrm{Mes}} \mathrm{PDP}{ }^{\mathrm{Ph}}\right) \mathrm{Fe}\left(\mathrm{C} \equiv \mathrm{N}-2,6\left(\mathrm{CH}_{3}\right)_{2} \mathrm{Ph}\right)_{2}$ in dichloromethane- $d_{2}$. 303 6.15. ${ }^{13} \mathrm{C}$, DEPT 135 , and APT spectra of $\left(\mathrm{CPh}_{2}{ }^{\mathrm{Mes}} \mathrm{PDP}{ }^{\mathrm{Ph}}\right) \mathrm{Fe}\left(\mathrm{C} \equiv \mathrm{N}-2,6\left(\mathrm{CH}_{3}\right)_{2} \mathrm{Ph}\right)_{2}$ in dichloromethane- $d_{2}$. 304 
6.16. ORTEP depictions of two perspectives of $\left(\mathrm{CPh}_{2}{ }^{\mathrm{Mes}} \mathrm{PDP}{ }^{\mathrm{Ph}}\right) \mathrm{Fe}\left(\mathrm{C} \equiv \mathrm{N}-2,6-\left(\mathrm{CH}_{3}\right)_{2}(\mathrm{Ph})_{2}\right)_{2}$ at $30 \%$ probability ellipsoids. 306

6.17. Zero-field ${ }^{57} \mathrm{Fe}$ Mössbauer spectra of $\left(\mathrm{CPh}_{2}{ }^{\mathrm{Mes}} \mathrm{PDP}{ }^{\mathrm{Ph}}\right) \mathrm{Fe}(\mathrm{CO})_{2}$ and $\left(\mathrm{CPh}_{2}{ }^{\mathrm{Mes}} \mathrm{PDP}{ }^{\mathrm{Ph}}\right) \mathrm{Fe}\left(\mathrm{C} \equiv \mathrm{N}-2,6-\left(\mathrm{CH}_{3}\right)_{2} \mathrm{Ph}\right)_{2}$ recorded at $80 \mathrm{~K}$. 308

6.18. IR spectrum of $\left({ }^{\mathrm{Mes} P D P}{ }^{\mathrm{Ph}}\right) \mathrm{Fe}\left(\mathrm{C} \equiv \mathrm{N}-\left(\mathrm{CH}_{3}\right)_{2} \mathrm{Ph}\right)_{3}(\mathrm{KBr})$. 309

6.19. IR spectrum of $\left({ }^{\mathrm{Mes}} \mathrm{PDP} \mathrm{Ph}^{\mathrm{Ph}}\right) \mathrm{Fe}\left(\mathrm{C} \equiv \mathrm{N}-{ }^{1} \mathrm{Ad}\right)_{3}(\mathrm{KBr})$. 310

6.20. ORTEP of $\left({ }^{\mathrm{Mes}} \mathrm{PDP}{ }^{\mathrm{Ph}}\right) \mathrm{Fe}\left(\mathrm{C} \equiv \mathrm{N}-2,6-\left(\mathrm{CH}_{3}\right)_{2} \mathrm{Ph}\right)_{3}$ depicted

at $30 \%$ probability ellipsoids.

6.21. Zero-field ${ }^{57} \mathrm{Fe}$ Mössbauer spectra of $\left({ }^{\mathrm{Mes}} \mathrm{PDP}{ }^{\mathrm{Ph}}\right) \mathrm{Fe}\left(\mathrm{C} \equiv \mathrm{N}-2,6-\left(\mathrm{CH}_{3}\right)_{2} \mathrm{Ph}\right)_{3}$ and $\left({ }^{\mathrm{Mes}} \mathrm{PDP}{ }^{\mathrm{Ph}}\right) \mathrm{Fe}\left(\mathrm{C} \equiv \mathrm{N}-{ }^{1} \mathrm{Ad}\right)_{3}$ recorded at $80 \mathrm{~K}$.

6.22. ${ }^{1} \mathrm{H}$ NMR spectra $(600 \mathrm{MHz})$ in benzene- $d_{6}$ of upfield aliphatic resonances of an independently prepared sample of $\left({ }^{\mathrm{Mes} P D P}{ }^{\mathrm{Ph}}\right) \mathrm{Fe}\left(\mathrm{C} \equiv \mathrm{N}-2,6-\left(\mathrm{CH}_{3}\right)_{2} \mathrm{Ph}\right)_{3}$ and the crude reaction mixture obtained from heating $\left(\mathrm{CPh}_{2}{ }^{\mathrm{Mes}} \mathrm{PDP}{ }^{\mathrm{Ph}}\right) \mathrm{Fe}\left(\mathrm{C} \equiv \mathrm{N}-2,6-\left(\mathrm{CH}_{3}\right)_{2} \mathrm{Ph}\right)_{2}$ to $80^{\circ} \mathrm{C}$ for approximately $48 \mathrm{hrs}$.

6.23. ${ }^{1} \mathrm{H}$ NMR spectra $(600 \mathrm{MHz})$ in benzene- $d_{6}$ of downfield aryl resonances of an independently prepared sample of $\left({ }^{\mathrm{Mes}} \mathrm{PDP} \mathrm{Ph}^{\mathrm{Ph}}\right) \mathrm{Fe}\left(\mathrm{C} \equiv \mathrm{N}-2,6-\left(\mathrm{CH}_{3}\right)_{2} \mathrm{Ph}\right)_{3}$ and the crude reaction mixture obtained from heating $\left(\mathrm{CPh}_{2}{ }^{\mathrm{Mes}} \mathrm{PDP}{ }^{\mathrm{Ph}}\right) \mathrm{Fe}\left(\mathrm{C} \equiv \mathrm{N}-2,6-\left(\mathrm{CH}_{3}\right)_{2} \mathrm{Ph}\right)_{2}$ to $80^{\circ} \mathrm{C}$ for approximately $48 \mathrm{hrs}$. 316

6.24. ${ }^{1} \mathrm{H}$ NMR spectrum (400 MHz) in benzene- $d_{6}$ from -50 to $20 \mathrm{ppm}$ of crude reaction mixture obtained from heating $\left(\mathrm{CPh}_{2}{ }^{\mathrm{Mes}} \mathrm{PDP}{ }^{\mathrm{Ph}}\right) \mathrm{Fe}\left(\mathrm{C} \equiv \mathrm{N}-2,6-\left(\mathrm{CH}_{3}\right)_{2} \mathrm{Ph}\right)_{2}$ to $80^{\circ} \mathrm{C}$ for approximately $48 \mathrm{hrs}$.

6.25. Possible mechanisms for the formation of $\left(\mathrm{CPh}_{2}{ }^{\mathrm{Mes}} \mathrm{PDP}{ }^{\mathrm{Ph}}\right) \mathrm{Fe}\left(\mathrm{C} \equiv \mathrm{N}-2,6-\left(\mathrm{CH}_{3}\right)_{2} \mathrm{Ph}\right)_{2}$ from $\left({ }^{\mathrm{Mes}} \mathrm{PDP}{ }^{\mathrm{Ph}}\right) \mathrm{Fe}\left(\mathrm{CPh}_{2}\right)$. 
6.26. ORTEP of $\left({ }^{\mathrm{Mes}} \mathrm{PDP}{ }^{\mathrm{Ph}}\right) \mathrm{Fe}\left(\mathrm{CPh}_{2}\right)\left(\mathrm{C} \equiv \mathrm{N}-{ }^{1} \mathrm{Ad}\right)$ depicted

at $30 \%$ probability ellipsoids.

320

6.27. ${ }^{1} \mathrm{H}$ NMR spectrum of $\left({ }^{\mathrm{Mes}} \mathrm{PDP}^{\mathrm{Ph}}\right) \mathrm{Fe}\left(\mathrm{CPh}_{2}\right)\left(\mathrm{C} \equiv \mathrm{N}-{ }^{1} \mathrm{Ad}\right)$ at $600 \mathrm{MHz}$ in

benzene- $d_{6}$.

321

6.28. ${ }^{13} \mathrm{C}$ NMR labeling scheme for $\left(\mathrm{CPh}_{2}{ }^{\mathrm{Mes}} \mathrm{PDP}{ }^{\mathrm{Ph}}\right) \mathrm{Fe}\left(\mathrm{C} \equiv \mathrm{N}-2,6-\left(\mathrm{CH}_{3}\right)_{2} \mathrm{Ph}\right)_{2}$.

6.29. ${ }^{13} \mathrm{C}$ NMR labeling scheme for $\left({ }^{\mathrm{Mes}} \mathrm{PDP}{ }^{\mathrm{Ph}}\right) \mathrm{Fe}\left(\mathrm{C} \equiv \mathrm{N}-2,6-\left(\mathrm{CH}_{3}\right)_{2} \mathrm{Ph}\right)_{3}$.

6.30. ${ }^{13} \mathrm{C}$ NMR labeling scheme for $\left({ }^{\mathrm{Mes}} \mathrm{PDP}{ }^{\mathrm{Ph}}\right) \mathrm{Fe}\left(\mathrm{C} \equiv \mathrm{N}-{ }^{1} \mathrm{Ad}\right)_{3}$.

7.1. Neutral square-planar high-spin $\mathrm{Fe}^{\mathrm{II}}$ complexes $\left({ }^{\mathrm{Mes}} \mathrm{PDP}^{\mathrm{Ph}}\right) \mathrm{Fe}($ thf $)$ and

$\left.{ }^{\mathrm{Mes}} \mathrm{PDP}^{\mathrm{Ph}}\right) \mathrm{Fe}\left(\mathrm{OEt}_{2}\right)$

7.2. Paramagnetic PDP Fe nitrene complex $\left({ }^{\mathrm{C} 2 \mathrm{Ph}} \mathrm{PDP}^{\mathrm{Ph}}\right) \mathrm{Fe}(\mathrm{NMes})$ and square-planar iron carbene complex $\left({ }^{\mathrm{Mes}} \mathrm{PDP}^{\mathrm{Ph}}\right) \mathrm{Fe}\left(\mathrm{CPh}_{2}\right)$.

7.3. Stoichiometric synthesis of iron-bound 2,2-dimethyl-5-phenyl-pyrrolidine from 4-azido-4-methylpentylbenzene via a proposed intermediate $\left({ }^{\mathrm{C} 2 \mathrm{Ph}} \mathrm{PDP}^{\mathrm{Ph}}\right)$ iron nitrene intermediate. 350

7.4. Proposed ( $\left.{ }^{\mathrm{Mes}} \mathrm{PDP}{ }^{\mathrm{Ph}}\right) \mathrm{Fe}(\mathrm{thf})$ catalyzed cyclopropanation of styrene using methyl phenyldiazoacetate.

A.1.1. Examples of $\mathrm{Fe}^{\mathrm{II}}$ complexes carrying neutral, radical anion, and dianionic tetrazene ligands.

A.1.2. ORTEP of $\left.\left[\mathrm{Co}(\mathrm{Cp})_{2}\right]\left[{ }^{\mathrm{Mes}} \mathrm{PDP}^{\mathrm{Ph}}\right) \mathrm{Fe}\left(\mathrm{N}_{4} \mathrm{Tol}_{2}\right)\right]$ at $30 \%$ probability ellipsoids. 356

A.1.3. Zero-field ${ }^{57} \mathrm{Fe}$ Mössbauer spectrum of $\left[\mathrm{Co}(\mathrm{Cp})_{2}\right]\left[\left({ }^{\mathrm{Mes}} \mathrm{PDP}^{\mathrm{Ph}}\right) \mathrm{Fe}\left(\mathrm{N}_{4} \mathrm{Tol}_{2}\right)\right]$ acquired at $80 \mathrm{~K}$. 358

A.2.1. ORTEP depictions of $\left[\left({ }^{\mathrm{Me}} \mathrm{PDP}^{\mathrm{Ph}}\right) \mathrm{Fe}\left(\mathrm{OEt}_{2}\right)\right]_{2}$ and the asymmetric unit of $\left[\left({ }^{\mathrm{Me}} \mathrm{PDP}{ }^{\mathrm{Ph}}\right) \mathrm{Fe}\left(\mathrm{OEt}_{2}\right)\right]_{2}$ displayed at $30 \%$ probability ellipsoids. 364 
A.2.2. ORTEP of $\left({ }^{\mathrm{Me}} \mathrm{PDP} \mathrm{Ph}^{\mathrm{Ph}}\right) \mathrm{Fe}(\mathrm{py})_{3}$ displayed at $30 \%$ probability ellipsoids. 365

A.2.3. ORTEP of $\left({ }^{\mathrm{Mes}} \mathrm{PDP}{ }^{\mathrm{Ph}}\right) \mathrm{Fe}\left(\mathrm{NH}_{2} \mathrm{Bn}\right)_{3}$ displayed at $30 \%$ probability ellipsoids. 365

A.2.4. ORTEP of $\left({ }^{\mathrm{Ph}} \mathrm{PDP}{ }^{\mathrm{Ph}}\right) \mathrm{Fe}(\text { thf })_{3}$ displayed at $30 \%$ probability ellipsoids. 366

A.2.5. ORTEP of $\left({ }^{\mathrm{Mes}} \mathrm{PDP} \mathrm{Ph}^{\mathrm{Ph}}\right) \mathrm{Fe}(\mathrm{Cl})(\mathrm{py})$ displayed at $30 \%$ probability ellipsoids. 366

A.2.6. ORTEP of $\left({ }^{\mathrm{Mes}} \mathrm{PDP}{ }^{\mathrm{Ph}}\right) \mathrm{Fe}\left(\mathrm{N}_{3}\right)(\mathrm{py})(\mathrm{thf})$ displayed at $30 \%$ probability ellipsoids. 367

A.2.7. ORTEP of $\left({ }^{\mathrm{Mes}} \mathrm{PDP}{ }^{\mathrm{Ph}}\right) \mathrm{Fe}(\mathrm{pyrr})(\mathrm{py})$ displayed at $30 \%$ probability ellipsoids. 367

A.2.8. ORTEP of ( $\left.{ }^{\mathrm{Mes}} \mathrm{PDP}{ }^{\mathrm{Ph}}\right) \mathrm{Fe}\left(\mathrm{NH}_{2} \mathrm{Mes}\right)$ displayed at $30 \%$ probability ellipsoids. 368

A.2.9. ORTEP of $\left({ }^{\mathrm{Mes}} \mathrm{PDP}{ }^{\mathrm{Ph}}\right) \mathrm{Fe}\left(\mathrm{NH}_{2} \mathrm{Mes}\right)_{2}$ displayed at $30 \%$ probability ellipsoids. 368

A.2.10. ORTEP of $\left.{ }^{2,6-\mathrm{Cl} 2 \mathrm{Ph}} \mathrm{PDP}^{\mathrm{Ph}}\right) \mathrm{Fe}\left(\mathrm{OEt}_{2}\right)$ displayed at $30 \%$ probability ellipsoids. 369

A.2.11. ORTEP of ( $\left.{ }^{\mathrm{Mes}} \mathrm{PDP}{ }^{\mathrm{Ph}}\right) \mathrm{Fe}\left(\mathrm{C}(\mathrm{pMeOPh})\left(\mathrm{CO}_{2} \mathrm{Me}\right)\right)$ displayed at $30 \%$ probability ellipsoids. 369

A.2.12. ORTEP of $\left.\mathrm{Co}^{2,6-\mathrm{Cl} 2 \mathrm{Ph}} \mathrm{PDP}^{\mathrm{Ph}}\right)$ displayed at $30 \%$ probability ellipsoids. 370

A.2.13. ORTEP of $\left({ }^{\mathrm{C} 655} \mathrm{PDP}^{\mathrm{Ph}}\right) \mathrm{Fe}\left(\mathrm{OEt}_{2}\right)_{2}$ displayed at $30 \%$ probability ellipsoids. 370

A.2.14. ORTEP of $\mathrm{H}_{2}{ }^{\mathrm{pTol}} \mathrm{PDP}^{\mathrm{Ph}} \cdot \mathrm{DMSO}$ displayed at $30 \%$ probability ellipsoids. 371 A.2.15. ORTEP of $\left({ }^{\mathrm{C} 6}{ }^{5} \mathrm{PDP}^{\mathrm{Ph}}\right) \mathrm{Fe}(\mathrm{py})_{2} \bullet\left(\mathrm{C}_{6} \mathrm{H}_{5} \mathrm{~N}\right)$ displayed at $30 \%$ probability ellipsoids. 371 


\section{LIST OF TABLES}

2.1. Geometry analysis of reported square-planar high-spin $\mathrm{Fe}^{\mathrm{II}}$ complexes

by continuous shape measures.

46

2.2. Summary of structural metrics obtained via X-ray crystallography for

$\left({ }^{\mathrm{Mes}} \mathrm{PDP}{ }^{\mathrm{Ph}}\right) \mathrm{Fe}\left(\mathrm{OEt}_{2}\right),\left({ }^{\mathrm{Mes}} \mathrm{PDP}^{\mathrm{Ph}}\right) \mathrm{Fe}($ thf $),\left({ }^{\mathrm{Mes}} \mathrm{PDP}{ }^{\mathrm{Ph}}\right) \mathrm{Fe}(\mathrm{py})_{2}$,

and $\left({ }^{\mathrm{Mes}} \mathrm{PDP}{ }^{\mathrm{Ph}}\right) \mathrm{Fe}($ thf $)(\mu-\mathrm{Cl}) \mathrm{Li}(\text { thf })_{3}$.

60

2.3. Experimental and calculated Mössbauer parameters of

$\left({ }^{\mathrm{Mes}} \mathrm{PDP}{ }^{\mathrm{Ph}}\right) \mathrm{Fe}(\mathrm{L})_{\mathrm{n}}$ Complexes. 68

2.4. Reported ${ }^{57} \mathrm{Fe}$ Mössbauer parameters for square-planar high-spin

$\mathrm{Fe}^{\mathrm{II}}$ complexes.

71

3.1. Summary of ${ }^{57} \mathrm{Fe}$ Mössbauer spectroscopic data for PDP iron complexes.

3.2. Selected bond lengths $(\AA)$ and angles (deg) for $\left(\mathrm{NH}^{1} \mathrm{Ad}-{ }^{\mathrm{Mes}} \mathrm{PDP}^{\mathrm{Ph}}\right) \mathrm{Fe}($ thf $)$ and

$\left({ }^{\mathrm{Mes}} \mathrm{PDP}{ }^{\mathrm{Ph}}\right) \mathrm{Fe}\left(\mathrm{N}_{4} \mathrm{Tol}_{2}\right)$. 106

3.3. Relative energies and calculated Mössbauer parameters from DFT calculations.

3.4. Selected bond lengths $(\AA)$ and angles (deg) for Fe( $\left.\{\mathrm{NHBn}\}_{2^{-}}{ }^{\mathrm{Mes}} \mathrm{PDP} \mathrm{Ph}^{\mathrm{Ph}}\right)$ and $\left({ }^{\mathrm{Mes}} \mathrm{PDP}{ }^{\mathrm{Ph}}\right) \mathrm{Fe}\left(\mathrm{N}_{4} \mathrm{Bn}_{2}\right)(\mathrm{HN}=\mathrm{CHPh})$.

3.5. Selected bond lengths $(\AA)$ and angles (deg) for Fe(NHMes- $\left.{ }^{\mathrm{Mes}} \mathrm{PDP}^{\mathrm{Ph}}\right)$ and $\mathrm{Fe}\left(\mathrm{NH}\left(\mathrm{C}\left(\mathrm{CH}_{3}\right)_{2}\left(\mathrm{CH}_{2}\right)_{3} \mathrm{Ph}\right)-{ }^{\mathrm{Mes}} \mathrm{PDP}^{\mathrm{Ph}}\right)$.

3.6. Calculated energies and selected structural parameters for different electronic structures of $\left({ }^{\mathrm{Mes}} \mathrm{PDP}{ }^{\mathrm{Ph}}\right) \mathrm{Fe}(\mathrm{NR})\left(\mathrm{R}={ }^{1} \mathrm{Ad}\right.$, Tol, Bn, Mes $)$

obtained from DFT calculations.

3.7. Calculated energies and selected structural parameters for different electronic structures of $\left({ }^{\mathrm{H}} \mathrm{PDP}{ }^{\mathrm{H}}\right) \mathrm{Fe}\left(\mathrm{N}^{1} \mathrm{Ad}\right)$ obtained from DFT calculations. 140 
4.1 Selected bond lengths $(\AA)$ and angles (deg) for $\left({ }^{\mathrm{tBu}} \mathrm{PDP}^{\mathrm{Ph}}\right) \mathrm{Fe}\left(\mathrm{OEt}_{2}\right)$,

$\left({ }^{\mathrm{tBu}} \mathrm{PDP}^{\mathrm{Ph}}\right) \mathrm{Fe}(\text { thf })_{2},\left({ }^{\mathrm{tBu}} \mathrm{PDP} \mathrm{Ph}^{\mathrm{Ph}}\right) \mathrm{Fe}(\mathrm{py})_{2}$.

4.2. Selected bond lengths $(\AA)$ and angles (deg) for $\left({ }^{2,6-C l 2 P h} \mathrm{PDP}^{\mathrm{Ph}}\right) \mathrm{Fe}($ thf $)$,

(4- $\left.\mathrm{MeO}^{2,6-\mathrm{Cl} 2 \mathrm{Ph}} \mathrm{PDP}^{\mathrm{Ph}}\right) \mathrm{Fe}($ thf $),\left({ }^{2,6-\mathrm{Cl} 2 \mathrm{Ph}} \mathrm{PDP}^{\mathrm{Ph}}\right) \mathrm{Fe}(\mathrm{py})_{2}$.

4.3. Experimental and calculated Mössbauer parameters for high-spin

$\mathrm{Fe}^{\mathrm{II}}$ PDP complexes.

5.1. ${ }^{1} \mathrm{H}$ NMR chemical shifts (ppm) of cis-divacant octahedral PDP iron imides. 226

5.2. Selected bond lengths $(\AA)$ and angles (deg) obtained from X-ray crystallography

for $\left({ }^{\mathrm{tBu}} \mathrm{PDP}{ }^{\mathrm{tBu}}\right) \mathrm{Fe}\left(\mathrm{N}^{1} \mathrm{Ad}\right)$ and $\left({ }^{2,6-\mathrm{Cl} 2 \mathrm{Ph}} \mathrm{PDP}{ }^{\mathrm{Ph}}\right) \mathrm{Fe}\left(\mathrm{N}^{1} \mathrm{Ad}\right)$. 228

5.3. Selected bond lengths $(\AA)$ and angles $(\mathrm{deg})$ for $\left({ }^{\mathrm{Mes}} \mathrm{PDP}^{\mathrm{Ph}}\right) \mathrm{Fe}\left(\mathrm{N}_{4} \mathrm{Tol}_{2}\right)$ and (2,6-Cl2Ph $\left.\mathrm{PDP}^{\mathrm{Ph}}\right) \mathrm{Fe}\left(\mathrm{N}_{4}(\mathrm{pFPh})_{2}\right)$.

5.4. Experimental and calculated Mössbauer parameters

for $\left.{ }^{2,6-\mathrm{Cl} 2 \mathrm{Ph}} \mathrm{PDP}^{\mathrm{Ph}}\right) \mathrm{Fe}\left(\mathrm{N}_{4}(\mathrm{pFPh})_{2}\right)$.

5.5. Selected bond lengths $(\AA)$ and angles $(\mathrm{deg})$ for $\left({ }^{\mathrm{Mes}} \mathrm{PDP}{ }^{\mathrm{Ph}}\right) \mathrm{Fe}\left(\mathrm{N}_{4} \mathrm{Bn}_{2}\right)(\mathrm{HN}=\mathrm{CHPh})$ and $\left({ }^{2,6-\mathrm{Cl} 2 \mathrm{Ph}} \mathrm{PDP}{ }^{\mathrm{Ph}}\right) \mathrm{Fe}\left(\mathrm{N}_{4}(\mathrm{nBuPh})_{2}\right)\left(\mathrm{HN}=\mathrm{CH}\left(\mathrm{CH}_{2}\right)_{3} \mathrm{Ph}\right)$.

5.6. Calculated energies and selected structural parameters for different electronic structures of $\left({ }^{2,6-\mathrm{Cl} 2 \mathrm{Ph}} \mathrm{PDP}{ }^{\mathrm{Ph}}\right) \mathrm{Fe}\left(\mathrm{N}^{1} \mathrm{Ad}\right)$ obtained from DFT calculations.

5.7. Calculated energies and selected structural parameters for different electronic structures of $\left({ }^{2,6-\mathrm{Cl} 2 \mathrm{Ph}} \mathrm{PDP} \mathrm{Ph}^{\mathrm{Ph}}\right) \mathrm{Fe}(\mathrm{NMes})$ obtained from DFT calculations. 253

5.8. Calculated energies for different electronic structures of $\left({ }^{2,6-\mathrm{Cl} 2 \mathrm{Ph}} \mathrm{PDP}{ }^{\mathrm{Ph}}\right) \mathrm{Fe}\left(\mathrm{N}^{1} \mathrm{Ad}\right)$, $\left({ }^{2,6-\mathrm{Cl} 2 \mathrm{Ph}} \mathrm{PDP}{ }^{\mathrm{Ph}}\right) \mathrm{Fe}(\mathrm{NMes})$, and $\left({ }^{\mathrm{Mes}} \mathrm{PDP}^{\mathrm{Ph}}\right) \mathrm{Fe}(\mathrm{NMes})$ obtained from DFT calculations. ....... 255

6.1. Oxidation state, spin state, and iron carbene bond distances for selected crystallographically characterized iron carbene complexes. 276 
6.2. Fit parameters utilized in modeling experimental data obtained for $\left({ }^{\mathrm{Mes}} \mathrm{PDP}^{\mathrm{Ph}}\right) \mathrm{Fe}\left(\mathrm{CPh}_{2}\right)$ via variable-temperature applied-field Mössbauer spectroscopy. ........ 288

6.3. Summary of physical and computational metrics for ( $\left.{ }^{\mathrm{Mes}} \mathrm{PDP}^{\mathrm{Ph}}\right) \mathrm{Fe}\left(\mathrm{CPh}_{2}\right)$. 293

6.4. Selected bond lengths $(\AA)$ and angles $(\mathrm{deg})$ for $\left(\mathrm{CPh}_{2}{ }^{\mathrm{Mes}} \mathrm{PDP}{ }^{\mathrm{Ph}}\right) \mathrm{Fe}(\mathrm{CO})_{2}$, $\left(\mathrm{CPh}_{2}{ }^{\mathrm{Mes}} \mathrm{PDP}{ }^{\mathrm{Ph}}\right) \mathrm{Fe}\left(\mathrm{C} \equiv \mathrm{N}-2,6-\left(\mathrm{CH}_{3}\right)_{2} \mathrm{Ph}\right)_{2}$, and $\left({ }^{\mathrm{Mes}} \mathrm{PDP}{ }^{\mathrm{Ph}}\right) \mathrm{Fe}\left(\mathrm{C} \equiv \mathrm{N}-2,6-\left(\mathrm{CH}_{3}\right)_{2} \mathrm{Ph}\right)_{3}$.

6.5. Iron-PDP nitrogen bond lengths $(\AA)$ in high- and low-spin

$\mathrm{Fe}^{\mathrm{II}}{ }^{\mathrm{Mes}} \mathrm{PDP} \mathrm{Ph}^{\mathrm{Ph}}$ complexes.

6.6. Experimental and calculated Mössbauer parameters for ${ }^{\mathrm{Mes}} \mathrm{PDP}^{\mathrm{Ph}}$

complexes in this chapter.

6.7. Selected bond lengths $(\AA)$ and angles $(\mathrm{deg})$ for $\left({ }^{\mathrm{Mes}} \mathrm{PDP}{ }^{\mathrm{Ph}}\right) \mathrm{Fe}\left(\mathrm{CPh}_{2}\right)$ and $\left({ }^{\mathrm{Mes}} \mathrm{PDP}{ }^{\mathrm{Ph}}\right) \mathrm{Fe}\left(\mathrm{CPh}_{2}\right)\left(\mathrm{C} \equiv \mathrm{N}-{ }^{1} \mathrm{Ad}\right)$.

A.1.1. Selected bond lengths $(\AA)$ and angles (deg) for $\left[\mathrm{Co}(\mathrm{Cp})_{2}\right]\left[\left({ }^{\mathrm{Mes}} \mathrm{PDP}{ }^{\mathrm{Ph}}\right) \mathrm{Fe}\left(\mathrm{N}_{4} \mathrm{Tol}_{2}\right)\right]$. 


\section{LIST OF SCHEMES}

1.1. Substrate dependent catalytic hydrocarbon oxidation with (TPP)Fe(Cl) and iodosobenzene. 6

1.2. Catalytic intramolecular nitrene transfer with (TPP)Fe(Cl) or $\mathrm{Rh}_{2}(\mathrm{OAc})_{4}$. 7

1.3. Intramolecular $\mathrm{C}-\mathrm{H}$ amination with $\mathrm{Rh}_{2}(\mathrm{esp})_{2}$ catalyst. 8

1.4. Photogeneration of a dirhodium nitrene complex. 10

1.5. Synthesis of (TPP)Ru(NAr) $)_{2}$ and its stoichiometric and catalytic allylic $\mathrm{C}-\mathrm{H}$ amination reactivity.

1.6. $(\mathrm{Pc}) \mathrm{Fe}(\mathrm{Cl})$ catalyzed allylic $\mathrm{C}-\mathrm{H}$ amination. 16

1.7. Iron catalyzed $\mathrm{C}-\mathrm{H}$ amination of 1-azido-4-phenylbutane.

1.8. Pyrrolidine synthesis via direct Fe catalyzed $\mathrm{C}-\mathrm{H}$ amination and isolation of an $\mathrm{Fe}^{\mathrm{III}}$ iminyl radical intermediate. 18

1.9. Reactivity of $\mathrm{Fe}$ and $\mathrm{Co}\left({ }^{\mathrm{tBu}} \mathrm{PDP}^{\mathrm{tBu}}\right)$ complexes with 1-adamantyl azide. 21

1.10. Iron catalyzed carbene group transfer reactions. 24

1.11. $(\mathrm{Pc}) \mathrm{Fe}(\mathrm{Cl})$ catalyzed allylic $\mathrm{C}-\mathrm{H}$ alkylation. 25

1.12. Pyridine diimine iron complex catalyzed cyclopropanation of olefins. 26

2.1. Synthesis of $\left({ }^{\mathrm{Mes}} \mathrm{PDP}{ }^{\mathrm{Ph}}\right) \mathrm{Fe}\left(\mathrm{OEt}_{2}\right)$. 43

2.2. Synthesis of $\left({ }^{\mathrm{Mes}} \mathrm{PDP} \mathrm{P}^{\mathrm{Ph}}\right) \mathrm{Fe}($ thf $)(\mu-\mathrm{Cl}) \mathrm{Li}(\text { thf })_{3}$, $\left({ }^{\mathrm{Mes}} \mathrm{PDP} \mathrm{Ph}^{\mathrm{Ph}}\right) \mathrm{Fe}$ (thf), and $\left({ }^{\mathrm{Mes}} \mathrm{PDP}{ }^{\mathrm{Ph}}\right) \mathrm{Fe}(\text { thf })_{2}$. 55

2.3. Synthesis of $\left({ }^{\mathrm{Mes}} \mathrm{PDP} \mathrm{Ph}^{\mathrm{Ph}}\right) \mathrm{Fe}(\mathrm{py})_{2}$. 58

3.1. Synthesis of $\mathrm{Fe}\left(\mathrm{NH}-{ }^{1} \mathrm{Ad}^{\mathrm{Mes}} \mathrm{PDP}^{\mathrm{Ph}}\right)$. 99

3.2. Synthesis of $\left(\mathrm{NH}^{1} \mathrm{Ad}-{ }^{\mathrm{Mes}} \mathrm{PDP} \mathrm{Ph}^{\mathrm{Ph}}\right) \mathrm{Fe}(\mathrm{thf})$. 100

3.3. Synthesis of $\left({ }^{\mathrm{Mes}} \mathrm{PDP}{ }^{\mathrm{Ph}}\right) \mathrm{Fe}\left(\mathrm{N}_{4} \mathrm{Tol}_{2}\right)$. 105 
3.4. Synthesis of $\mathrm{Fe}\left(\{\mathrm{NHBn}\}_{2^{-}}{ }^{\mathrm{Mes}} \mathrm{PDP} \mathrm{Ph}^{\mathrm{Ph}}\right)$ and $\left({ }^{\mathrm{Mes}} \mathrm{PDP} \mathrm{Ph}^{\mathrm{Ph}}\right) \mathrm{Fe}\left(\mathrm{N}_{4} \mathrm{Bn}_{2}\right)(\mathrm{HN}=\mathrm{CHPh})$.

3.5. Synthesis of $\left({ }^{\mathrm{Mes}} \mathrm{PDP} \mathrm{Ph}^{\mathrm{Ph}}\right) \mathrm{Fe}(\mathrm{NMes})$.

3.6. Synthesis of Fe(NHMes- $\left.{ }^{\mathrm{Mes}} \mathrm{PDP}^{\mathrm{Ph}}\right)$ from $\left({ }^{\mathrm{Mes}} \mathrm{PDP} \mathrm{Ph}^{\mathrm{Ph}}\right) \mathrm{Fe}(\mathrm{NMes})$.

3.7. Proposed formation of $\left({ }^{\mathrm{Mes}} \mathrm{PDP} \mathrm{Ph}^{\mathrm{Ph}}\right) \mathrm{Fe}$ bound 2,2-dimethyl-5-phenylpyrrolidine

via direct $\mathrm{C}-\mathrm{H}$ bond amination from 4-azido-4-methylpentylbenzene.

3.8. Synthesis of $\mathrm{Fe}\left(\mathrm{NH}\left(\mathrm{C}\left(\mathrm{CH}_{3}\right)_{2}\left(\mathrm{CH}_{2}\right)_{3} \mathrm{Ph}\right){ }_{-}^{\mathrm{Mes}} \mathrm{PDP}^{\mathrm{Ph}}\right)$.

4.1. Synthesis of pyridine dipyrrolide ligands via tandem Stetter and Knorr reactions.

4.2. Synthesis of $\left({ }^{\mathrm{tBu}} \mathrm{PDP}{ }^{\mathrm{Ph}}\right) \mathrm{Fe}\left(\mathrm{OEt}_{2}\right)$ and $\mathrm{Fe}_{2}\left(\mu_{2}-\kappa^{2}{ }_{-}{ }^{\mathrm{Bu}} \mathrm{PDP}^{\mathrm{Ph}}\right)_{2}$.

4.3. Synthesis of $\left({ }^{\mathrm{R}} \mathrm{PDP}{ }^{\mathrm{Ph}}\right) \mathrm{Fe}(\mathrm{py})_{2}$ complexes.

4.4. Synthesis of $\left(\mathrm{R}^{2,6-\mathrm{Cl} 2 \mathrm{Ph}} \mathrm{PDP}^{\mathrm{Ph}}\right) \mathrm{Fe}(\mathrm{thf})$ complexes.

5.1. Synthesis of $\left({ }^{2,6-C l 2 P h} P D P P^{P h}\right) \mathrm{Fe}\left(\mathrm{N}^{1} \mathrm{Ad}\right)$.

5.2. Synthesis of $\left({ }^{2,6-\mathrm{Cl} 2 \mathrm{Ph}} \mathrm{PDP} \mathrm{Ph}^{\mathrm{Ph}}\right) \mathrm{Fe}\left(\mathrm{N}_{4}(\mathrm{pRPh})\right)_{2}$ complexes.

5.3. Synthesis of $\left({ }^{2,6-\mathrm{Cl} 2 \mathrm{Ph}} \mathrm{PDP}{ }^{\mathrm{Ph}}\right) \mathrm{Fe}(\mathrm{NMes})$ and $\left({ }^{2,6-\mathrm{Cl} 2 \mathrm{Ph}} \mathrm{PDP}^{\mathrm{Ph}}\right) \mathrm{Fe}(\mathrm{NX} \mathrm{Xl})$.

5.4. Proposed synthesis of iron bound 2-phenylpyrrolidine via decomposition of 4-azidobutyl-benzene in the presence of $\left({ }^{2,6-\mathrm{Cl} 2 \mathrm{Ph}} \mathrm{PDP}^{\mathrm{Ph}}\right) \mathrm{Fe}($ thf $)$.

5.5. Synthesis of $\left.{ }^{2,6-\mathrm{Cl} 2 \mathrm{Ph}} \mathrm{PDP}^{\mathrm{Ph}}\right) \mathrm{Fe}\left(\mathrm{N}_{4}(\mathrm{nBuPh})_{2}\right)\left(\mathrm{HN}=\mathrm{CH}\left(\mathrm{CH}_{2}\right)_{3} \mathrm{Ph}\right)$.

6.1. Synthesis of $\left({ }^{\mathrm{Mes}} \mathrm{PDP}{ }^{\mathrm{Ph}}\right) \mathrm{Fe}\left(\mathrm{CPh}_{2}\right)$.

6.2. Synthesis of $\left(\mathrm{CPh}_{2}{ }^{\mathrm{Mes}} \mathrm{PDP}{ }^{\mathrm{Ph}}\right) \mathrm{Fe}(\mathrm{CO})_{2}$. 298

6.3. Synthesis of $\left(\mathrm{CPh}_{2}{ }^{\mathrm{Mes}} \mathrm{PDP}{ }^{\mathrm{Ph}}\right) \mathrm{Fe}\left(\mathrm{C} \equiv \mathrm{N}-2,6-\left(\mathrm{CH}_{3}\right)_{2} \mathrm{Ph}\right)_{2}$. 302

6.4. Independent synthesis of $\left({ }^{\mathrm{Mes}} \mathrm{PDP} \mathrm{Ph}^{\mathrm{Ph}}\right) \mathrm{Fe}(\mathrm{C} \equiv \mathrm{NR})_{3}$ complexes. 310

6.5. Thermal decomposition of $\left(\mathrm{CPh}_{2}{ }^{\mathrm{Mes}} \mathrm{PDP} \mathrm{Ph}^{\mathrm{Ph}}\right) \mathrm{Fe}\left(\mathrm{C} \equiv \mathrm{N}-2,6-\left(\mathrm{CH}_{3}\right)_{2} \mathrm{Ph}\right)_{2}$.

6.6. Synthesis of $\left({ }^{\mathrm{Mes}} \mathrm{PDP} \mathrm{Ph}^{\mathrm{Ph}}\right) \mathrm{Fe}\left(\mathrm{CPh}_{2}\right)\left(\mathrm{C} \equiv \mathrm{N}-{ }^{1} \mathrm{Ad}\right)$. 320 
7.1. Synthesis of $\left({ }^{\mathrm{Mes}} \mathrm{PDP}{ }^{\mathrm{Ph}}\right) \mathrm{Fe}\left(\mathrm{C}\left(\mathrm{CO}_{2} \mathrm{Me}\right)(4-\mathrm{MeOPh})\right)$ from $\left({ }^{\mathrm{Mes}} \mathrm{PDP}{ }^{\mathrm{Ph}}\right) \mathrm{Fe}($ thf $)$

and methyl 4-methoxyphenyldiazoacetate.

A.1.1. Possible formal electronic configurations of a tetrazene ligand

complexed to a metal center.

354

A.1.2. Synthesis of $\left[\mathrm{Co}(\mathrm{Cp})_{2}\right]\left[\left({ }^{\mathrm{Mes}} \mathrm{PDP}{ }^{\mathrm{Ph}}\right) \mathrm{Fe}\left(\mathrm{N}_{4} \mathrm{Tol}_{2}\right)\right]$. 355 
List of Chemical Abbreviations

$\begin{array}{ll}\mathrm{Ad} \text { or }{ }^{1} \mathrm{Ad} & \text { 1-adamantyl } \\ \mathrm{Bn} & \text { benzyl } \\ \mathrm{Cp} & \text { cyclopentadienyl } \\ \text { dichloromethane } \\ \mathrm{DCM} & 2,6 \text {-diisopropylphenyl } \\ \mathrm{dipp} & \text { ethyl } \\ \mathrm{Et} & \text { diethylether } \\ \mathrm{Et} \mathrm{t}_{2} \mathrm{O} & \text { isopropyl } \\ { }^{\mathrm{i}} \mathrm{Pr} & \text { ligand } \\ \mathrm{L} & \text { lithium bis(trimethylsilyl)amide } \\ \mathrm{LiHMDS} & \text { methyl } \\ \mathrm{Me} & \text { mesityl or } 2,4,6 \text {-trimethylphenyl } \\ \mathrm{Mes} & n \text {-butyl } \\ { }^{n} \mathrm{Bu} & \text { pyridine diimine/ } \\ \mathrm{PDI} & 2,6 \text {-bis[1-(2,6-diisopropylphenylimino)ethyl]pyridine } \\ & \text { phenyl } \\ \mathrm{Ph} & \text { pyridine } \\ \text { py } & \text { tert-butyl } \\ { }^{t} \mathrm{Bu} & \text { tetrahydrofuran } \\ \text { thf or THF } & \text { trimethylsilyl } \\ \mathrm{TMS} & \text { toluene } \\ \mathrm{Tol} & \text { meta-xylyl or 2,6-dimethylphenyl } \\ \mathrm{Xyl} & \end{array}$


List of Acronyms, Symbols, and Units

\begin{tabular}{|c|c|}
\hline & radical \\
\hline$\left\{{ }^{1} \mathrm{H}\right\}$ & proton decoupled \\
\hline${ }^{13} \mathrm{C}$ & carbon-13 \\
\hline${ }^{1} \mathrm{H}$ & proton \\
\hline$\AA$ & angstrom, $10^{-10}$ meters \\
\hline avg & average \\
\hline br & broad \\
\hline $\mathrm{cm}^{-1}$ & wavenumbers or inverse centimeters \\
\hline$D$ & axial zero field splitting parameter \\
\hline $\mathrm{d}$ & doublet resonance \\
\hline$E$ & rhombic zero field splitting parameter \\
\hline $\mathrm{e}^{-}$ & electron \\
\hline $\mathrm{G}$ & gauss \\
\hline$g$ & $\begin{array}{l}\text { Landé g-factor (but may also refer to the anomalous gyromagnetic } \\
\text { ratio, } 2.0023 \text { ) }\end{array}$ \\
\hline $\boldsymbol{H}$ & Hamiltonian operator \\
\hline$H$ & magnetic field \\
\hline HAA & hydrogen atom abstraction \\
\hline HOMO & highest occupied molecular orbital \\
\hline HRMS & High-resolution mass spectrometry \\
\hline IR & infrared spectroscopy \\
\hline$J$ & coupling constant \\
\hline$k$ & Boltzmann constant, $0.695 \mathrm{~cm}-1 / \mathrm{K}$ \\
\hline $\mathrm{K}$ & kelvin \\
\hline LUMO & lowest unoccupied molecular orbital \\
\hline M & molar, moles per liter \\
\hline $\mathrm{m}$ & multiplet in NMR \\
\hline$m-$ & meta position on an aryl ring, indicating a 1,3 relationship \\
\hline$m / z$ & mass to charge ratio \\
\hline $\mathrm{MHz}$ & megahertz, $10^{6}$ Hertz or $10^{6} \mathrm{~s}^{-1}$ \\
\hline mmol & millimole, $10^{-3}$ moles \\
\hline MO & molecular orbital \\
\hline $\mathrm{nb}$ & non-bonding orbital \\
\hline $\mathrm{nm}$ & nanometer, $10^{-9}$ meters \\
\hline NMR & nuclear magnetic resonance \\
\hline$o-$ & ortho position on an aryl ring, indicating a 1,2 relationship \\
\hline$p$ - & para position on an aryl ring, indicating a 1,4 relationship \\
\hline ppm & parts per million \\
\hline $\mathrm{q}$ & quartet resonance \\
\hline $\mathrm{rt}$ & room temperature \\
\hline $\mathrm{s}$ & singlet resonance or second \\
\hline$S$ & spin \\
\hline$S$ & spin operator \\
\hline 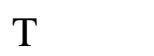 & tesla \\
\hline
\end{tabular}


$\mathrm{t}$

$T$ or $\mathrm{T}$

$\delta$

$\Delta \mathrm{E}_{\mathrm{Q}}$

$\eta^{\mathrm{n}}$

$\kappa^{\mathrm{n}}$

$\mu_{\mathrm{B}}$

$\mu_{\text {eff }}$

$v$

$\chi$

$\chi_{\mathrm{M}}$ or $\chi_{\mathrm{m}}$ triplet resonance

temperature

delta, chemical shift in ppm or isomer shift for ${ }^{57} \mathrm{Fe}$ Mössbauer in $\mathrm{mm} / \mathrm{s}$

quadrupole splitting for ${ }^{57} \mathrm{Fe}$ Mössbauer in $\mathrm{mm} / \mathrm{s}$

eta, hapticity or the number, $n$, of contiguous atoms in a ligand bound to a metal

kappa, denticity or the number, $n$, of atoms in a polydentate ligand bound to the metal

Bohr magneton, $9.274 \times 10^{-21} \mathrm{erg} / \mathrm{G}$

mu effective, effective magnetic moment in Bohr magnetons

frequency

magnetic susceptibility

molar magnetic susceptibility in $\mathrm{cm}^{3} / \mathrm{mol}$ 


\section{CHAPTER I: IRON: THE NATURAL CHOICE FOR GROUP TRANSFER CHEMISTRY}

\subsection{Iron Coordination Chemistry}

The chemistry of iron, the most abundant of the transition metal elements, has garnered longstanding attention owing to its diverse function in both anthropogenic and natural chemical processes. Particularly fascinating is the variety of electronic structures available to this particular element, which renders it inherently flexible in its application. Throughout decades of research, coordination complexes have been identified with iron centers spanning formal oxidations states from -2 to $+6 .^{1,2}$ This wealth of available oxidation states, coupled with the possibility for multiple spin-states to exist at each oxidation number obviates the fact that a myriad of potential electronic structures may be adopted by iron containing coordination compounds. Furthermore, by partnering the breadth of possible combinations of oxidation state and spin-state with the multitude of coordination geometries available to transition metal complexes, a seemingly limitless array of iron coordination compounds with disparate physical characteristics can be imagined. Accordingly, researchers have identified that by controlling the electronic structure of an iron complex via a well-defined ligand field may allow for the isolation of iron complexes well suited for use in catalysis, ${ }^{3}$ electron-transfer, ${ }^{4,5}$ magnetic materials, ${ }^{6}$ and photochemistry. ${ }^{7}$ Despite the intensive research and notable successes achieved within the context of synthetic inorganic and organometallic iron chemistry, the most elegant applications of this element are in biological systems. Prominent examples include iron's presence in active sites of enzymes which may engage small molecules substrates in both oxidative and reductive processes. Most notable are oxygenases, nitrogenases, and hydrogenases, examples of which are depicted in Figure 1.1.8,9 

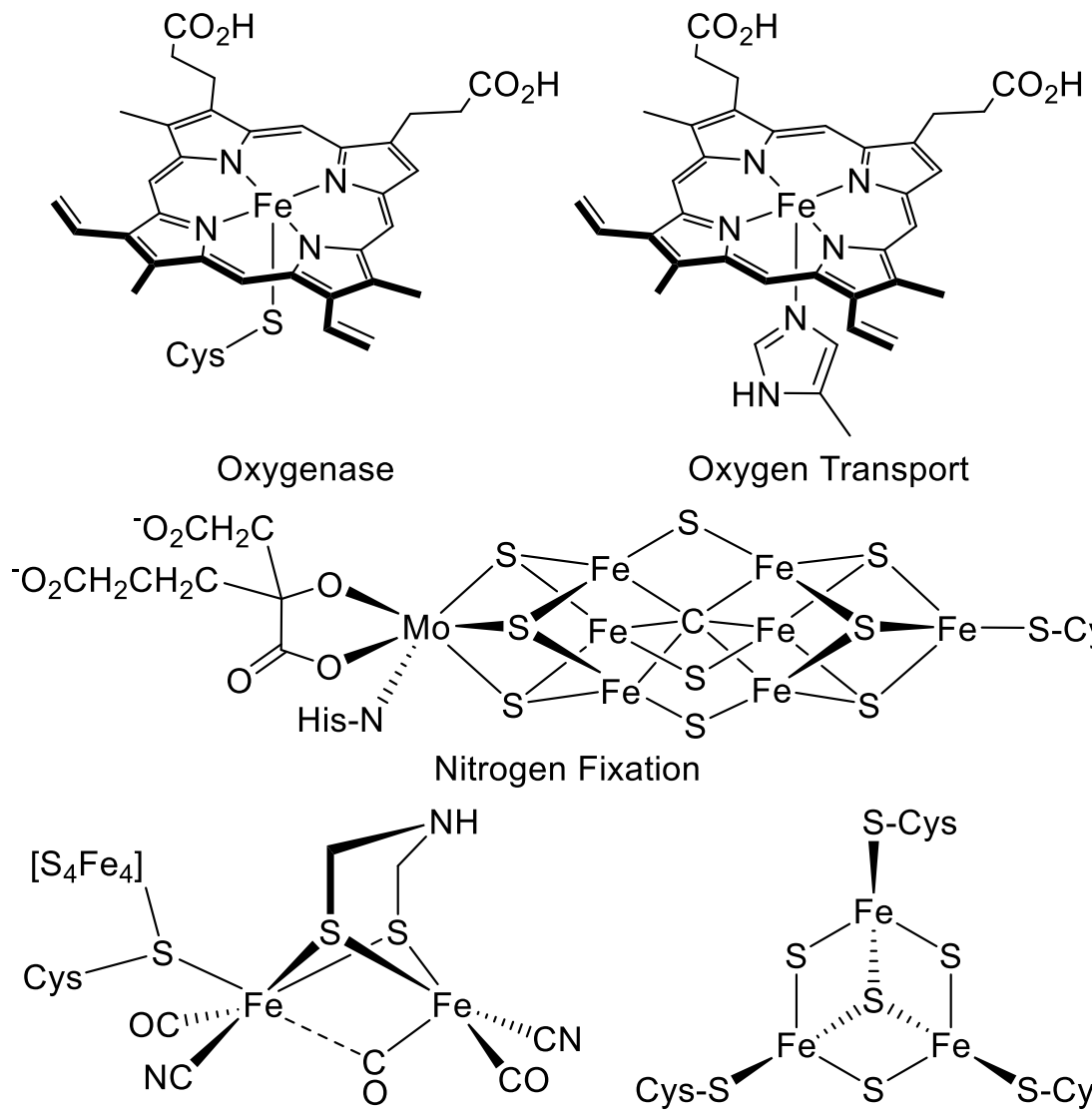

Hydrogen Evolution

Oxygen Transport
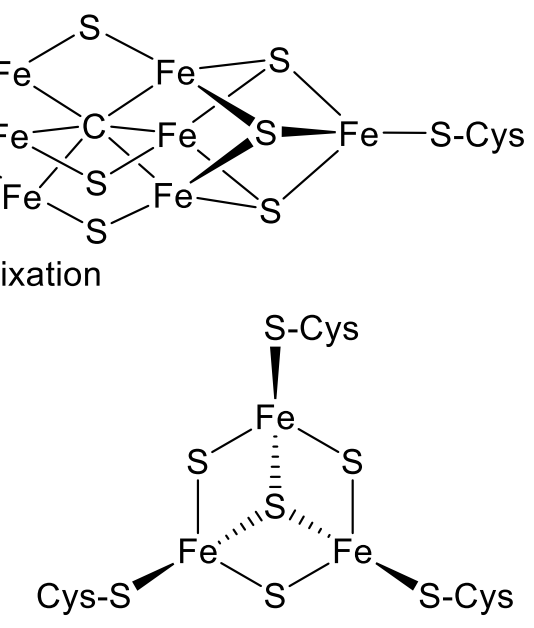

Electron Transfer

Figure 1.1. Important biological structures containing iron. Heme unit in cytochrome P450 (top left), Heme $b$ unit found in myoglobin (top right, note: histidine residue is truncated), FeMo cofactor of nitrogenase (middle), [FeFe] hydrogenase (bottom left), and $\left[\mathrm{Fe}_{3} \mathrm{~S}_{4}\right]$ cluster in A. vinelandii ferredoxin.

Moreover, the transport and storage of dioxygen via hemoglobin and myoglobin proteins and the electron transfer capabilities of iron-sulfur clusters are also critical for physiological function. ${ }^{8,9}$ Although the roles of these biological constructs are extremely diverse, one common theme that is critical for their successful operation is the redox flexibility available to the iron center(s). The seamless changes possible between formal oxidation states and accompanying spin-states of iron is what enables its utility in this variety of chemical processes. In consideration of this, it has become clear that the development of a thorough understanding of the electronic structures operative in these particular iron containing systems may offer tremendous promise for the 
informed development of synthetic mimics with applications in fields such as catalysis and sustainable fuel production. ${ }^{10,11}$

In this regard, a particularly striking example is considered within the context of a family of heme containing enzymes, the $\mathrm{P} 450$ monooxygenases. These enzymes are a fascinating example of how nature can leverage and exploit an iron containing complex to accomplish challenging chemical transformations under mild physiological conditions. Notably, the P450 family of enzymes are capable of leveraging highly-reactive iron-oxo intermediates towards the selective hydroxylation of inert $\mathrm{C}-\mathrm{H}$ bonds. This process occurs via the capture and scission of molecular dioxygen at the iron center, forming an iron-oxo intermediate, referred to as Compound I. Compound I is highly reactive, and thus, capable of performing such a challenging reaction. Mechanistically, $\mathrm{C}-\mathrm{H}$ hydroxylation is believed to occur via a stepwise process of hydrogen-atom abstraction to form an iron hydroxide intermediate. This is followed by radical recombination to form product, as depicted in Figure 1.2. ${ }^{8-10,12,13}$ 


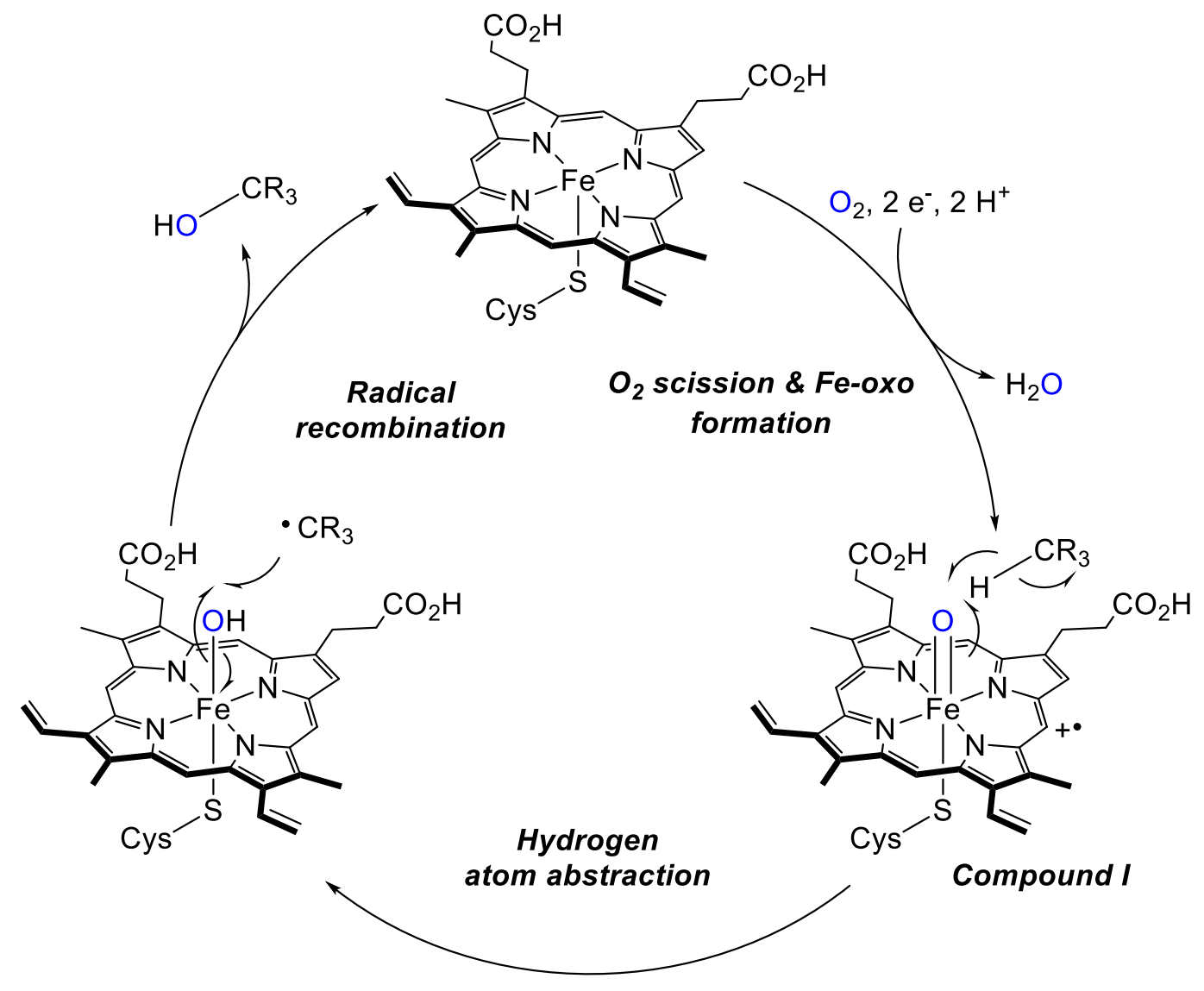

Figure 1.2. Proposed mechanism of $\mathrm{C}-\mathrm{H}$ hydroxylation facilitated via $\mathrm{P} 450$.

Thorough studies on P-450 and model systems have elucidated the electronic structure of Compound I, which is characterized as containing a triplet $\left(\mathrm{S}_{\mathrm{Fe}}=1\right)$ formally $\mathrm{Fe}(\mathrm{IV})$ center engaged in antiferromagnetic coupling to a porphyrin radical cation. The overall $S=1 / 2$ state has been corroborated via a combination of electron paramagnetic resonance and Mössbauer spectroscopies. ${ }^{12,14}$ An additional key characteristic of the electronic structure of Compound I is the presence of two unpaired electrons occupying Fe-O $\pi^{*}$ antibonding orbitals (Figure 1.3). ${ }^{15}$ The occupation of orbitals of antibonding character significantly destabilizes the iron-oxo or "ferryl" unit. This destabilization, in combination with the presence of significant unpaired spin 
density on the $\mathrm{Fe}-\mathrm{O}$ bond vector renders Compound I poised to engage a $\mathrm{C}-\mathrm{H}$ bond of a substrate molecule.
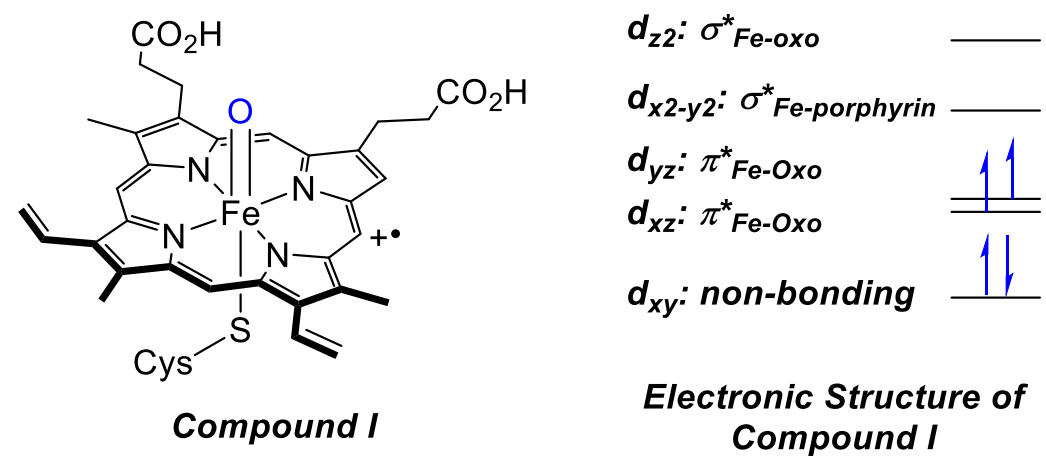

Figure 1.3. Simplified electronic structure of Compound I.

\subsection{Biomimetic Iron Chemistry: Atom and Group Transfer Reactivity}

Early researchers took notice of the remarkably reactivity of the P450 family of enzymes and sought to extend this reactivity to model systems. The development of biomimetic porphyrin complexes can be traced to the late 1970's when Groves and coworkers reported the application of (TPP) $\mathrm{Fe}(\mathrm{Cl})(\mathrm{TPP}=$ meso-tetraphenylporphyrin) in the oxidation of cyclohexane to cyclohexanol using iodosobenzene as the oxygen atom source. ${ }^{16}$ Using the same catalyst system, olefins, such as cyclohexene could also be converted to the corresponding epoxide (Scheme 1.1). This work has spurred decades of research in the areas of biomimetic iron-porphyrin chemistries, which is now a mature field. ${ }^{10,17}$ 

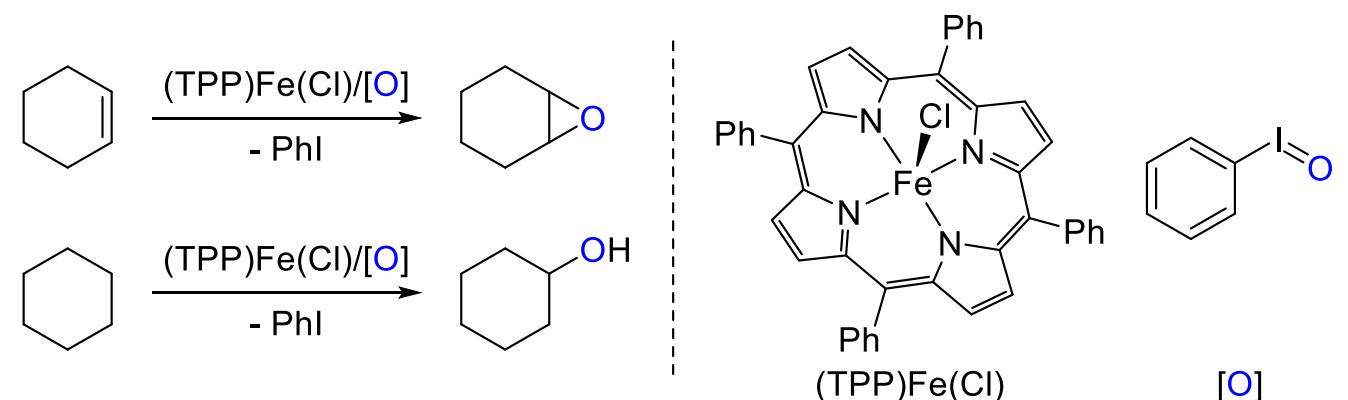

Scheme 1.1. Substrate dependent catalytic hydrocarbon oxidation with (TPP)Fe(Cl) and iodosobenzene.

Soon after, Breslow demonstrated the utility of (TPP) $\mathrm{Fe}(\mathrm{Cl})$ as an active catalyst in intramolecular nitrene transfer. Cyclic sulfonamides could be attained via the decomposition of the hypervalent iodine reagent 2,5-diisopropylbenzenesulfonylimidoiodobenzene as a model substrate (Scheme 1.2). ${ }^{18}$ In both cases, the formal insertion of an oxygen atom or an isoelectronic nitrene fragment $(\mathrm{N}-\mathrm{R})$ into a $\mathrm{C}-\mathrm{H}$ bond are believed to operate via a mechanistic pathways akin to Compound I, with iron-oxo and nitrene complexes implicated as penultimate intermediates.

In consideration of the demonstration of these porphyrin complexes as efficient atom or group transfer catalysts, significant attention has recently been devoted to further developing nitrene group transfer with other iron catalyst systems. Synthetic researchers have identified the practicality of direct nitrene insertion into a $\mathrm{C}-\mathrm{H}$ bond, or $\mathrm{C}-\mathrm{H}$ amination, as an efficient means to access valuable amine containing structures, which are ubiquitous in pharmaceuticals and bioactive molecules. ${ }^{19,20}$ Iron catalyzed C-H amination offers tremendous promise, not only due to the ubiquity of iron, but also in part to iron's biocompatibility. Despite the attractiveness of base metal catalyzed direct $\mathrm{C}-\mathrm{H}$ amination protocols, current practical synthetic methods employing small molecule catalysts are limited to systems containing scarce transition metals, such as rhodium and ruthenium. Despite the remarkable success and versatility of these noble 
metal catalyst systems (vide infra), obvious questions surrounding their long-term sustainability exist.

\subsection{Rhodium and Ruthenium Catalyzed Nitrene Group Transfer}

Presently, one of the most popular systems employed for selective nitrene transfer to $\mathrm{C}-\mathrm{H}$ bonds utilizes dirhodium complexes as catalysts. Ironically, dirhodium $\mathrm{C}-\mathrm{H}$ amination chemistry finds its origins in the same report disclosing the successful utilization of the (TPP)Fe( $\mathrm{Cl})$ as a nitrene group transfer catalyst. When evaluated under similar reaction conditions, $\mathrm{Rh}_{2}(\mathrm{OAc})_{4}$ demonstrated superior catalytic activity and efficiency relative to (TPP) $\mathrm{Fe}(\mathrm{Cl})$, as exemplified by both higher yield and selectively for the intramolecular $\mathrm{C}-\mathrm{H}$ amination product (Scheme 1.2). ${ }^{18}$
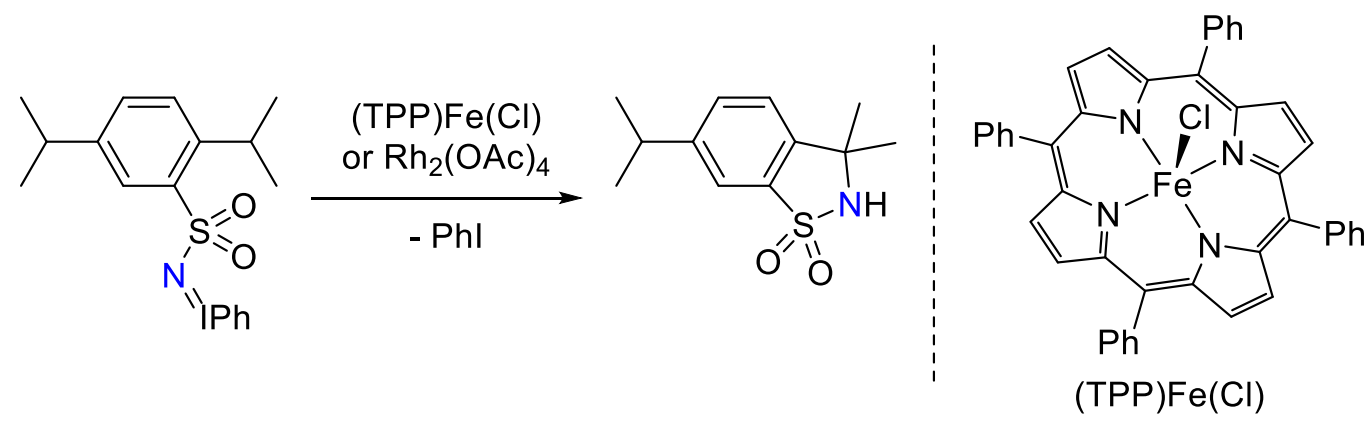

Scheme 1.2. Catalytic intramolecular nitrene transfer with $(\mathrm{TPP}) \mathrm{Fe}(\mathrm{Cl})$ or $\mathrm{Rh}_{2}(\mathrm{OAc})_{4}$.

This initial discovery has resulted in the subsequent development of a remarkably successful field employing dirhodium tetracarboxylate catalysts in catalytic nitrene transfer reactions. In recent decades, a combination of mechanistic insight and elegant ligand design has led to the advent of modern dirhodium catalyst systems with practical applications in the synthesis of highly complex molecular architectures. To date, the most popular and well-studied dirhodium carboxylate catalyst is $\mathrm{Rh}_{2}(\mathrm{esp})_{2}$ (where esp $=\alpha, \alpha, \alpha^{\prime}, \alpha^{\prime}$-tetramethyl-1,3-benzenedipropanoate) originally developed by Du Bois. ${ }^{21,22} \mathrm{In} \mathrm{Rh}_{2}(\mathrm{esp})_{2}$ the esp ligands impart stability via the chelate effect, which in turn effects higher catalytic efficiencies under low loadings, as compared to 
simpler dirhodium catalyst systems. An example is presented in Scheme 1.3, where an intramolecular $\mathrm{C}-\mathrm{H}$ amination reaction can be performed using only $0.15 \mathrm{~mol} \%$ of $\mathrm{Rh}_{2}(\mathrm{esp})_{2}$ as catalyst.

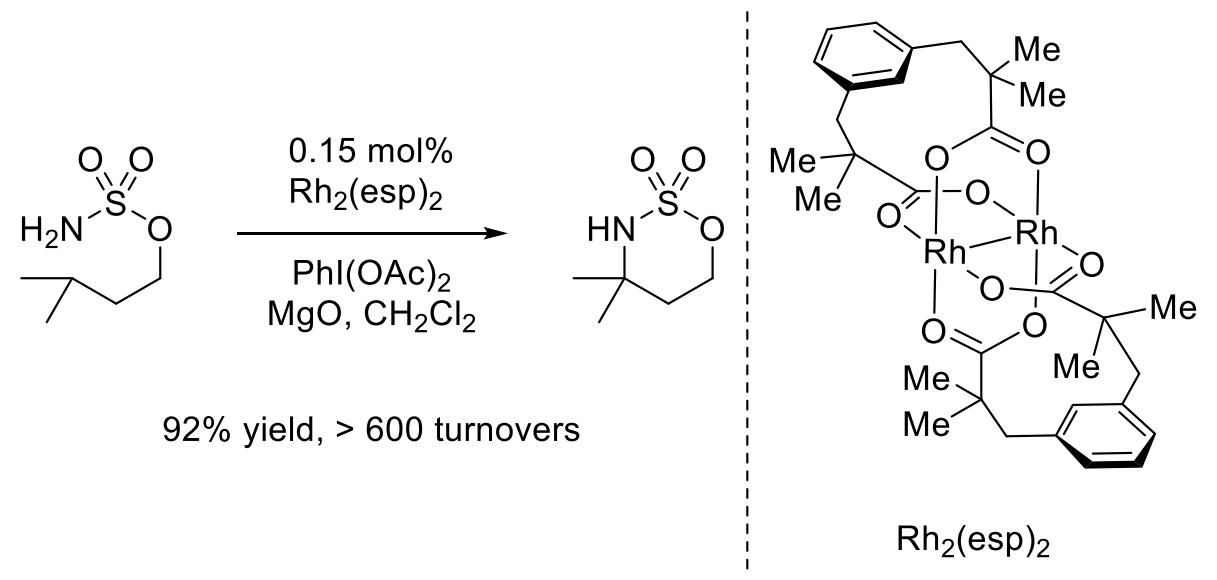

Scheme 1.3. Intramolecular C-H amination with $\mathrm{Rh}_{2}(\mathrm{esp})_{2}$ catalyst.

Further dirhodium catalyst elaboration has led to the discovery of asymmetric transformations, via informed ligand design. A noteworthy example is the intramolecular $\mathrm{C}-\mathrm{H}$ amination of aryl substituted sulfamate esters where the carboxamidate catalyst $\mathrm{Rh}_{2}(S \text {-nap })_{4}(S$ nap = 4-Methyl-N-(2-oxopiperidin-3-yl)benzenesulfonamide) effects the enantioselective intramolecular $\mathrm{C}-\mathrm{H}$ amination of sulfamate esters. ${ }^{23}$

In regard to mechanistic considerations, it is widely agreed upon that a discrete $\mathrm{Rh}_{2}$ nitrene intermediate is responsible for the observed reactivity (Figure 1.4). Generation of this nitrenoid species is typically accomplished in situ via the introduction of a hypervalent iodine reagent and oxidant, commonly $\mathrm{MgO}$, to a nitrogen containing substrate. Suitable nitrene precursors include carbamates, sulfamates, and ureas, for example. This strategy bypasses the 
direct isolation of the corresponding iminoiodinane nitrene precursors, which are generally challenging to manipulate and are potentially energetic materials. ${ }^{22}$

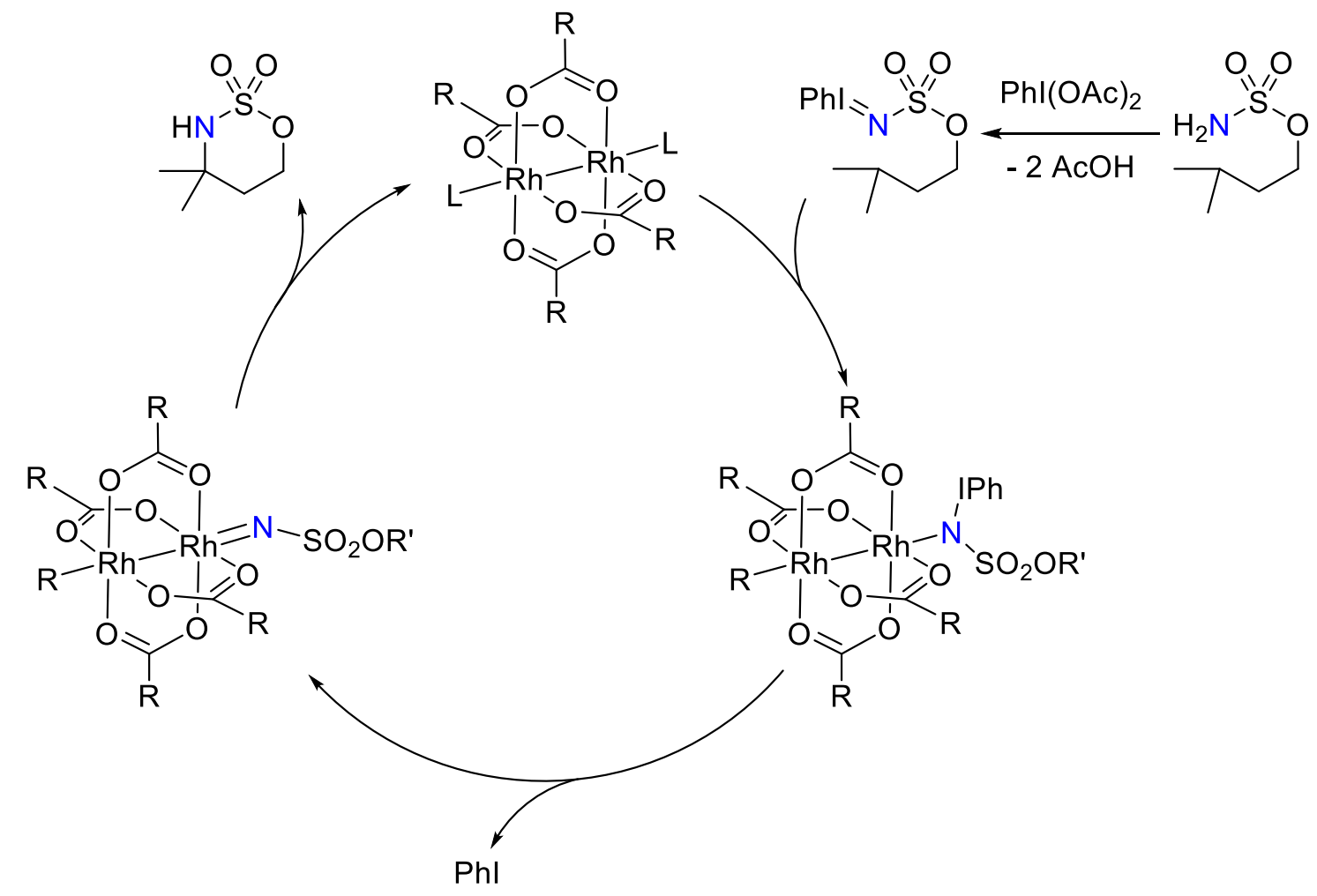

Figure 1.4. Proposed mechanism of dirhodium catalyzed $\mathrm{C}-\mathrm{H}$ amination. Note: $\mathrm{R}=$ solvent ligand and $\mathrm{R}^{\prime}=$ the hydrocarbon skeleton of the sulfamate ester starting material.

Despite the agreement that $\mathrm{Rh}_{2} \mathrm{C}-\mathrm{H}$ amination catalysis is facilitated by a $\mathrm{Rh}_{2}$-nitrenoid complex, the fleeting existence of such intermediates has complicated their characterization and study. Only recently has crystalline matrix isolation enabled the first X-ray crystallographically characterized example of a dirhodium nitrene complex, $\mathrm{Rh}_{2}(\operatorname{esp})_{2}\left(\mathrm{~N}^{1} \mathrm{Ad}\right)\left({ }^{1} \mathrm{AdN}_{3}\right)\left({ }^{1} \mathrm{Ad}=1\right.$ adamantyl) (Scheme 1.4). ${ }^{24}$ Generation of $\mathrm{Rh}_{2}(\mathrm{esp})_{2}\left(\mathrm{~N}^{1} \mathrm{Ad}\right)\left({ }^{1} \mathrm{AdN}_{3}\right)$ was accomplished via irradiation of a single crystal of the bis-azido precursor $\operatorname{Rh}_{2}(\operatorname{esp})_{2}\left({ }^{1} \mathrm{AdN}_{3}\right)_{2}$. In regard to electronic structure of this dirhodium nitrenoid, density functional theory studies favor a triplet ground state over a singlet for the truncated hypothetic nitrene model complex $\mathrm{Rh}_{2}(\mathrm{esp})_{2}\left(\mathrm{~N}^{\mathrm{t} B u}\right)($ 
${ }^{t} \mathrm{BuN}_{3}$ ). The electrophilic triplet nitrene is suggested to engage in two half order $\pi$ bonds stemming from the overlap of $\mathrm{Rh}-\mathrm{Rh} \pi^{*}$ orbitals with partially occupied orbitals of nitrene parentage.
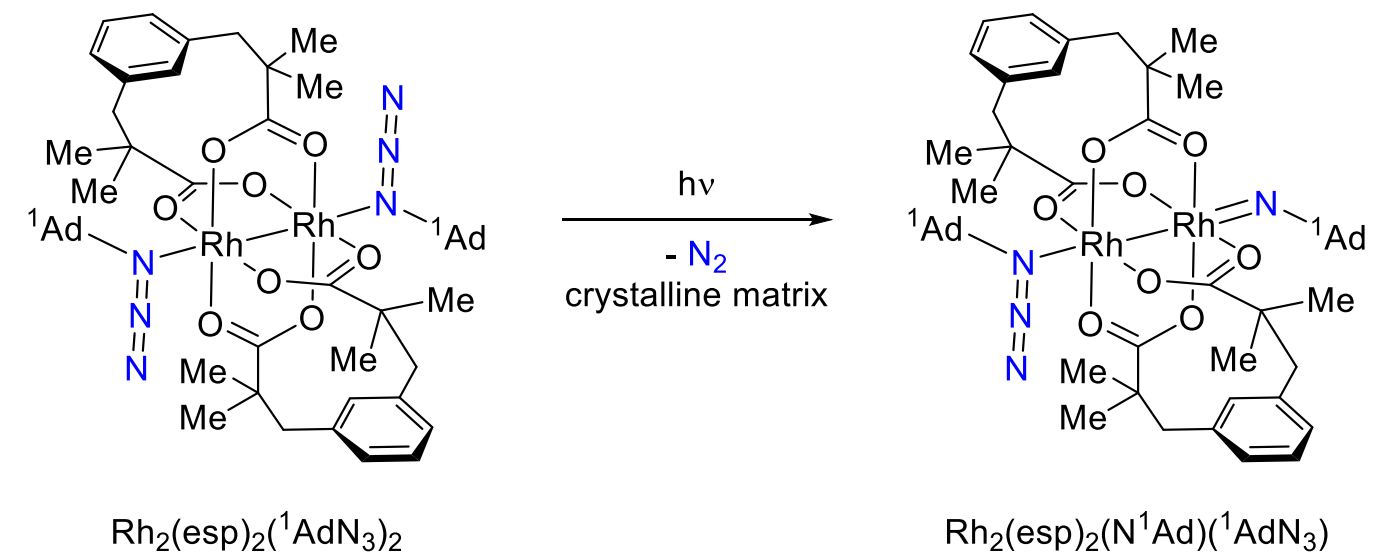

Scheme 1.4. Photogeneration of a dirhodium nitrene complex.

Prior to this report, Berry and coworkers examined the mechanism of dirhodium catalyzed C-H amination. ${ }^{25}$ In one aspect of this work, the electronic structures of $\left[\mathrm{Rh}_{2}(\mathrm{esp})_{2}\right]$ and $\left[\mathrm{Rh}_{2}(\mathrm{espn})_{2}\right]\left(\mathrm{espn}=\alpha, \alpha, \alpha^{\prime}, \alpha^{\prime}\right.$ - tetramethyl-1,3-benzenedipropanamidate $)$ catalytic intermediates were interrogated theoretically. Results of this study suggest that $\left[\mathrm{Rh}_{2}(\mathrm{esp})_{2}\right]$ and $\left[\mathrm{Rh}_{2}(\mathrm{espn})_{2}\right]$ catalysts may proceed through a concerted insertion of the nitrene into the $\mathrm{C}-\mathrm{H}$ bond, however, a stepwise mechanism involving radical intermediates was also identified. Currently, experimental evidence is available that is consistent with the concerted $\mathrm{C}-\mathrm{H}$ insertion pathway, such as stereoretention in optically active substrates, radical clock experiments, and KIE studies. ${ }^{22}$ Despite mechanistic questions still existing within the context of dirhodium catalyzed C-H amination, it has become clear that this methodology is a powerful means to perform nitrene transfer to $\mathrm{C}-\mathrm{H}$ bonds. 
Complimentary to dirhodium systems are diruthenium $\mathrm{C}-\mathrm{H}$ amination catalysts that have recently been developed. A noteworthy example is the diruthenium paddlewheel complex, tetrakis(2-oxypyridinato)diruthenium(II,III) chloride or $\left[\mathrm{Ru}_{2}(\mathrm{hp})_{4}(\mathrm{Cl})\right]$, where evidence has been garnered from experimental and computational studies that suggests that this catalysts operates via a stepwise radical pathway, contrary to the asynchronous $\mathrm{C}-\mathrm{H}$ insertion observed in $\mathrm{Rh}_{2}$ systems. ${ }^{26}$ The divergence in mechanistic pathways between $\mathrm{Ru}_{2}$ and $\mathrm{Rh}_{2}$ catalyst systems demonstrates the sensitivity of the electronic structure of the nitrene intermediate and its subsequent reactivity profile. An example that greatly exemplifies this dichotomy is found in allylic amination reactions of bis(homoallylic) sulfamate esters, where $\left[\mathrm{Ru}_{2}(\mathrm{hp})_{4}(\mathrm{Cl})\right]$ is an efficient precursor for the generation of a catalyst with high chemoselectivity for allylic amination. Whereas under the same reaction conditions, $\left[\mathrm{Rh}_{2}(\mathrm{esp})_{2}\right]$ and the diruthenium analogue $\left[\mathrm{Ru}_{2}(\mathrm{esp})_{2}\right]$ show little or no preference between allylic amination and olefin aziridination (Figure 1.5).
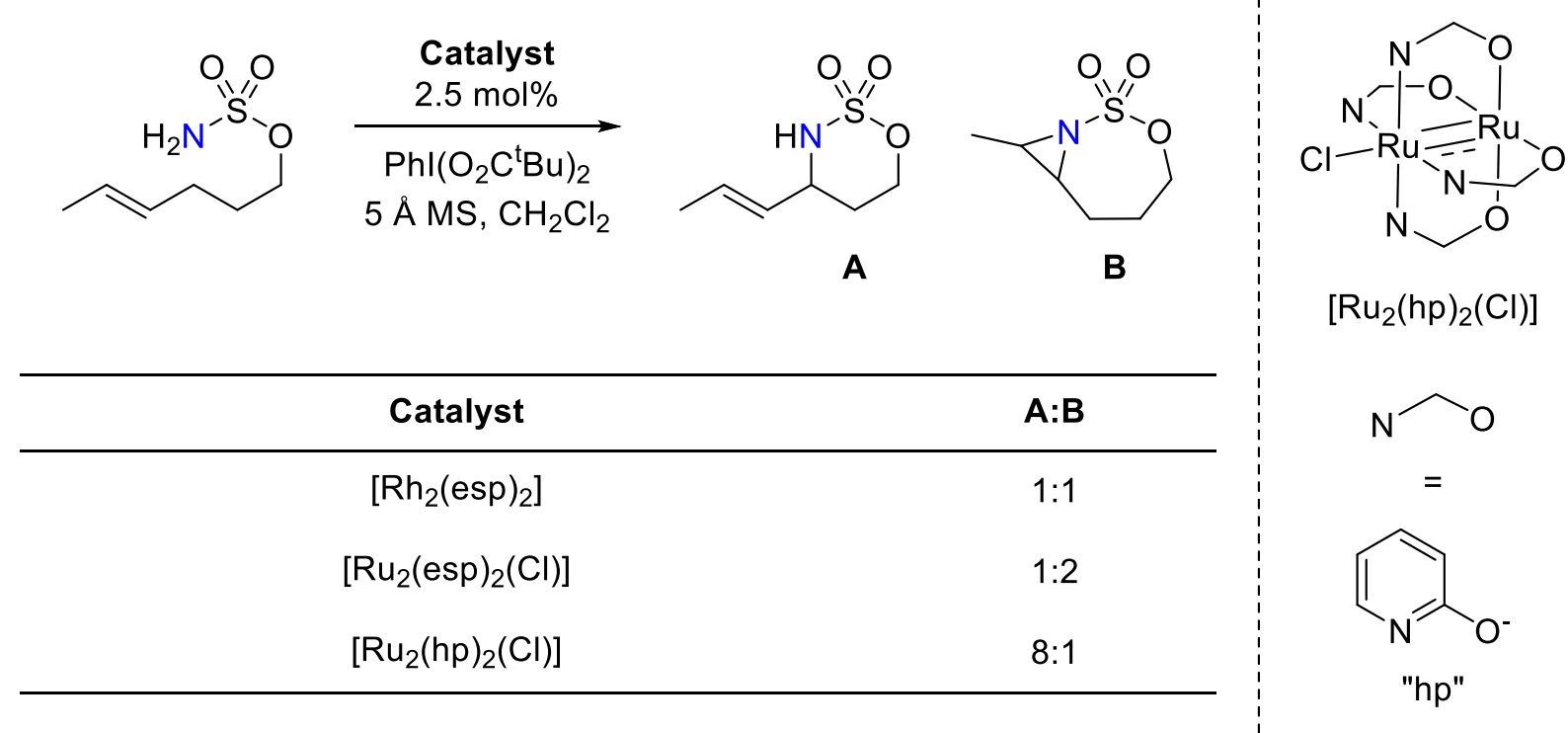

Figure 1.5. Selectivity for allylic C-H amination vs. olefin aziridination in dirhodium and diruthenium catalyst systems. 
Mononuclear ruthenium porphyrin complexes have also been extensively evaluated by Che, Gallo, and others as catalysts for the delivery of nitrene functionality to hydrocarbons. ${ }^{27-31}$ Isolation of bis-imido $\mathrm{Ru}(\mathrm{VI})$ porphyrin complexes has been accomplished via the reaction of the corresponding $\mathrm{Ru}(\mathrm{II})$ porphyrin carbonyl complexes with iminoiodinanes or organic azides. $(\mathrm{TPP}) \mathrm{Ru}(\mathrm{NAr})_{2}\left(\mathrm{Ar}=3,5-\left(\mathrm{CF}_{3}\right)_{2} \mathrm{C}_{6} \mathrm{H}_{3}\right)$ serves as a representative example of this class of compounds and has demonstrated activity in stoichiometric and catalytic allylic $\mathrm{C}-\mathrm{H}$ amination of hydrocarbons (Scheme 1.5).
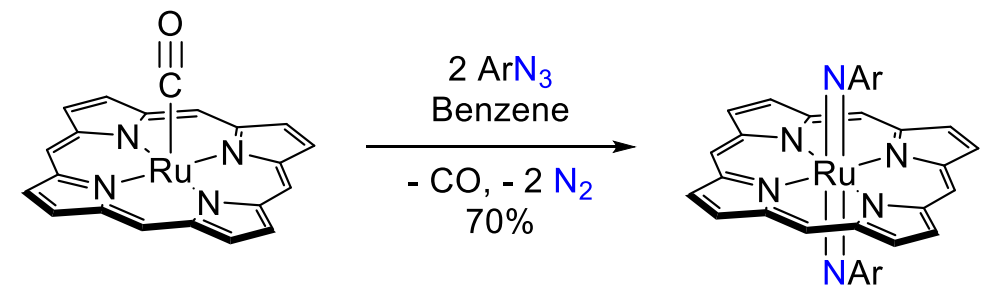

$(\mathrm{TPP}) \mathrm{Ru}(\mathrm{NAr})_{2}$

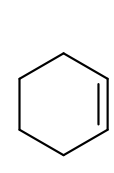

$(\mathrm{TPP}) \mathrm{Ru}(\mathrm{NAr})_{2}$

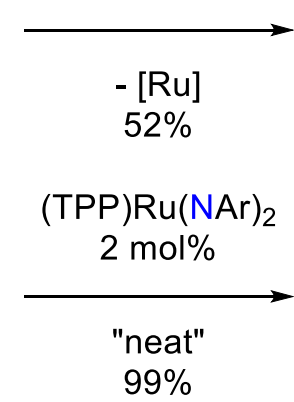<smiles>[AlH2]C([AlH2])NC1C=CCCC1</smiles><smiles>C1=CCCCC1</smiles>

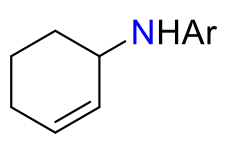

Scheme 1.5. Synthesis of (TPP)Ru(NAr) 2 and its stoichiometric and catalytic allylic C-H amination reactivity. Note: The TPP ligand is truncated via exclusion of the phenyl groups at the porphyrin meso positions.

An experimental mechanistic study of this system has suggested the likelihood of C-H abstraction from substrate in route to amidation product, while computational analysis has identified the subtle implications that the electronic structure of Ru imido species has on possible reaction manifolds. ${ }^{31}$ Results suggest that although these ruthenium complexes possess canonical dianionic closed shell imido ligands, intersystem crossing from the ground state singlet 
electronic structure to a thermally accessible triplet state results in the observation of significant spin-density imparted onto both imido nitrogens. The accumulation of spin density on the imido nitrogens is believed to facilitate $\mathrm{C}-\mathrm{H}$ functionalization via hydrogen atom abstraction from the substrate, followed by radical rebound to form the corresponding products. A second reaction manifold incorporating a mono-imido Ru(IV) carbonyl complex has also been identified. This intermediate is also proposed to undergo intersystem crossing to a triplet state and perform $\mathrm{C}-\mathrm{H}$ amination. Both mechanistic possibilities are presented in Figure 1.6. The observation of openshell electronic structures in silico in this system offers further evidence that the development of radical character at nitrene intermediates may be an important implication for the activation of C$\mathrm{H}$ bonds in some contexts. In light of this discovery, researchers have sought to develop base metal systems which seek to incorporate this design principle. 

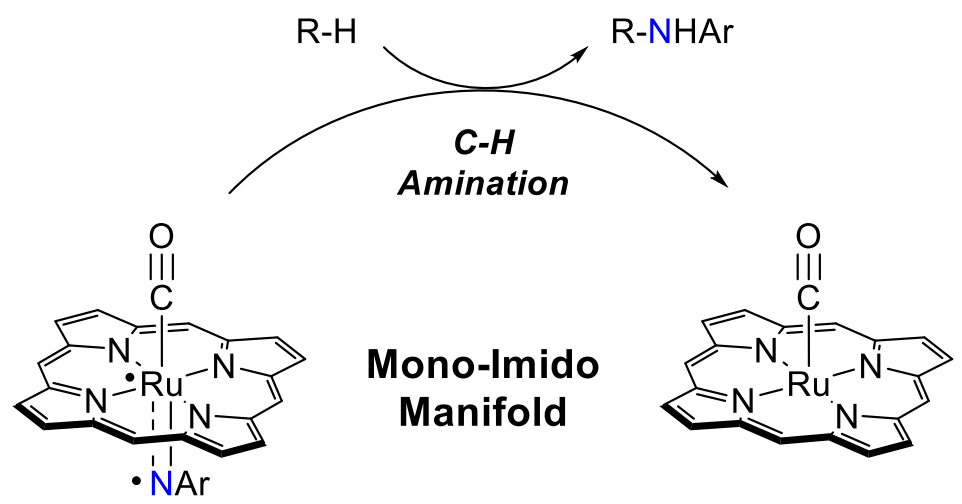

Triplet

Singlet

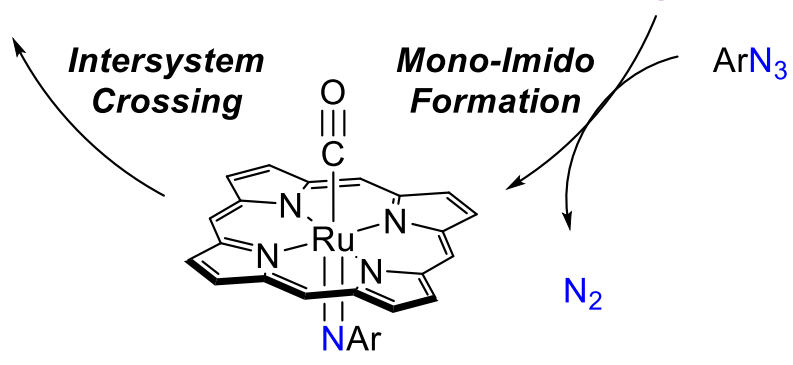

Singlet
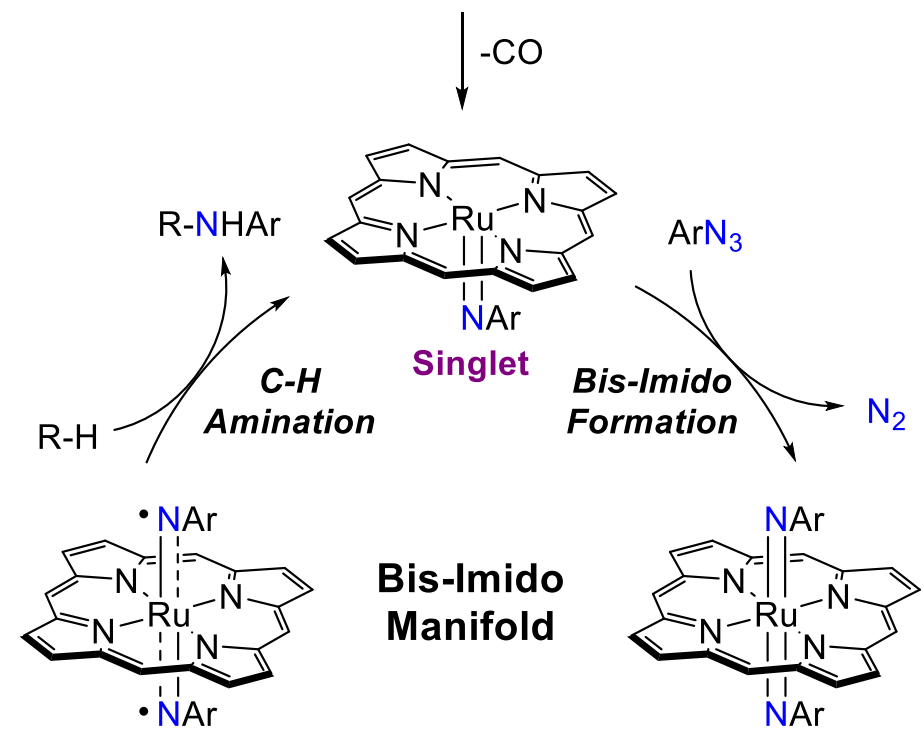

Triplet

Singlet

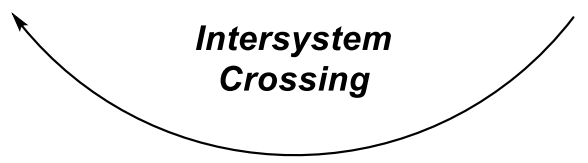

Figure 1.6. Proposed mechanisms of ruthenium porphyrin catalyzed $\mathrm{C}-\mathrm{H}$ amination. Note: The TPP ligand is truncated via exclusion of the phenyl groups. 


\subsection{Iron Mediated Nitrene Group Transfer}

Despite the tremendous success that has been realized by rhodium and ruthenium catalyst systems in nitrene group transfer reactions, a recent focus has returned to the examination of systems incorporating earth abundant metals in analogous reactions. Base metals offer not only a cost effective alternative to noble transition metal catalysts, but are also attractive due to their benign nature. Furthermore, the compressed ligand fields of $3 \mathrm{~d}$ metals relative to $4 \mathrm{~d}$ congeners may even offer the promise of complimentary reaction mechanisms. Although historically nitrene group transfer reactions have been widely explored for copper and manganese, ${ }^{32}$ a recent renewed interest in the development of highly active and selective iron nitrene group transfer catalyst systems has resulted in intensive efforts in this area of research.

Drawing motivation from P450 enzymatic catalysis, Arnold, Fasan, and others have leveraged abiological heme and non-heme catalysts engineered via directed evolution in selective nitrene transfer. ${ }^{33-40}$ Although this approach is environmentally considerate, complementary is the design of well-defined molecular catalysts. In contrast to the inherent complexity associated with enzymatic structures, molecular systems offer the promise of tunable ligand fields where informed design and modulation of electronic and steric environments can be performed when necessitated by particular reaction manifolds. In consideration of this, White and coworkers have recently extended the use of polypyrrole macrocycles in nitrene transfer reactions from porphyrins to the closely related macrocyclic iron pthalocyaninato chloride complex, $(\mathrm{Pc}) \mathrm{Fe}(\mathrm{Cl})\left(\right.$ Scheme 1.6). ${ }^{41}$ This catalyst has demonstrated activity in the selective allylic amination of $\mathrm{C}-\mathrm{H}$ bonds in the presence of iminoiodinane reagent $\mathrm{PhI}(\mathrm{OPiv})_{2}$ as oxidant. Mechanistic studies suggest the canonical radical rebound mechanism is operative in this system, as nitrene insertion is highly favored over the competitive aziridination pathway. 
Chemoselectivity for the $\mathrm{C}-\mathrm{H}$ bond is consistent with a rapid radical rebound upon formation of an allylic radical following hydrogen atom abstraction from the in situ generated iron nitrene. Furthermore, the observation of configurational retention and the lack of olefin isomerization in the substrates is consistent with this mechanistic proposal.
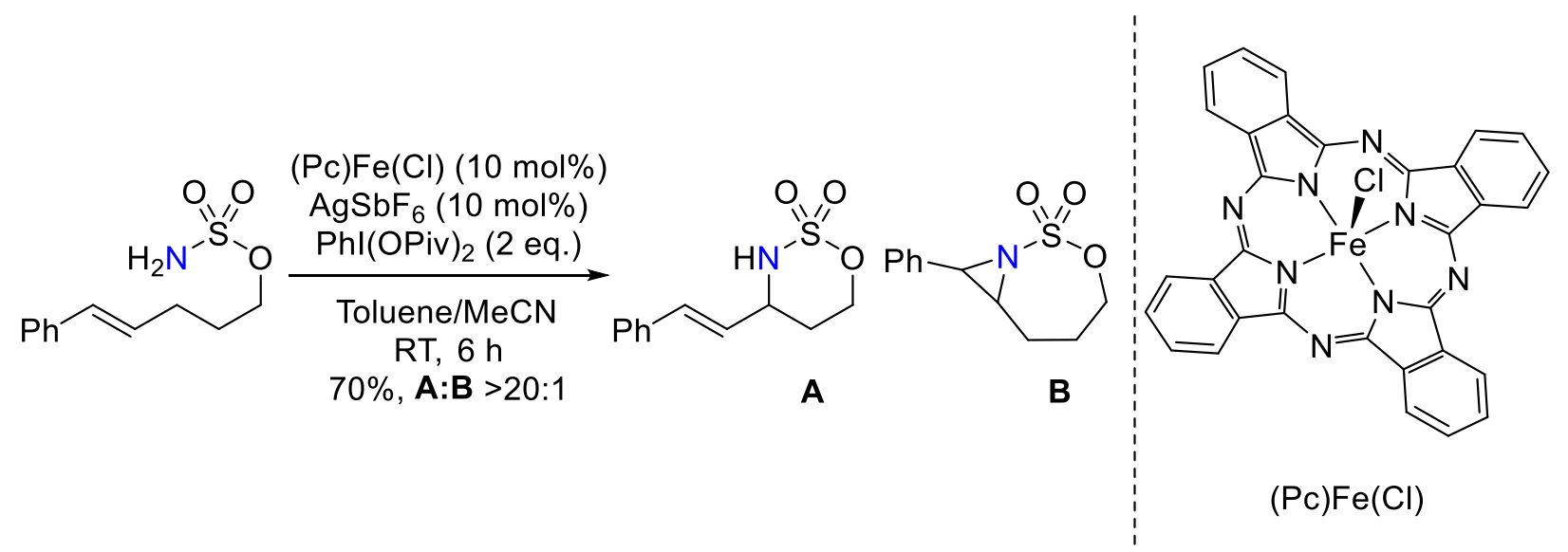

Scheme 1.6. $(\mathrm{Pc}) \mathrm{Fe}(\mathrm{Cl})$ catalyzed allylic $\mathrm{C}-\mathrm{H}$ amination.

Recently, attention has also been devoted to the exploration of catalytic nitrene group transfer reactions within the context of non-heme iron systems. An exciting development reported by Van der Vlugt et al. describes an air-stable $\mathrm{Fe}^{\mathrm{III}} \mathrm{C}-\mathrm{H}$ amination catalyst carrying a redox-active ligand, $\left(\mathrm{NNO}{ }^{\mathrm{ISQ}}\right) \mathrm{Fe}(\mathrm{Cl})_{2}{ }^{42}$ This complex is active in the direct intramolecular amination of $\mathrm{C}\left(\mathrm{sp}^{3}\right)-\mathrm{H}$ bonds in aliphatic azides to form a variety of saturated $\mathrm{N}$-heterocycles, such as pyrrolidines and piperidines with the highest TONs to date for this class of reactions. A variety of substrates, such as alkenyl, ethereal, and even carbonyl containing alkyl azides are amenable to the reaction. The direct $\mathrm{C}\left(\mathrm{sp}^{3}\right)-\mathrm{H}$ amination of representative substrate 1-azido-4phenylbutane to form the corresponding pyrrolidine product in moderate yield is depicted in Scheme 1.7. Although reactive intermediates have not yet been isolated within this system, mechanistic studies implicate a nitrenoid species. It is anticipated that the nitrenoid may either 
undergo direct insertion into a $\mathrm{C}-\mathrm{H}$ bond of the substrate to form the amine product or perform an H-atom abstraction followed by a radical rebound reminiscent of P450 chemistry.
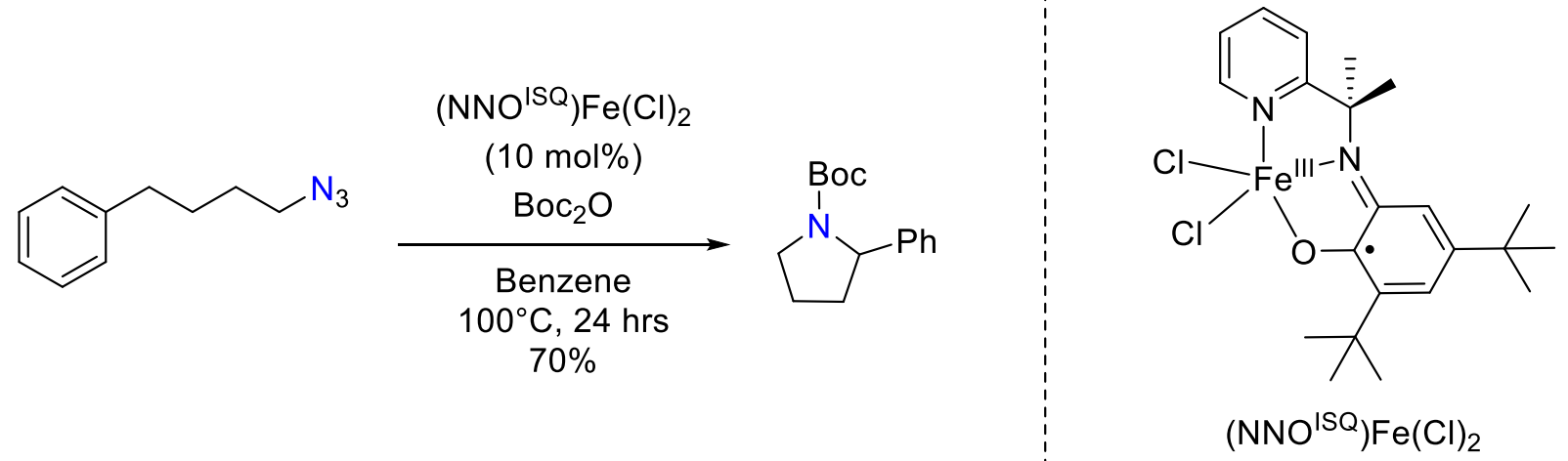

Scheme 1.7. Iron catalyzed C-H amination of 1-azido-4-phenylbutane.

Similarly, Betley and coworkers have also reported a well-defined iron C-H amination catalyst utilizing dipyrromethenes as supporting ligands. ${ }^{43,44}$ In these protocols, bulky high-spin $\mathrm{Fe}^{\mathrm{II}}$ dipyrromethene complexes, such as $\left({ }^{\mathrm{Ad}} \mathrm{L}^{2,6-\mathrm{Cl} 2 \mathrm{Ph}}\right) \mathrm{Fe}(\mathrm{Cl})\left(\mathrm{OEt}_{2}\right)\left(\right.$ where ${ }^{\mathrm{Ad}} \mathrm{L}^{2,6-\mathrm{Cl} 2 \mathrm{Ph}}=1$,9-di(1adamantyl)-5-(2,6-dichloro)benzene-dipyrromethene), are capable of catalytically decomposing aliphatic azides to generate pyrrolidines. It is anticipated that nitrene intermediates are responsible for the intramolecular $\mathrm{C}-\mathrm{H}$ amination reactivity. Notably, this system is able to generate valuable saturated N-heterocycle products with enantioselectivity (Scheme 1.8), a milestone for iron $\mathrm{C}-\mathrm{H}$ amination catalysts.

Thorough mechanistic and electronic structure analysis of this system has allowed for elucidation of possible reaction pathways. It is suggested that that the key penultimate intermediate is a high-spin Fe $\mathrm{III}^{\mathrm{II}}$ inyl radical species. Despite the high reactivity of such complexes, careful selection of the ancillary ligand has allowed for their isolation and 
crystallographically characterization, such as in the case of the $\left({ }^{\mathrm{Ar}} \mathrm{L}\right) \mathrm{Fe}(\mathrm{NAr})(\mathrm{Cl})$, (where ${ }^{\mathrm{Ar}} \mathrm{L}=$ 1,9- $\mathrm{Ar}_{2}$-5-mesityl-dipyrromethene, and $\left.\mathrm{Ar}=2,4,6-\mathrm{Ph}_{3}-\mathrm{C}_{6} \mathrm{H}_{2}\right)\left(\right.$ Scheme 1.8). ${ }^{45}$ Significant spindensity localized on the iron iminyl fragment of this and related compounds is considered a key characteristic of the electronic structure of this system which has direct implications for their efficacy in C-H amination catalysis of nitrene group transfer.
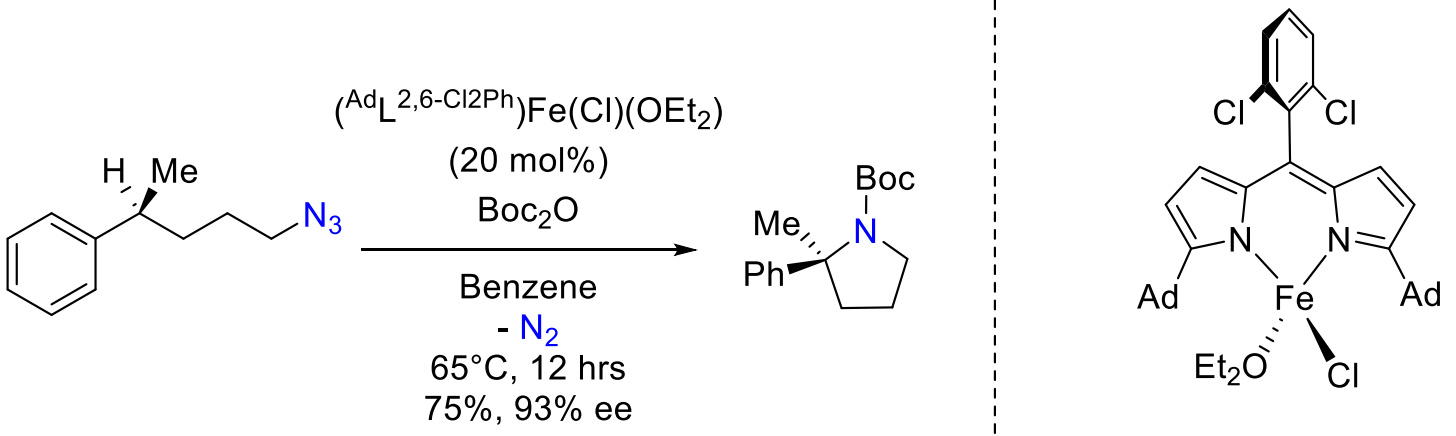

$\left({ }^{\mathrm{Ad}} \mathrm{L}^{2,6-\mathrm{Cl} 2 \mathrm{Ph}}\right) \mathrm{Fe}(\mathrm{Cl})\left(\mathrm{OEt}_{2}\right)$
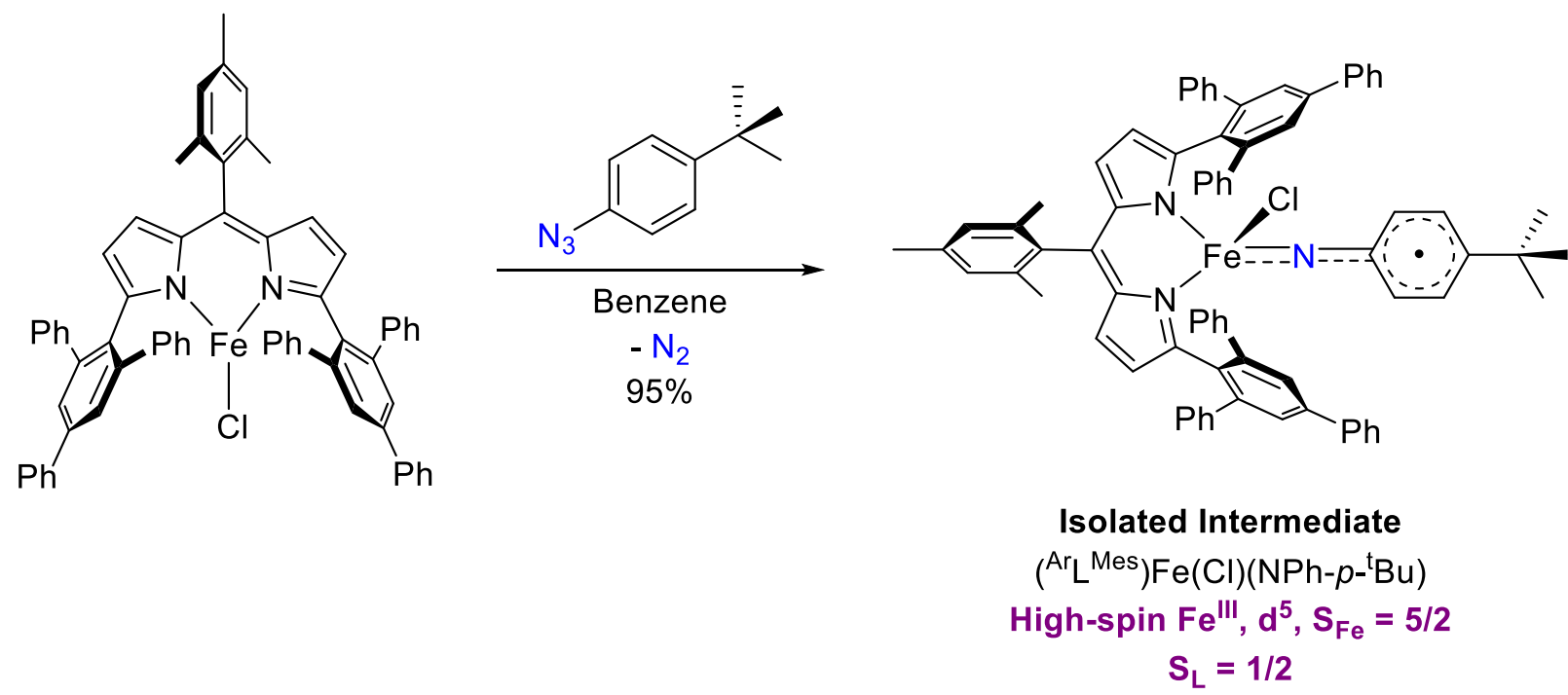

Scheme 1.8. Pyrrolidine synthesis via direct $\mathrm{Fe}$ catalyzed $\mathrm{C}-\mathrm{H}$ amination (top) and isolation of an $\mathrm{Fe} \mathrm{e}^{\mathrm{III}}$ iminyl radical intermediate (bottom). Note: $\mathrm{Ad}=1$-adamantyl, $\mathrm{Ar}=2,4,6$-triphenylbenzene, $\mathrm{L}=\mathrm{NPh}-\mathrm{p}^{\mathrm{t}} \mathrm{Bu}$.

Subsequent studies have allowed for further interrogation of the reaction mechanism, which is supported by the isolation and characterization of amine, amido, and terminal or 
bridging imido/iminyl intermediates (Figure 1.7). ${ }^{46} \mathrm{~A}$ mechanism has been proposed where upon addition of azide to the bridging dimeric $\mathrm{Fe}^{\mathrm{II}}$ complex, $\left.\left[{ }^{\mathrm{tBu}} \mathrm{L}\right) \mathrm{FeCl}\right]_{2}\left(\mu-\mathrm{NC}_{6} \mathrm{H}_{3}-3,5-\left(\mathrm{CF}_{3}\right)_{2}\right)$, a monomeric iminyl Fe ${ }^{\mathrm{III}}$ iminyl radical species $\left[\left({ }^{\mathrm{tBu}} \mathrm{L}\right) \mathrm{FeCl}\right]_{2}\left(\mathrm{NC}_{6} \mathrm{H}_{3}-3,5-\left(\mathrm{CF}_{3}\right)_{2}\right)$ is formed. $\left[\left({ }^{\mathrm{tBu}} \mathrm{L}\right) \mathrm{FeCl}\right]_{2}\left(\mathrm{NC}_{6} \mathrm{H}_{3}-3,5-\left(\mathrm{CF}_{3}\right)_{2}\right)$ is proposed to exist in equilibria in solution with the structurally characterized dimeric form. C-H abstraction from substrate forms a monomeric $\mathrm{Fe}^{\mathrm{III}}$ amido complex, which may recombine with an allylic radical to furnish the corresponding $\mathrm{C}-\mathrm{H}$ amination product with concomitant formation of the high-spin ferrous starting material.

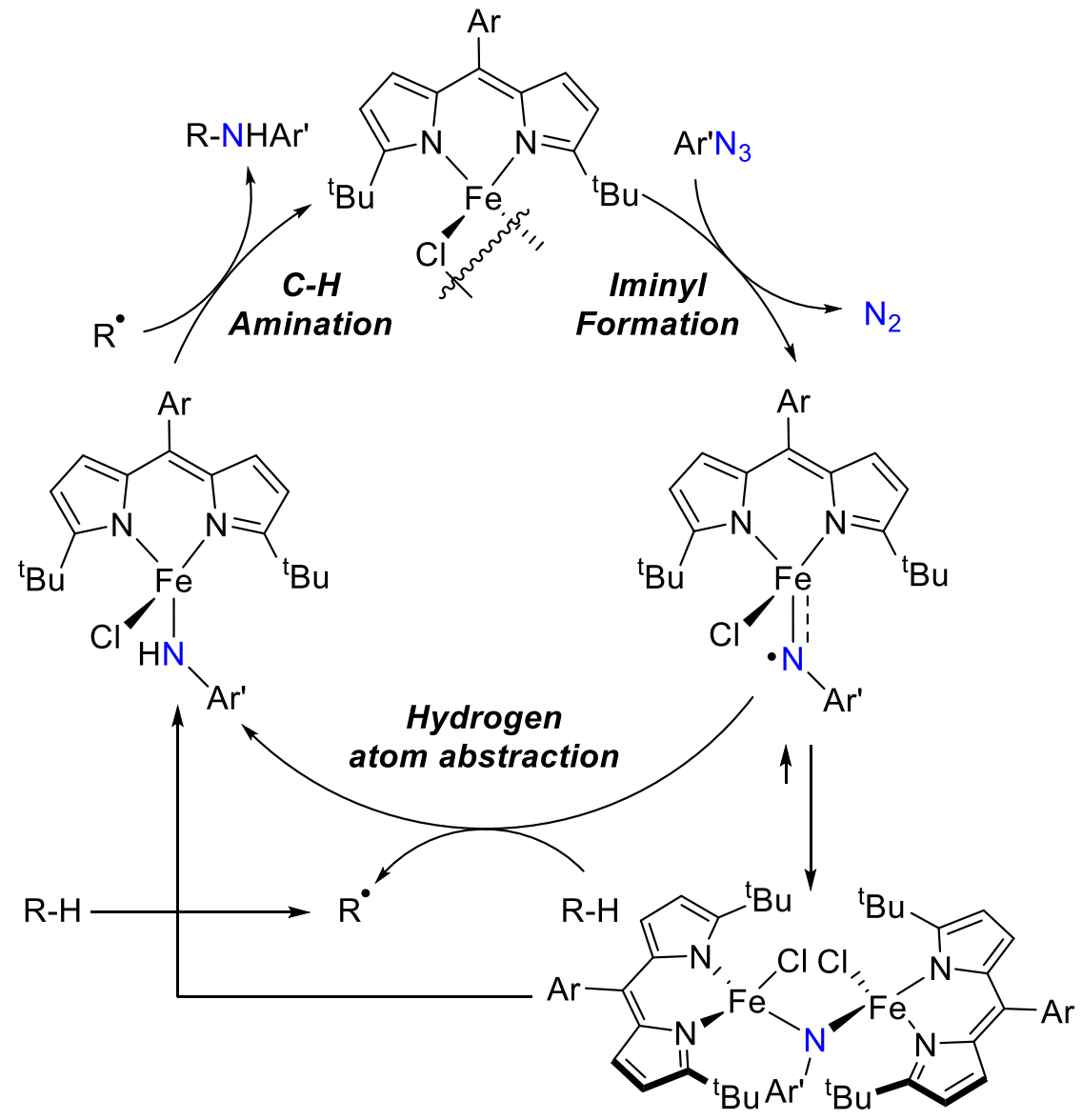

Figure 1.7. Proposed mechanism of allylic $\mathrm{C}-\mathrm{H}$ amination of cyclohexene with dipyrromethene iron iminyl complexes. Note: $\mathrm{Ar}=\mathrm{C}_{6} \mathrm{H}_{3}-2,6-(\mathrm{Cl})_{2}, \mathrm{Ar}^{\prime} \mathrm{C}_{6} \mathrm{H}_{3}-3,5-\left(\mathrm{CF}_{3}\right)_{2}, \mathrm{R}=$ cyclohexene or the cyclohexenyl allylic radical. 
Another ligand framework incorporating pyrrole moieties has recently been developed and utilized by Caulton, Mindiola, and others in the synthesis of the cis-divacant octahedral imido complex $\left({ }^{\mathrm{tBu}} \mathrm{PDP} \mathrm{P}^{\mathrm{tBu}}\right) \mathrm{Fe}\left(\mathrm{N}^{1} \mathrm{Ad}\right) .{ }^{47}$ Thorough spectroscopic and computational characterization of this complex has revealed a low-spin $\mathrm{Fe}^{\mathrm{IV}}$ ground state $\left(\mathrm{d}^{4}, \mathrm{~S}=0\right)$ for the iron ion and a dianionic closed-shell imide ligand. In line with this assessment, $\left({ }^{\mathrm{tBu} P D P} \mathrm{P}^{\mathrm{tBu}}\right) \mathrm{Fe}\left(\mathrm{N}^{1} \mathrm{Ad}\right)$ was found to be unreactive towards $\mathrm{C}-\mathrm{H}$ bonds, despite its high formal oxidation state. ${ }^{48}$ In consideration that spin-density along a metal-imido or nitrene bonding interaction may promote $\mathrm{C}-\mathrm{H}$ amination reactivity, the synthesis of the corresponding $\mathrm{Co}^{\mathrm{IV}}\left(\mathrm{d}^{5}, \mathrm{~S}=1 / 2\right)$ analogue, which was hypothesized to feature the additional d electron in a $\mathrm{Co}=\mathrm{N} * \pi$ orbital of $\mathrm{d}_{\mathrm{yz}}$ parentage (Scheme 1.9), was performed. Surprisingly, the reaction of the $\mathrm{Co}^{\mathrm{II}}$ synthon $\left.{ }^{\mathrm{tBu}}{ }^{\mathrm{PDP}}{ }^{\mathrm{tBu}}\right) \mathrm{Co}\left(\mathrm{OEt}_{2}\right)$ with 1-adamantyl azide resulted in the isolation of a $\mathrm{Co}^{\mathrm{II}}$ azido adduct, $\left({ }^{\mathrm{tBu}} \mathrm{PDP}^{\mathrm{tBu}}\right) \mathrm{Co}\left(\mathrm{N}_{3}{ }^{1} \mathrm{Ad}\right)$, instead of the anticipated imide $\left({ }^{\mathrm{tBu}} \mathrm{PDP}^{\mathrm{tBu}}\right) \mathrm{Co}\left(\mathrm{N}^{1} \mathrm{Ad}\right)$. However, upon exposure to UV light, $\left({ }^{\mathrm{tBu}} \mathrm{PDP}{ }^{\mathrm{tBu}}\right) \mathrm{Co}\left(\mathrm{N}_{3}{ }^{1} \mathrm{Ad}\right)$ underwent clean intramolecular $\mathrm{C}-\mathrm{H}$ amination of a $\mathrm{C}-\mathrm{H}$ bond of a proximal tert-butyl group of the supporting ligand, yielding the $\mathrm{Co}^{\mathrm{II}}$ amine adduct $\mathrm{Co}\left(\mathrm{NH}^{1} \mathrm{Ad}^{\mathrm{tBu}} \mathrm{PDP} \mathrm{P}^{\mathrm{tBu}}\right)$, as confirmed by X-ray crystallography (Scheme 1.9). Despite eluded direct observation, $\left({ }^{\mathrm{B} u} \mathrm{PDP}^{\mathrm{tBu}}\right) \mathrm{Co}\left(\mathrm{N}^{1} \mathrm{Ad}\right)$ has been implicated as the reactive intermediate responsible for this transformation. ${ }^{48}$ 
<smiles></smiles><smiles>CCOCn1c(C(C)(C)C)cc(C(C)(C)C)c1-c1cccc(-c2c(C(C)(C)C)cc(C(C)(C)C)n2OCC)n1</smiles>

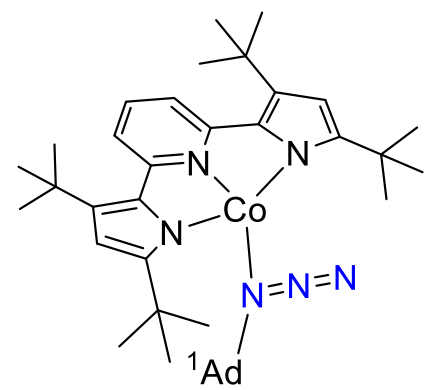<smiles>CC(C)(C)c1cc(C(C)(C)C)n(C#N)c1-c1cccc(-c2c(C(C)(C)C)cc(C(C)(C)C)n2C#N)n1</smiles>

Proposed Intermediate Low-spin Co(IV), $d^{5}, S_{C_{o}}=1 / 2$
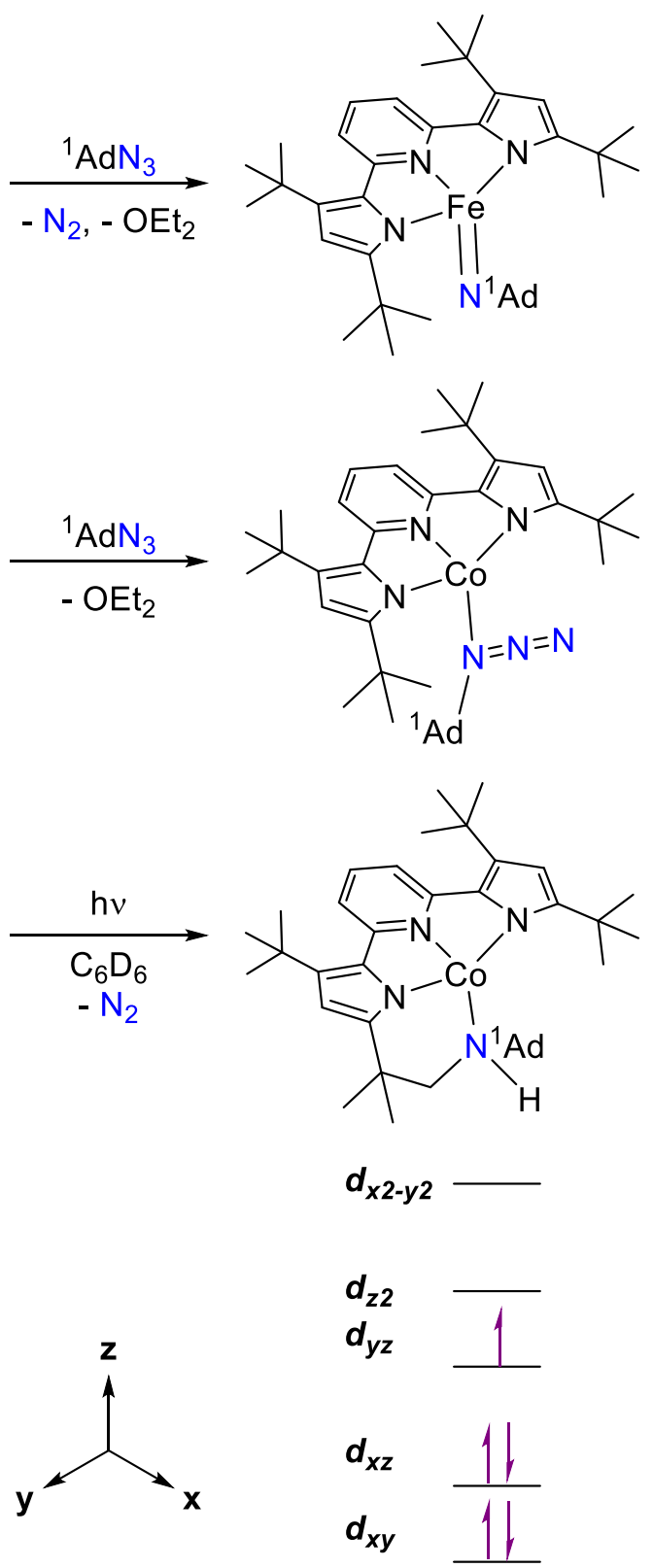

Electronic Structure of Proposed Intermediate

Scheme 1.9. Reactivity of $\mathrm{Fe}$ and $\mathrm{Co}\left({ }^{\mathrm{tBu}} \mathrm{PDP}^{\mathrm{tBu}}\right)$ complexes with 1-adamantyl azide.

In this dissertation, Chapter 2 discloses the development of the related ${ }^{\mathrm{Mes}} \mathrm{PDP}^{\mathrm{Ph}}$ ligand system and assessment of its $\mathrm{Fe}^{\mathrm{II}}$ coordination chemistry. In contrast to ${ }^{\mathrm{tBu}} \mathrm{PDP}^{\mathrm{tBu}} \mathrm{Fe}^{\mathrm{II}}$ complexes, which are characterized by cis-divacant octahedral geometries, ${ }^{\mathrm{Mes}} \mathrm{PDP}^{\mathrm{Ph}}$ has been found to 
support unusual square-planar high-spin $\mathrm{Fe}^{\mathrm{II}}$ complexes $\left({ }^{\mathrm{Mes}} \mathrm{PDP}{ }^{\mathrm{Ph}}\right) \mathrm{Fe}(\mathrm{L})($ where $\mathrm{L}=$ thf or $\mathrm{Et}_{2} \mathrm{O}$ ). Chapter 3 describes the reactivity of these complexes with a variety of organic azides as nitrene sources. A diverse array of reaction outcomes has been documented depending on the identity of the azide employed, including the formation of a reactive iron nitrene intermediate, $\left({ }^{\mathrm{Mes}} \mathrm{PDP}^{\mathrm{Ph}}\right) \mathrm{Fe}(\mathrm{NMes})$. Paramagnetic $\left({ }^{\mathrm{Mes}} \mathrm{PDP}^{\mathrm{Ph}}\right) \mathrm{Fe}(\mathrm{NMes})$ undergoes intramolecular nitrene group transfer to the ${ }^{\mathrm{Mes}} \mathrm{PDP}^{\mathrm{Ph}}$ supporting ligand, in stark contrast to $\left({ }^{\mathrm{CBu}} \mathrm{PDP}^{\mathrm{tBu}}\right) \mathrm{Fe}\left(\mathrm{N}^{1} \mathrm{Ad}\right)$, which is unreactive to $\mathrm{C}-\mathrm{H}$ bonds. Similarly, $\left({ }^{\mathrm{Mes}} \mathrm{PDP}{ }^{\mathrm{Ph}}\right) \mathrm{Fe}(\mathrm{L})$ complexes also undergo analogous $\mathrm{C}-\mathrm{H}$ amination chemistry when reacted with alkyl azides. A density functional theory study has illuminated a bias towards planar paramagnetic ${ }^{\mathrm{Mes}} \mathrm{PDP}^{\mathrm{Ph}}$ iron nitrene adducts that have paramagnetic electronic structures and iminyl radical character.

The investigations presented in Chapter 4 seek to build on the aforementioned developments and describes the synthesis and characterization of a variety of new pyridine dipyrrolide ligands. It is anticipated that these complexes may find utility in stabilizing new iron imide or iminyl complexes in various coordination geometries or ultimately finding utility in productive nitrene group transfer chemistry. Chapter 5 discloses initial investigations of the reactivity of one of these complexes, $\left({ }^{\mathrm{C} 12 \mathrm{Ph}} \mathrm{PDP}^{\mathrm{Ph}}\right) \mathrm{Fe}($ thf $)$, with an array of organic azides. The synthesis and characterization of the iron imide and iminyl complexes $\left({ }^{2,6-C l 2 P h} \mathrm{PDP}^{\mathrm{Ph}}\right) \mathrm{Fe}\left(\mathrm{N}^{1} \mathrm{Ad}\right)$ and $\left.{ }^{2,6-\mathrm{C} 12 \mathrm{Ph}} \mathrm{PDP}^{\mathrm{Ph}}\right) \mathrm{Fe}(\mathrm{NMes})$ is presented. Furthermore, the electronic structures of these two complexes are interrogated via complementary density functional theory studies.

\subsection{Iron Mediated Carbene Group Transfer}

Similar to the generation of metallonitrenes in $\mathrm{C}-\mathrm{H}$ amination, isoelectronic metallocarbene intermediates are utilized to effect the insertion of the carbene $\left(\mathrm{CR}_{2}\right)$ functionality into $\mathrm{C}-\mathrm{X}$ or $\mathrm{C}-\mathrm{H}$ bonds (where $\mathrm{X}=\mathrm{O}, \mathrm{N}$, etc.). These transformations offer 
significant appeal as the construction of new carbon-heteroelement or -carbon bonds allow for the rapid diversification of small molecules in one step. Owing to this efficiency, transition metal catalyzed carbene insertion reactions have become routinely implemented in modern organic synthesis ${ }^{49}$ Despite the variety of late transition metals that effect catalytic C-H insertion, this reaction is still underdeveloped for iron, which is unexpected given iron's ability to effect analogous C-H hydroxylation and amination chemistries. ${ }^{50-52}$ Despite the challenges that have accompanied the development of iron catalyzed $\mathrm{C}-\mathrm{H}$ insertion chemistry, other reactions implicating iron carbene intermediates, such as cyclopropanation of olefins and the aforementioned class of $\mathrm{C}$-X insertion reactions have been studied in recent decades. ${ }^{53}$

Consistent with the successes that have been realized via the directed evolution of enzymatic catalysts for oxygen atom and nitrene transfer, carbene transfer reactions have also been extensively explored in recent years. ${ }^{54-57}$ In contrast to these systems, the first example of a discrete small molecule iron catalyst capable of promoting carbene group transfer reactions was reported in the early 1990's by Hossain. ${ }^{58}$ The use of $\left[(\mathrm{Cp}) \mathrm{Fe}(\mathrm{CO})_{2}(\right.$ thf $\left.)\right]\left[\mathrm{BF}_{4}\right]$ in carbene group transfer catalysis came nearly 40 years after the first evidence of stoichiometric iron carbene group transfer from $(\mathrm{Cp}) \mathrm{Fe}(\mathrm{CO})_{2}\left(\mathrm{CH}_{2} \mathrm{OCH}_{3}\right)$ was disclosed by Jolly (Scheme 1.10). ${ }^{59}$ In recent decades, widespread investigations of small molecule iron catalysts in carbene group transfer reactions have been conducted by a variety of groups, with important contributions in the area of iron porphyrin group transfer catalysis made by Woo and coworkers. A notable advance includes Woo's report of insertion into aliphatic C-H bonds using $\alpha$-diazoesters and a simple (TPP)Fe(Cl) catalyst (Scheme 1.10). ${ }^{60,61}$ Subsequently, iron porphyrin complexes have been deemed privileged carbene group transfer catalysts due to their high activity in both olefin cyclopropanation and C-H/X insertion reactions. ${ }^{62,63}$ 


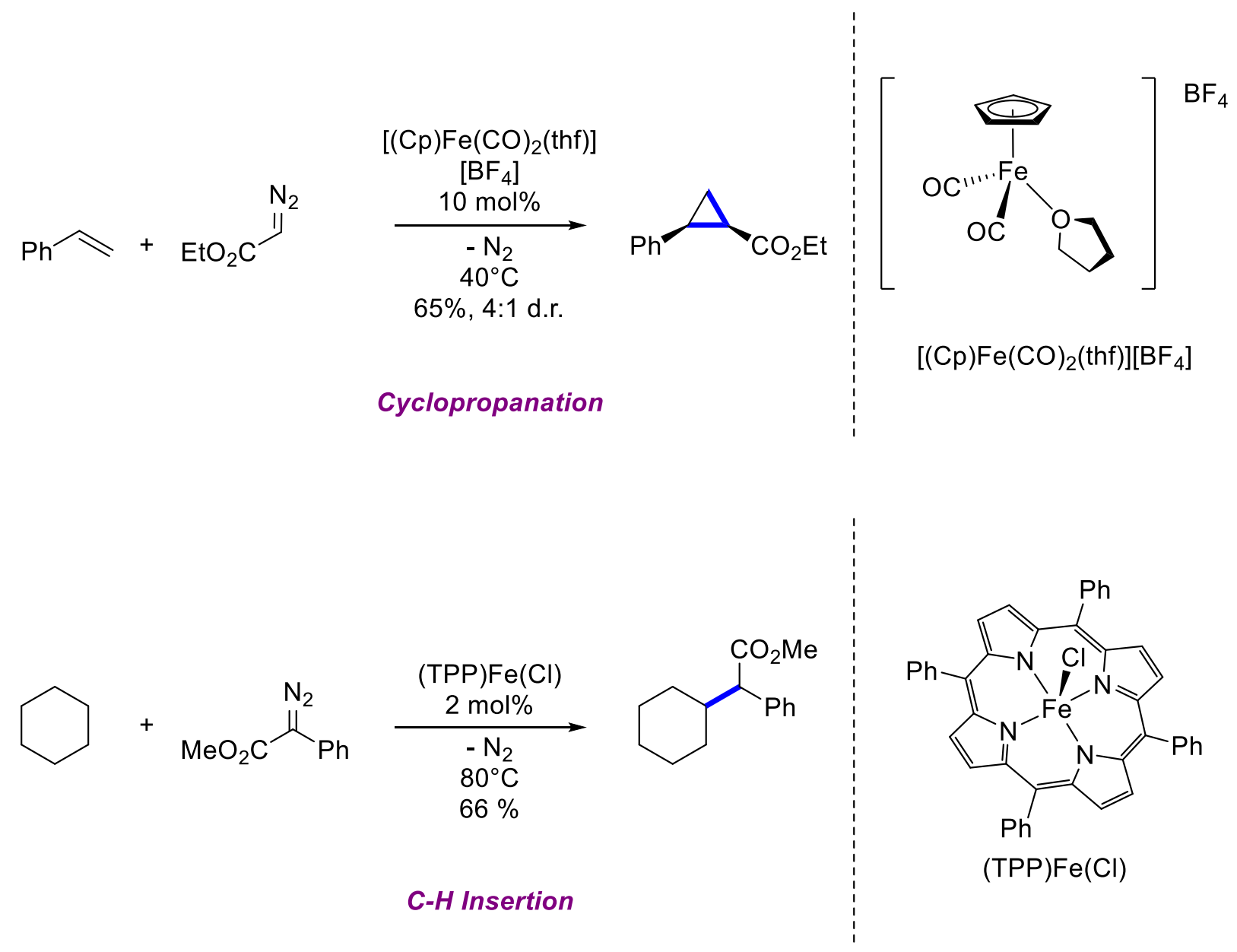

Scheme 1.10. Iron catalyzed carbene group transfer reactions.

More recently, an intramolecular C-H alkylation of diazoesters has been developed by White (Scheme 1.11). ${ }^{64}$ The combination of catalytic $\mathrm{NaBAr}_{4}{ }_{4}\left(\mathrm{NaBAr}_{4}=\right.$ sodium tetrakis $[3,5-$ bis(trifluoromethyl)phenylborate) and macrocyclic iron pthalocyanine $(\mathrm{Pc}) \mathrm{Fe}(\mathrm{Cl})$ is key to the success of this transformation, generating a sufficiently electrophilic active species. Despite its similarity to $(\mathrm{Pc}) \mathrm{Fe}(\mathrm{Cl}),(\mathrm{TPP}) \mathrm{Fe}(\mathrm{Cl})$ was found to be inactive in this transformation, a result ascribed to the greater $\pi$-accepting capability of the pthalocyanine macrocycle. Notably, this transformation is amenable to a diverse array of functional groups on the sulfonate ester and even found utility in the synthesis of biologically relevant $\delta$-tocopherol. Mechanistic studies have 
implicated an iron carbene intermediate capable of $\mathrm{C}-\mathrm{H}$ abstraction to form allylic or benzylic radicals, which are poised to undergo radical rebound to form the corresponding $\delta$-sultone products. Interestingly, this proposed mechanism is similar to those previously discussed for iron oxo and nitrene intermediates that promote $\mathrm{C}-\mathrm{H}$ hydroxylation and amination, respectively.
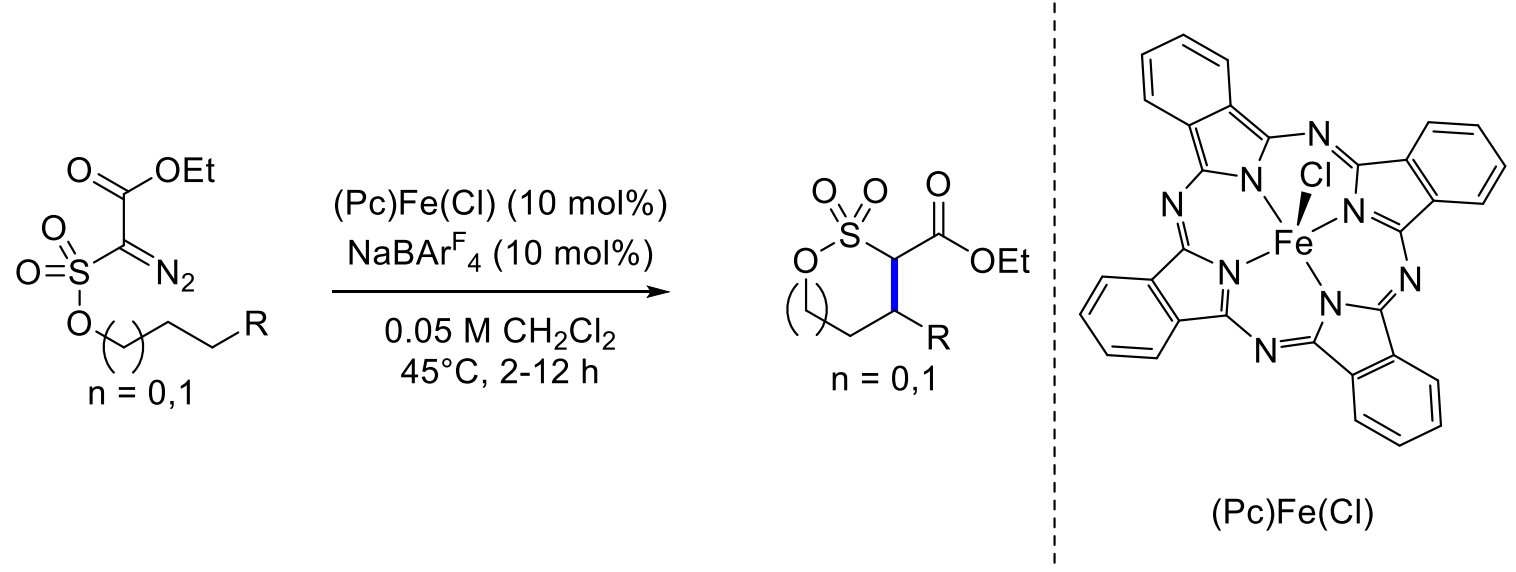

Scheme 1.11. $(\mathrm{Pc}) \mathrm{Fe}(\mathrm{Cl})$ catalyzed allylic $\mathrm{C}-\mathrm{H}$ alkylation.

The application of iron pincer complexes in the catalytic cyclopropanation of olefins as well as in a diverse array of insertion chemistries has also been recently developed.${ }^{65}$ Employing $\left.\left[{ }^{[\mathrm{Pr}} \mathrm{PDI}\right) \mathrm{Fe}\left(\mathrm{CH}_{3} \mathrm{CN}\right)_{2}\right]\left[\left(\mathrm{SbF}_{6}\right)_{2}\right]$ as a catalyst, Deng and coworkers have accomplished the cyclopropanation of cyclohexene was accomplished in good yield with high diastereometric ratio (>20:1) (Scheme 1.12). Additionally, it was found that the application of (S)- ${ }^{\mathrm{VME}} \mathrm{PDI}$ as ligand, featuring an L-valine methyl ester chiral element rendered the cyclopropanation of styrene enantioselective, albeit with a moderate ee of $67 \%$ (Scheme 1.12). This exciting result demonstrates that further tuning of PDI ligand environments may allow for future development of protocols capable of generating enantiomerically pure cyclopropanes from the corresponding vinyl arene. 


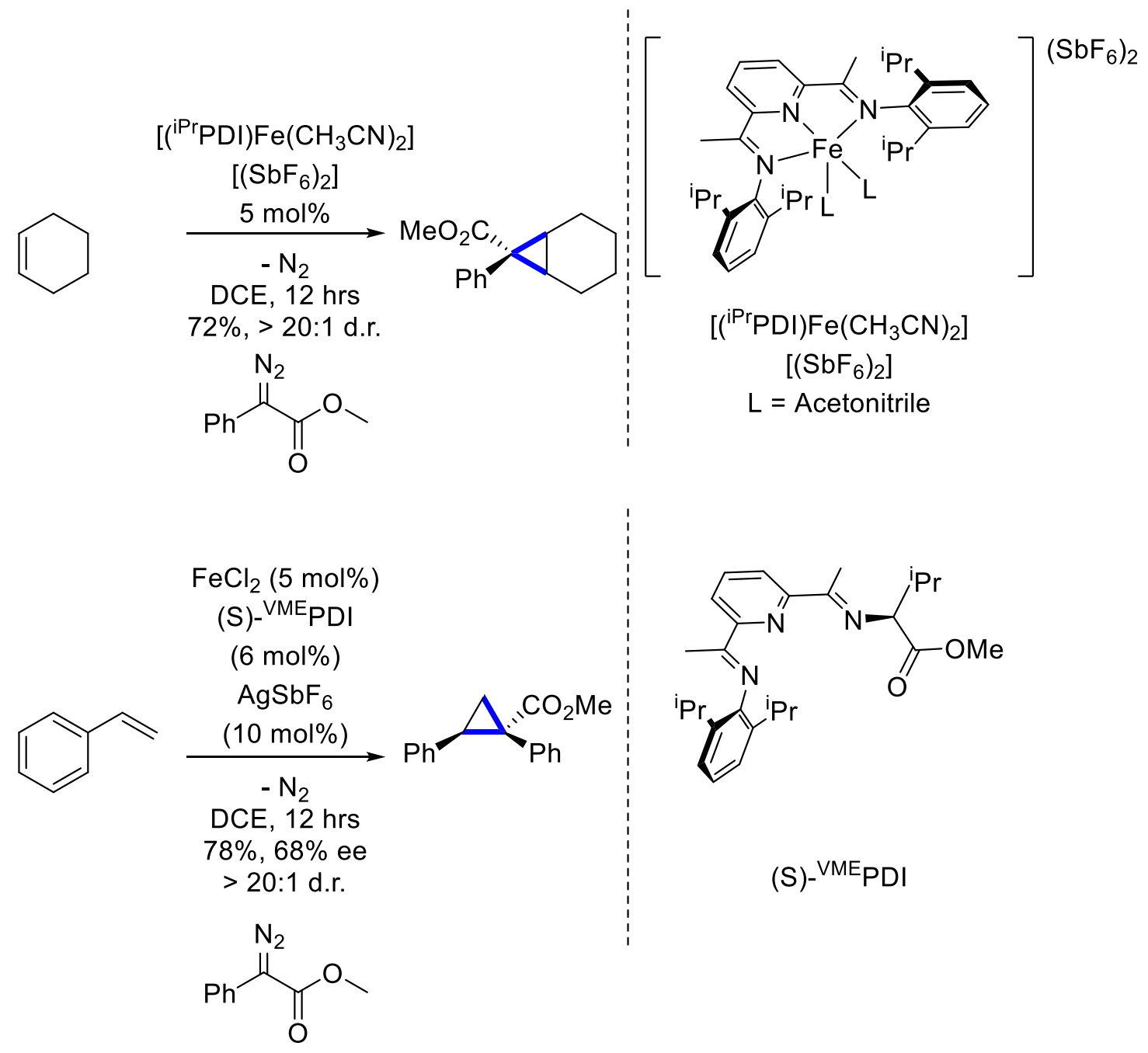

Scheme 1.12. Pyridine diimine iron complex catalyzed cyclopropanation of olefins.

Despite this array of catalytic methods operating via presumed iron carbene intermediates, isolated examples of iron carbene complexes are uncommon and are currently limited to a small number of supporting ligand systems. ${ }^{66}$ The precedent of pyridine dipyrrolide iron nitrene complexes that promote $\mathrm{C}-\mathrm{H}$ amination suggests that isoelectronic pyridine dipyrrolide iron carbene adducts are likely possible and may offer exciting reactivity profiles. Furthermore, the isolable nature of pyridine dipyrrolide iron nitrene complexes suggests that 
carbene analogues may be synthetically accessible and amenable to study via spectroscopic methods to ascertain their electronic structures. In Chapter 6 of this dissertation, such a pyridine dipyrrolide iron carbene system is presented. Utilizing the high-spin $\mathrm{Fe}^{\mathrm{II}}$ complex $\left({ }^{\mathrm{Mes}} \mathrm{PDP} \mathrm{Ph}^{\mathrm{Ph}}\right) \mathrm{Fe}($ thf $)$ as the starting material, an unprecedented square-planar iron carbene complex, $\left({ }^{\mathrm{Mes}} \mathrm{PDP}{ }^{\mathrm{Ph}}\right) \mathrm{Fe}\left(\mathrm{CPh}_{2}\right)$, has been isolated via reaction with diphenyldiazomethane as the carbene source. Physical characterization of $\left({ }^{\mathrm{Mes}} \mathrm{PDP}^{\mathrm{Ph}}\right) \mathrm{Fe}\left(\mathrm{CPh}_{2}\right)$ is consistent with a $\mathrm{S}=1$ ground state and an electronic structure best described as an intermediate-spin $\mathrm{Fe}^{\mathrm{III}}$ ion engaged in antiferromagnetically coupling to a monoanionic diphenylidene radical ligand. The preliminary reactivity of this compound has been explored and exhibits rich carbene group transfer chemistry. 


\section{References}

1. Berry, J. F.; Bill, E.; Bothe, E.; DeBeer-George, S.; Neese, F.; Wieghardt, K. An Octahedral Coordination Complex of Iron(VI). Science 2006, 312, 1937-1941.

2. Collman, J. P. Disodium Tetracarbonylferrate, a Transition Metal Analog of a Grignard Reagent. Acc. Chem. Res. 1975, 8, 342-347.

3. Bauer, I.; Knölker, H. -J. Iron Catalysis in Organic Synthesis. Chem. Rev. 2015, 115, 31703387.

4. Holm, R. H.; Lo, W. Structural Conversions of Synthetic and Protein-Bound Iron-Sulfur Clusters. Chem. Rev. 2016, 116, 13685-13713.

5. Lee, S. C.; Lo, W.; Holm, R. H. Developments in the Biomimetic Chemistry of Cubane-Type and Higher Nuclearity Iron-Sulfur Clusters. Chem. Rev. 2014, 114, 3579-3600.

6. Freedman, D. E.; Harman, W. H.; Harris, T. D.; Long, G. J.; Chang, C. J.; Long, J. R. Slow Magnetic Relaxation in a High-Spin Iron(II) Complex. J. Am. Chem. Soc. 2010, 132, 1224-1225.

7. Chen, J.; Browne, W. R. Photochemistry of Iron Complexes. Coord. Chem. Rev. 2018, 374, $15-35$.

8. Bertini, I. Gray, H. B.; Stiefel, E. I.; Valentine, J. S. Biological Inorganic Chemistry: Structure and Reactivity, University Science Books, Sausalito, CA, USA, 2007.

9. Lippard, S. J.; Berg, J. M. Principles of Bioinorganic Chemistry, University Science Books, Mill Valley, CA, USA, 1994.

10. Huang, X.; Groves, J. T. Oxygen Activation and Radical Transformations in Heme Proteins and Metalloporphyrins. Chem. Rev. 2018, 118, 2491-2553.

11. Lubitz, W.; Ogata, H.; Rüdiger, O. Reijerse, E. Hydrogenases. Chem. Rev. 2014, 114, 40814148. 
12. Rittle, J.; Green, M. T. Cytochrome P450 Compound I: Capture, Characterization, and C-H Bond Activation Kinetics. Science 2010, 330, 933-937.

13. Meunier, B.; de Visser, S. P.; Shaik, S. Mechanism of Oxidation Reactions Catalyzed by Cytochrome P450 Enzymes. Chem. Rev. 2004, 104, 3947-3980.

14. Rutter, R.; Hager, L. P.; Dhonau, H.; Hendrich, M.; Valentine, M.; Debrunner, M.

Chloroperoxidase Compound I: Electron Paramagnetic Resonance and Mössbauer Studies. Biochemistry 1984, 23, 6809-6816.

15. Nugent, W. A. Mayer, J. M. Metal-Ligand Multiple Bonds: The Chemistry of Transition Metal Complexes Containing Oxo, Nitrido, Imido, Alkylidene, or Alkylidyne Ligands, John Wiley and Sons, Inc., USA, 1988.

16. Groves, J. T.; Nemo, T. E.; Myers, R. S. Hydroxylation and Epoxidation Catalyzed by IronPorphine Complexes. Oxygen Transfer from Iodosylbenzene. J. Am. Chem. Soc. 1979, 101, 1032-1033.

17. Baglia, R. A.; Zaragoza, J. P. T.; Goldberg, D. P. Biomimetic Reactivity of Oxygen-Derived Manganese and Iron Porphyrinoid Complexes. Chem. Rev. 2017, 117, 13320-13352.

18. Breslow, R. Gellman, S. H.; Intramolecular Nitrene C-H Insertions Mediated by Transition Metal Complexes as Nitrogen Analogues of Cytochrome P-450 Reactions. J. Am. Chem. Soc. 1983, 105, 6728-6729.

19. Vitaka, E.; Smith, D. T.; Njardson, J. T. Analysis of the Structural Diversity, Substitution Patterns, and Frequency of Nitrogen Heterocycles Among U.S. FDA Approved Pharmaceuticals. J. Med. Chem. 2014, 57, 10257-10274. 
20. Welsch, M. E.; Snyder, S. A.; Stockwell, B. R. Privileged Scaffolds for Library Design and Drug Discovery. Curr. Opin. Chem. Biol. 14, 2010, 347-361.

21. Espino, C. G.; Williams Fiori, K.; Kim, M.; Du Bois, J. Expanding the Scope of C-H Amination through Catalyst Design. J. Am. Chem. Soc. 2004, 126, 15378-15379.

22. Roizen, J. L.; Harvey, M. E.; Du Bois, J. Metal-Catalyzed Nitrogen-Atom Transfer Methods for the Oxidation of Aliphatic C-H Bonds. Acc. Chem. Res. 2012, 45, 911-922.

23. Zalatan, D. N.; Du Bois, J. A Chiral Rhodium Carboxamidate Catalyst for Enantioselective C-H Amination. J. Am. Chem. Soc. 2008, 130, 29, 9220-9221.

24. Das, A.; Maher, A. G.; Telser, J.; Powers, D. C. Observation of a Photogenerated Rh 2 Nitrenoid Intermediate in C-H Amination. J. Am. Chem. Soc. 2018, 140, 10412-10415.

25. Varela-Álvarez, A.; Yang, T.; Jennings, H.; Kornecki, K. P.; Macmillan, S. N.; Lancaster, K. M.; Mack, J. B. C.; Du Bois, J.; Berry, J. F.; Musaev, D. G. Rh2(II,III) Catalysts with Chelating Carboxylate and Carboxamidate Supports: Electronic Structure and Nitrene Transfer Reactivity. J. Am. Chem. Soc. 2016, 138, 2327-2341.

26. Harvey, M. E.; Musaev, D. G.; Du Bois, J. A Diruthenium Catalyst for Selective, Intramolecular Allylic C-H Amination: Reaction Development and Mechanistic Insight Gained through Experiment and Theory. J. Am. Chem. Soc. 2011, 133, 17207-17216.

27. Leung, S. K.-Y.; Tsui, W. -M.; Huang, J. -S.; Che, C.-M.; Liang, J. -L.; Zhu, N. Imido Transfer from Bis(imido)ruthenium(VI) Porphyrins to Hydrocarbons: Effect of Imido Substituents, C-H Bond Dissociation Energies, and $\mathrm{Ru}{ }^{\mathrm{VI} / \mathrm{V}}$ Reduction Potentials. J. Am. Chem. Soc. 2005, 127, 16629-16640. 
28. Guo, Z.; Guan, X.; Huang, J.-S.; Tsui, W.-M.; Lin, Z.; Che, C.-M.

Bis(Sulfonylimide)Ruthenium(VI) Porphyrins: X-ray Crystal Structure and Mechanism of C-H Bond Amination by Density Functional Theory Calculations. Chem.-Eur. J., 2013, 19, 1132011331.

29. Intrieri, D.; Zardi, P.; Caselli, A.; Gallo, E. Organic Azides: "Energetic Reagents” for the Intermolecular Amination of C-H Bonds. Chem. Commun., 2014, 50, 11440-11453.

30. Fantauzzi, S.; Gallo, E.; Caselli, A.; Ragaini, F.; Casati, N.; Macchi, P.; Cenini, S. The Key Intermediate in the Amination of Saturated C-H Bonds: Synthesis, X-ray Characterization and Catalytic Activity of $\mathrm{Ru}(\mathrm{TPP})(\mathrm{NAr})_{2}\left(\mathrm{Ar}=3,5-\left(\mathrm{CF}_{3}\right)_{2} \mathrm{C}_{6} \mathrm{H}_{3}\right)$. Chem. Commun., 2009, 3952-3954.

31. Intrieri, D.; Caselli, A.; Ragaini, F.; Macchi, P.; Casati, N.; Gallo, E. Insights into the Mechanism of the Ruthenium-Porphyrin-Catalysed Allylic Amination of Olefins by Aryl Azides. Eur. J. Inorg. Chem., 2012, 569-580.

32. Müller, P.; Fruit, C. Enantioselective Catalytic Aziridinations and Asymmetric Nitrene Insertions into CH Bonds. Chem. Rev. 2003, 103, 2905-2919.

33. Arnold, F. H. Innovation by Evolution: Bringing New Chemistry to Life (Nobel Lecture). Angew. Chem., Int. Ed. 2019, 58, 14420-14426.

34. McIntosh, J. A.; Coelho, P. S.; Farwell, C. C.; Wang, Z. J.; Lewis, J. C.; Brown, T. R.; Arnold, F. H. Enantioselective Intramolecular C-H Amination Catalyzed by Engineered Cytochrome P450 Enzymes in Vitro and in Vivo. Angew. Chem., Int. Ed. 2013, 52, 9309-9312. 35. Hyster, T. K.; Farwell, C. C.; Buller, A. R.; McIntosh, J. A.; Arnold, F. H. EnzymeControlled Nitrogen-Atom Transfer Enables Regiodivergent C-H Amination. J. Am. Chem. Soc. 2014, 136, 15505-15508. 
36. Prier, C.; Zhang, R. K.; Buller, A. R.; Brinkmann-Chen, S.; Arnold, F. H. Enantioselective, Intermolecular Benzylic C-H Amination Catalyzed by an Engineered Iron-Haem Enzyme. Nat. Chem. 2017, 9, 629-634.

37. Singh, R.; Bordeaux, M.; Fasan, R. P450-Catalyzed Intramolecular $\mathrm{sp}^{3}$ C-H Amination with Arylsulfonyl Azide Substrates. ACS Catal. 2014, 4, 546-552.

38. Singh, R.; Kolev, J. N.; Sutera, P. A.; Fasan, R. Enzymatic C( $\left.\mathrm{sp}^{3}\right)-H$ Amination: P450-

Catalyzed Conversion of Carbonazidates into Oxazolidinones. ACS Catal. 2015, 5, 1685-1691.

39. Goldberg, W.; Knight, A. M.; Zhang, R. K.; Arnold, F. H. Nitrene Transfer Catalyzed by a Non-Heme Iron Enzyme and Enhanced by Non-Native Small-Molecule Ligands. J. Am. Chem. Soc. 2019, 141, 19585-19588.

40. Vila, M. A.; Steck, V. K.; Giordano, S. R.; Carrera, I.; Fasan, R. C-H Amination via Nitrene Transfer Catalyzed by Mononuclear Non-Heme Iron-Dependent Enzymes.

ChemBioChem 2020, 290, DOI: 10.1002/cbic.201900783.

41. Paradine, S. M.; White, M. C. Iron-Catalyzed Intramolecular Allylic C-H Amination. J. Am. Chem. Soc. 2012, 134, 2036-2039.

42. Bagh, B.; Broere, D. L. J.; Sinha, V.; Kuijpers, P. F.; van Leest, N. P.; de Bruin, B.;

Demeshko, S.; Siegler, M. A.; van der Vlugt, J. I. Catalytic Synthesis of N-Heterocycles via Direct C(sp3)-H Amination Using an Air-Stable Iron(III) Species with a Redox-Active Ligand. J. Am. Chem. Soc. 2017, 139, 5117-5124.

43. Hennessy, E. T.; Betley, T. A. Complex N-Heterocycle Synthesis via Iron-Catalyzed, Direct C-H Bond Amination. Science 2013, 340, 591-595. 
44. Iovan, D. A.; Wilding, M. J. T.; Baek, Y.; Hennessy, E. T.; Betley, T. A. Diastereoselective C-H Bond Amination for Disubstituted Pyrrolidines. Angew. Chem., Int. Ed. 2017, 56, 1559915602.

45. King, E. R.; Hennessy, E. T.; Betley, T. A. Catalytic C-H Bond Amination from High-Spin Iron Imido Complexes. J. Am. Chem. Soc. 2011, 133, 4917-4923.

46. Iovan, D. A.; Betley, T. A. Characterization of Iron-Imido Species Relevant for N-Group Transfer Chemistry. J. Am. Chem. Soc. 2016, 138, 1983-1993.

47. Searles, K.; Fortier, S.; Khusniyarov, M. M.; Carroll, P. J.; Sutter, J.; Meyer, K.; Mindiola, D. J.; Caulton, K. G. A Cis-Divacant Octahedral and Mononuclear Iron(IV) Imide. Angew. Chem., Int. Ed. 2014, 53, 14139-14143.

48. Grant, L. N.; Carroll, M. E.; Carroll, P. J.; Mindiola, D. J. An Unusual Cobalt Azide Adduct That Produces a Nitrene Species for Carbon-Hydrogen Insertion Chemistry. Inorg. Chem. 2016, $55,7997-8002$.

49. Davies, H. M. L.; Manning, J. R. Catalytic C-H Functionalization by Metal Carbenoid and Nitrenoid Insertion. Nature 2008, 451, 417-424.

50. Doyle, M. P.; Forbes, D. C. Recent Advances in Asymmetric Catalytic Metal Carbene Transformations. Chem. Rev. 1998, 98, 911-936.

51. Doyle, M. P.; Duffy, R.; Ratnikov, M.; Zhou, L. Catalytic Carbene Insertion into C-H Bonds. Chem. Rev. 2010, 110, 704-724.

52. Doyle, M. P. Perspective on Dirhodium Carboxamidates as Catalysts. J. Org. Chem. 2006, 71, 9253-9260.

53. Empel, C.; Jana, S.; Koenigs, R. M. C-H Functionalization via Iron-Catalyzed CarbeneTransfer Reactions. Molecules 2020, 25, 880. 
54. Lewis, R. D.; Garcia-Borràs, M.; Chalkley, M. J.; Buller, A. R.; Houk, K. N.; Kan, S. B. J.; Arnold, F. H. Catalytic Iron-Carbene Intermediate Revealed in a Cytochrome $\boldsymbol{C}$ Carbene Transferase. PNAS, 2018, 115, 7308-7313.

55. Zhang, R. K.; Chen, K.; Huang, X.; Wohlschlager, L.; Renata, H.; Arnold, F. H. Enzymatic Assembly of Carbon-Carbon Bonds via Iron-Catalysed $\mathrm{sp}^{3}$ C-H Functionalization. Nature 2019, $565,67-72$.

56. Alternate Heme Ligation Steers Activity and Selectivity in Engineered Cytochrome P450Catalyzed Carbene-Transfer Reactions. Chen, K.; Zhang, S. -Q.; Brandenberg, O. F.; Hong, X.; Arnold, F. H. J. Am. Chem. Soc. 2018, 48, 16402-16407.

57. Carminati, D. M.; Fasan, R. Stereoselective Cyclopropanation of Electron-Deficient Olefins with a Cofactor Redesigned Carbene Transferase Featuring Radical Reactivity. ACS Catal. 2019, 9, 9683-9697.

58. Seitz, W. J.; Saha, A. K.; Hossain, M. M. Iron Lewis Acid Catalyzed Cyclopropanation Reactions of Ethyl Diazoacetate and Olefins. Organometallics 1993, 12, 2604-2608.

59. Jolly, P. W.; Pettit, R. Evidence for a Novel Metal-Carbene System. J. Am. Chem. Soc. 1966, $88,5044$.

60. Wolf, J. R.; Hamaker, C. G.; Djukic, J. -R.; Kodadek, T.; Woo, L. K. Shape and Stereoselective Cyclopropanation of Alkenes Catalyzed by Iron Porphyrins. J. Am. Chem. Soc. 1995, 117, 9194-9199.

61. Hamaker, C. G.; Mirafzal, G. A.; Woo, L. K. Catalytic Cyclopropanation with Iron(II) Complexes. Organometallics 2001, 20, 5171-5176. 
62. Mbuvi, H. M.; Woo, L. K. Catalytic C-H Insertions Using Iron(III) Porphyrin Complexes. Organometallics 2008, 27, 637-645.

63. Empel, C.; Jana, S.; Koenigs, R. M. C-H Functionalization via Iron-Catalyzed CarbeneTransfer Reactions. Molecules 2020, 25, 880.

64. Griffin, J. R.; Wendell, C. I.; Garwin, J. A.; White, C. M. Catalytic C( $\left(\mathrm{sp}^{3}\right)-\mathrm{H}$ Alkylation via an Iron Carbene Intermediate. J. Am. Chem. Soc. 2017, 139, 13624-13627.

65. Wang, B.; Howard, I. G.; Pope, J. W.; Conte, E.; Deng, Y. Bis(imino)pyridine Iron Complexes for Catalytic Carbene Transfer Reactions. Chem. Sci. 2019, 10, 7958-7963.

66. For a summary of isolated iron carbene complexes see: Liu, J.; Hu, C.; Wang, C.; Chen, H.;

Deng, L. An Iron(II) Ylide Complex as a Masked Open-Shell Iron Alkylidene Species in Its Alkylidene-Transfer Reactions with Alkenes. J. Am. Chem. Soc. 2017, 139, 3876-3888. 


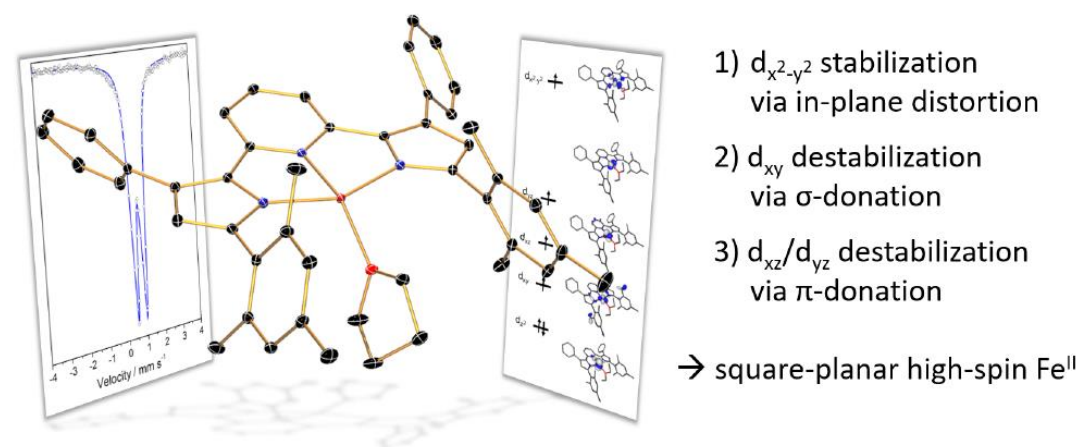

\section{CHAPTER II: SYNTHESIS AND ELECTRONIC STRUCTURE OF SQUARE PLANAR HIGH-SPIN IRON(II) PYRIDINE DIPYRROLIDE COMPLEXES}

\footnotetext{
Reproduced in part with permission from Hakey, B. M.; Darmon, J. M.; Zhang, Y.; Petersen, J. L.; Milsmann, C.
} Inorg. Chem. 2019, 58, 1252-1266. Copyright $\odot 2019$ American Chemical Society.

\subsection{Abstract}

Two square-planar high-spin $\mathrm{Fe}^{\mathrm{II}}$ complexes bearing a dianionic pyridine dipyrrolide pincer ligand and a diethyl ether or tetrahydrofuran ligand were synthesized and structurally characterized, and their electronic structures were elucidated by a combined spectroscopic and computational approach. In contrast to previous examples, the $S=2$ ground states of these square-planar $\mathrm{Fe}^{\mathrm{II}}$ complexes do not require an overall anionic charge of the compounds or incorporation of alkali metal cations. The tetrahydrofuran complex exhibits an equilibrium between four- and five-coordinate species in solution, which was supported by ${ }^{1} \mathrm{H} \mathrm{NMR}$ and ${ }^{57} \mathrm{Fe}$ Mössbauer spectroscopy and comparison to a structurally characterized five-coordinate pyridine dipyrrolide iron bis-pyridine adduct. A detailed computational analysis of the electronic structures of the four- and five-coordinate species via density functional theory provides insight 
into the origins of the unusual ground state configurations for $\mathrm{Fe}^{\mathrm{II}}$ in a square-planar ligand field and explains the associated characteristic spectroscopic parameters.

\subsection{Introduction}

The coordination chemistry of iron is characterized by a broad range of available oxidation states that can each exhibit several different spin states. This flexibility in electronic structure results in a large diversity of physical properties and reactivity among iron compounds. Whether in synthetic or biological systems, carefully controlling these attributes via a welldefined ligand environment, (i.e., coordination number, geometry, and ligand type), has been key to the development of iron complexes for various applications ranging from catalysis ${ }^{1-4}$ and single-electron transfer ${ }^{5}$ to magnetic materials ${ }^{6-9}$ and photochemistry. ${ }^{10-12}$

Among the many possible permutations of coordination geometry, oxidation state, and spin state, square-planar $\mathrm{Fe}^{\mathrm{II}}$ complexes with a high-spin ground state $(\mathrm{S}=2)$ are rare. This can readily be explained by the strong destabilization of the $\mathrm{d}_{x^{2}-y^{2}}$ orbital of the metal ion in a squareplanar ligand field compared to the remaining four d orbitals, which typically gives rise to intermediate-spin configurations with an $\mathrm{S}=1$ ground state for $\mathrm{d}^{6}$ systems such as Fe ${ }^{\mathrm{II}}{ }^{13}$ Until recently, high spin ferrous ions in square-planar coordination environments were only known for the iron-silicate minerals gillespite ${ }^{14}$ and eudialyte ${ }^{15}$ and macrocyclic ${ }^{16}$ complexes in which the unusual electronic structure is likely enforced by the steric environment of the solid-state materials or the tetradentate macrocycle. Aside from a fundamental curiosity for unusual electronic structures, the renewed interest in molecular, square-planar high-spin $\mathrm{Fe}^{\mathrm{II}}$ compounds over the past decade was fueled by the discovery of planar $\mathrm{Fe}^{\mathrm{II}} \mathrm{O}_{4}$ sites $(\mathrm{S}=2)$ in iron-oxide ceramics $^{17-19}$ and the remarkable reactivity of iron zeolites exhibiting similar motifs. ${ }^{20-22}$ In 2011 , 
Klüfers et al. described the first example of a molecular square-planar Fe ${ }^{\mathrm{II}}$ compound with an $\mathrm{S}=$ 2 ground state using non-macrocyclic ligands (Figure 1 ). ${ }^{23}$

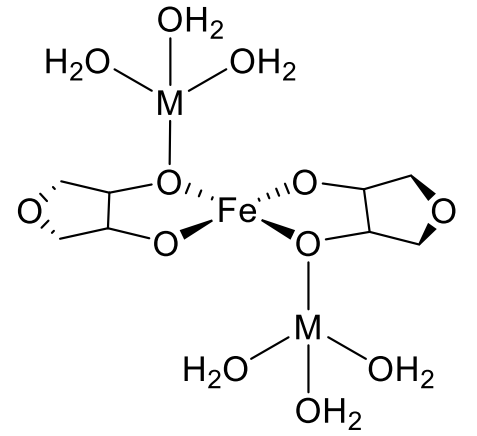

$\mathrm{M}=\mathrm{Li}$ or $\mathrm{Na}$

Klüfers, 2011

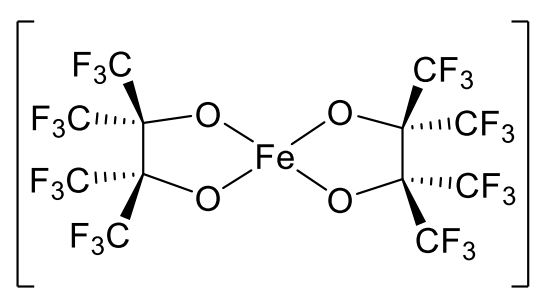

$\left[\mathrm{NMe}_{4}\right]_{2}$

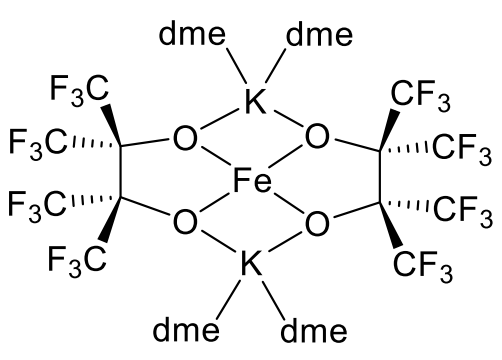

dme $=$ dimethoxyethane

Doerrer, 2012

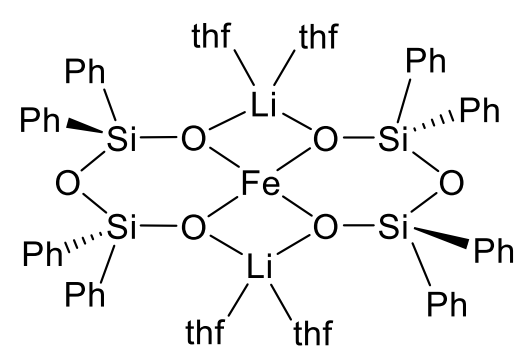

Doerrer, 2013

Limberg, 2017

Figure 2.1. Mononuclear square-planar high-spin Fe $\mathrm{Fe}^{\mathrm{II}}$ complexes featuring bidentate alkoxide or siloxide ligands.

On the basis of their report, Holland proposed several conditions that favor the high-spin state in a square planar ligand field through electronic rather than steric effects: (a) anionic ligands imposing an overall negative charge on the complex that prevents further ligand binding via electrostatic effects; (b) alkali metal binding to stabilize the negative charge; and (c) weakfield ligands that reduce the splitting between the $\mathrm{d}_{x^{2}-y^{2}}$ orbital and the remaining $\mathrm{d}$ orbitals via weak $\sigma$-donation (reducing the energy of $\mathrm{d}_{x^{2}-y^{2}}$ ) and strong $\pi$-donation (raising the energy of $\mathrm{d}_{x z}$, $\mathrm{d}_{y z}$, and $\left.\mathrm{d}_{x y}\right) .{ }^{13}$ Following these design principles, several complexes carrying chelating alkoxide 
or siloxide ligands have been reported by the groups of Doerrer and Limberg, respectively. ${ }^{24-26}$ Additionally, Veige and coworkers showed that the common $\mathrm{FeO}_{4}$ motif can be expanded to an $\mathrm{FeO}_{2} \mathrm{NCl}$ environment by replacing two alkoxide ligands with amide and chloride donors that retain the dianionic nature of the complex. ${ }^{27,28}$ Breaking with requirement (b), the groups of Doerrer ${ }^{29}$ and $\mathrm{Tamm}^{30}$ reported alkali metal-free examples.

Often overlooked early examples for compounds with square-planar high-spin $\mathrm{Fe}^{\mathrm{II}}$ centers are bis(imino)pyridine iron halide complexes reported by Chirik and co-workers in 2005. ${ }^{31}$ However, structural confirmation for a distorted square-planar coordination environment in these compounds was only provided in $2013 .{ }^{32}$ In contrast to the previously mentioned examples, these compounds possess an overall $\mathrm{S}=3 / 2$ ground state due to strong magnetic exchange coupling between the high-spin $\mathrm{Fe}^{\mathrm{II}}$ center and a bis(imino)pyridine ligand radical anion. ${ }^{33} \mathrm{~A}$ similar electronic structure has been proposed for bis(imino)pyridine iron alkoxide and siloxide complexes. ${ }^{32,34}$ The $S=2$ ground state of the central metal ion under a square-planar ligand field is remarkable considering the complexes defy all three conditions outlined by Klüfers and coworkers, given their neutral charge and the presence of a $\pi$-accepting pincer ligand. One important feature of the bis(imino)pyridine ligand is the reduced bite angle of the pincer that leads to an in-plane distortion from idealized square-planar geometry, which should stabilize the $\mathrm{d}_{x^{2}-y^{2}}$ orbital. To address whether this distortion or the magnetic interaction between the ligand radical and the metal center is responsible for the high-spin square-planar ground state of the metal center, we sought to investigate a related pincer type ligand based on a pyridine dipyrrolate(PDP) backbone ${ }^{35}$ Recently, this strongly $\pi$-donating dianionic ligand framework has been successfully employed in both early and late transition metal coordination chemistry. ${ }^{36-41}$ 


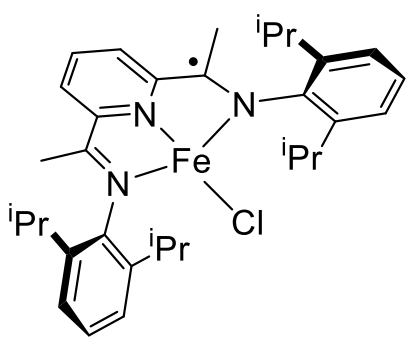

Chirik, 2006

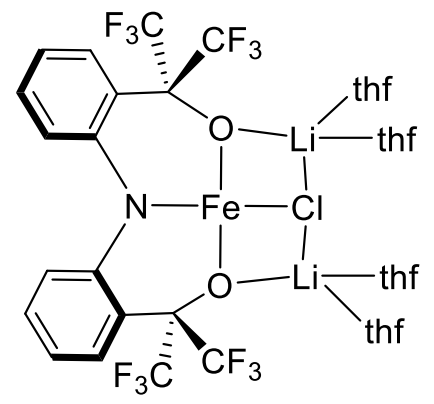

Veige, 2015

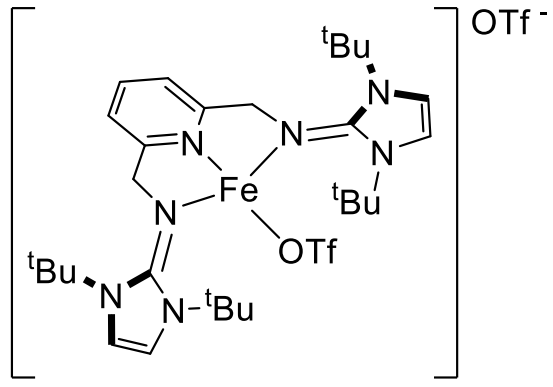

Tamm, 2014

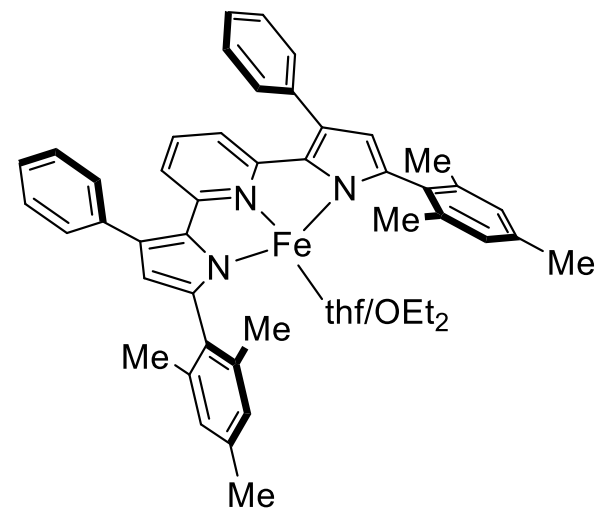

This work

Figure 2.2. Mononuclear square-planar high-spin $\mathrm{Fe}^{\mathrm{II}}$ complexes featuring tridentate pincer ligands.

For iron in particular, Mindiola and co-workers have shown that careful control of the steric environment imposed by the PDP ligand can yield unusual coordination environments and electronic structures..$^{42,43}$

Herein, is reported the synthesis, characterization, and electronic structure determination of $\left({ }^{\mathrm{Mes}} \mathrm{PDP}^{\mathrm{Ph}}\right) \mathrm{Fe}\left(\mathrm{OEt}_{2}\right)$ and $\left({ }^{\mathrm{Mes}} \mathrm{PDP}^{\mathrm{Ph}}\right) \mathrm{Fe}(\mathrm{thf})\left(\mathrm{H}_{2}{ }^{\mathrm{Mes}} \mathrm{PDP}^{\mathrm{Ph}}=\right.$ 2,6-bis(5-(2,4,6-trimethylphenyl)-3phenyl-1H-pyrrol-2-yl)pyridine) as examples for neutral high-spin $\mathrm{Fe}^{\mathrm{II}}$ complexes with a distorted square planar ligand environment. The unique steric and electronic characteristics of the PDP pincer ligand support an $\mathrm{FeN}_{3} \mathrm{O}$ core with $\mathrm{S}=2$ ground state in the absence of alkoxide or siloxide ligands. The high-spin ground states for these complexes expand the available electronic structures in pyrrole-containing pincer ligands and are distinct from the intermediate- 
spin configurations $(\mathrm{S}=1)$ recently reported for square-planar $\mathrm{Fe}^{\mathrm{II}}$ complexes with 2,5-bis(ditert-butylphosphinomethyl)pyrrolide ligands. ${ }^{44,45}$

\subsection{Synthesis and Characterization of $\left({ }^{\mathrm{Mes}} \mathrm{PDP} \mathrm{Ph}^{\mathrm{Ph}}\right) \mathrm{Fe}(\mathrm{L})_{\mathrm{n}}$ Complexes}

The ligand precursor $\mathrm{H}_{2}{ }^{\mathrm{Mes}} \mathrm{PDP}^{\mathrm{Ph}}$ was readily prepared following a synthetic route analogous to the one reported previously for $\mathrm{H}_{2}{ }^{\mathrm{Me}} \mathrm{PDP}{ }^{\mathrm{Ph}} \cdot{ }^{37}$ Starting from 2,6-

pyridinedicarboxaldehyde and the chalcone derivative 1-(2,4,6-trimethylphenyl)-3-phenyl-2-

propen-1-one, $\mathrm{H}_{2}{ }^{\mathrm{Mes}} \mathrm{PDP}^{\mathrm{Ph}}$ was obtained on a multigram scale via a straightforward two-step, one-pot protocol. Several different strategies for the synthesis of $\left({ }^{\mathrm{Mes}} \mathrm{PDP}{ }^{\mathrm{Ph}}\right) \mathrm{Fe}(\mathrm{L})_{n}$ complexes were explored. Following a procedure by Caulton, Mindiola, and co-workers, ${ }^{42}$ treatment of a diethyl ether solution of $\mathrm{Fe}\left[\mathrm{N}\left(\mathrm{SiMe}_{3}\right)_{2}\right]_{2}$ with a diethyl ether suspension of $\mathrm{H}_{2}{ }^{\mathrm{Mes}} \mathrm{PDP}^{\mathrm{Ph}}$ (1 equiv) resulted in a gradual dissolution of the ligand precursor accompanied by a color change of the reaction mixture from yellow to red (Scheme 2.1). Recrystallization of the red crude material via slow diffusion of pentane into a concentrated toluene solution yielded a dark red-purple, crystalline product identified as $\left({ }^{\mathrm{Mes}} \mathrm{PDP}{ }^{\mathrm{Ph}}\right) \mathrm{Fe}\left(\mathrm{OEt}_{2}\right)$. The relatively poor isolated yield (40\%) can be attributed to the formation of $\left(\mathrm{H}^{\mathrm{Mes}} \mathrm{PDP}{ }^{\mathrm{Ph}}\right)_{2} \mathrm{Fe}$ as the major byproduct, which requires careful repeated recrystallization to obtain analytically pure $\left({ }^{\mathrm{Mes}} \mathrm{PDP}{ }^{\mathrm{Ph}}\right) \mathrm{Fe}\left(\mathrm{OEt}_{2}\right)$. The structure of the $\left(\mathrm{H}^{\mathrm{Mes}} \mathrm{PDP} \mathrm{Ph}_{2} \mathrm{Fe}\right.$ impurity was established by X-ray crystallography and features a fourcoordinate, high-spin iron(II) center in a distorted tetrahedral coordination environment generated by the two singly deprotonated pincer ligands (Figure 2.3). 


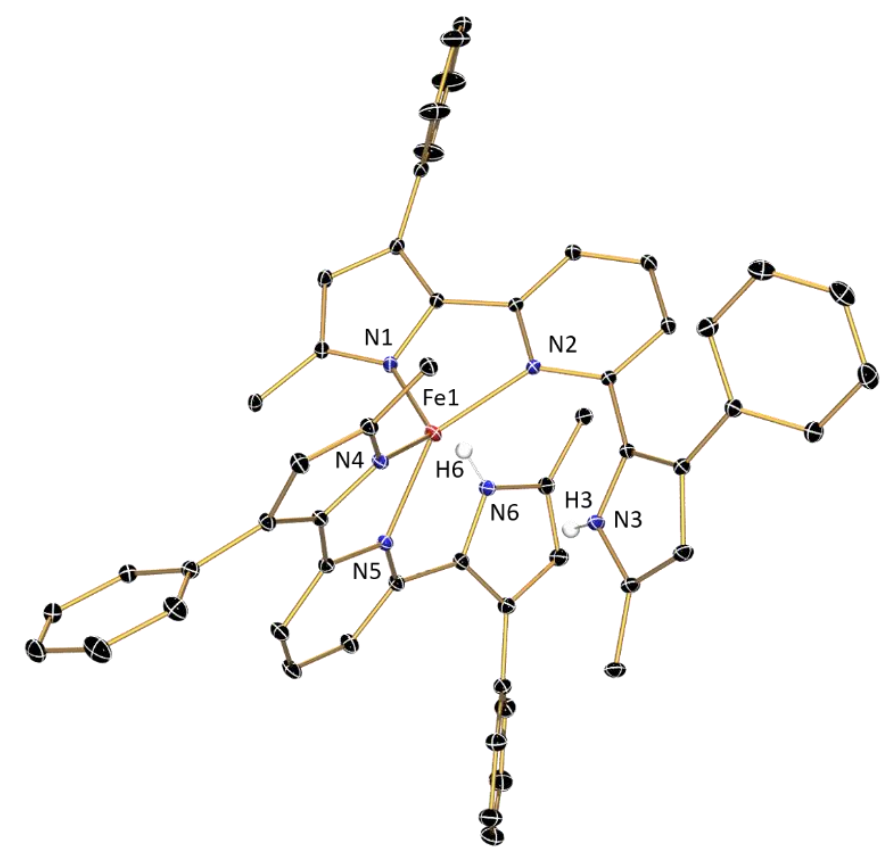

Figure 2.3. ORTEP of $\mathrm{Fe}\left(\mathrm{H}^{\mathrm{Mes} P D P}{ }^{\mathrm{Ph}}\right)_{2}$ displayed at $30 \%$ probability ellipsoids. Hydrogen atoms (excluding pyrrole hydrogens) and pyrrole mesityl substituents (with exception of the ipso carbon) have been excluded for clarity.

A similar complex, $\left(\mathrm{H}^{\mathrm{tBu}} \mathrm{PDP}^{\mathrm{tBu}}\right)_{2} \mathrm{Fe}$, was reported by Caulton and co-workers using a tert-butyl substituted PDP derivative. ${ }^{36}$ The ${ }^{1} \mathrm{H}$ NMR spectrum of $\left({ }^{\mathrm{Mes}} \mathrm{PDP}^{\mathrm{Ph}}\right) \mathrm{Fe}\left(\mathrm{OEt}_{2}\right)$ in benzene- $d_{6}$ is consistent with a $\mathrm{C}_{2 v}$ symmetric species in solution. Ten broad resonances are observed between 112 and $-11 \mathrm{ppm}$, indicative of a paramagnetic ground state. The absence of an 11th resonance expected for $\left({ }^{\mathrm{Mes}} \mathrm{PDP}{ }^{\mathrm{Ph}}\right) \mathrm{Fe}\left(\mathrm{OEt}_{2}\right)$ is likely due to significant broadening indistinguishable above the spectral baseline. The solid-state magnetic moment of $5.5 \mu_{\mathrm{B}}$ is consistent with a $\mathrm{d}^{6}$ high-spin $\mathrm{Fe}^{\mathrm{II}}$ species. The deviation from the spin-only value of $4.9 \mu_{\mathrm{B}}$ can be rationalized by contributions from unquenched orbital-angular momentum. Single crystals suitable for analysis by X-ray diffraction were obtained by cooling a concentrated diethyl ether solution of $\left({ }^{\mathrm{Mes}} \mathrm{PDP}^{\mathrm{Ph}}\right) \mathrm{Fe}\left(\mathrm{OEt}_{2}\right)$ to $-35^{\circ} \mathrm{C}$. A representation of the molecular structure is shown in Figure 2.4, and important bond lengths and angles are summarized in Table 2.1. 

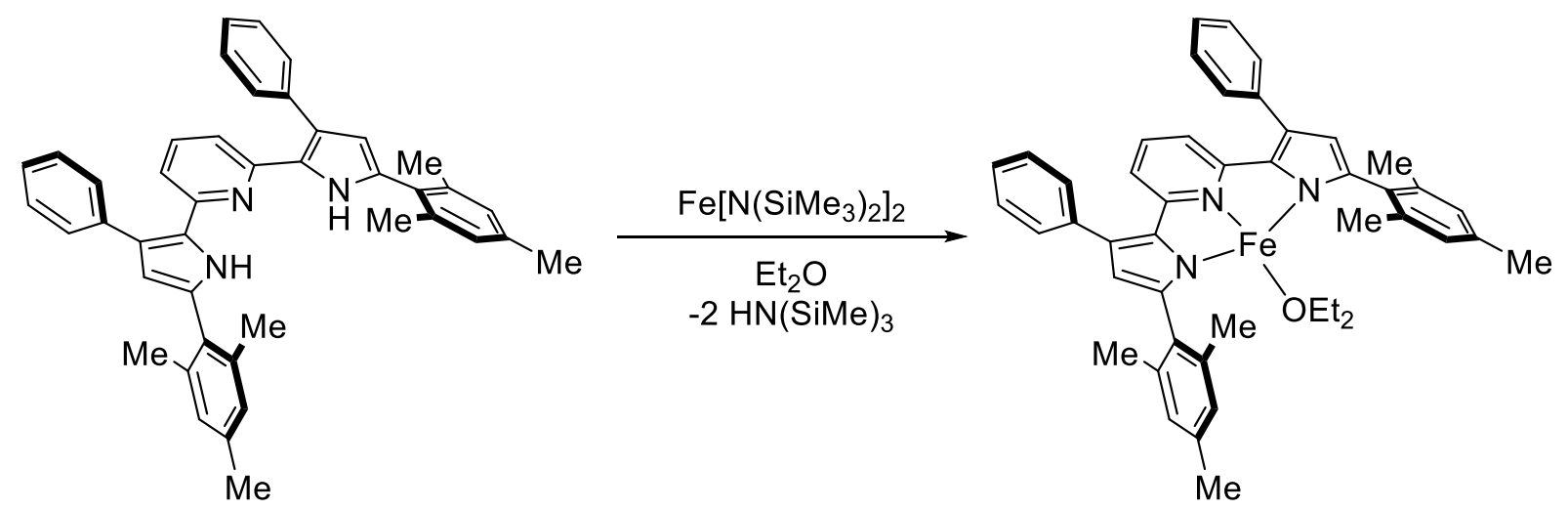

Scheme 2.1. Synthesis of $\left({ }^{\mathrm{Mes} P D P}{ }^{\mathrm{Ph}}\right) \mathrm{Fe}\left(\mathrm{OEt}_{2}\right)$.

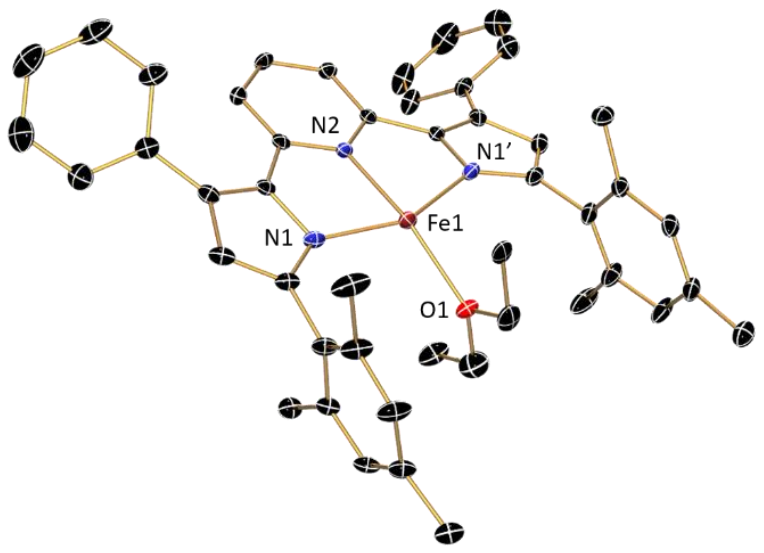

Figure 2.4. ORTEP of ( $\left.{ }^{\mathrm{Mes}} \mathrm{PDP}{ }^{\mathrm{Ph}}\right) \mathrm{Fe}\left(\mathrm{OEt}_{2}\right)$ displayed at $30 \%$ probability ellipsoids. Hydrogen atoms and cocrystallized solvent have been excluded for clarity. The second symmetry generated position of the disordered diethyl ether ligand is not depicted.

The compound crystallizes in the tetragonal space group $\mathrm{P} 4_{3} 2_{1} 2$, and each $\left({ }^{\mathrm{Mes}} \mathrm{PDP}{ }^{\mathrm{Ph}}\right) \mathrm{Fe}\left(\mathrm{OEt}_{2}\right)$ molecule lies on a crystallographic $\mathrm{C}_{2}$ axis, that coincides with the $\mathrm{Fe}(1)-\mathrm{N}(2)$ bond vector and renders the two halves of the pincer equivalent by symmetry. The coordination environment around the iron center is best described as distorted square-planar. The major deviation from rigorously square-planar geometry arises from the small bite angles of the pincer ligand enforced by the PDP backbone, which result in a $\mathrm{N}(1)-\mathrm{Fe}(1)-\mathrm{N}(1)^{\prime}$ angle of 
$155.02(15)^{\circ}$. Furthermore, the diethyl ether ligand is lifted slightly out of the plane described by the iron center and the three $\mathrm{N}$-donor atoms of the pincer, reflected in a $\mathrm{N}(2)-\mathrm{Fe}(1)-\mathrm{O}(1)$ angle of $160.54(15)^{\circ}$. However, the disorder of the $\mathrm{Et}_{2} \mathrm{O}$ ligand over two symmetry-generated sites in conjunction with the $\mathrm{C}_{2 v}$ symmetry observed in solution via ${ }^{1} \mathrm{H}$ NMR spectroscopy indicates the dynamic nature of this distortion and facile interconversion between linear and bent structures via a vibrational bending mode. In several previous reports on square-planar high-spin $\mathrm{Fe}^{\mathrm{II}}$ complexes, the $\tau_{4}$ value, first introduced by Houser et al., ${ }^{46}$ has been used as a convenient tool to quantify variations between square-planar $\left(\tau_{4}=0\right)$ and tetrahedral geometries $\left(\tau_{4}=1\right)$ for these systems. ${ }^{24,27,29}$ On the basis of this parameter, $\left({ }^{\mathrm{Mes}} \mathrm{PDP}^{\mathrm{Ph}}\right) \mathrm{Fe}\left(\mathrm{OEt}_{2}\right)$ is severely distorted with a $\tau_{4}$ value of 0.32 . However, caution should be taken in reducing a complex issue such as the description of coordination geometry to a single parameter. More specifically, the $\tau_{4}$ value must be critically evaluated in systems with chelating ligands and, if at all, should only be applied rigorously to systems with four independent ligands as originally defined. On the one hand, complexes with two bidentate ligands, as reported by Doerrer et al., can exhibit perfect values of $\tau_{4}=0$ despite clear deviations from square planar geometry indicated by bite angles of $84.30(4)^{\circ} \cdot{ }^{24,29}$ Even significantly smaller bite angles for the bidentate ligands would yield $\tau_{4}=0$ as long as the complexes are planar. On the other hand, the minimum $\tau_{4}$ value attainable for

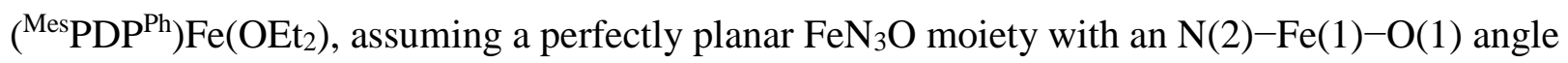
of $180^{\circ}$ and unchanged bond lengths from the X-ray diffraction analysis, is 0.10 due to the constraints imposed by the pincer backbone leading to an in-plane distortion. Both types of distortions should by no means be regarded as trending toward tetrahedral geometry. A more rigorous, quantitative approach to evaluating the structural features of four-coordinate transition metal complexes is provided by the continuous shape measures developed by Alvarez and co- 
workers ${ }^{47-49}$ based on early work on symmetry analysis by Pinsky and Avnir. ${ }^{50}$ This method offers a systematic way to measure the difference between an experimentally determined coordination environment and an idealized geometric shape such as a tetrahedron $\left(\mathrm{T}_{d}\right)$, a square $\left(\mathrm{D}_{4 h}\right)$, or a seesaw (cis-divacant octahedron, $\mathrm{SS}_{-} \mathrm{C}_{2 v}$ ). Following this formalism, the geometries of all structurally characterized square-planar high-spin $\mathrm{Fe}^{\mathrm{II}}$ complexes reported to date were analyzed, and the results are shown in Table 2.1. Within the framework of continuous shape measures, small values indicate close agreement with the idealized structure. For reference, a perfectly square-planar coordination environment exhibits deviation values of $0,33.33$, and 19.05 compared to square, tetrahedron, and seesaw, respectively. Deviations of 33.31, 0, and 9.78 are characteristic for tetrahedral coordination spheres, while values of 19.05, 9.79, and 0 are indicative of seesaw geometries. The outcome of the continuous shape measure analyses confirms that $\left({ }^{\mathrm{Mes}} \mathrm{PDP} \mathrm{P}^{\mathrm{Ph}}\right) \mathrm{Fe}\left(\mathrm{OEt}_{2}\right)$ is best described as a distorted square planar complex with deviations of $2.16\left(\mathrm{D}_{4 h}\right), 27.73\left(\mathrm{~T}_{d}\right)$, and $14.96\left(\mathrm{SS}_{-} \mathrm{C}_{2 v}\right)$. 
Table 2.1 Geometry analysis of reported square-planar high-spin $\mathrm{Fe}^{\mathrm{II}}$ complexes by continuous shape measures.

\begin{tabular}{ccccc}
\hline & square $\left(\mathrm{D}_{4 h}\right)$ & tetrahedron $\left(\mathrm{T}_{d}\right)$ & seesaw $^{\mathrm{a}}\left(\mathrm{C}_{2 v}\right)$ & ref \\
\hline $\mathrm{Li}_{2}\left[\mathrm{FeL}_{2}\right] \cdot 4 \mathrm{H}_{2} \mathrm{O}^{b}$ & 0.24 & 33.50 & 19.01 & 23 \\
$\left(\mathrm{Na}_{2}\left[\mathrm{FeL}_{2}\right] \cdot 4 \mathrm{H}_{2} \mathrm{O}^{b}\right.$ & 0.23 & 33.48 & 19.18 & 23 \\
$\mathrm{Na}_{2}\left[\mathrm{FeL}_{2}\right] \cdot 9 \mathrm{H}_{2} \mathrm{O}^{b}$ & 1.55 & 23.50 & 12.47 & 23 \\
$\left\{\mathrm{~K}(\mathrm{dme})_{2}\right\}_{2}\left[\mathrm{Fe}(\mathrm{ddfp}) 2^{c}\right.$ & 0.34 & 33.56 & 19.29 & 24 \\
$\left(\mathrm{Me}_{4} \mathrm{~N}\right)_{2}\left[\mathrm{Fe}(\mathrm{ddfp})_{2}\right]^{c}$ & 0.47 & 33.65 & 19.38 & 29 \\
{$\left[\left(\mathrm{TL}^{\mathrm{tBu}}\right) \mathrm{Fe}(\mathrm{OTf})\right] \mathrm{OTf}{ }^{d}$} & 1.78 & 27.21 & 14.87 & 30 \\
{$\left[\mathrm{Li}(\mathrm{thf})_{2}\right]_{2}\left[\left(\mathrm{CF}{ }_{3}-\mathrm{ONO}\right) \mathrm{FeCl}^{e}\right.$} & 0.52 & 31.57 & 16.83 & 27 \\
{$\left[\mathrm{Li}(\mathrm{thf})_{2}\right]_{2}\left[\mathrm{Fe}\left(\{\mathrm{OSiPh}\}_{2} \mathrm{O}\right)_{2}\right]$} & 0.24 & 33.49 & 19.13 & 26 \\
$\left({ }^{\mathrm{Mes}} \mathrm{PDP}^{\mathrm{Ph}}\right) \mathrm{Fe}\left(\mathrm{OEt}{ }_{2}\right)$ & 2.16 & 27.73 & 14.96 & This work \\
$\left({ }^{\mathrm{Mes} P D P}{ }^{\mathrm{Ph}}\right) \mathrm{Fe}(\mathrm{thf})$ & 3.43 & 22.11 & 11.27 & This work
\end{tabular}

${ }^{a}$ Vacant Trigonal bipyramid. ${ }^{b} \mathrm{~L}=$ meso-oxolane-3,4-diolate dianion. ${ }^{c} \mathrm{ddfp}=$ perfluoropinacolate dianion. ${ }^{d} \mathrm{TL}{ }^{\mathrm{tBu}}=2,6$-bis[(1,3-di-tertbutylimidazolin-2-imino)methyl]pyridine.

${ }^{e} \mathrm{H}_{3}\left(\mathrm{CF}_{3}-\mathrm{ONO}\right)=2,2^{\prime}$-(azanediylbis(2,1-phenylene) $)$ bis(1,1,1,3,3,3-hexafluoropropan-2-ol).

The relatively long metal-ligand bond distances $(>2 \AA)$ in $\left({ }^{\mathrm{Mes}} \mathrm{PDP}{ }^{\mathrm{Ph}}\right) \mathrm{Fe}\left(\mathrm{OEt}_{2}\right)$ are consistent with a high-spin $\mathrm{Fe}^{\mathrm{II}}$ description but are shorter than typically observed for tetrahedral or octahedral complexes of the same spin state. To rule out a potential spin-crossover from highspin at room temperature to intermediate-spin under crystallography conditions at $100 \mathrm{~K}$, the zero-field ${ }^{57} \mathrm{Fe}$ Mössbauer spectrum of a solid sample of $\left({ }^{\mathrm{Mes}} \mathrm{PDP}{ }^{\mathrm{Ph}}\right) \mathrm{Fe}\left(\mathrm{OEt}_{2}\right)$ was recorded at 80 $\mathrm{K}$ (Figure 2.6). The large isomer shift, $\delta$, of $0.87 \mathrm{~mm} \mathrm{~s}^{-1}$ unambiguously confirms the high-spin $\mathrm{Fe}^{\mathrm{II}}$ assignment at low temperature. The remarkably small quadrupole splitting, $\left|\Delta \mathrm{E}_{\mathrm{Q}}\right|$, of 0.50 $\mathrm{mm} \mathrm{s}^{-1}$ is unusual for a high-spin $\mathrm{Fe}^{\mathrm{II}}$ species and supports a description as a square-planar complex with a doubly occupied $\mathrm{d}_{z^{2}}$ orbital (vide infra). In this particular ground state configuration, the asymmetry in charge distribution caused by the additional electron in the $\mathrm{d}_{z^{2}}$ 
orbital is compensated by ligand field contributions from the four ligands in the xy-plane resulting in a near radially symmetric electric field gradient at the iron nucleus. Veige and coworkers have suggested that small values of $\left|\Delta \mathrm{E}_{\mathrm{Q}}\right|$ can be considered a fingerprint of squareplanar high-spin $\mathrm{Fe}^{\mathrm{II}} \cdot{ }^{27,28}$ This proposal was further supported by data from Limberg and coworkers and is consistent with earlier studies of the electronic structure of the iron sites in gillespite. ${ }^{51,52}$

Inspired by the unusual electronic structure of $\left({ }^{\mathrm{Mes}} \mathrm{PDP}^{\mathrm{Ph}}\right) \mathrm{Fe}\left(\mathrm{OEt}_{2}\right)$, the synthesis of $\left({ }^{\mathrm{Mes}} \mathrm{PDP}^{\mathrm{Ph}}\right) \mathrm{Fe}(\mathrm{L})_{n}$ complexes with other L-type ligands was investigated. Deprotonation of $\mathrm{H}_{2}{ }^{\mathrm{Mes}} \mathrm{PDP}^{\mathrm{Ph}}$ with 2 equiv of LiHMDS in THF followed by slow addition to a slurry of $\mathrm{FeCl}_{2}$ in the same solvent resulted in the formation of an orange-red solution. Addition of pentane and cooling to $-35{ }^{\circ} \mathrm{C}$ yielded a microcrystalline, orange solid. Importantly, only trace amounts of $\left(\mathrm{H}^{\mathrm{Mes}} \mathrm{PDP}{ }^{\mathrm{Ph}}\right)_{2} \mathrm{Fe}$ were observed under these reaction conditions in THF, as confirmed by ${ }^{1} \mathrm{H}$ NMR analysis of the crude reaction mixture. Recrystallization via slow diffusion of pentane into a concentrated THF solution of the orange product at $-35{ }^{\circ} \mathrm{C}$ yielded single crystals suitable for $\mathrm{X}$-ray diffraction analysis, which allowed for identification of the compound as $\left({ }^{\mathrm{Mes}} \mathrm{PDP}^{\mathrm{Ph}}\right) \mathrm{Fe}(\mathrm{thf})(\mu-\mathrm{Cl}) \mathrm{Li}(\text { thf })_{3}$. A representation of the molecular structure is shown in Figure 2.5 and reveals a five-coordinate iron center with distorted square-pyramidal geometry. A THF ligand and the three nitrogen donors of the pincer ligand form the base of the square pyramid, while a chloro ligand is located in the apical position and forms a bridge to a $\mathrm{Li}(\text { thf })_{3}$ unit. The three THF molecules coordinated to the lithium center were found to be heavily disordered in the crystal structure and were treated isotropically during structure refinement. On the basis of the overall neutral charge of the complex and the long iron-ligand bond distances, the complex contains a high-spin $\mathrm{Fe}^{\mathrm{II}}$ center, which was confirmed by a room-temperature magnetic moment 
of 5.4 $\mu_{\mathrm{B}}$ and solid state Mössbauer parameters of $\delta=1.09 \mathrm{~mm} \mathrm{~s}^{-1}$ and $\left|\Delta \mathrm{E}_{\mathrm{Q}}\right|=2.63 \mathrm{~mm} \mathrm{~s}^{-1}$

(Figure 2.6).

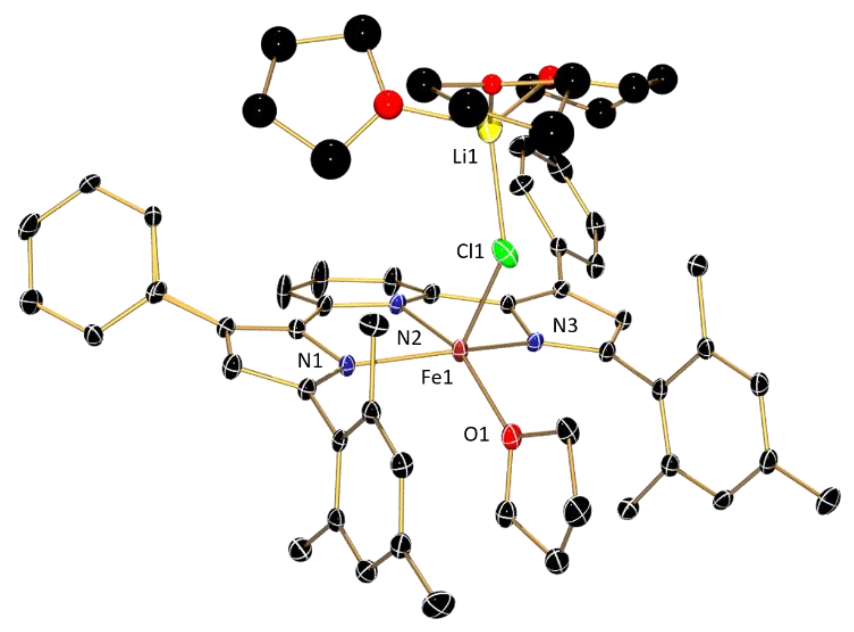

Figure 2.5. ORTEP of $\left({ }^{\mathrm{Mes}} \mathrm{PDP} \mathrm{Ph}^{\mathrm{Ph}}\right) \mathrm{Fe}(\mathrm{thf})(\mu-\mathrm{Cl}) \mathrm{Li}(\text { thf })_{3}$ displayed at $30 \%$ probability ellipsoids. Hydrogen atoms and co-crystallized solvent molecules have been excluded for clarity. Note: only one occupancy of the disordered THF ligands is depicted. 

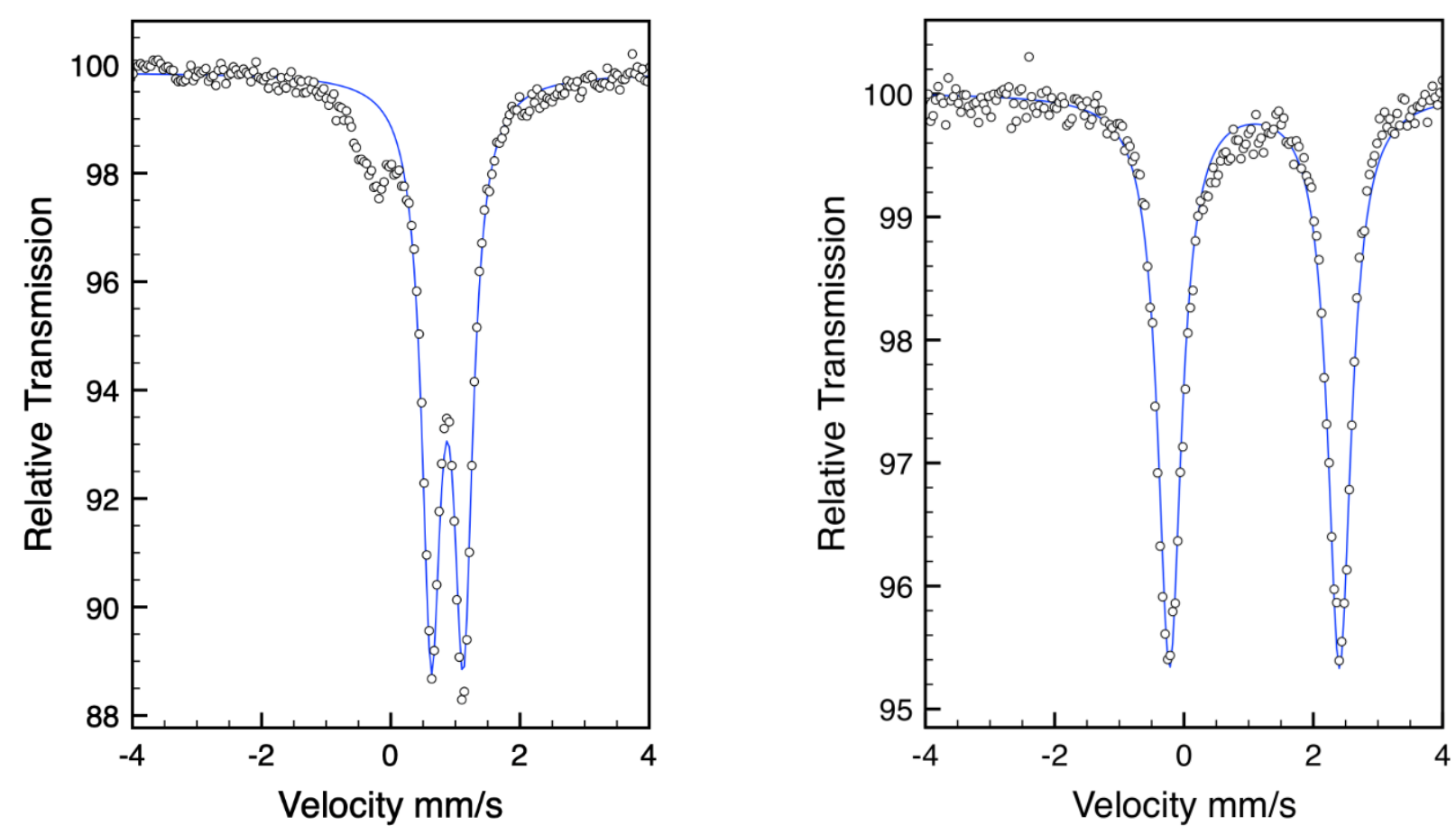

Figure 2.6. Zero field ${ }^{57} \mathrm{Fe}$ Mössbauer spectra of $\left({ }^{{ }^{M e s}} \mathrm{PDP}^{\mathrm{Ph}}\right) \mathrm{Fe}\left(\mathrm{OEt}_{2}\right)(\mathrm{left})$ and $\left({ }^{\mathrm{Mes}} \mathrm{PDP} \mathrm{Ph}^{\mathrm{Ph}}\right) \mathrm{Fe}(\mathrm{thf})(\mu-\mathrm{Cl}) \mathrm{Li}(\mathrm{thf})_{3}$ (right) recorded at $80 \mathrm{~K}$. White circles represent experimental data and the blue line represents the fit of the data. Note, the shoulder present in the spectrum of $\left({ }^{\mathrm{Mes}} \mathrm{PDP}^{\mathrm{Ph}}\right) \mathrm{Fe}\left(\mathrm{OEt}_{2}\right)$ is attributed to the presence of a minor unknown iron containing impurity.

The ${ }^{1} \mathrm{H}$ NMR spectrum of $\left({ }^{\mathrm{Mes}} \mathrm{PDP}{ }^{\mathrm{Ph}}\right) \mathrm{Fe}(\mathrm{thf})(\mu-\mathrm{Cl}) \mathrm{Li}(\text { thf })_{3}$ in benzene- $d_{6}$ exhibits 11 broad resonances between 115 and $-15 \mathrm{ppm}$, which is inconsistent with the solid-state molecular structure. Assuming the connectivity established by X-ray diffraction, the highest possible symmetry for $\left({ }^{\mathrm{Mes}} \mathrm{PDP}{ }^{\mathrm{Ph}}\right) \mathrm{Fe}(\mathrm{thf})(\mu-\mathrm{Cl}) \mathrm{Li}(\text { thf })_{3}$ in solution should be $\mathrm{C}_{s}$, which would result in at least 15 resonances assuming free rotation of the phenyl substituents in the back of the ${ }^{\text {Mes }} \mathrm{PDP}^{\mathrm{Ph}}$ ligand. Additionally, precipitation of a white solid in conjunction with a color change to red in benzene compared to the orange color of the solid material suggested loss of $\mathrm{LiCl}$ and concurrent formation of a new, $\mathrm{C}_{2 v}$ symmetric product consistent with the 11 resonances observed in solution. Due to the similarities of the chemical shifts in the spectrum compared to those recorded for $\left({ }^{\mathrm{Mes}} \mathrm{PDP}{ }^{\mathrm{Ph}}\right) \mathrm{Fe}\left(\mathrm{OEt}_{2}\right)$, the new species was tentatively assigned as the desired complex $\left({ }^{\mathrm{Mes}} \mathrm{PDP}^{\mathrm{Ph}}\right) \mathrm{Fe}($ thf). However, on further inspection, small, but significant, differences 
between the two species are apparent and most clearly illustrated in the chemical shift of the para-pyridine protons. Despite the paramagnetic broadening of all resonances, which complicates the overall assignment of the spectra, these resonances are easily identified via integration. While the 4-pyridine resonance appears at $1.66 \mathrm{ppm}$ for $\left({ }^{\mathrm{Mes}} \mathrm{PDP}^{\mathrm{Ph}}\right) \mathrm{Fe}\left(\mathrm{OEt}_{2}\right)$ in benzene- $d_{6}$, the position of the same proton in benzene- $d_{6}$ solutions of $\left({ }^{\mathrm{Mes}} \mathrm{PDP}^{\mathrm{Ph}}\right) \mathrm{Fe}($ thf $)(\mu-\mathrm{Cl}) \mathrm{Li}(\text { thf })_{3}$ varied significantly from approximately -2 ppm to 3 ppm between different independently prepared samples. Additional NMR studies revealed that the chemical shifts of the $\mathrm{C}_{2 v}$-symmetric product were highly sensitive to the addition of THF to the benzene- $d_{6}$ solution, indicating a rapid equilibrium between species with different numbers of THF ligands, most likely $\left({ }^{\mathrm{Mes}} \mathrm{PDP}^{\mathrm{Ph}}\right) \mathrm{Fe}($ thf $)$ and $\left({ }^{\mathrm{Mes}} \mathrm{PDP}^{\mathrm{Ph}}\right) \mathrm{Fe}(\mathrm{thf})_{2}$. To further support this hypothesis, ${ }^{1} \mathrm{H}$ NMR data of the reaction product were recorded in THF- $d_{8}$ solution. The resonance for the 4-pyridine proton in the resulting spectrum is found at $20.32 \mathrm{ppm}$. This chemical shift is consistent with formation of a fivecoordinate complex $\left({ }^{\mathrm{Mes}} \mathrm{PDP} \mathrm{P}^{\mathrm{Ph}}\right) \mathrm{Fe}(\mathrm{thf})_{2}$ (vide infra). Importantly, this peak position downfield of the diamagnetic reference value of the 4-pyridine proton in $\mathrm{H}_{2}{ }^{\mathrm{Mes}} \mathrm{PDP}^{\mathrm{Ph}}$ indicates a difference in the electronic structure of the product compared to $\left({ }^{\mathrm{Mes}} \mathrm{PDP}^{\mathrm{Ph}}\right) \mathrm{Fe}\left(\mathrm{OEt}_{2}\right)$, for which the same proton resonance is shifted upfield. Altogether, the experimental data support a complex speciation for $\left({ }^{\mathrm{Mes}} \mathrm{PDP}^{\mathrm{Ph}}\right) \mathrm{Fe}(\mathrm{thf})$ adducts in solution (Scheme 2.2). The initially formed contact ion pair $\left({ }^{\mathrm{Mes}} \mathrm{PDP}{ }^{\mathrm{Ph}}\right) \mathrm{Fe}(\mathrm{thf})(\mu-\mathrm{Cl}) \mathrm{Li}(\text { thf })_{3}$ dissociates in THF solution, yielding the five coordinate complex $\left({ }^{\mathrm{Mes}} \mathrm{PDP}{ }^{\mathrm{Ph}}\right) \mathrm{Fe}(\text { thf })_{2}$ and THF-solvated lithium chloride. This process is reversible and $\left({ }^{\mathrm{Mes}} \mathrm{PDP}^{\mathrm{Ph}}\right) \mathrm{Fe}(\mathrm{thf})(\mu-\mathrm{Cl}) \mathrm{Li}(\text { thf })_{3}$ selectively crystallizes upon addition of pentane. Upon dissolution of the contact ion pair in aromatic solvents, $\mathrm{LiCl}$ precipitates to yield the fourcoordinate species $\left({ }^{\mathrm{Mes}} \mathrm{PDP}^{\mathrm{Ph}}\right) \mathrm{Fe}($ thf $)$, which is in rapid equilibrium with $\left({ }^{\mathrm{Mes}} \mathrm{PDP}^{\mathrm{Ph}}\right) \mathrm{Fe}(\text { thf })_{2}$ due to the presence of three additional equivalents of THF. To isolate the desired four-coordinate 
$\left({ }^{\text {Mes }} \mathrm{PDP}^{\mathrm{Ph}}\right) \mathrm{Fe}($ thf $)$ species on preparative scale, $\left({ }^{\mathrm{Mes}} \mathrm{PDP}^{\mathrm{Ph}}\right) \mathrm{Fe}($ thf $)\left(\mu\right.$-Cl) $\mathrm{Li}(\text { thf })_{3}$ was dissolved and stirred in toluene, resulting in precipitation of lithium chloride and a color change from orange to red. Filtration, followed by removal of all volatiles, provided a red solid. This process was repeated several times to remove excess THF and push the equilibrium completely toward $\left({ }^{\text {Mes }} \mathrm{PDP}^{\mathrm{Ph}}\right) \mathrm{Fe}\left(\right.$ thf). The resulting solid exhibits Mössbauer parameters of $\delta=0.78 \mathrm{~mm} \mathrm{~s}^{-1}$ and $\left|\Delta \mathrm{E}_{\mathrm{Q}}\right|=0.48 \mathrm{~mm} \mathrm{~s}^{-1}$ (Figure 2.13), which are consistent with the formation of the desired squareplanar high-spin $\mathrm{Fe}^{\mathrm{II}}$ complex $\left({ }^{\mathrm{Mes}} \mathrm{PDP}^{\mathrm{Ph}}\right) \mathrm{Fe}(\mathrm{thf})$. The ${ }^{1} \mathrm{H}$ NMR spectrum of the compound in benzene- $d_{6}$ and toluene- $d_{8}$ shows a substantially upfield-shifted resonance for the 4-pyridine proton at $-5.98 \mathrm{ppm}$ (Figure 2.7 and Figure 2.9).

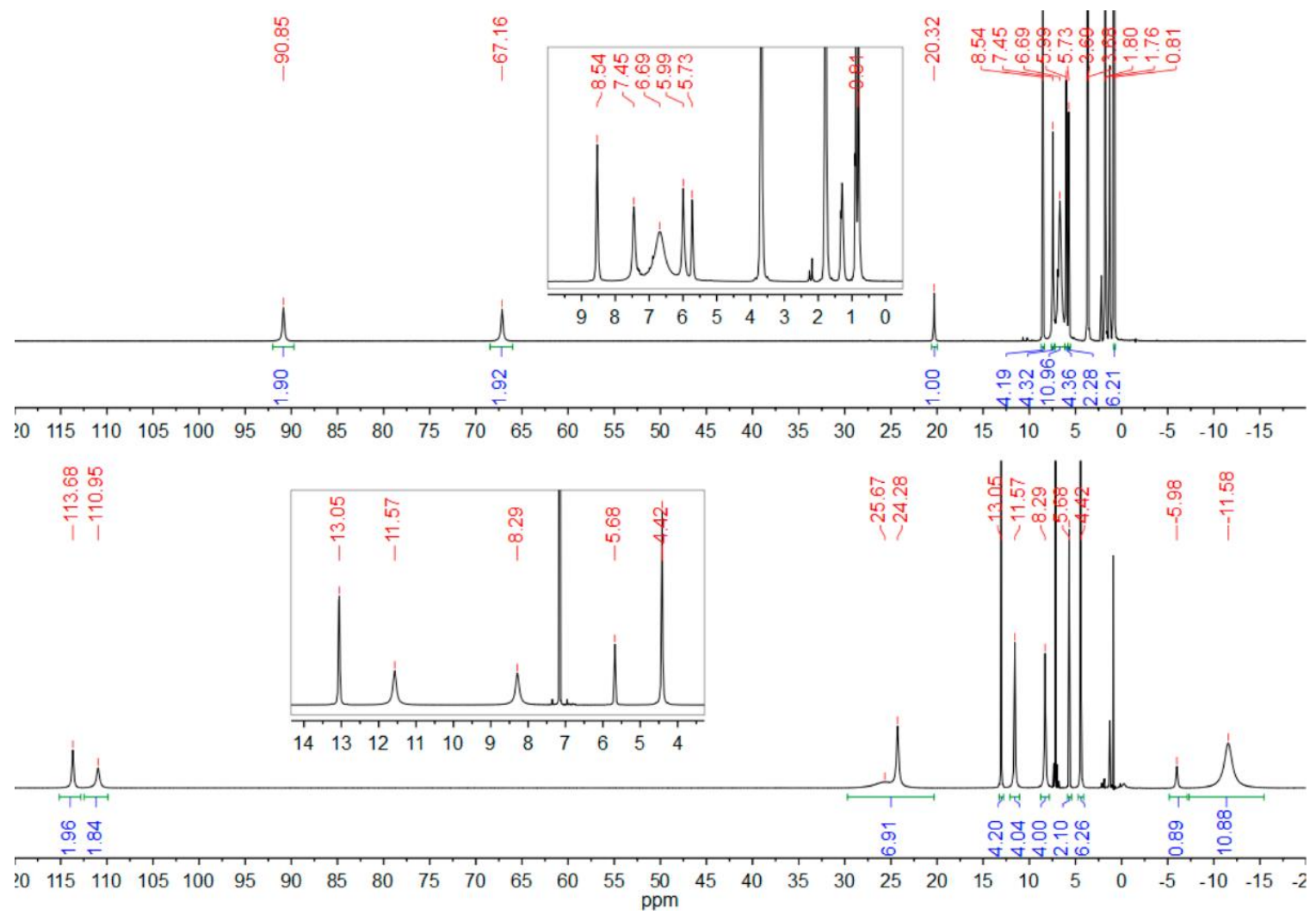

Figure 2.7. Comparison of the ${ }^{1} \mathrm{H}$ NMR spectra of $\left({ }^{\mathrm{Mes}} \mathrm{PDP}^{\mathrm{Ph}}\right) \mathrm{Fe}(\text { thf })_{2}$ in THF- $d_{8}$ (top) and $\left({ }^{\mathrm{Mes}} \mathrm{PDP} \mathrm{P}^{\mathrm{Ph}}\right) \mathrm{Fe}($ thf $)$ in benzene- $d_{6}$ (bottom). 
Single crystals suitable for X-ray diffraction analysis were obtained from slow diffusion of pentane into a concentrated fluorobenzene solution of the compound. A representation of the molecular structure is shown in Figure 2.8, and geometric parameters are summarized in Table 2.2. The compound crystallizes in the monoclinic space group $\mathrm{P} 2{ }_{1} / \mathrm{n}$. In contrast to $\left({ }^{\mathrm{Mes}} \mathrm{PDP}{ }^{\mathrm{Ph}}\right) \mathrm{Fe}\left(\mathrm{OEt}_{2}\right)$, the individual molecules do not lie on special positions in the unit cell. The molecular structure of $\left({ }^{\mathrm{Mes}} \mathrm{PDP}{ }^{\mathrm{Ph}}\right) \mathrm{Fe}(\mathrm{thf})$ is very similar to that of the $\mathrm{Et}_{2} \mathrm{O}$ adduct, but exhibits a significantly shorter $\mathrm{Fe}(1)-\mathrm{O}(1)$ bond of $2.055(1) \AA$. The decrease in bond length by approximately $5 \mathrm{pm}$ is consistent with the stronger $\sigma$-donor ability of the THF ligand compared to diethyl ether. A second difference can be seen in the $\mathrm{N}(2)-\mathrm{Fe}(1)-\mathrm{O}(1)$ angle at $152.99(5)^{\circ}$, which indicates a slightly more pronounced distortion from square planarity for $\left({ }^{\mathrm{Mes}} \mathrm{PDP}{ }^{\mathrm{Ph}}\right) \mathrm{Fe}($ thf $)$.

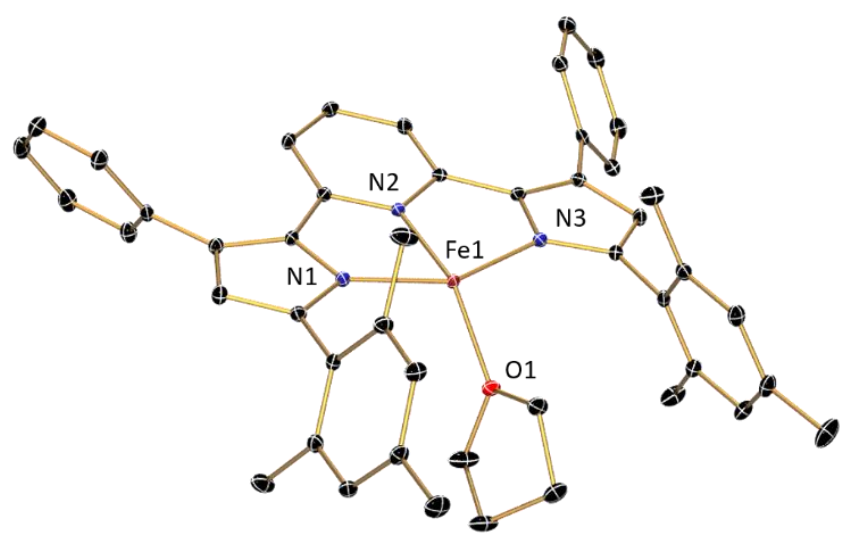

Figure 2.8. ORTEP of $\left({ }^{\mathrm{Mes}} \mathrm{PDP}^{\mathrm{Ph}}\right) \mathrm{Fe}(\mathrm{thf})$ displayed at $30 \%$ probability ellipsoids. Hydrogen atoms and cocrystallized solvent have been excluded for clarity. 


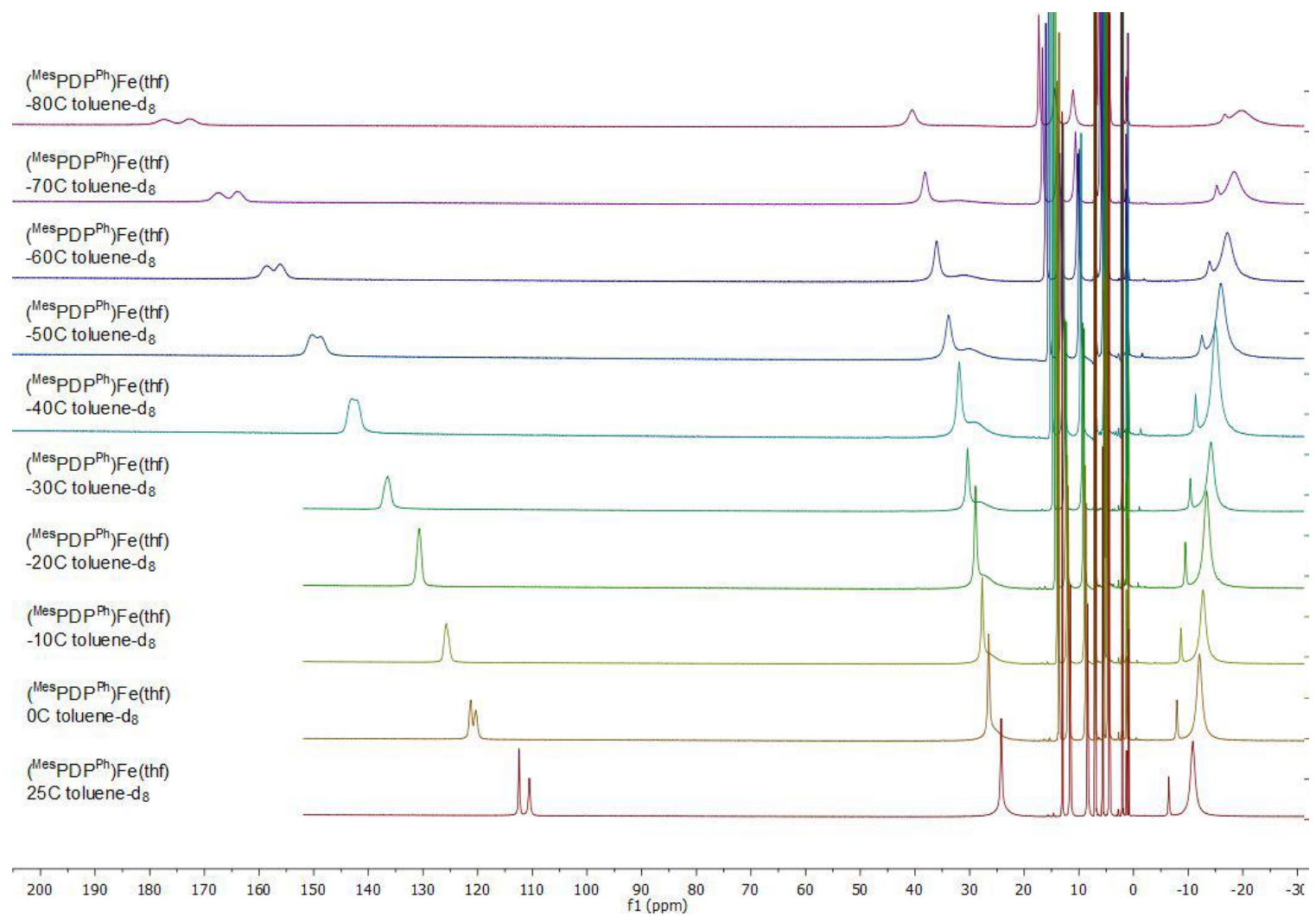

Figure 2.9. Variable temperature ${ }^{1} \mathrm{H} N M R$ data from $25{ }^{\circ} \mathrm{C}$ to $-80{ }^{\circ} \mathrm{C}$ for $\left({ }^{\mathrm{Mes}} \mathrm{PDP}{ }^{\mathrm{Ph}}\right) \mathrm{Fe}$ (thf) in toluene- $d_{8}$ at 400 $\mathrm{MHz}$.

This is also reflected in the $\tau_{4}$ value of 0.38 and deviations obtained via continuous shape measures analysis of 3.43 (square), 22.11 (tetrahedron), and 11.27 (seesaw).

With the clean four-coordinate complex in hand, the equilibrium between $\left({ }^{\mathrm{Mes}} \mathrm{PDP}^{\mathrm{Ph}}\right) \mathrm{Fe}($ thf $)$ and $\left({ }^{\mathrm{Mes}} \mathrm{PDP}^{\mathrm{Ph}}\right) \mathrm{Fe}(\text { thf })_{2}$ in the presence of THF was studied via NMR titration experiments. Addition of exact amounts of rigorously dried THF was performed via vacuum transfer using a calibrated gas bulb to a solution of ( $\left.{ }^{\mathrm{Mes}} \mathrm{PDP}{ }^{\mathrm{Ph}}\right) \mathrm{Fe}(\mathrm{thf})$ in benzene- $d_{6}$ at room temperature, resulting in systematic shifts of the observed resonances. The resulting ${ }^{1} \mathrm{H}$ NMR spectra were recorded and the changes in chemical shifts were fit using the nonlinear least squares method to extract the stability constant, $\mathrm{K}$, for the formation of $\left({ }^{\mathrm{Mes}} \mathrm{PDP}^{\mathrm{Ph}}\right) \mathrm{Fe}(\text { thf })_{2}$ from $\left({ }^{\mathrm{Mes}} \mathrm{PDP}{ }^{\mathrm{Ph}}\right) \mathrm{Fe}($ thf $)$ and THF. 
Assuming rapid ligand exchange on the NMR timescale, the following equation was used for the 1:1 complexation event:

$$
\left.\delta_{o b s}=\left(\frac{\delta_{5}-\delta_{4}}{2}\right) *\left\{\left(\frac{[T H F]_{0}}{\left[F e_{4}\right]_{0}}\right)+1+\left(\frac{1}{K *\left[F e_{4}\right]_{0}}\right)\right\}-\sqrt{\left\{\left\{\left(\frac{[T H F]_{0}}{\left[F e_{4}\right]_{0}}\right)+1+\left(\frac{1}{K *\left[F e_{4}\right]_{0}}\right)\right\}^{2}-4 *\left(\frac{[T H F]_{0}}{\left[F e_{4}\right]_{0}}\right)\right.}\right\}+\delta_{4}
$$

where $\delta_{4}$ and $\delta_{5}$ are the chemical shifts of $\left({ }^{\mathrm{Mes}} \mathrm{PDP}^{\mathrm{Ph}}\right) \mathrm{Fe}(\mathrm{thf})$ and $\left({ }^{\mathrm{Mes}} \mathrm{PDP}^{\mathrm{Ph}}\right) \mathrm{Fe}(\mathrm{thf})_{2}$, respectively, $\left[\mathrm{Fe}_{4}\right]_{0}$ is the starting concentration of $\left({ }^{\mathrm{Mes}} \mathrm{PDP}{ }^{\mathrm{Ph}}\right) \mathrm{Fe}(\mathrm{thf})$, and $[\mathrm{THF}]_{0}$ is the concentration of added THF. No resonances for free THF were observed, indicating that ligand exchange occurs rapidly on the NMR time scale. The most significant changes in chemical shift were observed for the 4-pyridine proton as well as the 3-pyridine and pyrrole protons (Figure 2.10). Assuming a simple 1:1 equilibrium, the data were readily fit using nonlinear least-squares methods, providing a stability constant of $26(2) \mathrm{L} \mathrm{mol}^{-1}$ for $\left({ }^{\mathrm{Mes}} \mathrm{PDP}{ }^{\mathrm{Ph}}\right) \mathrm{Fe}(\text { thf })_{2}$ at $298 \mathrm{~K}^{53-55}$ 

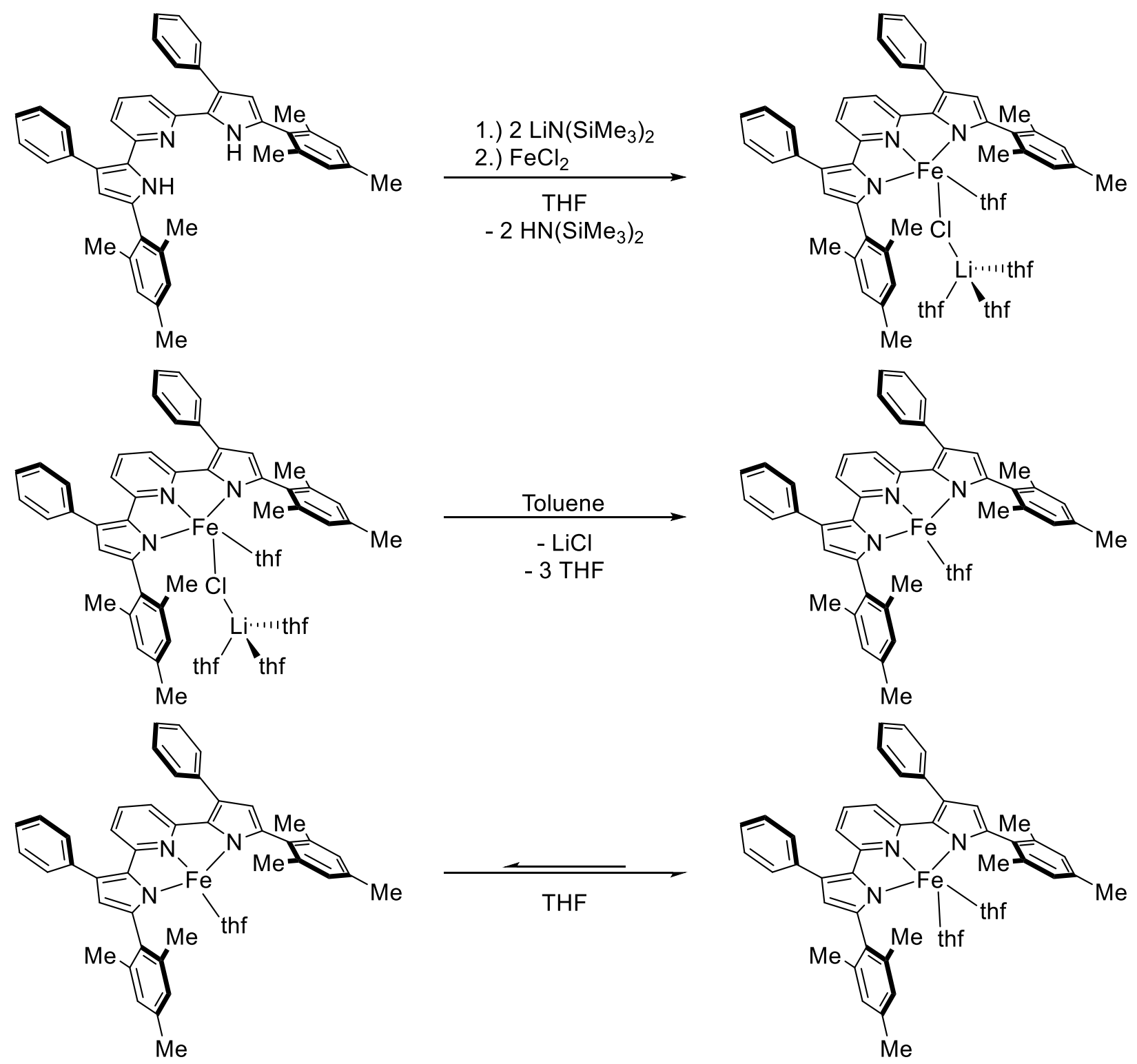

Scheme 2.2. Synthesis of $\left({ }^{\mathrm{Mes}} \mathrm{PDP}^{\mathrm{Ph}}\right) \mathrm{Fe}(\mathrm{thf})(\mu-\mathrm{Cl}) \mathrm{Li}(\mathrm{thf})_{3},\left({ }^{\mathrm{Mes} P D P} \mathrm{Ph}^{\mathrm{Ph}}\right) \mathrm{Fe}($ thf $)$, and $\left({ }^{\mathrm{Mes} P D P}{ }^{\mathrm{Ph}}\right) \mathrm{Fe}(\text { thf })_{2}$. 


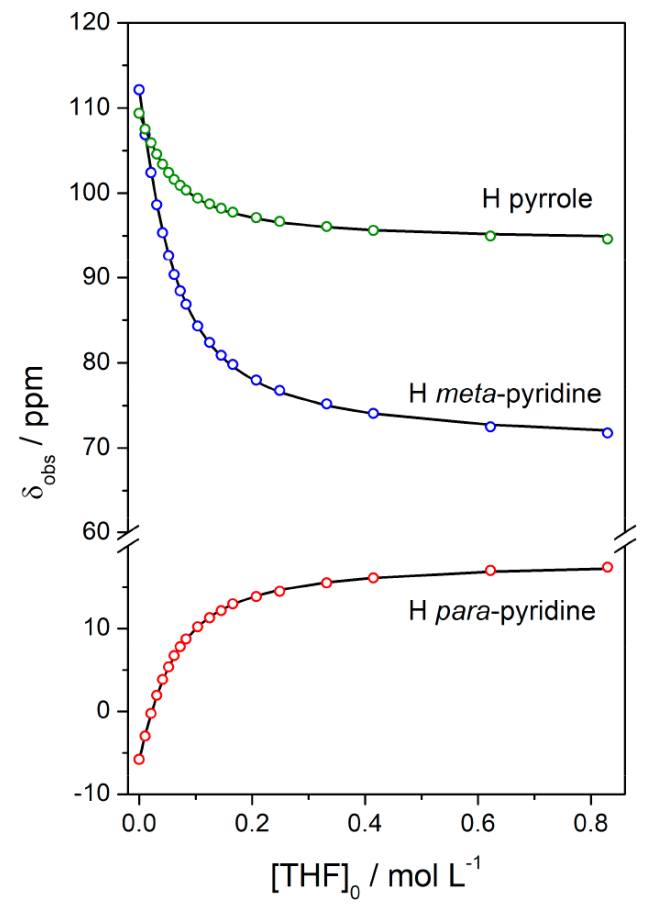

Figure 2.10. Changes in selected chemical shifts with added THF. Conditions: $\left.\left[{ }^{\mathrm{Mes}} \mathrm{PDP}^{\mathrm{Ph}}\right) \mathrm{Fe}(\mathrm{thf})\right] 0=41.5 \mathrm{mM}$, benzene- $d_{6}, 298 \mathrm{~K}$. The black lines were obtained via a nonlinear least-squares fit.

To further study the differences in electronic structure between four- and five coordinate complexes in the absence of structural data for $\left({ }^{\mathrm{Mes}} \mathrm{PDP}{ }^{\mathrm{Ph}}\right) \mathrm{Fe}(\mathrm{thf})_{2}$, the synthesis of an isolable, exclusively five-coordinate complex was pursued employing pyridine as a neutral donor ligand. Addition of excess pyridine to solutions of $\left({ }^{\mathrm{Mes}} \mathrm{PDP}^{\mathrm{Ph}}\right) \mathrm{Fe}(\mathrm{thf})$ in benzene or toluene yielded $\left({ }^{\mathrm{Mes}} \mathrm{PDP}{ }^{\mathrm{Ph}}\right) \mathrm{Fe}(\mathrm{py})_{2}$. 


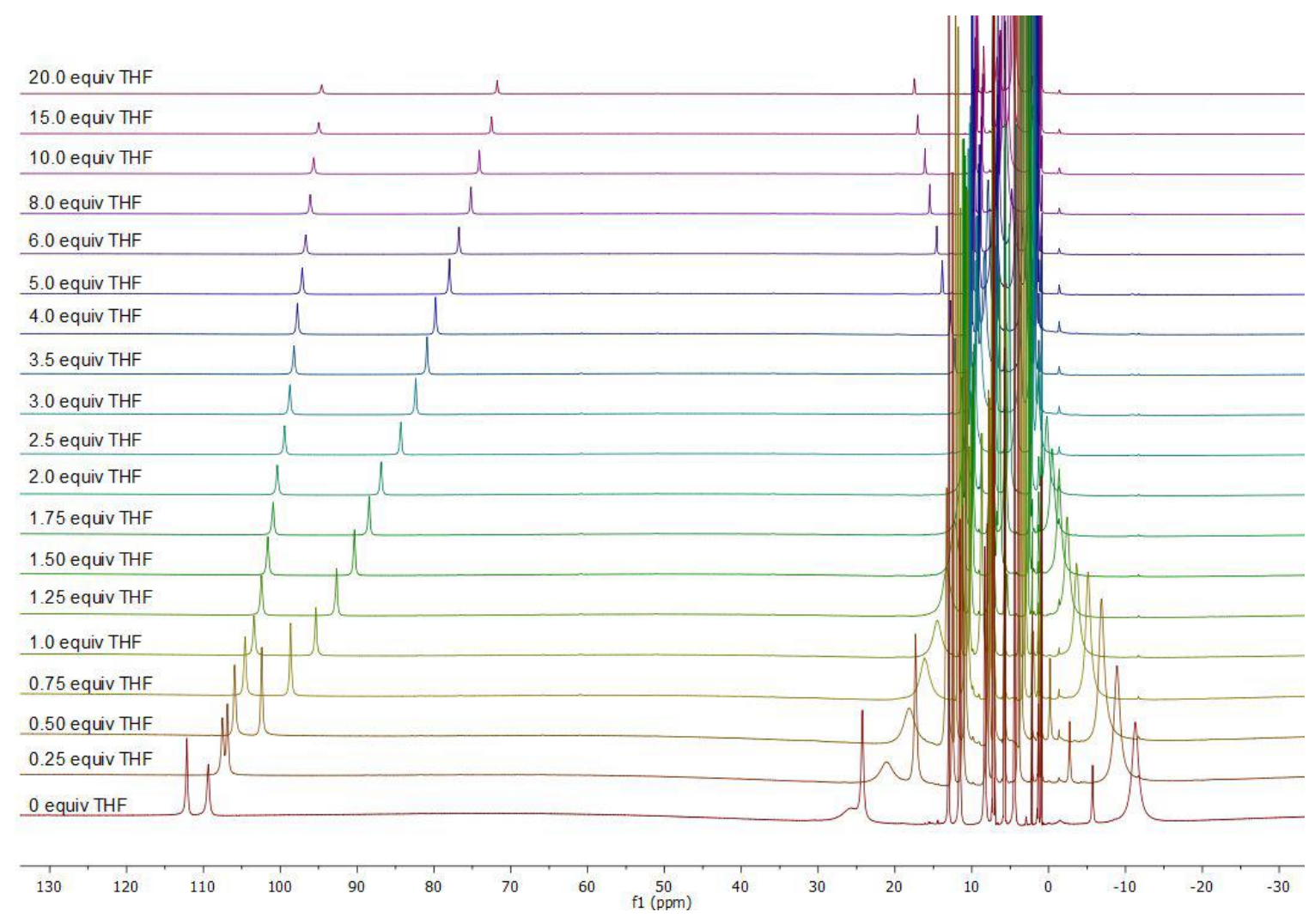

Figure 2.11. ${ }^{1} \mathrm{H}$ NMR spectra of a titration of THF against $\left({ }^{\mathrm{Mes}} \mathrm{PDP}{ }^{\mathrm{Ph}}\right) \mathrm{Fe}(\mathrm{thf})$ in benzene- $d_{6}$ at $298 \mathrm{~K}$.

In a more synthetically convenient route, the five-coordinate complex $\left({ }^{\mathrm{Mes}} \mathrm{PDP}{ }^{\mathrm{Ph}}\right) \mathrm{Fe}(\mathrm{py})_{2}$ was also obtained following the reaction of $\mathrm{Fe}(\mathrm{Ns})_{2}(\mathrm{py})_{2}\left(\mathrm{Ns}=\mathrm{CH}_{2} \mathrm{SiMe}_{3}\right)$ with $\mathrm{H}_{2}{ }^{\mathrm{Mes}} \mathrm{PDP} \mathrm{Ph}^{\mathrm{Ph}}$ (Scheme 2.3). The iron dialkyl starting material was prepared in situ as described by Campora and co-workers. ${ }^{56}$ The molecular structure of $\left({ }^{\mathrm{Mes}} \mathrm{PDP}{ }^{\mathrm{Ph}}\right) \mathrm{Fe}(\mathrm{py})_{2}$ was established by single-crystal X-ray diffraction following recrystallization via slow diffusion of $\mathrm{Et}_{2} \mathrm{O}$ into a toluene solution of the compound at $-35^{\circ} \mathrm{C}$ (Figure 2.12 and Table 2.2). The complex is best described as distorted square-pyramidal with an iron center that is located only $0.21 \AA$ above the plane described by the four nitrogen atoms of the pincer ligand and the pyridine ligand in the basal position. The most significant distortion within the square base of the structure is again introduced by the small bite angles of the pincer ligand $\left(\mathrm{N}(1)-\mathrm{Fe}(1)-\mathrm{N}(3)=148.42(5)^{\circ}\right)$. The $\mathrm{Fe}-\mathrm{N}$ bond distances are 
consistent with a high-spin $\mathrm{Fe}^{\mathrm{II}}$ ground state $(\mathrm{S}=2)$, which was confirmed by magnetic susceptibility measurements $\left(\mu_{\mathrm{eff}}=5.5 \mu_{\mathrm{B}}\right)$.
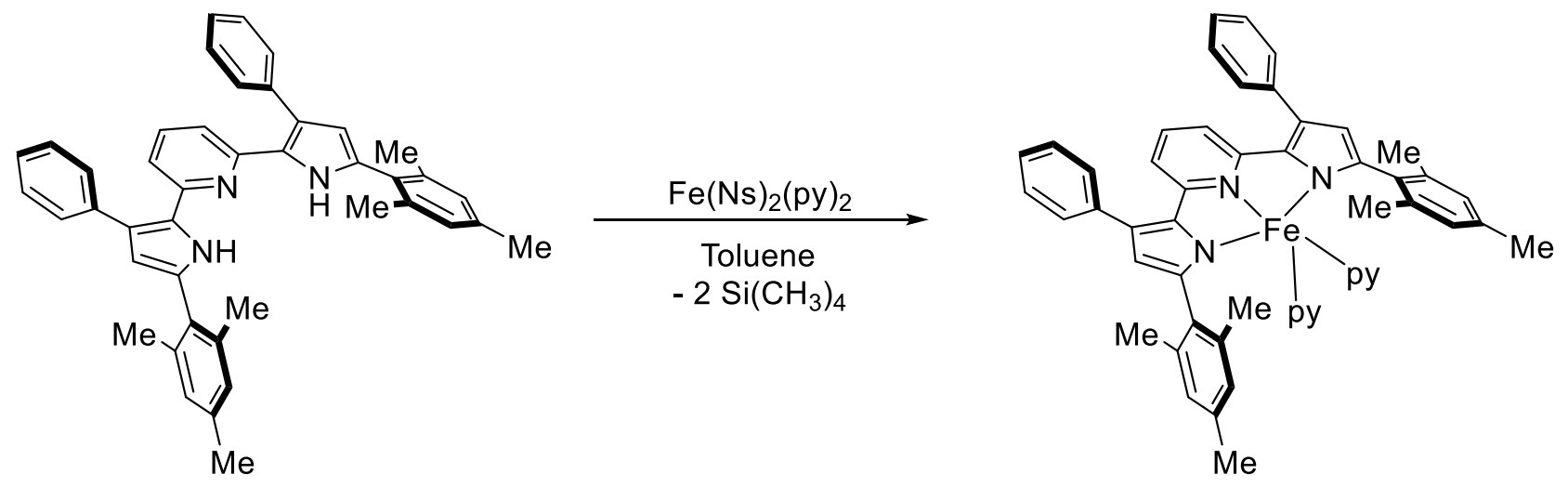

Scheme 2.3. Synthesis of $\left({ }^{\mathrm{Mes}} \mathrm{PDP} \mathrm{Ph}^{\mathrm{Ph}}\right) \mathrm{Fe}(\mathrm{py})_{2}$.

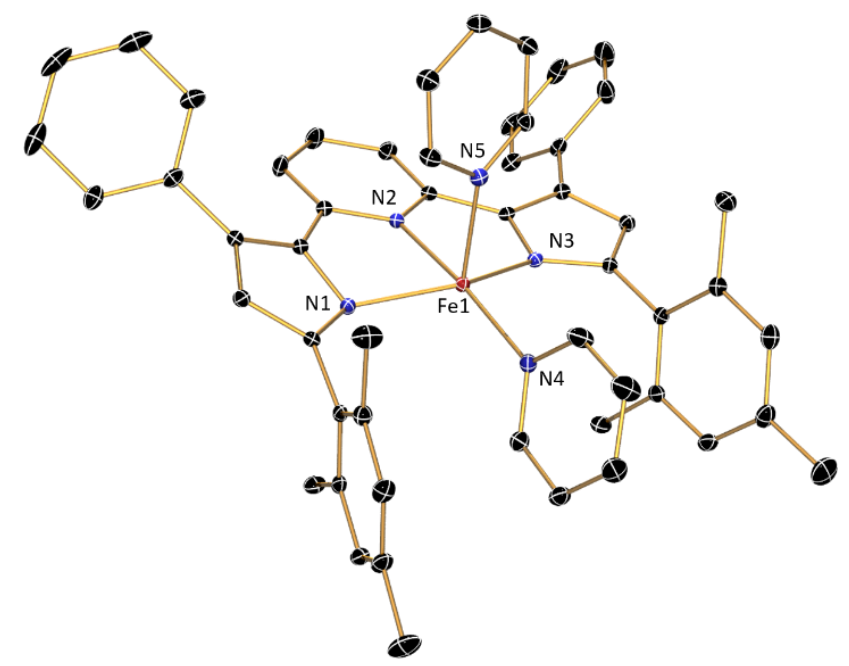

Figure 2.12. ORTEP of $\left({ }^{\mathrm{Mes}} \mathrm{PDP} \mathrm{Ph}^{\mathrm{Ph}} \mathrm{Fe}(\mathrm{py})_{2}\right.$ depicted at $30 \%$ probability ellipsoids. Hydrogen atoms and cocrystallized solvent have been excluded for clarity.

The zero-field Mössbauer parameters of $\delta=0.98 \mathrm{~mm} \mathrm{~s}^{-1}$ and $\left|\Delta \mathrm{E}_{\mathrm{Q}}\right|=2.92 \mathrm{~mm} \mathrm{~s}^{-1}$ are further evidence for this electron configuration (Figure 2.14). 

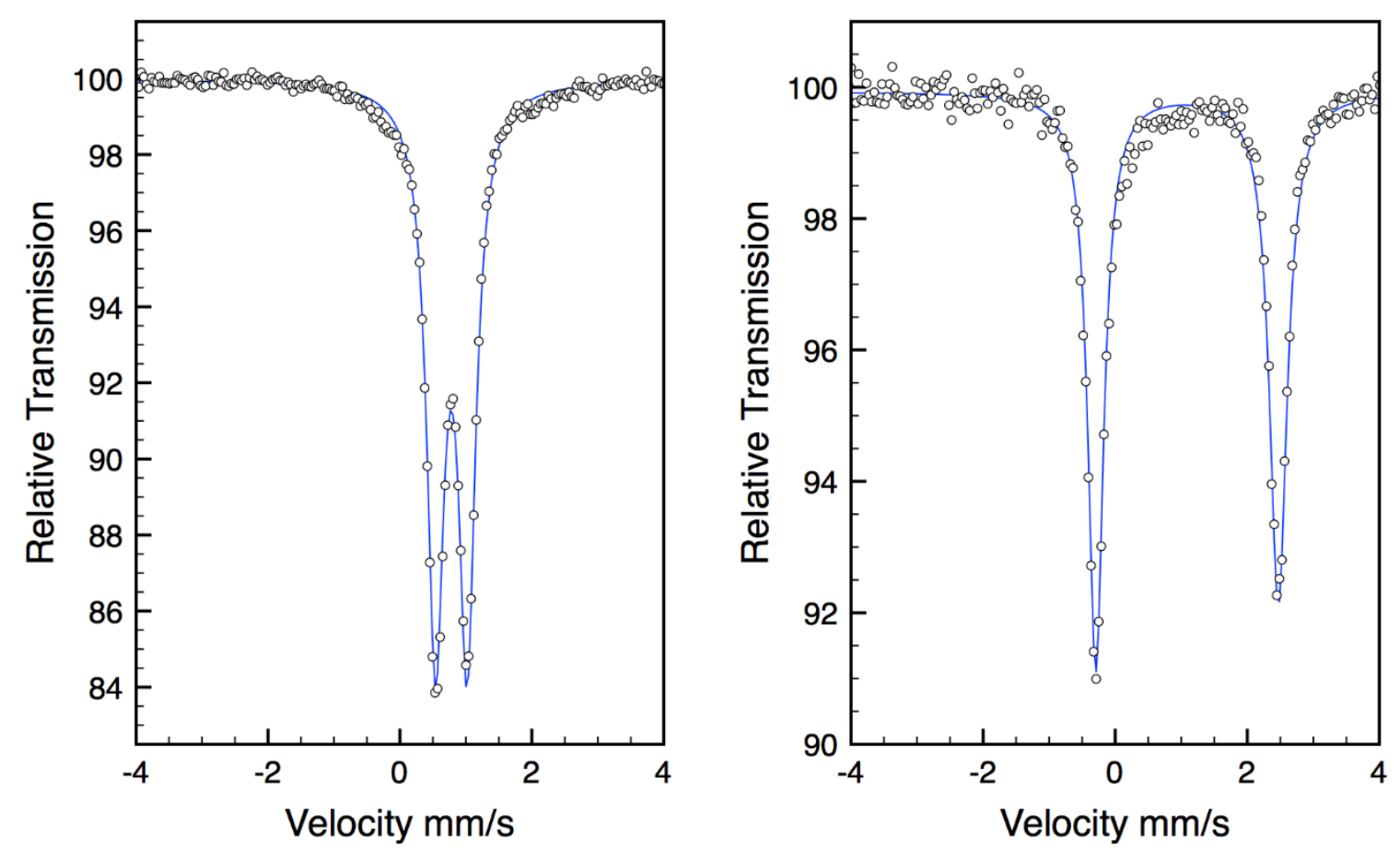

Figure 2.13. Zero-field ${ }^{57} \mathrm{Fe}$ Mössbauer spectra of $\left({ }^{\mathrm{Mes}} \mathrm{PDP}^{\mathrm{Ph}}\right) \mathrm{Fe}(\mathrm{thf})$ and $\left({ }^{\mathrm{Mes}} \mathrm{PDP}^{\mathrm{Ph}}\right) \mathrm{Fe}(\text { thf })_{2}$ recorded at $80 \mathrm{~K}$. White circles represent experimental data and the blue line represents the fit of the data.

The significantly increased quadrupole splitting compared to $\left({ }^{\mathrm{Mes}} \mathrm{PDP}^{\mathrm{Ph}}\right) \mathrm{Fe}\left(\mathrm{OEt}_{2}\right)$ is more typical for high-spin $\mathrm{Fe}^{\mathrm{II}}$ and consistent with a change in electronic structure between the two compounds. The addition of a fifth ligand along the z-axis of the square-pyramidal structure raises the energy of the $\mathrm{d}_{z^{2}}$ orbital $\left(\sigma^{*}\right)$ and results in a configuration with a doubly occupied $\mathrm{d}_{x z}$, $\mathrm{d}_{y z}$, or $\mathrm{d}_{x y}$ orbital. A more detailed analysis of the electronic structure of $\left({ }^{\mathrm{Mes}} \mathrm{PDP}^{\mathrm{Ph}}\right) \mathrm{Fe}(\mathrm{py})_{2}$ is provided in a later section (vide infra). The similarity in the Mössbauer parameters between $\left.{ }^{(\mathrm{Mes}} \mathrm{PDP}^{\mathrm{Ph}}\right) \mathrm{Fe}(\mathrm{py})_{2}$ and the proposed five-coordinate THF adduct supports the characterization as $\left({ }^{\mathrm{Mes}} \mathrm{PDP}^{\mathrm{Ph}}\right) \mathrm{Fe}(\text { thf })_{2}$ in the absence of structural data. The ${ }^{1} \mathrm{H}$ NMR spectrum of $\left({ }^{\mathrm{Mes}} \mathrm{PDP}{ }^{\mathrm{Ph}}\right) \mathrm{Fe}(\mathrm{py})_{2}$ recorded in benzene- $d_{6}$ exhibits 12 paramagnetically broadened resonances between 104 and 0 ppm, suggesting fast interconversion between square-pyramidal and trigonal-bipyramidal structures on the NMR time scale and apparent $\mathrm{C}_{2 v}$ symmetry in solution. The resonance for the 
4-pyridine proton of the PDP pincer ligand is located at $21.54 \mathrm{ppm}$, further indicating a close similarity in electronic structure between $\left({ }^{\mathrm{Mes}} \mathrm{PDP}{ }^{\mathrm{Ph}}\right) \mathrm{Fe}(\mathrm{py})_{2}$ and $\left({ }^{\mathrm{Mes}} \mathrm{PDP}{ }^{\mathrm{Ph}}\right) \mathrm{Fe}(\text { thf })_{2}$.

Table 2.2. Summary of structural metrics obtained via $X$-ray crystallography for $\left({ }^{\mathrm{Mes}} \mathrm{PDP}^{\mathrm{Ph}}\right) \mathrm{Fe}\left(\mathrm{OEt}_{2}\right)$, $\left({ }^{\mathrm{Mes} P D P} \mathrm{Ph}^{\mathrm{Ph}}\right) \mathrm{Fe}($ thf $),\left({ }^{\mathrm{Mes} P D P} \mathrm{Ph}^{\mathrm{Ph}}\right) \mathrm{Fe}(\mathrm{py})_{2}$, and $\left({ }^{\mathrm{Mes}} \mathrm{PDP}^{\mathrm{Ph}}\right) \mathrm{Fe}($ thf $)(\mu-\mathrm{Cl}) \mathrm{Li}(\text { thf })_{3}$.

\begin{tabular}{|c|c|c|c|c|c|}
\hline & $\left({ }^{\mathrm{Mes}} \mathrm{PDP}{ }^{\mathrm{Ph}}\right) \mathrm{Fe}\left(\mathrm{OEt}_{2}\right)^{a}$ & $\left({ }^{\mathrm{Mes}} \mathrm{PDP} \mathrm{Ph}^{\mathrm{Ph}}\right) \mathrm{Fe}(\mathrm{thf})$ & $\left({ }^{\mathrm{Mes}} \mathrm{PDP}{ }^{\mathrm{Ph}}\right) \mathrm{Fe}(\mathrm{py})_{2}$ & \multicolumn{2}{|c|}{$\left({ }^{\mathrm{Mes}} \mathrm{PDP}{ }^{\mathrm{Ph}}\right) \mathrm{Fe}($ thf $)(\mu-\mathrm{Cl}) \mathrm{Li}(\text { thf })_{3}$} \\
\hline $\mathrm{Fe}(1)-\mathrm{N}(1)$ & $2.069(3)$ & $2.0596(14)$ & $2.1126(13)$ & $\mathrm{Fe}(1)-\mathrm{N}(1)$ & $2.137(3)$ \\
\hline $\mathrm{Fe}(1)-\mathrm{N}(2)$ & $2.066(4)$ & $2.0693(13)$ & $2.0968(13)$ & $\mathrm{Fe}(1)-\mathrm{N}(2)$ & $2.132(3)$ \\
\hline $\mathrm{Fe}(1)-\mathrm{N}(3)$ & $2.069(3)$ & $2.0419(14)$ & $2.0863(13)$ & $\mathrm{Fe}(1)-\mathrm{N}(3)$ & $2.130(3)$ \\
\hline $\mathrm{Fe}(1)-\mathrm{N}(4)$ & - & - & $2.1506(14)$ & $\mathrm{Fe}(1)-\mathrm{O}(1)$ & $2.142(3)$ \\
\hline $\mathrm{Fe}(1)-\mathrm{N}(5)$ & - & - & $2.1649(14)$ & $\mathrm{Fe}(1)-\mathrm{Cl}(1)$ & $2.412(1)$ \\
\hline $\mathrm{Fe}(1)-\mathrm{O}(1)$ & $2.100(5)$ & $2.0550(12)$ & - & $\mathrm{Cl}(1)-\mathrm{Li}(1)$ & $2.256(10)$ \\
\hline $\mathrm{N}(1)-\mathrm{Fe}(1)-\mathrm{N}(2)$ & $77.51(8)$ & $78.04(5)$ & $76.59(5)$ & $\mathrm{N}(1)-\mathrm{Fe}(1)-\mathrm{N}(2)$ & $75.81(11)$ \\
\hline $\mathrm{N}(1)-\mathrm{Fe}(1)-\mathrm{N}(3)$ & $155.02(2)$ & $154.07(5)$ & $148.42(5)$ & $\mathrm{N}(1)-\mathrm{Fe}(1)-\mathrm{N}(3)$ & $147.95(12)$ \\
\hline $\mathrm{N}(2)-\mathrm{Fe}(1)-\mathrm{N}(3)$ & $77.51(8)$ & $77.67(5)$ & $76.28(5)$ & $\mathrm{N}(2)-\mathrm{Fe}(1)-\mathrm{N}(3)$ & $76.39(11)$ \\
\hline $\mathrm{N}(2)-\mathrm{Fe}(1)-\mathrm{O}(1)$ & $160.54(15)$ & $152.99(5)$ & - & $\mathrm{N}(2)-\mathrm{Fe}(1)-\mathrm{O}(1)$ & $157.88(12)$ \\
\hline $\mathrm{N}(2)-\mathrm{Fe}(1)-\mathrm{N}(4)$ & - & - & $173.86(5)$ & $\mathrm{N}(2)-\mathrm{Fe}(1)-\mathrm{Cl}(1)$ & $110.32(9)$ \\
\hline $\mathrm{N}(2)-\mathrm{Fe}(1)-\mathrm{N}(5)$ & - & - & $86.20(5)$ & - & - \\
\hline
\end{tabular}

${ }^{a}$ A crystallographic two-fold axis renders N(1) and N(3) equivalent; the coordinates of the second pyrrolide nitrogen, $\mathrm{N}(3)$, were determined by the application of the symmetry relationship: $y \mathrm{x}-\mathrm{z}$, to $\mathrm{N}(1)$. 


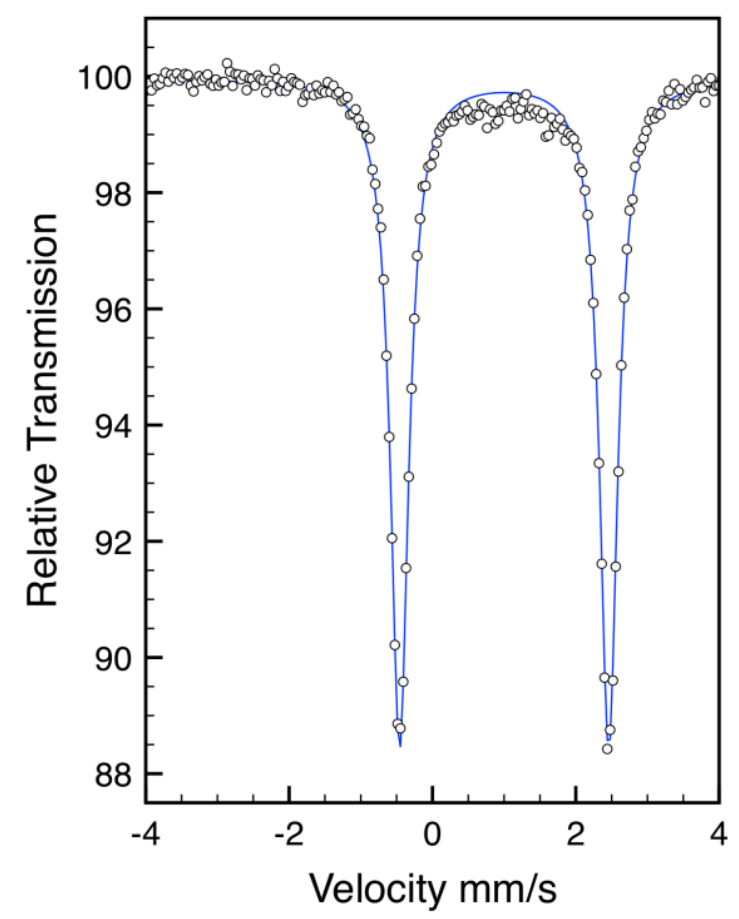

Figure 2.14. Zero-field ${ }^{57} \mathrm{Fe}$ Mössbauer spectra of $\left({ }^{\mathrm{Mes}} \mathrm{PDP} \mathrm{Ph}^{\mathrm{Ph}}\right) \mathrm{Fe}(\mathrm{py})_{2}$ recorded at $80 \mathrm{~K}$. White circles represent experimental data and the blue line represents the fit of the data.

With clear spectroscopic markers for four- and five-coordinate $\left({ }^{\mathrm{Mes}} \mathrm{PDP} \mathrm{P}^{\mathrm{Ph}}\right) \mathrm{Fe}(\mathrm{L})_{n}$ complexes in hand, the electronic structures of all four compounds were investigated computationally by DFT. Considering that $\left({ }^{\mathrm{Mes}} \mathrm{PDP}^{\mathrm{Ph}}\right) \mathrm{Fe}\left(\mathrm{OEt}_{2}\right)$ and $\left({ }^{\mathrm{Mes}} \mathrm{PDP}^{\mathrm{Ph}}\right) \mathrm{Fe}($ thf $)$ do not follow two of the three proposed design principles for square-planar high-spin complexes, we were particularly interested in explaining the unusual spin-state/geometry combination. All calculations were performed at the B3LYP level using the crystallographically determined molecular structure as the starting point for geometry optimizations. For $\left({ }^{\mathrm{Mes}} \mathrm{PDP}^{\mathrm{Ph}}\right) \mathrm{Fe}\left(\mathrm{OEt}_{2}\right)$, three separate calculations representing high-spin $(S=2)$, intermediate-spin $(S=1)$, and lowspin $(\mathrm{S}=0)$ configurations for the central $\mathrm{Fe}^{\mathrm{II}}$ ion were conducted without truncation or imposing any symmetry constraints. All three approaches yielded close to perfectly planar, $\mathrm{C}_{2 v}$ symmetric structures with $\mathrm{N}(2)-\mathrm{Fe}(1)-\mathrm{O}(1)$ angles of approximately $178^{\circ}$ and an iron center 
located within $1 \mathrm{pm}$ of the plane defined by the three $\mathrm{N}$ donor atoms of the pincer. Consistent with the experimentally determined $S=2$ ground state, the high-spin calculation was found to be lowest in energy and accurately reproduced the metal-ligand and intraligand bond lengths.A slight overestimation of the $\mathrm{Fe}-\mathrm{N}$ and $\mathrm{Fe}-\mathrm{O}$ bond distances by up to $6 \mathrm{pm}$ is typical for B3LYP calculations of coordination compounds. ${ }^{57} \mathrm{~A}$ spin-density value of 3.78 on the iron center obtained via Mulliken population analysis is consistent with four unpaired electrons on the metal center and a high-spin $\mathrm{Fe}^{\mathrm{II}}$ center.

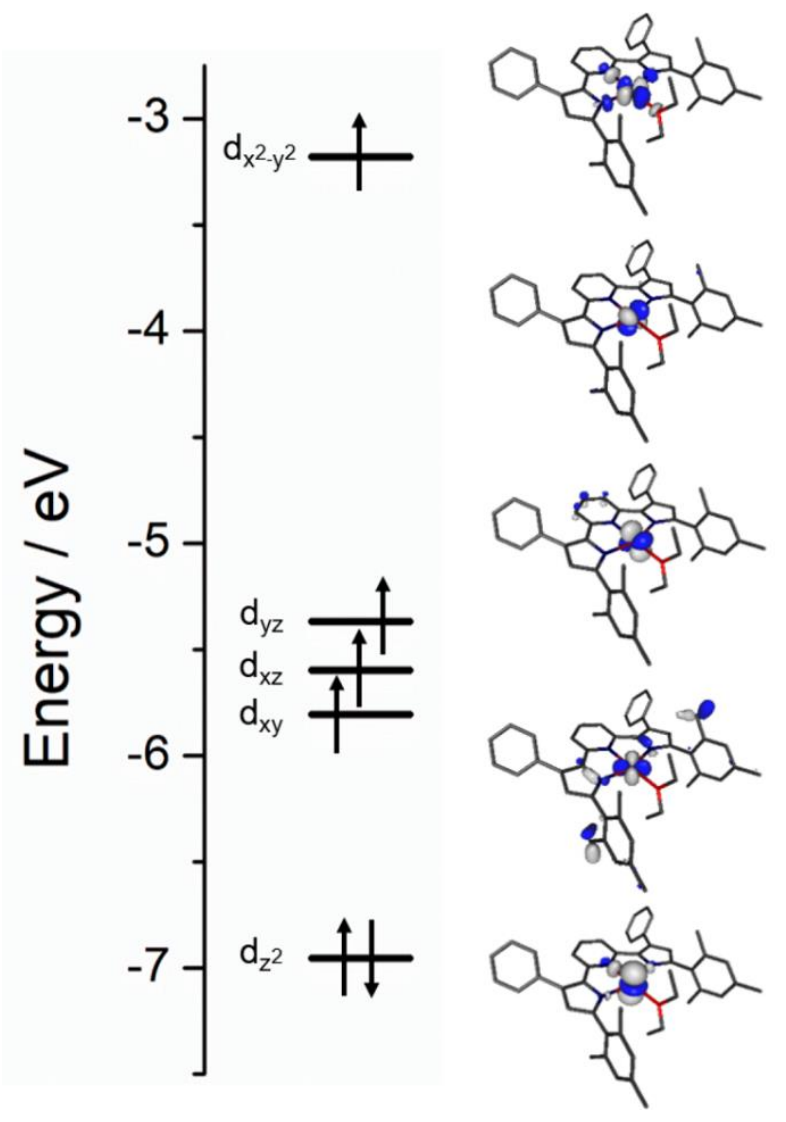

Figure 2.15. Splitting diagram for the iron $3 \mathrm{~d}$ orbitals in $\left({ }^{\mathrm{Mes}} \mathrm{PDP}{ }^{\mathrm{Ph}}\right) \mathrm{Fe}\left(\mathrm{OEt}_{2}\right)$ obtained via DFT calculations at the B3LYP level. The orbital energies were extracted by taking the average of the corresponding single-electron $\alpha$ - and $\beta$-spin orbital energies for each d orbital from the unrestricted Kohn-Sham solution. 

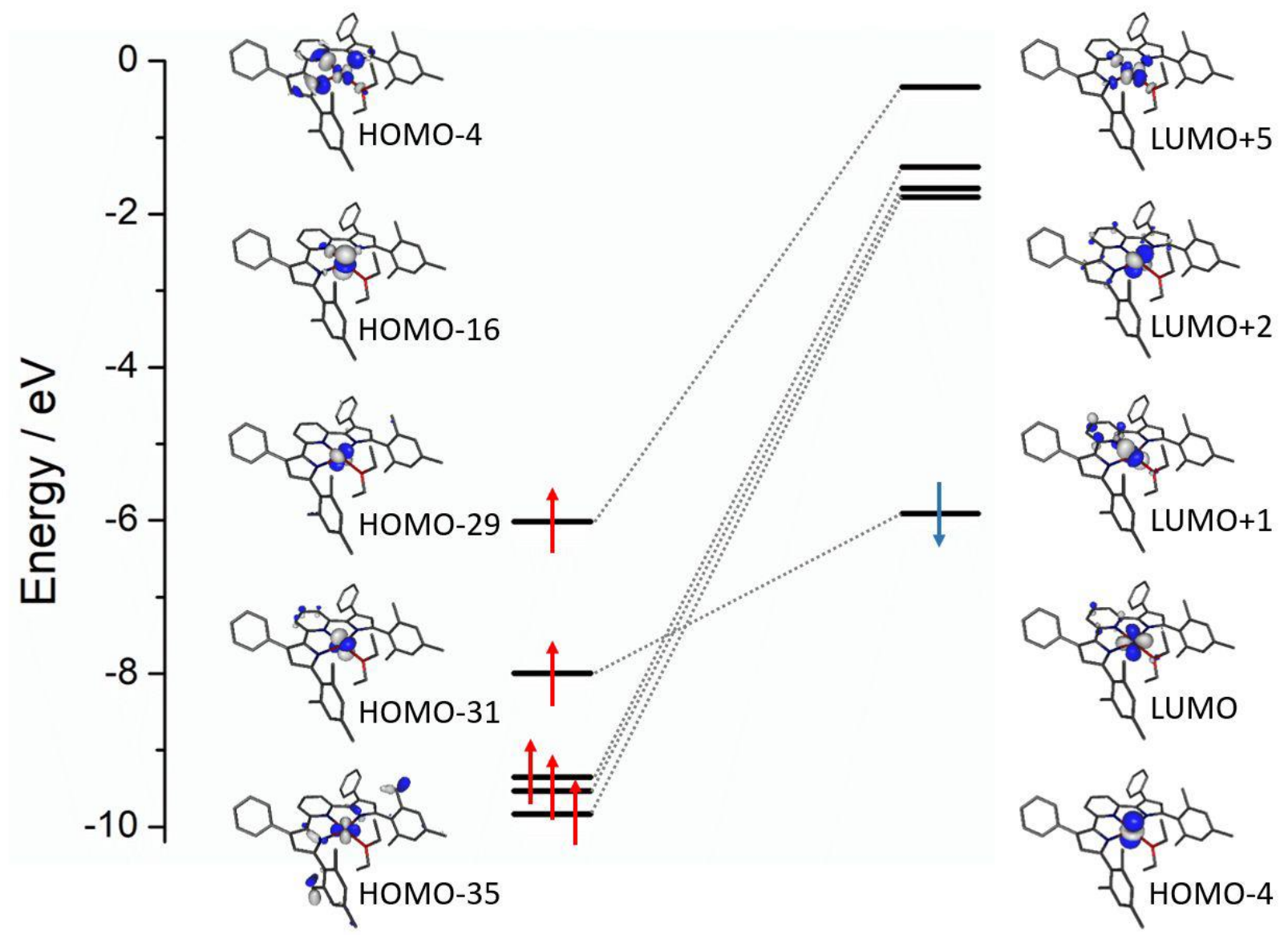

Figure 2.16. Molecular orbital diagram depicting the metal d orbitals obtained via unrestricted DFT calculations at the B3LYP level.

The $S=1$ solution representing an intermediate-spin configuration was found to be 4.3 $\mathrm{kcal} / \mathrm{mol}$ higher in energy, while the closed shell $\mathrm{S}=0$ solution was even less favorable at 35.8 $\mathrm{kcal} / \mathrm{mol}$ relative to the computed high-spin ground state. The small energy difference between high spin and intermediate spin is not surprising given the general favorability of $S=1$ ground states for square-planar $\mathrm{Fe}^{\mathrm{II}}$ complexes. It should be noted that small energy gaps $(<10 \mathrm{kcal} / \mathrm{mol})$ in spin-state comparisons by DFT should be treated with great caution due to the tendency of hybrid functionals to overestimate the stability of high-spin configurations. ${ }^{58}$ Whenever possible, the results of such calculations should be calibrated against experimental parameters. For 
$\left.{ }^{(\mathrm{Mes} \mathrm{PDP}}{ }^{\mathrm{Ph}}\right) \mathrm{Fe}\left(\mathrm{OEt}_{2}\right)$, the computed intermediate and low-spin structures exhibit significantly shortened metal-ligand bonds that are inconsistent with the experimental structure, which further supports the high-spin $\mathrm{Fe}^{\mathrm{II}}$ assignment. The comparison of computed and experimental ${ }^{57} \mathrm{Fe}$ Mössbauer parameters has been established as a reliable tool to corroborate electronic structures obtained from DFT. Reassuringly, the calculated Mössbauer isomer shift and quadrupole splitting for the quintet ground state of $\left({ }^{\mathrm{Mes}} \mathrm{PDP}^{\mathrm{Ph}}\right) \mathrm{Fe}\left(\mathrm{OEt}_{2}\right)$ are in excellent agreement with the experimental values (Table 2.3).

A closer inspection of the molecular orbital manifold for the high-spin solution revealed that $\left({ }^{\mathrm{Mes}} \mathrm{PDP}^{\mathrm{Ph}}\right) \mathrm{Fe}\left(\mathrm{OEt}_{2}\right)$ contains a doubly occupied $\mathrm{d}_{z^{2}}$ orbital while the remaining four $\mathrm{d}$ orbitals are singly occupied (Figures 2.15 and 2.16). This electron configuration is similar to the one reported for all previous examples of square-planar high-spin $\mathrm{Fe}^{\mathrm{II}}$ compounds and has been identified as the cause for the exceptionally small quadrupole splitting observed by Mössbauer spectroscopy and reproduced in our calculations. At first glance, the lowest energy position for the $\mathrm{d}_{z^{2}}$ orbital is surprising given its weakly $\sigma$-antibonding character $\left(\sigma^{*}\right)$ in square-planar geometry. For all previously reported complexes containing alkoxide or siloxide ligands, this is readily explained by the strong $\pi$-donation of the ligands both in- and out-of-plane which substantially destabilizes the $\mathrm{d}_{x z}, \mathrm{~d}_{y z}$, and $\mathrm{d}_{x y}$ orbitals $\left(\pi^{*}\right)$. In contrast, $\pi$-donation in $\left.{ }^{\text {Mes }} \mathrm{PDP}^{\mathrm{Ph}}\right) \mathrm{Fe}\left(\mathrm{OEt}_{2}\right)$ is restricted to the pyrrolide moieties, which can also confer amide character to the pyridine nitrogen via conjugation. Due to the orientation of the N-heterocycles in the PDP ligand, $\pi$-donation alone would only destabilize the out-of-plane $\mathrm{d}_{x z}$ and $\mathrm{d}_{y z}$ orbitals in perfectly square-planar geometry, as shown in the center-right diagram in Figure 2.17. The resulting $d$ orbital splitting diagram features the nonbonding $\mathrm{d}_{x y}$ orbital as the lowest orbital, slightly below the weakly $\sigma$ antibonding $\mathrm{d}_{z^{2}}$ orbital. This orbital arrangement would likely favor an 
intermediate-spin configuration due to the large energy gap between the second lowest $\mathrm{d}$ orbital (here $\mathrm{d}_{z^{2}}$ ) and the $\mathrm{d}_{x^{2}-y^{2}}$ orbital. This particular energy difference in comparison to the spinpairing energy is the critical parameter that distinguishes intermediate-spin and high-spin configurations. The in-plane distortion of the square-planar ligand field imposed by the PDP ligand is the key feature that allows $\left({ }^{\mathrm{Mes}} \mathrm{PDP}^{\mathrm{Ph}}\right) \mathrm{Fe}\left(\mathrm{OEt}_{2}\right)$ to adopt a high-spin state in the absence of in-plane $\pi$-donation. The slight off-axis positioning of the pyrrolide donors results in a stabilization of the $\mathrm{d}_{x^{2}-y^{2}}$ orbital and an equivalent destabilization of the $\mathrm{d}_{x y}$ orbital, which is now weakly $\sigma$-antibonding (Figure 2.17). This effect leads to a significant decrease of the energy difference between the second lowest iron $\mathrm{d}$ orbital (now $\mathrm{d}_{x y}$ ) and the $\mathrm{d}_{x^{2}-y^{2}}$ orbital and favors the $\mathrm{S}=2$ ground state. We note that any in-plane deviation from ideal square-planar geometry as observed for $\mathrm{FeO}_{4}$ cores with bidentate chelate ligands results in a similar stabilization of the $\mathrm{d}_{x^{2}-y^{2}}$ orbital (Figure 2.17). 


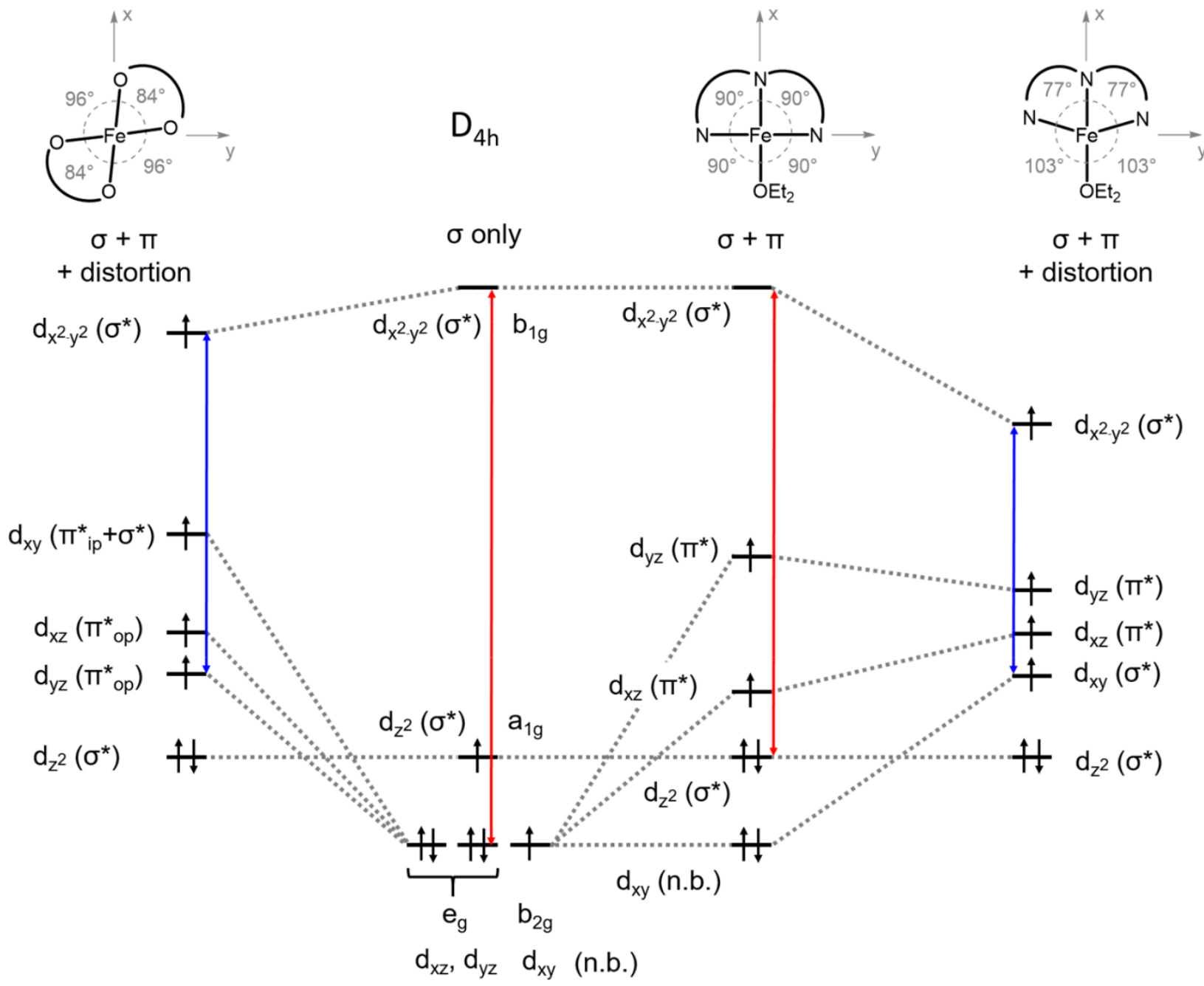

Figure 2.17. Qualitative d-orbital splitting diagrams for square-planar high-spin $\mathrm{Fe}^{\mathrm{II}}$ complexes showing the effect of $\sigma$ - and $\pi$-interactions for compounds with two bidentate bis(alkoxide) or bis(siloxide) ligands (left) and $\left.{ }^{\mathrm{Mes}} \mathrm{PDP}^{\mathrm{Ph}}\right) \mathrm{Fe}\left(\mathrm{OEt}_{2}\right)$ (right).

Computations for the THF adduct ( $\left.{ }^{\mathrm{Mes}} \mathrm{PDP}{ }^{\mathrm{Ph}}\right) \mathrm{Fe}($ thf $)$, assuming the experimentally established $\mathrm{S}=2$ ground state, yielded a nearly identical electronic structure to the one described for $\left({ }^{\mathrm{Mes}} \mathrm{PDP}^{\mathrm{Ph}}\right) \mathrm{Fe}\left(\mathrm{OEt}_{2}\right)$. The calculations accurately reproduced the geometric and Mössbauer spectroscopic parameters (Table 1.3). Notably, the slightly smaller $\mathrm{N}(2)-\mathrm{Fe}(1)-\mathrm{O}(1)$ angle observed experimentally in $\left({ }^{\mathrm{Mes}} \mathrm{PDP}^{\mathrm{Ph}}\right) \mathrm{Fe}($ thf $)$ compared to $\left({ }^{\mathrm{Mes}} \mathrm{PDP}{ }^{\mathrm{Ph}}\right) \mathrm{Fe}\left(\mathrm{OEt}_{2}\right)$ and the characteristically small quadrupole splitting are mirrored by the calculations. The electronic 
structures of the two five-coordinate complexes $\left({ }^{\mathrm{Mes}} \mathrm{PDP}^{\mathrm{Ph}}\right) \mathrm{Fe}(\text { thf })_{2}$ and $\left({ }^{\mathrm{Mes}} \mathrm{PDP}{ }^{\mathrm{Ph}}\right) \mathrm{Fe}(\mathrm{py})_{2}$ are very similar to each other, but distinct from those described for the four-coordinate species. For the pyridine adduct, the structural parameters are in good agreement with the experimental data and show a square-pyramidal coordination environment.
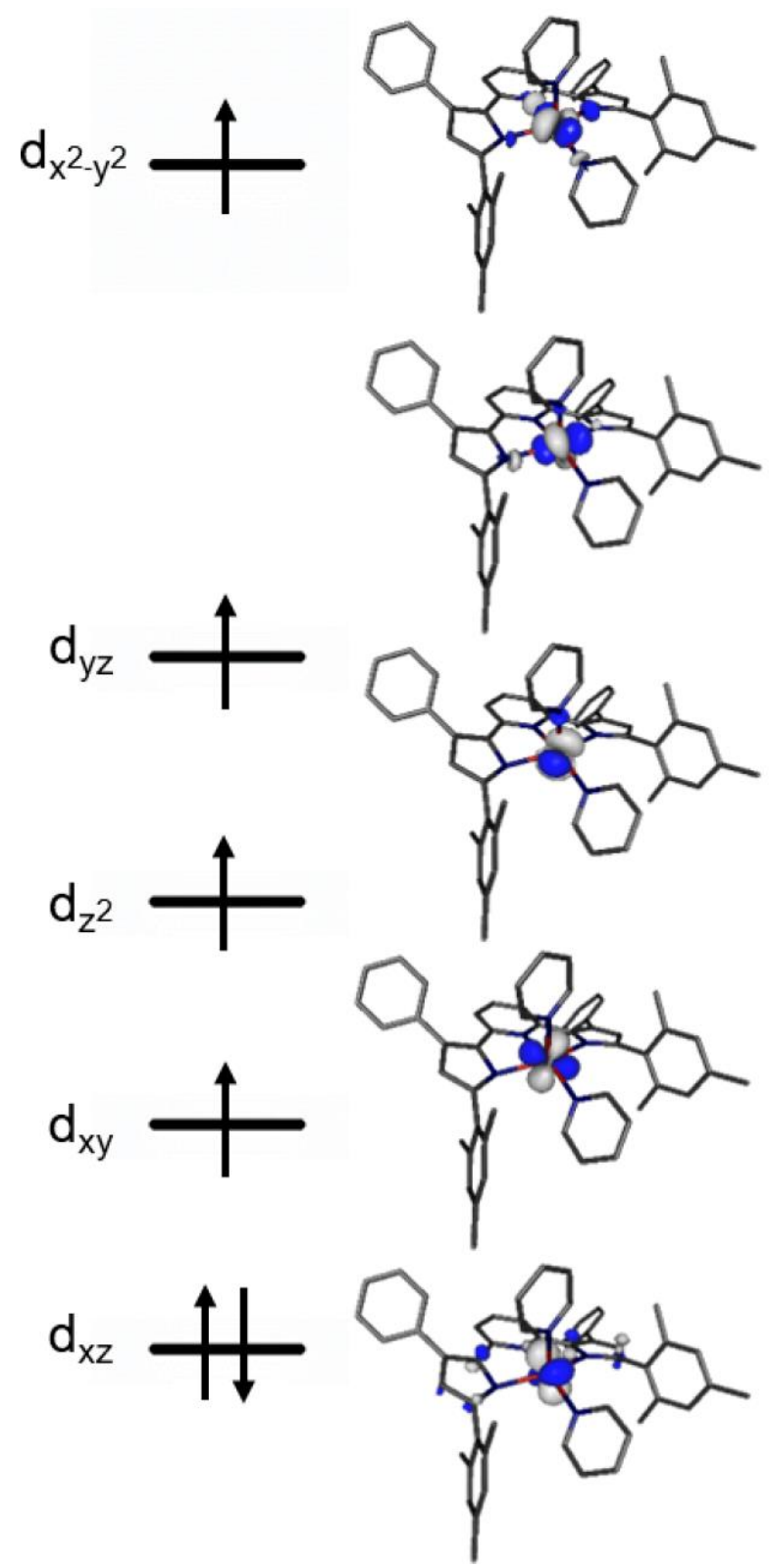

Figure 2.18. Qualitative d-orbital diagram for $\left({ }^{\mathrm{Mes}} \mathrm{PDP}^{\mathrm{Ph}}\right) \mathrm{Fe}(\mathrm{py})_{2}$ obtained from DFT calculations at the B3LYP level. 
Exceptions are the values obtained for the $\mathrm{Fe}-\mathrm{N}_{\text {pyrrole }}$ bond lengths, which are overestimated by more than $10 \mathrm{pm}$. Despite this unusually large discrepancy, the Mössbauer parameters calculated based on the obtained structure are in good agreement with the experimental values (Table 2.3). A qualitative MO diagram for $\left({ }^{\mathrm{Mes}} \mathrm{PDP}^{\mathrm{Ph}}\right) \mathrm{Fe}(\mathrm{py})_{2}$ is shown in Figure 2.18 and clearly establishes that the doubly occupied metal $\mathrm{d}$ orbital is predominantly of $\mathrm{d}_{x z}$ character. In the absence of structural data for $\left({ }^{\mathrm{Mes}} \mathrm{PDP}^{\mathrm{Ph}}\right) \mathrm{Fe}(\text { thf })_{2}$, the DFT-predicted Mössbauer parameters are the only piece of data to calibrate the computational results against experiment. Their excellent agreement provides support for the obtained electronic structure with a doubly occupied $\mathrm{d}_{x z}$ orbital. A summary of the experimental and computed Mössbauer parameters are provided in Table 2.3.

Table 2.3. Experimental (in parentheses) and calculated Mössbauer parameters of $\left({ }^{\mathrm{Mes}} \mathrm{PDP}{ }^{\mathrm{Ph}}\right) \mathrm{Fe}(\mathrm{L})_{n}$ complexes.

\begin{tabular}{|c|c|c|c|}
\hline & $\delta / \mathrm{mms}^{-1}$ (calc) & $\Delta \mathrm{E}_{\mathrm{Q}} / \mathrm{mms}^{-1}$ (calc) & $\overline{\eta^{a}(\mathrm{calc})}$ \\
\hline$\left({ }^{\mathrm{Mes}} \mathrm{PDP}^{\mathrm{Ph}}\right) \mathrm{Fe}\left(\mathrm{OEt}_{2}\right)$ & $0.87(0.71)$ & $|0.50|^{b}(-0.79)$ & $0.95^{c}$ \\
\hline$\left({ }^{\text {Mes }} \mathrm{PDP}^{\mathrm{Ph}}\right) \mathrm{Fe}(\mathrm{thf})$ & $0.78(0.67)$ & $|0.48|^{b}(0.78)$ & 0.72 \\
\hline$\left({ }^{\mathrm{Mes}} \mathrm{PDP} \mathrm{Ph}^{\mathrm{Ph}}\right) \mathrm{Fe}(\mathrm{thf})_{2}{ }^{d}$ & $1.09(0.93)$ & $|2.76|^{b}(2.90)$ & $0.89^{c}$ \\
\hline$\left({ }^{\mathrm{Mes}} \mathrm{PDP}^{\mathrm{Ph}}\right) \mathrm{Fe}(\mathrm{py})_{2}$ & $0.98(0.84)$ & $|2.92|^{b}(3.15)$ & $0.86^{c}$ \\
\hline$\left({ }^{\text {Mes }} \mathrm{PDP}^{\mathrm{Ph}}\right) \mathrm{Fe}(\mathrm{thf})(\mu-\mathrm{Cl}) \mathrm{Li}(\mathrm{thf})_{3}$ & $1.09(0.94)$ & $|2.63|^{b}(2.69)$ & $0.80^{c}$ \\
\hline
\end{tabular}

${ }^{a}$ Asymmetry parameter of the electronic field gradient. ${ }^{b}$ Sign not determined experimentally. ${ }^{c}$ Not determined experimentally. ${ }^{d}$ Recorded in frozen THF solution.

One interesting feature of the optimized structure is the $\mathrm{Fe}-\mathrm{O}$ bond for the apical THF ligand in the overall square-pyramidal molecule, which is significantly longer than the one predicted for the basal THF ligand and the $\mathrm{Fe}-\mathrm{N}$ bonds for the pyridine ligands in $\left({ }^{\mathrm{Mes}} \mathrm{PDP}^{\mathrm{Ph}}\right) \mathrm{Fe}(\mathrm{py})_{2}$. This elongation is indicative of a weaker $\mathrm{Fe}-\mathrm{O}$ bond for this ligand and is consistent with the experimentally observed equilibrium between four- and five coordinate THF 
adducts. Aside from the Mössbauer quadrupole splitting, the chemical shift of the 4-pyridine proton of the PDP ligand in ${ }^{1} \mathrm{H}$ NMR spectroscopy is the most sensitive reporter for the change in electronic structure between four- and five coordinate $\left({ }^{\mathrm{Mes}} \mathrm{PDP} \mathrm{P}^{\mathrm{Ph}}\right) \mathrm{Fe}(\mathrm{L})_{n}$ complexes. Considering that the electronic structures obtained via DFT reproduce the change in Mössbauer quadrupole splitting, we were interested to establish a qualitative connection between the observed NMR shifts and the ground-state configurations. The NMR shifts for nuclei in paramagnetic iron compounds are the result of three separate terms: diamagnetic or orbital contributions equivalent to shielding effects in diamagnetic systems; Fermi contact shifts due to interactions between the magnetic moment of the nucleus and the magnetic field arising from unpaired electron density at the site of the nucleus; and pseudo-contact shifts. ${ }^{59-62}$ Previous studies have shown that the dominating term for most iron compounds is the Fermi contact shift that can be related to the spin density at the nucleus of interest. ${ }^{62}$ On the basis of this assumption, the spin densities on the 4-pyridine protons obtained via Mulliken population analysis were compared for the four $\left({ }^{\mathrm{Mes}} \mathrm{PDP}{ }^{\mathrm{Ph}}\right) \mathrm{Fe}(\mathrm{L})_{n}$ complexes described herein (Figure 2.19). As further reference points, the values for the meta-pyridine and the pyrrole protons were examined as well. These protons are expected to carry the largest amount of spin density due to their direct connectivity to the $\pi$ system of the PDP backbone, which can directly interact with the SOMOs of the iron center, resulting in delocalization of unpaired electron density and large Fermi contact shifts. For the four-coordinate complexes, the 3-pyridine protons carry the largest amount of spin density, closely followed by the pyrrole protons. This is consistent with the significant downfield shifts observed for two resonances corresponding to two protons each in the ${ }^{1} \mathrm{H}$ NMR spectra of $\left({ }^{\mathrm{Mes}} \mathrm{PDP}^{\mathrm{Ph}}\right) \mathrm{Fe}\left(\mathrm{OEt}_{2}\right)(111.69$ and $92.58 \mathrm{ppm})$ and $\left({ }^{\mathrm{Mes}} \mathrm{PDP}{ }^{\mathrm{Ph}}\right) \mathrm{Fe}($ thf $)(113.68$ and $110.95 \mathrm{ppm})$. In contrast, the 4-pyridine proton carries negative spin density, which is due to spin polarization 
effects from $\pi$-interactions between the metal $\mathrm{d}_{x z}$ SOMO and the pyridine $\pi$-system. As a result, the 4-pyridine proton is shifted upfield with respect to its diamagnetic reference value in $\left({ }^{\mathrm{Mes}} \mathrm{PDP}{ }^{\mathrm{Ph}}\right) \mathrm{Fe}\left(\mathrm{OEt}_{2}\right)(1.66 \mathrm{ppm})$ and $\left({ }^{\mathrm{Mes}} \mathrm{PDP}{ }^{\mathrm{Ph}}\right) \mathrm{Fe}(\mathrm{thf})(-5.98 \mathrm{ppm})$.
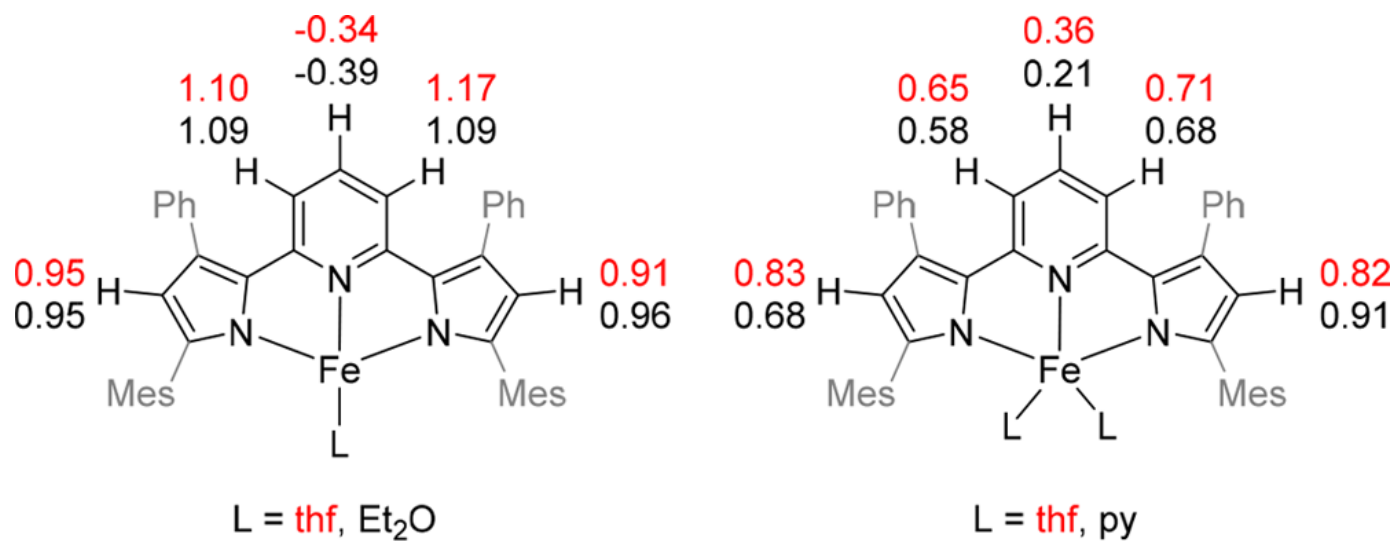

Figure 2.19. Mulliken spin populations for selected protons of the ${ }^{\mathrm{Mes}} \mathrm{PDP}^{\mathrm{Ph}}$ ligand in four- (left) and five-coordinate

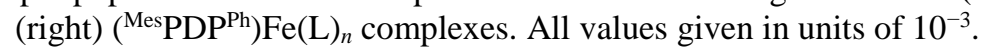

The change in ground-state electronic structure for the five coordinate complexes is clearly reflected in the calculated spin density distributions. In contrast to the four-coordinate compounds, the 4-pyridine protons show positive values in these complexes consistent with the observed downfield shifts in $\left({ }^{\mathrm{Mes}} \mathrm{PDP} \mathrm{Ph}^{\mathrm{Ph}}\right) \mathrm{Fe}(\mathrm{py})_{2}(21.54 \mathrm{ppm})$ and $\left({ }^{\mathrm{Mes}} \mathrm{PDP}{ }^{\mathrm{Ph}}\right) \mathrm{Fe}(\mathrm{thf})_{2}(20.32$ ppm). The change in sign can be directly correlated with the now doubly occupied $\mathrm{d}_{x z}$ orbital, which removes the spin-polarization mechanism for spin delocalization via the $\pi$ system of the pyridine moiety. In addition, the positive spin density at meta-pyridine, and to a lesser extent at the pyrrole protons, is reduced compared to the four coordinate complexes and results in smaller downfield shifts for these signals in $\left({ }^{\mathrm{Mes}} \mathrm{PDP}{ }^{\mathrm{Ph}}\right) \mathrm{Fe}(\mathrm{py})_{2}(87.89$ and $77.20 \mathrm{ppm})$ and $\left({ }^{\mathrm{Mes}} \mathrm{PDP}{ }^{\mathrm{Ph}}\right) \mathrm{Fe}(\text { thf })_{2}(90.85$ and $67.16 \mathrm{ppm})$. 
Table 2.4 Reported ${ }^{57} \mathrm{Fe}$ Mössbauer parameters for square-planar high-spin $\mathrm{Fe}^{\mathrm{II}}$ complexes.

\begin{tabular}{|c|c|c|c|}
\hline & $\delta / \mathrm{mms}^{-1}$ & $\left|\Delta \mathrm{E}_{\mathrm{Q}}\right| / \mathrm{mms}^{-1}$ & Ref \\
\hline Gillespite & 0.66 & 0.56 & 51 \\
\hline$\left({ }^{i P r} \mathrm{PDI}\right) \mathrm{FeCl}^{a}$ & 0.77 & 0.73 & 32 \\
\hline$\left[\mathrm{Li}(\mathrm{thf})_{2}\right]_{2}\left[\left(\mathrm{CF}_{3}-\mathrm{ONO}\right) \mathrm{FeCl}\right]^{b}$ & 0.83 & 0.45 & 27 \\
\hline$\left[\left(\mathrm{TL}^{\mathrm{tBu}}\right) \mathrm{Fe}(\mathrm{OTf})\right] \mathrm{OTf}^{c}$ & 0.81 & 0.64 & 30 \\
\hline$\left[\mathrm{Li}(\text { thf })_{2}\right]_{2}\left[\mathrm{Fe}\left(\left\{\mathrm{OSiPh}_{2}\right\}_{2} \mathrm{O}\right)_{2}\right]$ & 0.87 & 0.52 & 26 \\
\hline$\left({ }^{\text {Mes }} \mathrm{PDP}^{\mathrm{Ph}}\right) \mathrm{Fe}\left(\mathrm{OEt}_{2}\right)$ & 0.87 & 0.50 & This work \\
\hline$\left({ }^{\text {Mes }} \mathrm{PDP}^{\mathrm{Ph}}\right) \mathrm{Fe}(\mathrm{thf})$ & 0.78 & 0.48 & This work \\
\hline
\end{tabular}

\subsection{Conclusion}

In this study, the synthesis and characterization of two distorted square-planar high-spin $\mathrm{Fe}^{\mathrm{II}}$ complexes, $\left({ }^{\mathrm{Mes}} \mathrm{PDP}{ }^{\mathrm{Ph}}\right) \mathrm{Fe}\left(\mathrm{OEt}_{2}\right)$ and $\left({ }^{\mathrm{Mes}} \mathrm{PDP}{ }^{\mathrm{Ph}}\right) \mathrm{Fe}($ thf $)$, supported by a pyridine dipyrrolide pincer ligand is described. These complexes are the first examples for this rare spin state/oxidation state combination that are of neutral charge and do not contain anionic oxygen donor ligands. Consistent with previous reports, the unique electronic structures imposed by the unusual coordination environment for $\mathrm{Fe}^{\mathrm{II}}$ ions with a quintet ground state are reflected in characteristic ${ }^{57} \mathrm{Fe}$ Mössbauer parameters with small quadrupole splitting (Table 1.4). In the presence of excess THF, $\left({ }^{\mathrm{Mes}} \mathrm{PDP} \mathrm{Ph}^{\mathrm{Ph}}\right) \mathrm{Fe}(\mathrm{thf})$ establishes an equilibrium with the five-coordinate complex $\left({ }^{\mathrm{Mes}} \mathrm{PDP} \mathrm{Ph}^{\mathrm{Ph}}\right) \mathrm{Fe}(\text { thf })_{2}$ as was elucidated by ${ }^{1} \mathrm{H}$ NMR spectroscopy. The resulting change in electronic structure from a configuration with a doubly occupied $\mathrm{d}_{z^{2}}$ orbital to a configuration with a doubly occupied $\mathrm{d}_{x z}$ orbital was established by DFT studies and tracked experimentally by Mössbauer and ${ }^{1} \mathrm{H}$ NMR spectroscopy. The stronger-field ligand pyridine resulted in formation 
of the five coordinate complex $\left({ }^{\mathrm{Mes}} \mathrm{PDP}{ }^{\mathrm{Ph}}\right) \mathrm{Fe}(\mathrm{py})_{2}$, which does not undergo ligand loss in solution. With the addition of $\left({ }^{\mathrm{Mes}} \mathrm{PDP}{ }^{\mathrm{Ph}}\right) \mathrm{Fe}\left(\mathrm{OEt}_{2}\right)$ and $\left({ }^{\mathrm{Mes}} \mathrm{PDP}{ }^{\mathrm{Ph}}\right) \mathrm{Fe}($ thf $)$ as examples for alkali

metal-free, neutral, high-spin $\mathrm{Fe}^{\mathrm{II}}$ complexes with distorted square-planar geometry, a revision of the conditions promoting this unusual spin state/geometry pairing that is consistent with all examples reported to date is proposed: (a) destabilization of the $\mathrm{d}_{x z}$ and $\mathrm{d}_{y z}$ orbitals via strong out-of-plane $\pi$-donation, (b) destabilization of the $\mathrm{d}_{x y}$ orbital via strong in-plane $\pi$-donation and/or $\sigma$-donation resulting from reduced bite angles of the chelating ligands, and (c) decreased destabilization of the $\mathrm{d}_{x^{2}-y^{2}}$ orbital by weak $\sigma$-donating ligands and/or in-plane deviations from ideal square planar geometry. The three conditions outlined above compel $\mathrm{S}=2$ ground states with a doubly occupied $\mathrm{d}_{z}^{2}$ orbital which disfavors additional ligand binding by reducing the Lewis acidic character of the metal center along the z-axis and gives rise to the characteristically small Mössbauer quadrupole splitting.

\subsection{Experimental Procedures}

\section{General Considerations}

All air- and moisture-sensitive manipulations were carried out using standard Schlenk line and cannula techniques or in an MBraun inert atmosphere drybox containing an atmosphere of purified nitrogen. Solvents for air- and moisture sensitive manipulations were dried and deoxygenated using a Glass Contour Solvent Purification System and stored over $4 \AA$ molecular sieves. All solids were dried under high vacuum; all liquids were dried over $\mathrm{CaH}_{2}$ and vacuum transferred into oven-dried glassware in order to bring into the glovebox. Deuterated benzene (benzene- $d_{6}$ ) and tetrahydrofuran $\left(\mathrm{THF}-d_{8}\right)$ for NMR spectroscopy were distilled from sodium metal and sodium benzophenone, respectively. 3-Phenyl-1-(2,4,6-trimethylphenyl)2-propen-1- 
one, ${ }^{63}$ 2,6-pyridinedicarboxaldehyde $,{ }^{64} \mathrm{Fe}\left[\mathrm{N}\left(\mathrm{SiMe}_{3}\right)_{2}\right]_{2},{ }^{65,66}$ and $\mathrm{Fe}(\mathrm{Cl})_{2}(\mathrm{py}){ }_{4}{ }^{56}$ were prepared following reported literature procedures.

Preparation of 2,6-Bis(5-(2,4,6-trimethylphenyl)-3-phenyl-1H-pyrrol-2-yl)-pyridine, $\mathrm{H}_{2}{ }^{\mathrm{Mes} P D P} P^{P h}$

A $500 \mathrm{~mL}$ Schlenk flask was charged with 2,6-pyridinedicarboxaldehyde (1.016 g, 7.52 mmol), 3-phenyl-1-(2,4,6-trimethylphenyl)-2-propen-1-one (3.86 g 15.4 mmol), 3-benzyl-5-(2hydroxyethyl)-4-methylthiazolium chloride (1.52 g, $5.64 \mathrm{mmol}), 20 \mathrm{~mL}$ of anhydrous absolute ethanol, and a magnetic stirrer. A jacketed condenser was attached to the flask, and the apparatus was degassed three times and filled with an atmosphere of argon. Under a heavy flow of argon, a solution of $900 \mathrm{mg}$ of sodium tert-butoxide $(543 \mathrm{mg}, 5.63 \mathrm{mmol}$ ) in $10 \mathrm{~mL}$ of anhydrous ethanol was added via syringe, resulting in an immediate change in the color of the reaction mixture from yellow to dark brown. The solvent was brought to reflux and maintained at temperature for $24 \mathrm{~h}$. The intermediate diketone was not isolated. The reaction mixture was cooled to room temperature, and $\mathrm{NH}_{4} \mathrm{OAc}(5 \mathrm{~g}, 45.1 \mathrm{mmol})$ was added in air. The mixture was returned to reflux which was maintained for $72 \mathrm{~h}$. Progress of the reaction was monitored via ${ }^{1} \mathrm{H}$ NMR spectroscopy by sampling small aliquots of the crude reaction mixture. The yellow solid which precipitated from the reaction mixture was isolated on a medium porosity glass frit, washed three times with $0{ }^{\circ} \mathrm{C}$ ethanol, and dried in vacuo. The yellow powder was then transferred to a flask and dried under high vacuum at $200{ }^{\circ} \mathrm{C}$ for $48 \mathrm{~h}$ to remove any trace solvent and water, as confirmed via ${ }^{1} \mathrm{H}$ NMR spectroscopy. Yield $2.4 \mathrm{~g}(4.01 \mathrm{mmol}, 53 \%) .{ }^{1} \mathrm{H}$ NMR (400 MHz, benzene- $d_{6} ; \delta$, ppm) $11.51(\mathrm{~s}, 2 \mathrm{H}, \mathrm{N} H), 7.64(\mathrm{~d}, J=7.6 \mathrm{~Hz}, 4 \mathrm{H}$, ortho- $\mathrm{Ph} H), 7.39(\mathrm{~m}, 6 \mathrm{H}$, metaand para- $\mathrm{Ph} H$ ), $6.78(\mathrm{~d}, J=8.0 \mathrm{~Hz}, 2 \mathrm{H}, 3$-pyridine $H), 6.57$ (s, 2H, mesityl-meta $H), 6.06$ (t, $J=$ $8.0 \mathrm{~Hz}, 1 \mathrm{H}, 4$-pyridine $H$ ), 6.01 (s, 2H, pyrrole- $H$ ), 1.96 (s, 12H, mesityl-ortho- $\mathrm{CH}_{3}$ ), 1.93 (s, 6H, 
mesityl-para-CH ). ${ }^{13} \mathrm{C}$ NMR (101 MHz, benzene- $d_{6}$; $\delta$, ppm): $150.42,138.76,138.62,137.19$, $136.53,133.37,130.03,129.92,128.82,128.00,127.45,126.94,125.67,117.74,112.58,21.02$, 20.52. HRMS (ESI) calcd for $\mathrm{C}_{43} \mathrm{H}_{39} \mathrm{~N}_{3}{ }^{+}[\mathrm{M}+\mathrm{H}]^{+} \mathrm{m} / \mathrm{z}$ 598.32222. Found 598.32301. Note, $\mathrm{H}_{2}{ }^{\mathrm{Mes}} \mathrm{PDP}^{\mathrm{Ph}}$ can exist in either monomeric or hydrogen bonded dimeric forms, depending on the nature of the solvent. In benzene- $d_{6}$ the major species in the ${ }^{1} \mathrm{H}$ NMR spectra is tentatively assigned as the hydrogen bonded dimer $\left[\mathrm{H}_{2}{ }^{\mathrm{Mes}} \mathrm{PDP}^{\mathrm{Ph}}\right]_{2}$, whereas the minor species is assigned as monomeric $\mathrm{H}_{2}{ }^{\mathrm{Mes}} \mathrm{PDP}^{\mathrm{Ph}}$. See Chapter 4 for details presented within the context of similar $\mathrm{H}_{2}{ }^{\mathrm{Ar}} \mathrm{PDP}^{\mathrm{Ph}}$ ligands.

\section{Preparation of $\left(^{\left({ }^{M e s} P D P\right.} P^{P h}\right) \mathrm{Fe}\left(\mathrm{OEt}_{2}\right)$.}

$\mathrm{Fe}\left[\mathrm{N}\left(\mathrm{SiMe}_{3}\right)_{2}\right]_{2}(100 \mathrm{mg}, 0.27 \mathrm{mmol})$ was added to a $20 \mathrm{~mL}$ scintillation vial equipped with a magnetic stirrer and dissolved in $5 \mathrm{~mL}$ of diethyl ether. $\mathrm{H}_{2}{ }^{\mathrm{Mes}} \mathrm{PDP}^{\mathrm{Ph}}(159 \mathrm{mg}, 0.27 \mathrm{mmol})$ was added to a separate vial and suspended in $5 \mathrm{~mL}$ of diethyl ether. The suspension of $\mathrm{H}_{2}{ }^{\mathrm{Mes}} \mathrm{PDP}^{\mathrm{Ph}}$ was added dropwise to the pale-green solution of $\mathrm{Fe}\left[\mathrm{N}\left(\mathrm{SiMe}_{3}\right)_{2}\right]_{2}$. The resulting mixture was vigorously stirred for $24 \mathrm{~h}$. The bright red insoluble crude product precipitated from solution and was isolated on a medium porosity glass frit and washed with excess pentane. The resulting powder was dissolved in the minimum amount of toluene, filtered into a separate 20 $\mathrm{mL}$ vial, and layered with excess pentane. Storage at $-35^{\circ} \mathrm{C}$ resulted in the formation of dark red-purple crystals. The product was washed with excess pentane and dried in vacuo. Yield 78 $\mathrm{mg}(0.11 \mathrm{mmol}, 40 \%) . \mu_{\text {eff }}=5.5 \mu_{\mathrm{B}}\left(295 \mathrm{~K}\right.$, magnetic susceptibility balance). ${ }^{1} \mathrm{H}$ NMR (400 MHz, benzene- $d_{6}$; $\delta$, ppm; fwhm, Hz) 111.69 (s, $120 \mathrm{~Hz}, 2 \mathrm{H}, 3$-pyridine $H$ ), 92.58 (s, $152 \mathrm{~Hz}$, 2H, pyrrole-CH), 74.69 (s, $2423 \mathrm{~Hz}, 4 \mathrm{H}), 12.18$ (s, $17 \mathrm{~Hz}, 4 \mathrm{H}), 9.32$ (s, $56 \mathrm{~Hz}, 4 \mathrm{H}), 7.45$ (s, 62 $\mathrm{Hz}, 4 \mathrm{H}), 5.12$ (s, $18 \mathrm{~Hz}, 2 \mathrm{H}$, para- $\mathrm{Ph} H), 4.17$ (s, $17 \mathrm{~Hz}, 6 \mathrm{H}$, mesityl-para-CH ), 1.66 (s, $19 \mathrm{~Hz}$, 1H, 4-pyridine $H$ ), -10.38 (s, $405 \mathrm{~Hz}, 12 \mathrm{H}$, mesityl-ortho- $\mathrm{CH}_{3}$ ). Anal. Calcd for 
$\left({ }^{\mathrm{Mes}} \mathrm{PDP}^{\mathrm{Ph}}\right) \mathrm{Fe}\left(\mathrm{OEt}_{2}\right), \mathrm{C}_{47} \mathrm{H}_{47} \mathrm{FeN}_{3} \mathrm{O}: \mathrm{C}, 77.78 ; \mathrm{H}, 6.53 ; \mathrm{N}, 5.79$. Found: C, 77.92; H, 6.78; N,

5.57. Crystals suitable for X-ray diffraction were obtained from layering a concentrated toluene solution with excess pentane and storing the mixture at $-35^{\circ} \mathrm{C}$.

\section{Preparation of $\left({ }^{\text {Mes } P D P P h}\right) \mathrm{Fe}($ thf $)(\mu-\mathrm{Cl}) \mathrm{Li}(\text { thf })_{3}$.}

A $20 \mathrm{~mL}$ scintillation vial equipped with a magnetic stirrer was charged with $500 \mathrm{mg}$ (0.84 mmol) of $\mathrm{H}_{2}{ }^{\mathrm{Mes}} \mathrm{PDP}^{\mathrm{Ph}}$ and $10 \mathrm{~mL}$ of THF, resulting in a pale yellow solution. In a separate vial, $280 \mathrm{mg}$ (167 mmol) of lithium bis(trimethylsilyl)amide (LiHMDS) was dissolved in THF. The solution of $\mathrm{Li}(\mathrm{HMDS})$ was added dropwise to the solution of $\mathrm{H}_{2}{ }^{\mathrm{Mes}} \mathrm{PDP}^{\mathrm{Ph}}$, resulting in an immediate color change to a yellow/ orange luminescent solution. Ligand deprotonation was allowed to proceed for approximately $2 \mathrm{~h}$ to ensure complete conversion. After this time, $106 \mathrm{mg}$ ( $0.84 \mathrm{mmol})$ of $\mathrm{FeCl}_{2}$ and $8 \mathrm{~mL}$ of THF were added to a separate vial equipped with a magnetic stirrer, forming a pale brown suspension. To the stirring slurry of $\mathrm{FeCl}_{2}$ was added the solution of deprotonated ligand, resulting in an immediate color change to orange/red. The reaction mixture was allowed to stir for $12 \mathrm{~h}$. The resulting solution was filtered through a pad of Celite supported on a glass wool plug into a separate vial and concentrated to approximately $5 \mathrm{~mL}$. An excess of n-pentane was added to the vial and mixed with the THF solution. Storage of the $\mathrm{THF} /$ pentane solution at $-35^{\circ} \mathrm{C}$ for $12 \mathrm{~h}$ resulted in precipitation of the orange microcrystalline product, $\left({ }^{\mathrm{Mes}} \mathrm{PDP}{ }^{\mathrm{Ph}}\right) \mathrm{Fe}($ thf $)(\mu-\mathrm{Cl}) \mathrm{Li}(\text { thf })_{3}$. Yield: $518 \mathrm{mg}(0.53 \mathrm{mmol}, 63 \%) . \mu_{\mathrm{eff}}=5.4 \mu_{\mathrm{B}}(295 \mathrm{~K}$, magnetic susceptibility balance). Anal. Calcd for $\left({ }^{\mathrm{Mes}} \mathrm{PDP}^{\mathrm{Ph}}\right) \mathrm{Fe}($ thf $)(\mu-\mathrm{Cl}) \mathrm{Li}(\text { thf })_{3}$, $\mathrm{C}_{59} \mathrm{H}_{69} \mathrm{ClFeLiN}_{3} \mathrm{O}_{4}: \mathrm{C}, 72.13 ; \mathrm{H}, 7.08 ; \mathrm{N}, 4.28$. Found: $\mathrm{C}, 74.03 ; \mathrm{H}, 6.15 ; \mathrm{N}, 5.55$. The results of the elemental analysis suggest that 3 equivalence of THF were lost during the drying of the sample under high vacuum. Considering that the THF molecules coordinated to the lithium cation are readily lost upon stirring the complex in pentane, this is a likely candidate for the 
deviation from the theoretical $\mathrm{CHN}$ values. Anal. Calcd for $\mathrm{C}_{47} \mathrm{H}_{45} \mathrm{ClFeLiN}_{3} \mathrm{O}$ : C, 73.68; $\mathrm{H}$, 5.92; N, 5.48. Found: C, 74.03; H, 6.15; N, 5.55.

\section{Preparation of $\left({ }^{M e s} P D P^{P h}\right) F e(t h f)$.}

To a $20 \mathrm{~mL}$ scintillation vial equipped with a magnetic stirrer was added $390 \mathrm{mg}(0.397$ mmol) of $\left({ }^{\mathrm{Mes} P D P}{ }^{\mathrm{Ph}}\right) \mathrm{Fe}(\mathrm{thf})(\mu-\mathrm{Cl}) \mathrm{Li}(\mathrm{thf})_{3}$. Addition of $10 \mathrm{~mL}$ of a 1:1 mixture of toluene and pentane dissolved the material. Upon stirring, $\mathrm{LiCl}$ began to precipitate from solution. The suspension was filtered through a Celite pad supported by a glass wool plug to remove precipitated $\mathrm{LiCl}$. The dark red filtrate was collected in a $50 \mathrm{~mL}$ round bottom flask, and the solvent was removed in vacuo. The aforementioned procedure was repeated with an additional $10 \mathrm{~mL}$ of a 1:1 mixture of toluene and pentane to further precipitate $\mathrm{LiCl}$. To the resulting dark red solid, approximately $15 \mathrm{~mL}$ of toluene was added, and the dark red solution was filtered into a tared $20 \mathrm{~mL}$ scintillation vial. Removal of volatiles and subsequent trituration with pentane afforded $200 \mathrm{mg}$ of a red solid identified as $\left({ }^{\mathrm{Mes}} \mathrm{PDP}{ }^{\mathrm{Ph}}\right) \mathrm{Fe}(\mathrm{thf})$. Yield: $200 \mathrm{mg}(0.276 \mathrm{mmol}$, $70 \%) . \mu_{\mathrm{eff}}=5.2 \mu_{\mathrm{B}}(295 \mathrm{~K}$, magnetic susceptibility balance $) .{ }^{1} \mathrm{H}$ NMR $\left(400 \mathrm{MHz}\right.$, benzene- $d_{6} ; \delta$, ppm; fwhm, Hz): 113.68 (s, 78 Hz, 2H, 3-pyridine $H$ ), 110.95 (s, $142 \mathrm{~Hz}, 2 \mathrm{H}$, pyrrole-CH), 25.67(s, $135 \mathrm{~Hz}, 4 \mathrm{H}), 24.28$ (s, $107 \mathrm{~Hz}, 4 \mathrm{H}), 13.05$ (s, $16 \mathrm{~Hz}, 4 \mathrm{H}), 11.57$ (s, $41 \mathrm{~Hz}, 4 \mathrm{H}), 8.29$ (s, $44 \mathrm{~Hz}, 4 \mathrm{H}), 5.68$ (s, $16 \mathrm{~Hz}, 2 \mathrm{H}$, para- $\mathrm{PhH}), 4.42$ (s, $11 \mathrm{~Hz}, 6 \mathrm{H}$, mesityl-ortho-CH3), -5.98 (s, 69 $\mathrm{Hz}, 1 \mathrm{H}$, 4-pyridine $H),-11.58$ (s, $393 \mathrm{~Hz}, 12 \mathrm{H}$, mesityl-ortho-CH3). Anal. Calcd for $\left.{ }^{\left({ }^{M e s} P D P\right.}{ }^{\mathrm{Ph}}\right) \mathrm{Fe}($ thf $), \mathrm{C}_{47} \mathrm{H}_{45} \mathrm{FeN}_{3} \mathrm{O}: \mathrm{C}, 78.00 ; \mathrm{H}, 6.27 ; \mathrm{N}, 5.81$. Found: C, 76.81; H, 6.19; N, 5.39. The deviation in the elemental analysis results from the expected values is likely due to incomplete removal of $\mathrm{LiCl}$. Anal. Calcd for $\left({ }^{\mathrm{Mes}} \mathrm{PDP}^{\mathrm{Ph}}\right) \mathrm{Fe}($ thf $) \cdot 0.3 \mathrm{LiCl}, \mathrm{C}_{47} \mathrm{H}_{45} \mathrm{Cl}_{0.3} \mathrm{FeLi}_{0.3} \mathrm{~N}_{3} \mathrm{O}$ : C, 76.65; H, 6.16; N, 5.71. Recrystallization via slow diffusion of pentane into a concentrated 
fluorobenzene solution at $-35{ }^{\circ} \mathrm{C}$ provided dark red crystals of $\left({ }^{\mathrm{Mes}} \mathrm{PDP}{ }^{\mathrm{Ph}}\right) \mathrm{Fe}($ thf $)$ suitable for Xray diffraction.

\section{Preparation of $\left({ }^{M e s} P D P^{P h}\right) F e(t h f)_{2}$.}

To a $20 \mathrm{~mL}$ scintillation vial equipped with a magnetic stirrer was added $376 \mathrm{mg}(0.520$ mmol) of ( $\left.{ }^{\mathrm{Mes}} \mathrm{PDP}{ }^{\mathrm{Ph}}\right) \mathrm{Fe}(\mathrm{thf})$. The solid was dissolved in approximately $3 \mathrm{~mL}$ of THF. $15 \mathrm{~mL}$ of pentane was added to the solution, and upon stirring, an abundant bright orange precipitate was observed. The mixture was stored at $-35^{\circ} \mathrm{C}$ overnight to induce complete precipitation. The resulting orange solid was isolated on a fine porosity frit and briefly dried in vacuo. Yield: 290 $\mathrm{mg}, 0.364 \mathrm{mmol}, 70 \% . \mu_{\mathrm{eff}}=5.4 \mu_{\mathrm{B}} .{ }^{1} \mathrm{H} \mathrm{NMR}\left(400 \mathrm{MHz}, \mathrm{THF}-d_{8} ; \delta, \mathrm{ppm} ;\right.$ fwhm, Hz): 90.85 (s, $90 \mathrm{~Hz}, 2 \mathrm{H}$, pyrrole-CH), 67.16 (s, $94 \mathrm{~Hz}, 2 \mathrm{H}, 3$-pyridine $H$ ), 20.32 (s, 35 Hz, 1H, 4-pyridine $H$ ), 8.54 (s, $18 \mathrm{~Hz}, 4 \mathrm{H}), 7.45$ (s, $34 \mathrm{~Hz}, 4 \mathrm{H}), 6.69$ (s, $133 \mathrm{~Hz}, 12 \mathrm{H}$, mesityl-ortho-CH ), 5.99 (s, 26 $\mathrm{Hz}, 4 \mathrm{H}), 5.73$ (s, $18 \mathrm{~Hz}, 2 \mathrm{H}$, para- $\mathrm{PhH}), 0.81$ (s, $11 \mathrm{~Hz}, 6 \mathrm{H}$, mesityl-para- $\left.\mathrm{CH}_{3}\right)$. Resonances for the THF ligands were not detected due to rapid exchange with THF- $d_{8}$.

\section{Preparation of $\left({ }^{M e s} P D P^{P h}\right) F e(p y)_{2}$.}

$\mathrm{FeCl}_{2}(\mathrm{py})_{4}(300 \mathrm{mg}, 0.677 \mathrm{mmol})$ was suspended in $5 \mathrm{~mL}$ of pentane in a $20 \mathrm{~mL}$ scintillation vial equipped with a Teflon-coated stirrer. (Trimethylsilyl)methyllithium (NsLi) (127 mg, $1.35 \mathrm{mmol}$ ) was dissolved in $5 \mathrm{~mL}$ pentane in a separate vial. The solution of NsLi in pentane was added dropwise with stirring to the $\mathrm{Fe}(\mathrm{Cl})_{2}(\mathrm{py})_{4}$ suspension, immediately generating a dark purple solution. After $2 \mathrm{~h}$ of stirring, the mixture was filtered through a plug of glass wool to remove precipitated $\mathrm{LiCl}$ and was concentrated in vacuo to approximately $2 \mathrm{~mL}$. The dark purple solution was diluted with $8 \mathrm{~mL}$ of toluene. In a separate vial, $\mathrm{H}_{2}{ }^{\mathrm{Mes}} \mathrm{PDP}^{\mathrm{Ph}}(405 \mathrm{mg}, 0.677$ mmol) was dissolved in $10 \mathrm{~mL}$ of toluene. The pale yellow ligand solution was added slowly dropwise to the solution containing the iron complex while vigorously stirring. Within minutes, a 
color change to dark red/orange was observed. After $2 \mathrm{~h}$ of stirring, the crude reaction mixture was concentrated to dryness, leaving a bright orange powder. A minimum amount of toluene was used to dissolve the crude material, and the solution was filtered and layered with $10 \mathrm{~mL}$ of npentane. Red/orange plates of crystalline material precipitated from solution after storage at -35 ${ }^{\circ} \mathrm{C}$ for $12 \mathrm{~h}$. The mother liquor was decanted, and the product was transferred to a medium porosity glass frit where it was washed with $20 \mathrm{~mL}$ of cold pentane and dried under reduced pressure. Yield: $510 \mathrm{mg}(0.630 \mathrm{mmol}), 93 \%$. Single crystals suitable for X-ray crystallography were obtained via slow diffusion of diethyl ether into a concentrated toluene solution of $\left({ }^{\text {Mes }} \mathrm{PDP}^{\mathrm{Ph}}\right) \mathrm{Fe}(\mathrm{py})_{2}$ at $-35^{\circ} \mathrm{C} . \mu_{\text {eff }}=5.5 \mu_{\mathrm{B}}\left(295 \mathrm{~K}\right.$, magnetic susceptibility balance) ${ }^{1} \mathrm{H}$ NMR $(400$ MHz, benzene- $d 6$; $\delta$, ppm; fwhm, Hz) 103.96 (s, $1386 \mathrm{~Hz}, 2 \mathrm{H}), 87.89$ (s, $111 \mathrm{~Hz}, 2 \mathrm{H}), 77.20$ (s, $115 \mathrm{~Hz}, 2 \mathrm{H}), 36.56$ (s, $121 \mathrm{~Hz}, 4 \mathrm{H}), 21.54$ (s, $64 \mathrm{~Hz}, 1 \mathrm{H}, \mathrm{PDP}-4$-pyridine $H$ ), 9.73 (s, $15 \mathrm{~Hz}, 4 \mathrm{H}$ ), 7.37 (s, $37 \mathrm{~Hz}, 4 \mathrm{H}), 6.58$ (s, $32 \mathrm{~Hz}, 6 \mathrm{H}), 4.86(\mathrm{~s}, 15 \mathrm{~Hz}, 2 \mathrm{H}), 1.91$ (s, $9 \mathrm{~Hz}, 6 \mathrm{H}$, mesityl-para$\left.\mathrm{CH}_{3}\right), 0.80$ (s, $187 \mathrm{~Hz}, 12 \mathrm{H}$, mesityl-ortho- $\left.\mathrm{CH}_{3}\right)$. Anal. Calcd for $\left({ }^{\mathrm{Mes}} \mathrm{PDP}^{\mathrm{Ph}}\right) \mathrm{Fe}(\mathrm{py})_{2}$, $\mathrm{C}_{53} \mathrm{H}_{47} \mathrm{FeN}_{5}: \mathrm{C}, 78.61 ; \mathrm{H}, 5.85 ; \mathrm{N}, 8.65$. Found: C, 78.35; H, 6.11; N, 8.38.

\section{Physical Measurements.}

${ }^{1} \mathrm{H}$ and ${ }^{13} \mathrm{C}\left\{{ }^{1} \mathrm{H}\right\}$ NMR spectra were recorded on an Agilent $400 \mathrm{MHz}$ spectrometer, JEOL 400 MHz YH spectrometer, or a Varian INOVA 600 MHz spectrometer. All chemical shifts are reported relative to $\mathrm{SiMe}_{4}$ using ${ }^{1} \mathrm{H}$ (residual) chemical shifts of the solvent as a secondary standard. Assignments of resonances for paramagnetic compounds are based on integration and only reported in the experimental procedures for conclusive cases. High resolution mass spectra were obtained on a Thermo Finnigan Linear Trapping Quadrupole mass spectrometer. Elemental analyses were performed at Robertson Microlit Laboratories, Inc., in

Ledgewood, NJ. Room temperature magnetic susceptibility measurements were performed with 
a Johnson Matthey Mark 1 instrument that was calibrated with $\mathrm{HgCo}(\mathrm{SCN}) 4$. Zero field ${ }^{57} \mathrm{Fe}$ Mössbauer spectra were collected on a SEE Co. Mössbauer spectrometer (MS4) with a ${ }^{57} \mathrm{Co} / \mathrm{Rh}$ radiation source at $80 \mathrm{~K}$ in constant acceleration mode. The temperature in the sample chamber was controlled by a Janis Research Co. CCS $-850 \mathrm{He} / \mathrm{N}_{2}$ cryostat within an accuracy of $\pm 0.3 \mathrm{~K}$. The data were calibrated relative to $\alpha$-iron at $298 \mathrm{~K}$ with minimum experimental line widths of $0.23 \mathrm{~mm} / \mathrm{s}$. The fitting procedure to extract quantitative spectral parameters uses a least squares Lorentzian fitting method implemented in the WMOSS software developed by SEE Co.

\section{X-ray Crystallography.}

Single crystals suitable for X-ray diffraction were coated with polyisobutylene oil (Sigma-Aldrich) in a drybox, mounted on a nylon loop, and then quickly transferred to the goniometer head of a Bruker AXS D8 Venture fixed-chi X-ray diffractometer equipped with a Triumph monochromator, a Mo K $\alpha$ radiation source $(1=0.71073 \AA$ ), and a PHOTON 100 CMOS detector. The samples were cooled to $100 \mathrm{~K}$ with an Oxford Cryostream 700 system and optically aligned. The APEX3 software program (version 2016.9-0) ${ }^{67}$ was used for diffractometer control, preliminary frame scans, indexing, orientation matrix calculations, leastsquares refinement of cell parameters, and the data collection. Three sets of 12 frames each were collected using the omega scan method with a $10 \mathrm{~s}$ exposure time. Integration of these frames, followed by reflection indexing and least-squares refinement, produced a crystal orientation matrix for the crystal lattice that was used for the structural analysis. The data collection strategy was optimized for completeness and redundancy using the Bruker COSMO software suite. The space group was identified, and the data were processed using the Bruker SAINT+ program and corrected for absorption using SADABS. The structures were solved using direct methods 
(SHELXS) completed by subsequent Fourier synthesis and refined by full-matrix least-squares procedures using the programs provided by SHELXL-2014. ${ }^{68}$

\section{Density Functional Theory Calculations.}

All DFT calculations were performed with the ORCA program package. ${ }^{69}$ Geometry optimizations of the complexes and single-point calculations on the optimized geometries were carried out at the B3LYP level of DFT. ${ }^{70-72}$ The all-electron Gaussian basis sets were those developed by the Ahlrichs group. ${ }^{73-75}$ Triple- $\zeta$ quality basis sets def2-TZVP with one set of polarization functions on the metal and on the atoms directly coordinated to the metal center were used. For the carbon and hydrogen atoms, slightly smaller polarized split-valence def2-SVP basis sets were used that were of double- $\zeta$ quality in the valence region and contained a polarizing set of $d$ functions on the nonhydrogen atoms. Auxiliary basis sets to expand the electron density in the resolution-of-the-identity (RIJCOSX) ${ }^{76-78}$ approach were chosen to match the orbital basis. ${ }^{79-81}$ All molecular orbital and spin density plots were generated using the program Gabedit. ${ }^{82}$ Nonrelativistic single-point calculations on the optimized geometry were carried out to predict Mössbauer spectral parameters (isomer shifts and quadrupole splittings). These calculations employed the CP(PPP) basis set for iron. ${ }^{83}$ The Mössbauer isomer shifts were calculated from the computed electron densities at the iron centers as previously described. ${ }^{84,85}$

\section{Accession Codes}

CCDC 1869113-1869118 contain the supplementary crystallographic data for this chapter. 


\section{References}

1. Bolm, C.; Legros, J.; Le Paih, J.; Zani, L. Iron-Catalyzed Reactions in Organic Synthesis. Chem. Rev. 2004, 104, 6217-6254.

2. Bauer, I.; Knölker, H. J. Iron Catalysis in Organic Synthesis. Chem. Rev. 2015, 115, 31703387.

3. Gopalaiah, K. Chiral Iron Catalysts for Asymmetric Synthesis. Chem. Rev. 2013, 113, 32483296.

4. Shang, R.; Ilies, L.; Nakamura, E. Iron-Catalyzed C-H Bond Activation. Chem. Rev. 2017, $117,9086-9139$.

5. Lee, S. C.; Lo, W.; Holm, R. H. Developments in the Biomimetic Chemistry of Cubane-Type and Higher Nuclearity Iron-Sulfur Clusters. Chem. Rev. 2014, 114, 3579-3600.

6. Reiff, W. M.; LaPointe, A. M.; Witten, E. H. Virtual Free Ion Magnetism and the Absence of Jahn-Teller Distortion in a Linear Two-Coordinate Complex of High-Spin Iron(II). J. Am. Chem. Soc. 2004, 126, 10206-10207.

7. Atanasov, M.; Zadrozny, J. M.; Long, J. R.; Neese, F. A Theoretical Analysis of Chemical Bonding, Vibronic Coupling, and Magnetic Anisotropy in Linear Iron(II) Complexes with Single-Molecule Magnet Behavior. Chem. Sci. 2013, 4, 139-156.

8. Zadrozny, J. M.; Atanasov, M.; Bryan, A. M.; Lin, C. Y.; Rekken, B. D.; Power, P. P.; Neese, F.; Long, J. R. Slow Magnetization Dynamics in a Series of Two-Coordinate Iron(II) Complexes. Chem. Sci. 2013, 4, 125-138.

9. Zadrozny, J. M.; Xiao, D. J.; Atanasov, M.; Long, G. J.; Grandjean, F.; Neese, F.; Long, J. R. Magnetic Blocking in a Linear Iron(I) Complex. Nat. Chem. 2013, 5, 577-581. 
10. Duchanois, T.; Etienne, T.; Cebrián, C.; Liu, L.; Monari, A.; Beley, M.; Assfeld, X.; Haacke, S.; Gros, P. C. An Iron-Based Photosensitizer with Extended Excited-State Lifetime:

Photophysical and Photovoltaic Properties. Eur. J. Inorg. Chem. 2015, 2015, 2469-2477.

11. Chábera, P.; Liu, Y.; Prakash, O.; Thyrhaug, E.; Nahhas, A. El; Honarfar, A.; Essén, S.;

Fredin, L. A.; Harlang, T. C. B.; Kjær, K. S.; Handrup, K.; Ericson, F.; Tatsuno, H.; Morgan, K.;

Schnadt, J.; Häggström, L.; Ericsson, T.; Sobkowiak, A.; Lidin, S.; Huang, P.; Styring, S.; Uhlig, J.; Bendix, J.; Lomoth, R.; Sundström, V.; Persson, P.; Wärnmark, K. A Low-Spin Fe(III) Complex with 100-Ps Ligand to-Metal Charge Transfer Photoluminescence. Nature 2017, 543, 695-699.

12. Zimmer, P.; Müller, P.; Burkhardt, L.; Schepper, R.; Neuba, A.; Steube, J.; Dietrich, F.;

Flörke, U.; Mangold, S.; Gerhards, M.; Bauer, M. N-Heterocyclic Carbene Complexes of Iron as Photosensitizers for Light-Induced Water Reduction. Eur. J. Inorg. Chem. 2017, 2017, 15041509.

13. Holland, P. L. Coordination Chemistry: All Square for High-Spin Iron(II). Nat. Chem. 2011, $3,507-508$.

14. Hazen, R. M.; Burnham, C. W. The Crystal Structures of Gillespite I and II: A Structure Determination at High Pressure. Am. Mineral. 1974, 59, 1166-1176.

15. Johnsen, O.; Ferraris, G.; Gault, R. A.; Grice, J. D.; Kampf, A. R.; Pekov, I. V. The Nomenclature of Eudialyte-Group Minerals. Can. Mineral. 2003, 41, 785-794.

16. Esposito, V.; Solari, E.; Floriani, C.; Re, N.; Rizzoli, C.; Chiesi-Villa, A. Binding and Redox Properties of Iron(II) Bonded to an Oxo Surface Modeled by Calix[4]Arene. Inorg. Chem. 2000, 39, 2604-2613. 
17. Tsujimoto, Y.; Tassel, C.; Hayashi, N.; Watanabe, T.; Kageyama, H.; Yoshimura, K.;

Takano, M.; Ceretti, M.; Ritter, C.; Paulus, W. Infinite-Layer Iron Oxide with a Square-Planar Coordination. Nature 2007, 450, 1062-1065.

18. Tassel, C.; Pruneda, J. M.; Hayashi, N.; Watanabe, T.; Kitada, A.; Tsujimoto, Y.; Kageyama, H.; Yoshimura, K.; Takano, M.; Nishi, M.; Ohoyama, K.; Mizumaki, M.; Kawamura, N.; Iniguez, J.; Canadell, E. $\mathrm{CaFeO}_{2}$ : A New Type of Layered Structure with Iron in a Distorted Square Planar Coordination. J. Am. Chem. Soc. 2009, 131, 221-229.

19. Kageyama, H.; Watanabe, T.; Tsujimoto, Y.; Kitada, A.; Sumida, Y.; Kanamori, K.; Yoshimura, K.; Hayashi, N.; Muranaka, S.; Takano, M.; Ceretti, M.; Paulus, W.; Ritter, C.; André, G. Spin-Ladder Iron Oxide: $\mathrm{Sr}_{3} \mathrm{Fe}_{2} \mathrm{O}_{5}$. Angew. Chem., Int. Ed. 2008, 47, 5740-5745. 20. Brandenberger, S.; Kröcher, O.; Tissler, A.; Althoff, R. The State of the Art in Selective Catalytic Reduction of $\mathrm{NO}_{\mathrm{x}}$ by Ammonia Using Metal-Exchanged Zeolite Catalysts. Catal. Rev.: Sci. Eng. 2008, 50, 492-531.

21. Parfenov, M. V.; Starokon, E. V.; Pirutko, L. V.; Panov, G. I. Quasicatalytic and Catalytic Oxidation of Methane to Methanol by Nitrous Oxide over FeZSM-5 Zeolite. J. Catal. 2014, 318, $14-21$.

22. Yun, J. H.; Lobo, R. F. Catalytic Dehydrogenation of Propane over Iron-Silicate Zeolites. J. Catal. 2014, 312, 263-270.

23. Wurzenberger, X.; Piotrowski, H.; Klüfers, P. A Stable Molecular Entity Derived from Rare Iron(II) Minerals: The Square-Planar High-Spin-d ${ }^{6} \mathrm{Fe}^{\mathrm{II}} \mathrm{O}_{4}$ Chromophore. Angew. Chem., Int. Ed. 2011, 50, 4974-4978. 
24. Cantalupo, S. A.; Fiedler, S. R.; Shores, M. P.; Rheingold, A. L.; Doerrer, L. H. High-Spin Square-Planar $\mathrm{Co}^{\mathrm{II}}$ and $\mathrm{Fe}^{\mathrm{II}}$ Complexes and Reasons for Their Electronic Structure. Angew.

Chem., Int. Ed. 2012, 51, 1000-1005.

25. Pinkert, D.; Demeshko, S.; Schax, F.; Braun, B.; Meyer, F.; Limberg, C. A Dinuclear Molecular Iron(II) Silicate with Two High-Spin Square-Planar $\mathrm{FeO}_{4}$ Units. Angew. Chem., Int. Ed. 2013, 52, 5155-5158.

26. Pinkert, D.; Keck, M.; Tabrizi, S. G.; Herwig, C.; Beckmann, F.; Braun-Cula, B.; Kaupp, M.; Limberg, C. A High-Spin Square Planar Iron(II)-Siloxide and Its Tetrahedral Allogon-Structural and Spectroscopic Models of Fe-Zeolite Sites. Chem. Commun. 2017, 53, 8081-8084.

27. Pascualini, M. E.; Di Russo, N. V.; Thuijs, A. E.; Ozarowski, A.; Stoian, S. A.; Abboud, K. A.; Christou, G.; Veige, A. S. A High-Spin Square-Planar Fe(II) Complex Stabilized by a Trianionic Pincer-Type Ligand and Conclusive Evidence for Retention of Geometry and Spin State in Solution. Chem. Sci. 2015, 6, 608-612.

28. Pascualini, M. E.; Stoian, S. A.; Ozarowski, A.; Abboud, K. A.; Veige, A. S. Solid State Collapse of a High-Spin Square-Planar Fe(II) Complex, Solution Phase Dynamics, and Electronic Structure Characterization of an Fe(II)2 Dimer. Inorg. Chem. 2016, 55, 5191-5200. 29. Tahsini, L.; Specht, S. E.; Lum, J. S.; Nelson, J. J. M.; Long, A. F.; Golen, J. A.; Rheingold, A. L.; Doerrer, L. H. Structural and Electronic Properties of Old and New $A_{2}\left[M\left(\operatorname{Pin}^{\mathrm{F}}\right)\right]_{2}$ Complexes. Inorg. Chem. 2013, 52, 14050-14063.

30. Filimon, S. A.; Petrovic, D.; Volbeda, J.; Bannenberg, T.; Jones, P. G.; Freiherr Von Richthofen, C. G.; Glaser, T.; Tamm, M. 3d Metal Complexes Supported by a Bis(Imidazolin-2Imino)Pyridine Pincer Ligand - Synthesis, Structural Characterisation, and Magnetic Properties. Eur. J. Inorg. Chem. 2014, 2014, 5997-6012. 
31. Bouwkamp, M. W.; Bart, S. C.; Hawrelak, E. J.; Trovitch, R. J.; Lobkovsky, E.; Chirik, P. J. Square Planar Bis(Imino)Pyridine Iron Halide and Alkyl Complexes. Chem. Commun. 2005, 3406-3408.

32. Stieber, S. C. E. Methods for Determining Electronic Structures and Mechanisms of Bis(Imino)Pyridine Iron Pre-Catalysts. Ph.D. Thesis, Princeton University, Princeton, NJ, 2013. 33. Bart, S. C.; Chlopek, K.; Bill, E.; Bouwkamp, M. W.; Lobkovsky, E.; Neese, F.; Wieghardt, K.; Chirik, P. J. Electronic Structure of Bis(Imino)Pyridine Iron Dichloride, Monochloride, and Neutral Ligand Complexes: A Combined Structural, Spectroscopic, and Computational Study. J. Am. Chem. Soc. 2006, 128, 13901-13912.

34. Delle Chiaie, K. R.; Biernesser, A. B.; Ortuño, M. A.; Dereli, B.; Iovan, D. A.; Wilding, M. J. T.; Li, B.; Cramer, C. J.; Byers, J. A. The Role of Ligand Redox Non-Innocence in RingOpening Polymerization Reactions Catalysed by Bis(Imino)Pyridine Iron Alkoxide Complexes. Dalton Trans. 2017, 46, 12971-12980.

35. McPherson, J. N.; Das, B.; Colbran, S. B. Tridentate Pyridine-pyrrolide Chelate Ligands: An Under-Appreciated Ligand Set with an Immensely Promising Coordination Chemistry. Coord. Chem. Rev. 2018, 375, 285-332.

36. Komine, N.; Buell, R. W.; Chen, C.-H.; Hui, A. K.; Pink, M.; Caulton, K. G. Probing the Steric and Electronic Characteristics of a New Bis-Pyrrolide Pincer Ligand. Inorg. Chem. 2014, 53, 1361-1369.

37. Zhang, Y.; Petersen, J. L.; Milsmann, C. A Luminescent Zirconium(IV) Complex as a Molecular Photosensitizer for Visible Light Photoredox Catalysis. J. Am. Chem. Soc. 2016, 138, $13115-13118$. 
38. Zhang, Y.; Lee, T. S.; Petersen, J. L.; Milsmann, C. A Zirconium Photosensitizer with a Long-Lived Excited State: Mechanistic Insight into Photo-Induced Single Electron Transfer. $J$. Am. Chem. Soc. 2018, 140, 5934-5947.

39. Gowda, A. S.; Petersen, J. L.; Milsmann, C. Redox Chemistry of Bis(Pyrrolyl)Pyridine Chromium and Molybdenum Complexes: An Experimental and Density Functional Theoretical Study. Inorg. Chem. 2018, 57, 1919-1934.

40. Yadav, S.; Singh, A.; Rashid, N.; Ghotia, M.; Roy, T. K.; Ingole, P. P.; Ray, S.; Mobin, S. M.; Dash, C. Phosphine-Free Bis(Pyrrolyl)Pyridine Based NNN-Pincer Palladium(II) Complexes as Efficient Catalysts for Suzuki-Miyaura Cross-Coupling Reactions of Aryl Bromides in Aqueous Medium. ChemistrySelect 2018, 3, 9469-9475.

41. Grant, L. N.; Carroll, M. E.; Carroll, P. J.; Mindiola, D. J. An Unusual Cobalt Azide Adduct That Produces a Nitrene Species for Carbon-Hydrogen Insertion Chemistry. Inorg. Chem. 2016, $55,7997-8002$.

42. Searles, K.; Fortier, S.; Khusniyarov, M. M.; Carroll, P. J.; Sutter, J.; Meyer, K.; Mindiola, D. J.; Caulton, K. G. A Cis-Divacant Octahedral and Mononuclear Iron(IV) Imide. Angew. Chem., Int. Ed. 2014, 53, 14139-14143.

43. Sorsche, D.; Miehlich, M. E.; Zolnhofer, E. M.; Carroll, P. J.; Meyer, K.; Mindiola, D. J. Metal-Ligand Cooperativity Promoting Sulfur Atom Transfer in Ferrous Complexes and Isolation of a Sulfurmethylenephosphorane Adduct. Inorg. Chem. 2018, 57, 11552-11559. 44. Ehrlich, N.; Kreye, M.; Baabe, D.; Schweyen, P.; Freytag, M.; Jones, P. G.; Walter, M. D. Synthesis and Electronic Ground-State Properties of Pyrrolyl-Based Iron Pincer Complexes: Revisited. Inorg. Chem. 2017, 56, 8415-8422. 
45. Higuchi, J.; Kuriyama, S.; Eizawa, A.; Arashiba, K.; Nakajima, K.; Nishibayashi, Y. Preparation and Reactivity of Iron Complexes Bearing Anionic Carbazole-Based PNP-Type Pincer Ligands toward Catalytic Nitrogen Fixation. Dalton Trans. 2018, 47, 1117-1121.

46. Yang, L.; Powell, D. R.; Houser, R. P. Structural Variation in Copper(I) Complexes with Pyridylmethylamide Ligands: Structural Analysis with a New Four-Coordinate Geometry Index, $\tau_{4}$. Dalton Trans. 2007, 9, 955-964.

47. Cirera, J.; Alemany, P.; Alvarez, S. Mapping the Stereochemistry and Symmetry of Tetracoordinate Transition-Metal Complexes. Chem. - Eur. J. 2004, 10, 190-207. 48. Alvarez, S.; Alemany, P.; Casanova, D.; Cirera, J.; Llunell, M.; Avnir, D. Shape Maps and Polyhedral Interconversion Paths in Transition Metal Chemistry. Coord. Chem. Rev. 2005, 249, 1693-1708.

49. Cirera, J.; Ruiz, E.; Alvarez, S. Stereochemistry and Spin State in Four-Coordinate Transition Metal Compounds. Inorg. Chem. 2008, 47, 2871-2889.

50. Pinsky, M.; Avnir, D. Continuous Symmetry Measures. 5. The Classical Polyhedra. Inorg. Chem. 1998, 37, 5575-5582.

51. Clark, M. G.; Bancroft, G. M.; Stone, A. J. Mössbauer Spectrum of Fe ${ }^{2+}$ in a Square-Planar Environment. J. Chem. Phys. 1967, 47, 4250-4261.

52. Burns, R. G.; Clark, M. G.; Stone, A. J. Vibronic Polarization in the Electronic Spectra of Gillespite, a Mineral Containing Iron(II) in Square-Planar Coordination. Inorg. Chem. 1966, 5, $1268-1272$.

53. Bertini, I.; Luchinat, C. NMR of Paramagnetic Molecules in Biological Systems; Lever, A. B. P., Gray, H. B., Eds.; The Benjamin/Cummings Publishing Company, Inc.: Menlo Park, CA, 1986. 
54. Hirose, K. A Practical Guide for the Determination of Binding Constants. J. Inclusion

Phenom. Mol. Recognit. Chem. 2001, 39, 193-209.

55. Thordarson, P. Determining Association Constants from Titration Experiments in

Supramolecular Chemistry. Chem. Soc. Rev. 2011, 40, 1305-1323.

56. Cámpora, J.; Naz, A. M.; Palma, P.; Álvarez, E.; Reyes, M. L. 2,6-Diiminopyridine Iron(II)

Dialkyl Complexes. Interaction with Aluminum Alkyls and Ethylene Polymerization Catalysis.

Organometallics 2005, 24, 4878-4881.

57. Neese, F. A Critical Evaluation of DFT, Including Time-Dependent DFT, Applied to

Bioinorganic Chemistry. J. Biol. Inorg. Chem. 2006, 11, 702-711.

58. Ye, S.; Neese, F. Accurate Modeling of Spin-State Energetics in Spin-Crossover Systems with Modern Density Functional Theory. Inorg. Chem. 2010, 49, 772-774.

59. Pritchard, B.; Autschbach, J. Theoretical Investigation of Paramagnetic NMR Shifts in Transition Metal Acetylacetonato Complexes: Analysis of Signs, Magnitudes, and the Role of the Covalency of Ligand-Metal Bonding. Inorg. Chem. 2012, 51, 8340-8351.

60. Hrobárik, P.; Reviakine, R.; Arbuznikov, A. V.; Malkina, O. L.; Malkin, V. G.; Köhler, F. H.; Kaupp, M. Density Functional Calculations of NMR Shielding Tensors for Paramagnetic Systems with Arbitrary Spin Multiplicity: Validation on 3d Metallocenes. J. Chem. Phys. 2007, $126,024107$.

61. Martin, B.; Autschbach, J. Kohn-Sham Calculations of NMR Shifts for Paramagnetic 3d Metal Complexes: Protocols, Delocalization Error, and the Curious Amide Proton Shifts of a High-Spin Iron(II) Macrocycle Complex. Phys. Chem. Chem. Phys. 2016, 18, 21051-21068. 
62. Borgogno, A.; Rastrelli, F.; Bagno, A. Characterization of Paramagnetic Reactive Intermediates: Predicting the NMR Spectra of Iron(IV)-Oxo Complexes by DFT. Chem. Eur. J. 2015, 21, 12960-12970.

63. More, P. E.; Bandgar, B. P.; Kamble, V. T. Zinc Oxide as a Regioselective and Heterogeneous Catalyst for the Synthesis of Chalcones at Room Temperature. Catal. Commun. 2012, 27, 30-32.

64. Peng, Y.; Li, Z.; Zeng, Y.; Xie, X.; Wang, H.; Li, L.; Liu, X. Solid Phase Extractors Derived by Functionalising Sub-Micro Silica Gel with Chelating Agents and Their PH-Tunable Adsorbing Capability towards $\mathrm{Pb}(\mathrm{II})$ and $\mathrm{Ag}(\mathrm{I})$. Microchim. Acta 2010, 170, 17-26.

65. Bürger, H.; Wannagat, U. Silylamido-Derivate von Eisen Und Kobalt. Monatshefte für Chemie und verwandte Teile anderer Wissenschaften 1963, 94, 1007-1012.

66. Andersen, R. A.; Faegri, K.; Haaland, A.; Rypdal, K.; Green, J. C.; Lappert, M. F.; Leung, W. P. Synthesis of Bis[Bis(Trimethylsilyl)Amido]Iron(II). Structure and Bonding in $\mathrm{M}\left[\mathrm{N}\left(\mathrm{SiMe}_{3}\right)_{2}\right]_{2}(\mathrm{M}=\mathrm{Mn}, \mathrm{Fe}, \mathrm{Co})$ : Two-Coordinate Transition-Metal Amides. Inorg. Chem. 1988, $27,1782-1786$.

67. APEX3: Crystallographic Software Package for Single Crystal Data Collection, Reduction and Preparation, Version 2016.9-0; Bruker AXS: Madison, WI, 2016.

68. Sheldrick, G. M. SHELXL-2014: Crystallographic Software Package; Bruker AXS, Inc.: Madison, WI, 2014.

69. Neese, F. The ORCA Program System. Wiley Interdiscip. Rev. Comput. Mol. Sci. 2012, 2 , 73-78.

70. Becke, A. D. Density Functional Calculations of Molecular Bond Energies. J. Chem. Phys. 1986, $84,4524-4529$. 
71. Becke, A. D. Density-Functional Thermochemistry. III. The Role of Exact Exchange. J. Chem. Phys. 1993, 98, 5648-5652.

72. Lee, C.; Yang, W.; Parr, R. G. Development of the Colle-Salvetti Correlation-Energy Formula into a Functional of the Electron Density. Phys. Rev. B: Condens. Matter Mater. Phys. 1988, 37, 785-789.

73. Schäfer, A.; Horn, H.; Ahlrichs, R. Fully Optimized Contracted Gaussian-Basis Sets for Atoms Li to Kr. J. Chem. Phys. 1992, 97, 2571-2577.

74. Schäfer, A.; Huber, C.; Ahlrichs, R. Fully Optimized Contracted Gaussian Basis Sets of Triple Zeta Valence Quality for Atoms Li to Kr. J. Chem. Phys. 1994, 100, 5829.

75. Weigend, F.; Ahlrichs, R. Balanced Basis Sets of Split Valence, Triple Zeta Valence and Quadruple Zeta Valence Quality for H to Rn: Design and Assessment of Accuracy. Phys. Chem. Chem. Phys. 2005, 7, 3297-3305.

76. Neese, F.; Wennmohs, F.; Hansen, A.; Becker, U. Efficient, Approximate and Parallel Hartree-Fock and Hybrid DFT Calculations. A “Chain-of-Spheres” Algorithm for the HartreeFock Exchange. Chem. Phys. 2009, 356, 98-109.

77. Kossmann, S.; Neese, F. Comparison of Two Efficient Approximate Hartee-Fock Approaches. Chem. Phys. Lett. 2009, 481, 240-243.

78. Neese, F. An Improvement of the Resolution of the Identity Approximation for the Formation of the Coulomb Matrix. J. Comput. Chem. 2003, 24, 1740-1747.

79. Eichkorn, K.; Treutler, O.; Öhm, H.; Häser, M.; Ahlrichs, R. Auxiliary Basis Sets to Approximate Coulomb Potentials. Chem. Phys. Lett. 1995, 240, 283-289. 
80. Eichkorn, K.; Treutler, O.; Öhm, H.; Häser, M.; Ahlrichs, R. Erratum: Auxiliary Basis Sets to Approximate Coulomb Potentials (Chem. Phys. Letters 240 (1995) 283). Chem. Phys. Lett. 1995, $242,652-660$.

81. Eichkorn, K.; Weigend, F.; Treutler, O.; Ahlrichs, R. Auxiliary Basis Sets for Main Row Atoms and Transition Metals and Their Use to Approximate Coulomb Potentials. Theor. Chem. Acc. 1997, 97, 119-124.

82. Allouche, A.-R. Software News and Updates Gabedit-A Graphical User Interface for Computational Chemistry Softwares. J. Comput. Chem. 2011, 32, 174-182.

83. Neese, F. Prediction and Interpretation of the ${ }^{57} \mathrm{Fe}$ Isomer Shift in Mössbauer Spectra by Density Functional Theory. Inorg. Chim. Acta 2002, 337, 181-192.

84. Sinnecker, S.; Slep, L. D.; Bill, E.; Neese, F. Performance of Nonrelativistic and QuasiRelativistic Hybrid DFT for the Prediction of Electric and Magnetic Hyperfine Parameters in ${ }^{57}$ Fe Mössbauer Spectra. Inorg. Chem. 2005, 44, 2245-2254.

85. Römelt, M.; Ye, S.; Neese, F. Calibration of Modern Density Functional Theory Methods for the Prediction of ${ }^{57} \mathrm{Fe}$ Mössbauer Isomer Shifts : Meta-GGA and Double-Hybrid Functionals. Inorg. Chem. 2009, 48, 784-785. 


\begin{tabular}{|c|c|c|c|c|c|c|}
\hline $\begin{array}{l}\text { Copyright } \\
\text { Clearance } \\
\text { Center }\end{array}$ & RightsLink & $\underset{\text { Home }}{\widehat{\mathbf{A}}}$ & $\begin{array}{c}? \\
\text { Help }\end{array}$ & $\underset{\text { Email Support }}{\boldsymbol{\square}}$ & $\underset{\text { Sign in }}{2}$ & $\underset{\mathbf{\bullet}_{+}}{\text {Create Account }}$ \\
\hline
\end{tabular}

ACSPublications Synthesis and Electronic Structure of Neutral Square-Planar High-Spin Iron(II) Complexes Supported by a Dianionic Pincer Ligand

Author: Brett M. Hakey, Jonathan M. Darmon, Yu Zhang, et al

Publication: Inorganic Chemistry

Publisher: American Chemical Society

Date: Jan 1, 2019

Copyright (1) 2019, American Chemical Society

PERMISSION/LICENSE IS GRANTED FOR YOUR ORDER AT NO CHARGE

This type of permission/license, instead of the standard Terms \& Conditions, is sent to you because no fee is being charged for your order. Please note the following:

Permission is granted for your request in both print and electronic formats, and translations.

- If figures and/or tables were requested, they may be adapted or used in part.

- Please print this page for your records and send a copy of it to your publisher/graduate school.

Appropriate credit for the requested material should be given as follows: "Reprinted (adapted) with permission

from (COMPLETE REFERENCE CITATION). Copyright (YEAR) American Chemical Society." Insert appropriate

information in place of the capitalized words.

- One-time permission is granted only for the use specified in your request. No additional uses are granted (such as derivative works or other editions). For any other uses, please submit a new request.

BACK

CLOSE WINDOW

(c) 2020 Copyright - All Rights Reserved | Copyright Clearance Center, Inc. | Privacy statement | Terms and Conditions

Comments? We would like to hear from you. E-mail us at customercare@copyright.com 


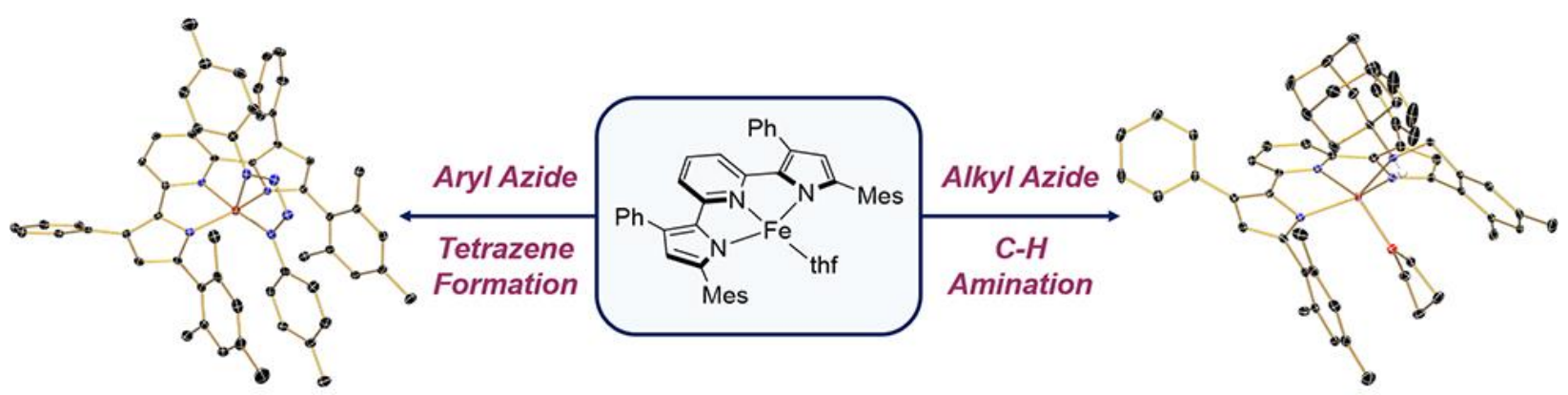

CHAPTER III: REACTIVITY OF HIGH-SPIN IRON(II) PYRIDINE BISPYRROLIDE COMPLEXES WITH ORGANIC AZIDES

Reproduced in part with permission from Hakey, B. M.; Darmon, J. M.; Akhmedov, N. G.; Petersen, J. L.; Milsmann, C. Inorg. Chem. 2019, 58, 16, 110282-11042. Copyright @ 2019 American Chemical Society.

\subsection{Abstract}

The reactions of ( $\left.{ }^{\mathrm{Mes}} \mathrm{PDP}{ }^{\mathrm{Ph}}\right) \mathrm{Fe}(\mathrm{thf})\left(\mathrm{H}_{2}{ }^{\mathrm{Mes}} \mathrm{PDP}^{\mathrm{Ph}}=2,6-\right.$ bis(5-(2,4,6-trimethylphenyl)-3phenyl-1H-pyrrol-2-yl)- pyridine) with organic azides have been studied. The identity of the azide substituent had a profound impact on the transformation type and nature of the observed products. Reaction with aromatic p-tolyl azide, $\mathrm{N}_{3}$ Tol, resulted in exclusive formation of the corresponding iron tetrazene complex $\left({ }^{\mathrm{Mes}} \mathrm{PDP}{ }^{\mathrm{Ph}}\right) \mathrm{Fe}\left(\mathrm{N}_{4} \mathrm{Tol}_{2}\right)$. In contrast, the use of bulky 1adamantyl azide or 4-azido-4-methylpentylbenzene led to clean intramolecular $\mathrm{C}-\mathrm{H}$ amination of one of the benzylic $\mathrm{C}-\mathrm{H}$ bonds of a mesityl substituent on the pyridine dipyrrolide, PDP, supporting ligand. The smaller aliphatic substituent in benzyl azide allowed for the isolation of two different compounds from distinct reaction pathways. One product is the result of double $\mathrm{C}-\mathrm{H}$ amination of the PDP ligand via nitrene transfer, while the second one contains a dibenzyl tetrazene and a benzaldimine ligand. The bulky aromatic mesityl azide, $\mathrm{MesN}_{3}$, allows for suppression of tetrazene formation and the spectroscopic observation of the reactive imidyl radical intermediate $\left({ }^{\mathrm{Mes}} \mathrm{PDP} \mathrm{Ph}^{\mathrm{Ph}}\right) \mathrm{Fe}(\mathrm{NMes})$. This complex decomposes in the presence of the weak 
benzylic bonds of the ${ }^{\mathrm{Mes}} \mathrm{PDP}^{\mathrm{Ph}}$ supporting ligand to form the $\mathrm{C}-\mathrm{H}$ amination product $\mathrm{Fe}\left(\mathrm{NHMes}-{ }^{\mathrm{Mes}} \mathrm{PDP}^{\mathrm{Ph}}\right)$. All isolated complexes were characterized using a combination of X-ray crystallography, solid state magnetic susceptibility measurements, ${ }^{1} \mathrm{H}$ NMR and ${ }^{57} \mathrm{Fe}$ Mössbauer spectroscopy, and density functional theory (DFT), and their electronic structures were elucidated. Potential electronic structures for putative iron(IV) imido or iron(III) iminyl radical complexes were explored via DFT calculations.

\subsection{Introduction}

Reactions between organic azides and various transition metal complexes have been intensively studied due to their relevance in nitrogen-group transfer reactions. ${ }^{1}$ As a consequence of this research, nitrene transfer to olefins and insertion into $\mathrm{C}-\mathrm{H}$ bonds has become a viable strategy for the synthesis of important nitrogen-containing organic compounds such as aziridines and functionalized amines, respectively. ${ }^{2-8}$ Inspired initially by the related oxygen atom-transfer reactivity of $\mathrm{P} 450^{9}$ and nonheme iron enzymes, ${ }^{10}$ nitrene transfer via iron catalysis has received particular attention. ${ }^{11-15}$ Based on the seminal work on biomimetic iron porphyrin complexes that promote $\mathrm{C}-\mathrm{H}$ amination and the presence of iron-oxo intermediates in biological systems, ${ }^{16-19} \mathrm{a}$ substantial number of isoelectronic iron-imido species with numerous supporting ligand systems has been prepared and studied over the last two decades. ${ }^{20-46}$ This class of compounds displays a remarkable range of different electronic structures with iron centers in oxidation states from $+\mathrm{II}$ to $+\mathrm{V}$ and various spin states combined with dianionic imido $\left(\mathrm{NR}^{2-}\right)$ or monoanionic iminyl radical $\left(\mathrm{NR}^{\cdot{ }^{1-}}\right)$ ligands. In addition to iron-imido species, iron-tetrazene complexes, formed via $[2+3]$ cycloaddition of an $\mathrm{Fe}=\mathrm{NR}$ unit with an additional equivalent of organic azide, can often be isolated in reactions with organic azides as the nitrene source ${ }^{46-53}$ Due to the redox-active nature of the tetrazene ligand, which can exist in three different oxidation states, multiple distinct 
electronic structures are possible in combination with iron and have been explored by a number of researchers. ${ }^{54}$ While many iron tetrazene complexes are inert, several examples have recently been suggested as intermediates in the formation of azoarenes via nitrene homocoupling, and catalytic protocols for azoarene synthesis from aromatic organic azides have been developed. ${ }^{54,55}$ Additionally, Jenkins and co-workers have shown that iron tetrazene complexes can be competent intermediates in catalytic aziridination reactions. ${ }^{52}$ For both types of reactivity, the iron tetrazenes were proposed to act as a "masked form" of a reactive iron-imido species. Despite the ever-growing sample size of well-characterized intermediates obtained from the reaction of organic azides with iron precursors, the exact factors that govern the diverse reactivity of iron compounds in nitrene transfer reactions continue to be unclear. Specifically, examples of $\mathrm{C}-\mathrm{H}$ amination facilitated by iron catalysts remain scarce. ${ }^{2,4}$ The most successful and best-understood catalyst system was reported by Betley and co-workers using dipyrromethenes as the supporting ligand. ${ }^{43-46,56-59}$ The ability of this ligand system to support high-spin ferric imido or iminyl species has been proposed as a key feature to allow facile intra- and intermolecular $\mathrm{C}-\mathrm{H}$ amination via nitrene transfer. An interesting characteristic of dipyrromethene ligands is their close relationship to the porphyrin ligands used in the initial discovery of iron mediated $\mathrm{C}-\mathrm{H}$ amination (Figure 3.1). 
Breslow, 1982

Che, 2010

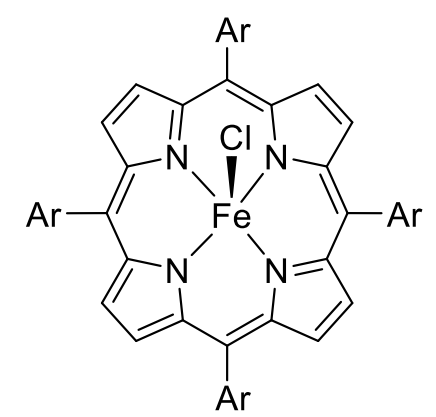

Jameson, de Visser,

Goldberg, 2013

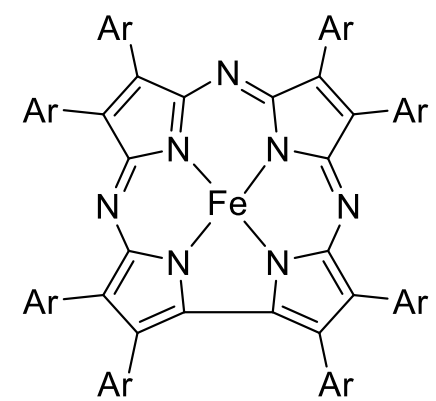

Betley, 2013<smiles></smiles>

Figure 3.1. Iron complexes with pyrrole-based ligands employed in nitrene transfer reactions.

In a similar manner, pyridine dipyrrolide (PDP) ligands with two anionic pyrrolide moieties separated by a neutral pyridine donor can be viewed as a porphyrin fragment (Figure 3.2). However, the pincer-type ligand structure allows for the stabilization of different coordination geometries and resulting electronic structures compared to both the parent macrocycle and dipyrromethenes. For example, we have recently shown that the PDP platform supports unusual high-spin ferrous configurations in a distorted square-planar ligand field. ${ }^{60}$ Based on these observations, we were curious to investigate whether PDP ligands are capable of supporting rare high-spin $\mathrm{Fe}^{\mathrm{III}}$-iminyl or $\mathrm{Fe}^{\mathrm{IV}}$-imido complexes that can facilitate nitrene transfer. The steric profile of the PDP ligand was identified as a critical parameter to fine tune the desired electronic structure. Mindiola, Caulton, and co-workers recently reported the synthesis and characterization of the stable $\mathrm{Fe}^{\mathrm{IV}}$ imido complex $\left({ }^{\mathrm{tBu}} \mathrm{PDP} \mathrm{P}^{\mathrm{tBu}}\right) \mathrm{Fe}\left(\mathrm{N}^{1} \mathrm{Ad}\right)\left(\mathrm{H}_{2}{ }^{\mathrm{tBu}} \mathrm{PDP}^{\mathrm{tBu}}=2,6-\right.$ bis(3,5-di-tert-butyl-1H-pyrrol-2-yl)pyridine). ${ }^{28}$ As established by their thorough electronic structure analysis, the unusual cis-divacant octahedral geometry enforced by the bulky ${ }^{\mathrm{tBu}} \mathrm{PDP}^{\mathrm{tBu}}$ ligand results in a low-spin $\mathrm{Fe}^{\mathrm{IV}}(\mathrm{S}=0)$ configuration with a closed-shell $\mathrm{NR}^{2-}$ ligand. In line with the proposed requirement for high-spin ferric imido/iminyl intermediates for nitrene transfer, this complex is remarkably inert toward nitrene transfer to both olefins and $\mathrm{C}-\mathrm{H}$ 
bonds. ${ }^{61}$ We hypothesized that opening of a coordination site trans to the central pyridine donor by using ${ }^{\mathrm{Mes}} \mathrm{PDP}^{\mathrm{Ph}}$ as a supporting ligand could result in four-coordinate square-planar or fivecoordinate square-pyramidal nitrene intermediates exhibiting higher spin states and increased reactivity. Herein, we describe the reactivity of organic azides with the $\mathrm{Fe}^{\mathrm{II}}$ complex $\left({ }^{\mathrm{Mes}} \mathrm{PDP}^{\mathrm{Ph}}\right) \mathrm{Fe}($ thf $)$ to yield iron tetrazene complexes and products resulting from intramolecular $\mathrm{C}-\mathrm{H}$ amination.

Mindiola, Caulton, 2014
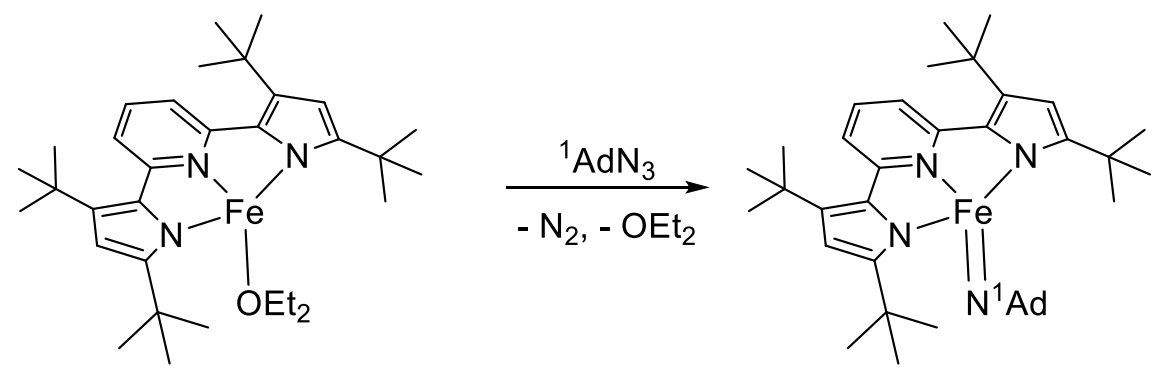

This Study

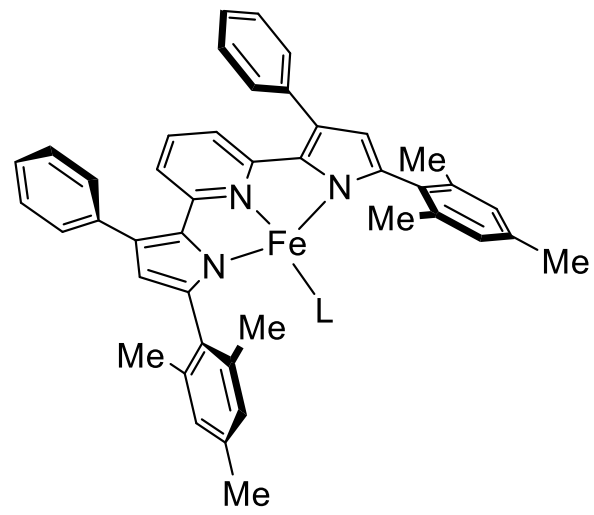

$\mathrm{L}=$ thf, $\mathrm{OEt}_{2}$

Figure 3.2. Pyridine dipyrrolide (PDP) iron complexes with distinct coordination geometries investigated for their reactivity with organic azides.

\subsection{Reactivity of $\left({ }^{\mathrm{Mes} P D P}{ }^{\mathrm{Ph}}\right) \mathrm{Fe}(\mathrm{L})\left(\mathrm{L}=\mathrm{Et}_{2} \mathrm{O}\right.$ or thf $)$ with 1-Adamantyl Azide}

The addition of one equivalent of $\mathrm{N}_{3}{ }^{1}$ Ad to dark-red solutions of $\left({ }^{\mathrm{Mes}} \mathrm{PDP}^{\mathrm{Ph}}\right) \mathrm{Fe}\left(\mathrm{OEt}_{2}\right)$ or $\left({ }^{\mathrm{Mes}} \mathrm{PDP}^{\mathrm{Ph}}\right) \mathrm{Fe}(\mathrm{thf})$ in benzene- $d_{6}$ resulted in complete conversion of the starting complex within 1 
$\mathrm{h}$ to a new paramagnetic species, as detected by ${ }^{1} \mathrm{H}$ NMR spectroscopy. No obvious color change was observed during the reaction; however, upon addition of azide, evolution of $\mathrm{N}_{2}$ was observed. The absence of a signal for an azide stretching mode in the IR spectrum of the crude reaction mixture indicated complete consumption of 1-adamantyl azide and ruled out formation of a simple iron azide adduct. The appearance of a signal at $3198 \mathrm{~cm}^{-1}$ suggested the formation of an $\mathrm{N}-\mathrm{H}$ bond. Based on the ${ }^{1} \mathrm{H}$ NMR data, the symmetry of the product is significantly reduced compared to the $\mathrm{C}_{2 v}$ symmetric starting material, as evidenced by a total of 24 paramagnetically shifted resonances between -96.42 and $203.45 \mathrm{ppm}$, which indicates a $\mathrm{C}_{1}$ symmetric molecule. Reactions with excess azide under otherwise identical conditions yielded the same paramagnetic product in the presence of unreacted $\mathrm{N}_{3}{ }^{1} \mathrm{Ad}$. Following recrystallization from toluene/pentane mixtures, the new complex was obtained as red microcrystalline needles and further characterized by zero-field ${ }^{57} \mathrm{Fe}$ Mössbauer spectroscopy (Figure 3.3). The large isomer shift, $\delta$, of $0.75 \mathrm{~mm} \mathrm{~s}^{-1}$ is consistent with a central high-spin $\mathrm{Fe}^{\mathrm{II}}$ metal center, which was further supported by a room temperature effective magnetic moment, $\mu_{\mathrm{eff}}$, of $5.2 \mu_{\mathrm{B}}$. Deviation from the spin-only value expected for four unpaired electrons is typical for PDP iron complexes and is likely due to contributions from unquenched orbital angular momentum. ${ }^{28,60}$ Previously reported Mössbauer data for high-spin ferrous PDP complexes by Mindiola and co-workers and our group provide further insight into the likely coordination environment around the metal center (Table 3.1). The unusually small quadrupole splitting, $\left|\Delta \mathrm{E}_{\mathrm{Q}}\right|$, of $0.41 \mathrm{~mm} \mathrm{~s}^{-1}$ for a highspin ferrous species is indicative of a four coordinate species with planar geometry. ${ }^{60}$ In contrast, well characterized examples for five-coordinate $\mathrm{Fe}^{\mathrm{II}} \mathrm{PDP}$ complexes exhibit significantly larger values of $\left|\Delta \mathrm{E}_{\mathrm{Q}}\right|{ }^{60}$ while the cis-divacant high-spin $\mathrm{Fe}^{\mathrm{II}}$ complex $\left({ }^{(\mathrm{Bu}} \mathrm{PDP}^{\mathrm{tBu}}\right) \mathrm{Fe}\left(\mathrm{OEt}_{2}\right)$ is characterized by a splitting of intermediate size at $1.12 \mathrm{mms}^{-1} \cdot{ }^{28}$ In combination, the collected 
analytical data are most consistent with nitrene insertion into a benzylic $\mathrm{C}-\mathrm{H}$ bond of an orthomethyl group of one of the mesityl substituents. The product of this intramolecular group transfer reaction was tentatively assigned as $\mathrm{Fe}\left(\mathrm{NH}^{1} \mathrm{Ad}-{ }^{\mathrm{Mes}} \mathrm{PDP}^{\mathrm{Ph}}\right)$ shown in Scheme 3.1.
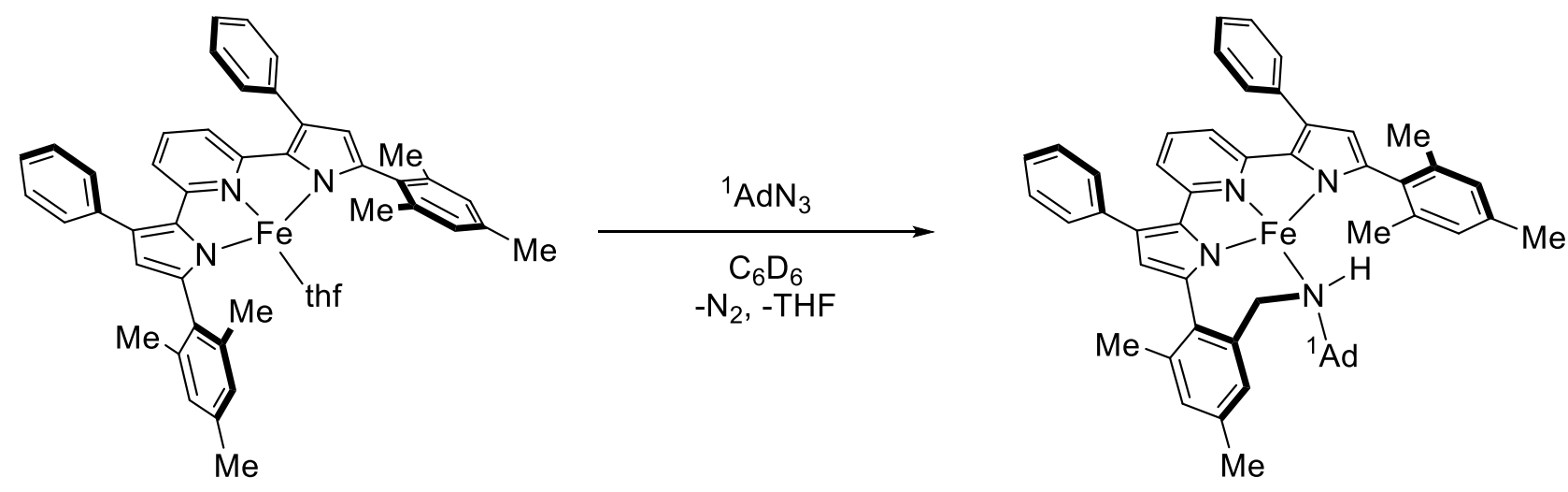

Scheme 3.1. Synthesis of $\mathrm{Fe}\left(\mathrm{NH}^{-1} \mathrm{Ad}^{\mathrm{Mes}} \mathrm{PDP}^{\mathrm{Ph}}\right)$.

Despite repeated efforts, single crystalline samples suitable for X-ray diffraction studies could not be obtained from hydrocarbon solvents. Interestingly, the solid state Mössbauer data for $\mathrm{Fe}\left(\mathrm{NH}^{1} \mathrm{Ad}-{ }^{\mathrm{Mes}} \mathrm{PDP}^{\mathrm{Ph}}\right)$ indicated the presence of a minor impurity $(<10 \%)$ of a second iron species with parameters $\delta=0.94 \mathrm{~mm} \mathrm{~s}^{-1}$ and $\Delta \mathrm{E}_{\mathrm{Q}}=2.14 \mathrm{~mm} \mathrm{~s}^{-1}$, which are indicative of a five coordinate PDP iron complex (Figure 3.6). Based on the previously established ability of the starting material $\left({ }^{\mathrm{Mes}} \mathrm{PDP}{ }^{\mathrm{Ph}}\right) \mathrm{Fe}($ thf $)$ to reversibly bind an additional THF ligand, this minor species was attributed to a diethyl ether or THF adduct of $\mathrm{Fe}\left(\mathrm{NH}^{1} \mathrm{Ad}-{ }^{\mathrm{Mes}} \mathrm{PDP}{ }^{\mathrm{Ph}}\right)$ due to the presence of ethereal solvents in the glovebox atmosphere. Notably, dissolution of $\mathrm{Fe}\left(\mathrm{NH}^{1} \mathrm{Ad}-\right.$ ${ }^{\mathrm{Mes}} \mathrm{PDP}^{\mathrm{Ph}}$ ) in THF- $d_{8}$ resulted in an immediate color change from intense red to orange and led to substantial changes to the chemical shifts observed in the ${ }^{1} \mathrm{H}$ NMR spectrum (Scheme 3.2 and Figure 3.3). 

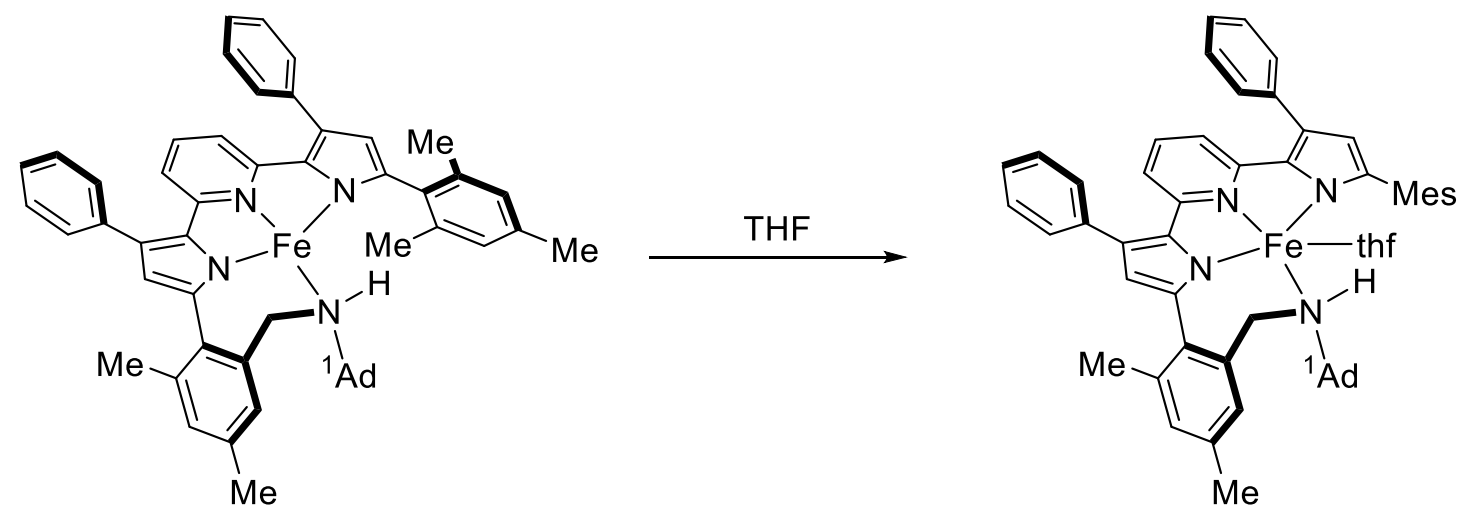

Scheme 3.2. Synthesis of $\left(\mathrm{NH}^{1} \mathrm{Ad}-{ }^{\mathrm{Mes}} \mathrm{PDP}^{\mathrm{Ph}}\right) \mathrm{Fe}(\mathrm{thf})$. Note, for clarity the mesityl substituent of one pyrrole has been truncated and is denoted as "Mes".

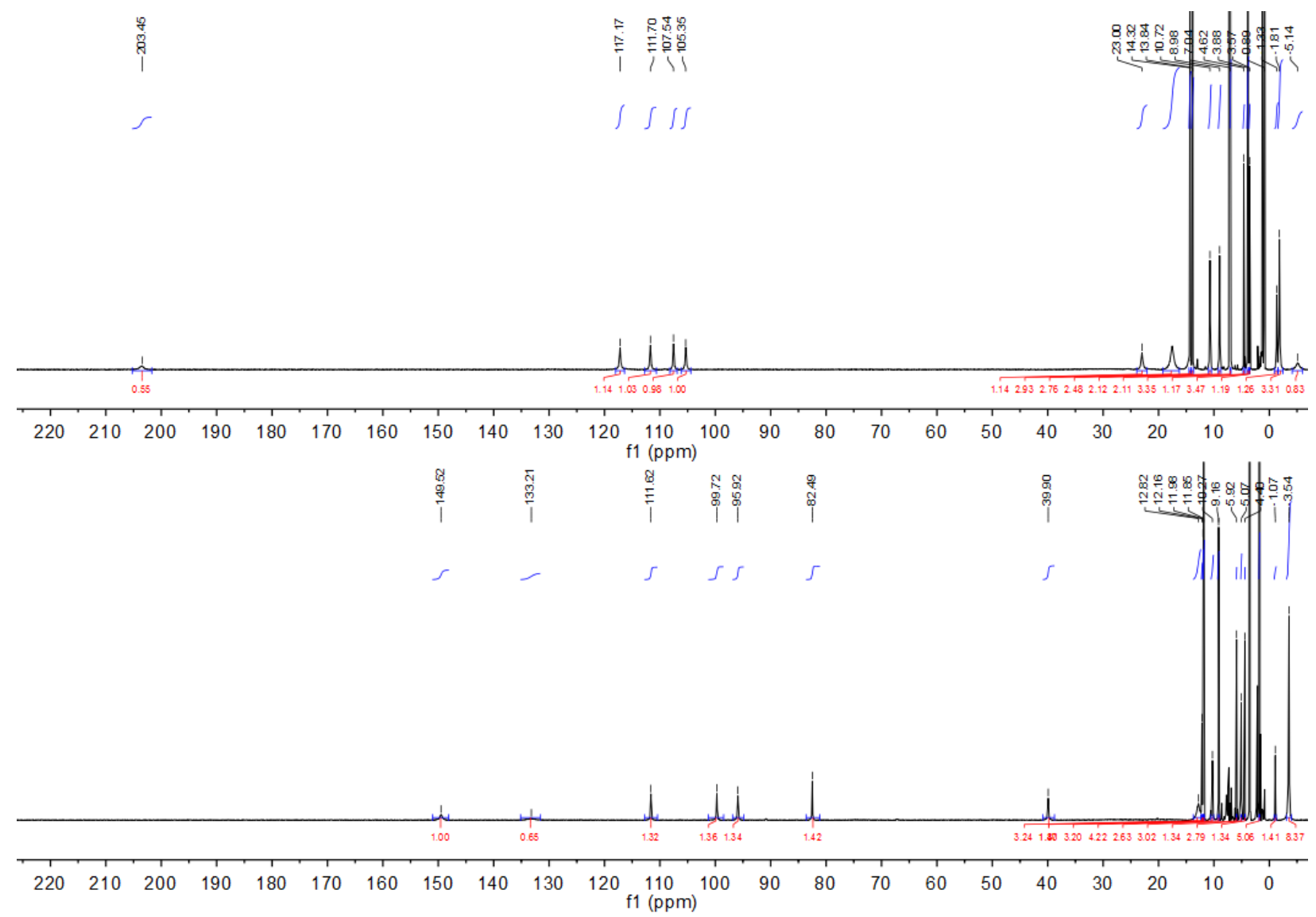

Figure 3.3. Comparison of the ${ }^{1} \mathrm{H}$ NMR spectra of $\mathrm{Fe}\left(\mathrm{NH}^{1} \mathrm{Ad}^{-\mathrm{Mes}} \mathrm{PDP}^{\mathrm{Ph}}\right)$ in benzene- $d_{6}$ and $\left(\mathrm{NH}^{1} \mathrm{Ad}^{-}{ }^{\mathrm{Mes}} \mathrm{PDP}^{\mathrm{Ph}}\right) \mathrm{Fe}$ (thf) in THF- $d_{8}$ (bottom).

Further support for the formation of a new species was obtained from the Mössbauer spectrum recorded in THF solution (Figure 3.5), which shows a complete absence of the signal for the 
four-coordinate complex and a majority quadrupole doublet with parameters $\delta=1.12 \mathrm{~mm} \mathrm{~s}^{-1}$ and $\left|\Delta \mathrm{E}_{\mathrm{Q}}\right|=2.16 \mathrm{~mm} \mathrm{~s}^{-1}$. These values are similar to those of the minor species from the solid state measurement and consistent with a five-coordinate high-spin ferrous species $\left(\mathrm{NH}^{1} \mathrm{Ad}-\right.$ $\left.{ }^{\mathrm{Mes}} \mathrm{PDP}{ }^{\mathrm{Ph}}\right) \mathrm{Fe}(\mathrm{thf})$. The second observed species, with Mössbauer parameters of $\delta=0.46 \mathrm{~mm} \mathrm{~s}^{-1}$ and $\left|\Delta \mathrm{E}_{\mathrm{Q}}\right|=0.99 \mathrm{~mm} \mathrm{~s}^{-1}$, likely stems from decomposition encountered during sample preparation, as the values are consistent with those reported for colloidal $\mathrm{FeO}(\mathrm{OH})$ (rust). ${ }^{62}$
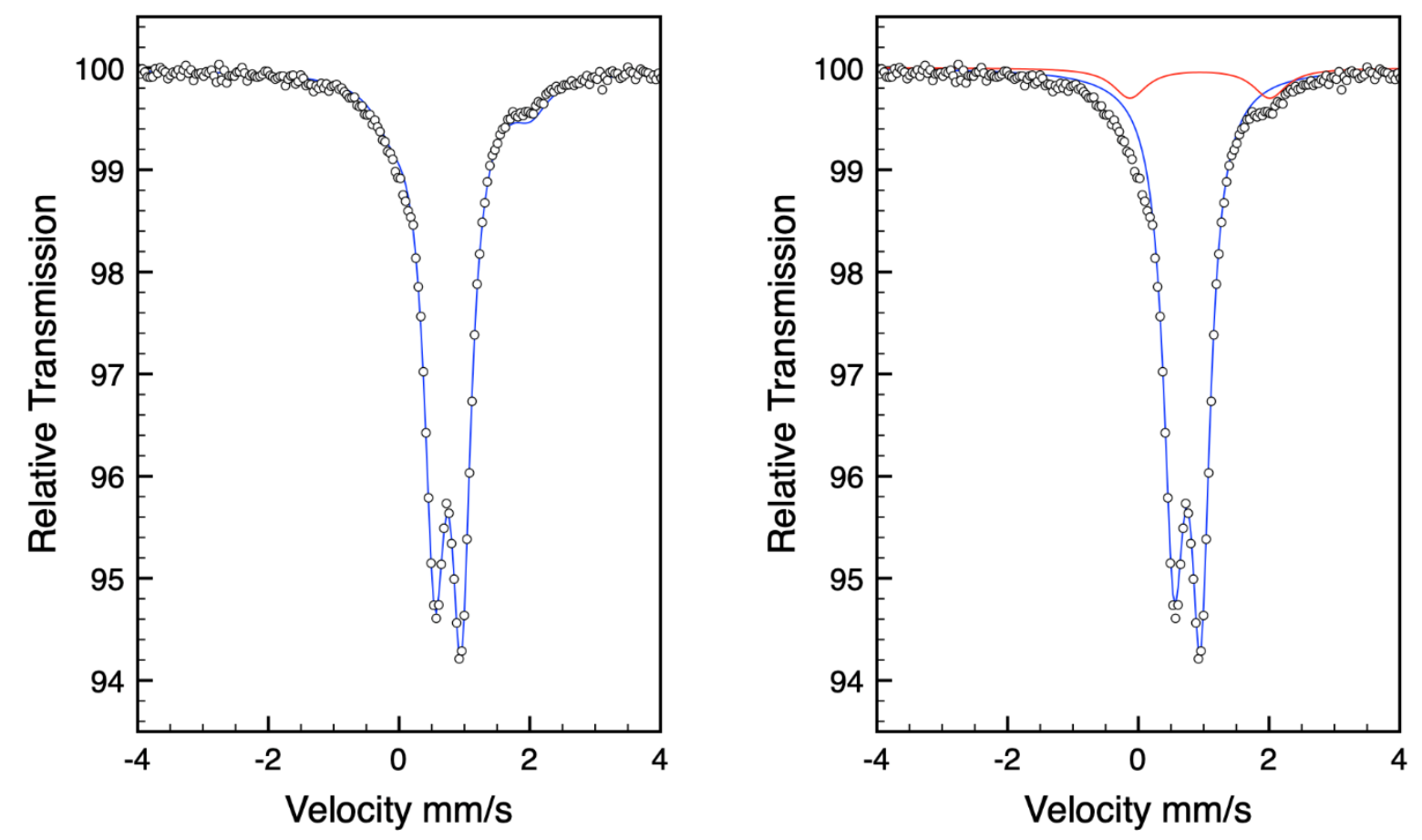

Figure 3.4. Zero-field Mössbauer spectrum of $\mathrm{Fe}\left(\mathrm{NH}-{ }^{1} \mathrm{Ad}^{\mathrm{Mes}} \mathrm{PDP}^{\mathrm{Ph}}\right)$ acquired at $80 \mathrm{~K}$. For the composite spectrum (left), the white circles indicate the experimental data and the blue line corresponds to the fit. For the component spectrum (right), the white circles indicate experimental data and the blue and red lines are the fits for $\mathrm{Fe}(\mathrm{NH}-$ $\left.{ }^{1} \mathrm{Ad}^{\mathrm{Mes}} \mathrm{PDP}^{\mathrm{Ph}}\right)$ and a species tentatively assigned as $\left(\mathrm{NH}^{-}{ }^{1} \mathrm{Ad}^{\mathrm{Mes}} \mathrm{PDP}^{\mathrm{Ph}}\right) \mathrm{Fe}\left(\mathrm{thf}_{\mathrm{O}} / \mathrm{OEt}_{2}\right)$, respectively. 
Table 3.1. Summary of ${ }^{57} \mathrm{Fe}$ Mössbauer spectroscopic data for PDP iron complexes.

\begin{tabular}{|c|c|c|c|}
\hline & $\delta / m m s^{-1}$ & $\left|\Delta E_{Q}\right| / m m s^{-1}$ & Ref \\
\hline$\left({ }^{(\mathrm{Bu}} \mathrm{PDP}^{\mathrm{tBu}}\right) \mathrm{Fe}^{\mathrm{II}}\left(\mathrm{OEt}_{2}\right)(S=2)$ & 0.86 & 1.12 & 28 \\
\hline$\left({ }^{\mathrm{tBu}} \mathrm{PDP}^{\mathrm{tBu}}\right) \mathrm{Fe}^{\mathrm{III}}(\mathrm{Cl})(S=5 / 2)$ & 0.39 & 2.38 & 28 \\
\hline$\left({ }^{\mathrm{tBu}} \mathrm{PDP}^{\mathrm{tBu}}\right) \mathrm{Fe}^{\mathrm{IV}}\left(\mathrm{N}^{1} \mathrm{Ad}\right)(S=0)$ & -0.09 & 2.78 & 28 \\
\hline$\left({ }^{\mathrm{Mes}} \mathrm{PDP}^{\mathrm{Ph}}\right) \mathrm{Fe}^{\mathrm{II}}(\mathrm{thf})(\mu-\mathrm{Cl}) \mathrm{Li}(\operatorname{thf})_{3}(S=2)$ & 1.09 & 2.63 & 60 \\
\hline$\left({ }^{\mathrm{Mes}} \mathrm{PDP}^{\mathrm{Ph}}\right) \mathrm{Fe}^{\mathrm{II}}\left(\mathrm{OEt}_{2}\right)(S=2)$ & 0.87 & 0.50 & 60 \\
\hline$\left({ }^{\text {Mes }} \mathrm{PDP}^{\mathrm{Ph}}\right) \mathrm{Fe}^{\mathrm{II}}(\mathrm{thf})(S=2)$ & 0.78 & 0.48 & 60 \\
\hline$\left({ }^{\mathrm{Mes}} \mathrm{PDP}^{\mathrm{Ph}}\right) \mathrm{Fe}^{\mathrm{II}}(\operatorname{thf})_{2}^{a}(S=2)$ & 1.09 & 2.76 & 60 \\
\hline$\left({ }^{\mathrm{Mes}} \mathrm{PDP}^{\mathrm{Ph}}\right) \mathrm{Fe}^{\mathrm{II}}(\mathrm{py})_{2}(S=2)$ & 0.98 & 2.92 & 60 \\
\hline $\mathrm{Fe}^{\mathrm{II}}\left(\mathrm{NH}^{1} \mathrm{Ad}^{\mathrm{Mes}} \mathrm{PDP}^{\mathrm{Ph}}\right)(S=2)$ & 0.75 & 0.41 & This work \\
\hline$\left(\mathrm{NH}^{1} \mathrm{Ad}^{-{ }^{\mathrm{Mes}}} \mathrm{PDP}^{\mathrm{Ph}}\right) \mathrm{Fe}^{\mathrm{II}}(\mathrm{thf})^{a}(S=2)$ & 1.12 & 2.16 & This work \\
\hline$\left({ }^{\mathrm{Mes}} \mathrm{PDP}^{\mathrm{Ph}}\right) \mathrm{Fe}^{\mathrm{III}}\left(\mathrm{N}_{4} \mathrm{Tol}_{2}{ }^{*}\right)(S=0)$ & 0.12 & 3.12 & This work \\
\hline $\mathrm{Fe}^{\mathrm{II}}\left(\{\mathrm{NHBn}\}_{2^{-}}{ }^{\mathrm{Mes}} \mathrm{PDP}^{\mathrm{Ph}}\right)(S=2)$ & 0.93 & 1.48 & This work \\
\hline$\left({ }^{\text {Mes }} \mathrm{PDP}^{\mathrm{Ph}}\right) \mathrm{Fe}^{\mathrm{II}}\left(\mathrm{N}_{4} \mathrm{Bn}_{2}\right)(\mathrm{HN}=\mathrm{CHPh})(S=0)$ & 0.15 & 2.26 & This work \\
\hline
\end{tabular}

${ }^{a}$ Recorded in frozen THF solution. 

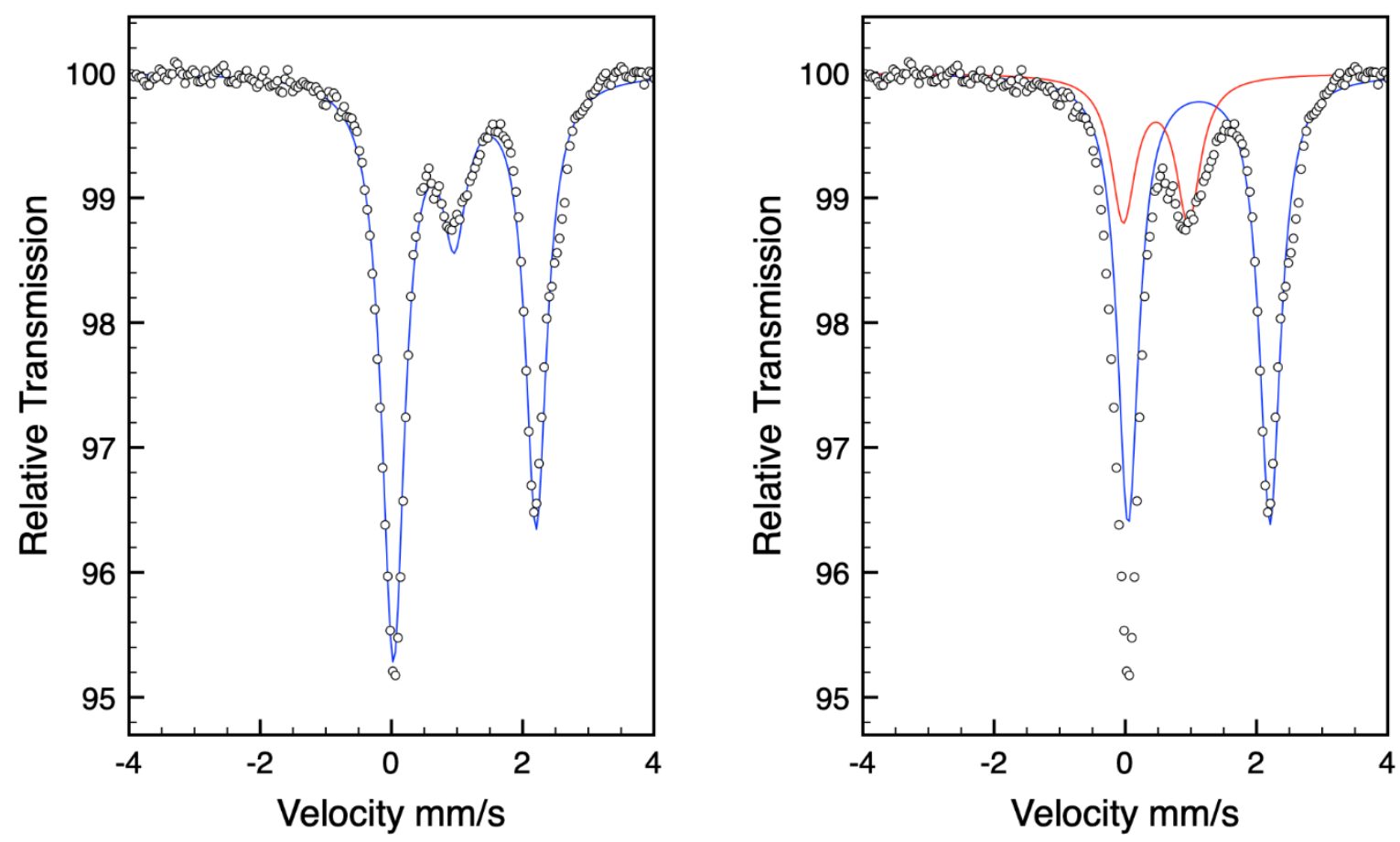

Figure 3.5. Zero-field Mössbauer spectrum of $\left(\mathrm{NH}^{1} \mathrm{Ad}-{ }^{\mathrm{Mes}} \mathrm{PDP} \mathrm{Ph}^{\mathrm{Ph}}\right) \mathrm{Fe}(\mathrm{thf})$ acquired at $80 \mathrm{~K}$. For the composite spectrum (left), the white circles indicate the experimental data and the blue line corresponds to the fit. For the component spectrum (right), the white circles indicate experimental data and the blue and red lines are the fits for $\left(\mathrm{NH}^{1} \mathrm{Ad}-{ }^{\mathrm{Mes}} \mathrm{PDP}{ }^{\mathrm{Ph}}\right) \mathrm{Fe}(\mathrm{thf})$ and a species tentatively assigned as $\mathrm{FeO}(\mathrm{OH})$, respectively. Note: The spectrum was acquired in frozen THF solution.

Slow diffusion of pentane into a concentrated THF solution of the new compound resulted in the isolation of red-orange single crystals identified as $\left(\mathrm{NH}^{1} \mathrm{Ad}-{ }^{\mathrm{Mes}} \mathrm{PDP}{ }^{\mathrm{Ph}}\right) \mathrm{Fe}($ thf $)$ by $\mathrm{X}-\mathrm{ray}$ crystallography. The molecular structure shown in Figure 3.6 confirms intramolecular nitrene insertion into a benzylic $\mathrm{C}-\mathrm{H}$ bond of an ortho-methyl group of one of the mesityl substituents. The five-coordinate geometry around the iron center can be described as heavily distorted square pyramidal or trigonal bipyramidal with $\mathrm{N}(2)-\mathrm{Fe}(1)-(\mathrm{N} 4), \mathrm{N}(2)-\mathrm{Fe}(1)-\mathrm{O}(1)$, and $\mathrm{O}(1)-\mathrm{Fe}(1)-\mathrm{N}(4)$ angles of $118.46(7)^{\circ}, 149.61(6)^{\circ}$, and $91.04(6)^{\circ}$, respectively. Due to the small bite angle of the pincer ligand, the two pyrrole nitrogen atoms $\mathrm{N}(1)$ and $\mathrm{N}(3)$ are not perfectly 
trans to each other with an $\mathrm{N}(1)-\mathrm{Fe}(1)-\mathrm{N}(3)$ angle of $147.17(7)^{\circ}$. The long $\mathrm{Fe}-\mathrm{N}$ and $\mathrm{Fe}-\mathrm{O}$ bond lengths (Table 3.1) are consistent with a high-spin iron center. The angles around N(4) indicate the presence of a neutral amine ligand, and the $\mathrm{N}-\mathrm{H}$ hydrogen atom was located in the electron density map.

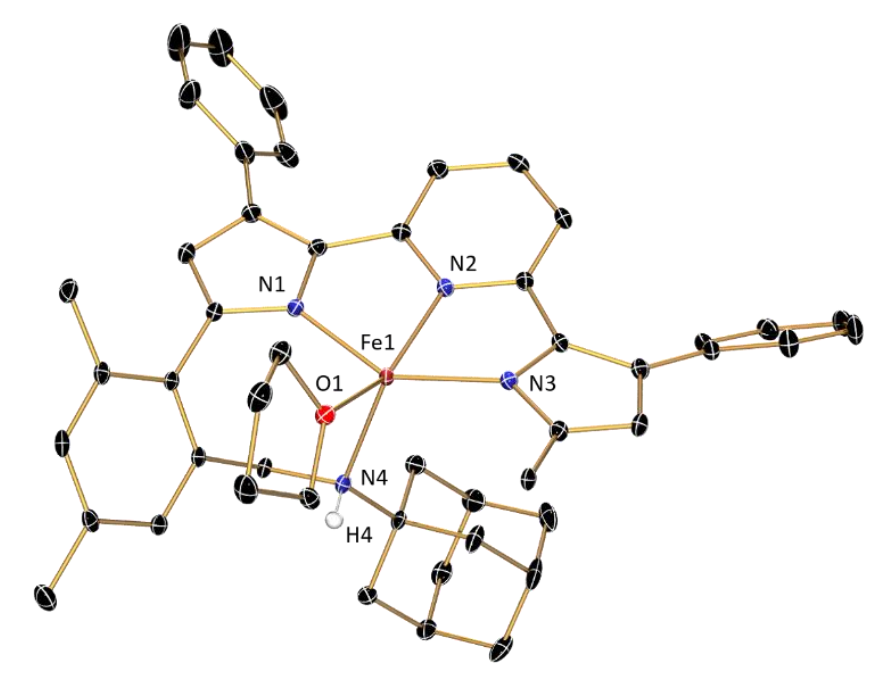

Figure 3.6. ORTEP of $\left(\mathrm{NH}^{1} \mathrm{Ad}^{-\mathrm{Mes}} \mathrm{PDP}^{\mathrm{Ph}}\right) \mathrm{Fe}($ thf $)$ displayed at $30 \%$ probability ellipsoids. Hydrogen atoms (with exception of the amine $\mathrm{H}$ ), co-crystallized solvent molecules, and a mesityl pyrrole substituent (with exception of the ipso carbon) have been excluded for clarity.

\subsection{Reactivity with the Aromatic Azide Paratolyl Azide}

Encouraged by the observed intramolecular $\mathrm{C}-\mathrm{H}$ activation using ${ }^{1} \mathrm{AdN}_{3}$, reactions using an aromatic azide were targeted next to explore whether the different electronic and steric properties of the nitrene source would enable intermolecular $\mathrm{C}-\mathrm{H}$ amination reactions. Addition of one equivalent of paratolyl azide to $\left({ }^{\mathrm{Mes}} \mathrm{PDP} \mathrm{Ph}^{\mathrm{Ph}}\right) \mathrm{Fe}(\mathrm{thf})$ in aromatic solvents at room temperature resulted in an immediate color change from red to brown. Analysis of the reaction mixture by ${ }^{1} \mathrm{H}$ NMR spectroscopy revealed the formation of a new diamagnetic species but revealed incomplete consumption of the starting material. An approximate ratio of 1:1 for the 
new complex and the starting material was determined via integration of the 4-pyridine proton resonances. Repeating the experiment with an organic azide to $\left({ }^{\mathrm{Mes}} \mathrm{PDP}{ }^{\mathrm{Ph}}\right) \mathrm{Fe}($ thf $)$ ratio of 2:1 produced the new diamagnetic complex with complete consumption of ( $\left.{ }^{\mathrm{Mes}} \mathrm{PDP}{ }^{\mathrm{Ph}}\right) \mathrm{Fe}(\mathrm{thf})$. Recrystallization from toluene/pentane solutions at $-35^{\circ} \mathrm{C}$ yielded a dark brown, microcrystalline solid identified as the tetrazene complex $\left({ }^{\mathrm{Mes}} \mathrm{PDP}{ }^{\mathrm{Ph}}\right) \mathrm{Fe}\left(\mathrm{N}_{4} \mathrm{Tol}_{2}\right)$ (Scheme 3.3).
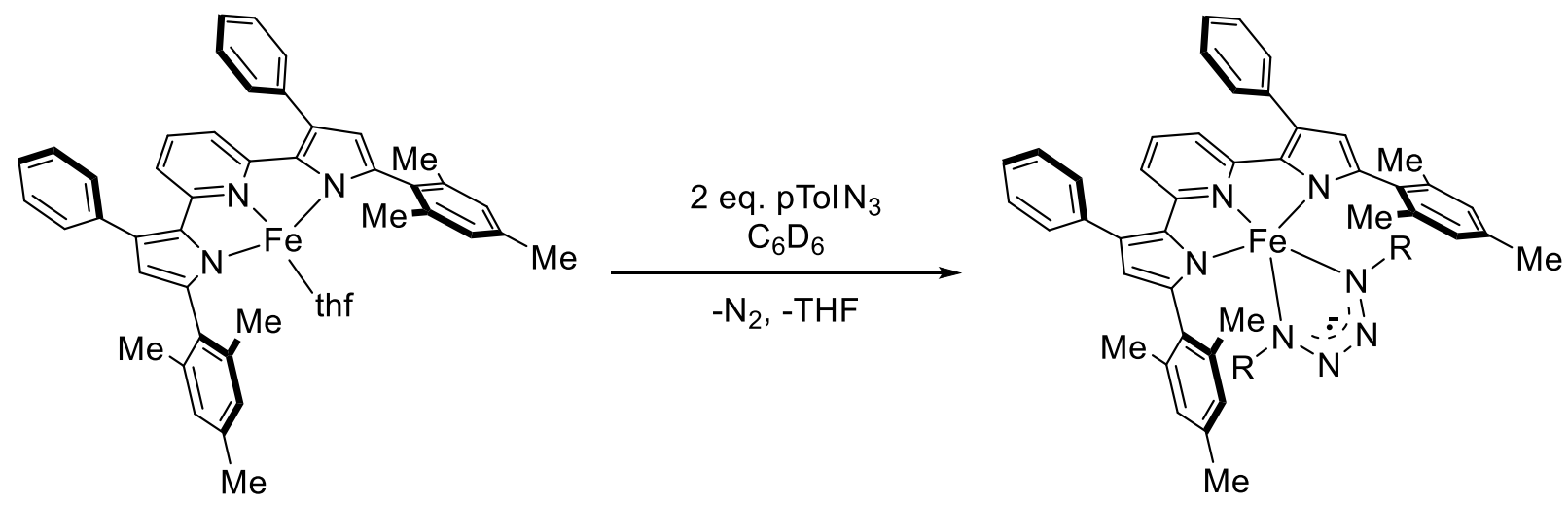

Scheme 3.3. Synthesis of $\left({ }^{\mathrm{Mes}} \mathrm{PDP}{ }^{\mathrm{Ph}}\right) \mathrm{Fe}\left(\mathrm{N}_{4} \mathrm{Tol}_{2}\right)$. R denotes $p$-tolyl.

Single crystals suitable for characterization by X-ray diffraction were obtained via slow diffusion of pentane into a concentrated solution of $\left({ }^{\mathrm{Mes}} \mathrm{PDP}{ }^{\mathrm{Ph}}\right) \mathrm{Fe}\left(\mathrm{N}_{4} \mathrm{Tol}_{2}\right)$ in toluene at $-35^{\circ} \mathrm{C}$. The molecular structure of the complex is illustrated in Figure 3.7 and contains an iron center in a distorted square pyramidal coordination environment. The short $\mathrm{Fe}-\mathrm{N}$ bond distances (Table 3.1) suggest a low-spin configuration consistent with the diamagnetic ground state. 
Table 3.2. Selected bond lengths $(\AA)$ and angles (deg) for $\left(\mathrm{NH}^{1} \mathrm{Ad}-{ }^{\mathrm{Mes}} \mathrm{PDP}^{\mathrm{Ph}}\right) \mathrm{Fe}($ thf $)$ and $\left({ }^{\mathrm{Mes}} \mathrm{PDP}^{\mathrm{Ph}}\right) \mathrm{Fe}\left(\mathrm{N}_{4} \mathrm{Tol}_{2}\right)$.

\begin{tabular}{cccc}
\hline & $\left({ }^{\mathrm{Mes} P D P}{ }^{\mathrm{Ph}}\right) \mathrm{Fe}\left(\mathrm{N}_{4} \mathrm{Tol}_{2}\right)$ & $\left(\mathrm{NH}^{1} \mathrm{Ad}-{ }^{\mathrm{Mes}} \mathrm{PDP}^{\mathrm{Ph}}\right) \mathrm{Fe}(\mathrm{thf})$ \\
\hline $\mathrm{Fe}(1)-\mathrm{N}(1)$ & $1.946(3)$ & $\mathrm{Fe}(1)-\mathrm{N}(1)$ & $2.092(2)$ \\
$\mathrm{Fe}(1)-\mathrm{N}(2)$ & $1.943(3)$ & $\mathrm{Fe}(1)-\mathrm{N}(2)$ & $2.130(2)$ \\
$\mathrm{Fe}(1)-\mathrm{N}(3)$ & $1.955(3)$ & $\mathrm{Fe}(1)-\mathrm{N}(3)$ & $2.128(2)$ \\
$\mathrm{Fe}(1)-\mathrm{N}(4)$ & $1.867(3)$ & $\mathrm{Fe}(1)-\mathrm{N}(4)$ & $2.240(2)$ \\
$\mathrm{Fe}(1)-\mathrm{N}(7)$ & $1.803(3)$ & $\mathrm{Fe}(1)-\mathrm{O} 1$ & $2.144(2)$ \\
$\mathrm{N}(4)-\mathrm{N}(5)$ & $1.299(4)$ & $\mathrm{N}(1)-\mathrm{Fe}(1)-\mathrm{N}(2)$ & $75.10(6)$ \\
$\mathrm{N}(5)-\mathrm{N}(6)$ & $1.336(4)$ & $\mathrm{N}(1)-\mathrm{Fe}(1)-\mathrm{N}(3)$ & $147.17(7)$ \\
$\mathrm{N}(6)-\mathrm{N}(7)$ & $1.318(4)$ & $\mathrm{N}(2)-\mathrm{Fe}(1)-\mathrm{N}(3)$ & $76.26(6)$ \\
$\mathrm{N}(1)-\mathrm{Fe}(1)-\mathrm{N}(2)$ & $79.87(11)$ & $\mathrm{N}(2)-\mathrm{Fe}(1)-\mathrm{N}(4)$ & $118.46(7)$ \\
$\mathrm{N}(1)-\mathrm{Fe}(1)-\mathrm{N}(3)$ & $153.02(11)$ & $\mathrm{N}(2)-\mathrm{Fe}(1)-\mathrm{O}(1)$ & $149.61(6)$ \\
$\mathrm{N}(2)-\mathrm{Fe}(1)-\mathrm{N}(3)$ & $79.80(11)$ & $\mathrm{N}(4)-\mathrm{Fe}(1)-\mathrm{O}(1)$ & $91.04(6)$ \\
$\mathrm{N}(2)-\mathrm{Fe}(1)-\mathrm{N}(4)$ & $174.94(12)$ & - & - \\
$\mathrm{N}(2)-\mathrm{Fe}(1)-\mathrm{N}(7)$ & $96.34(12)$ & - & - \\
$\mathrm{N}(4)-\mathrm{Fe}(1)-\mathrm{N}(7)$ & $78.75(12)$ & - & - \\
\hline & & & - \\
\hline
\end{tabular}




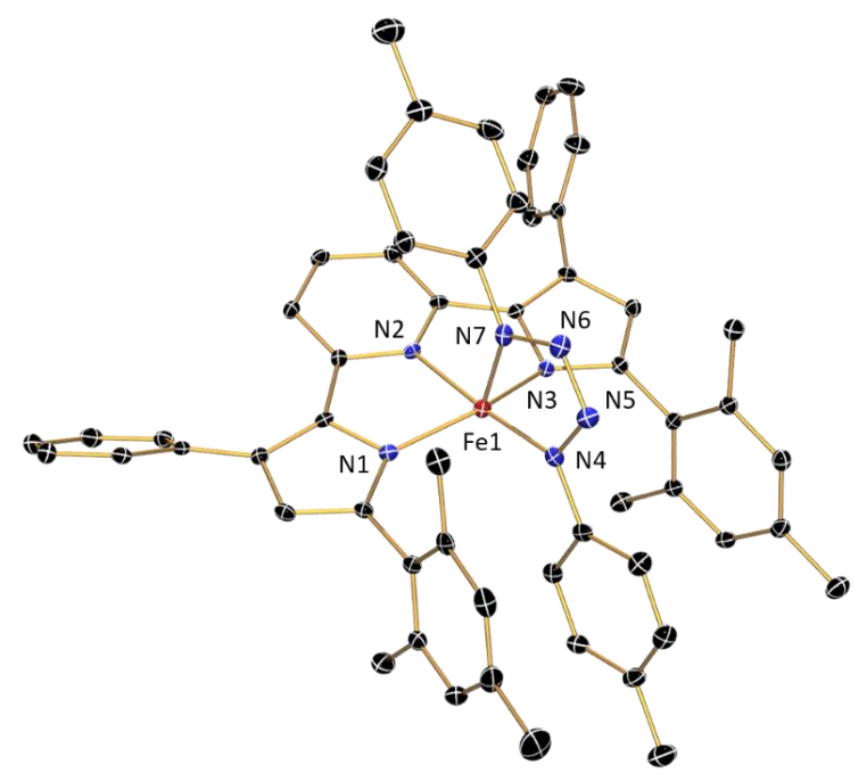

Figure 3.7. ORTEP of $\left({ }^{\mathrm{Mes}} \mathrm{PDP}^{\mathrm{Ph}}\right) \mathrm{Fe}\left(\mathrm{N}_{4} \mathrm{Tol}_{2}\right)$ displayed at $30 \%$ probability ellipsoids. Hydrogen atoms and cocrystallized solvent molecules have been excluded for clarity.

However, due to the well-established redox activity of tetrazene ligands, a broader analysis of the structural features is necessary to establish the oxidation states of the iron center and the $\mathrm{N}_{4} \mathrm{Tol}_{2}$ fragment. Several studies have shown that the redox state of tetrazene ligands can be determined via inspection of the $\mathrm{N}-\mathrm{N}$ bond lengths in the $\mathrm{MN}_{4}$ chelate ring. ${ }^{63}$ For $\left({ }^{\mathrm{Mes}} \mathrm{PDP}^{\mathrm{Ph}}\right) \mathrm{Fe}\left(\mathrm{N}_{4} \mathrm{Tol}_{2}\right)$, the $\mathrm{N}-\mathrm{N}$ distances within the iron tetrazene unit (N(4)- $\mathrm{N}(5)$ 1.299(4) $\AA$, $\mathrm{N}(5)-\mathrm{N}(6) 1.336(4) \AA, \mathrm{N}(6)-\mathrm{N}(7) 1.318(4) \AA$ ) are most consistent with a tetrazene radical anion and infer an oxidation state of + III for the iron center. Antiferromagnetic coupling between the ligand radical $\left(\mathrm{S}_{\mathrm{L}}=1 / 2\right)$ and a low-spin ferric ion $\left(\mathrm{d}^{5}, \mathrm{~S}_{\mathrm{Fe}}=1 / 2\right)$ gives rise to the overall $\mathrm{S}=0$ ground state. The Mössbauer parameters for $\left({ }^{\mathrm{Mes}} \mathrm{PDP}^{\mathrm{Ph}}\right) \mathrm{Fe}\left(\mathrm{N}_{4} \mathrm{Tol}_{2}\right)$ of $\delta=0.12 \mathrm{~mm} \mathrm{~s}^{-1}$ and $\left|\Delta \mathrm{E}_{\mathrm{Q}}\right|$ $=3.12 \mathrm{~mm} \mathrm{~s}^{-1}$ are also consistent with a low-spin Fe ${ }^{\mathrm{III}}$ center (Figure 3.8). 


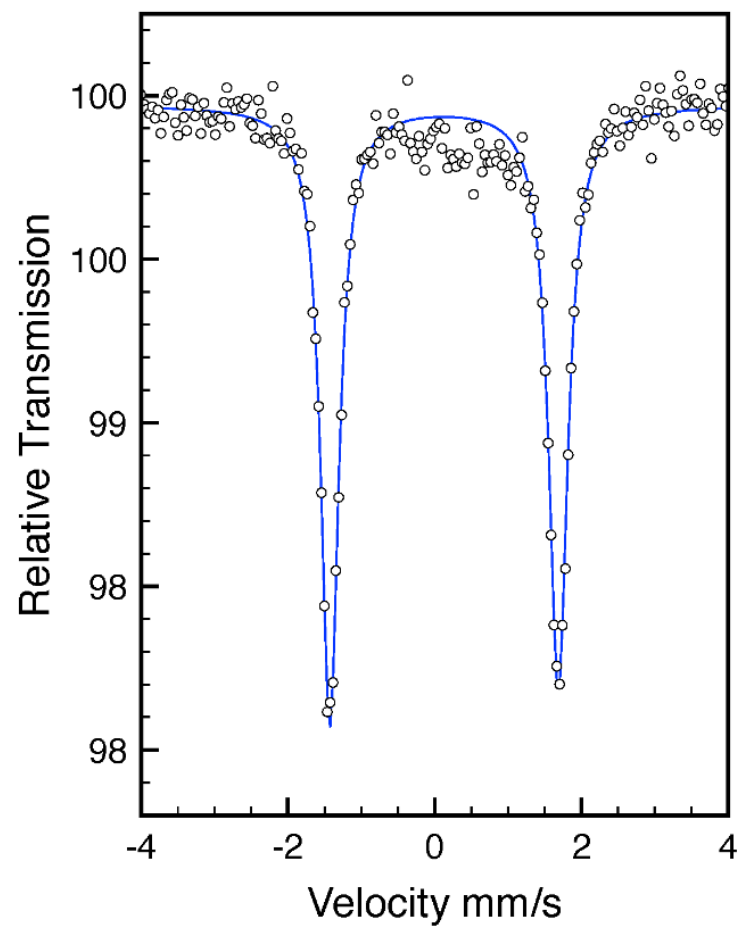

Figure 3.8. Zero-field Mössbauer spectrum of $\left({ }^{\mathrm{Mes}} \mathrm{PDP}^{\mathrm{Ph}}\right) \mathrm{Fe}\left(\mathrm{N}_{4} \mathrm{Tol}_{2}\right)$ acquired at $80 \mathrm{~K}$. The white circles indicate the experimental data and the blue line corresponds to the fit.

While the observed isomer shift would be unusually high for an alternative assignment as a lowspin $\mathrm{Fe}^{\mathrm{IV}}$ complex with a dianionic tetrazene ligand, the large quadrupole splitting is inconsistent with a low-spin $\mathrm{Fe}^{\mathrm{II}}$ configuration with a neutral tetrazene fragment. For the latter electronic configuration, a nearly isotropic electric field gradient and a resulting small quadrupole splitting are expected due to three doubly filled $\mathrm{d}$ orbitals $\left(\mathrm{d}_{x z}, \mathrm{~d}_{y z}, \mathrm{~d}_{x y}\right)$ for the low-spin $\mathrm{d}^{6}$ ion under the influence of a square-pyramidal ligand field. Further evidence for an unusual electronic structure was obtained from NMR spectroscopy. The ${ }^{1} \mathrm{H}$ NMR spectrum of $\left({ }^{\mathrm{Mes}} \mathrm{PDP}^{\mathrm{Ph}}\right) \mathrm{Fe}\left(\mathrm{N}_{4} \mathrm{Tol}_{2}\right)$ exhibits 12 resonances consistent with $\mathrm{C}_{2 v}$ symmetry in solution on the NMR time scale (Figure 3.9). Whereas, in the solid-state the structure exhibits approximate $\mathrm{C}_{s}$ symmetry, the wagging motion of the tetrazene ligand renders the top and bottom faces of the PDP ligand and the two tolyl substituents of the tetrazene ligand equivalent, thus affording a higher effective symmetry in 
solution. Variable-temperature NMR (VT-NMR) data collected over a range of -90 to $90{ }^{\circ} \mathrm{C}$ in toluene- $d_{8}$ (Figure 3.10) indicate that the energy barrier for this dynamic process is too low to observe discrete $\mathrm{C}_{s}$ symmetric isomers while maintaining fluid toluene solution. However, significant broadening of the resonances assigned to the protons of the tolyl and mesityl groups at $-90{ }^{\circ} \mathrm{C}$ suggests that the sample is close to the decoalescence temperature of two $\mathrm{C}_{s^{-}}$ symmetric conformations. More importantly, and relevant to the electronic structure assignment, the chemical shifts of several resonances are highly sensitive to changes in temperature.

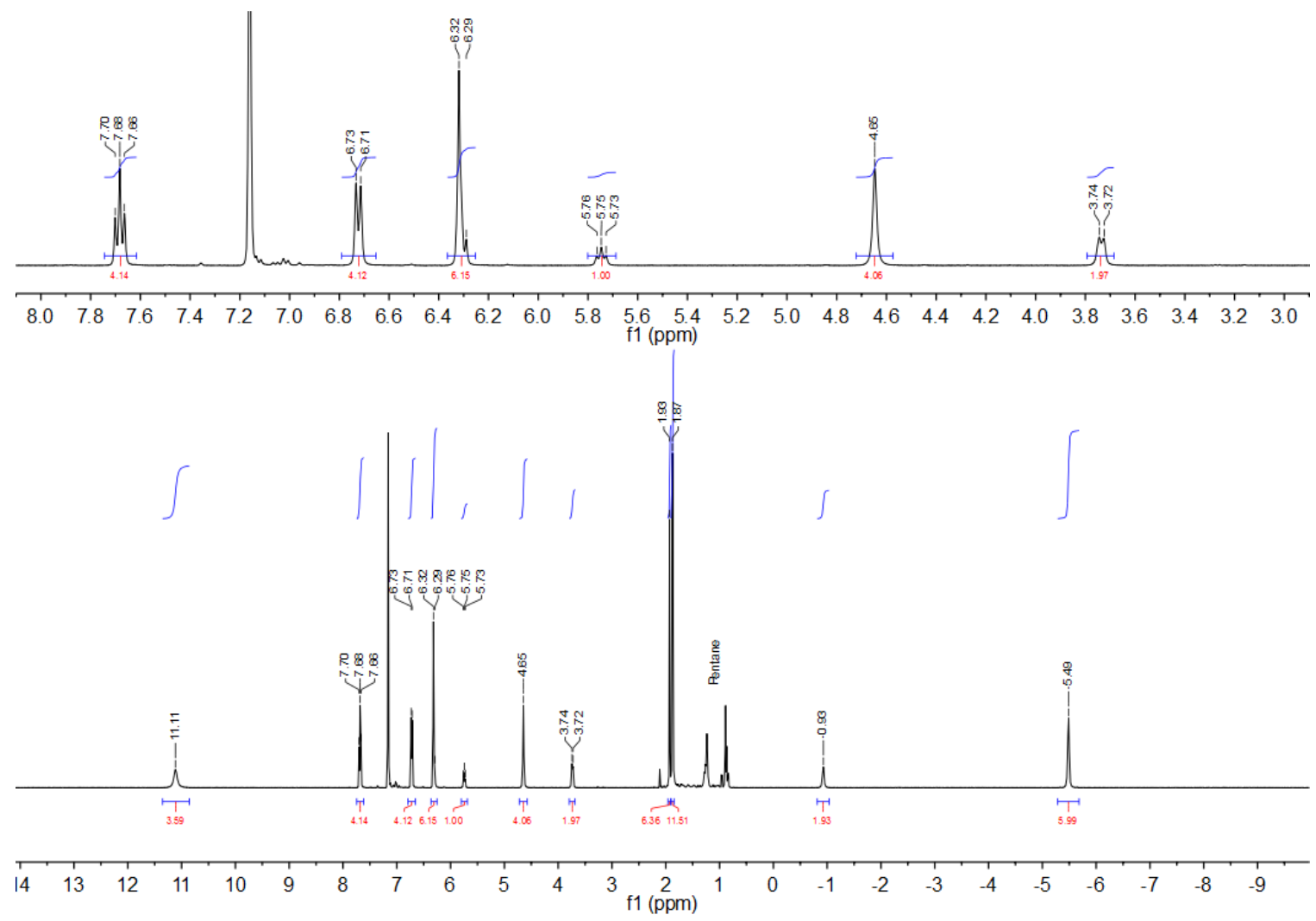

Figure 3.9. ${ }^{1} \mathrm{H} \mathrm{NMR}$ spectra of $\left({ }^{\mathrm{Mes}} \mathrm{PDP}{ }^{\mathrm{Ph}}\right) \mathrm{Fe}\left(\mathrm{N}_{4} \mathrm{Tol}_{2}\right)$ at $400 \mathrm{MHz}$ in benzene- $d_{6}$. 


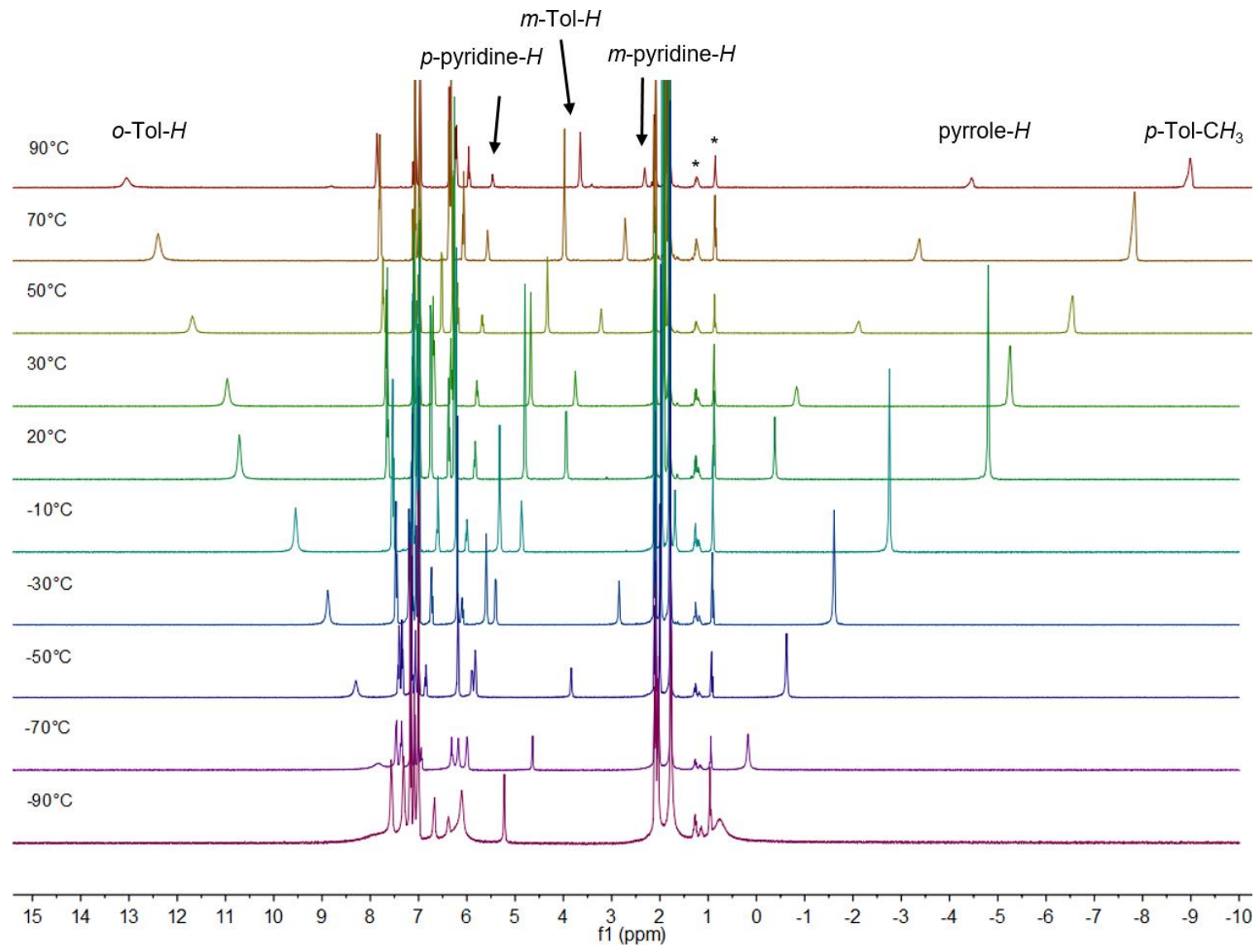

Figure 3.10. Variable temperature ${ }^{1} \mathrm{H}$ NMR spectra of $\left({ }^{\mathrm{Mes}} \mathrm{PDP}^{\mathrm{Ph}}\right) \mathrm{Fe}\left(\mathrm{N}_{4} \mathrm{Tol}_{2}\right)$ at $400 \mathrm{MHz}$ in toluene- $d_{8}$. Resonances marked by an asterisk are due to small amounts of pentane in the sample.

The most striking temperature-dependent shifts are observed for resonances associated with the protons of the tetrazene moiety, the 3-pyridine protons, and the pyrrole protons. This behavior is consistent with thermal population of paramagnetic excited states. However, the persistence of clearly resolved $J$ couplings for the proton resonances of the phenyl substituents and the 4pyridine proton suggests only minor contributions from the paramagnetic state(s) even at the highest experimentally probed temperature of $90{ }^{\circ} \mathrm{C}$.

Broken-symmetry DFT computational studies were conducted to complement the experimental electronic structure assignment for $\left({ }^{\mathrm{Mes}} \mathrm{PDP}^{\mathrm{Ph}}\right) \mathrm{Fe}\left(\mathrm{N}_{4} \mathrm{Tol}_{2}\right)$. Within the broken symmetry formalism, the notation $\mathrm{BS}(m, n)$ describes a state with $\mathrm{m}$ unpaired spin-up electrons 
and $\mathrm{n}$ unpaired spin-down electrons localized on separate fragments of the molecule. Several computational models were tested in full molecule geometry optimizations at the B3LYP level of theory to account for possible electronic structures of the diamagnetic ground state and potentially low-lying paramagnetic excited states. A comparison of the computed structural parameters can be found in Table 3.3. For the ground state, a BS(1,1) approach was employed to provide an open-shell singlet configuration with a tetrazene radical anion antiferromagnetically coupled to a low-spin ferric ion, and a restricted Kohn- Sham (RKS) approach was used to enforce an alternative closed-shell singlet configuration describing either a low-spin $\mathrm{Fe}^{\mathrm{II}}$ complex with a neutral tetrazene ligand or a low-spin $\mathrm{Fe}^{\mathrm{IV}}$ species with a dianionic tetrazene unit. Both formalisms yielded optimized structures that are in excellent agreement with the experimental data from crystallography and reproduced the Mössbauer parameters within generally accepted computational accuracy (Table 3.3). ${ }^{64}$ Therefore, neither solution can be excluded based on structural or spectroscopic arguments. A comparison of the obtained total energies showed that the $\mathrm{BS}(1,1)$ solution is only $1.9 \mathrm{kcal} / \mathrm{mol}$ more stable than the RKS solution. The modest energy lowering induced by symmetry breaking reflects singlet diradical character for $\left({ }^{\mathrm{Mes}} \mathrm{PDP}{ }^{\mathrm{Ph}}\right) \mathrm{Fe}\left(\mathrm{N}_{4} \mathrm{Tol}_{2}\right)$, albeit lower than in many previously reported open-shell singlet systems. ${ }^{65}$ This is also apparent from the relatively large spatial overlap between the magnetic orbitals of $S=0.70$. As a result, the spin density values on iron and the tetrazene moiety deviate significantly from the idealized values of one unpaired electron for each fragment (Figure 3.11). To investigate the nature of potentially low-lying paramagnetic states, calculations were performed assuming triplet and quintet configurations. For $\mathrm{S}=1$ states, a $\mathrm{BS}(3,1)$ approach and a simple unrestricted Kohn-Sham (UKS3) calculation converged to identical brokensymmetry solutions representing an intermediate-spin $\mathrm{Fe}^{\mathrm{III}}$ center antiferromagnetically coupled 
to a tetrazene radical anion $(\mathrm{BS}(3,1))$. Surprisingly, this broken-symmetry triplet state was found to be $6.6 \mathrm{kcal} / \mathrm{mol}$ lower in energy than the open-shell singlet $\mathrm{BS}(1,1)$ state. However, the computed structural parameters for the $\mathrm{BS}(3,1)$ solution are inconsistent with the experimentally observed values for $\left({ }^{\mathrm{Mes}} \mathrm{PDP}{ }^{\mathrm{Ph}}\right) \mathrm{Fe}\left(\mathrm{N}_{4} \mathrm{Tol}_{2}\right)$. Most notably, the $\mathrm{Fe}-\mathrm{N}$ bond to the apical nitrogen donor of the tetrazene unit $(\mathrm{Fe}(1)-\mathrm{N}(7): 2.121 \AA$ ) is significantly elongated, reflecting occupation of the $\sigma$-antibonding $\mathrm{d}_{\mathrm{z}^{2}}$ orbital in an intermediate-spin $\mathrm{Fe}^{\mathrm{III}}$ configuration. Providing further evidence that the $\mathrm{BS}(3,1)$ solution does not represent the ground state of $\left({ }^{\mathrm{Mes}} \mathrm{PDP}{ }^{\mathrm{Ph}}\right) \mathrm{Fe}\left(\mathrm{N}_{4} \mathrm{Tol}_{2}\right)$, the calculated Mössbauer isomer shift deviates substantially from the experimentally observed values (Table 3.3). Additionally, two distinct $\mathrm{S}=2$ states were located at moderately higher energies than the triplet configuration but slightly below the computed energy of the diamagnetic $\mathrm{BS}(1,1)$ state. $\mathrm{A} B S(5,1)$ configuration representing a high spin $\mathrm{Fe}^{\mathrm{III}}$ ion antiferromagnetically coupled to a tetrazene radical anion was found to be only $2.9 \mathrm{kcal} / \mathrm{mol}$ above the BS $(3,1)$ solution. Using a UKS5 approach, a different quintet state corresponding to an intermediate-spin $\mathrm{Fe}^{\mathrm{III}}$ center ferromagnetically coupled to a tetrazene radical was identified at $6.4 \mathrm{kcal} / \mathrm{mol}$ above the lowest energy $\mathrm{BS}(3,1)$ solution. As is the case for the $\mathrm{BS}(3,1)$ solution, the calculated geometries and Mössbauer parameters for the quintet configurations are inconsistent with the experimental data. These computational studies highlight that the reliable prediction of accurate spin state energetics remains a substantial challenge for DFT methods and often requires higher levels of theory that are beyond the scope of this work. For hybrid functionals such as B3LYP, the relative energies of different spin states depend strongly on the admixed fraction of exact Hartree-Fock exchange and an overestimation of the stability of higher spin states is typical for molecules with low-lying high-spin states or spin-crossover behavior. $^{66}$ 

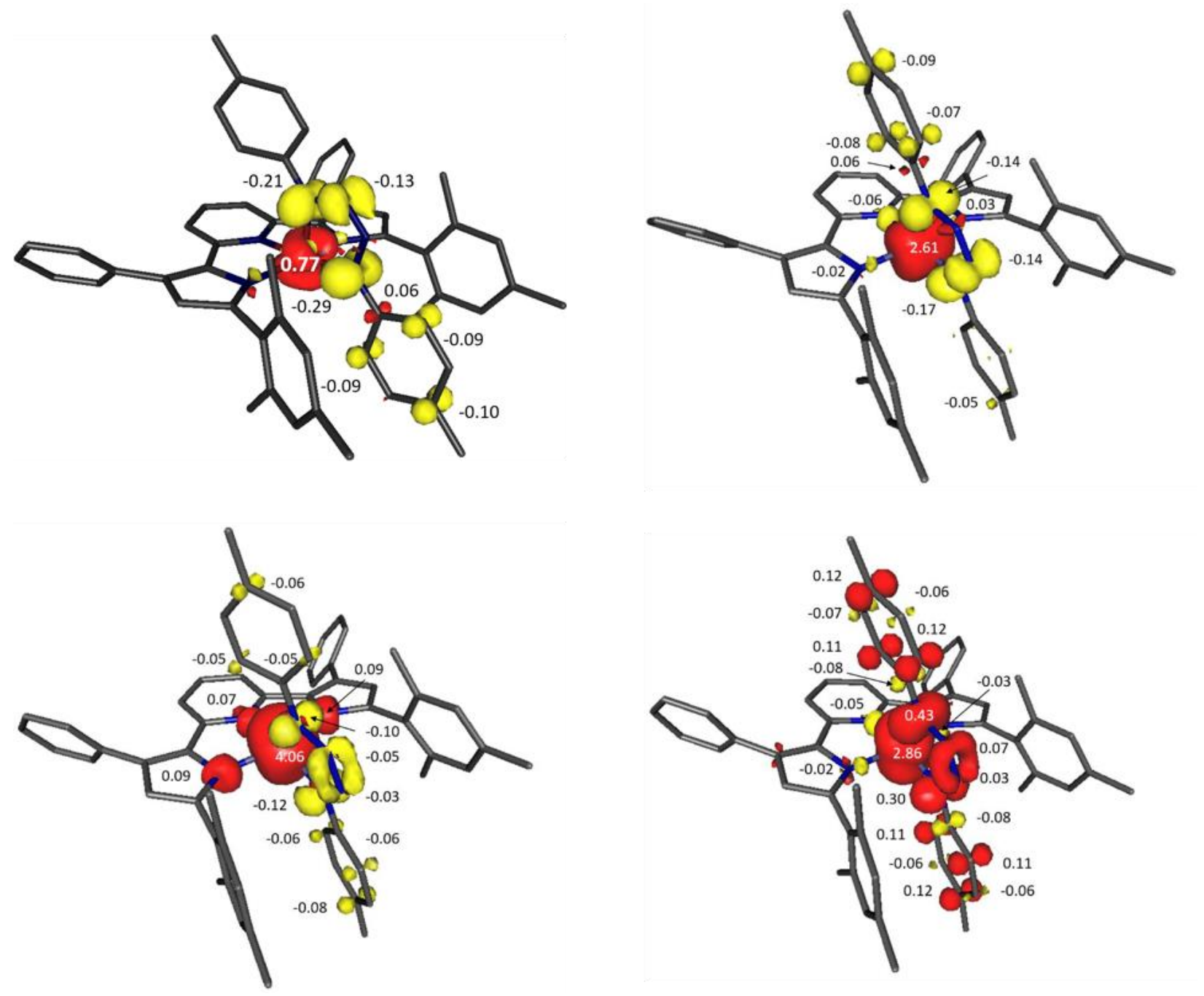

Figure 3.11. Spin density distributions obtained via Mulliken population analysis for $\left({ }^{\mathrm{Mes}} \mathrm{PDP}{ }^{\mathrm{Ph}}\right) \mathrm{Fe}\left(\mathrm{N}_{4} \mathrm{Tol}_{2}\right)$ using BS $(1,1)$ (top-left), BS(3,1) (top-right), BS(5,1) (bottom-left), and UKS5 (bottom-right) computational approaches. 
Table 3.3. Relative energies and calculated Mössbauer parameters from DFT calculations

\begin{tabular}{ccccc}
\hline & & $\Delta E /$ cal mol $^{1}$ & $\delta / \mathrm{mms}^{-1}$ & $\left|\Delta E_{Q}\right| / \mathrm{mms}^{-1}$ \\
\hline$S=0$ & RKS & 8.5 & 0.14 & -3.16 \\
& $\mathrm{BS}(1,1)$ & 6.6 & 0.16 & -3.23 \\
$S=1$ & $\mathrm{BS}(3,1) / \mathrm{UKS} 3$ & 0 & 0.29 & 2.53 \\
& $\mathrm{BS}(5,1)$ & 2.9 & 0.43 & 2.91 \\
& UKS5 & 6.4 & 0.21 & 3.20 \\
\hline
\end{tabular}

Altogether, the experimental and computational characterization of $\left({ }^{\mathrm{Mes}} \mathrm{PDP}^{\mathrm{Ph}}\right) \mathrm{Fe}\left(\mathrm{N}_{4} \mathrm{Tol}_{2}\right)$ suggests that the ground state is best described as $\left({ }^{\mathrm{Mes}} \mathrm{PDP}^{\mathrm{Ph}}\right) \mathrm{Fe}^{\mathrm{III}}\left(\mathrm{N}_{4} \mathrm{Tol}_{2}{ }^{\cdot 1-}\right)$ with strong antiferromagnetic coupling between the tetrazene radical and the low-spin Fe ${ }^{\mathrm{III}}$ ion. Several lowlying paramagnetic states identified via computational analysis contain a Fe ${ }^{\mathrm{III}}$ ion in intermediate- or high-spin configurations and a tetrazene radical anion, indicating that the paramagnetic contributions observed by VT-NMR are due to spin state changes at the metal center. While an alternative ground state description of a closed-shell singlet composed of the two resonance structures $\left({ }^{\mathrm{Mes}} \mathrm{PDP}^{\mathrm{Ph}}\right) \mathrm{Fe}^{\mathrm{II}}\left(\mathrm{N}_{4} \mathrm{Tol}_{2}{ }^{0}\right) \leftrightarrow\left({ }^{\mathrm{Mes}} \mathrm{PDP}^{\mathrm{Ph}}\right) \mathrm{Fe}^{\mathrm{IV}}\left(\mathrm{N}_{4} \mathrm{Tol}_{2}{ }^{2-}\right)$ cannot be excluded by comparison with experimental data from Mössbauer spectroscopy and X-ray diffraction, the prevalence of a tetrazene radical anion next to an $\mathrm{Fe}^{\mathrm{III}}$ center in all identified excited states favors the open-shell singlet description. Based on a recent compilation of known iron tetrazene complexes by Groysman and co-workers,${ }^{54}$ the open shell singlet configuration with a low-spin ferric center of $\left({ }^{\mathrm{Mes}} \mathrm{PDP}^{\mathrm{Ph}}\right) \mathrm{Fe}\left(\mathrm{N}_{4} \mathrm{Tol}_{2}\right)$ is unique and expands the range of available electronic structures for this compound class. 


\subsection{Reactivity of $\left({ }^{\mathrm{Mes} P D P}{ }^{\mathrm{Ph}}\right) \mathrm{Fe}(\mathrm{L})\left(\mathrm{L}=\right.$ thf or $\left.\mathrm{Et}_{2} \mathrm{O}\right)$ with Benzyl Azide}

The divergent reactivity of $\mathrm{N}_{3}\left(\mathrm{p}\right.$-tolyl) and $\mathrm{N}_{3}{ }^{1} \mathrm{Ad}$ raised the question whether tetrazene formation versus $\mathrm{C}-\mathrm{H}$ amination, respectively, was due to the steric profiles or the electronic properties of the azide substituents. To address this question, benzyl azide, $\mathrm{N}_{3} \mathrm{Bn}$, was chosen as an example for an alkyl-substituted nitrene source with reduced steric bulk compared to $\mathrm{N}_{3}{ }^{1} \mathrm{Ad}$. Addition of 1 equivalent of $\mathrm{N}_{3} \mathrm{Bn}$ to $\left({ }^{\mathrm{Mes}} \mathrm{PDP} \mathrm{Ph}^{\mathrm{Ph}}\right) \mathrm{Fe}(\mathrm{thf})$ provided a mixture of two major products, one diamagnetic and one paramagnetic iron complex in addition to minor unidentified paramagnetic species. Conducting the reaction using excess $\mathrm{N}_{3} \mathrm{Bn}$ (three equivalents) resulted in complete consumption of the iron starting material and yielded the two new species in an approximate 1:1 ratio as determined by ${ }^{1} \mathrm{H}$ NMR spectroscopy (Scheme 3.4). Mössbauer spectroscopy performed on a sample of the crude reaction mixture after complete removal of all volatiles confirmed the presence of two iron complexes with clearly distinguishable quadrupole doublets (Figure 3.12). Simulation of the data confirmed the 1:1 ratio obtained via ${ }^{1} \mathrm{H}$ NMR spectroscopy and provided parameters of $\delta=0.93 \mathrm{~mm} \mathrm{~s}^{-1}$ and $\left|\Delta \mathrm{E}_{\mathrm{Q}}\right|=1.48 \mathrm{~mm} \mathrm{~s}^{-1}$, indicative of high-spin $\mathrm{Fe}^{\mathrm{II}}$, for product $\mathrm{A}$ and $\delta=0.15 \mathrm{~mm} \mathrm{~s}^{-1}$ and $\left|\Delta \mathrm{E}_{\mathrm{Q}}\right|=2.26 \mathrm{~mm} \mathrm{~s}^{-1}$, consistent with a low-spin configuration, for product B. 

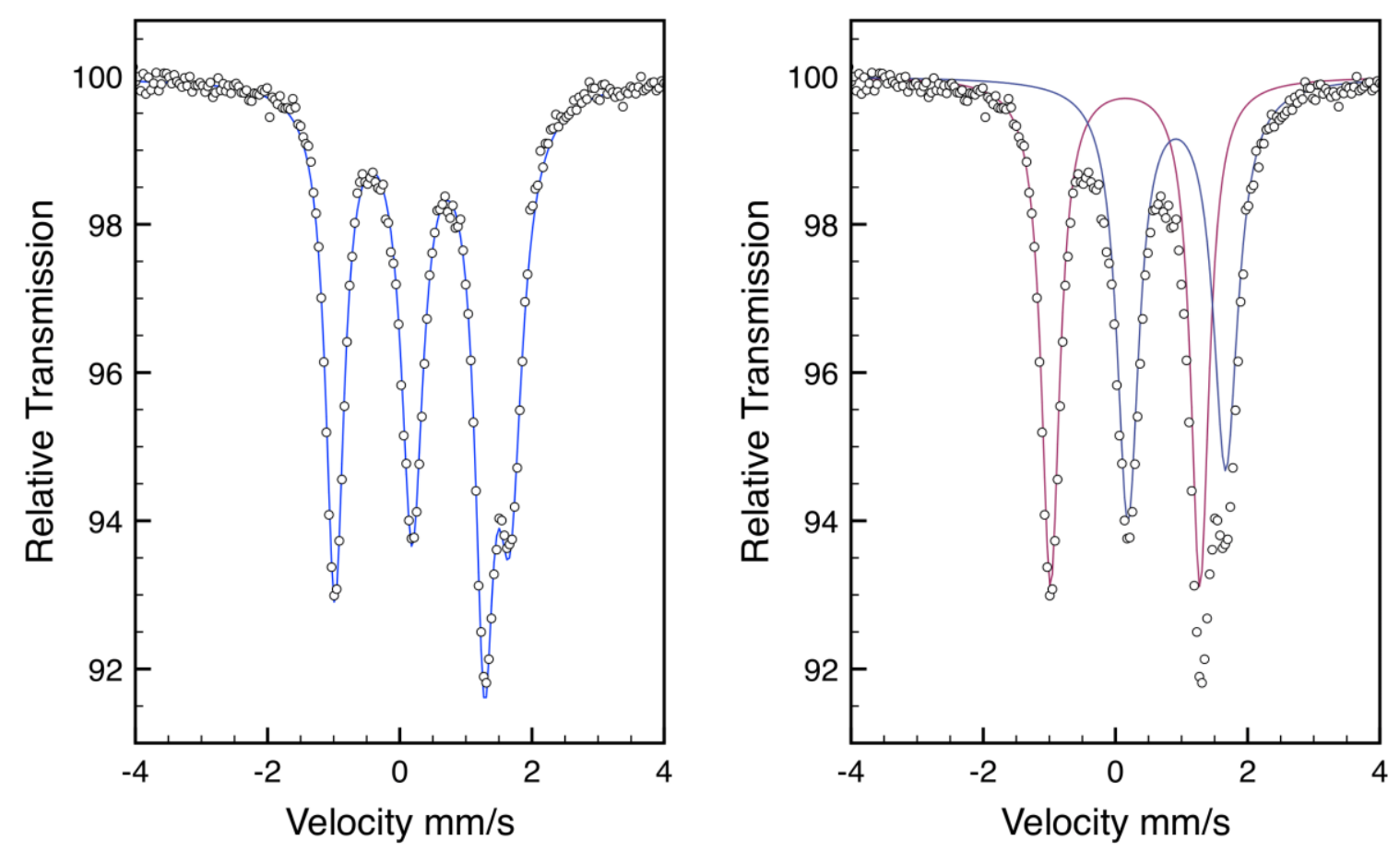

Figure 3.12. Zero-field Mössbauer spectra of $\mathrm{Fe}\left(\{\mathrm{NHBn}\}_{2^{-}}{ }^{\mathrm{Mes}} \mathrm{PDP}^{\mathrm{Ph}}\right)$ and $\left({ }^{\mathrm{Mes}} \mathrm{PDP}^{\mathrm{Ph}}\right) \mathrm{Fe}\left(\mathrm{N}_{4} \mathrm{Bn}_{2}\right)(\mathrm{HN}=\mathrm{CHPh})$ at $80 \mathrm{~K}$. For the composite spectrum (left), the white circles indicate the experimental data and the blue line corresponds to the fit. For the component spectrum (right), the white circles indicate experimental data and the purple and dark-blue lines are the fits for $\left({ }^{\mathrm{Mes}} \mathrm{PDP}^{\mathrm{Ph}}\right) \mathrm{Fe}\left(\mathrm{N}_{4} \mathrm{Bn} 2\right)(\mathrm{HN}=\mathrm{CHPh})$ and $\mathrm{Fe}\left(\{\mathrm{NHBn}\}_{2^{-}}{ }^{\mathrm{Mes}} \mathrm{PDP}^{\mathrm{Ph}}\right)$, respectively.

Despite our best efforts, a reliable separation of these two compounds on a preparative scale has so far been unsuccessful. However, cooling a concentrated toluene/pentane solution of the mixture to $-35^{\circ} \mathrm{C}$ yielded single crystals suitable for X-ray analysis allowing the structural characterization of $\mathrm{Fe}\left(\{\mathrm{NHBn}\}_{2}{ }^{\mathrm{Mes}} \mathrm{PDP}^{\mathrm{Ph}}\right)$. A representation of the molecular structure is shown in Figure 3.13 and confirms double $\mathrm{C}-\mathrm{H}$ amination of the ${ }^{\mathrm{Mes}} \mathrm{PDP}^{\mathrm{Ph}}$ ligand via nitrene insertion into one methyl group of each mesityl substituent. 


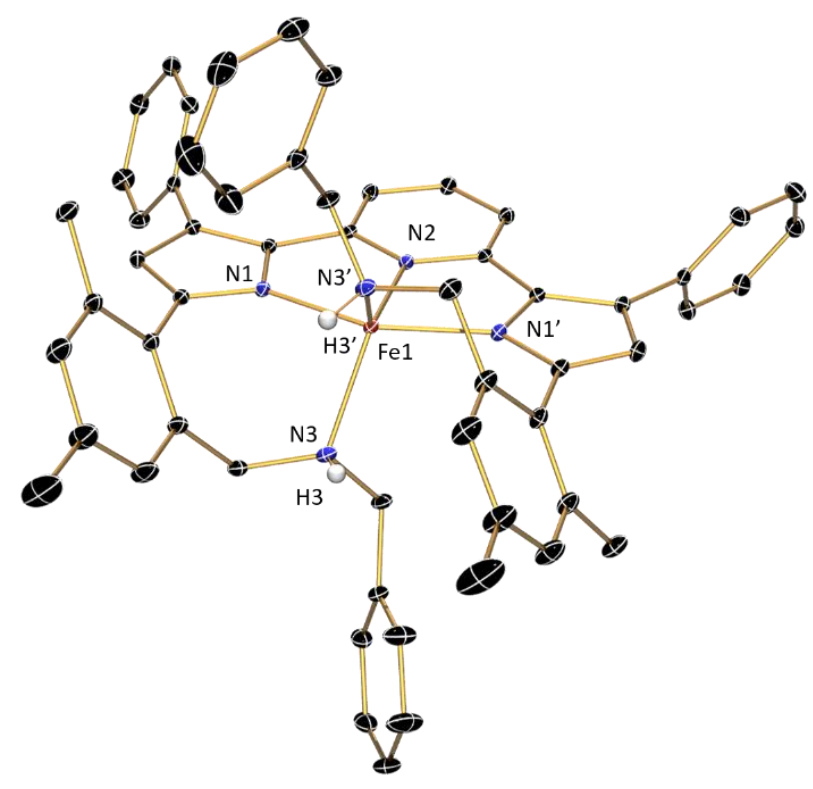

Figure 3.13. ORTEP of $\mathrm{Fe}\left(\{\mathrm{NHBn}\}_{2_{2}}{ }^{\mathrm{Mes}} \mathrm{PDP}^{\mathrm{Ph}}\right)_{2}$ displayed at $30 \%$ probability ellipsoids. Hydrogen atoms (with exception of amine hydrogens) and co-crystallized solvent molecules have been excluded for clarity.

The newly generated pendent amines are coordinated to the iron center and in combination with the PDP pincer enforce a distorted trigonal-bipyramidal ligand environment. Taking into account the dianionic charge of the newly formed $\left(\{\mathrm{NHBn}\}_{2^{-}}{ }^{\mathrm{Mes}} \mathrm{PDP} \mathrm{Ph}^{\mathrm{P}}\right)^{2-}$ ligand and the long $\mathrm{Fe}-\mathrm{N}$ bond lengths (Table 3.4), the iron center is in a high-spin ferrous configuration consistent with component A observed by Mössbauer spectroscopy. Analysis of the remaining crystals by ${ }^{1} \mathrm{H}$ NMR spectroscopy confirmed that $\mathrm{Fe}\left(\{\mathrm{NHBn}\}_{2^{-}}{ }^{\mathrm{Mes}} \mathrm{PDP} P{ }^{\mathrm{Ph}}\right)$ is indeed the paramagnetic product observed in the reaction, as evidenced by the symmetric and paramagnetically shifted resonances. A second recrystallization via slow diffusion of pentane into a toluene solution of the crude reaction mixture yielded single crystals of the diamagnetic component B identified as $\left({ }^{\mathrm{Mes}} \mathrm{PDP}{ }^{\mathrm{Ph}}\right) \mathrm{Fe}\left(\mathrm{N}_{4} \mathrm{Bn}_{2}\right)(\mathrm{HN}=\mathrm{CHPh})$ (Figure 3.14). The low-spin configuration of the central $\mathrm{Fe}$ ion is supported by short $\mathrm{Fe}-\mathrm{N}$ bond distances to the PDP pincer ligand (Table 3.4). The $\mathrm{N}-\mathrm{N}$ distances in the tetrazene fragment are consistent with the fully oxidized, neutral form of the ligand with short bond lengths between the terminal and internal 
nitrogen atoms $(\mathrm{N}(4)-\mathrm{N}(5) 1.303(2) \AA$ and $\mathrm{N}(6)-\mathrm{N}(7)$ 1.302(2) $\AA$ ) and longer bond lengths between the internal nitrogen atoms $(\mathrm{N}(5)-\mathrm{N}(6) 1.350(2) \AA)$. The sixth coordination site in the distorted octahedral complex is occupied by a benzaldimine ligand, which is an isomer of benzyl nitrene. The short C(58)-N(8) bond length of 1.271(2) $\AA$ confirms the presence of a double bond, and the aldimine and the imine protons were located in the electron density map.

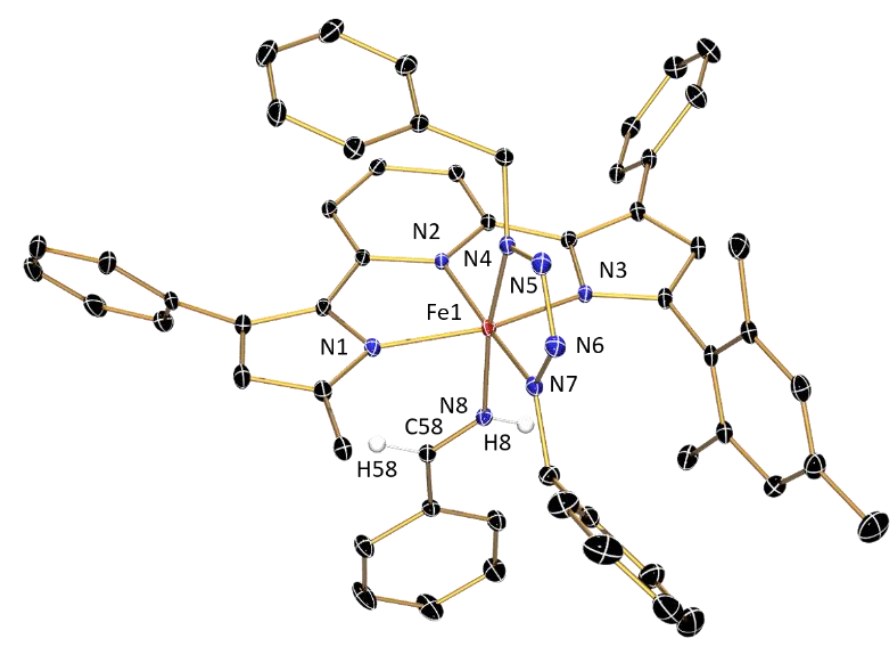

Figure 3.14. ORTEP of $\left({ }^{\mathrm{Mes}} \mathrm{PDP}^{\mathrm{Ph}}\right) \mathrm{Fe}\left(\mathrm{N}_{4} \mathrm{Bn}_{2}\right)(\mathrm{HN}=\mathrm{CHPh})$ displayed at $30 \%$ probability ellipsoids. Hydrogen atoms (with exception of imine $\mathrm{NH}$ and $\mathrm{CH}$ ), co-crystallized toluene, and a pyrrole mesityl substituent (with exception of the ipso carbon) have been excluded for clarity. 


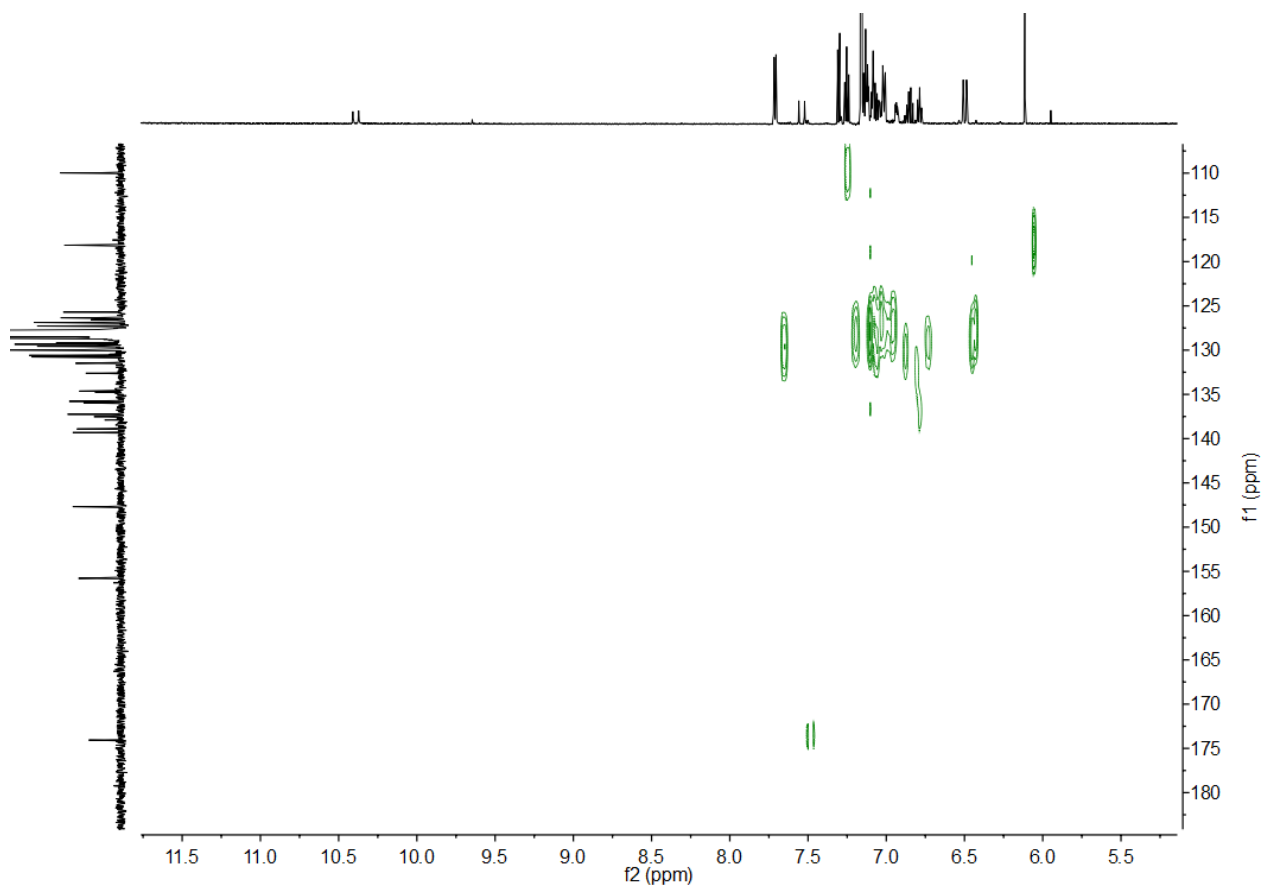

Figure 3.15. ${ }^{1} \mathrm{H}^{-13} \mathrm{C} \mathrm{HSQC}$ spectrum of $\left({ }^{\mathrm{Mes}} \mathrm{PDP}^{\mathrm{Ph}}\right) \mathrm{Fe}\left(\mathrm{N}_{4} \mathrm{Bn}_{2}\right)(\mathrm{HN}=\mathrm{CHPh})$ in benzene- $d_{6}$ indicating aldimine $\mathrm{C} H$ correlation.

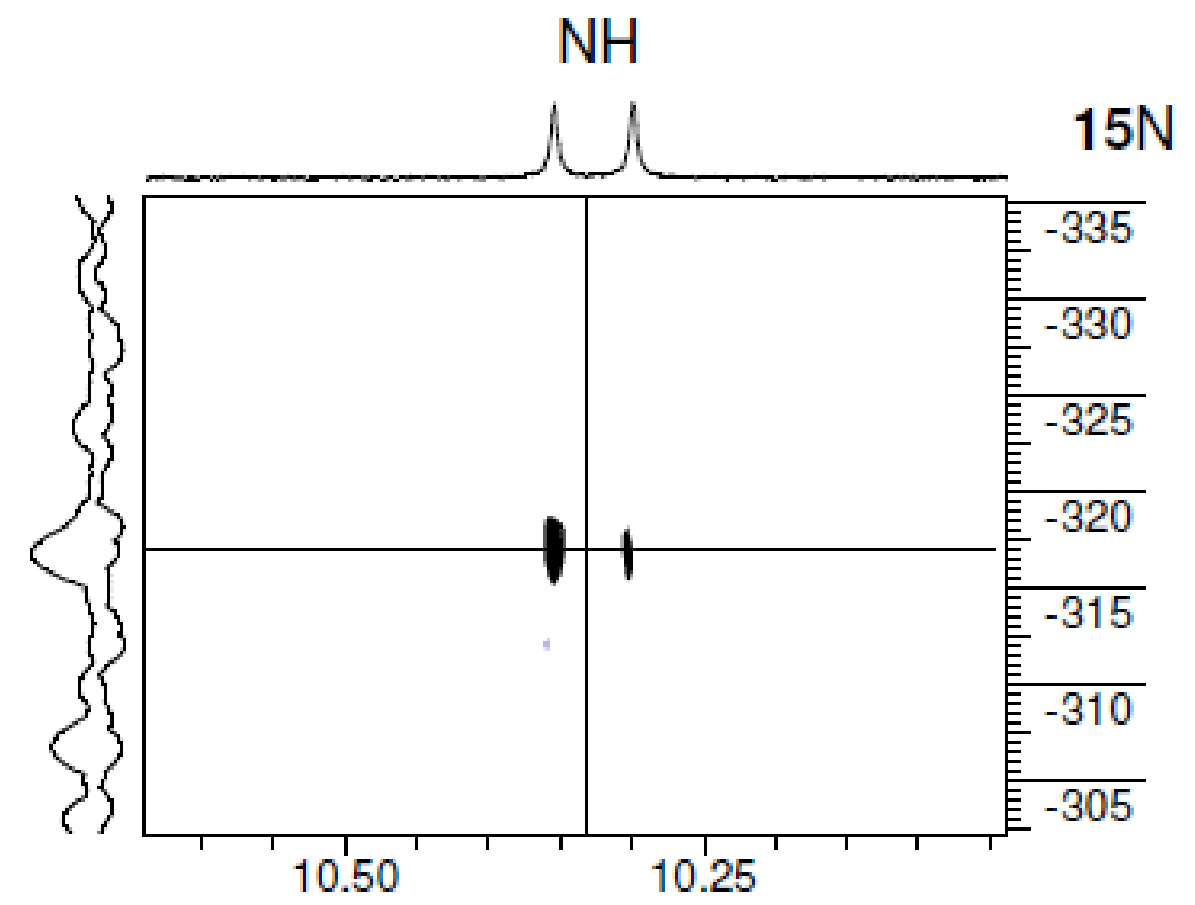

Figure 3.16. ${ }^{1} \mathrm{H}_{-}{ }^{15} \mathrm{~N}$ HSQC spectrum of $\left({ }^{\mathrm{Mes}} \mathrm{PDP}^{\mathrm{Ph}}\right) \mathrm{Fe}\left(\mathrm{N}_{4} \mathrm{Bn}_{2}\right)(\mathrm{HN}=\mathrm{CHPh})$ in benzene- $d_{6}$ indicating aldimine $\mathrm{N} H$ correlation. 


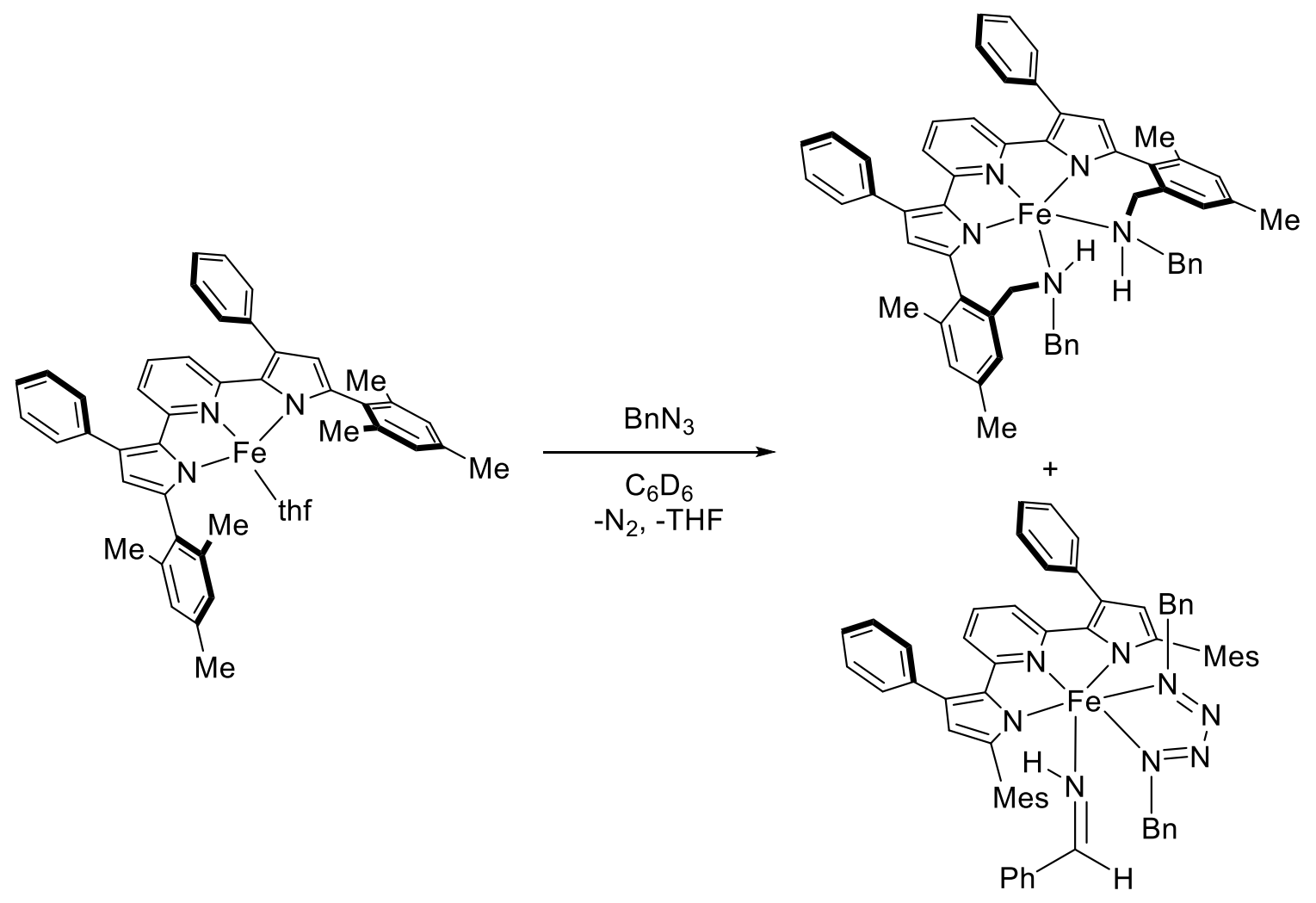

Scheme 3.4. Synthesis of $\mathrm{Fe}\left(\{\mathrm{NHBn}\}_{2^{-}}{ }^{\mathrm{Mes}} \mathrm{PDP}^{\mathrm{Ph}}\right)$ and $\left({ }^{\mathrm{Mes}} \mathrm{PDP}^{\mathrm{Ph}}\right) \mathrm{Fe}\left(\mathrm{N}_{4} \mathrm{Bn} n_{2}\right)(\mathrm{HN}=\mathrm{CHPh})$. Bn denotes benzyl and Mes denotes mesityl.

The presence of the imine ligand was also confirmed by ${ }^{1} \mathrm{H}$ NMR spectroscopy with diagnostic doublet resonances at $7.54 \mathrm{ppm}(\mathrm{HN}=\mathrm{C} H \mathrm{Ph})$ and $10.39 \mathrm{ppm}(H \mathrm{~N}=\mathrm{CHPh})$ featuring a large coupling constant of $22 \mathrm{~Hz}$. The structure was confirmed via a combination of 2D NMR experiments, including ${ }^{1} \mathrm{H}-{ }^{13} \mathrm{C}$ and ${ }^{1} \mathrm{H}-{ }^{15} \mathrm{~N}$ HSQC (Figures 3.15 and 3.16).

As a whole, the experimental data for $\left({ }^{\mathrm{Mes}} \mathrm{PDP}^{\mathrm{Ph}}\right) \mathrm{Fe}\left(\mathrm{N}_{4} \mathrm{Bn}_{2}\right)(\mathrm{HN}=\mathrm{CHPh})$ are consistent with an electronic structure containing a low-spin $\mathrm{Fe}^{\mathrm{II}}$ center, a neutral dibenzyl tetrazene unit, and a benzaldimine ligand. Crystallographically characterized N-protio imine complexes of transition metals are rare. However, examples for benzaldimine formation via reaction of benzyl azide with second and third row transition metals (Ru, Os, and Ir) have been reported. ${ }^{67-70}$ For these transformations, the mechanism of imine formation is proposed to proceed via metal 
nitrene formation by $\mathrm{N}_{2}$ extrusion followed by a 1,2-shift of a benzylic hydrogen atom. A similar mechanism was recently proposed by Betley and co-workers for reactions of iron and cobalt complexes with primary alkyl azides. ${ }^{59-71}$ However, no coordination of the resulting imine products to the metal center was observed in these cases. The only known crystallographically characterized example of a benzaldimine iron complex was reported by Chirik and co-workers. ${ }^{72}$ In their study, the complex $\left({ }^{\mathrm{iPr} P D I}\right) \mathrm{Fe}(\mathrm{NH}=\mathrm{CHPh})\left({ }^{\mathrm{iPr}} \mathrm{PDI}=2,6-\right.$ (2,6- $\left.\left.{ }^{\mathrm{i}} \mathrm{Pr}_{2}-\mathrm{C}_{6} \mathrm{H}_{3} \mathrm{~N}=\mathrm{CMe} 2\right)_{2} \mathrm{C}_{5} \mathrm{H}_{3} \mathrm{~N}\right)$ was derived in a bimolecular fashion from the reaction of phenyl diazomethane with $\left({ }^{i \mathrm{Pr}} \mathrm{PDI}\right) \mathrm{Fe}\left(\mathrm{N}_{2}\right)_{2}$. Despite a lack of clear mechanistic information, the two products observed in the reaction between $\left({ }^{\mathrm{Mes}} \mathrm{PDP}{ }^{\mathrm{Ph}}\right) \mathrm{Fe}(\mathrm{L})\left(\mathrm{L}=\mathrm{OEt}_{2}\right.$ or thf $)$ and $\mathrm{N}_{3} \mathrm{Bn}$ suggest three distinct pathways that are all consistent with a reactive iron imido/iminyl/nitrene intermediate: (a) intramolecular $\mathrm{C}-\mathrm{H}$ amination; (b) tetrazene formation likely to proceed via $[2+3]$-cycloaddition with a second equivalent of azide; and (c) aldimine formation via 1,2-shift in the presence of $\mathrm{C}-\mathrm{H}$ bonds in the $\alpha$-position to the nitrogen atom. 
Table 3.4. Selected bond lengths $(\AA)$ and angles $(\mathrm{deg})$ for $\mathrm{Fe}\left(\{\mathrm{NHBn}\}_{2^{-}}{ }^{\mathrm{Mes}} \mathrm{PDP} \mathrm{Ph}^{\mathrm{Ph}}\right)$ and $\left({ }^{\mathrm{Mes}} \mathrm{PDP}{ }^{\mathrm{Ph}}\right) \mathrm{Fe}\left(\mathrm{N}_{4} \mathrm{Bn}_{2}\right)(\mathrm{HN}=\mathrm{CHPh})$.

\begin{tabular}{|c|c|c|c|}
\hline & $\mathrm{Fe}\left(\{\mathrm{NHBn}\}_{2^{-}}{ }^{\mathrm{Mes}} \mathrm{PDP} \mathrm{Ph}^{\mathrm{Ph}}\right)^{a}$ & \multicolumn{2}{|c|}{$\left({ }^{\mathrm{Mes}} \mathrm{PDP}{ }^{\mathrm{Ph}}\right) \mathrm{Fe}\left(\mathrm{N}_{4} \mathrm{Bn}_{2}\right)(\mathrm{HN}=\mathrm{CHPh})$} \\
\hline $\mathrm{Fe}(1)-\mathrm{N}(1)$ & $2.064(1)$ & $\mathrm{Fe}(1)-\mathrm{N}(1)$ & $1.996(1)$ \\
\hline $\mathrm{Fe}(1)-\mathrm{N}(2)$ & $2.131(2)$ & $\mathrm{Fe}(1)-\mathrm{N}(2)$ & $1.938(1)$ \\
\hline $\mathrm{Fe}(1)-\mathrm{N}(3)$ & $2.191(1)$ & $\mathrm{Fe}(1)-\mathrm{N}(3)$ & $1.995(1)$ \\
\hline $\mathrm{N}(1)-\mathrm{Fe}(1)-\mathrm{N}(2)$ & $75.62(3)$ & $\mathrm{Fe}(1)-\mathrm{N}(4)$ & $1.848(1)$ \\
\hline $\mathrm{N}(1)-\mathrm{Fe}(1)-\mathrm{N}(1)$, & $151.23(6)$ & $\mathrm{Fe}(1)-\mathrm{N}(7)$ & $1.855(1)$ \\
\hline $\mathrm{N}(2)-\mathrm{Fe}(1)-(\mathrm{N} 3)$ & $131.20(3)$ & $\mathrm{Fe}(1)-\mathrm{N}(8)$ & $1.983(1)$ \\
\hline $\mathrm{N}(3)-\mathrm{Fe}(1)-\mathrm{N}(3)$, & $97.59(7)$ & $\mathrm{N}(4)-\mathrm{N}(5)$ & $1.303(2)$ \\
\hline- & - & $\mathrm{N}(5)-\mathrm{N}(6)$ & $1.350(2)$ \\
\hline- & - & $\mathrm{N}(6)-\mathrm{N}(7)$ & $1.302(2)$ \\
\hline- & - & $\mathrm{N}(8)-\mathrm{C}(58)$ & $1.271(2)$ \\
\hline- & - & $\mathrm{N}(1)-\mathrm{Fe}(1)-\mathrm{N}(2)$ & $80.85(6)$ \\
\hline- & - & $\mathrm{N}(1)-\mathrm{Fe}(1)-\mathrm{N}(3)$ & $160.11(6)$ \\
\hline- & - & $\mathrm{N}(2)-\mathrm{Fe}(1)-\mathrm{N}(3)$ & $79.88(5)$ \\
\hline- & - & $\mathrm{N}(2)-\mathrm{Fe}(1)-\mathrm{N}(7)$ & $174.00(6)$ \\
\hline- & - & $\mathrm{N}(4)-\mathrm{Fe}(1)-\mathrm{N}(8)$ & $172.46(6)$ \\
\hline
\end{tabular}

${ }^{a}$ The molecule lies on a crystallographic 2 -fold rotation axis that passes through $\mathrm{Fe}(1), \mathrm{N}(2)$, and $\mathrm{C}(7)$. Coordinates for the symmetry-related primed $\left({ }^{\prime}\right)$ atoms were generated via the symmetry relationship: $1-\mathrm{x}, \mathrm{y}, 0.5-\mathrm{z}$.

\subsection{Reactivity of $\left({ }^{\mathrm{Mes} P D P}{ }^{\mathrm{Ph}}\right) \mathrm{Fe}(\mathrm{thf})$ with Mesityl Azide}

The disparate reaction outcomes for $\left({ }^{\mathrm{Mes}} \mathrm{PDP}{ }^{\mathrm{Ph}}\right) \mathrm{Fe}($ thf $)$ with various organic azides suggested that careful tuning of the substitution of the azide used as the nitrene source may render intermediate $\left({ }^{\mathrm{Mes}} \mathrm{PDP}^{\mathrm{Ph}}\right) \mathrm{Fe}(\mathrm{NR})$ species isolable. Accordingly, a benzene- $d_{6}$ solution of $\left({ }^{\mathrm{Mes}} \mathrm{PDP}^{\mathrm{Ph}}\right) \mathrm{Fe}\left(\right.$ thf) was treated with one equivalent of bulky aryl azide, mesityl azide, $\mathrm{MesN}_{3}$. An 
immediate color change of the solution from dark-red to dark-brown was noted. ${ }^{1} \mathrm{H}$ NMR spectroscopy of the crude reaction mixture evidenced complete consumption of starting material and the formation of a new paramagnetic species featuring apparent $\mathrm{C}_{2 v}$ symmetry. 12 paramagnetically shifted and broadened resonances were observed spanning a range of -214.36 to $21.74 \mathrm{ppm}$, prompting tentative assignment of the species as either the azido adduct, $\left({ }^{\mathrm{Mes}} \mathrm{PDP}^{\mathrm{Ph}}\right) \mathrm{Fe}\left(\mathrm{N}_{3} \mathrm{Mes}\right)$, or the iron bound nitrene, $\left({ }^{\mathrm{Mes}} \mathrm{PDP}^{\mathrm{Ph}}\right) \mathrm{Fe}(\mathrm{NMes})$ (Scheme 3.5). Recently, Mindiola and coworkers have disclosed the synthesis and characterization of a related cobalt azido species, $\left({ }^{(\mathrm{Bu} u} \mathrm{PDP}^{\mathrm{tBu}}\right) \mathrm{Co}\left(\mathrm{N}_{3}{ }^{1} \mathrm{Ad}\right)$, via the reaction of $\left({ }^{\mathrm{tBu}} \mathrm{PDP}^{\mathrm{tBu}}\right) \mathrm{Co}\left(\mathrm{OEt}_{2}\right)$ and ${ }^{1} \mathrm{AdN}_{3} \cdot{ }^{61}$ This compound readily extrudes dinitrogen when irradiated to generate the fleeting nitrene intermediate $\left({ }^{(\mathrm{Bu}} \mathrm{PDP}^{\mathrm{tBu}}\right) \mathrm{Co}\left(\mathrm{N}^{1} \mathrm{Ad}\right)$, as evidenced by the clean intramolecular $\mathrm{C}-\mathrm{H}$ amination of a proximal tert-butyl group of the $\left({ }^{\mathrm{CBu}} \mathrm{PDP}^{\mathrm{tBu}}\right)$ supporting ligand, yielding $\mathrm{Co}\left(\mathrm{NH}^{1} \mathrm{Ad}_{-}{ }^{\mathrm{BBu}} \mathrm{PDP}^{\mathrm{tBu}}\right)$. In consideration of this result and the plausibility that a $\mathrm{C}_{2 v}$ symmetric ${ }^{1} \mathrm{H}$ NMR spectrum may be consistent with either $\left({ }^{\mathrm{Mes}} \mathrm{PDP}^{\mathrm{Ph}}\right) \mathrm{Fe}\left(\mathrm{N}_{3} \mathrm{Mes}\right)$ or $\left({ }^{\mathrm{Mes}} \mathrm{PDP}^{\mathrm{Ph}}\right) \mathrm{Fe}(\mathrm{NMes})$, an IR spectrum was acquired of the crude product in a $\mathrm{KBr}$ matrix. The resulting IR spectra is devoid of any feature consistent with an azido functionality, inconsistent with the assignment of the product as $\left({ }^{\mathrm{Mes}} \mathrm{PDP}^{\mathrm{Ph}}\right) \mathrm{Fe}\left(\mathrm{N}_{3} \mathrm{Mes}\right)$. 

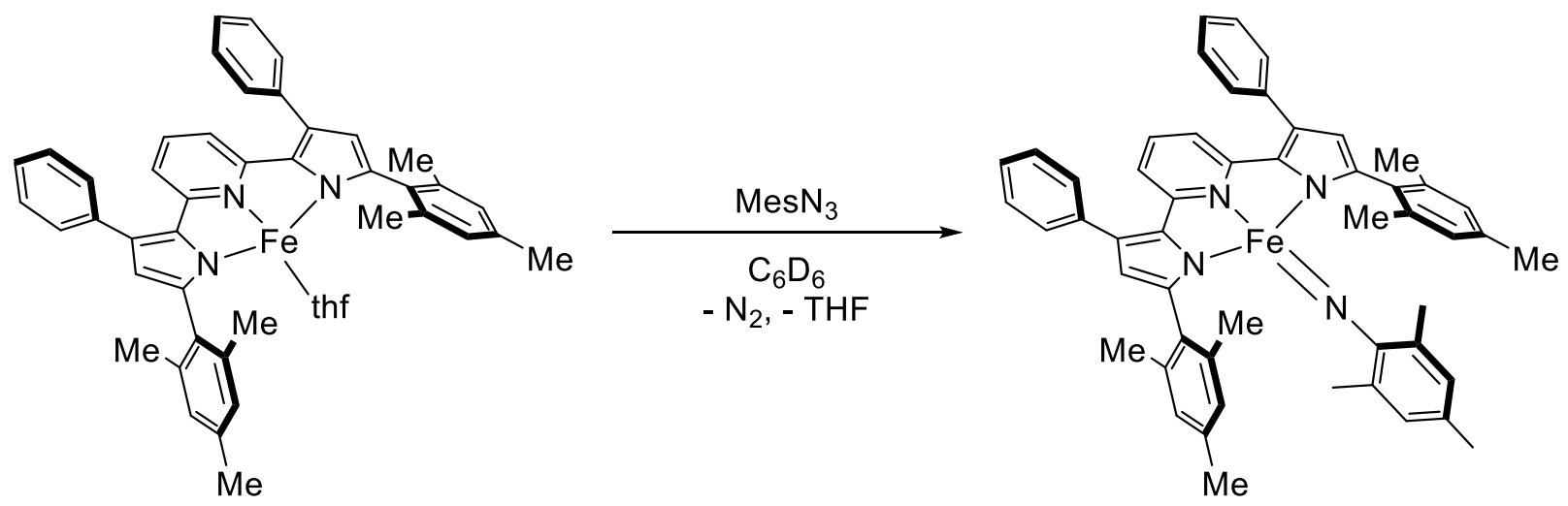

Scheme 3.5. Synthesis of ( ${ }^{\mathrm{Mes}} \mathrm{PDP} \mathrm{Ph}^{\mathrm{Ph}} \mathrm{Fe}(\mathrm{NMes})$.

Monitoring solutions of $\left({ }^{\mathrm{Mes}} \mathrm{PDP}^{\mathrm{Ph}}\right) \mathrm{Fe}(\mathrm{NMes})$ in benzene- $d_{6}$ over time demonstrated significant product decomposition to a new paramagnetic species, as discerned by ${ }^{1} \mathrm{H}$ NMR spectroscopy. Similarly, an aliquot of the preparative scale reaction mixture of ( $\left.{ }^{\mathrm{Mes}} \mathrm{PDP}{ }^{\mathrm{Ph}}\right) \mathrm{Fe}(\mathrm{thf})$ with $\mathrm{MesN}_{3}$ in benzene- $d_{6}$ was subjected to ${ }^{1} \mathrm{H}$ NMR analysis after 12 hours and demonstrated spectral features consistent with the presence of $\left({ }^{\mathrm{Mes}} \mathrm{PDP}{ }^{\mathrm{Ph}}\right) \mathrm{Fe}(\mathrm{NMes})$ and the unidentified paramagnetic species. Based on the number of paramagnetically shifted resonances, consistent with a $\mathrm{C} 1$ symmetric MesPDPPh ligand environment, this species was tentatively assigned as $\mathrm{Fe}\left(\mathrm{NHMes}^{\mathrm{Mes}}{ }^{\mathrm{PDP}} \mathrm{Ph}^{\mathrm{Ph}}\right)$, proposed to have arisen from the intramolecular $\mathrm{C}-\mathrm{H}$ amination of one mesityl group of the ${ }^{\mathrm{Mes}} \mathrm{PDP}^{\mathrm{Ph}}$ supporting ligand.

In an attempt to obtain structural characterization of $\left({ }^{\mathrm{Mes}} \mathrm{PDP} \mathrm{Ph}^{\mathrm{Ph}}\right) \mathrm{Fe}(\mathrm{NMes})$ or the decomposition product, pentane was diffused into a crude benzene- $d_{6}$ solution, resulting in the isolation of red crystals amenable to characterization via X-ray crystallography. The resulting structure allowed for the unambiguous identification of the crystalline material as $\mathrm{Fe}(\mathrm{NHMes}-$ ${ }^{\mathrm{Mes}} \mathrm{PDP}{ }^{\mathrm{Ph}}$ ) (Figure 3.17). This compound is anticipated to have resulted from intramolecular C-H amination of a benzylic C-H bond of the mesityl substituent of the ${ }^{\mathrm{Mes}} \mathrm{PDP}^{\mathrm{Ph}}$ chelate ligand, reactivity akin to that observed with ${ }^{1} \mathrm{AdN}_{3}$ and benzyl azide as the nitrene source (Scheme 3.6). 

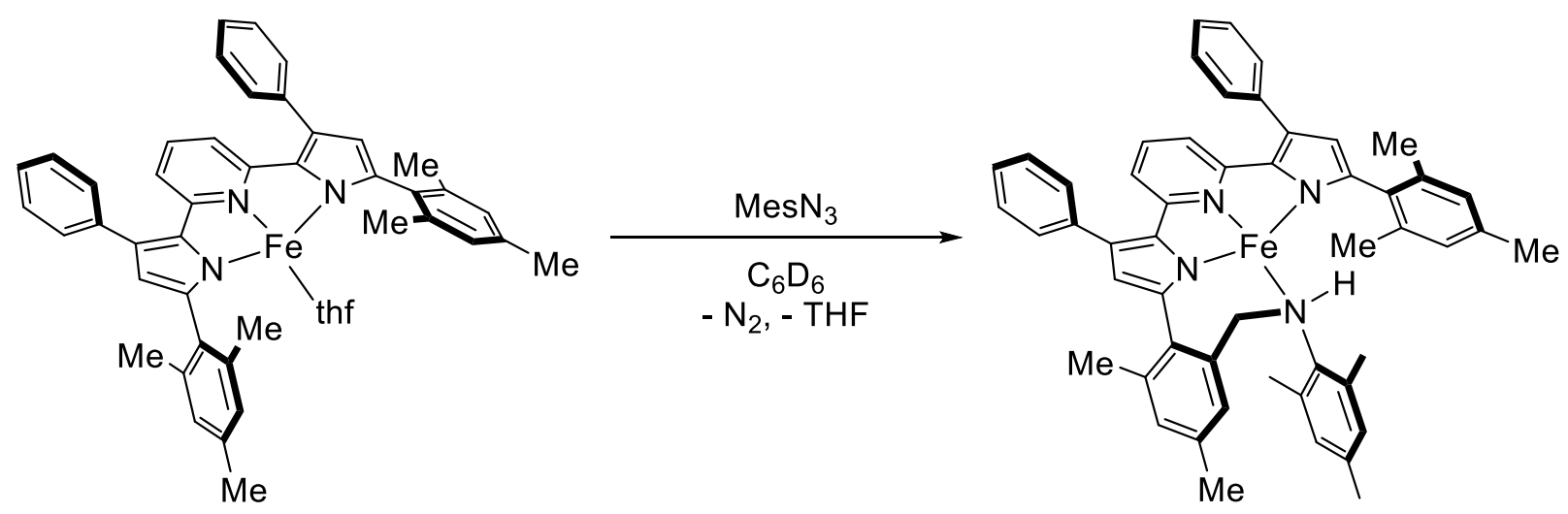

Scheme 3.6. Synthesis of Fe(NHMes- $\left.{ }^{\mathrm{Mes}} \mathrm{PDP}^{\mathrm{Ph}}\right)$ from $\left({ }^{\mathrm{Mes}} \mathrm{PDP}^{\mathrm{Ph}}\right) \mathrm{Fe}(\mathrm{NMes})$.

Fe(NHMes- $\left.{ }^{\mathrm{Mes}} \mathrm{PDP}^{\mathrm{Ph}}\right)$ crystallizes in the triclinic space group P-1 and the hydrogen of the newly formed amine moiety was located in the electron difference map.. The geometry about the iron center is similar to that of the starting material, $\left({ }^{\mathrm{Mes}} \mathrm{PDP}{ }^{\mathrm{Ph}}\right) \mathrm{Fe}(\mathrm{thf})$, as the amine nitrogen is lowered beneath the plane established by the PDP chelate. The N2-Fe1-N4 bond angle was found to be $144.47(9)^{\circ}$, compared to the N2-Fe1-O1 angle of 152.99 in $\left({ }^{\mathrm{Mes}} \mathrm{PDP}{ }^{\mathrm{Ph}}\right) \mathrm{Fe}(\mathrm{thf})$. This deviation demonstrates a more significant departure from planarity in the solid-state for $\mathrm{Fe}\left(\mathrm{NHMes}-{ }^{\mathrm{Mes}} \mathrm{PDP}{ }^{\mathrm{Ph}}\right)$. Bond lengths of 2.012(2) for Fe1-N1, 2.073(2) for Fe1-N2, 2.017(2) for Fe1-N3, and 2.134(2) for Fe1-N4 are consistent with a high-spin state for the iron center. Consideration of the retention of the dianionic charge in the modified dipyrrolide ligand prompts an assignment of the electronic structure of Fe(NHMes- $\left.{ }^{\mathrm{Mes}} \mathrm{PDP}^{\mathrm{Ph}}\right)$ as a high-spin ferrous species. It should be highlighted that in the case of the reaction of ${ }^{1} \mathrm{AdN}_{3}$ with $\left({ }^{\mathrm{Mes}} \mathrm{PDP}{ }^{\mathrm{Ph}}\right) \mathrm{Fe}(\mathrm{thf})$, a product assignment as $\mathrm{Fe}\left(\mathrm{NH}^{1} \mathrm{Ad}-{ }^{\mathrm{Mes}} \mathrm{PDP}{ }^{\mathrm{Ph}}\right)$ was in part based upon a Mössbauer spectra consistent with a planar or pseudo square planar high-spin Fe $\mathrm{F}^{\mathrm{II}}$ PDP complex. The isolation and characterization of $\mathrm{Fe}\left(\mathrm{NHMes}-{ }^{\mathrm{Mes}} \mathrm{PDP}^{\mathrm{Ph}}\right)$ as a four-coordinate species devoid of coordinated THF ligand lends further credence to this previously made assignment, in lieu of its unambiguous solid-state characterization via X-ray crystallography. 


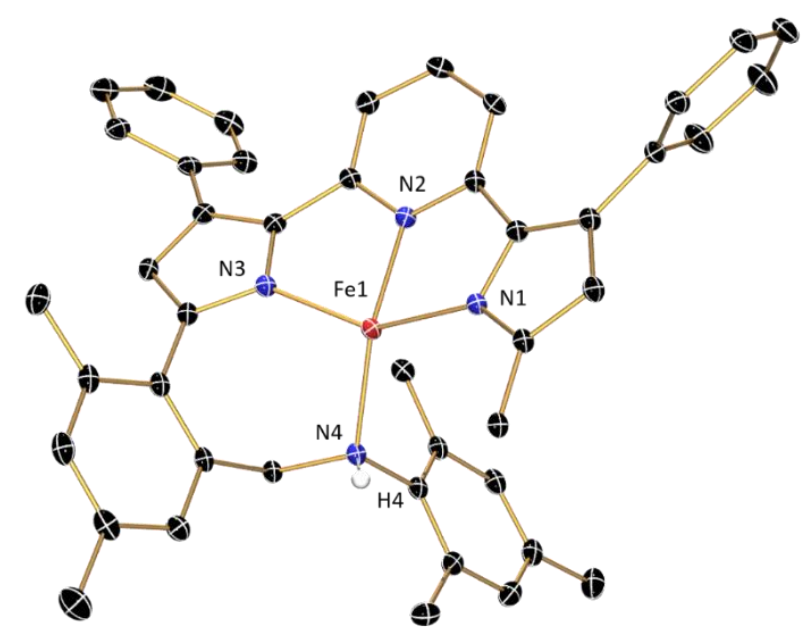

Figure 3.17. ORTEP of $\mathrm{Fe}\left(\mathrm{NHMes}^{\mathrm{Mes}} \mathrm{PDP}^{\mathrm{Ph}}\right)$ at $30 \%$ probability ellipsoids. Hydrogen atoms (with exception of the amine $\mathrm{H}$ ) and cocrystallized benzene solvent have been removed for clarity. A mesityl substituent of the ( ${ }^{\mathrm{Mes}} \mathrm{PDP}^{\mathrm{Ph}}$ ) ligand has been truncated (with exception of the arene ipso carbon) for clarity.

Interestingly, the isolation of $\mathrm{Fe}\left(\mathrm{NHMes}-{ }^{\mathrm{Mes}} \mathrm{PDP}{ }^{\mathrm{Ph}}\right)$ using the bulky aromatic azide $\mathrm{MesN}_{3}$ as the nitrene source contrasts with the observed reactivity for the less bulky aromatic azide pTolN $_{3}$, where no ligand C-H amination was observed. For example, an experiment probing the addition of one molar equivalence of pTolN $_{3}$ to $\left({ }^{\mathrm{Mes}} \mathrm{PDP}{ }^{\mathrm{Ph}}\right) \mathrm{Fe}($ thf $)$ in benzene- $d_{6}$ solution resulted in the metallotetrazene $\left({ }^{\mathrm{Mes}} \mathrm{PDP}{ }^{\mathrm{Ph}}\right) \mathrm{Fe}\left(\mathrm{N}_{4} \mathrm{pTol}_{2}\right)$ and unreacted $\left({ }^{\mathrm{Mes}} \mathrm{PDP}{ }^{\mathrm{Ph}}\right) \mathrm{Fe}(\mathrm{thf})$ being the only species discernable by ${ }^{1} \mathrm{H}$ NMR spectroscopy (vide supra). Alternatively, in the case of reaction of one molar equivalence of $\mathrm{MesN}_{3}$ with $\left({ }^{\mathrm{Mes}} \mathrm{PDP}{ }^{\mathrm{Ph}}\right) \mathrm{Fe}($ thf $)$ in benzene- $d_{6}$ solution, no evidence of metallotetrazene formation was observed via ${ }^{1} \mathrm{H}$ NMR. An additional experiment was conducted where a benzene- $d_{6}$ solution of $\left({ }^{\mathrm{Mes}} \mathrm{PDP}{ }^{\mathrm{Ph}}\right) \mathrm{Fe}($ thf $)$ was treated with two molar equivalents of $\mathrm{MesN}_{3}$. Analysis of the resulting ${ }^{1} \mathrm{H} \mathrm{NMR}$ spectrum indicated the presence of paramagnetically shifted and broadened resonances consistent with $\left({ }^{\mathrm{Mes}} \mathrm{PDP}{ }^{\mathrm{Ph}}\right) \mathrm{Fe}(\mathrm{NMes})$ and unreacted $\mathrm{MesN}_{3}$ and no evidence of formation of the corresponding tetrazene complex, $\left({ }^{\mathrm{Mes}} \mathrm{PDP}{ }^{\mathrm{Ph}}\right) \mathrm{Fe}\left(\mathrm{N}_{4} \mathrm{Mes}_{2}\right)$. These result prompt two hypotheses about the fate of the spectroscopically characterized intermediate $\left({ }^{\mathrm{Mes}} \mathrm{PDP}{ }^{\mathrm{Ph}}\right) \mathrm{Fe}(\mathrm{NMes})$ : 1.) Intramolecular nitrene 
insertion into a benzylic $\mathrm{C}-\mathrm{H}$ bond kinetically outcompetes metallotetrazene formation via the $[2+3]$-cycloaddition of a second equivalent of $\mathrm{MesN}_{3}$ to form the species $\left({ }^{\mathrm{Mes}} \mathrm{PDP}{ }^{\mathrm{Ph}}\right) \mathrm{Fe}\left(\mathrm{N}_{4} \mathrm{Mes}_{2}\right)$.

2.) The 2,6-dimethyl substitution of the organic fragment of the imparts steric protection of intermediate $\left({ }^{\mathrm{Mes}} \mathrm{PDP} \mathrm{Ph}^{\mathrm{Ph}}\right) \mathrm{Fe}(\mathrm{NMes})$ and disallows [2+3] cycloaddition by a second azide equivalent of $\mathrm{MesN}_{3}$, based solely on steric grounds. In consideration of the combined data for the $\left({ }^{\mathrm{Mes}} \mathrm{PDP} \mathrm{Ph}^{\mathrm{Ph}}\right) \mathrm{Fe}(\mathrm{NR})$ system, the steric argument is favored at this time. This insights suggest that for metastable $\left({ }^{\mathrm{Mes}} \mathrm{PDP} \mathrm{Ph}^{\mathrm{Ph}} \mathrm{Fe}(\mathrm{NR})\right.$ intermediates to be isolated and fully characterized, significantly bulky aryl nitrene fragments are necessitated.

\subsection{Reactivity of (MesPDPPh)Fe(thf) with 4-Azido-4-methylpentylbenzene}

Considering the propensity for intermediate $\left({ }^{\mathrm{Mes}} \mathrm{PDP} \mathrm{Ph}^{\mathrm{Ph}}\right) \mathrm{Fe}(\mathrm{NR})$ species to undergo a variety of reaction pathways, including ligand $\mathrm{C}-\mathrm{H}$ amination, iron tetrazene formation, and hydrogen atom abstraction, it was hypothesized that careful tailoring of the azide as a nitrene source may allow for productive intramolecular $\mathrm{C}-\mathrm{H}$ amination of aliphatic azides to form saturated N-heterocycles. In consideration of these details, it was anticipated that selection of an azide possessing both alpha substitution (to eliminate hydrogen atom abstraction), steric hindrance (to suppress tetrazene formation), and weak benzylic C-H bonds (to suppress ${ }^{\mathrm{Mes}} \mathrm{PDP}^{\mathrm{Ph}}$ C-H amination) would be a suitable substrate to explore. Recently, 4-azido-4methylpentylbenzene and related $\alpha$-geminal dimethyl substituted azides have been identified as a suitable substrates for intramolecular benzylic $\mathrm{C}-\mathrm{H}$ amination via pyrrole based iron and cobalt platforms. $^{56,71}$ 

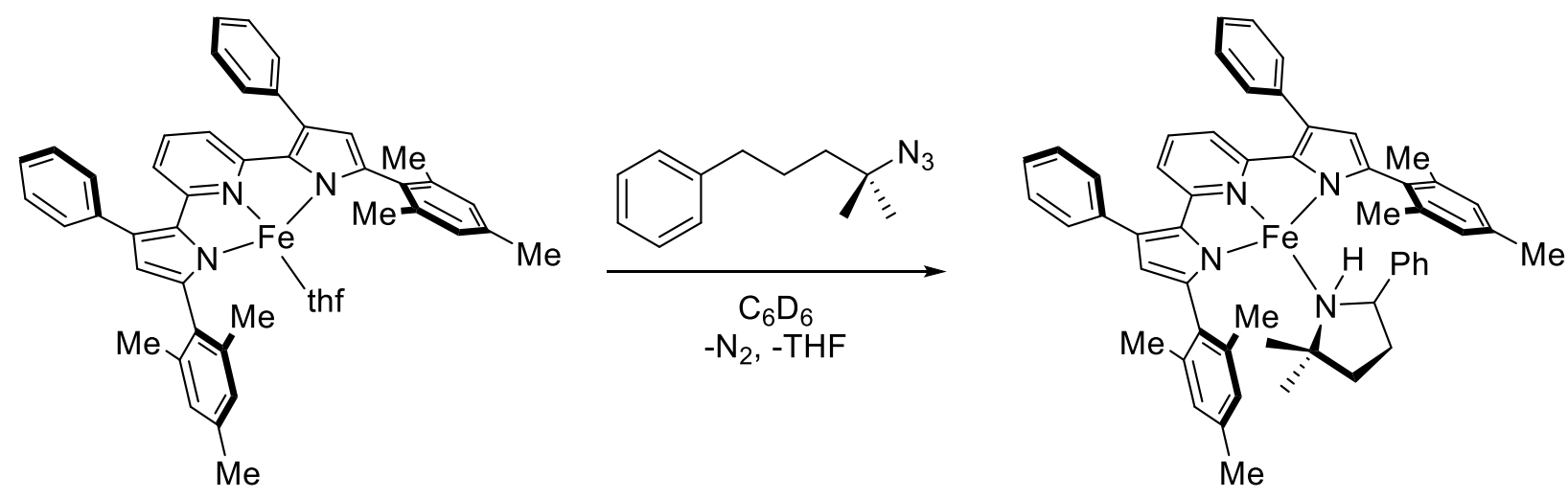

Scheme 3.7. Proposed formation of $\left({ }^{\mathrm{Mes} P D P^{P h}}\right) \mathrm{Fe}$ bound 2,2-dimethyl-5-phenylpyrrolidine via direct $\mathrm{C}-\mathrm{H}$ bond amination from 4-azido-4-methylpentylbenzene.

Accordingly, a benzene- $d_{6}$ solution of $\left({ }^{\mathrm{Mes}} \mathrm{PDP}^{\mathrm{Ph}}\right) \mathrm{Fe}(\mathrm{thf})$ was treated with one equivalent of 4-azido-4-methylpentylbenzene anticipating the formation of a $\left({ }^{\mathrm{Mes}} \mathrm{PDP}^{\mathrm{Ph}}\right) \mathrm{Fe}$ bound 2,2dimethyl-5-phenylpyrrolidine adduct, as demonstrated in Scheme 3.7. Notably, no discernable color change of the solution or $\mathrm{N}_{2}$ evolution was observed upon addition of the azide. The reaction progress was monitored via ${ }^{1} \mathrm{H}$ NMR spectroscopy and after eight hours complete consumption of the starting materials was observed, concomitant with the presence of a new paramagnetic species with apparent $C_{1}$ symmetry, as evidenced by 31 paramagnetically shifted and broadened resonances spanning a range of -92.76 to $202.64 \mathrm{ppm}$. Removal of volatiles and subsequent crystallization by diffusion of pentane into a concentrated benzene solution at ambient temperature afforded red single crystals suitable for X-ray crystallographic analysis. The $\mathrm{X}$-ray crystallographic study identified the reaction product as $\mathrm{Fe}\left(\mathrm{NH}\left(\mathrm{C}\left(\mathrm{CH}_{3}\right)_{2}\left(\mathrm{CH}_{2}\right)_{3} \mathrm{Ph}\right)\right.$ $\left.{ }^{\mathrm{Mes}} \mathrm{PDP}^{\mathrm{Ph}}\right)$, arising from intramolecular $\mathrm{C}-\mathrm{H}$ amination of a benzylic $\mathrm{C}-\mathrm{H}$ bond of the ${ }^{\mathrm{Mes}} \mathrm{PDP}^{\mathrm{Ph}}$ ligand (Figure 3.18 and Scheme 3.8). This result suggests that kinetically the $\mathrm{C}-\mathrm{H}$ amination of 
the ${ }^{\mathrm{Mes}} \mathrm{PDP}^{\mathrm{Ph}}$ chelate outcompetes the intramolecular amination of a benzylic $\mathrm{C}-\mathrm{H}$ bond of the intermediate nitrene.

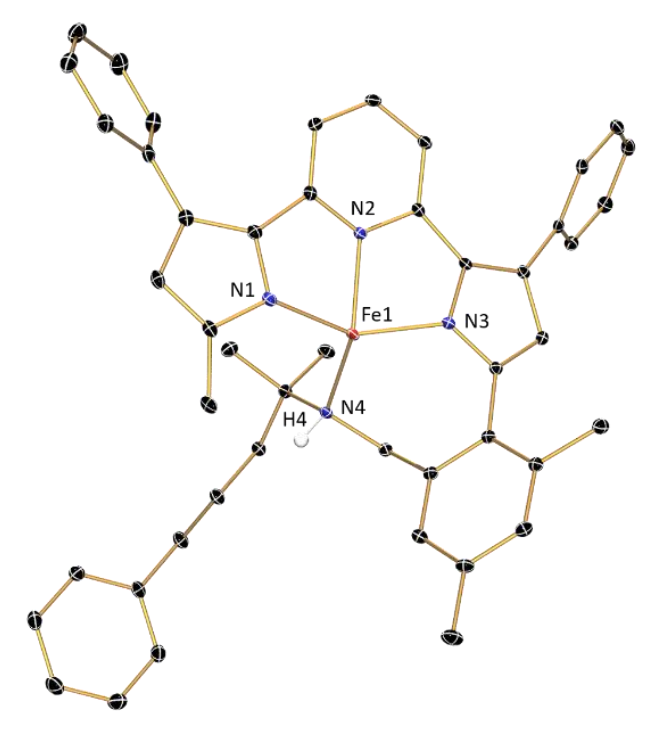

Figure 3.18. ORTEP of $\mathrm{Fe}\left(\mathrm{NH}\left(\mathrm{C}\left(\mathrm{CH}_{3}\right)_{2}\left(\mathrm{CH}_{2}\right)_{3} \mathrm{Ph}\right){ }^{\text {Mes }} \mathrm{PDP}^{\mathrm{Ph}}\right)$ displayed at $30 \%$ probability ellipsoids. Hydrogen atoms (with exception of the amine $\mathrm{H}$ ) and co-crystallized pentane solvent have been excluded for clarity.

The proximity of benzylic C-H bonds of the mesityl PDP substituent is likely to account for this preference. $\mathrm{Fe}\left(\mathrm{NH}\left(\mathrm{C}\left(\mathrm{CH}_{3}\right)_{2}\left(\mathrm{CH}_{2}\right)_{3} \mathrm{Ph}\right)_{-}{ }^{\mathrm{Mes}} \mathrm{PDP}^{\mathrm{Ph}}\right)$ was found to crystallize in the triclinic space group P-1. The geometry about the iron center is highly distorted. A limiting geometric description of a see-saw coordination geometry is appropriate, as evidenced by the bent $\mathrm{N} 2-\mathrm{Fe}-$ $\mathrm{N} 4$ bond angle of $130.22(5)^{\circ}$. This is further reinforced via the $\tau_{4}$ value of 0.57 . In regard to the electronic structure of the iron center, a high-spin ferrous formulation is inferred from the relatively long iron nitrogen bond distances of 2.0149(13) (Fe-N1), 2.0624(13) (Fe-N2), 1.9973(13) (Fe-N3), and 2.1321(13) (Fe-N4). These values are in reasonable agreement with the $\mathrm{Fe}\left(\{\mathrm{NHBn}\}_{2-}{ }^{\mathrm{Mes}} \mathrm{PDP} \mathrm{Ph}^{\mathrm{Ph}}\right)$ (vide supra), which Mössbauer spectroscopy has characterized as possessing a high-spin $\mathrm{Fe}^{\mathrm{II}}$ center. The slightly contracted bond lengths of 
$\mathrm{Fe}\left(\mathrm{NH}\left(\mathrm{C}\left(\mathrm{CH}_{3}\right)_{2}\left(\mathrm{CH}_{2}\right)_{3} \mathrm{Ph}\right)_{-}{ }^{\mathrm{Mes}} \mathrm{PDP} \mathrm{Ph}^{\mathrm{Ph}}\right)$ relative to $\mathrm{Fe}\left(\{\mathrm{NHBn}\}_{2^{-}}{ }^{\mathrm{Mes}} \mathrm{PDP}^{\mathrm{Ph}}\right)$ is attributed to the less congested coordination environment present in the four vs. five-coordinate structure. The amine proton was identified in the electron difference map, confirming the tetrahedral coordination environment about the nitrogen atom and formal nitrene insertion. The structural metrics are summarized in Table 3.5 for comparison to isostructural Fe(NHMes- $\left.{ }^{\text {Mes }} \mathrm{PDP}^{\mathrm{Ph}}\right)$.
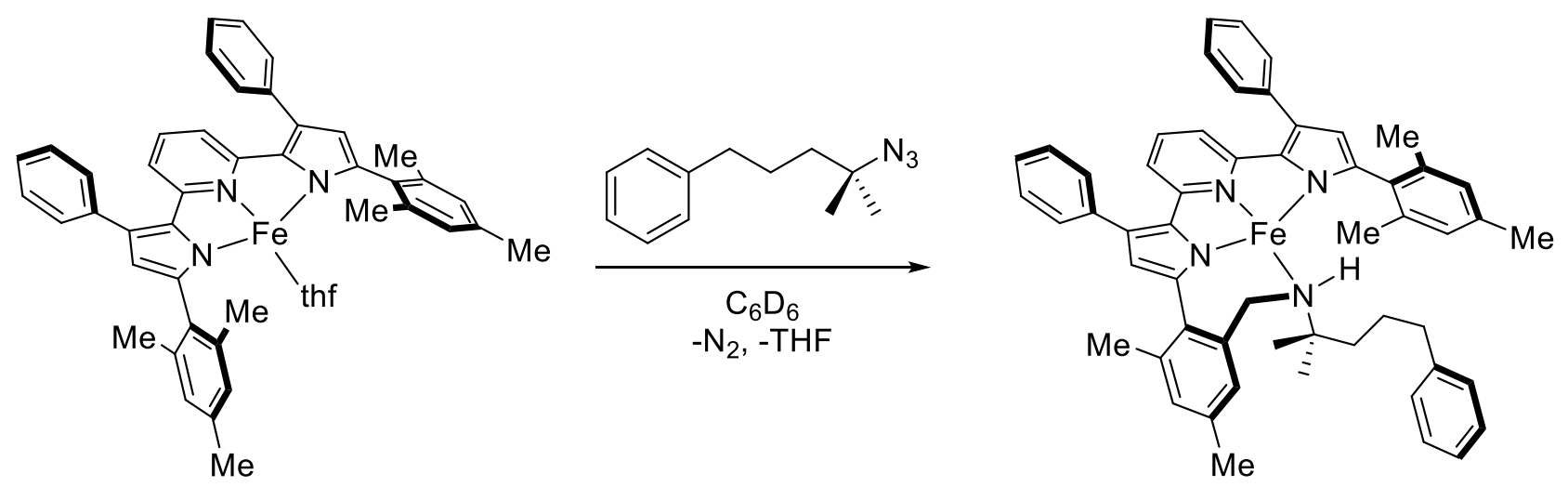

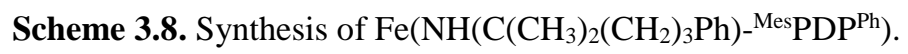


Table 3.5. Selected bond lengths $(\AA)$ and angles $(\mathrm{deg})$ for $\mathrm{Fe}\left(\mathrm{NHMes}^{\mathrm{Mes}} \mathrm{PDP} \mathrm{P}^{\mathrm{Ph}}\right)$ and $\mathrm{Fe}\left(\mathrm{NH}\left(\mathrm{C}\left(\mathrm{CH}_{3}\right)_{2}\left(\mathrm{CH}_{2}\right)_{3} \mathrm{Ph}\right)^{-\mathrm{Mes}} \mathrm{PDP}^{\mathrm{Ph}}\right)$.

\begin{tabular}{ccc}
\hline & $\mathrm{Fe}\left(\mathrm{NHMes}-{ }^{\mathrm{Mes}} \mathrm{PDP}^{\mathrm{Ph}}\right)$ & $\mathrm{Fe}\left(\mathrm{NH}\left(\mathrm{C}\left(\mathrm{CH}_{3}\right)_{2}\left(\mathrm{CH}_{2}\right)_{3} \mathrm{Ph}\right){ }^{\mathrm{Mes}} \mathrm{PDP}^{\mathrm{Ph}}\right)$ \\
\hline $\mathrm{Fe}(1)-\mathrm{N}(1)$ & $2.012(2)$ & $2.0149(13)$ \\
$\mathrm{Fe}(1)-\mathrm{N}(2)$ & $2.073(2)$ & $2.0624(13)$ \\
$\mathrm{Fe}(1)-\mathrm{N}(3)$ & $2.017(2)$ & $1.9973(13)$ \\
$\mathrm{Fe}(1)-\mathrm{N}(4)$ & $2.134(2)$ & $2.1321(13)$ \\
$\mathrm{N}(1)-\mathrm{Fe}(1)-\mathrm{N}(2)$ & $78.43(9)$ & $78.90(5)$ \\
$\mathrm{N}(1)-\mathrm{Fe}(1)-\mathrm{N}(3)$ & $150.85(9)$ & $149.37(5)$ \\
$\mathrm{N}(1)-\mathrm{Fe}(1)-\mathrm{N}(4)$ & $110.67(9)$ & $110.22(5)$ \\
$\mathrm{N}(2)-\mathrm{Fe}(1)-\mathrm{N}(3)$ & $77.43(9)$ & $77.15(5)$ \\
$\mathrm{N}(2)-\mathrm{Fe}(1)-\mathrm{N}(4)$ & $144.47(9)$ & $130.22(5)$ \\
$\mathrm{N}(3)-\mathrm{Fe}(1)-\mathrm{N}(4)$ & $98.48(9)$ & $99.80(5)$ \\
\hline
\end{tabular}

In consideration of this experimental outcome, it has become obvious that in order to leverage productive $\mathrm{C}-\mathrm{H}$ amination reactivity within the Fe-PDP system three critical design parameters must be included. These considerations are as follows: 1.) The PDP pincer ligand must possess a chemically robust substitution pattern, excluding weak benzylic $\mathrm{C}-\mathrm{H}$ bonds susceptible to intramolecular $\mathrm{C}-\mathrm{H}$ amination. 2.) The steric environment must afford access to nitrene coordination trans to the central pyridine unit comprising the tridentate pincer ligand. This critical geometric concern affords access to electronic structures featuring higher spin states and destabilization of the iron bound nitrene. Consequently, destabilization of the $\mathrm{Fe}=\mathrm{NR}$ fragment results in increased reactivity that is not observed in systems with the nitrene unit coordinated cis to the pyridine (i.e. $\left({ }^{\mathrm{CBu}} \mathrm{PDP}{ }^{\mathrm{BBu}}\right) \mathrm{Fe}\left(\mathrm{N}^{1} \mathrm{Ad}\right)$, featuring a cis-divacant octahedral geometry). 3.) Steric considerations about the nitrene must also be made. In combination, these 
results demonstrate that insufficiently bulky nitrene sources, i.e. unsubstituted aryl azides, suffer from kinetically rapid tetrazene formation as a reaction outcome, suggesting that intercepting nitrene intermediates of this nature is a significant challenge. Furthermore, the utilization of azides lacking substitution alpha to the intermediate nitrene are susceptibility to kinetically competitive $\alpha$-HAA.

\subsection{Calculations of Putative ( $\left.{ }^{\mathrm{Mes}} \mathrm{PDP} \mathrm{Ph}^{\mathrm{Ph}}\right) \mathrm{Fe}(\mathrm{NR})$ Intermediates}

To gain further insight into the electronic structures and differences in reactivity of potential imido/iminyl/nitrene intermediates formed for the three different organic azides, broken symmetry DFT calculations were performed at the B3LYP level. An important question in these studies was the interplay of molecular geometry and electronic structure to address the marked difference in reactivity between Caulton and Mindiola's isolable imido complex $\left({ }^{\mathrm{tBu}} \mathrm{PDP}{ }^{\mathrm{tBu}}\right) \mathrm{Fe}\left(\mathrm{N}^{1} \mathrm{Ad}\right)$ and the proposed reactive intermediates employing the ${ }^{\mathrm{Mes}} \mathrm{PDP} \mathrm{Ph}^{\mathrm{Ph}}$ supporting ligand. Therefore, all computations were conducted using untruncated structures to account for the potential steric interplay between the ${ }^{\mathrm{Mes}} \mathrm{PDP}^{\mathrm{Ph}}$ ligand and the substituent on nitrogen. Unless otherwise noted, all geometry optimizations were started from planar structures with a $\mathrm{N}_{\mathrm{py}}-\mathrm{Fe}-\mathrm{N}_{\mathrm{im}}$ angle of $180^{\circ}$. In the absence of information on the spin states of the proposed intermediates several computational approaches were taken to account for a wide range of potential electronic structures: (a) a spin restricted approach (RKS) was used to model a closedshell singlet ground state representing either a low-spin $\mathrm{Fe}^{\mathrm{II}}$ complex with a neutral singlet nitrene, a low-spin $\mathrm{Fe}^{\mathrm{IV}}$ center with a dianionic imido ligand, or a resonance form of both; (b) a $\mathrm{BS}(1,1)$ approach was chosen to represent a low-spin ferric ion $\left(\mathrm{S}_{\mathrm{Fe}}=1 / 2\right)$ antiferromagnetically coupled to an iminyl radical $(\mathrm{S}=1 / 2)$; (c) spin-unrestricted triplet (UKS3) and quintet (UKS5) approaches were taken to represent a number of different electronic structure possibilities 
including intermediate- $\operatorname{spin}(\mathrm{S}=1)$ and high-spin $\mathrm{Fe}^{\mathrm{IV}}(\mathrm{S}=2)$ configurations with a dianionic imido ligand; (d) BS(3,1) and $\mathrm{BS}(5,1)$ calculations were performed to test for electronic structures with intermediate-spin $\left(\mathrm{S}_{\mathrm{Fe}}=3 / 2\right)$ or high-spin Fe ${ }^{\mathrm{III}}\left(\mathrm{S}_{\mathrm{Fe}}=5 / 2\right)$ centers antiferromagnetically coupled to an iminyl radical $(S=1 / 2)$. Table 3.6 summarizes the relative energies and important structural features of the $\mathrm{Fe}=\mathrm{NR}$ unit for $\left({ }^{\mathrm{Mes}} \mathrm{PDP} \mathrm{P}^{\mathrm{Ph}}\right) \mathrm{Fe}(\mathrm{NR})$ with $\mathrm{R}=$ ${ }^{1} \mathrm{Ad}, \mathrm{Bn}, \mathrm{Tol}$, and Mes obtained after geometry optimization. For all four R groups, the lowest energy solution is a BS $(3,1)$ state, which corresponds to a $\left({ }^{\mathrm{Mes}} \mathrm{PDP}^{\mathrm{Ph}}\right) \mathrm{Fe}^{\mathrm{III}}\left(\mathrm{NR}^{\cdot{ }^{-}-}\right)$electronic structure with an intermediate spin ferric ion. Reassuringly, the UKS3 calculations provided the same solution as the $\mathrm{BS}(3,1)$ approach with spontaneous symmetry breaking, indicating that this state is the lowest energy configuration on the triplet surface. Spin density plots visualizing this configuration for all four derivatives are shown in Figure 3.20, and a representative qualitative molecular orbital diagram for $\left({ }^{\mathrm{Mes}} \mathrm{PDP}^{\mathrm{Ph}}\right) \mathrm{Fe}^{\mathrm{III}}\left(\mathrm{N}^{1} \mathrm{Ad}^{\cdot 1-}\right)$ is shown in Figure 3.19. Consistent with iminyl radical character, the nitrogen atoms of the $\mathrm{Fe}=\mathrm{NR}$ moieties carry significant spin density. The spin density map of $\left({ }^{\mathrm{Mes}} \mathrm{PDP}^{\mathrm{Ph}}\right) \mathrm{Fe}(\mathrm{NBn})$ shows substantial delocalization of the unpaired electron onto the benzylic protons of the iminyl substituent, which could favor facile 1,2hydrogen atom shift to furnish the experimentally observed benzaldimine fragment. Even stronger delocalization into the aromatic substituent is observed for $\left({ }^{\mathrm{Mes}} \mathrm{PDP} \mathrm{Ph}^{\mathrm{Ph}}\right) \mathrm{Fe}(\mathrm{NTol})$ and $\left.{ }^{\left({ }^{M e s}\right.} \mathrm{PDP}^{\mathrm{Ph}}\right) \mathrm{Fe}(\mathrm{NMes})$. Betley and co-workers have recently suggested that the concentration of spin density on the iminyl/imido nitrogen atom (i.e., iminyl radical character) could play an important role in $\mathrm{C}-\mathrm{H}$ functionalization processes ${ }^{46}$ Based on this assumption, the complete lack of iminyl radical character in $\left({ }^{\mathrm{tBu}} \mathrm{PDP}{ }^{\mathrm{tBu}}\right) \mathrm{Fe}\left(\mathrm{N}^{1} \mathrm{Ad}\right)$, which is best described as a low-spin $\mathrm{Fe}^{\mathrm{IV}}$ species with a dianionic imido ligand, could also be responsible for the poor reactivity of this complex toward $\mathrm{C}-\mathrm{H}$ bonds. A closer inspection of the structural parameters reveals that the 
$\mathrm{N}_{\mathrm{py}}-\mathrm{Fe}-\mathrm{N}_{\mathrm{im}}$ angle for all four compounds is close to $180^{\circ}\left(165.1-177.7^{\circ}\right)$, indicating nearly planar coordination environments around the iron centers. This structural motif favors an intermediate-spin iron center by strongly destabilizing the $\mathrm{d}_{\mathrm{x}}{ }^{2-} \mathrm{y}^{2}$ orbital. The $\mathrm{Fe}-\mathrm{N}_{\mathrm{im}}-\mathrm{C}_{\mathrm{im}}$ angles show a clear deviation from linearity for the $\mathrm{Fe}=\mathrm{NR}$ unit independent of the substituent, which suggests that this bend is due to electronic rather than steric effects. However, the bulky ${ }^{1} \mathrm{Ad}$ group causes a significant twist of the mesityl substituents away from the nearly coplanar arrangement observed for the benzyl, tolyl, and mesityl derivatives. This distortion results in a complete steric protection of the $\mathrm{Fe}=\mathrm{NR}$ unit and is consistent with the lack of tetrazene formation in the reaction of $\mathrm{N}_{3}{ }^{1} \mathrm{Ad}$ with $\left({ }^{\mathrm{Mes}} \mathrm{PDP}^{\mathrm{Ph}}\right) \mathrm{Fe}($ thf $)$ or $\left({ }^{\mathrm{Mes}} \mathrm{PDP}^{\mathrm{Ph}}\right) \mathrm{Fe}\left(\mathrm{OEt}_{2}\right)$. Independent of substituent, the closed-shell singlet state (RKS) is found slightly higher in energy than the BS( 3,1$)$ triplet state and shows a much smaller $\mathrm{N}_{\mathrm{py}}-\mathrm{Fe}-\mathrm{N}_{\mathrm{im}}$ angle consistent with the cisdivacant octahedral geometry reported for diamagnetic $\left({ }^{\mathrm{tBu}} \mathrm{PDP}^{\mathrm{tBu}}\right) \mathrm{Fe}^{\mathrm{IV}}\left(\mathrm{N}^{1} \mathrm{Ad}^{2-}\right)$. 

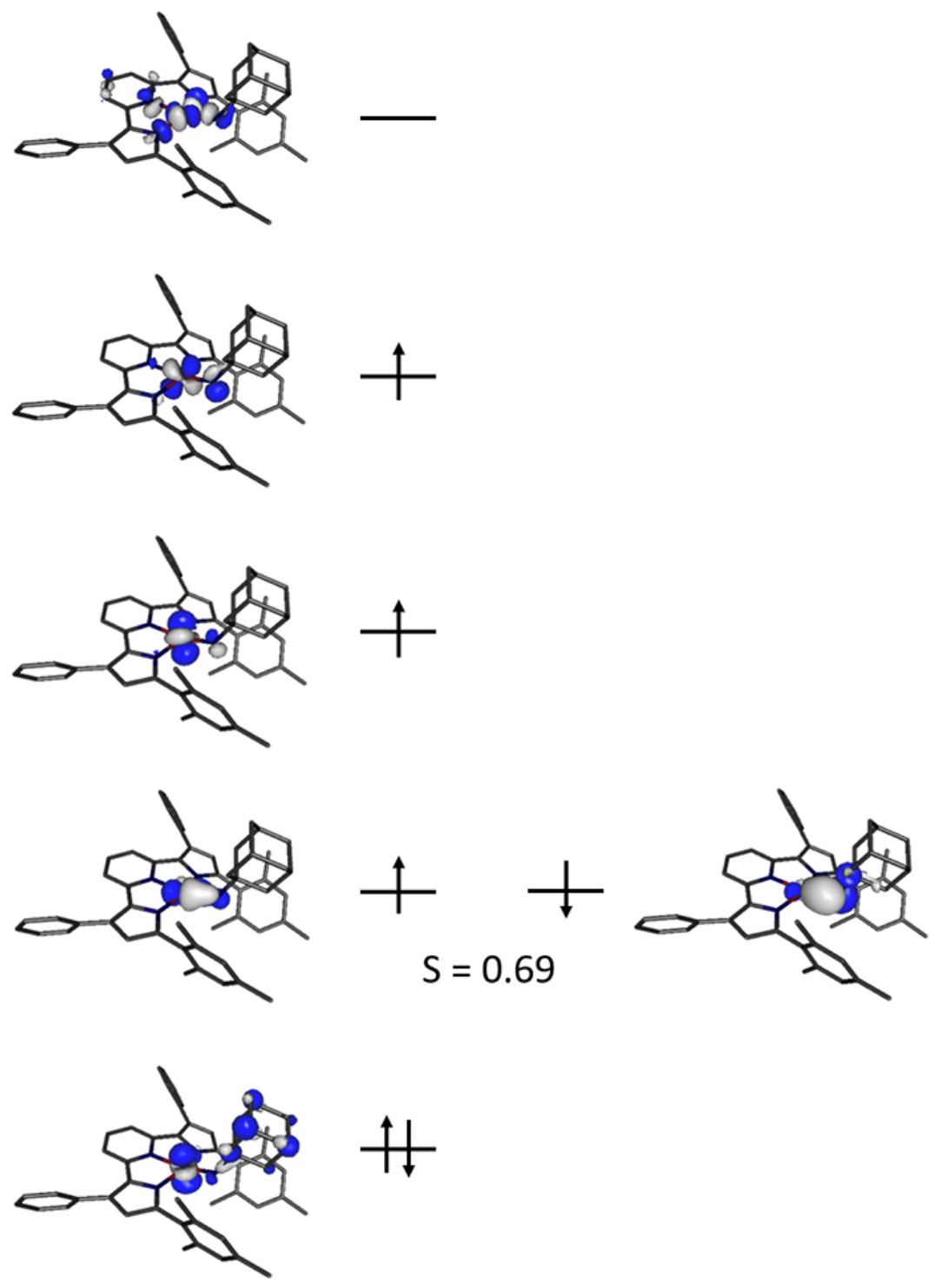

Figure 3.19. Qualitative molecular orbital diagram visualizing the electronic structure of ( $\left.{ }^{\mathrm{Mes}} \mathrm{PDP}^{\mathrm{Ph}}\right) \mathrm{Fe}^{\mathrm{III}}\left(\mathrm{N}^{1} \mathrm{Ad}^{\cdot 1-}\right)$ showing the d orbital occupation of the intermediate-spin $\mathrm{Fe}^{\mathrm{III}}$ ion and the singly occupied molecular orbital of the iminyl ligand radical.

The preference for this geometry and electronic structure given an $\mathrm{S}=0$ ground state is consistent with Caulton and Mindiola's calculations of their compound using identical computational methods to those employed in the study presented herein (functional, basis sets, ORCA program suite). Nevertheless, our results challenge their conclusion that the cis-divacant octahedral structure of $\left.{ }^{(\mathrm{Bu} u} \mathrm{PDP}{ }^{\mathrm{tBu}}\right) \mathrm{Fe}\left(\mathrm{N}^{1} \mathrm{Ad}\right)$ is enforced by electronic effects rather than steric 
bulk of the supporting ligand. Allowing a more planar coordination environment results in an energetically preferable electronic structure change in our computational study. However, it should be noted that the accurate calculation of spin state energetics remains a substantial challenge for modern DFT methods and can depend on the functional used. Given that all solutions calculated by us to cover the numerous potential electronic configurations are within less than $10 \mathrm{kcal} \mathrm{mol}^{-1}$ of each other for all $\left({ }^{\mathrm{Mes}} \mathrm{PDP}^{\mathrm{Ph}}\right) \mathrm{Fe}(\mathrm{NR})$ complexes, more sophisticated computational methods may be necessary to elucidate the complex ground states of these compounds. The close energy of the remaining computational approaches highlights this phenomenon. The $\mathrm{BS}(1,1)$ approach converges to a diamagnetic $\mathrm{BS}(2,2)$ state that is best described as containing an intermediate-spin $\mathrm{Fe}^{\mathrm{II}}$ ion $\left(\mathrm{S}_{\mathrm{Fe}}=1\right)$ antiferromagnetically coupled to a triplet nitrene $(\mathrm{S}=1)$. Furthermore, the two quintet solutions obtained via BS(5,1) and UKS5 approaches provide two additional electronic structures of only slightly higher energy than the $\mathrm{BS}(3,1)$ ground state and correspond to electronic configurations best described by a high-spin ferric metal center antiferromagnetically coupled to an iminyl radical and an intermediate-spin ferric metal center exhibiting a ferromagnetic interaction with an iminyl radical, respectively. It should be noted that a bent starting geometry was required to converge on a $\mathrm{BS}(5,1)$ solution. The otherwise employed linear Fe=NR starting structure led to convergence to the UKS5 solution despite using the BS formalism. The presence of several electronic states within a few kilocalories per mole of each other is consistent with the proposal of two-state reactivity for the iron-mediated amination of hydrocarbons by the $\mathrm{Fe}=\mathrm{NH}^{+}$ion in the gas phase. ${ }^{73}$ 

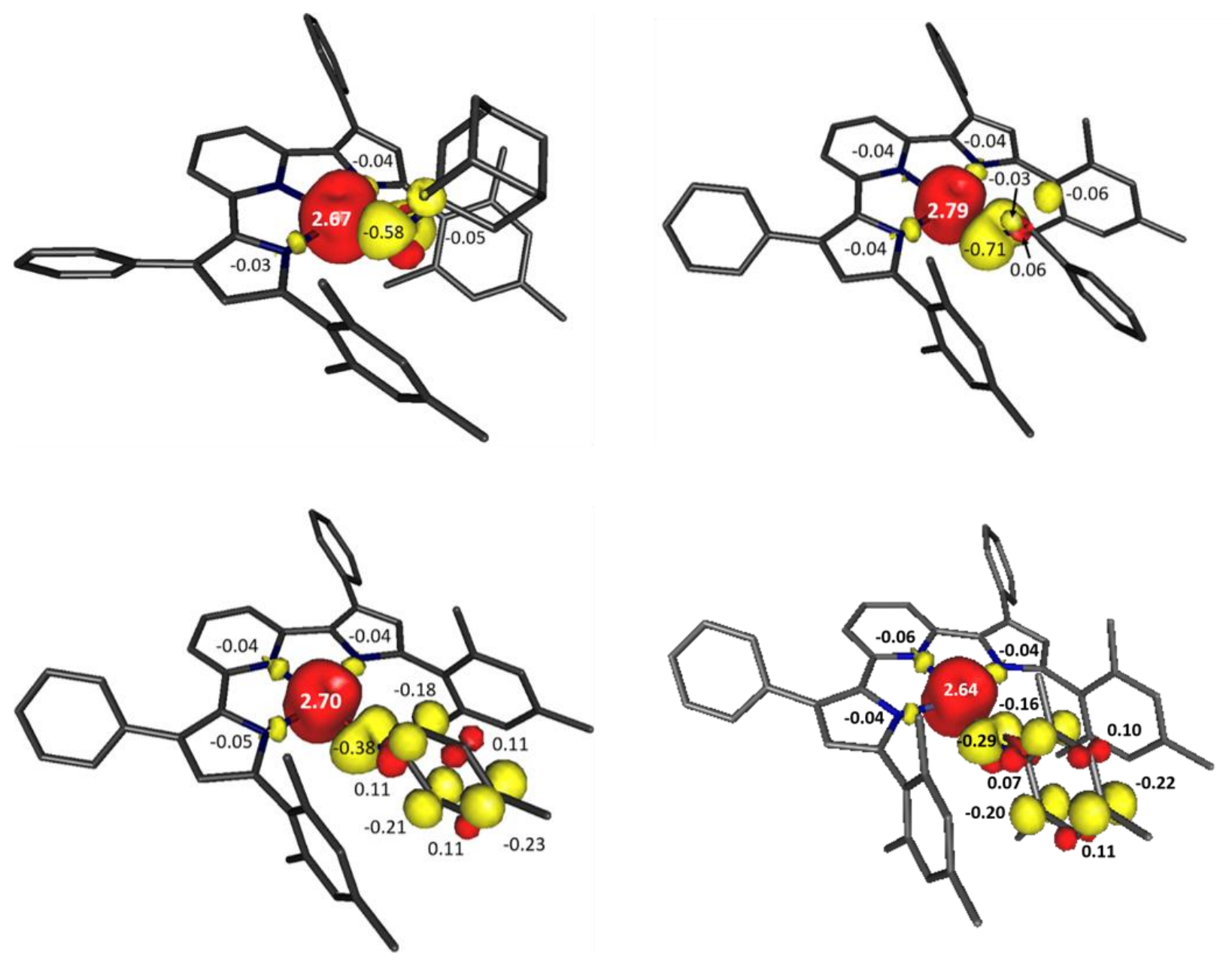

Figure 3.20. Spin density distributions obtained via Mulliken population analysis for ( $\left.{ }^{\mathrm{Mes}} \mathrm{PDP}{ }^{\mathrm{Ph}}\right) \mathrm{Fe}\left(\mathrm{N}^{1} \mathrm{Ad}\right.$ ) (top-left), $\left({ }^{\mathrm{Mes}} \mathrm{PDP}^{\mathrm{Ph}}\right) \mathrm{Fe}(\mathrm{NBn})$ (top-right), $\left({ }^{\mathrm{Mes}} \mathrm{PDP} \mathrm{Ph}^{\mathrm{Ph}}\right) \mathrm{Fe}(\mathrm{NTol})$ (bottom-left) and $\left({ }^{\mathrm{Mes}} \mathrm{PDP}^{\mathrm{Ph}}\right) \mathrm{Fe}(\mathrm{NMes})$ (bottom-right) using a $\mathrm{BS}(3,1)$ or UKS3 computational approach. 
Table 3.6. Calculated energies and selected structural parameters for different electronic structures of $\left({ }^{\mathrm{Mes}} \mathrm{PDP}{ }^{\mathrm{Ph}}\right) \mathrm{Fe}(\mathrm{NR})\left(\mathrm{R}={ }^{1} \mathrm{Ad}, \mathrm{Tol}, \mathrm{Bn}, \mathrm{Mes}\right)$ obtained from DFT calculations.

\begin{tabular}{|c|c|c|c|c|c|}
\hline & & $\Delta$ Energy $/ \mathrm{kcal} \mathrm{mol}^{-1}$ & $\mathrm{~N}_{\mathrm{py}}-\mathrm{Fe}-\mathrm{N}_{\mathrm{im}} /^{\circ}$ & $\mathrm{Fe}-\mathrm{N}_{\mathrm{im}}-\mathrm{C}_{\mathrm{im}} /^{\circ}$ & $\mathrm{Fe}-\mathrm{N}_{\mathrm{im}} / \AA$ \\
\hline \multirow{5}{*}{ 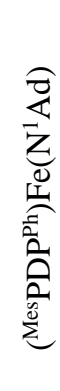 } & RKS & +4.7 & 120.9 & 138.2 & 1.603 \\
\hline & $\mathrm{BS}(2,2)$ & +3.2 & 149.0 & 152.8 & 1.743 \\
\hline & $\mathrm{BS}(3,1) / \mathrm{UKS}^{\mathrm{a}}$ & 0 & 165.4 & 133.5 & 1.722 \\
\hline & $\mathrm{UKS}^{\mathrm{b}}$ & +0.9 & 165.1 & 147.4 & 1.782 \\
\hline & $\operatorname{BS}(5,1)^{\mathrm{c}}$ & +4.8 & 136.5 & 160.4 & 1.772 \\
\hline \multirow{5}{*}{ 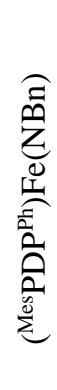 } & RKS & +4.8 & 114.6 & 131.4 & 1.610 \\
\hline & $\mathrm{BS}(2,2)$ & +6.7 & 139.6 & 137.2 & 1.721 \\
\hline & $\mathrm{BS}(3,1) / \mathrm{UKS}^{\mathrm{a}}$ & 0 & 177.7 & 129.2 & 1.732 \\
\hline & $\mathrm{UKS}^{\mathrm{b}}$ & +3.5 & 176.0 & 146.9 & 1.758 \\
\hline & $\operatorname{BS}(5,1)^{\mathrm{c}}$ & +3.9 & 173.89 & 144.07 & 1.764 \\
\hline \multirow{5}{*}{ 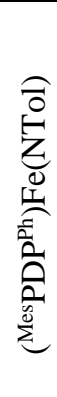 } & RKS & +9.7 & 119.1 & 138.9 & 1.631 \\
\hline & $\mathrm{BS}(2,2)$ & +5.5 & 146.9 & 146.9 & 1.759 \\
\hline & $\mathrm{BS}(3,1) / \mathrm{UKS}^{\mathrm{a}}$ & 0 & 172.4 & 145.7 & 1.734 \\
\hline & $\mathrm{UKS}^{\mathrm{b}}$ & +2.1 & 177.6 & 166.2 & 1.778 \\
\hline & $\operatorname{BS}(5,1)^{\mathrm{c}}$ & +4.3 & 128.2 & 165.3 & 1.795 \\
\hline \multirow{5}{*}{ 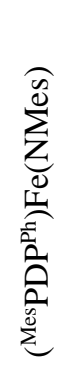 } & RKS & +8.7 & 131.51 & 152.71 & 1.623 \\
\hline & $\mathrm{BS}(2,2)$ & +7.6 & 166.92 & 169.05 & 1.791 \\
\hline & $\mathrm{BS}(3,1) / \mathrm{UKS}^{\mathrm{a}}$ & 0 & 173.42 & 149.56 & 1.732 \\
\hline & $\mathrm{UKS}^{\mathrm{b}}$ & +2.2 & 175.27 & 162.17 & 1.784 \\
\hline & $\mathrm{BS}(5,1)^{\mathrm{c}}$ & +2.6 & 153.86 & 167.58 & 1.791 \\
\hline
\end{tabular}

${ }^{\mathrm{a}}$ antiferromagnetic coupling between i.s. $\mathrm{Fe}^{\mathrm{III}}(\mathrm{S}=3 / 2)$ and iminyl radical $(\mathrm{S}=1 / 2)$. ${ }^{\mathrm{b}}$ ferromagnetic coupling between i.s. $\mathrm{Fe}^{\mathrm{III}}(\mathrm{S}=3 / 2)$ and iminyl(1-) radical $(\mathrm{S}=1 / 2)$. ${ }^{c}$ antiferromagnetic coupling between h.s. Fe ${ }^{\mathrm{III}}(\mathrm{S}=5 / 2)$ and iminyl(1-) radical $(\mathrm{S}=1 / 2)$. 
To compliment this study, additional calculations were performed on the hypothetical nitrene complex $\left({ }^{\mathrm{H} P D P}{ }^{\mathrm{H}}\right) \mathrm{Fe}\left(\mathrm{N}^{1} \mathrm{Ad}\right)$, featuring the unsubstituted parent PDP ligand. This hypothetical complex was explored in silico via Caulton, Mindiola, and coworkers to examine the possibility of steric bias that tert-butyl substitution at the five position of the PDP pyrrolide imparts on the corresponding iron nitrene. An RKS calculation was performed on $\left({ }^{\mathrm{H}} \mathrm{PDP} \mathrm{H}^{\mathrm{H}}\right) \mathrm{Fe}\left(\mathrm{N}^{1} \mathrm{Ad}\right)$ which demonstrated that the complex maintains an electronic preference for the cis-divacant octahedral geometry when in a closed-shell diamagnetic configuration. The aforementioned computational study of $\left({ }^{\mathrm{Mes}} \mathrm{PDP} \mathrm{P}^{\mathrm{Ph}}\right) \mathrm{Fe}(\mathrm{NR})$ complexes highlights that by altering the substitution of the PDP ligand, an electronic preference exists for the nitrene fragment to adopt a planar coordination geometry trans to the central pyridine in paramagnetic electronic structural configurations. Taking this result into consideration, the computational study was extended to include the hypothetical $\left({ }^{\mathrm{H}} \mathrm{PDP}^{\mathrm{H}}\right) \mathrm{Fe}\left(\mathrm{N}^{1} \mathrm{Ad}\right)$ to further explore this phenomena. The same array of computational approaches that were explored for $\left({ }^{\mathrm{Mes}} \mathrm{PDP} \mathrm{P}^{\mathrm{Ph}}\right) \mathrm{Fe}(\mathrm{NR})$ were probed for $\left({ }^{\mathrm{H}} \mathrm{PDP}{ }^{\mathrm{H}}\right) \mathrm{Fe}\left(\mathrm{N}^{1} \mathrm{Ad}\right)$. Interestingly, in agreement with $\left({ }^{\mathrm{Mes}} \mathrm{PDP}{ }^{\mathrm{Ph}}\right) \mathrm{Fe}(\mathrm{NR})$ computations, the UKS3 calculation for $\left({ }^{\mathrm{H} P D P}{ }^{\mathrm{H}}\right) \mathrm{Fe}\left(\mathrm{N}^{1} \mathrm{Ad}\right)$ spontaneously converges to a $\mathrm{BS}(3,1)$ solution with the imide fragment existing in a planar geometry, with an $\mathrm{N}_{\mathrm{py}}-\mathrm{Fe}-\mathrm{N}_{\mathrm{im}}$ angle of $175.68^{\circ}$. This renders the geometric configuration of the complex square planar. The bent $\mathrm{Fe}-\mathrm{N}_{\mathrm{im}}-\mathrm{C}_{\mathrm{im}}$ angle of $146.15^{\circ}$ and the Fe- $\mathrm{N}_{\text {im }}$ bond length of $1.712 \AA$ are also in good agreement with the values obtained from the $\mathrm{BS}(3,1)$ computations for the $\left({ }^{\mathrm{Mes}} \mathrm{PDP}{ }^{\mathrm{Ph}}\right) \mathrm{Fe}(\mathrm{NR})$ complexes. The most intriguing discovery is that the $\mathrm{BS}(3,1)$ solution featuring a square planar geometry lies $10.8 \mathrm{kcal} \mathrm{mol}^{-1}$ lower in energy than the corresponding RKS solution with cis-divacant octahedral geometry. The spin density plot obtained via Mulliken population analysis of this computation is presented in Figure 3.20 and clearly demonstrates the square-planar geometry adopted by ${ }^{\mathrm{H}} \mathrm{PDP}^{\mathrm{H}} \mathrm{FeN}^{1} \mathrm{Ad}$ as well as the 
significant radical character imparted throughout the nitrene fragment. These result are in excellent agreement with the aforementioned computational study performed on $\left({ }^{\mathrm{Mes}} \mathrm{PDP}{ }^{\mathrm{Ph}}\right) \mathrm{Fe}(\mathrm{NR})$ derivatives and highlights that the preference for a square-planar intermediate-spin $\mathrm{Fe}^{\mathrm{III}}$ center engaged in antiferromagnetic coupling with an iminyl radical ligand vs. a low-spin $\mathrm{Fe}^{\mathrm{IV}}$ iron imide in cis-divacant octahedral geometry is a sterically driven phenomena that can be influenced via the identity of the substituent at the 5-position of the PDP pyrrolides.

Table 3.7. Calculated energies and selected structural parameters for different electronic structures of $\left({ }^{\mathrm{H}} \mathrm{PDP}{ }^{\mathrm{H}}\right) \mathrm{Fe}\left(\mathrm{N}^{1} \mathrm{Ad}\right)$ obtained from DFT calculations.

\begin{tabular}{|c|c|c|c|c|}
\hline & $\Delta$ Energy $/ \mathrm{kcal} \mathrm{mol}^{-1}$ & $N_{p y}-\mathrm{Fe}-N_{i m} /^{\circ}$ & $F e-N_{i m}-C_{i m} /^{\circ}$ & $\mathrm{Fe}-\mathrm{N}_{\text {im }} / \AA$ \\
\hline RKS & +10.8 & 124.16 & 141.75 & 1.595 \\
\hline $\mathrm{BS}(1,1)^{\mathrm{a}}$ & +9.8 & 129.53 & 139.76 & 1.667 \\
\hline $\mathrm{BS}(3,1) / \mathrm{UKS} 3^{\mathrm{b}}$ & 0 & 175.68 & 146.15 & 1.712 \\
\hline $\mathrm{BS}(5,1) / \mathrm{UKS}^{\mathrm{c}}$ & +12.4 & 129.76 & 147.08 & 1.778 \\
\hline
\end{tabular}

${ }^{a}$ antiferromagnetic coupling between 1.s. $\mathrm{Fe}^{\mathrm{IIII}}(\mathrm{S}=1 / 2)$ and iminyl radical $(\mathrm{S}=1 / 2)$. ${ }^{\mathrm{b}}$ antiferromagnetic coupling between i.s. $\mathrm{Fe}^{\mathrm{III}}(\mathrm{S}=3 / 2)$ and iminyl radical $(\mathrm{S}=1 / 2)$. ${ }^{\mathrm{c}}$ antiferromagnetic coupling between h.s. $\mathrm{Fe}^{\mathrm{III}}(\mathrm{S}=5 / 2)$ and iminyl $(1-)$ radical $(\mathrm{S}=1 / 2)$.

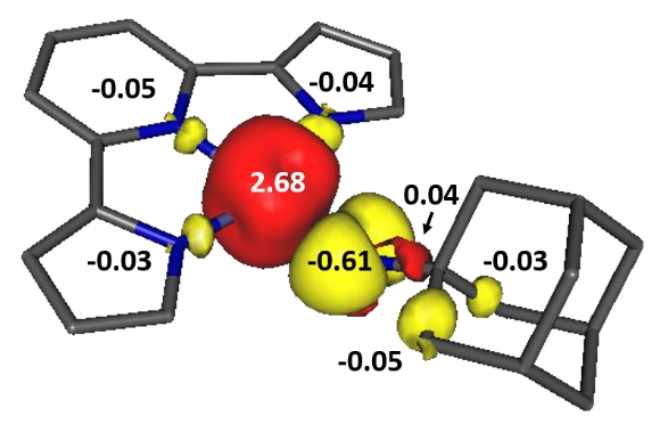

Figure 3.21. Spin density plot obtained from Mulliken population from BS(3,1)/UKS3 calculation of $\left({ }^{\mathrm{H} D P}{ }^{\mathrm{H}}\right) \mathrm{Fe}\left(\mathrm{N}^{1} \mathrm{Ad}\right)$. 


\subsection{Conclusion}

The reaction of the square-planar high-spin $\mathrm{Fe}^{\mathrm{II}}$ complexes $\left({ }^{\mathrm{Mes}} \mathrm{PDP}{ }^{\mathrm{Ph}}\right) \mathrm{Fe}\left(\mathrm{OEt}_{2}\right)$ or $\left({ }^{\mathrm{Mes}} \mathrm{PDP}^{\mathrm{Ph}}\right) \mathrm{Fe}($ thf), with organic azides proceeds readily to provide products consistent with intramolecular $\mathrm{C}-\mathrm{H}$ amination, tetrazene formation via $[2+3]$-cycloaddition, $\alpha-\mathrm{HAA}$, and a reactive but spectroscopically observable $\mathrm{Fe}^{\mathrm{III}}$ iron iminyl radical species. The observed reactivity depends strongly on the nature of the organic azide and reflects the steric and electronic properties of the organic substituent. This reactivity is in stark contrast to the previously reported reaction of cis-divacant octahedral $\left({ }^{\mathrm{tBu}} \mathrm{PDP}^{\mathrm{tBu}}\right) \mathrm{Fe}\left(\mathrm{OEt}_{2}\right)$ with $\mathrm{N}_{3}{ }^{1} \mathrm{Ad}$ that furnishes an isolable and remarkably inert $\mathrm{Fe}^{\mathrm{IV}}$ imido complex. For the planar compounds described herein, reactions with 1-adamantyl azide yield the $\mathrm{C}-\mathrm{H}$ amination products $\mathrm{Fe}\left(\mathrm{NH}^{1} \mathrm{Ad}^{-{ }^{\mathrm{Mes}}} \mathrm{PDP}^{\mathrm{Ph}}\right)$ and $\left(\mathrm{NH}^{1} \mathrm{Ad}-{ }^{\mathrm{Mes}} \mathrm{PDP}^{\mathrm{Ph}}\right) \mathrm{Fe}($ thf $)$, depending on the solvent environment. Both complexes were characterized by ${ }^{1} \mathrm{H}$ NMR and Mössbauer spectroscopy and magnetic susceptibility measurements. Structural characterization for $\left(\mathrm{NH}^{1} \mathrm{Ad}^{-\mathrm{Mes}} \mathrm{PDP}^{\mathrm{Ph}}\right) \mathrm{Fe}($ thf $)$ confirms $\mathrm{C}-\mathrm{N}$ and $\mathrm{N}-\mathrm{H}$ bond formation via nitrene insertion.

The non-bulky aromatic organic azide $\mathrm{N}_{3} \mathrm{Tol}$ enables exclusive formation of the iron tetrazene complex $\left({ }^{\mathrm{Mes}} \mathrm{PDP}{ }^{\mathrm{Ph}}\right) \mathrm{Fe}\left(\mathrm{N}_{4} \mathrm{Tol}_{2}\right)$, which was characterized structurally and spectroscopically. The electronic structure of this complex is unprecedented for iron tetrazenes and is best described as $\left({ }^{\mathrm{Mes}} \mathrm{PDP}^{\mathrm{Ph}}\right) \mathrm{Fe}^{\mathrm{IIII}}\left(\mathrm{N}_{4} \mathrm{Tol}_{2}{ }^{\cdot{ }^{\cdot-}}\right)$ according to the combined experimental and computational data. The small aliphatic nitrene source benzyl azide provides the structurally and spectroscopically characterized complexes $\mathrm{Fe}\left(\{\mathrm{NHBn}\}_{2^{-}}{ }^{\mathrm{Mes}} \mathrm{PDP}^{\mathrm{Ph}}\right)$ and $\left({ }^{\mathrm{Mes}} \mathrm{PDP}^{\mathrm{Ph}}\right) \mathrm{Fe}\left(\mathrm{N}_{4} \mathrm{Bn}_{2}\right)(\mathrm{HN}=\mathrm{CHPh})$, highlighting the availability of both $\mathrm{C}-\mathrm{H}$ amination and tetrazene formation pathways. Additional reactivity resulting in benzaldimine ligand formation is enabled by the presence of $\alpha$-hydrogen atoms in benzyl azide. The bulky azide, $\mathrm{MesN}_{3}$ allows for 
suppression of tetrazene formation and the spectroscopic observation of the reactive imidyl radical intermediate $\left({ }^{\mathrm{Mes}} \mathrm{PDP}^{\mathrm{Ph}}\right) \mathrm{Fe}(\mathrm{NMes})$ via ${ }^{1} \mathrm{H}$ NMR. This complex decomposes in the presence of the weak benzylic bonds of the ${ }^{\mathrm{Mes}} \mathrm{PDP}^{\mathrm{Ph}}$ supporting ligand to form the $\mathrm{C}-\mathrm{H}$ amination product $\mathrm{Fe}\left(\mathrm{NHMes}-{ }^{\mathrm{Mes}} \mathrm{PDP}^{\mathrm{Ph}}\right)$, characterized via X-ray crystallography.

Finally, in an attempt to sequester C-H amination of the PDP chelate and intercept the reactive nitrene fragment with other weak benzylic C-H bonds, 4-azido-4-methylpentylbenzene was explored as a nitrene source. The clean conversion to $\mathrm{Fe}\left(\mathrm{NH}\left(\mathrm{C}\left(\mathrm{CH}_{3}\right)_{2}\left(\mathrm{CH}_{2}\right)_{3} \mathrm{Ph}\right)-{ }^{\mathrm{Mes}} \mathrm{PDP}{ }^{\mathrm{Ph}}\right)$, characterized via X-ray crystallography, demonstrates that the $\mathrm{C}-\mathrm{H}$ amination of the mesityl group of the PDP ligand kinetically outcompetes the $\mathrm{C}-\mathrm{H}$ amination of a benzylic $\mathrm{C}-\mathrm{H}$ bond of the iron bound 4-methylpentylbenzene nitrene fragment, disallowing formation of the desired 2,2-dimethyl-5-phenylpyrrolidine product.

All reaction products observed in this study are consistent with the formation of highly reactive $\mathrm{Fe}=\mathrm{NR}$ intermediates. $\mathrm{DFT}$ studies for the proposed four-coordinate intermediates show several energetically close lying electronic states and do not allow a conclusive evaluation of the exact ground state configuration consistent with potential two-state reactivity. However, it is clear that different spin states favor distinct iron imido/iminyl/nitrene geometries. The lowest energy configuration for all studied intermediates $\left({ }^{\mathrm{Mes}} \mathrm{PDP}^{\mathrm{Ph}}\right) \mathrm{Fe}(\mathrm{NR})$ contains an intermediatespin $\mathrm{Fe}^{\mathrm{III}}$ ion antiferromagnetically coupled to an iminyl radical and favors a planar coordination environment. In contrast, diamagnetic singlet configurations prefer substantially bent structures. Furthermore, the computed structure of the hypothetical parent PDP nitrene complex, $\left({ }^{\mathrm{H}} \mathrm{PDP}{ }^{\mathrm{H}}\right) \mathrm{Fe}\left(\mathrm{N}^{1} \mathrm{Ad}\right)$, are consistent with the results obtained for $\left({ }^{\mathrm{Mes}} \mathrm{PDP}^{\mathrm{Ph}}\right) \mathrm{Fe}(\mathrm{NR})$ complexes. In combination, these studies provide strong evidence that the electronic structure of the iron nitrene fragment is directly attenuated by the steric profile of the PDP ligand, which is governed 
by the substituents located at the five position of the pyrrolide heterocycles. Furthermore, these results provide direct insight into the divergent reactivity of PDP iron complexes with different coordination environments and suggests that the stability of the PDP iron nitrene fragment can be controlled by careful design of the appropriate ligand environment.

\subsection{Experimental Procedures}

All air- and moisture-sensitive manipulations were carried out using standard Schlenk line and cannula techniques or in an MBraun inert atmosphere drybox containing an atmosphere of purified nitrogen. Solvents for air- and moisture sensitive manipulations were dried and deoxygenated using a Glass Contour Solvent Purification System and stored over 4 Å molecular sieves. All solids were dried under high vacuum; all liquids were dried over $\mathrm{CaH}_{2}$ and vacuum transferred into oven-dried glassware in order to bring into the glovebox. Deuterated benzene (benzene- $d_{6}$ ) and tetrahydrofuran (THF- $d_{8}$ ) for NMR spectroscopy were distilled from sodium metal and sodium benzophenone, respectively. 1-Adamantyl azide was obtained from SigmaAldrich, dried under high vacuum, and recrystallized at $-35^{\circ} \mathrm{C}$ from pentane prior to use.

$\left({ }^{\text {Mes }} \mathrm{PDP}^{\mathrm{Ph}}\right) \mathrm{Fe}(\mathrm{thf}),{ }^{60}\left({ }^{\mathrm{Mes}} \mathrm{PDP}^{\mathrm{Ph}}\right) \mathrm{Fe}\left(\mathrm{OEt}_{2}\right),{ }^{60}$ para-tolyl azide,${ }^{74}$ mesityl azide,${ }^{75}$ benzyl azide, ${ }^{76}$ and 4-azido-4-methylpentylbenzene ${ }^{71}$ were synthesized according to literature procedures.

\section{Safety Considerations.}

Organic azides are known energetic materials that may decompose violently via explosion upon input of energy from external sources (heat, light, pressure). While we did not encounter any problems or dangerous situations during the course of this study, all experiments involving organic azides were performed on small scale with less than $100 \mathrm{mg}$ of azide material. All manipulations outside of the glovebox were performed behind a blast shield. The organic 
azides were stored in the dark at $-35^{\circ} \mathrm{C}$ in the glovebox. $\left({ }^{\mathrm{Mes}} \mathrm{PDP}{ }^{\mathrm{Ph}}\right) \mathrm{Fe}\left(\mathrm{N}_{4} \mathrm{pTol} 2\right)$ is thermally stable upon heating to $80{ }^{\circ} \mathrm{C}$ in benzene- $d_{6}$.

Preparation of Fe(NH $\left.{ }^{1} A d-^{M e s} P D P^{P h}\right)$.

To a $20 \mathrm{~mL}$ scintillation vial equipped with a magnetic stirrer was added $200 \mathrm{mg}(0.28$ mmol) of ( $\left.{ }^{\mathrm{Mes}} \mathrm{PDP}{ }^{\mathrm{Ph}}\right) \mathrm{Fe}(\mathrm{thf})$ in $10 \mathrm{~mL}$ of benzene, affording a dark red solution. In a separate vial, $54 \mathrm{mg}$ ( $0.30 \mathrm{mmol}, 1.07$ eq.) of 1-adamantyl azide was dissolved in $5 \mathrm{~mL}$ of benzene. The adamantyl azide solution was added dropwise to the solution of ( $\left.{ }^{\mathrm{Mes}} \mathrm{PDP} \mathrm{Ph}^{\mathrm{Ph}}\right) \mathrm{Fe}(\mathrm{thf})$ over a period of approximately $10 \mathrm{~min}$. Upon addition of the azide, evolution of $\mathrm{N}_{2}$ was observed, as evidenced by bubbling of the solution. The reaction mixture was allowed to stir for $12 \mathrm{~h}$, at which time it was reduced to dryness. The resulting red powder was dissolved in a minimum amount of toluene, approximately $5 \mathrm{~mL}$, and filtered through a pipet containing a pad of Celite supported on a glass microfiber plug. The resulting solution was layered with $10 \mathrm{~mL}$ of pentane and stored at $-35^{\circ} \mathrm{C}$. After $12 \mathrm{~h}$, red crystalline needles had formed and were isolated via vacuum filtration on a medium porosity glass frit. The crystalline product was washed with 10 $\mathrm{mL}$ of pentane and dried in vacuo. Yield: $151 \mathrm{mg}(0.19 \mathrm{mmol}, 68 \%) . \mu_{\mathrm{eff}}=5.2 \mu_{\mathrm{B}}(295 \mathrm{~K}) .{ }^{1} \mathrm{H}$ NMR (600 MHz, benzene- $\left.d_{6} ; \delta / p p m\right): 203.45,117.17,111.70,107.54,105.35,23.00,14.32$, $13.84,10.72,8.98,7.04,4.62,3.88,3.57,0.89,-1.33,-1.81,-5.14,-9.34,-10.92,-15.71$, -17.16, -47.02, -96.42. Anal. Calcd for $\mathrm{Fe}\left(\mathrm{NH}^{1} \mathrm{Ad}_{-}{ }^{\mathrm{Mes}} \mathrm{PDP}^{\mathrm{Ph}}\right) \mathrm{C}_{53} \mathrm{H}_{52} \mathrm{FeN}_{4}: \mathrm{C}, 79.49 ; \mathrm{H}, 6.54$;

N, 7.00. Found: C, 79.66; H, 6.28; N, 7.41.

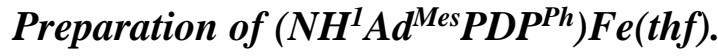

A $20 \mathrm{~mL}$ scintillation vial was charged with $15 \mathrm{mg}$ of $\mathrm{Fe}\left(\mathrm{NH}^{1} \mathrm{Ad}-{ }^{\mathrm{Mes}} \mathrm{PDP}{ }^{\mathrm{Ph}}\right)$ and $500 \mu \mathrm{L}$ of THF- $d_{8}$. The solution was filtered through a glass microfiber plug into a J. Young NMR tube, affording a homogeneous red/orange solution. The tube was sealed, removed from the glovebox, 
and a ${ }^{1} \mathrm{H}$ NMR spectrum was acquired. Analysis of the resulting spectrum demonstrated quantitative conversion to $\left(\mathrm{NH}^{1} \mathrm{Ad}-{ }^{\mathrm{Mes}} \mathrm{PDP}{ }^{\mathrm{Ph}}\right) \mathrm{Fe}(\mathrm{thf}) .{ }^{1} \mathrm{H}$ NMR $\left(600 \mathrm{MHz}, \mathrm{THF}-d_{8} ; \delta / \mathrm{ppm}\right)$ : $149.52,133.21,111.62,99.72,95.92,82.49,39.90,12.82,12.16,11.98,11.85,10.27,9.16,5.92$, $5.07,4.40,-1.07,-3.54,-15.14,-16.67,-22.12,-57.79,-67.96$.

\section{Preparation of $\left({ }^{M e s} \mathrm{PDP} P h\right) \mathrm{Fe}\left(\mathrm{N}_{4} \mathrm{Tol}_{2}\right)$.}

In the glovebox, $200 \mathrm{mg}(0.28 \mathrm{mmol})$ of $\left({ }^{\mathrm{Mes}} \mathrm{PDP}{ }^{\mathrm{Ph}}\right) \mathrm{Fe}(\mathrm{thf})$ was transferred to a $20 \mathrm{~mL}$ scintillation vial equipped with a magnetic stirrer. $10 \mathrm{~mL}$ of toluene was added to the solid affording a dark red solution. In a separate vial, $74 \mathrm{mg}(0.56 \mathrm{mmol}, 2.0$ eq.) of p-tolyl azide was dissolved in approximately $5 \mathrm{~mL}$ of toluene. The toluene solution of p-tolyl azide was added dropwise to the stirring solution of $\left({ }^{\mathrm{Mes}} \mathrm{PDP}^{\mathrm{Ph}}\right) \mathrm{Fe}(\mathrm{thf})$, resulting in evolution of $\mathrm{N}_{2}$ and an immediate color change of the solution to dark-brown. The reaction mixture was allowed to stir for $2 \mathrm{~h}$, at which time the solvent was removed, affording a dark brown powder. The crude material was dissolved in a minimum amount of toluene and filtered through a pipet fitted with a microfiber glass plug. The solution was collected in a separate $20 \mathrm{~mL}$ vial and layered with 10 $\mathrm{mL}$ of pentane. Storage of the solution at $-35^{\circ} \mathrm{C}$ for $48 \mathrm{~h}$ afforded dark-brown/black crystalline material which was isolated via vacuum filtration on a medium porosity frit. The crystals were washed with three-5 mL aliquots of pentane, and dried in vacuo. Yield: $165 \mathrm{mg}, 0.19 \mathrm{mmol}$, $67 \%$. Single crystals of $\left({ }^{\mathrm{Mes}} \mathrm{PDP}{ }^{\mathrm{Ph}}\right) \mathrm{Fe}\left(\mathrm{N}_{4} \mathrm{Tol}_{2}\right)$ were obtained via slow diffusion of pentane into a concentrated toluene solution at $-35{ }^{\circ} \mathrm{C} .{ }^{1} \mathrm{H}$ NMR $\left(400 \mathrm{MHz}\right.$, benzene- $\left.d_{6}, \delta / \mathrm{ppm}\right) 11.11(\mathrm{~s}, 4 \mathrm{H}$, ortho-tolyl-H), 7.68 (t, $J=7.4 \mathrm{~Hz}, 4 \mathrm{H}$, meta-phenyl-H), 6.72 (d, J = 7.5 Hz, 4H, ortho-phenyl$\mathrm{H}), 6.30$ (overlapping s and t, $6 \mathrm{H}$ (total), meta-mesityl-H (s, 4H), para-phenyl-H (t, 2H)), 5.75 (t, $J=7.5 \mathrm{~Hz}, 1 \mathrm{H}, 4$-pyridine-H), 4.65 (s, 4H, meta-tolyl-H), 3.73 (d, J=7.7 Hz, 2H, 2-pyridine-H), 1.93 (s, 6H, para-mesityl- $\left.\mathrm{CH}_{3}\right), 1.87$ (s, 12H, ortho-mesityl- $\left.\mathrm{CH}_{3}\right),-0.93$ (s, 2H, pyrrole-H), 
-5.49 (s, 6H, para-tolyl-CH $).{ }^{13} \mathrm{C}$ NMR (150 MHz, benzene- $\left.d_{6}, \delta / \mathrm{ppm}\right) 187.10,178.73,165.66$, $163.42,159.36,151.36,144.32,141.96,136.27,131.45,128.35,127.04,126.94,126.24,124.28$, 121.53, 116.28, 104.74, 91.78, 21.45, 19.37. $\left({ }^{\mathrm{Mes}} \mathrm{PDP}^{\mathrm{Ph}}\right) \mathrm{Fe}\left(\mathrm{N}_{4} \mathrm{Tol}_{2}\right)$ crystallizes as a toluene solvate. Analysis calcd for $\left({ }^{\mathrm{Mes}} \mathrm{PDP}^{\mathrm{Ph}}\right) \mathrm{Fe}\left(\mathrm{N}_{4} \mathrm{Tol}_{2}\right) \cdot \mathrm{C}_{7} \mathrm{H}_{8} \mathrm{C}_{53} \mathrm{H}_{52} \mathrm{FeN} \mathrm{N}_{4}$ : C, 78.27; H, 6.06; N, 9.98. Found: C, 77.87; H, 5.95; N, 10.27 .

\section{Preparation of $\left({ }^{\text {Mes }} \mathrm{PDP}^{\mathrm{Ph}}\right) \mathrm{Fe}\left(\mathrm{N}_{4} \mathrm{~B} n_{2}\right)(\mathrm{HN}=\mathrm{CHPh})$.}

To a $20 \mathrm{~mL}$ scintillation vial equipped with a magnetic stirrer was added $150 \mathrm{mg}(0.21$ mmol) of $\left({ }^{\mathrm{Mes}} \mathrm{PDP}^{\mathrm{Ph}}\right) \mathrm{Fe}(\mathrm{thf})$ in $10 \mathrm{~mL}$ of benzene. In a separate vial, $85 \mathrm{mg}(0.64 \mathrm{mmol})$ of benzyl azide was dissolved in $3 \mathrm{~mL}$ of benzene. The azide solution was added to the solution of the iron complex dropwise over the course of several minutes, inducing a darkening of the solution, accompanied by effervescence of $\mathrm{N}_{2}$. The reaction mixture was allowed to stir for $12 \mathrm{~h}$. The crude reaction mixture was filtered through a plug of Celite supported on a glass microfiber filter and collected in a $50 \mathrm{~mL}$ round-bottom flask. Here, $1 \mathrm{~mL}$ portions of benzene were used to extract the products from the Celite plug until washings were clear. Solvent was removed in vacuo, and a sample of the resulting red powder was subjected to ${ }^{1} \mathrm{H}$ NMR analysis, indicating the presence of $\left({ }^{\mathrm{Mes}} \mathrm{PDP}^{\mathrm{Ph}}\right) \mathrm{Fe}\left(\mathrm{N}_{4} \mathrm{Bn} 2\right)(\mathrm{HN}=\mathrm{CHPh})$. Analysis of the crude reaction mixture via Mössbauer spectroscopy indicated $\mathrm{Fe}\left(\{\mathrm{NHBn}\}_{2^{-}}{ }^{\mathrm{Mes}} \mathrm{PDP}^{\mathrm{Ph}}\right)$ and $\left({ }^{\mathrm{Mes}} \mathrm{PDP}^{\mathrm{Ph}}\right) \mathrm{Fe}\left(\mathrm{N}_{4} \mathrm{Bn}_{2}\right)(\mathrm{HN}=\mathrm{CHPh})$ as the only iron containing species present in the sample, in approximate 1:1 ratio. Crystallization via slow diffusion of pentane into a toluene solution of $\mathrm{Fe}\left(\{\mathrm{NHBn}\}_{2^{-}}{ }^{\mathrm{Mes}} \mathrm{PDP}^{\mathrm{Ph}}\right)$ and $\left({ }^{\mathrm{Mes}} \mathrm{PDP}^{\mathrm{Ph}}\right) \mathrm{Fe}\left(\mathrm{N}_{4} \mathrm{Bn}_{2}\right)(\mathrm{HN}=\mathrm{CHPh})$ afforded crystals of $\left({ }^{\text {Mes }} \mathrm{PDP}^{\mathrm{Ph}}\right) \mathrm{Fe}\left(\mathrm{N}_{4} \mathrm{Bn}_{2}\right)(\mathrm{HN}=\mathrm{CHPh})$ suitable for study via X-ray. ${ }^{1} \mathrm{H}$ NMR (600 MHz, benzene- $d_{6}$;

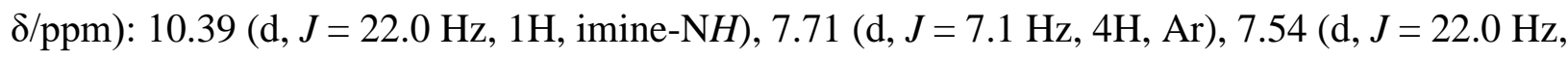
1H, imine-CH), 7.30 (d, $J=8.0 \mathrm{~Hz}, 2 \mathrm{H}, \mathrm{Ar}), 7.25$ (t, $J=7.6 \mathrm{~Hz}, 4 \mathrm{H}, \mathrm{Ar}), 7.10-7.07$ (m, 4H, Ar), 
6.98-6.82 (m, 4H, Ar), 6.79 (m, 2H, Ar), 6.50 (d, $J=8.4 \mathrm{~Hz}, 4 \mathrm{H}, \mathrm{Ar}), 6.11$ (s, 2H, pyrrole-H), $4.69\left(\mathrm{~s}, 2 \mathrm{H}\right.$, benzyl- $\left.\mathrm{CH}_{2}\right), 4.27$ (s, 2H, benzyl- $\left.\mathrm{CH}_{2}\right), 2.27$ (s, 6H, mesityl- $\left.\mathrm{CH}_{3}\right), 1.88(\mathrm{~s}, 6 \mathrm{H}$, mesityl- $\left.\mathrm{CH}_{3}\right), 1.43$ (s, $6 \mathrm{H}$, mesityl- $\mathrm{CH}_{3}$ ). Eight aryl protons could not be located and assigned unambiguously as they are obscured by benzene and toluene residual solvent peaks present in the ${ }^{1} \mathrm{H}$ NMR spectrum. ${ }^{13} \mathrm{C}$ NMR (151 MHz, benzene- $\left.d_{6}, \delta / \mathrm{ppm}\right) 174.06,155.79,147.68,139.31$, 138.91, 137.52, 137.25, 135.96, 135.78, 134.77, 134.72, 134.63, 132.64, 132.61, 131.49, 130.77, $130.59,129.97,129.57,129.21,128.65,127.28,126.88,126.57,126.35,118.14,109.98,69.91$, $66.22,22.06,21.44,20.76$. Three resonances were not located.

$\left({ }^{\text {Mes }} \mathrm{PDP}^{\mathrm{Ph}}\right) \mathrm{Fe}\left(\mathrm{N}_{4} \mathrm{Bn}_{2}\right)(\mathrm{HN}=\mathrm{CHPh})$ crystallizes as a toluene solvate. Analysis calcd for $\mathrm{C}_{64} \mathrm{H}_{58} \mathrm{FeN}_{8} \cdot \mathrm{C}_{7} \mathrm{H}_{8}: \mathrm{C}, 78.44 ; \mathrm{H}, 6.12 ; \mathrm{N}, 10.31$. Found: C, 78.21; H, 5.90; N, 10.36.

\section{Preparation of Fe(\{NHBn\}-MesPDPPh$)_{2}$.}

To a $20 \mathrm{~mL}$ scintillation vial equipped with a magnetic stirrer was added $150 \mathrm{mg}(0.21$ $\mathrm{mmol})$ of $\left({ }^{\mathrm{Mes}} \mathrm{PDP}{ }^{\mathrm{Ph}}\right) \mathrm{Fe}(\mathrm{thf})$ in $10 \mathrm{~mL}$ of benzene. In a separate vial, $85 \mathrm{mg}(0.64 \mathrm{mmol})$ of benzyl azide was dissolved in $3 \mathrm{~mL}$ of benzene. The azide solution was added to the solution of the iron complex dropwise over the course of several minutes, inducing a darkening of the solution, accompanied by effervescence of $\mathrm{N}_{2}$. The reaction mixture was allowed to stir for $12 \mathrm{~h}$. The crude reaction mixture was filtered through a plug of Celite supported on a glass microfiber filter and collected in a $50 \mathrm{~mL}$ round-bottom flask. One $\mathrm{mL}$ portions of benzene were used to extract the products from the Celite plug until washings were clear. Solvent was removed in vacuo and a sample of the resulting red powder was subjected to ${ }^{1} \mathrm{H}$ NMR analysis, indicating the presence of $\mathrm{Fe}\left(\{\mathrm{NHBn}\}_{2^{-}}{ }^{\mathrm{Mes}} \mathrm{PDP}^{\mathrm{Ph}}\right)$. Analysis of the crude reaction mixture via Mössbauer spectroscopy indicated $\mathrm{Fe}\left(\{\mathrm{NHBn}\}_{2^{-}}{ }^{\mathrm{Mes}} \mathrm{PDP}^{\mathrm{Ph}}\right)$ and $\left({ }^{\mathrm{Mes}} \mathrm{PDP}^{\mathrm{Ph}}\right) \mathrm{Fe}\left(\mathrm{N}_{4} \mathrm{Bn}_{2}\right)(\mathrm{HN}=\mathrm{CHPh})$ as the only iron containing species present in the sample, in approximate 1:1 ratio. Crystallization via 
slow diffusion of pentane into a toluene solution of $\mathrm{Fe}\left(\{\mathrm{NHBn}\}_{2^{-}}{ }^{\mathrm{Mes}} \mathrm{PDP} \mathrm{Ph}^{\mathrm{Ph}}\right)$ and $\left({ }^{\mathrm{Mes}} \mathrm{PDP}{ }^{\mathrm{Ph}}\right)-$ $\mathrm{Fe}\left(\mathrm{N}_{4} \mathrm{Bn}_{2}\right)(\mathrm{HN}=\mathrm{CHPh})$ afforded crystals of $\mathrm{Fe}\left(\{\mathrm{NHBn}\}_{2^{-}}{ }^{\mathrm{Mes}} \mathrm{PDP}^{\mathrm{Ph}}\right)$ suitable for study via X-ray crystallography. Analysis of the crystalline sample via ${ }^{1} \mathrm{H}$ NMR confirmed its identity as $\mathrm{Fe}\left(\{\mathrm{NHBn}\}_{2^{-}}{ }^{\mathrm{Mes}} \mathrm{PDP} \mathrm{Ph}^{\mathrm{Ph}}\right){ }^{1} \mathrm{H}$ NMR (400 MHz, benzene- $\left.d_{6} ; \delta / \mathrm{ppm}\right): 166.29,107.61,107.13$, $55.16,39.34,34.09,12.41,12.18,11.89,8.84,4.43,-6.07,-12.48,-71.38,-81.52$. Difficulty in attaining bulk purity of the compound, due to challenges associated with fractional crystallization of $\mathrm{Fe}\left(\{\mathrm{NHBn}\}-{ }^{\mathrm{Mes}} \mathrm{PDP}^{\mathrm{Ph}}\right)_{2}$ away from $\left({ }^{\mathrm{Mes}} \mathrm{PDP}^{\mathrm{Ph}}\right) \mathrm{Fe}\left(\mathrm{N}_{4} \mathrm{Bn}_{2}\right)(\mathrm{HN}=\mathrm{CHPh})$ precluded obtaining a sample suitable for elemental analysis.

\section{Preparation of $\left({ }^{M e s} \mathrm{PDP} P h\right) \mathrm{Fe}(\mathrm{NMes})$.}

To a J. Young NMR tube was added containing $10 \mathrm{mg}(0.012 \mathrm{mmols})$ of $\left({ }^{\mathrm{Mes}} \mathrm{PDP}{ }^{\mathrm{Ph}}\right) \mathrm{Fe}(\mathrm{thf})$ and $500 \mu \mathrm{L}$ of benzene- $d_{6}$, , affording a dark-red solution. In a separate dram vial was added $2 \mathrm{mg}\left(0.012 \mathrm{mmols}, 1.0\right.$ eq.) of mesityl azide and $100 \mu \mathrm{L}$ of benzene- $d_{6}$. The resulting azide solution was added to the NMR tube containing the solution of the iron complex, inducing an immediate color change of the solution to dark-brown. $\mathrm{A}^{1} \mathrm{H}$ NMR spectrum was acquired and indicated quantitative conversion of the starting material to a new paramagnetic species assigned as $\left({ }^{\mathrm{Mes}} \mathrm{PDP}{ }^{\mathrm{Ph}}\right) \mathrm{Fe}(\mathrm{NMes}) .{ }^{1} \mathrm{H}$ NMR (400 MHz, benzene- $\left.d_{6} ; \delta / \mathrm{ppm}\right):-214.36(3 \mathrm{H}$, p-MesCH$\left.H_{3}\right),-155.87\left(6 \mathrm{H}, o-\mathrm{MesCH}_{3}\right),-48.17$ (2H, $m$-MesCH), -6.89 (12H, o-MesCH $H_{3},-5.96$ (2H), $2.80\left(6 \mathrm{H}, p-\mathrm{MesCH}_{3}\right), 3.02(2 \mathrm{H}), 3.22(4 \mathrm{H}), 11.28(4 \mathrm{H}), 13.61(4 \mathrm{H}), 21.74(2 \mathrm{H})$. Note, the 4-pyridine resonance could not be unambiguously assigned. Additionally, resonances for free THF were not observed at 3.57 and $1.40 \mathrm{ppm}$, respectively, complicating the unambiguous assignment of the ${ }^{1} \mathrm{H}$ NMR spectrum. 


\section{Preparation of $\mathrm{Fe}\left(\mathrm{NHMes}^{\mathrm{Mes}}{ }^{\mathrm{PDP}} \mathrm{Ph}^{\mathrm{Ph}}\right)$.}

In a $20 \mathrm{~mL}$ scintillation vial, $48 \mathrm{mg}(0.066 \mathrm{mmol})$ of $\left({ }^{\mathrm{Mes}} \mathrm{PDP}^{\mathrm{Ph}}\right) \mathrm{Fe}(\mathrm{thf})$ was dissolved in 5 $\mathrm{mL}$ of benzene affording a dark-red solution. In a separate vial, $10 \mathrm{mg}$ of mesityl azide $(0.062$ mmol) was dissolved in approximately $5 \mathrm{~mL}$ of benzene. The azide solution was added to the solution of the iron complex, which induced a gradual darkening of the solution to brown-red. The mixture was allowed to stir for $18 \mathrm{hrs.} \mathrm{Solvent} \mathrm{was} \mathrm{removed} \mathrm{in} \mathrm{vacuo} \mathrm{leaving} \mathrm{a} \mathrm{dark} \mathrm{residue.}$ ${ }^{1} \mathrm{H}$ NMR analysis in benzene- $d_{6}$ of the crude reaction mixture revealed two paramagnetic species, one of which was identified as $\left({ }^{\mathrm{Mes}} \mathrm{PDP}^{\mathrm{Ph}}\right) \mathrm{Fe}(\mathrm{NMes})$ via comparison to an authentic sample. A crystallization was performed via diffusion of pentane into a concentrated benzene solution of the crude mixture and after $48 \mathrm{hrs}$. red crystals had formed that were found to be suitable for X-ray crystallography, which identified the additional product as $\mathrm{Fe}$ (NHMes$\left.{ }^{\mathrm{Mes}} \mathrm{PDP}^{\mathrm{Ph}}\right)$.

\section{Preparation of $\mathrm{Fe}\left(\mathrm{NH}\left(\mathrm{C}\left(\mathrm{CH}_{3}\right)_{2}\left(\mathrm{CH}_{2}\right)_{3}\right)^{\mathrm{Mes} P D P} P^{\mathrm{Ph}}\right)$.}

In a $20 \mathrm{~mL}$ scintillation vial equipped with a magnetic stirrer was combined $25 \mathrm{mg}(0.035$ mmols) of $\left({ }^{\mathrm{Mes}} \mathrm{PDP}^{\mathrm{Ph}}\right) \mathrm{Fe}(\mathrm{thf})$ and approximately $500 \mu \mathrm{L}$ of benzene- $d_{6}$. Vigorous stirring resulted in dissolution of all solids and formation of a dark-red solution. In a separate vial, $8 \mathrm{mg}(0.039$ mmols, 1.1 eq.) of 4-azido-4-methylpentylbenzene was dissolved in approximately $100 \mu \mathrm{L}$ of benzene- $d_{6}$, yielding a colorless solution. The solution of 4-azido-4-methylpentylbenzene was added dropwise via pipette to the stirring solution of $\left({ }^{\mathrm{Mes}} \mathrm{PDP}^{\mathrm{Ph}}\right) \mathrm{Fe}($ thf $)$. No evident color change or evolution of $\mathrm{N}_{2}$ gas was noted. The mixture was stirred for five minutes and then filtered through a glass microfiber plug into a J. Young NMR tube. After 8 hrs, ${ }^{1} \mathrm{H}$ NMR analysis indicated complete consumption of the starting material and quantitative formation of $\mathrm{Fe}\left(\mathrm{NH}\left(\mathrm{C}\left(\mathrm{CH}_{3}\right)_{2}\left(\mathrm{CH}_{2}\right)_{3}\right)^{\mathrm{Mes}} \mathrm{PDP}^{\mathrm{Ph}}\right)$. The solvent was removed in vacuo, leaving a dark-red film, 
subsequent trituration and washing with pentane which afforded a red powder. The material was taken up in a minimum amount of benzene $(1 \mathrm{~mL})$ and filtered through a pipette fitted with a glass microfiber plug into a dram vial. Diffusion of pentane into the benzene solution at ambient temperature afforded ruby colored plates of the title compound suitable for X-ray crystallographic analysis. ${ }^{1} \mathrm{H}$ NMR $\left(400 \mathrm{MHz}\right.$, benzene- $\left.d_{6}\right) \delta-92.76,-63.86,-10.93,-8.73,-4.55$, $-2.38,-1.59,-1.04,-0.46,1.82,3.21,3.33,3.86,6.51,7.77,7.98,8.34,10.44,11.18,11.65$ $13.72,14.44,16.46,23.28,97.45,104.03,104.94,107.83,112.98,116.60,202.64$.

\section{Physical Measurements.}

${ }^{1} \mathrm{H}$ and ${ }^{13} \mathrm{C}\left\{{ }^{1} \mathrm{H}\right\}$ NMR spectra were acquired at $25{ }^{\circ} \mathrm{C}$ on a Varian Unity INOVA 600 $\mathrm{MHz}$ spectrometer equipped with a $5 \mathrm{~mm}$ inverse broadband PFG probe, on an Agilent $400 \mathrm{MHz}$ DD2 spectrometer equipped with a 5 mm One NMR probe, or a JNM-ECZ400S/L1 spectrometer equipped with a $5 \mathrm{~mm}$ ROYAL NMR probe. All chemical shifts are reported relative to $\mathrm{SiMe}_{4}$ using ${ }^{1} \mathrm{H}$ (residual) chemical shifts of the solvent as a secondary standard. Elemental analyses were performed at Robertson Microlit Laboratories, Inc., in Ledgewood, NJ. Room temperature magnetic susceptibility measurements were performed with a Johnson Matthey Mark 1 instrument that was calibrated with $\mathrm{HgCo}(\mathrm{SCN})_{4}$. Zero field ${ }^{57} \mathrm{Fe}$ Mössbauer spectra were collected on a SEE Co. Mössbauer spectrometer (MS4) with a ${ }^{57} \mathrm{Co} / \mathrm{Rh}$ radiation source at $80 \mathrm{~K}$ in constant acceleration mode. The temperature in the sample chamber was controlled by a Janis Research Co. CCS-850 He/ $\mathrm{N}_{2}$ cryostat within an accuracy of $\pm 0.3 \mathrm{~K}$. The data were calibrated relative to $\alpha$-iron at $298 \mathrm{~K}$. The fitting procedure to extract quantitative spectral parameters uses a least-squares Lorentzian fitting method implemented in the WMOSS software developed by SEE Co. 


\section{$X$-ray Crystallography.}

Single crystals suitable for X-ray diffraction were coated with polyisobutylene oil (Sigma-Aldrich) in a drybox, mounted on a nylon loop, and then quickly transferred to the goniometer head of a Bruker AXS D8 Venture fixed-chi X-ray diffractometer equipped with a Triumph monochromator, a Mo K $\alpha$ radiation source $(\lambda=0.71073 \AA$ ), and a PHOTON 100 CMOS detector. The samples were cooled to $100 \mathrm{~K}$ with an Oxford Cryostream 700 system and optically aligned. The APEX3 software program (version 2016.9-0) ${ }^{77}$ was used for diffractometer control, preliminary frame scans, indexing, orientation matrix calculations, leastsquares refinement of cell parameters, and the data collection. Three sets of 12 frames each were collected using the omega scan method with a $10 \mathrm{~s}$ exposure time. Integration of these frames followed by reflection indexing and least-squares refinement produced a crystal orientation matrix for the crystal lattice that was used for the structural analysis. The data collection strategy was optimized for completeness and redundancy using the Bruker COSMO software suite. The space group was identified, and the data were processed using the Bruker SAINT+ program and corrected for absorption using SADABS. The structures were solved using direct methods (SHELXS) completed by subsequent Fourier synthesis and refined by full-matrix least-squares procedures using the programs provided by SHELXL-2014. ${ }^{78}$

\section{Density Functional Theory Calculations.}

All DFT calculations were performed with the ORCA program package. ${ }^{79}$ Geometry optimizations of the complexes and single-point calculations on the optimized geometries were carried out at the B3LYP level of DFT. ${ }^{80-82}$ The all-electron Gaussian basis sets were those developed by the Ahlrichs group. ${ }^{83-85}$ Triple- $\zeta$ quality basis sets def2-TZVP with one set of polarization functions on the metal and on the atoms directly coordinated to the metal center 
were used. For the carbon and hydrogen atoms, slightly smaller polarized split-valence def2-SVP basis sets were used that were of double- $\zeta$ quality in the valence region and contained a polarizing set of $d$ functions on the nonhydrogen atoms. Auxiliary basis sets to expand the electron density in the resolution-of-the-identity (RIJCOSX) ${ }^{86-88}$ approach were chosen to match the orbital basis. ${ }^{89-91}$ Throughout this chapter computational results are described by using the broken-symmetry (BS) approach by Ginsberg ${ }^{92}$ and Noodleman. ${ }^{93}$ Because several broken symmetry solutions to the spin-unrestricted Kohn-Sham equations may be obtained, the general notation $\mathrm{BS}(m, n)$ has been adopted, where $m(n)$ denotes the number of spin-up (spin-down) electrons at the two interacting fragments. All molecular orbital and spin density plots were generated using the program Gabedit. ${ }^{94}$ Nonrelativistic single-point calculations on the optimized geometry were carried out to predict Mössbauer spectral parameters (isomer shifts and quadrupole splittings). These calculations employed the $\mathrm{CP}(\mathrm{PPP})$ basis set for iron. ${ }^{95}$ Mössbauer isomer shifts were calculated from the computed electron densities at the iron centers as previously described..$^{64,96}$

\section{Accession Codes}

CCDC entries 1918285-1918288 contain the supplementary crystallographic data for some of the compounds described in this chapter. 


\section{References}

1. Driver, T. G. Recent Advances in Transition Metal-Catalyzed N Atom Transfer Reactions of Azides. Org. Biomol. Chem. 2010, 8, 3831-3846.

2. Wang, P.; Deng, L. Recent Advances in Iron-Catalyzed C-H Bond Amination via Iron Imido Intermediate. Chin. J. Chem. 2018, 36, 1222-1240.

3. Park, Y.; Kim, Y.; Chang, S. Transition Metal-Catalyzed C-H Amination: Scope, Mechanism, and Applications. Chem. Rev. 2017, 117, 9247-9301.

4. Zhang, L.; Deng, L. C-H Bond Amination by Iron-Imido/Nitrene Species. Chin. Sci. Bull. 2012, 57, 2352-2360.

5. Che, C.; Zhou, C.; Wong, E. L. Catalysis by Fe = X Complexes $\left(\mathrm{X}=\mathrm{NR}, \mathrm{CR}_{2}\right)$. Top. Organomet. Chem. 2011, 33, 111-138.

6. Jung, N.; Bräse, S. New Catalysts for the Transition-Metal-Catalyzed Synthesis of Aziridines. Angew. Chem., Int. Ed. 2012, 51, 5538-5540.

7. Chandrachud, P. P.; Jenkins, D. M. Transition Metal Aziridination Catalysis. Encycl. Inorg. Bioinorg. Chem. 2017, 1-11.

8. Cramer, S. A.; Jenkins, D. M. Synthesis of Aziridines from Alkenes and Aryl Azides with a Reusable Macrocyclic Tetracarbene Iron Catalyst. J. Am. Chem. Soc. 2011, 133, 19342-19345.

9. Ortiz de Montellano, P. R. Hydrocarbon Hydroxylation by Cytochrome P450 Enzymes. Chem. Rev. 2010, 110, 932-948.

10. Abu-Omar, M. M.; Loaiza, A.; Hontzeas, N. Reaction Mechanisms of Mononuclear NonHeme Iron Oxygenases. Chem. Rev. 2005, 105, 2227-2252.

11. Svastits, E. W.; Dawson, J. H.; Breslow, R.; Gellman, S. H. Functionalized Nitrogen Atom Transfer Catalyzed by Cytochrome P-450. J. Am. Chem. Soc. 1985, 107, 6427-6428. 
12. McIntosh, J. A.; Coelho, P. S.; Farwell, C. C.; Wang, Z. J.; Lewis, J. C.; Brown, T. R.; Arnold, F. H. Enantioselective Intramolecular C-H Amination Catalyzed by Engineered Cytochrome P450 Enzymes in Vitro and in Vivo. Angew. Chem., Int. Ed. 2013, 52, 9309-9312. 13. Singh, R.; Bordeaux, M.; Fasan, R. P450-Catalyzed Intramolecular $\mathrm{sp}^{3} \mathrm{C}-\mathrm{H}$ Amination with Arylsulfonyl Azide Substrates. ACS Catal. 2014, 4, 546-552.

14. Singh, R.; Kolev, J. N.; Sutera, P. A.; Fasan, R. Enzymatic C(sp³)-H Amination: P450Catalyzed Conversion of Carbonazidates into Oxazolidinones. ACS Catal. 2015, 5, 1685-1691.

15. Hyster, T. K.; Farwell, C. C.; Buller, A. R.; McIntosh, J. A.; Arnold, F. H. EnzymeControlled Nitrogen-Atom Transfer Enables Regiodivergent C-H Amination. J. Am. Chem. Soc. 2014, 136, 15505-15508.

16. Breslow, R.; Gellman, S. H. Tosylamidation of Cyclohexane by a Cytochrome P-450 Model. J. Chem. Soc., Chem. Commun. 1982, 1400-1401.

17. Breslow, R.; Gellman, S. H. Intramolecular Nitrene C-H Insertions Mediated by TransitionMetal Complexes as Nitrogen Analogues of Cytochrome P-450 Reactions. J. Am. Chem. Soc. 1983, 105, 6728-6729.

18. Fantauzzi, S.; Caselli, A.; Gallo, E. Nitrene Transfer Reactions Mediated by MetalloPorphyrin Complexes. Dalt. Trans. 2009, 5434-5443.

19. Liu, Y.; Che, C. M. [Fe $\left.{ }^{\mathrm{III}}\left(\mathrm{F}_{20}-\mathrm{TPP}\right) \mathrm{Cl}\right]$ Is an Effective Catalyst for Nitrene Transfer Reactions and Animation of Saturated Hydrocarbons with Sulfonyl and Aryl Azides as Nitrogen Source Under Thermal and Microwave-Assisted Conditions. Chem. Eur. J. 2010, 16, 10494-10501. 20. Brown, S. D.; Betley, T. A.; Peters, J. C. A Low-Spin d ${ }^{5}$ Iron Imide: Nitrene Capture by Low-Coordinate Iron(I) Provides the 4-Coordinate Fe(III) Complex $\left[\mathrm{PhB}\left(\mathrm{CH}_{2} \mathrm{PPh}_{2}\right)_{3}\right] \mathrm{Fe} \equiv \mathrm{N}-\mathrm{p}-$ Tolyl. J. Am. Chem. Soc. 2003, 125, 322-323. 
21. Brown, S. D.; Peters, J. C. Hydrogenolysis of $\left[\mathrm{PhBP}_{3}\right] \mathrm{Fe} \equiv \mathrm{N}-\mathrm{p}$-Tolyl: Probing the Reactivity of an Iron Imide with $\mathrm{H}_{2}$. J. Am. Chem. Soc. 2004, 126, 4538-4539.

22. Cowley, R. E.; Deyonker, N. J.; Eckert, N. A.; Cundari, T. R.; Debeer, S.; Bill, E.;

Ottenwaelder, X.; Flaschenriem, C.; Holland, P. L. Three-Coordinate Terminal Imidoiron(III)

Complexes: Structure, Spectroscopy, and Mechanism of Formation. Inorg. Chem. 2010, 49, $6172-6187$.

23. Cowley, R. E.; Eckert, N. A.; Vaddadi, S.; Figg, T. M.; Cundari, T. R.; Holland, P. L. Selectivity and Mechanism of Hydrogen Atom Transfer by an Isolable Imidoiron(III) Complex. J. Am. Chem. Soc. 2011, 133, 9796-9811.

24. Bowman, A. C.; Milsmann, C.; Bill, E.; Turner, Z. R.; Lobkovsky, E. B.; DeBeer, S.;

Wieghardt, K.; Chirik, P. J. Synthesis and Electronic Structure Determination of N-AlkylSubstituted Bis(Imino)Pyridine Iron Imides Exhibiting Spin Crossover Behavior. J. Am. Chem. Soc. 2011, 133, 17353-17369.

25. Moret, M. E.; Peters, J. C. Terminal Iron Dinitrogen and Iron Imide Complexes Supported by a Tris(Phosphino)Borane Ligand. Angew. Chem., Int. Ed. 2011, 50, 2063-2067.

26. Cowley, R. E.; Holland, P. L. Ligand Effects on Hydrogen Atom Transfer from Hydrocarbons to Three-Coordinate Iron Imides. Inorg. Chem. 2012, 51, 8352-8361.

27. Leeladee, P.; Jameson, G. N. L.; Siegler, M. A.; Kumar, D.; DeVisser, S. P.; Goldberg, D. P. Generation of a High-Valent Iron Imido Corrolazine Complex and NR Group Transfer Reactivity. Inorg. Chem. 2013, 52, 4668-4682.

28. Searles, K.; Fortier, S.; Khusniyarov, M. M.; Carroll, P. J.; Sutter, J.; Meyer, K.; Mindiola, D. J.; Caulton, K. G. A Cis-Divacant Octahedral and Mononuclear Iron(IV) Imide. Angew. Chem., Int. Ed. 2014, 53, 14139-14143. 
29. Zhang, H.; Ouyang, Z.; Liu, Y.; Zhang, Q.; Wang, L.; Deng, L.

(Aminocarbene)(Divinyltetramethyldisiloxane)Iron(0) Compounds: A Class of Low-Coordinate Iron(0) Reagents. Angew. Chem., Int. Ed. 2014, 53, 8432-8436.

30. Kuppuswamy, S.; Powers, T. M.; Johnson, B. M.; Brozek, C. K.; Krogman, J. P.; Bezpalko, M. W.; Berben, L. A.; Keith, J. M.; Foxman, B. M.; Thomas, C. M. One-Electron Oxidation Chemistry and Subsequent Reactivity of Diiron Imido Complexes. Inorg. Chem. 2014, 53, 54295437.

31. Wang, L.; Hu, L.; Zhang, H.; Chen, H.; Deng, L. Three-Coordinate Iron(IV) Bisimido

Complexes with Aminocarbene Ligation: Synthesis, Structure, and Reactivity. J. Am. Chem. Soc. 2015, 137, 14196-14207.

32. Brown, S. D.; Peters, J. C. Ground-State Singlet $\mathrm{L}_{3} \mathrm{Fe}-(\mu-\mathrm{N})-\mathrm{FeL}_{3}$ and $\mathrm{L}_{3} \mathrm{Fe}(\mathrm{NR})$ Complexes Featuring Pseudotetrahedral Fe(II) Centers. J. Am. Chem. Soc. 2005, 127, 1913-1923.

33. Jacobs, B. P.; Wolczanski, P. T.; Jiang, Q.; Cundari, T. R.; MacMillan, S. N. Rare Examples of Fe(IV) Alkyl-Imide Migratory Insertions: Impact of Fe-C Covalency in $\left(\mathrm{Me}_{2} \operatorname{IPr}\right) \mathrm{Fe}(=\mathrm{NAd}) \mathrm{R}_{2}$ ( $\mathrm{R}={ }^{\mathrm{Neo}} \mathrm{Pe}, 1$-Nor). J. Am. Chem. Soc. 2017, 139, 12145-12148.

34. Kuppuswamy, S.; Powers, T. M.; Johnson, B. M.; Bezpalko, M.W.; Brozek, C. K.; Foxman, B. M.; Berben, L. A.; Thomas, C. M. Metal-Metal Interactions in $\mathrm{C}_{3}$-Symmetric Diiron Imido Complexes Linked by Phosphinoamide Ligands. Inorg. Chem. 2013, 52, 4802-4811.

35. Bucinsky, L.; Breza, M.; Lee, W. T.; Hickey, A. K.; Dickie, D. A.; Nieto, I.; Degayner, J. A.; Harris, T. D.; Meyer, K.; Krzystek, J.; Ozarowski, A.; Nehrkorn, J.; Schnegg, A.; Holldack, K.; Herber, R. H.; Telser, J.; Smith, J. M. Spectroscopic and Computational Studies of Spin States of Iron(IV) Nitrido and Imido Complexes. Inorg. Chem. 2017, 56, 4751-4768. 
36. Lucas, R. L.; Powell, D. R.; Borovik, A. S. Preparation of Iron Amido Complexes via Putative Fe(IV) Imido Intermediates. J. Am. Chem. Soc. 2005, 127, 11596-11597.

37. Bart, S. C.; Lobkovsky, E.; Bill, E.; Chirik, P. J. Synthesis and Hydrogenation of Bis(Imino)Pyridine Iron Imides. J. Am. Chem. Soc. 2006, 128, 5302-5303.

38. Thomas, C. M.; Mankad, N. P.; Peters, J. C. Characterization of the Terminal Iron(IV) Imides $\left\{\left[\mathrm{PhBPtBu}_{2}\left(\mathrm{Pz}^{\prime}\right)\right] \mathrm{FeIV} \equiv \mathrm{NAd}\right\}^{+}$. J. Am. Chem. Soc. 2006, 128, 4956-4957.

39. Eckert, N. A.; Vaddadi, S.; Stoian, S.; Lachicotte, R. J.; Cundari, T. R.; Holland, P. L. Coordination-Number Dependence of Reactivity in an Imidoiron(III) Complex. Angew. Chem., Int. Ed. 2006, 45, 6868-6871.

40. Ni, C.; Fettinger, J. C.; Long, G. J.; Brynda, M.; Power, P. P. Reaction of a Sterically Encumbered Iron(I) Aryl/Arene with Organoazides: Formation of an Iron(V) Bis(Imide). Chem. Commun. 2008, 45, 6045-6047.

41. Nieto, I.; Ding, F.; Bontchev, R. P.; Wang, H.; Smith, J. M. Thermodynamics of Hydrogen Atom Transfer to a High-Valent Iron Imido Complex. J. Am. Chem. Soc. 2008, 130, 2716-2717. 42. Cowley, R. E.; Eckert, N. A.; Elhaïk, J.; Holland, P. L. Catalytic Nitrene Transfer from an Imidoiron(III) Complex to Form Carbodiimides and Isocyanates. Chem. Commun. 2009, 17601762.

43. King, E. R.; Hennessy, E. T.; Betley, T. A. Catalytic C-H Bond Amination from High-Spin Iron Imido Complexes. J. Am. Chem. Soc. 2011, 133, 4917-4923.

44. Iovan, D. A.; Betley, T. A. Characterization of Iron-Imido Species Relevant for N-Group Transfer Chemistry. J. Am. Chem. Soc. 2016, 138, 1983-1993.

45. Wilding, M. J. T.; Iovan, D. A.; Betley, T. A. High-Spin Iron Imido Complexes Competent for C-H Bond Amination. J. Am. Chem. Soc. 2017, 139, 12043-12049. 
46. Wilding, M. J. T.; Iovan, D. A.; Wrobel, A. T.; Lukens, J. T.; Macmillan, S. N.; Lancaster, K. M.; Betley, T. A. Direct Comparison of C-H Bond Amination Efficacy through Manipulation of Nitrogen-Valence Centered Redox: Imido versus Iminyl. J. Am. Chem. Soc. 2017, 139, 1475714766.

47. Dekker, M.; Knox, G. R. Nitrene Capture by Iron Carbonyls. Chem. Commun. 1967, $1243-1244$.

48. Doedens, R. J. Molecular Configuration of $(\mathrm{Me})_{2} \mathrm{~N}_{4} \mathrm{Fe}(\mathrm{CO})_{3}$, a Tetrazadiene-Tricarbonyliron Complex. Chem. Commun. 1968, 0, 1271-1272.

49. Hansert, B.; Vahrenkamp, H. Preparation, Structure, and Some Reactions of the Evasive Azobenzene Complex $\left[\mathrm{Fe}_{2}(\mathrm{CO})_{6}\left(\mu-\mathrm{Ph}_{2} \mathrm{~N}_{2}\right)\right]$. J. Organomet. Chem. 1993, 459, 265-269.

50. Mock, M. T.; Popescu, C. V.; Yap, G. P. A.; Dougherty, W. G.; Riordan, C. G. Monovalent Iron in a Sulfur-Rich Environment. Inorg. Chem. 2008, 47, 1889-1891.

51. Cowley, R. E.; Bill, E.; Neese, F.; Brennessel, W. W.; Holland, P. L. Iron(II) Complexes with Redox-Active Tetrazene (RNNNNR) Ligands. Inorg. Chem. 2009, 48, 4828-4836.

52. Cramer, S. A.; Hernández Sánchez, R.; Brakhage, D. F.; Jenkins, D. M. Probing the Role of an $\mathrm{Fe}^{\mathrm{IV}}$ Tetrazene in Catalytic Aziridination. Chem. Commun. 2014, 50, 13967-13970.

53. Hashimoto, T.; Hoshino, R.; Hatanaka, T.; Ohki, Y.; Tatsumi, K. Dinuclear Iron(0) Complexes of N-Heterocyclic Carbenes. Organometallics 2014, 33, 921-929.

54. Yousif, M.; Wannipurage, D.; Huizenga, C. D.; Washnock-Schmid, E.; Peraino, N. J.; Ozarowski, A.; Stoian, S. A.; Lord, R. L.; Groysman, S. Catalytic Nitrene Homocoupling by an Iron(II) Bis(Alkoxide) Complex: Bulking Up the Alkoxide Enables a Wider Range of Substrates and Provides Insight into the Reaction Mechanism. Inorg. Chem. 2018, 57, 9425-9438. 
55. Bellow, J. A.; Yousif, M.; Cabelof, A. C.; Lord, R. L.; Groysman, S. Reactivity Modes of an Iron Bis(Alkoxide) Complex with Aryl Azides: Catalytic Nitrene Coupling vs Formation of Iron(III) Imido Dimers. Organometallics 2015, 34, 2917-2923.

56. Hennessy, E. T.; Betley, T. A. Complex N-Heterocycle Synthesis via Iron-Catalyzed, Direct C-H Bond Amination. Science 2013, 340, 591-595.

57. King, E. R.; Betley, T. A. C-H Bond Amination from a Ferrous Dipyrromethene Complex. Inorg. Chem. 2009, 48, 2361-2363.

58. Hennessy, E. T.; Liu, R. Y.; Iovan, D. A.; Duncan, R. A.; Betley, T. A. Iron-Mediated Intermolecular N-Group Transfer Chemistry with Olefinic Substrates. Chem. Sci. 2014, 5, 15261532.

59. Iovan, D. A.; Wilding, M. J. T.; Baek, Y.; Hennessy, E. T.; Betley, T. A. Diastereoselective C-H Bond Amination for Disubstituted Pyrrolidines. Angew. Chem., Int. Ed. 2017, 56, 1559915602.

60. Hakey, B. M.; Darmon, J. M.; Zhang, Y.; Petersen, L.; Milsmann, C. Synthesis and Electronic Structure of Neutral Square-Planar High-Spin Iron(II) Complexes Supported by a Dianionic Pincer Ligand. Inorg. Chem. 2019, 58, 1252-1266.

61. Grant, L. N.; Carroll, M. E.; Carroll, P. J.; Mindiola, D. J. An Unusual Cobalt Azide Adduct That Produces a Nitrene Species for Carbon-Hydrogen Insertion Chemistry. Inorg. Chem. 2016, $55,7997-8002$.

62. Roy, N.; Sproules, S.; Bill, E.; Weyhermueller, T.; Wieghardt, K. Molecular and Electronic Structure of the Square Planar Bis(o-Amidobenzenethiolato)Iron(III) Anion and Its Bis(oQuinoxalinedithiolato)Iron(III) Analogue. Inorg. Chem. 2008, 47, 10911-10920. 
63. Bellows, S. M.; Brennessel, W. W.; Holland, P. L. Effects of Ligand Halogenation on the Electron Localization, Geometry and Spin State of Low-Coordinate ( $\beta$-Diketiminato)Iron Complexes. Eur. J. Inorg. Chem. 2016, 2016, 3344-3355.

64. Römelt, M.; Ye, S.; Neese, F. Calibration of Modern Density Functional Theory Methods for the Prediction of ${ }^{57} \mathrm{Fe}$ Mössbauer Isomer Shifts : Meta-GGA and Double-Hybrid Functionals. Inorg. Chem. 2009, 48, 784-785.

65. Bachler, V.; Olbrich, G.; Neese, F.; Wieghardt, K. Theoretical Evidence for the Singlet Diradical Character of Square Planar Nickel Complexes Containing Two $o$-Semiquinonato Type Ligands. Inorg. Chem. 2002, 41, 4179-4193.

66. Ye, S.; Neese, F. Accurate Modeling of Spin-State Energetics in Spin-Crossover Systems with Modern Density Functional Theory. Inorg. Chem. 2010, 49, 772-774.

67. Albertin, G.; Antoniutti, S.; Baldan, D.; Castro, J.; García-Fontän, S. Preparation of Benzyl Azide Complexes of Iridium(III). Inorg. Chem. 2008, 47, 742-748.

68. Risse, J.; Scopelliti, R.; Severin, K. Beyond Click-Chemistry: Transformation of Azides with Cyclopentadienyl Ruthenium Complexes. Organometallics 2011, 30, 3412-3418.

69. Lo, Y. H.; Wang, T. H.; Lee, C. Y.; Feng, Y. H. Preparation, Characterization, and Reactivity of Azido Complex Containing a $\mathrm{Tp}\left({ }^{\mathrm{t}} \mathrm{BuNC}\right)\left(\mathrm{PPh}_{3}\right) \mathrm{Ru}$ Fragment and Ruthenium-Catalyzed Cycloaddition of Organic Azides with Alkynes in Organic and Aqueous Media. Organometallics 2012, 31, 6887-6899.

70. Albertin, G.; Antoniutti, S.; Bonaldo, L.; Botter, A.; Castro, J. Azo Complexes of Osmium(II): Preparation and Reactivity of Organic Azide and Hydrazine Derivatives. Inorg. Chem. 2013, 52, 2870-2879. 
71. Baek, Y.; Betley, T. A. Catalytic C-H Amination Mediated by Dipyrrin Cobalt Imidos. J. Am. Chem. Soc. 2019, 141, 7797-7806.

72. Russell, S. K.; Lobkovsky, E.; Chirik, P. J. N-N Bond Cleavage in Diazoalkanes by a Bis(Imino)Pyridine Iron Complex. J. Am. Chem. Soc. 2009, 131, 36-37.

73. Brönstrup, M.; Kretzschmar, I.; Schröder, D.; Schwarz, H. Iron-Mediated Amination of Hydrocarbons in the Gas Phase. Helv. Chim. Acta 1998, 81, 2348-2369.

74. Kutonova, K. V.; Trusova, M. E.; Postnikov, P.; Filimonov, V. D.; Parello, J. A Simple and Effective Synthesis of Aryl Azides via Arenediazonium Tosylates. Synthesis 2013, 45, 27062710.

75. Zhao, J.; Li, Z.; Yan, S.; Xu, S.; Wang, M. A.; Fu, B.; Zhang, Z. Pd/C Catalyzed Carbonylation of Azides in the Presence of Amines. Org. Lett. 2016, 18, 1736-1739. 76. Alvarez, S. G.; Alvarez, M. T. A Practical Procedure for the Synthesis of Alkyl Azides at Ambient Temperature in Dimethyl Sulfoxide in High Purity and Yield. Synthesis 1997, 4, 413414.

77. APEX3 is a Bruker AXS crystallographic software package for single crystal data collection, reduction and preparation.

78. Sheldrick, G. M. SHELXL-2014, Crystallographic Software Package; Bruker AXS, Inc.: Madison, Wisconsin, USA.

79. Neese, F. The ORCA Program System. Wiley Interdiscip. Rev. Comput. Mol. Sci. 2012, 2, 73-78.

80. Becke, A. D. Density Functional Calculations of Molecular Bond Energies. J. Chem. Phys. 1986, $84,4524-4529$. 
81. Becke, A. D. Density-Functional Thermochemistry. III. The Role of Exact Exchange. J. Chem. Phys. 1993, 98, 5648-5652.

82. Lee, C.; Yang, W.; Parr, R. G. Development of the Colle-Salvetti Correlation-Energy Formula into a Functional of the Electron Density. Phys. Rev. B: Condens. Matter Mater. Phys. 1988, $37,785-789$.

83. Schäfer, A.; Horn, H.; Ahlrichs, R. Fully Optimized Contracted Gaussian-Basis Sets for Atoms Li to Kr. J. Chem. Phys. 1992, 97, 2571-2577.

84. Schäfer, A.; Huber, C.; Ahlrichs, R. Fully Optimized Contracted Gaussian Basis Sets of Triple Zeta Valence Quality for Atoms Li to Kr. J. Chem. Phys. 1994, 100, 5829.

85. Weigend, F.; Ahlrichs, R. Balanced Basis Sets of Split Valence, Triple Zeta Valence and Quadruple Zeta Valence Quality for H to Rn: Design and Assessment of Accuracy. Phys. Chem. Chem. Phys. 2005, 7, 3297-3305.

86. Neese, F.; Wennmohs, F.; Hansen, A.; Becker, U. Efficient, Approximate and Parallel Hartree-Fock and Hybrid DFT Calculations. A "Chain-of-Spheres" Algorithm for the HartreeFock Exchange. Chem. Phys. 2009, 356, 98-109.

87. Kossmann, S.; Neese, F. Comparison of Two Efficient Approximate Hartee-Fock Approaches. Chem. Phys. Lett. 2009, 481, 240-243.

88. Neese, F. An Improvement of the Resolution of the Identity Approximation for the Formation of the Coulomb Matrix. J. Comput. Chem. 2003, 24, 1740-1747.

89. Eichkorn, K.; Treutler, O.; Öhm, H.; Häser, M.; Ahlrichs, R. Auxiliary Basis Sets to Approximate Coulomb Potentials. Chem. Phys. Lett. 1995, 240, 283-289. 
90. Eichkorn, K.; Treutler, O.; Öhm, H.; Häser, M.; Ahlrichs, R. Erratum: Auxiliary Basis Sets to Approximate Coulomb Potentials (Chem. Phys. Letters 240 (1995) 283). Chem. Phys. Lett. 1995, $242,652-660$.

91. Eichkorn, K.; Weigend, F.; Treutler, O.; Ahlrichs, R. Auxiliary Basis Sets for Main Row Atoms and Transition Metals and Their Use to Approximate Coulomb Potentials. Theor. Chem. Acc. 1997, 97, 119-124.

92. Ginsberg, A. P. Magnetic Exchange in Transition Metal Complexes 12. Calculation of Cluster Exchange Coupling Constants with the X $\alpha$-Scattered Wave Method. J. Am. Chem. Soc. 1980, 102, 111-117.

93. Noodleman, L.; Peng, C. Y.; Case, D. A.; Mouesca, J. M. Orbital Interactions, Electron Delocalization and Spin Coupling in Iron-Sulfur Clusters. Coord. Chem. Rev. 1995, 144, 199244.

94. Allouche, A.-R. Gabedit-A Graphical User Interface for Computational Chemistry Softwares. J. Comput. Chem. 2011, 32, 174-182.

95. Neese, F. Prediction and Interpretation of the ${ }^{57}$ Fe Isomer Shift in Mössbauer Spectra by Density Functional Theory. Inorg. Chim. Acta 2002, 337, 181-192.

96. Sinnecker, S.; Slep, L. D.; Bill, E.; Neese, F. Performance of Nonrelativistic and QuasiRelativistic Hybrid DFT for the Prediction of Electric and Magnetic Hyperfine Parameters in ${ }^{57}$ Fe Mössbauer Spectra. Inorg. Chem. 2005, 44, 2245-2254. 


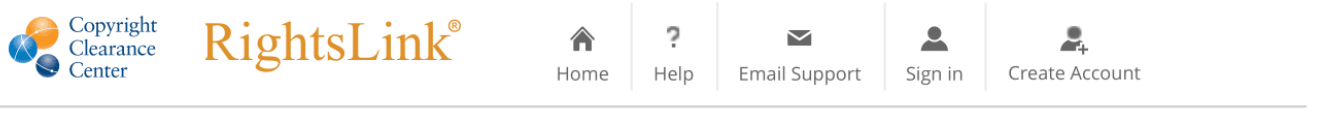

\section{ACS Publications Reactivity of Pyridine Dipyrrolide Iron(II) Complexes with} Organic Azides: C-H Amination and Iron Tetrazene Formation

Author: Brett M. Hakey, Jonathan M. Darmon, Novruz G. Akhmedov, et al

Publication: Inorganic Chemistry

Publisher: American Chemical Society

Date: Aug 1, 2019

Copyright @ 2019, American Chemical Society

\section{PERMISSION/LICENSE IS GRANTED FOR YOUR ORDER AT NO CHARGE}

This type of permission/license, instead of the standard Terms \& Conditions, is sent to you because no fee is being charged for your order. Please note the following:

- Permission is granted for your request in both print and electronic formats, and translations.

- If figures and/or tables were requested, they may be adapted or used in part.

- Please print this page for your records and send a copy of it to your publisher/graduate school.

- Appropriate credit for the requested material should be given as follows: "Reprinted (adapted) with permission

from (COMPLETE REFERENCE CITATION). Copyright (YEAR) American Chemical Society." Insert appropriate

information in place of the capitalized words.

- One-time permission is granted only for the use specified in your request. No additional uses are granted (such as

derivative works or other editions). For any other uses, please submit a new request.

BACK

CLOSE WINDOW

(c) 2020 Copyright - All Rights Reserved ｜ Copyright Clearance Center, Inc. I Privacy statement ｜ Terms and Conditions Comments? We would like to hear from you. E-mail us at customercare@copyright.com 

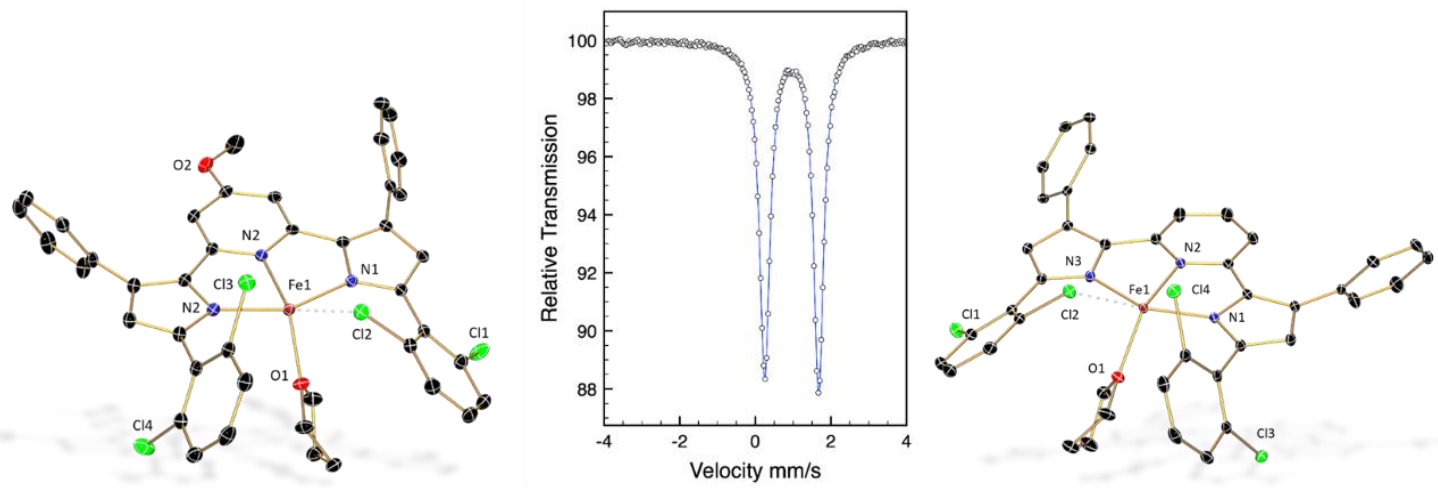

CHAPTER IV: SYNTHESIS AND CHARACTERIZATION OF HIGH-SPIN IRON(II) COMPLEXES OF VARIOUS PYRIDINE DIPYRROLIDE LIGANDS

\subsection{Abstract}

A family of high-spin $\mathrm{Fe}^{\mathrm{II}}$ complexes carrying the new pyridine dipyrrolide ligands $\mathrm{H}_{2}{ }^{\mathrm{tBu}} \mathrm{PDP}{ }^{\mathrm{Ph}}, \mathrm{H}_{2}{ }^{2,6-\mathrm{Cl} 2 \mathrm{Ph}} \mathrm{PDP}^{\mathrm{Ph}}, \mathrm{H}_{2} 4-\mathrm{MeO}^{2,6-\mathrm{Cl} 2 \mathrm{Ph}} \mathrm{PDP}^{\mathrm{Ph}}$ and $\mathrm{H}_{2}{ }^{\mathrm{C} 6 \mathrm{~F} 5} \mathrm{PDP}^{\mathrm{Ph}}$ was synthesized and structurally characterized. For $\mathrm{H}_{2}{ }^{\mathrm{tBu}} \mathrm{PDP}^{\mathrm{Ph}}$, it was discovered that four-coordinate $\left({ }^{\mathrm{tBu}} \mathrm{PDP}{ }^{\mathrm{Ph}}\right) \mathrm{Fe}\left(\mathrm{OEt}_{2}\right)$ or five-coordinate complexes $\left({ }^{\mathrm{tBu}} \mathrm{PDP}^{\mathrm{Ph}}\right) \mathrm{Fe}(\mathrm{thf})_{2}$, and $\left({ }^{\mathrm{tBu}} \mathrm{PDP}{ }^{\mathrm{Ph}}\right) \mathrm{Fe}(\mathrm{py})_{2}$ could be isolated depending on the identity of the exogenous Lewis base employed during synthesis. $\left({ }^{\mathrm{tBu}} \mathrm{PDP}{ }^{\mathrm{Ph}}\right) \mathrm{Fe}\left(\mathrm{OEt}_{2}\right)$ was found to undergo loss of the diethyl ether ligand in noncoordinating solvent, forming the dimeric species $\mathrm{Fe}_{2}\left(\mu_{2}-\kappa^{2}{ }_{-}{ }^{\mathrm{tBu}} \mathrm{PDP}^{\mathrm{Ph}}\right)_{2}$, as evidenced ${ }^{1} \mathrm{H} \mathrm{NMR}$ and Mössbauer spectroscopies. For $\mathrm{H}_{2}{ }^{2,6-\mathrm{Cl} 2 \mathrm{Ph}} \mathrm{PDP}^{\mathrm{Ph}}$ and $\mathrm{H}_{2} 4-\mathrm{MeO}^{2,6-\mathrm{Cl} 2 \mathrm{Ph}} \mathrm{PDP}^{\mathrm{Ph}}$, the four coordinate thf adducts $\left({ }^{2,6-\mathrm{Cl} 2 \mathrm{Ph}} \mathrm{PDP} \mathrm{Ph}^{\mathrm{Ph}}\right) \mathrm{Fe}($ thf $)$ and $\left(4-\mathrm{MeO}^{2,6-\mathrm{Cl} 2 \mathrm{Ph}} \mathrm{PDP}^{\mathrm{Ph}}\right) \mathrm{Fe}($ thf $)$ were synthesized. $\left.{ }^{2,6-\mathrm{Cl} 2 \mathrm{Ph}} \mathrm{PDP}^{\mathrm{Ph}}\right) \mathrm{Fe}($ thf $)$ was found to exhibit an equilibrium between four- and five-coordinate species in solution, which was supported by ${ }^{1} \mathrm{H}$ NMR and ${ }^{57} \mathrm{Fe}$ Mössbauer spectroscopy. For $\mathrm{H}_{2}{ }^{2,6-\mathrm{Cl} 2 \mathrm{Ph}} \mathrm{PDP}^{\mathrm{Ph}}$ and $\mathrm{H}_{2}{ }^{\mathrm{C} 6 \mathrm{~F} 5} \mathrm{PDP}^{\mathrm{Ph}}$, the five coordinate bis-pyridine adducts ( $\left.{ }^{2,6-\mathrm{Cl} 2 \mathrm{Ph}} \mathrm{PDP}{ }^{\mathrm{Ph}}\right) \mathrm{Fe}(\mathrm{py})_{2}$ and $\left(\mathrm{H}_{2}{ }^{\mathrm{C} 6 \mathrm{~F} 5} \mathrm{PDP}{ }^{\mathrm{Ph}}\right) \mathrm{Fe}(\mathrm{py})_{2}$ have been also been synthesized. 


\subsection{Introduction}

The manipulation of the coordination environments available to high-spin $\mathrm{Fe}^{\mathrm{II}} \mathrm{PDP}$ complexes has been demonstrated to have a profound impact upon the electronic structure of the resulting complexes. ${ }^{1-3}$ Recently, our group has reported a convenient synthetic procedure that allows access to pyridine dipyrrolide ligands with various substitution patterns at the 3- and 5pyrrolide positions as well as at the 4-pyridine position via tandem Stetter and Paul-Knorr reactions. ${ }^{4-6}$ The development of this protocol has allowed for the development of a library of PDP ligands which may find utility in systematically modifying the steric and electronic properties of the resulting iron complexes for desired applications. In the context of nitrene group transfer, it has been previously demonstrated that high-spin $\mathrm{Fe}^{\mathrm{II}} \mathrm{PDP}$ complexes are capable of decomposing organic azides to forming iron imido/iminyl complexes. ${ }^{3,7}$ The Mindiola and Caulton groups have shown that when a bulky tert-butyl substituent is present at the 5position of the PDP pyrrolide rings unusual cis-divacant octahedral iron complexes can be isolated, including a diamagnetic $\mathrm{Fe}^{\mathrm{IV}}$ imido complex. ${ }^{2,3,8}$ Surprisingly, this genuine $\mathrm{Fe}^{\mathrm{IV}}$ complex is unreactive towards $\mathrm{C}-\mathrm{H}$ bonds, possibly due to a lack of destabilization of the iron imido nitrogen bond. ${ }^{9}$ Alternatively, as demonstrated in Chapter 3, experimental and computational evidence demonstrates that when the 5-position of the PDP pyrrolides is a mesityl group, planar imido complexes best described as intermediate spin $\mathrm{Fe}^{\mathrm{III}}$ ions antiferromagnetically coupled to iminyl radicals are formed. ${ }^{7,10}$ These complexes are highly reactive and facilitate intramolecular $\mathrm{C}-\mathrm{H}$ amination of benzylic $\mathrm{C}-\mathrm{H}$ bonds present on the mesityl group of the PDP ligand. $\left({ }^{\mathrm{Mes}} \mathrm{PDP}{ }^{\mathrm{Ph}}\right) \mathrm{Fe}(\mathrm{NR})$ intermediates have also been shown to undergo tetrazene formation when the nitrene source is not sufficiently bulky, or alpha hydrogen atom abstraction, when hydrogen atoms are available in the position alpha to the intermediate 
nitrene. In consideration of the susceptibility for the ${ }^{\mathrm{Mes}} \mathrm{PDP}^{\mathrm{Ph}}$ supporting ligand to undergo facile $\mathrm{C}-\mathrm{H}$ amination, even when other benzylic $\mathrm{C}-\mathrm{H}$ bonds are present in the substrate, PDP ligands featuring more robust arene substitution were envisioned. It was anticipated that such ligands may be suitable for imparting stability onto $\left({ }^{\mathrm{Ar}} \mathrm{PDP}^{\mathrm{Ph}}\right) \mathrm{Fe}(\mathrm{NR})$ complexes and render them suitable for study and potential use as intermolecular group transfer reagents. Herein is described the synthesis and spectroscopic characterization of a new family of high-spin ferrous PDP complexes featuring robust substitution patterns at the 5-position of the pyrrole heterocycles, including $\mathrm{H}_{2}{ }^{\mathrm{tBu}} \mathrm{PDP}^{\mathrm{Ph}}, \mathrm{H}_{2}{ }^{2,6-\mathrm{ClPh}} \mathrm{PDP}^{\mathrm{Ph}}, \mathrm{H}_{2} 4-\mathrm{MeO}^{2,6 \mathrm{Cl} 2 \mathrm{Ph}} \mathrm{PDP}^{\mathrm{Ph}}$, and $\mathrm{H}_{2}{ }^{\mathrm{C} 6 \mathrm{~F} 5} \mathrm{PDP}^{\mathrm{Ph}}$.

\subsection{Synthesis and Characterization of $\left({ }^{(\mathrm{Bu}} \mathrm{PDP} \mathrm{P}^{\mathrm{Ph}}\right)$ High-Spin $\mathrm{Fe}^{\mathrm{II}}$ Complexes}

Due to unusual physical characteristics of $\left({ }^{\mathrm{Mes}} \mathrm{PDP}{ }^{\mathrm{Ph}}\right) \mathrm{Fe}(\mathrm{L})$ (where $\mathrm{L}=\mathrm{OEt}_{2}$ or THF), and $\left({ }^{\mathrm{tBu}} \mathrm{PDP}^{\mathrm{tBu}}\right) \mathrm{Fe}\left(\mathrm{OEt}_{2}\right),{ }^{1,3}$ (i.e., coordination environment and electronic structure), the synthesis of other high-spin Fe ${ }^{\mathrm{II}}$ PDP iron complexes was pursued. The synthesis of the new PDP ligand $\mathrm{H}_{2}{ }^{\mathrm{tBu}} \mathrm{PDP}{ }^{\mathrm{Ph}}$, an analogue to previously described $\mathrm{H}_{2}{ }^{\mathrm{tBu}} \mathrm{PDP}^{\mathrm{tBu}}$, was accomplished on a multigram scale via a tandem Stetter and Paul-Knorr reactions (Scheme 4.1) in $65 \%$ yield. ${ }^{1,4,5}$<smiles>[R]C=CC([R])=O</smiles>

Scheme 4.1. Synthesis of pyridine dipyrrolide ligands via tandem Stetter and Knorr reactions. 

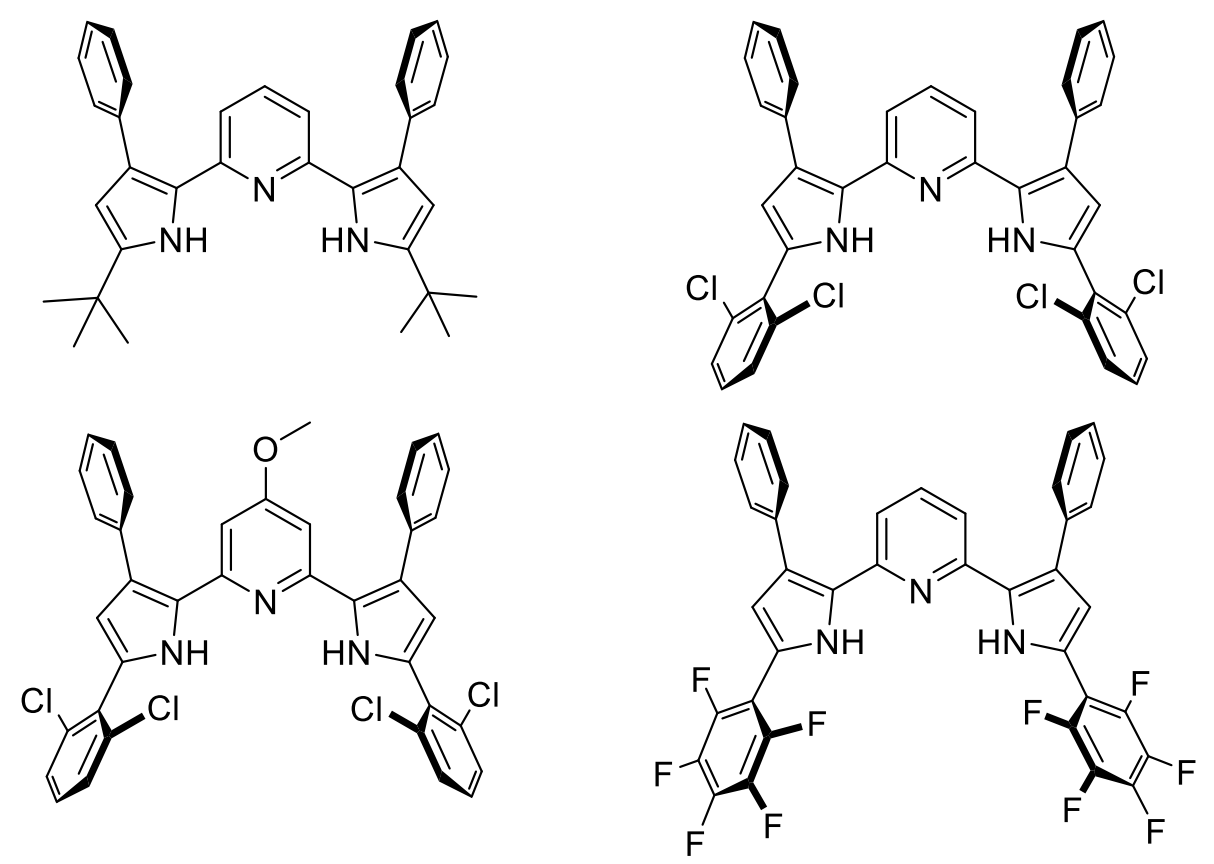

Figure 4.1. Pyridine dipyrrolide ligands used in this study.

In consideration of the diverse coordination chemistry of the previously described $\left({ }^{\mathrm{Mes}} \mathrm{PDP} \mathrm{Ph}^{\mathrm{Ph}} \mathrm{Fe}(\mathrm{L})_{n}\right.$ species, metalation of the new ligand precursors was explored via a variety of conditions. For $\mathrm{H}_{2}{ }^{\mathrm{tBu}} \mathrm{PDP}{ }^{\mathrm{Ph}}$, treatment of a diethyl ether solution of $\mathrm{Fe}\left[\mathrm{N}\left(\mathrm{SiMe}_{3}\right)_{2}\right]_{2}$ with a slurry of the ligand in the same solvent induced an immediate color change to red orange accompanied by precipitation of an orange solid. Following isolation by filtration, analysis of the resulting solid in benzene- $d_{6}$ solution via ${ }^{1} \mathrm{H}$ NMR spectroscopy indicated a $\mathrm{C}_{2 v}$ symmetric major product with nine paramagnetically shifted and broadened resonances. Integrations relative to the 4pyridine proton $(25.87 \mathrm{ppm})$ and tert-butyl protons $(33.52 \mathrm{ppm})$ were consistent with a product assignment as a diethyl ether adduct, $\left({ }^{(\mathrm{Bu} \mathrm{PDP}}{ }^{\mathrm{Ph}}\right) \mathrm{Fe}\left(\mathrm{OEt}_{2}\right)$. The minor species, also paramagnetic in nature, was noted to have apparent $\mathrm{C}_{2 v}$ symmetry based on a total of seven observed resonances. Relative integrations of the tert-butyl methyl protons (30.86 ppm) and the 4-pyridine proton (-0.91 ppm) along with the absence of resonances attributed to a diethyl ether ligand 
suggested an initial product assignment as a three-coordinate pyridine dipyrrolide iron complex, $\mathrm{Fe}\left({ }^{\mathrm{tBu} P D P}{ }^{\mathrm{Ph}}\right)($ Figure 4.1).

Crystallization of the crude orange solid from a concentrated diethyl ether solution at $35^{\circ} \mathrm{C}$ afforded a single crystal suitable for analysis via X-ray crystallography. The structural analysis confirmed the identity of the major species present in the ${ }^{1} \mathrm{H}$ NMR spectrum as the mono-diethyl ether adduct, $\left({ }^{\mathrm{tBu}} \mathrm{PDP}{ }^{\mathrm{Ph}}\right) \mathrm{Fe}\left(\mathrm{OEt}_{2}\right)$ (Figure 4.2). $\left({ }^{\mathrm{tBu}} \mathrm{PDP}^{\mathrm{Ph}}\right) \mathrm{Fe}\left(\mathrm{OEt}_{2}\right)$ was found to crystallize in the orthorhombic unit cell $\mathrm{Pca} 2{ }_{1}$ in a cis-divacant octahedral geometry, consistent with the closely related analogue $\left({ }^{\mathrm{tBu}} \mathrm{PDP}^{\mathrm{tBu}}\right) \mathrm{Fe}\left(\mathrm{OEt}_{2}\right)$, recently reported by Caulton et al. ${ }^{3}$ Relatively long bond lengths of 2.020(2), 2.031(2), 2.020(2), and 2.105(2) A from the iron center to N1, N2, N3, and O1, are consistent with a high-spin ferrous state. The presence of an S = 2 iron center was confirmed via a room-temperature magnetic moment of $5.1 \mu_{\mathrm{B}}$. In order to further probe the two species that were present in the crude benzene- $d_{6}{ }^{1} \mathrm{H}$ NMR spectrum, a zero-field Mössbauer spectrum was acquired of a powder sample obtained from the crude reaction mixture. Surprisingly, the Mössbauer spectrum indicated the presence of only a single quadrupole doublet with parameters $\delta=0.91 \mathrm{mms}^{-1}$ and $\left|\Delta \mathrm{E}_{\mathrm{Q}}\right| 1.25 \mathrm{mms}^{-1}$, in good agreement with $\delta=0.86 \mathrm{mms}^{-1}$ and $\left|\Delta \mathrm{E}_{\mathrm{Q}}\right| 1.21 \mathrm{mms}^{-1}$ measured for $\left.{ }^{\left({ }^{\mathrm{BB} u}{ }^{2} \mathrm{PDP}\right.}{ }^{\mathrm{tBu}}\right) \mathrm{Fe}\left(\mathrm{OEt}_{2}\right)$ and confirming the high-spin $\mathrm{Fe}^{\mathrm{II}}$ ground state of $\left({ }^{\mathrm{tBu}} \mathrm{PDP}^{\mathrm{Ph}}\right) \mathrm{Fe}\left(\mathrm{OEt}_{2}\right) .{ }^{3}$ Intrigued by the observation of only a single quadrupole doublet, a benzene- $d_{6}$ solution of the crude orange material obtained from the reaction of $\mathrm{H}_{2}{ }^{\mathrm{tBu}}{ }^{\mathrm{PDPP}}{ }^{\mathrm{Ph}}$ and $\mathrm{Fe}\left[\mathrm{N}\left(\mathrm{SiMe}_{3}\right)_{2}\right]_{2}$ was monitored via ${ }^{1} \mathrm{H}$ NMR spectroscopy over time. Interestingly, the ratio of the two species slowly changed over a period of hours, with the concentration of $\left({ }^{\mathrm{tBu}} \mathrm{PDP}{ }^{\mathrm{Ph}}\right) \mathrm{Fe}\left(\mathrm{OEt}_{2}\right)$ diminishing over time cleanly to the species tentatively assigned as the three-coordinate $\mathrm{Fe}\left({ }^{\mathrm{tBu}} \mathrm{PDP}^{\mathrm{Ph}}\right)$ complex. In an attempt to drive the observed reaction to completion, samples of the crude orange material were suspended in pentane and 
vigorously stirred. A color change of the suspension from orange to dark-red/brown was observed within minutes. The resulting suspension was reduced to dryness and extracted into benzene. Filtration through celite and subsequent removal of the solvent in vacuo afforded a dark-red/brown powder. Analysis of the resulting material via ${ }^{1} \mathrm{H}$ NMR in benzene- $d_{6}$ revealed the presence of only the species assigned as $\mathrm{Fe}\left({ }^{(\mathrm{Bu}}{ }^{\mathrm{PDP}}{ }^{\mathrm{Ph}}\right)$, suggesting lability and loss of the diethyl ether ligand of $\left({ }^{\mathrm{B} u} \mathrm{PDP}^{\mathrm{Ph}}\right) \mathrm{Fe}\left(\mathrm{OEt}_{2}\right)$ upon dissolution in hydrocarbon solvent.

A single crystal of this material grown from diffusion of pentane into a concentrated benzene solution allowed for unambiguous assignment of the identity of the compound via X-ray crystallography. Surprisingly, the identity of the crystalline material was found to be the helical dimeric species $\mathrm{Fe}_{2}\left(\mu_{2}-\kappa^{2}-\mathrm{tBu}^{\mathrm{BuDP}}{ }^{\mathrm{Ph}}\right)_{2}$, and not the anticipated three coordinate complex $\mathrm{Fe}\left({ }^{(\mathrm{Bu} u} \mathrm{PDP}^{\mathrm{Ph}}\right)$. The formation of $\mathrm{Fe}_{2}\left(\mu_{2}-\kappa^{2}-{ }^{2 \mathrm{Bu}} \mathrm{PDP}^{\mathrm{Ph}}\right)_{2}$ demonstrates loss of a diethyl ether ligand from two $\left({ }^{\mathrm{tBu}} \mathrm{PDP}^{\mathrm{Ph}}\right) \mathrm{Fe}\left(\mathrm{OEt}_{2}\right)$ complexes and subsequent reorganization of the PDP ligand coordination motif to form the observed structure. Furthermore, the resulting migration of one arm pyrrolide arm of a PDP ligand to a second iron center suggests that loss of a diethyl ether ligand induces iron pyrrolide nitrogen bond breaking and bond forming events. Unfortunately, due to the weak diffraction of the sample, only atomic connectivity of the molecule was established, precluding meaningful discussion of the structural metrics. The synthesis and X-ray structures of $\left({ }^{\mathrm{tBu}} \mathrm{PDP}^{\mathrm{Ph}}\right) \mathrm{Fe}\left(\mathrm{OEt}_{2}\right)$ and $\mathrm{Fe}_{2}\left(\mu_{2}-\kappa^{2}-{ }^{\mathrm{tBu}} \mathrm{PDP}^{\mathrm{Ph}}\right)_{2}$ (preliminary) are presented in Scheme 4.2 and Figure 4.2. 

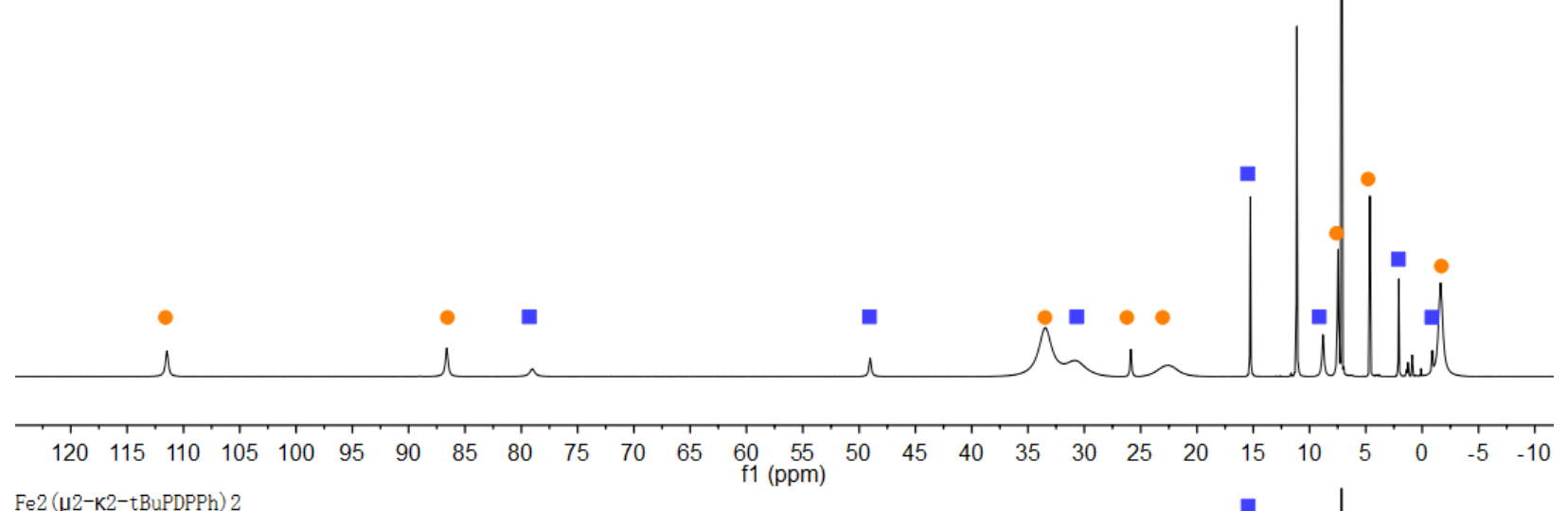

$\mathrm{Fe} 2(\mu 2-\mathrm{K} 2-\mathrm{tBuPDPPh}) 2$

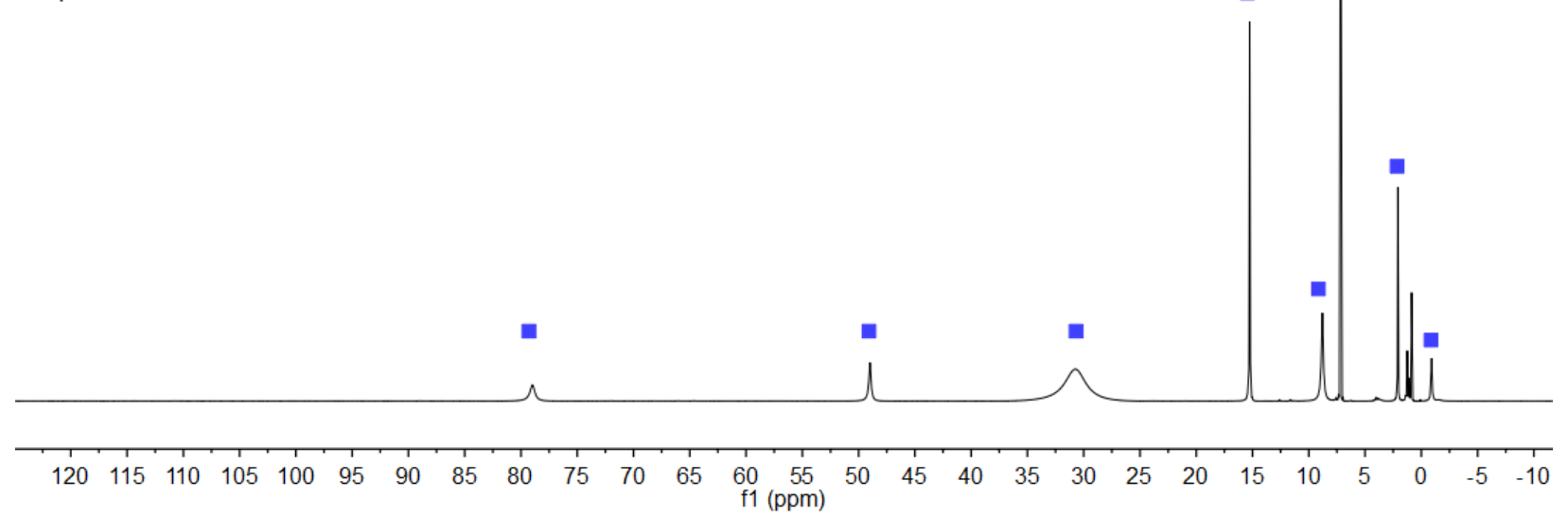

Figure 4.2. ${ }^{1} \mathrm{H}$ NMR spectra of the mixture of $\left({ }^{\mathrm{tBu}} \mathrm{PDPPh}\right) \mathrm{Fe}\left(\mathrm{OEt}_{2}\right)$ and $\mathrm{Fe}_{2}\left(\mu_{2}-\kappa^{2}-{ }^{\mathrm{BBu}} \mathrm{PDP}^{\mathrm{Ph}}\right)_{2}$ (top) and isolated $\mathrm{Fe}_{2}\left(\mu_{2}-\kappa^{2}{ }_{-} \mathrm{tBu} P D P^{\mathrm{Ph}}\right)_{2}$ (bottom) at $400 \mathrm{MHz}$ in benzene- $d_{6}$. The unmarked resonances correspond to pentane present in the samples. 


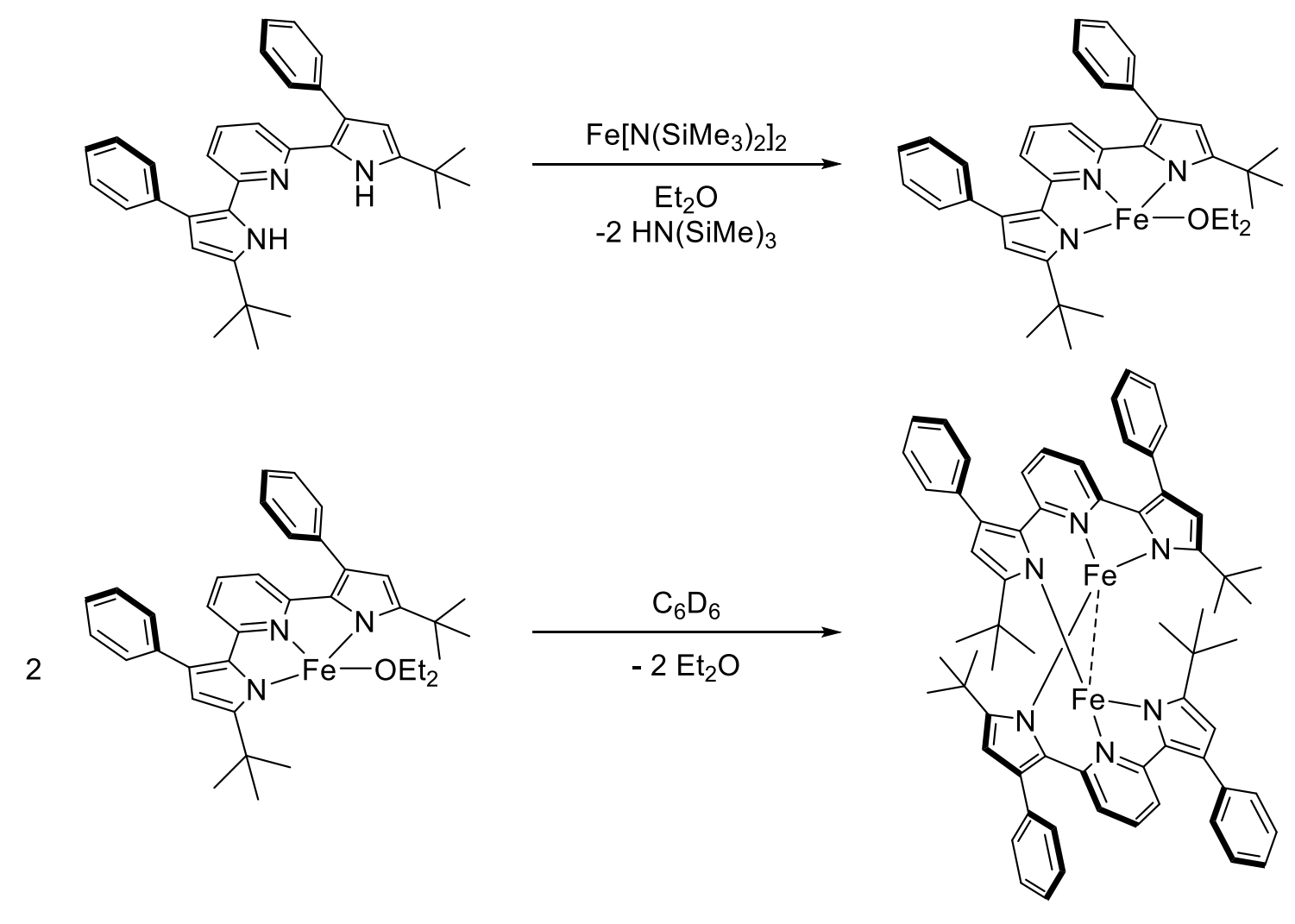

Scheme 4.2. Synthesis of ( $\left.{ }^{\mathrm{tBu} P D P}{ }^{\mathrm{Ph}}\right) \mathrm{Fe}\left(\mathrm{OEt}_{2}\right)$ and $\mathrm{Fe}_{2}\left(\mu_{2}-\kappa^{2}-\mathrm{tBu}^{\mathrm{BDDP}}{ }^{\mathrm{Ph}}\right)_{2}$.
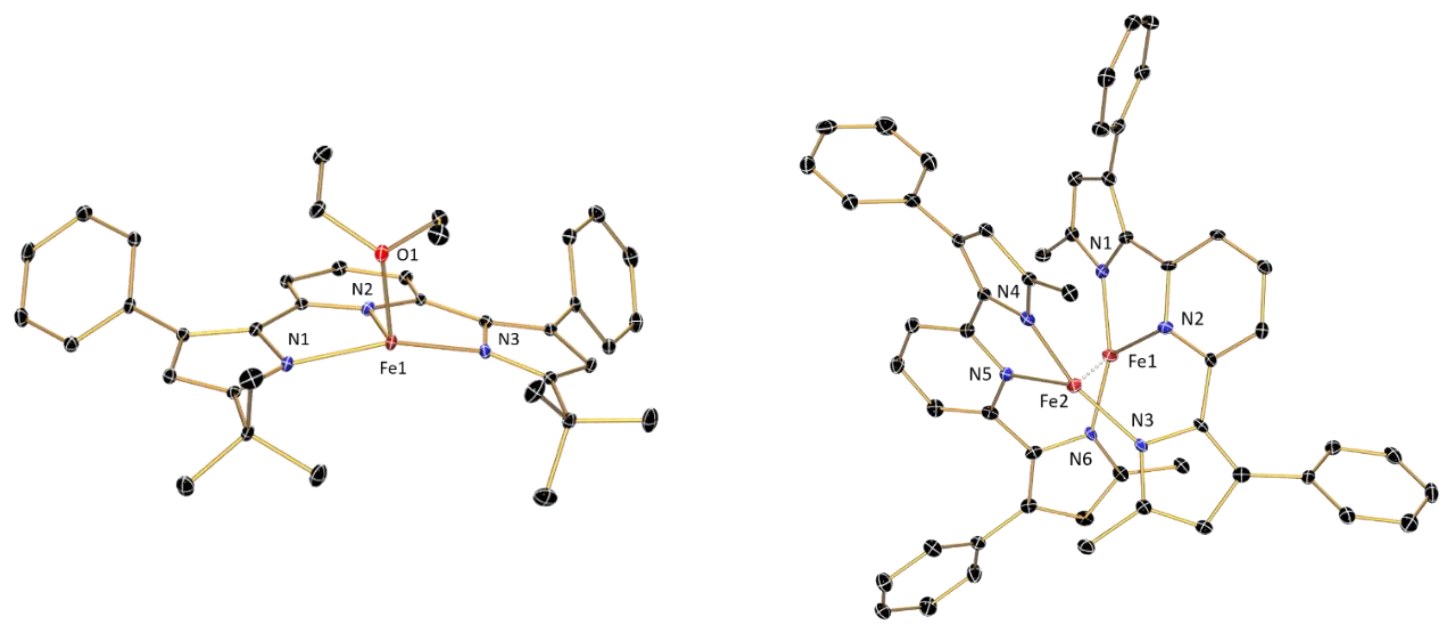

Figure 4.3. ORTEP of ( $\left.{ }^{\mathrm{tBu}} \mathrm{PDP}{ }^{\mathrm{Ph}}\right) \mathrm{Fe}\left(\mathrm{OEt}_{2}\right)$ (left) and $\mathrm{Fe}_{2}\left(\mu_{2}-\kappa^{2}-\mathrm{tBu}^{\mathrm{Bu}} \mathrm{PDPh}^{\mathrm{Ph}}\right)_{2}$ (right) at $30 \%$ probability ellipsoids. Hydrogen atoms and co-crystallized solvent are omitted for clarity. For $\mathrm{Fe}_{2}\left(\mu_{2}-\kappa^{2}-{ }_{-} \mathrm{Bu} \mathrm{PDP}^{\mathrm{Ph}}\right)_{2}$ only the quaternary carbons of the tert-butyl substituents are depicted. 
In lieu of a high-resolution X-ray crystal structure of $\mathrm{Fe}_{2}\left(\mu_{2}-\kappa^{2}{ }_{-}{ }^{\mathrm{Bu}} \mathrm{PDP}^{\mathrm{Ph}}\right)_{2}$, a zero-field Mössbauer spectrum was acquired at $80 \mathrm{~K}$ to interrogate the electronic structure(s) and potential electronic communication between the two iron centers. The resulting spectrum (Figure 4.3) features a single quadrupole doublet with $\delta=0.82 \mathrm{mms}^{-1}$ and $\left|\Delta \mathrm{E}_{\mathrm{Q}}\right|=1.68 \mathrm{mms}^{-1}$, unambiguous evidence of both iron centers adopting a high-spin ferrous configuration. It should be noted that the observed doublet possesses asymmetry, with linewidths of $\Gamma_{L}=0.44 \mathrm{mms}^{-1}$ and $\Gamma_{\mathrm{R}}=0.38$ $\mathrm{mms}^{-1}$, respectively. This observation hints that in the solid state slightly different coordination environments may exist for each iron center, resulting in similar but non identical spectra.

Previously, the Mindiola group has described the synthesis and characterization of a

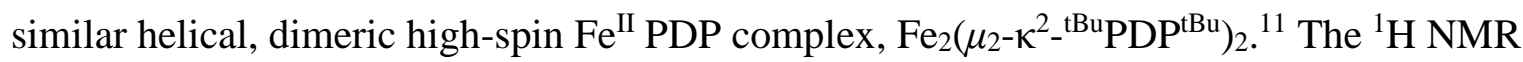
spectrum of $\mathrm{Fe}_{2}\left(\mu_{2}-\kappa^{2}{ }^{\mathrm{tBu}}{ }^{\mathrm{PDDP}} \mathrm{P}^{\mathrm{BBu}}\right)_{2}$ is also in good agreement with $\mathrm{Fe}_{2}\left(\mu_{2}-\kappa^{2}{ }_{-}{ }^{\mathrm{Bu}} \mathrm{PDP}^{\mathrm{Ph}}\right)_{2}$ which displays five paramagnetically shifted resonances spanning a range of 0.50 to $82.5 \mathrm{ppm}$ in benzene- $d_{6}$ solution. The apparent $C_{2 v}$ symmetry is ascribed to fluxional behavior of the complex in solution at room-temperature. The solid-state zero field Mössbauer parameters of $\mathrm{Fe}_{2}\left(\mu_{2}-\kappa^{2}-\right.$ $\left.{ }^{\mathrm{tBu}} \mathrm{PDP}^{\mathrm{tBu}}\right)_{2}, \delta=0.80(1) \mathrm{mms}^{-1}$ and $\left|\Delta \mathrm{E}_{\mathrm{Q}}\right|=1.76(1) \mathrm{mms}^{-1}$, are essentially identical to those of $\mathrm{Fe}_{2}\left(\mu_{2}-\kappa^{2}-{ }^{\mathrm{tBu}} \mathrm{PDP}{ }^{\mathrm{Ph}}\right)_{2}$. 

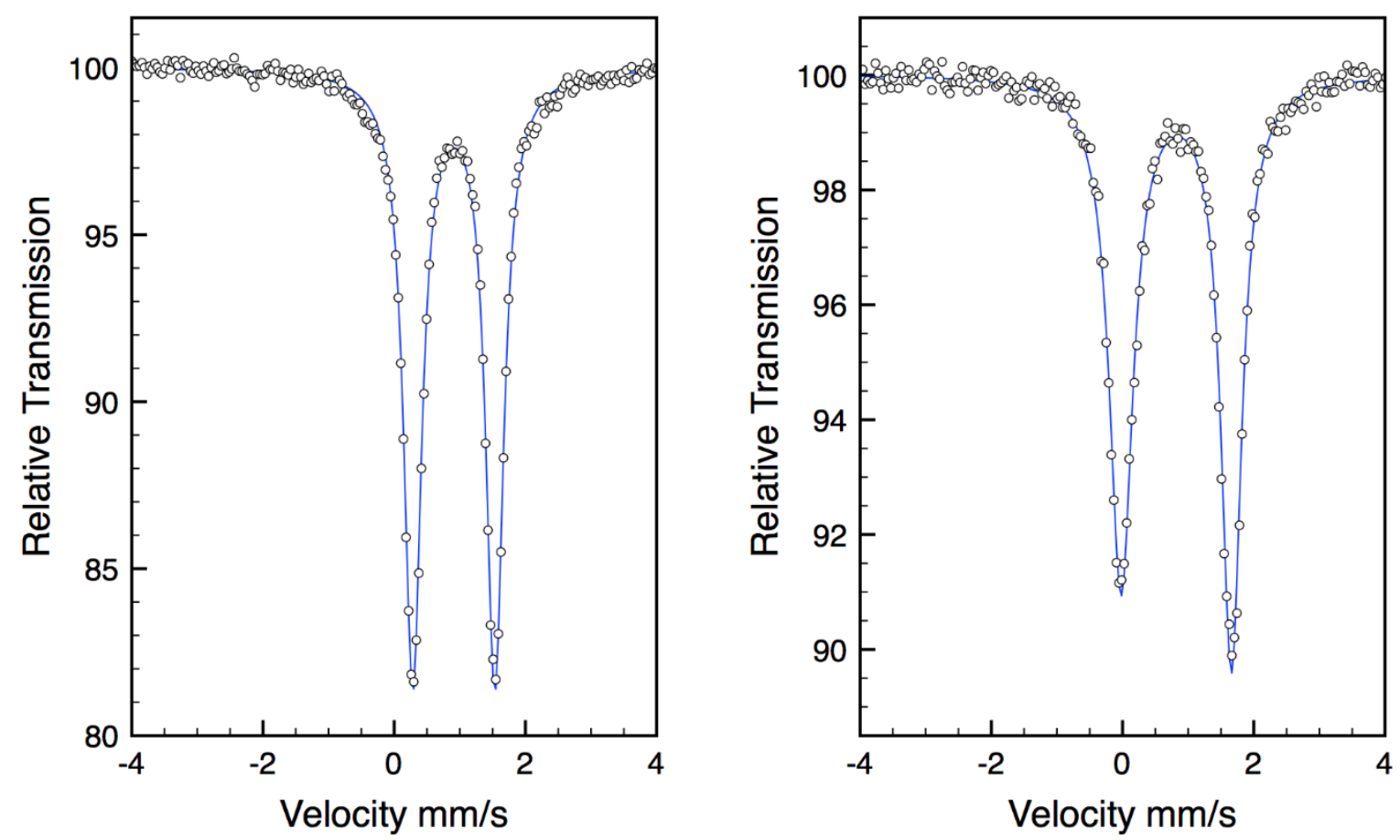

Figure 4.4. Zero-field ${ }^{57} \mathrm{Fe}$ Mössbauer spectra of $\left({ }^{(\mathrm{Bu}} \mathrm{PDP}{ }^{\mathrm{Ph}}\right) \mathrm{Fe}\left(\mathrm{OEt}_{2}\right)($ left $)$ and $\mathrm{Fe}_{2}\left(\mu_{2}-\kappa^{2}-\mathrm{BB}^{\mathrm{B}} \mathrm{PDP}^{\mathrm{Ph}}\right)_{2}$ (right) recorded at $80 \mathrm{~K}$.

Investigations of the magnetic behavior of $\mathrm{Fe}_{2}\left(\mu_{2}-\kappa^{2}-{ }^{\mathrm{BBu}} \mathrm{PDP}^{\mathrm{tBu}}\right)_{2}$ were performed via the Evans method, revealing $\mu_{\mathrm{eff}}$ value of $6.9 \mu_{\mathrm{B}}$ at room temperature in benzene- $d_{6}$. A complementary SQUID magnetization measurement spanning a temperature range of 20-300 K revealed a temperature dependence to the magnetic moment of $\mathrm{Fe}_{2}\left(\mu_{2}-\mathrm{K}^{2}-{ }_{-} \mathrm{Bu}^{\mathrm{PuDP}}{ }^{\mathrm{tBu}}\right)_{2}$, as demonstrated by an increase in $\mu_{\text {eff }}$ from 3.02 to $7.50 \mu_{\text {B }}$ over the measured conditions. ${ }^{11}$ Similarly, the room temperature magnetic moment $\mathrm{Fe}_{2}\left(\mu_{2}-\kappa^{2}{ }_{-}{ }^{\mathrm{Bu}} \mathrm{PDPP}^{\mathrm{Ph}}\right)_{2}$ was found to be $7.0 \mu_{\mathrm{B}}$, consistent with weak coupling between two independent high-spin $\mathrm{Fe}^{\mathrm{II}}$ centers, as demonstrated by agreement with the high temperature spin-only value of $6.9 \mu_{\text {B }}$ for two uncoupled $\mathrm{S}=2$ spin systems. This was further verified via a density functional theory study. A BS $(4,4)$ calculation performed at the B3LYP level converged to an optimized structure featuring two antiferromagnetically coupled $\mathrm{S}=2$ iron centers. This was evidenced via analysis of the 
Mulliken spin populations of the iron atoms, with spin-density values of -3.78 and 3.78 , respectively (Figure 4.4). The energy difference between the high-spin state and broken symmetry solution was calculated to be $120.439 \mathrm{~cm}^{-1}$ and the exchange coupling constant, $J$, was calculated to be $-7.53 \mathrm{~cm}^{-1}$. These values were obtained using the following Hamiltonian (top) and formula (bottom), where $E_{B S}$ is the energy of the low-spin solution, $E_{H S}$ is the energy of the high-spin solution, and $S_{\max }{ }^{2}$ is the total spin of the high-spin state. ${ }^{12,13}$

$$
\begin{gathered}
H=-2 J \vec{S}_{F e 1} \cdot \vec{S}_{F e 2} \\
J=-\frac{E_{H S}-E_{B S}}{S_{\max }^{2}}
\end{gathered}
$$

Previously, the Betley group has reported a similar diiron dimer within the context of a pyrrole based dipyrromethene ligand environment. ${ }^{14}$ This complex, $\left[\left({ }^{\mathrm{tBu}} \mathrm{L}\right) \mathrm{FeCl}\right]_{2}\left({ }^{\mathrm{tBu}} \mathrm{L}=1,9\right.$-ditert-butyl-5-(2,6-dichlorophenyl)dipyrromethene), which is best described as featuring two antiferromagnetically coupled high-spin $\mathrm{Fe}^{\mathrm{II}}$ centers is characterized by Mössbauer parameters of $\delta=0.94 \mathrm{mms}^{-1}$ and $\Delta \mathrm{E}_{\mathrm{Q}}=1.96 \mathrm{mms}^{-1}$ and magnetic moment of $7.2 \mu_{\mathrm{B}}$ determined via SQUID magnetometry at $295 \mathrm{~K}$, in good agreement with experimentally determined magnetic susceptibilities of $\mathrm{Fe}_{2}\left(\mu_{2}-\kappa^{2}-{ }^{\mathrm{tBu}} \mathrm{PDP}^{\mathrm{tBu}}\right)_{2}$ and $\mathrm{Fe}_{2}\left(\mu_{2}-\kappa^{2}-{ }^{\mathrm{tBu}} \mathrm{PDP}^{\mathrm{Ph}}\right)_{2}$. A very similar coupling constant of $J=-6.92 \mathrm{~cm}^{-1}$ was calculated for this complex via a BS $(4,4)$ calculation using the same functional and the ORCA program suite and is in good agreement with the experimentally determined value of $-1.95 \mathrm{~cm}^{-1}$. Furthermore, Mössbauer parameters obtained from the same $\mathrm{BS}(4,4)$ calculation computed identical isomer shifts of $0.69 \mathrm{mms}^{-1}$ for both iron centers in $\mathrm{Fe}_{2}\left(\mu_{2}-\kappa^{2}{ }^{\mathrm{tBu}} \mathrm{PDP}^{\mathrm{Ph}}\right)_{2}$. However, different quadrupole splittings for the two iron nuclei, -1.62 $\mathrm{mms}^{-1}$ and $-1.71 \mathrm{mms}^{-1}$, were computed, which may explain the origin of the broadness and asymmetry present in the experimentally determined Mössbauer spectra of $\mathrm{Fe}_{2}\left(\mu_{2}-\kappa^{2}{ }_{-}{ }^{\mathrm{Bu}} \mathrm{PDP}^{\mathrm{Ph}}\right)_{2}$. 


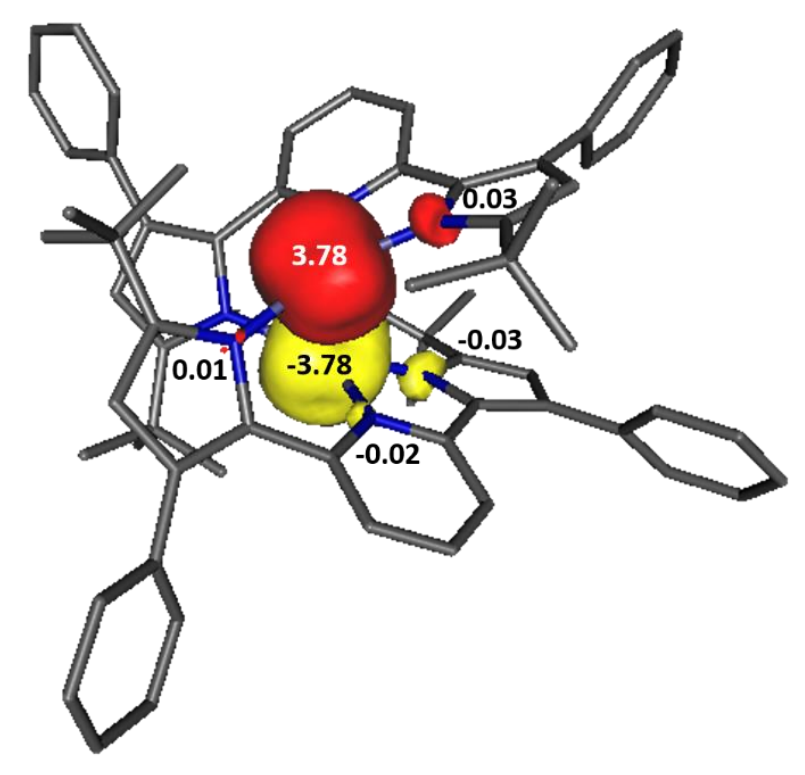

Figure 4.5. Spin-density plot obtained from Mulliken population analysis of BS $(4,4)$ calculation of $\mathrm{Fe}_{2}\left(\mu_{2}-\kappa^{2}{ }_{-}{ }^{\mathrm{Bu}} \mathrm{PDP}^{\mathrm{Ph}}\right)_{2}$.

Due to the lability of the diethyl ether ligand in solution for $\left({ }^{\mathrm{tBu}}{ }^{\mathrm{PDP}}{ }^{\mathrm{Ph}}\right) \mathrm{Fe}\left(\mathrm{OEt}_{2}\right)$, exploration of metalation protocols in the presence of stronger Lewis bases was also studied to gain more insight into the coordination chemistry of the $\left({ }^{\mathrm{tBu}} \mathrm{PDP}^{\mathrm{Ph}}\right)^{2-}$ ligand. The reaction of a THF solution of $\mathrm{Fe}\left[\mathrm{N}\left(\mathrm{SiMe}_{3}\right)_{2}\right]_{2}$ and $\mathrm{H}_{2}{ }^{\mathrm{tBu}} \mathrm{PDP}^{\mathrm{Ph}}$ in the same solvent was found to immediately afford a red homogenous mixture. The ${ }^{1} \mathrm{H}$ NMR spectrum of the crude product in benzene- $d_{6}$ suggested clean and quantitative conversion to the corresponding thf adduct, as evidenced by nine paramagnetically shifted and broadened resonances spanning a chemical shift range of 110.80 to $1.87 \mathrm{ppm}$. In totality, integration of the diagnostic tert-butyl methyl groups signal $(36.27 \mathrm{ppm}, 18 \mathrm{H})$ and the 4-pyridine proton $(26.82 \mathrm{ppm}, 1 \mathrm{H})$ were consistent with a preliminary product assignment as the five-coordinate bis-THF adduct, $\left({ }^{\mathrm{tBu}} \mathrm{PDP}^{\mathrm{Ph}}\right) \mathrm{Fe}(\text { thf })_{2}$. The presence of the 4-pyridine proton at $26.82 \mathrm{ppm}$ is consistent with the chemical shift values for the related five-coordinate PDP high-spin $\mathrm{Fe}^{\mathrm{II}}$ complexes, $\left({ }^{\mathrm{Mes}} \mathrm{PDP}^{\mathrm{Ph}}\right) \mathrm{Fe}(\text { thf })_{2}$ and $\left({ }^{\mathrm{Mes}} \mathrm{PDP}{ }^{\mathrm{Ph}}\right) \mathrm{Fe}(\mathrm{py})_{2}$, which 
were found to have 4-pyridine proton resonances at 20.32 and $21.54 \mathrm{ppm}$ in THF- $d_{8}$ and benzene- $d_{6}$, respectively. Importantly, monitoring benzene- $d_{6}$ solutions of $\left({ }^{\mathrm{tBu}} \mathrm{PDP}{ }^{\mathrm{Ph}}\right) \mathrm{Fe}(\mathrm{thf})_{2}$ via ${ }^{1} \mathrm{H}$ NMR demonstrated no irreversible solvent ligand lability, as no resonances consistent with the formation of $\mathrm{Fe}_{2}\left(\mu_{2}-\kappa_{2}-{ }^{\mathrm{tBu}} \mathrm{PDP}^{\mathrm{Ph}}\right)_{2}$ and free THF were observed. Recrystallization of the crude product from a concentrated THF solution layered with pentane at $-35^{\circ} \mathrm{C}$ afforded large red blocks suitable for analysis via X-ray crystallography. The X-ray analysis confirmed the identity of the product as the pentacoordinate bis-THF adduct (Figure 4.5). The structural metrics are consistent with previously characterized high-spin Fe ${ }^{\mathrm{II}}$ PDP complexes and are summarized in Table 4.1. Within the context of the previously reported $\left({ }^{\mathrm{tBu}}{ }^{\mathrm{PDP}}{ }^{\mathrm{tBu}}\right)$ ligand, a high-spin $\mathrm{Fe}^{\mathrm{II}} \mathrm{THF}$ adduct was reported via treatment of $\left({ }^{\mathrm{tBu}} \mathrm{PDP}^{\mathrm{tBu}}\right) \mathrm{Fe}\left(\mathrm{OEt}_{2}\right)$ with $\mathrm{THF}$ or alternatively via a deprotonation and metalation procedure from $\mathrm{H}_{2}{ }^{\mathrm{tBu}} \mathrm{PDP}^{\mathrm{tBu}}$ and $\mathrm{FeCl}_{2}$ in THF solvent. The product of these reactions was assigned as a mono-THF adduct, based upon ${ }^{1} \mathrm{H}$ NMR analysis. ${ }^{3}$
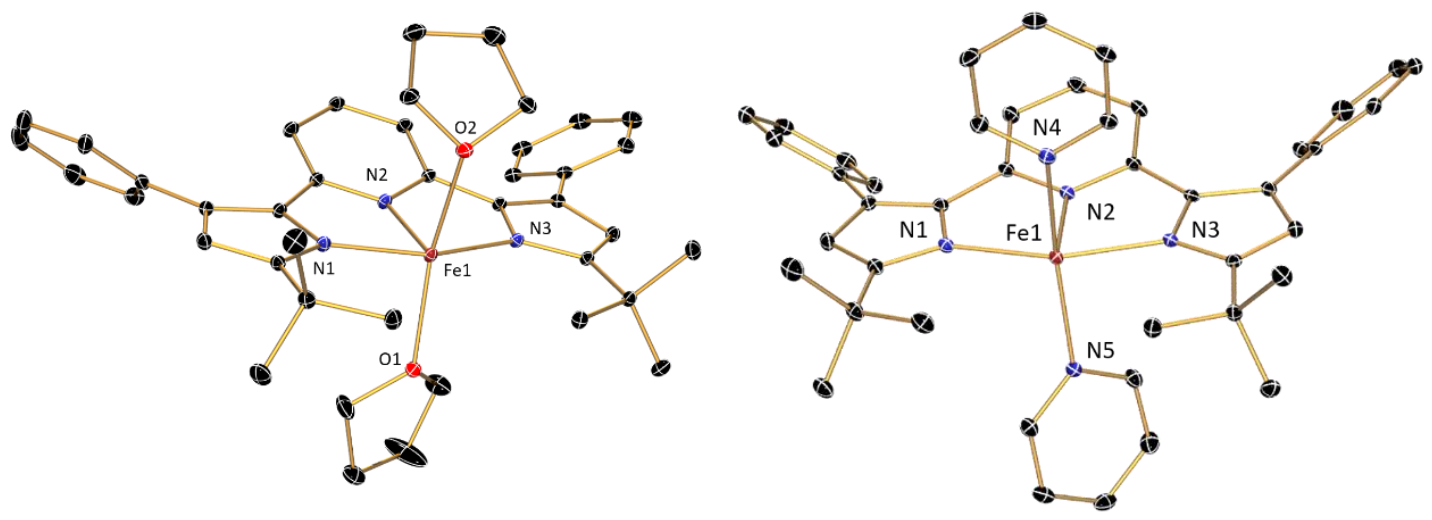

Figure 4.6. ORTEPs of $\left({ }^{(\mathrm{Bu}} \mathrm{PDP}^{\mathrm{Ph}}\right) \mathrm{Fe}(\mathrm{thf})_{2}$ (left) and $\left({ }^{\mathrm{tBu}} \mathrm{PDP}^{\mathrm{Ph}}\right) \mathrm{Fe}(\mathrm{py})_{2}$ (right) at $30 \%$ probability ellipsoids. Hydrogen atoms and co-crystallized solvent are omitted for clarity.

In consideration of the unprecedented coordination geometry of $\left({ }^{\mathrm{tBu}} \mathrm{PDP}{ }^{\mathrm{Ph}}\right) \mathrm{Fe}(\text { thf })_{2}$ for high-spin ferrous PDP complexes, a zero-field Mössbauer spectrum was acquired at $80 \mathrm{~K}$. The 
resulting single quadrupole doublet featured $\delta=1.07 \mathrm{mms}^{-1}$ and $\left|\Delta \mathrm{E}_{\mathrm{Q}}\right|=1.42 \mathrm{mms}^{-1}$. The high isomer shift value is consistent with a high-spin $\mathrm{Fe}^{\mathrm{II}}$ center and is in good agreement with that of $\left({ }^{\mathrm{Mes}} \mathrm{PDP}{ }^{\mathrm{Ph}}\right) \mathrm{Fe}(\text { thf })_{2}$ which features $\delta=1.09 \mathrm{mms}^{-1}{ }^{1}$ The large deviation in the quadrupole splitting in $\left({ }^{\mathrm{tBu}} \mathrm{PDP}{ }^{\mathrm{Ph}}\right) \mathrm{Fe}(\text { thf })_{2}\left(1.42 \mathrm{mms}^{-1}\right)$ relative to $\left({ }^{\mathrm{Mes}} \mathrm{PDP}^{\mathrm{Ph}}\right) \mathrm{Fe}(\text { thf })_{2}\left(2.76 \mathrm{mms}^{-1}\right)$ is consistent with the markedly different coordination geometries for the two complexes with transand cis-coordinating THF ligands, respectively. This is reflected in the DFT calculated asymmetry parameter of the electric field gradient, $\eta$, which is 0.56 for $\left({ }^{\mathrm{tBu} P D P}{ }^{\mathrm{Ph}}\right) \mathrm{Fe}(\mathrm{thf})_{2}$ and 0.89 for $\left({ }^{\mathrm{Mes}} \mathrm{PDP}{ }^{\mathrm{Ph}}\right) \mathrm{Fe}(\text { thf })_{2}$. The isomer shift is also noticeably lower than the four-coordinate cis-divacant octahedral diethyl ether adducts of $\left({ }^{\mathrm{tBu}}{ }^{\mathrm{PDP}}{ }^{\mathrm{Ph}}\right) \mathrm{Fe}\left(\mathrm{OEt}_{2}\right)$ and $\left({ }^{\mathrm{tBu}} \mathrm{PDP}^{\mathrm{tBu}}\right) \mathrm{Fe}\left(\mathrm{OEt}_{2}\right)$ $\left(0.86(1) \mathrm{mms}^{-1}\right) .^{3}$

A final metalation protocol of $\mathrm{H}_{2}{ }^{\mathrm{tBu}} \mathrm{PDP}^{\mathrm{Ph}}$ was explored with the iron dialkyl reagent $\mathrm{Fe}(\mathrm{Ns})_{2}(\mathrm{py})_{2}$, as previously demonstrated for $\mathrm{H}_{2}{ }^{\mathrm{Mes}} \mathrm{PDP}^{\mathrm{Ph}}{ }^{1}$ Accordingly, treatment of a solution of $\mathrm{Fe}(\mathrm{Ns})_{2}(\mathrm{py})_{2}$ in a mixture of pentane and toluene with a toluene solution of $\mathrm{H}_{2}{ }^{\mathrm{tBu}} \mathrm{PDP} \mathrm{P}^{\mathrm{Ph}}$ resulted in a gradual color change from purple to red. Upon removal of volatiles, ${ }^{1} \mathrm{H}$ NMR analysis of the crude mixture evidenced clean and quantitative conversion to a $\mathrm{C}_{2 v}$ symmetric product, as evidenced by 10 paramagnetically shifted and broadened resonances spanning a chemical shift range of 4.43 to $104.00 \mathrm{ppm}$. Relative integrations compared to the 4-pyridine proton $(30.33 \mathrm{ppm})$ were consistent with assignment of the product as the bis-pyridine adduct, $\left({ }^{\mathrm{tBu}} \mathrm{PDP} \mathrm{P}^{\mathrm{Ph}}\right) \mathrm{Fe}(\mathrm{py})_{2}$. Furthermore, the appearance of the 4-pyridine resonance downfield from its diamagnetic reference value is consistent with previously characterized five-coordinate high-spin ferrous PDP complexes. ${ }^{1}$

Recrystallization of the crude product via diffusion of pentane into a concentrated toluene solution afforded orange single crystals suitable for X-ray crystallography. The structural 
analysis identified the sample as a penta-coordinate bis-pyridine adduct, $\left({ }^{\mathrm{CBu}} \mathrm{PDP}{ }^{\mathrm{Ph}}\right) \mathrm{Fe}(\mathrm{py})_{2}$, which adopts a geometry analogous to that observed for $\left({ }^{\mathrm{tBu}} \mathrm{PDP}^{\mathrm{Ph}}\right) \mathrm{Fe}(\text { thf })_{2}$ in the solid-state with trans apical pyridine ligands (Figure 4.5). The Mössbauer parameters of a solid sample of $\left({ }^{\mathrm{tBu}} \mathrm{PDP}^{\mathrm{Ph}}\right) \mathrm{Fe}(\mathrm{py})_{2}$ were found to be $\delta=1.02 \mathrm{mms}^{-1}$ and $|\Delta \mathrm{E} \mathrm{Q}|=1.94 \mathrm{mms}^{-1}$ in good agreement for the five-coordinate analogue $\left({ }^{(\mathrm{Bu} u} \mathrm{PDP} \mathrm{Ph}^{\mathrm{Ph}}\right) \mathrm{Fe}(\text { thf })_{2}$. The difference in the quadrupole splitting values between the $\left({ }^{(\mathrm{Bu} u} \mathrm{PDP}^{\mathrm{Ph}}\right) \mathrm{Fe}(\mathrm{thf})_{2}$ and $\left({ }^{\mathrm{(Bu}} \mathrm{PDP}^{\mathrm{Ph}}\right) \mathrm{Fe}(\mathrm{py})_{2}$ is not entirely clear at this time and is tentatively ascribed to solid-state effects, as the coordination environments of the two compounds and iron THF-oxygen and pyridine-nitrogen bonds are very similar $(\sim 2.25 \AA)$. In all, the characterization data suggests that the substitution of the stronger Lewis basic ligand pyridine for THF imparts no significant perturbation on the electronic structure of the resulting compound, and the high-spin ferrous state is retained. The Mössbauer spectra for $\left({ }^{(\mathrm{Bu}} \mathrm{PDP}^{\mathrm{Ph}}\right) \mathrm{Fe}(\text { thf })_{2}$ and $\left({ }^{\mathrm{BBu}} \mathrm{PDP} \mathrm{P}^{\mathrm{Ph}}\right) \mathrm{Fe}(\mathrm{py})_{2}$ are depicted in Figure 4.6 and a complete summary of available Mössbauer parameters for all $\left({ }^{\mathrm{B} u} \mathrm{PDP}^{\mathrm{Ph}}\right)$ and $\left({ }^{\mathrm{B} u} \mathrm{PDP}^{\mathrm{tBu}}\right) \mathrm{Fe}^{\mathrm{II}}$ iron complexes is provided in Table 4.13. Solid-state magnetic susceptibility values of 5.1 and $5.4 \mu_{\mathrm{B}}$ (magnetic susceptibility balance) at room temperature for $\left({ }^{\mathrm{tBu}} \mathrm{PDP}^{\mathrm{Ph}}\right) \mathrm{Fe}(\text { thf })_{2}$ and $\left({ }^{\mathrm{tBu}} \mathrm{PDP}^{\mathrm{Ph}}\right) \mathrm{Fe}(\mathrm{py})_{2}$, respectively, are in agreement with high-spin $\mathrm{Fe}^{\mathrm{II}}$ formulations for the central metal ions, as inferred from X-ray crystallography and Mössbauer spectroscopy. 

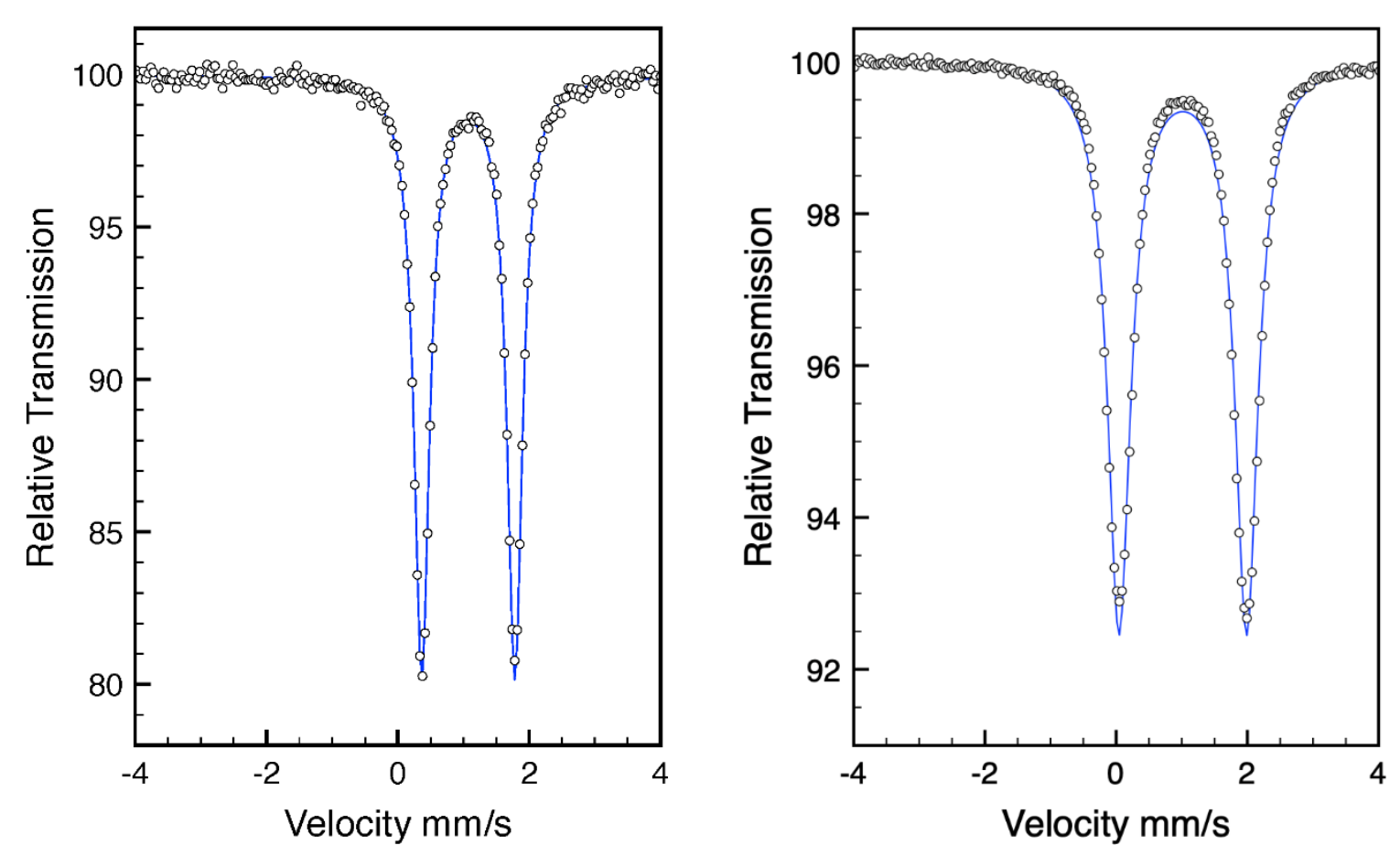

Figure 4.7. Zero-field ${ }^{57} \mathrm{Fe}$ Mössbauer spectra of $\left({ }^{(\mathrm{Bu} u} \mathrm{PDP}^{\mathrm{Ph}}\right) \mathrm{Fe}(\mathrm{thf})_{2}$ (left) and $\left({ }^{(\mathrm{Bu} u} \mathrm{PDP}{ }^{\mathrm{Ph}}\right) \mathrm{Fe}(\mathrm{py})_{2}$ (right) recorded at $80 \mathrm{~K}$. 
Table 4.1. Selected bond lengths $(\AA)$ and angles (deg) for $\left({ }^{(\mathrm{Bu} u} \mathrm{PDP}^{\mathrm{Ph}}\right) \mathrm{Fe}\left(\mathrm{OEt}_{2}\right),\left({ }^{\mathrm{tBu}} \mathrm{PDP}^{\mathrm{Ph}}\right) \mathrm{Fe}(\mathrm{thf})_{2}$, and $\left.{ }^{(\mathrm{Bu} u} \mathrm{PDP}{ }^{\mathrm{Ph}}\right) \mathrm{Fe}(\mathrm{py})_{2}$.

\begin{tabular}{|c|c|c|c|}
\hline & $\left({ }^{\mathrm{tBu}} \mathrm{PDP} \mathrm{Ph}^{\mathrm{Ph}}\right) \mathrm{Fe}\left(\mathrm{OEt}_{2}\right)$ & $\left({ }^{(\mathrm{Bu} u} \mathrm{PDP}^{\mathrm{Ph}}\right) \mathrm{Fe}(\mathrm{thf})_{2}$ & $\left({ }^{(\mathrm{BB} u} \mathrm{PDP}^{\mathrm{Ph}}\right) \mathrm{Fe}(\mathrm{py})_{2}$ \\
\hline $\mathrm{Fe}(1)-\mathrm{N}(1)$ & $2.020(2)$ & $2.0609(8)$ & $2.0937(15)$ \\
\hline $\mathrm{Fe}(1)-\mathrm{N}(2)$ & $2.031(2)$ & $2.0628(8)$ & $2.0624(15)$ \\
\hline $\mathrm{Fe}(1)-\mathrm{N}(3)$ & $2.020(2)$ & $2.0611(8)$ & $2.0825(15)$ \\
\hline $\mathrm{Fe}(1)-\mathrm{N}(4)$ & - & - & $2.2561(15)$ \\
\hline $\mathrm{Fe}(1)-\mathrm{N}(5)$ & - & - & $2.2491(15)$ \\
\hline $\mathrm{Fe}(1)-\mathrm{O}(1)$ & $2.105(2)$ & $2.2478(7)$ & - \\
\hline $\mathrm{Fe}(1)-\mathrm{O}(2)$ & - & $2.2897(7)$ & - \\
\hline $\mathrm{N}(1)-\mathrm{Fe}(1)-\mathrm{N}(2)$ & 79.23(9) & $79.07(3)$ & $78.50(6)$ \\
\hline $\mathrm{N}(1)-\mathrm{Fe}(1)-\mathrm{N}(3)$ & $146.55(8)$ & $157.26(3)$ & $156.60(6)$ \\
\hline $\mathrm{N}(2)-\mathrm{Fe}(1)-\mathrm{N}(3)$ & $79.38(9)$ & $78.31(3)$ & $78.13(6)$ \\
\hline $\mathrm{N}(2)-\mathrm{Fe}(1)-\mathrm{O}(1)$ & $107.31(8)$ & $100.01(3)$ & - \\
\hline $\mathrm{N}(2)-\mathrm{Fe}(1)-\mathrm{O}(2)$ & - & $95.76(3)$ & - \\
\hline $\mathrm{N}(2)-\mathrm{Fe}(1)-\mathrm{N}(4)$ & - & - & $92.48(6)$ \\
\hline $\mathrm{N}(2)-\mathrm{Fe}(1)-\mathrm{N}(5)$ & - & - & $100.57(6)$ \\
\hline
\end{tabular}

\subsection{Synthesis and Characterization of ( $\left.{ }^{\mathrm{Ar} P D P}{ }^{\mathrm{Ph}}\right)$ High-Spin $\mathrm{Fe}^{\mathrm{II}}$ Complexes}

With the disparate geometric and electronic structures observed for $\left({ }^{\mathrm{tBu}} \mathrm{PDP}^{\mathrm{R}}\right)$ complexes relative to $\left({ }^{\mathrm{Mes}} \mathrm{PDP}{ }^{\mathrm{Ph}}\right)$ high-spin $\mathrm{Fe}^{\mathrm{II}}$ complexes, the iron coordination chemistry of other aryl substituted PDP ligands was explored. The synthesis of the new PDP ligand $\mathrm{H}_{2}{ }^{\mathrm{C} 6 \mathrm{~F} 5} \mathrm{PDP}^{\mathrm{Ph}}$ was accomplished in a $64 \%$ yield in a two-step one pot reaction sequence akin to previously described PDP ligands synthesized in our group. $\mathrm{H}_{2}^{2,6-\mathrm{Cl} 2 \mathrm{Ph}} \mathrm{PDP}^{\mathrm{Ph}}$ was also synthesized in a similar manner from 2,6-pyridinecarboxaldehyde and the corresponding chalcone, 1-(2,6dichlorophenyl)-3-phenyl-2-propen-1-one. ${ }^{1,4}$ However, Paul-Knorr cyclization of the intermediate diketone in ethanol which has been successful for the synthesis of a variety of 
$\mathrm{H}_{2}{ }^{\mathrm{R}} \mathrm{PDP}^{\mathrm{R}}$ ligands did not proceed. This is likely due to poor solubility of the intermediate diketone in this solvent. Solvent screening found that glacial acetic acid afforded the desired $\mathrm{H}_{2}{ }^{2,6-\mathrm{Cl} 2 \mathrm{Ph}} \mathrm{PDP}^{\mathrm{Ph}}$ in a moderate yield of $67 \%$ (50\% over the two steps). The corresponding 4methoxy pyridine analogue $\mathrm{H}_{2} 4-\mathrm{MeO}^{2,6-\mathrm{Cl} 2 \mathrm{Ph}} \mathrm{PDP}^{\mathrm{Ph}}$ was also synthesized, yielding the corresponding diketone in 62\% from 4-methoxy-2,6-pyridinecarboxaldehyde and 1-(2,6dichlorophenyl)-3-phenyl-2-propen-1-one under analogous Stetter conditions. Treatment of the diketone with an excess of $\mathrm{NH}_{4} \mathrm{OAc}$ in refluxing glacial acetic acid afforded $\mathrm{H}_{2} 4-\mathrm{MeO}^{2,6-\mathrm{Cl} 2 \mathrm{Ph}} \mathrm{PDP}^{\mathrm{Ph}}$ in $43 \%$ yield (unoptimized). X-ray structures of both $\mathrm{H}_{2}^{2,6-\mathrm{Cl} 2 \mathrm{Ph}} \mathrm{PDP}^{\mathrm{Ph}}$ and $\mathrm{H}_{2} 4-\mathrm{MeO}^{2,6-\mathrm{Cl} 2 \mathrm{Ph}} \mathrm{PDP}^{\mathrm{Ph}}$ were determined at $100 \mathrm{~K}$ and an ORTEP of each is depicted in Figures 4.7 and 4.8. The structure of $\mathrm{H}_{2}{ }^{2,6-\mathrm{Cl} 2 \mathrm{Ph}} \mathrm{PDP}^{\mathrm{Ph}}$ is monomeric and features hydrogen bonding interactions to a dimethylsulfoxide solvent molecule. In contrast, $\mathrm{H}_{2} 4-\mathrm{MeO}^{2,6-\mathrm{Cl} 2 \mathrm{Ph}} \mathrm{PDP}^{\mathrm{Ph}}$, which was crystallized from dichloromethane solvent, is characterized by a dimeric structure. This is due to the absence of a solvent molecule in the crystal lattice capable of participating in hydrogen bonding with the pyrrole protons.
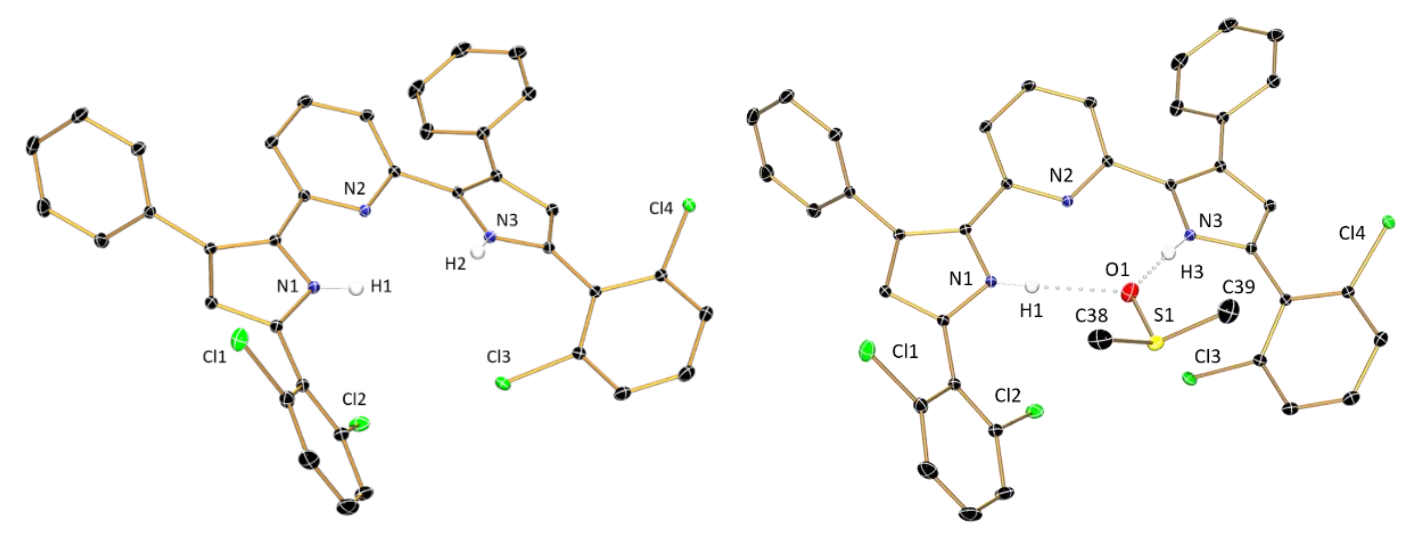

Figure 4.8. ORTEP of $\mathrm{H}_{2}^{2,6-C l 2 P h} \mathrm{PDP}^{\mathrm{Ph}}$ excluding DMSO solvent (left) and $\mathrm{H}_{2}{ }^{2,6-\mathrm{Cl} 2 \mathrm{Ph}} \mathrm{PDP}^{\mathrm{Ph}}$ (right) depicting the hydrogen bonding interaction between the pyrrole hydrogens and DMSO oxygen atom. Both structures displayed at $30 \%$ probability ellipsoids. Hydrogen atoms (with exception of pyrrole hydrogens) are excluded for clarity. 

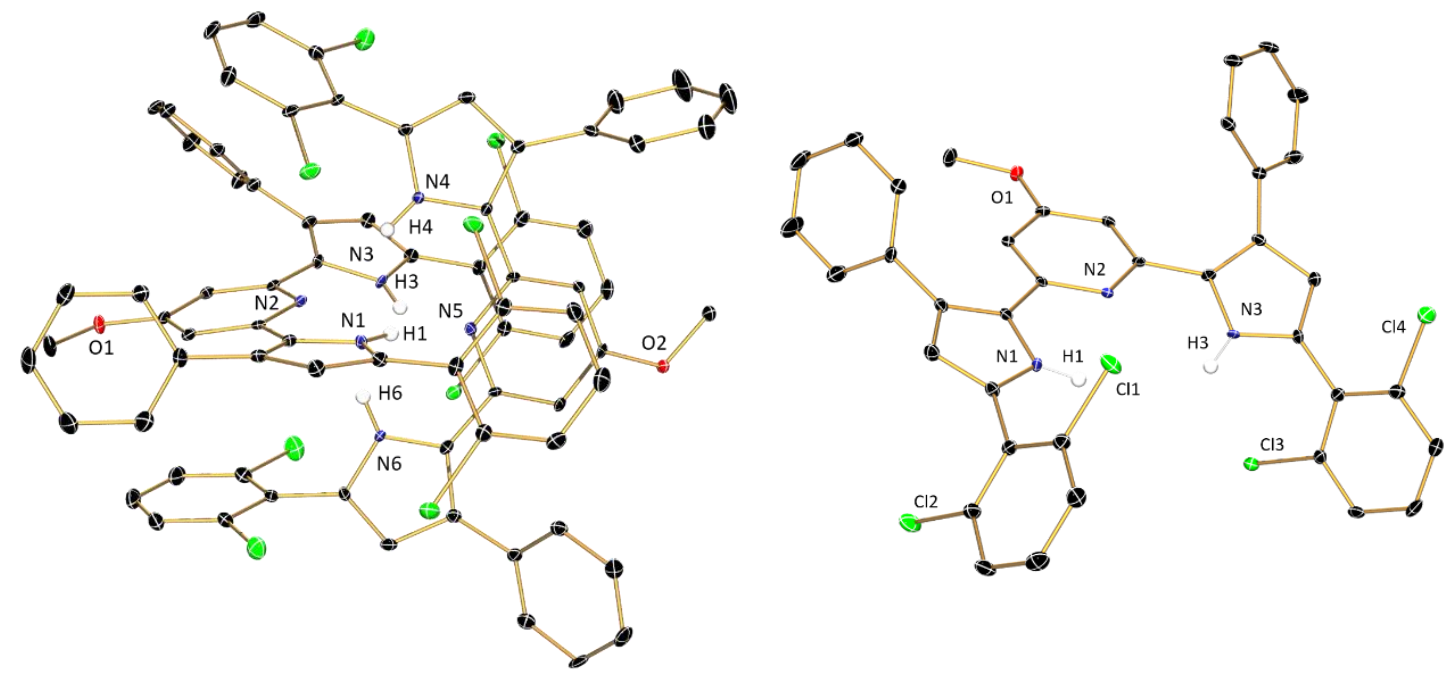

Figure 4.9. ORTEP of the hydrogen bonded dimer $\left[\mathrm{H}_{2} 4-\mathrm{MeO}^{2,6-\mathrm{Cl} 2 \mathrm{Ph}} \mathrm{PDP}^{\mathrm{Ph}}\right]_{2}$ (left) and $\mathrm{H}_{2} 4-\mathrm{MeO}^{2,6-\mathrm{Cl} 2 \mathrm{Ph}} \mathrm{PDP}^{\mathrm{Ph}}$ (right) displayed at 30\% probability ellipsoids. Co-crystallized solvent molecules and hydrogen atoms (with exception of pyrrole hydrogens) are removed for clarity.

Metalation of $\mathrm{H}_{2}{ }^{\mathrm{C} 6 \mathrm{~F} 5} \mathrm{PDP}^{\mathrm{Ph}}$ and $\mathrm{H}_{2}{ }^{2,6-\mathrm{Cl} 2 \mathrm{Ph}} \mathrm{PDP}^{\mathrm{Ph}}$ was first explored via treatment of $\mathrm{Fe}(\mathrm{Ns})_{2}(\mathrm{py})_{2}$ with the corresponding ligand in toluene solvent (Scheme 4.3). In each case, precipitation of the corresponding iron bis-pyridine compounds, $\left({ }^{\mathrm{C} 6 \mathrm{F5}} \mathrm{PDP}^{\mathrm{Ph}}\right) \mathrm{Fe}(\mathrm{py})_{2}$ and $\left.{ }^{2,6-\mathrm{Cl} 2 \mathrm{Ph}} \mathrm{PDP}^{\mathrm{Ph}}\right) \mathrm{Fe}(\mathrm{py})_{2}$, was observed and the compounds were isolated in high purity via filtration followed by washing with pentane in yields of 88 and 56\%, respectively.
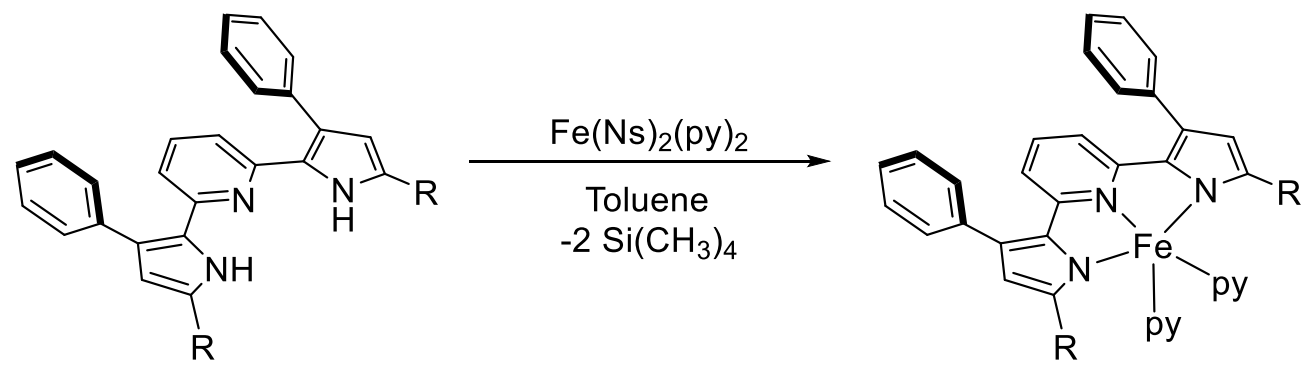

Scheme 4.3. Synthesis of $\left({ }^{\mathrm{R}} \mathrm{PDP}{ }^{\mathrm{Ph}}\right) \mathrm{Fe}(\mathrm{py})_{2}$ complexes. $\mathrm{R}={ }^{\mathrm{t}} \mathrm{Bu}, \mathrm{C}_{6} \mathrm{~F}_{5}$, or $2,6-\mathrm{Cl}_{2} \mathrm{Ph}$.

In benzene- $d_{6}$ solution, $\left({ }^{\mathrm{C} 655} \mathrm{PDP}^{\mathrm{Ph}}\right) \mathrm{Fe}(\mathrm{py})_{2}$ and $\left({ }^{2,6-\mathrm{Cl} 12 \mathrm{Ph}} \mathrm{PDP}^{\mathrm{Ph}}\right) \mathrm{Fe}(\mathrm{py})_{2}$ show nine and eleven paramagnetically shifted resonances, respectively, consistent with the anticipated number 
of resonances for a $\mathrm{C}_{2 v}$ symmetric $\left({ }^{\mathrm{R}} \mathrm{PDP} \mathrm{P}^{\mathrm{R}}\right) \mathrm{Fe}(\mathrm{py})_{2}$ environment in solution. ${ }^{19} \mathrm{~F}$ NMR analysis of $\left({ }^{\mathrm{C} 6 \mathrm{F5}} \mathrm{PDP}^{\mathrm{Ph}}\right) \mathrm{Fe}(\mathrm{py})_{2}$ demonstrated 3 paramagnetically broadened resonances in relative 1:2:2 ration, consistent with the symmetry observed in the ${ }^{1} \mathrm{H}$ NMR measurement for this complex. A single crystal of $\left(^{2,6-\mathrm{Cl} 2 \mathrm{Ph}} \mathrm{PDP}^{\mathrm{Ph}}\right) \mathrm{Fe}(\mathrm{py})_{2}$ was grown via slow evaporation of a concentrated dichloromethane solution of the compound and allowed for confirmation of its structure via X-ray crystallography. An ORTEP of the complex is shown in Figure 4.9. The structure of $\left.{ }^{2,6-\mathrm{Cl} 2 \mathrm{Ph}} \mathrm{PDP}^{\mathrm{Ph}}\right) \mathrm{Fe}(\mathrm{py})_{2}$ in the solid state is $\mathrm{C}_{s}$ symmetric, very similar to $\left({ }^{\mathrm{Mes}} \mathrm{PDP}{ }^{\mathrm{Ph}}\right) \mathrm{Fe}(\mathrm{py})_{2}$, existing in a square pyramidal geometry about the iron center. Presumably, as with $\left({ }^{\mathrm{Mes}} \mathrm{PDP}^{\mathrm{Ph}}\right) \mathrm{Fe}(\mathrm{py})_{2}$, dynamic movement of the pyridine ligands of $\left({ }^{\mathrm{C} 6 \mathrm{F5}} \mathrm{PDP}^{\mathrm{Ph}}\right) \mathrm{Fe}(\mathrm{py})_{2}$ and $\left.{ }^{2,6-\mathrm{Cl} 2 \mathrm{Ph}} \mathrm{PDP}^{\mathrm{Ph}}\right) \mathrm{Fe}(\mathrm{py})_{2}$ above and below the plane of the PDP pincer renders the two ligands equivalent on the ${ }^{1} \mathrm{H}$ NMR time scale, hence the observed $\mathrm{C}_{2 v}$ symmetric spectrum.

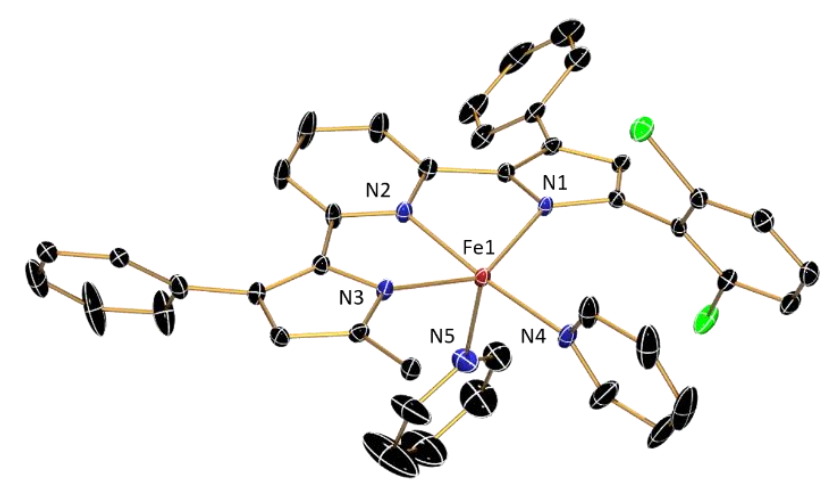

Figure 4.10. ORTEP of (2,6-Cl2PhPDPPh)Fe(py $)_{2}$ at $30 \%$ probability ellipsoids. Hydrogen atoms and co-crystallized solvent are omitted for clarity. Only the ipso carbon of one 2,6-dichlorophenyl pyrrole substituent is depicted.

Zero-field Mössbauer spectra acquired on powder samples of (2,6-Cl2Ph $\left.\mathrm{PDP}^{\mathrm{Ph}}\right) \mathrm{Fe}(\mathrm{py})_{2}$ (Figure 4.13) and $\left({ }^{\mathrm{C} 6 \mathrm{~F} 5} \mathrm{PDP}^{\mathrm{Ph}}\right) \mathrm{Fe}(\mathrm{py})_{2}$ (Figure 4.10) at $80 \mathrm{~K}$ were fit satisfactorily with parameters $\delta=0.99 \mathrm{mms}^{-1}$ and $\left|\Delta \mathrm{E}_{\mathrm{Q}}\right|=3.12 \mathrm{mms}^{-1}$ for $\left.{ }^{2,6-\mathrm{Cl} 2 \mathrm{Ph}} \mathrm{PDP}^{\mathrm{Ph}}\right) \mathrm{Fe}(\mathrm{py})_{2}$ and $\delta=1.08 \mathrm{mms}^{-1}$ and $\left|\Delta \mathrm{E}_{\mathrm{Q}}\right|=$ $2.91 \mathrm{mms}^{-1}$ for $\left({ }^{\mathrm{C} 6 \mathrm{~F} 5} \mathrm{PDP}^{\mathrm{Ph}}\right) \mathrm{Fe}(\mathrm{py})_{2}$. These values are nearly identical to the Mössbauer 
parameters of $\delta=0.98 \mathrm{mms}^{-1}$ and $\left|\Delta \mathrm{E}_{\mathrm{Q}}\right|=2.92 \mathrm{mms}^{-1}$ determined for $\left({ }^{\mathrm{Mes}} \mathrm{PDP}{ }^{\mathrm{Ph}}\right) \mathrm{Fe}(\mathrm{py})_{2}$ measured under the same conditions.

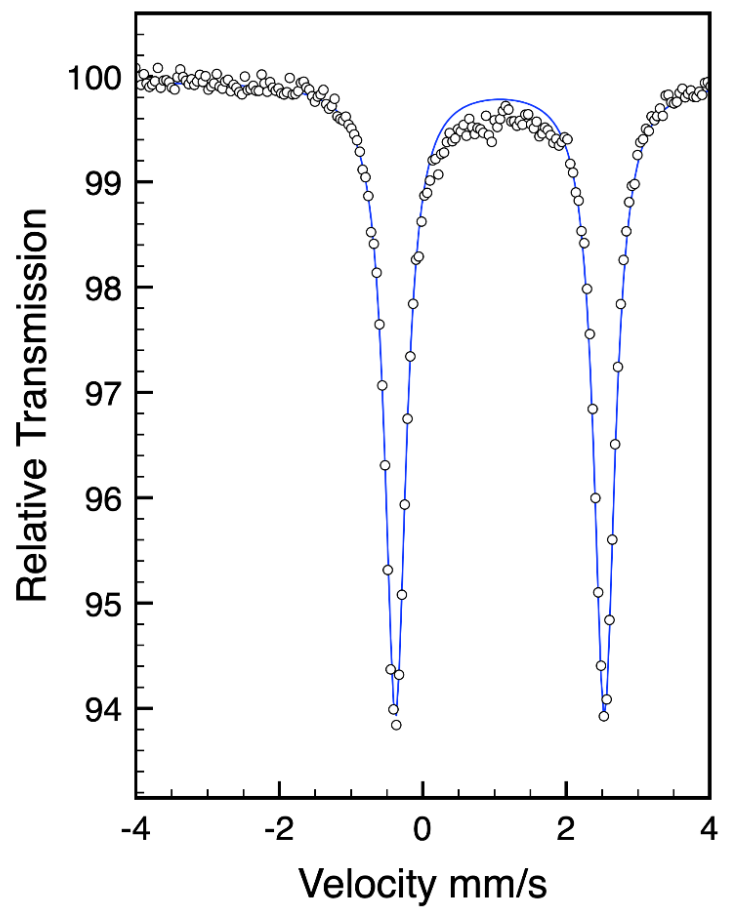

Figure 4.11. Zero-field ${ }^{57} \mathrm{Fe}$ Mössbauer spectrum of $\left({ }^{\mathrm{C} 6 \mathrm{F5}} \mathrm{PDP}^{\mathrm{Ph}}\right) \mathrm{Fe}(\mathrm{py})_{2}$ recorded at $80 \mathrm{~K}$.

The metalation of $\mathrm{H}_{2}{ }^{2,6-\mathrm{Cl} 2 \mathrm{Ph}} \mathrm{PDP}^{\mathrm{Ph}}$ and $\mathrm{H}_{2} 4-\mathrm{MeO}^{2,6-\mathrm{Cl} 2 \mathrm{Ph}} \mathrm{PDP}^{\mathrm{Ph}}$ was performed by treatment of $\mathrm{FeCl}_{2}$ with the deprotonated ligand (Scheme 4.4). To stirring solutions of either $\mathrm{H}_{2}{ }^{2,6-\mathrm{Cl} 2 \mathrm{Ph}} \mathrm{PDP}^{\mathrm{Ph}}$ and $\mathrm{H}_{2} 4-\mathrm{MeO}^{2,6-\mathrm{Cl} 2 \mathrm{Ph}} \mathrm{PDP}^{\mathrm{Ph}}$ in $\mathrm{THF}$ solvent was added a solution of LiHMDS in the same solvent, resulting in a rapid color change of the solution from colorless to a luminescent yellow. Addition of the solution of the in situ generated doubly deprotonated ligand to a THF suspension of $\mathrm{FeCl}_{2}$ resulted in an immediate color change to red-orange. After stirring overnight, the resulting solution was concentrated in vacuo and pentane was added, inducing precipitation of an orange microcrystalline solid. Filtration, subsequent extraction of the material into dichloromethane solvent, and filtration through a pad of celite afforded a dark-red solution. The resulting filtrate was concentrated and triturated multiple times, affording 
$\left.{ }^{2,6-\mathrm{Cl} 2 \mathrm{Ph}} \mathrm{PDP}^{\mathrm{Ph}}\right) \mathrm{Fe}$ (thf) and (4- $\left.\mathrm{MeO}^{2,6-\mathrm{Cl} 2 \mathrm{Ph}} \mathrm{PDP}^{\mathrm{Ph}}\right) \mathrm{Fe}($ thf $)$ as bright orange powders in 74 and $77 \%$ yields, respectively.

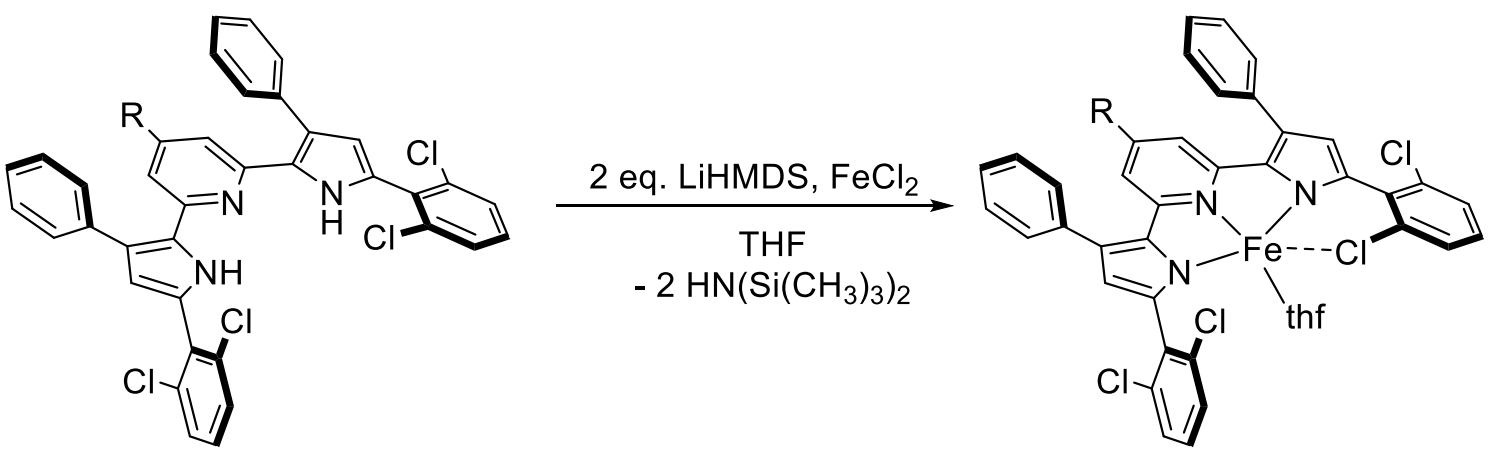

Scheme 4.4. Synthesis of $\left(\mathrm{R}^{2,6-\mathrm{Cl} 2 \mathrm{Ph}} \mathrm{PDP}^{\mathrm{Ph}}\right) \mathrm{Fe}($ thf $)$ complexes. $\mathrm{R}=\mathrm{H}$ or OMe.

Red single crystals of both complexes could be obtained from diffusion of pentane into concentrated benzene solutions at room temperature. Interestingly, in a departure from $\left({ }^{\mathrm{Mes}} \mathrm{PDP}{ }^{\mathrm{Ph}}\right) \mathrm{Fe}(\mathrm{thf}),\left({ }^{2,6-\mathrm{Cl} 2 \mathrm{Ph}} \mathrm{PDP}^{\mathrm{Ph}}\right) \mathrm{Fe}(\mathrm{thf})$ and $\left(4-\mathrm{MeO}^{2,6-\mathrm{Cl} 2 \mathrm{Ph}} \mathrm{PDP}^{\mathrm{Ph}}\right) \mathrm{Fe}($ thf $)$ both feature geometries that are not pseudo-square planar. The presence of the ortho chloride substitution patterns on the arene ring results in an iron-chloride $(\mathrm{Fe}(1)-\mathrm{Cl}(2))$ interaction in the solid state, with the experimentally determined $\mathrm{Fe} \cdots \mathrm{Cl}$ interatomic distances being $2.7161(5)$ and 2.6853(6) $\AA$ for $\left({ }^{2,6-\mathrm{Cl} 2 \mathrm{Ph}} \mathrm{PDP}^{\mathrm{Ph}}\right) \mathrm{Fe}($ thf $)$ and $\left(4-\mathrm{MeO}^{2,6-\mathrm{Cl} 2 \mathrm{Ph}} \mathrm{PDP}^{\mathrm{Ph}}\right) \mathrm{Fe}$ (thf), respectively. ORTEP depictions of each compound are depicted in Figure 4.11, demonstrating their solid-state structures as determined by X-ray crystallography. The solid-state $\mathrm{C}_{1}$ symmetric structures are in disagreement with the solution phase ${ }^{1} \mathrm{H}$ NMR spectrum, which evidences $\mathrm{C}_{2 v}$ symmetry. For a discrete $\mathrm{C}_{1}$ structures, 19 resonances would be expected for $\left({ }^{2,6-\mathrm{Cl} 2 \mathrm{Ph}} \mathrm{PDP} \mathrm{Ph}^{\mathrm{Ph}}\right) \mathrm{Fe}($ thf $)$ and (4- $\left.\mathrm{MeO}^{2,6-\mathrm{Cl} 2 \mathrm{Ph}} \mathrm{PDP}^{\mathrm{Ph}}\right) \mathrm{Fe}(\mathrm{thf})$, assuming free rotation of the PDP pyrrolide 3-phenyl substituents and iron bound THF ligands. Presumably, the weak interaction between the iron and chlorides of the 2,6-dichlorophenyl substituents of the PDP ligand is dynamic in solution, and the THF ligand is on average planar, resulting in the observed $\mathrm{C}_{2 \mathrm{v}}$ symmetric spectrum. Due to their similarities 
only the structural metrics of $\left.{ }^{2,6-\mathrm{Cl} 2 \mathrm{Ph}} \mathrm{PDP}^{\mathrm{Ph}}\right) \mathrm{Fe}($ thf $)$ will be described in further detail. A more complete description of both the structural features of $\left({ }^{2,6-C l 2 P h} \mathrm{PDP}^{\mathrm{Ph}}\right) \mathrm{Fe}(\mathrm{thf})$ and (4-MeO $\left.{ }^{2,6-\mathrm{Cl} 2 \mathrm{Ph}} \mathrm{PDP}^{\mathrm{Ph}}\right) \mathrm{Fe}$ (thf) can be found in Table 4.2. In ( $\left.{ }^{2,6-\mathrm{Cl} 2 \mathrm{Ph}} \mathrm{PDP}^{\mathrm{Ph}}\right) \mathrm{Fe}($ thf $)$, the THF ligand is bent below the plane established by the PDP pincer. The Fe-O1 bond to the THF oxygen is $2.0555(13) \AA$, the Fe-N1 and N3 bonds to the pyrrolide nitrogens are 2.0732(15) and 2.0599(14) $\AA$, and the Fe1-N2 bond to the pyridine nitrogen is $2.0749(14) \AA$. These values are in good agreement with the observed structure of $\left({ }^{\mathrm{Mes}} \mathrm{PDP}{ }^{\mathrm{Ph}}\right) \mathrm{Fe}(\mathrm{thf})$ and are consistent with other high-spin Fe ${ }^{\mathrm{II}} \mathrm{PDP}$ complexes. ${ }^{1,3}$ Notably, however, is one structural discrepancy in the $\left.{ }^{2,6-\mathrm{Cl} 2 \mathrm{Ph}} \mathrm{PDP}^{\mathrm{Ph}}\right) \mathrm{Fe}($ thf $)$, the $\mathrm{N} 2-\mathrm{Fe} 1-\mathrm{O} 1$ bond angle is bent at $135.32(6)^{\circ}$, whereas in $\left({ }^{\mathrm{Mes}} \mathrm{PDP}^{\mathrm{Ph}}\right) \mathrm{Fe}\left(\right.$ thf) the same bond angle is much closer to planarity, measured at $152.99(5)^{\circ} .{ }^{1}$

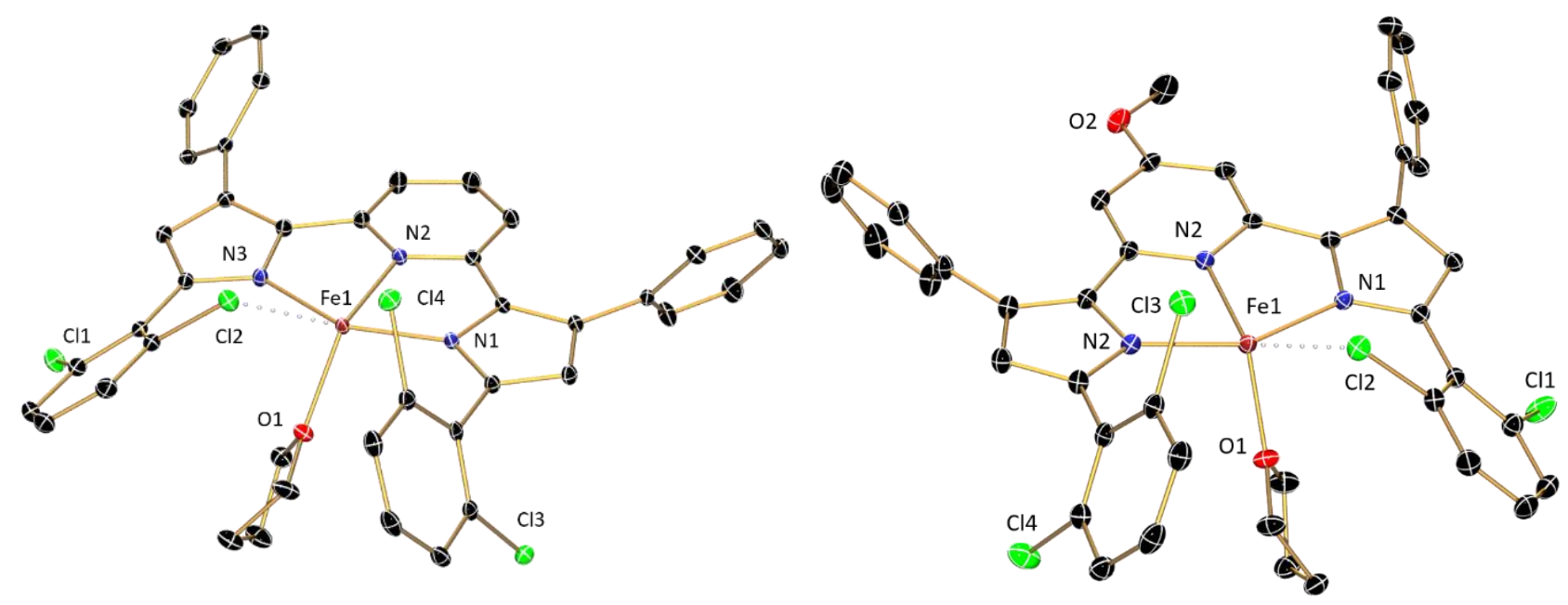

Figure 4.12. ORTEP of (2,6-Cl2Ph $\mathrm{PDPPh}) \mathrm{Fe}$ (thf) (left) and (4- $\left.\mathrm{MeO}^{2,6-\mathrm{Cl} 2 \mathrm{Ph}} \mathrm{PDP} \mathrm{Ph}^{\mathrm{Ph}}\right) \mathrm{Fe}($ thf) (right) at $30 \%$ probability ellipsoids. Hydrogen atoms and co-crystallized solvent molecules are omitted for clarity.

In light of the observation of the chloride substituents perturbing the coordination environment about iron, both $\left({ }^{2,6-\mathrm{Cl} 2 \mathrm{Ph}} \mathrm{PDP}^{\mathrm{Ph}}\right) \mathrm{Fe}($ thf $)$ and $\left(4-\mathrm{MeO}^{2,6-\mathrm{Cl} 2 \mathrm{Ph}} \mathrm{PDP}^{\mathrm{Ph}}\right) \mathrm{Fe}($ thf $)$ were analyzed by zero-field ${ }^{57} \mathrm{Fe}$ Mössbauer spectroscopy to assess their electronic structures relative to previously prepared high-spin Fe ${ }^{\mathrm{II}} \mathrm{PDP}$ complexes. The observed quadrupole doublets were 
each fitted as one component spectra with identical isomer shifts, $\delta=0.96 \mathrm{mms}^{-1}$, and $\left|\Delta \mathrm{E}_{\mathrm{Q}}\right|=$ $1.43 \mathrm{mms}^{-1}$ and $2.00 \mathrm{mms}^{-1}$, confirming the high-spin ferrous formulation of the iron centers (Figure 4.12). The DFT computed values for both compounds were found to be $\delta=0.81 \mathrm{mms}^{-1}$ and $\Delta \mathrm{E}_{\mathrm{Q}}=2.00 \mathrm{mms}^{-1}$, and are in good agreement with the experimental data. However, it should be noted that the discrepancy between the computed and experimental quadrupole splitting values of $\left.{ }^{2,6-\mathrm{Cl} 2 \mathrm{Ph}} \mathrm{PDP}^{\mathrm{Ph}}\right) \mathrm{Fe}(\mathrm{thf})$ are not clear at this time. The quadrupole splitting is known to be sensitive to subtle changes in the coordination environment, and thus, the deviation between the experimental values in the two complexes is tentatively attributed to solid-state packing effects. Consequently, the iron-chloride interactions observed in the solid state structures of $\left({ }^{2,6-\mathrm{Cl} 2 \mathrm{Ph}} \mathrm{PDP}^{\mathrm{Ph}}\right) \mathrm{Fe}$ (thf) and (4- $\left.\mathrm{MeO}^{2,6-\mathrm{Cl} 2 \mathrm{Ph}} \mathrm{PDP}^{\mathrm{Ph}}\right) \mathrm{Fe}$ (thf) may be the primary reason for the significant increase in their quadrupole splitting values relatives to those obtained from the corresponding Mössbauer spectra of the four-coordinate square planar complexes $\left({ }^{\mathrm{Mes}} \mathrm{PDP}^{\mathrm{Ph}}\right) \mathrm{Fe}\left(\mathrm{OEt}_{2}\right)$ and $\left({ }^{\mathrm{Mes}} \mathrm{PDP}^{\mathrm{Ph}}\right) \mathrm{Fe}(\mathrm{thf}){ }^{1}$ 

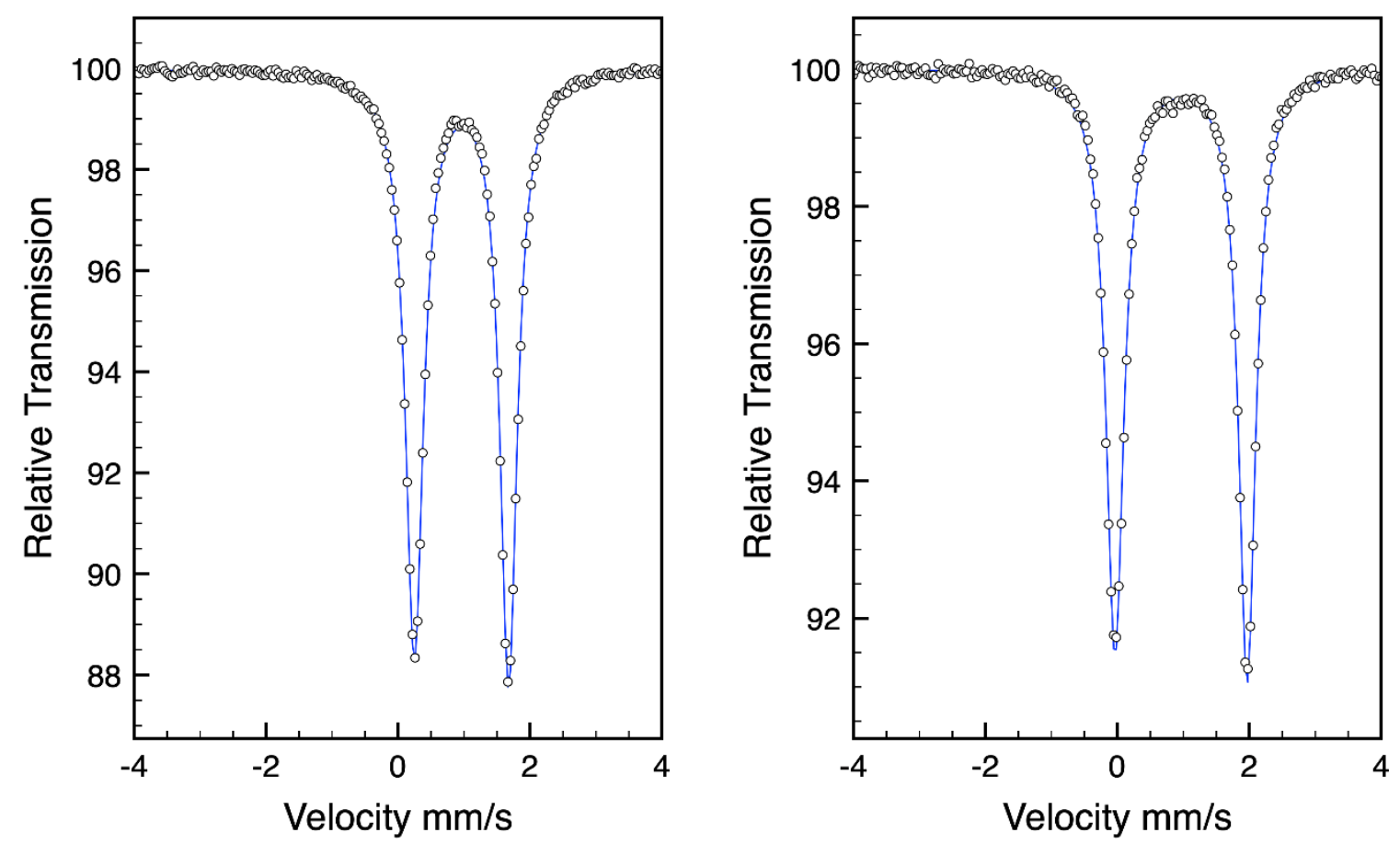

Figure 4.13. Zero-field ${ }^{57} \mathrm{Fe}$ Mössbauer spectra of $\left({ }^{2,6-C l 2 P h} \mathrm{PDP}^{\mathrm{Ph}}\right) \mathrm{Fe}($ thf $)$ and $\left(4-\mathrm{MeO}^{2,6-\mathrm{Cl} 2 \mathrm{Ph}} \mathrm{PDP}^{\mathrm{Ph}}\right) \mathrm{Fe}($ thf $)$ recorded at $80 \mathrm{~K}$.

Dissolution of $\left({ }^{2,6-C l 2 P h} \mathrm{PDP}^{\mathrm{Ph}}\right) \mathrm{Fe}(\mathrm{thf})$ in THF- $d_{8}$ and acquisition of an ${ }^{1} \mathrm{H}$ NMR spectrum demonstrated significant shifts in the chemical shifts of the observed resonances (Figure 4.13). For $\left.{ }^{(2,6-\mathrm{Cl} 2 \mathrm{Ph}} \mathrm{PDP}^{\mathrm{Ph}}\right) \mathrm{Fe}(\mathrm{thf})_{2}$ the 4-pyridine proton resonances was identified at $22.14 \mathrm{ppm}$ in THF- $d_{8}$, while in benzene- $d_{6}$ the 4-pyridine proton resonance for $\left({ }^{2,6-C 12 P h} \mathrm{PDP}^{\mathrm{Ph}}\right) \mathrm{Fe}($ thf $)$ was observed at $0.36 \mathrm{ppm}$, consistent with five and four coordinate high-spin $\mathrm{Fe}^{\mathrm{II}} \mathrm{PDP}$ complexes, respectively. ${ }^{1}$ Note that for $\left({ }^{2,6-\mathrm{Cl} 2 \mathrm{Ph}} \mathrm{PDP}{ }^{\mathrm{Ph}}\right) \mathrm{Fe}(\text { thf })_{2}$ resonances corresponding to the THF protons were not observed due to rapid equilibrium with THF- $d_{8}$. For $\left({ }^{2,6-\mathrm{Cl} 2 \mathrm{Ph}} \mathrm{PDP}^{\mathrm{Ph}}\right) \mathrm{Fe}($ thf) the resonances at 106.58 and $98.12 \mathrm{ppm}$ are assigned to the 3-pyridine and 4-pyrrole protons, respectively. Alternatively, for $\left({ }^{2,6-\mathrm{Cl} 2 \mathrm{Ph}} \mathrm{PDP}^{\mathrm{Ph}}\right) \mathrm{Fe}(\text { thf })_{2}$, the resonances at 85.40 and $65.88 \mathrm{ppm}$ are assigned as the 3-pyridine and 4-pyrrole protons. The shift in the frequency of the resonances corresponding to the 4-pyridine, 3-pyridine, and 4-pyrrole protons is due to changes in the 
amount of spin density imparted on the respective nuclei. Our group has previously demonstrated that the origin of this subtle phenomena is a change in the ground-state electronic structure between four and five coordinate high-spin $\mathrm{Fe}^{\mathrm{II}}$ PDP complexes. ${ }^{1}$

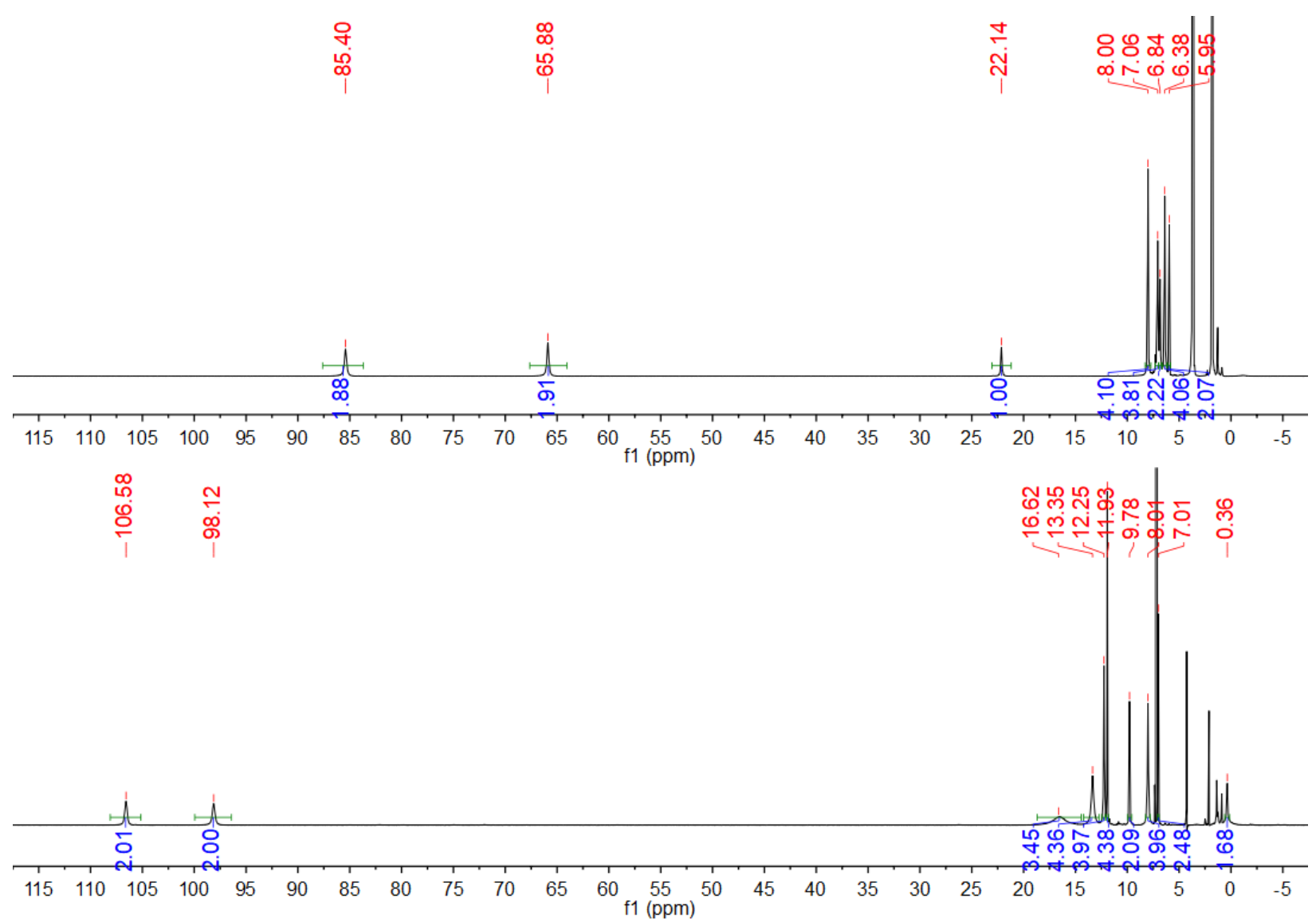

Figure 4.14. Comparison of the ${ }^{1} \mathrm{H}$ NMR spectra of $\left({ }^{2,6-C l 2 P h} \mathrm{PDP}^{\mathrm{Ph}}\right) \mathrm{Fe}(\mathrm{thf})_{2}$ in THF- $d_{8}$ (top) and $\left.{ }^{(2,6-\mathrm{Cl} 2 \mathrm{Ph}} \mathrm{PDP} \mathrm{Ph}^{\mathrm{Ph}}\right) \mathrm{Fe}$ (thf) in benzene- $d_{6}$ (bottom). Note, in the top spectrum the unmarked resonances correspond to THF while in the bottom spectrum the unmarked resonances are DCM and toluene present in the sample.

To further validate the existence of discrete four- and five-coordinate thf adducts, a powder sample of $\left(^{2,6-\mathrm{Cl} 2 \mathrm{Ph}} \mathrm{PDP}{ }^{\mathrm{Ph}}\right) \mathrm{Fe}(\mathrm{thf})$ was dissolved in THF and a zero-field Mössbauer spectrum was acquired. The resulting spectrum contained a single quadrupole doublet which was satisfactorily fit with $\delta=1.20 \mathrm{mms}^{-1}$ and $|\Delta \mathrm{EQ}|=3.02 \mathrm{mms}^{-1}$. Note that these values are markedly 
different that the solid-state Mössbauer parameters of $\left({ }^{2,6-\mathrm{Cl} 2 \mathrm{Ph}} \mathrm{PDP}^{\mathrm{Ph}}\right) \mathrm{Fe}($ thf $)$ and are in good agreement with the previously reported values for $\left({ }^{\mathrm{Mes}} \mathrm{PDP}{ }^{\mathrm{Ph}}\right) \mathrm{Fe}(\mathrm{thf})_{2} .{ }^{1}$ Furthermore, these values are in excellent agreement with the Mössbauer parameters of five-coordinate $\left.{ }^{2,6-\mathrm{Cl} 2 \mathrm{Ph}} \mathrm{PDP}^{\mathrm{Ph}}\right) \mathrm{Fe}(\mathrm{py})_{2}$, which further evidences this assignment. Both spectra are depicted in Figure 4.14.
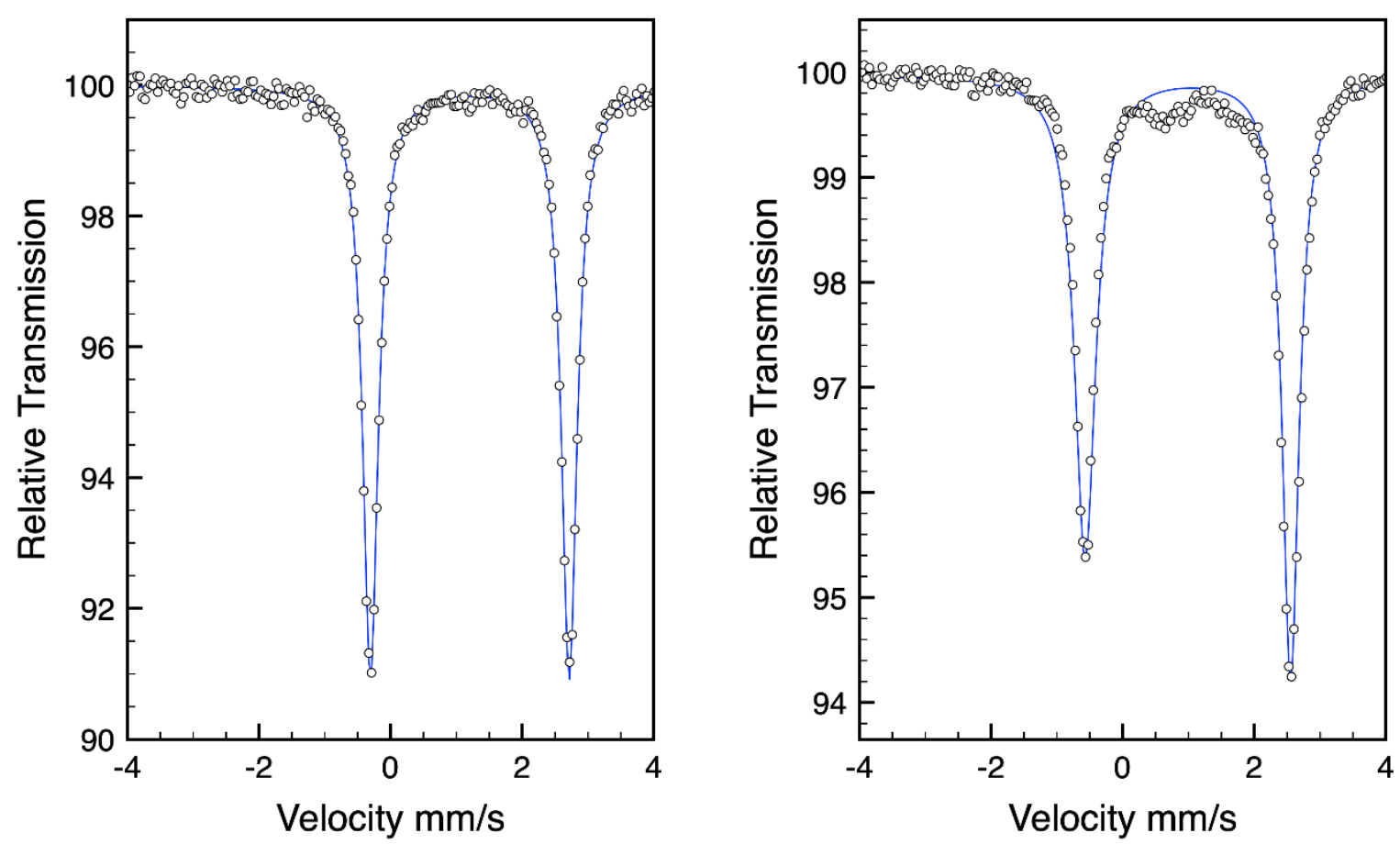

Figure 4.15. Zero-field ${ }^{57} \mathrm{Fe}$ Mössbauer spectra of $\left({ }^{2,6-\mathrm{Cl} 2 \mathrm{Ph}} \mathrm{PDP}^{\mathrm{Ph}}\right) \mathrm{Fe}(\mathrm{thf})_{2}$ (left, in frozen THF solution) and $\left({ }^{2,6-\mathrm{Cl} 2 \mathrm{Ph}} \mathrm{PDP}{ }^{\mathrm{Ph}}\right) \mathrm{Fe}(\mathrm{py})_{2}$ (right) recorded at $80 \mathrm{~K}$.

A preliminary X-ray structure of $\left({ }^{2,6-\mathrm{Cl} 2 \mathrm{Ph}} \mathrm{PDP}^{\mathrm{Ph}}\right) \mathrm{Fe}(\text { thf })_{2}$ was obtained allowing for assignment of the atom connectivity and confirmation of the identity of the species. Akin to $\left.{ }^{2,6-\mathrm{Cl} 2 \mathrm{Ph}} \mathrm{PDP}{ }^{\mathrm{Ph}}\right) \mathrm{Fe}(\mathrm{py})_{2},\left({ }^{2,6-\mathrm{Cl} 2 \mathrm{Ph}} \mathrm{PDP}^{\mathrm{Ph}}\right) \mathrm{Fe}(\text { thf })_{2}$ was found to adopt a square pyramidal geometry in the solid state. The addition of the second solvent ligand further congests the coordination sphere and interrupts the interaction between an ortho-phenyl chloride substituent(s) and the iron center that was observed in the four-coordinate THF analogue. This consistent with the apparent 
$\mathrm{C}_{2 v}$ symmetry observed in the ${ }^{1} \mathrm{H}$ NMR spectrum of $\left({ }^{2,6-\mathrm{C} 2 \mathrm{Ph}} \mathrm{PDP}^{\mathrm{Ph}}\right) \mathrm{Fe}(\mathrm{thf})_{2}$. An ORTEP of the preliminary X-ray structure of $\left({ }^{2,6-C l 2 P h} \mathrm{PDP}^{\mathrm{Ph}}\right) \mathrm{Fe}(\text { thf })_{2}$ is presented in Figure 4.15.

Table 4.2. Selected bond lengths $(\AA)$ and angles (deg) for $\left({ }^{2,6-\mathrm{Cl} 2 \mathrm{Ph}} \mathrm{PDP} \mathrm{Ph}^{\mathrm{Ph}}\right) \mathrm{Fe}(\mathrm{thf}),\left(4-\mathrm{MeO}^{2,6-\mathrm{Cl} 2 \mathrm{Ph}} \mathrm{PDP}^{\mathrm{Ph}}\right) \mathrm{Fe}(\mathrm{thf})$, and $\left({ }^{2,6-\mathrm{Cl} 2 \mathrm{Ph}} \mathrm{PDP} \mathrm{Ph}^{\mathrm{Ph}}\right) \mathrm{Fe}(\mathrm{py})_{2}$. Note, the apical pyridine in $\left(^{2,6-\mathrm{Cl} 2 \mathrm{Ph}} \mathrm{PDP}{ }^{\mathrm{Ph}}\right) \mathrm{Fe}(\mathrm{py})_{2}$ is disordered over two positions. Only metrics for one pyridine ring position are disclosed.

\begin{tabular}{cccc}
\hline & $\left(2,6-\mathrm{Cl} 2 \mathrm{Ph} P P^{\mathrm{Ph}}\right) \mathrm{Fe}(\mathrm{thf})$ & $\left(4-\mathrm{MeO}^{2,6-\mathrm{Cl} 2 \mathrm{Ph}} \mathrm{PDP}^{\mathrm{Ph}}\right) \mathrm{Fe}(\mathrm{thf})$ & $\left(2,6-\mathrm{Cl} 2 \mathrm{Ph} P \mathrm{PP}^{\mathrm{Ph}}\right) \mathrm{Fe}(\mathrm{py})_{2}$ \\
\hline $\mathrm{Fe}(1)-\mathrm{N}(1)$ & $2.0732(15)$ & $2.0695(16)$ & $2.072(3)$ \\
$\mathrm{Fe}(1)-\mathrm{N}(2)$ & $2.0749(14)$ & $2.0735(16)$ & $2.073(3)$ \\
$\mathrm{Fe}(1)-\mathrm{N}(3)$ & $2.0599(14)$ & $2.0553(16)$ & $2.077(3)$ \\
$\mathrm{Fe}(1)-\mathrm{N}(4)$ & - & - & $2.118(4)$ \\
$\mathrm{Fe}(1)-\mathrm{N}(5)$ & - & - & $2.112(3)$ \\
$\mathrm{Fe}(1)-\mathrm{O}(1)$ & $2.0555(13)$ & $2.0477(14)$ & - \\
$\mathrm{Fe}(1)-\mathrm{Cl}(1)$ & $2.7161(5)$ & $2.6853(6)$ & - \\
$\mathrm{N}(1)-\mathrm{Fe}(1)-\mathrm{N}(2)$ & $77.03(6)$ & $76.51(6)$ & $76.26(13)$ \\
$\mathrm{N}(1)-\mathrm{Fe}(1)-\mathrm{N}(3)$ & $154.40(6)$ & $153.82(6)$ & $146.10(13)$ \\
$\mathrm{N}(2)-\mathrm{Fe}(1)-\mathrm{N}(3)$ & $77.50(6)$ & $77.78(6)$ & $76.37(13)$ \\
$\mathrm{N}(2)-\mathrm{Fe}(1)-\mathrm{O}(1)$ & $135.32(6)$ & $131.84(6)$ & - \\
$\mathrm{N}(2)-\mathrm{Fe}(1)-\mathrm{N}(4)$ & - & - & $174.15(15)$ \\
$\mathrm{N}(2)-\mathrm{Fe}(1)-\mathrm{N}(5)$ & - & - & $87.56(16)$ \\
\hline
\end{tabular}




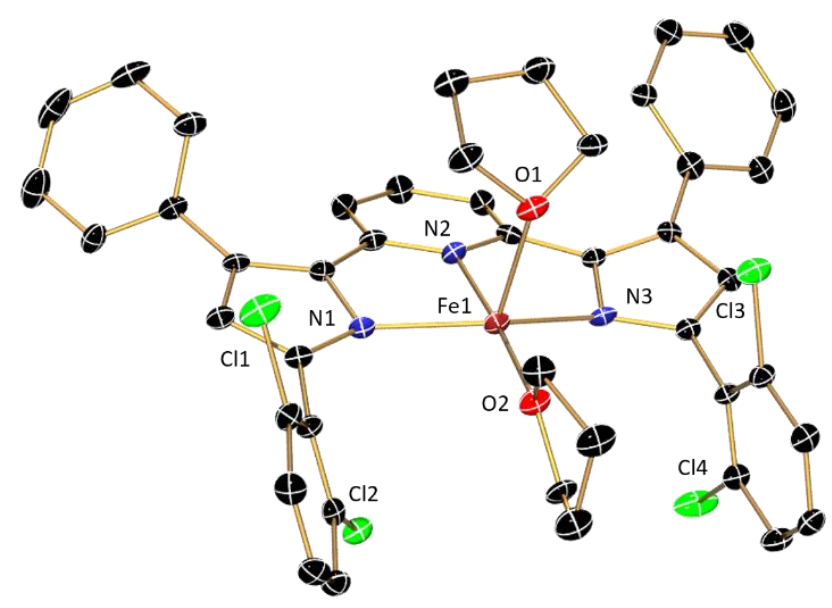

Figure 4.16. ORTEP of $\left({ }^{2,6-\mathrm{C} 12 \mathrm{Ph}} \mathrm{PDP} \mathrm{Ph}^{\mathrm{Ph}}\right) \mathrm{Fe}(\mathrm{thf})_{2}$ at $30 \%$ probability ellipsoids. Hydrogen atoms and a co-crystallized diethyl ether solvent molecule are omitted for clarity.

Table 4.3. Experimental and calculated Mössbauer parameters for high-spin $\mathrm{Fe}^{\mathrm{II}} \mathrm{PDP}$ complexes

\begin{tabular}{|c|c|c|c|}
\hline & $\delta / \mathrm{mms}^{-1}$ (calc) & $\Delta E_{Q} / \mathrm{mms}^{-1}(\text { calc })^{a}$ & $\eta^{b, c}$ \\
\hline$\left({ }^{(\mathrm{Bu}} \mathrm{PDP}^{\mathrm{Ph}}\right) \mathrm{Fe}\left(\mathrm{OEt}_{2}\right)$ & $0.91(0.76)$ & $|1.25|(1.75)$ & 0.913 \\
\hline \multirow[t]{2}{*}{ 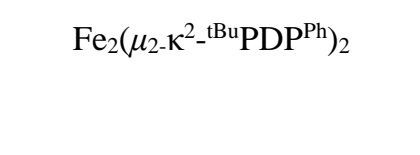 } & $0.82(0.69)$ & $|1.68|(-1.62)$ & 0.375 \\
\hline & $0.82(0.69)$ & $|1.68|(-1.71)$ & 0.546 \\
\hline$\left({ }^{(\mathrm{Bu}} \mathrm{PDP} \mathrm{Ph}^{\mathrm{Ph}}\right) \mathrm{Fe}(\mathrm{thf})_{2}$ & $1.07(0.87)$ & $|1.42|(1.85)$ & 0.557 \\
\hline$\left({ }^{(\mathrm{Bu} u} \mathrm{PDP}^{\mathrm{Ph}}\right) \mathrm{Fe}(\mathrm{py})_{2}$ & $1.02(0.85)$ & |1.94|(4.66) & 0.507 \\
\hline$\left({ }^{2,6-\mathrm{Cl} 2 \mathrm{Ph}} \mathrm{PDP}^{\mathrm{Ph}}\right) \mathrm{Fe}(\mathrm{thf})$ & $0.96(0.81)$ & $|1.43|(2.14)$ & 0.417 \\
\hline$\left({ }^{2,6-\mathrm{Cl} 2 \mathrm{Ph}} \mathrm{PDP}^{\mathrm{Ph}}\right) \mathrm{Fe}(\mathrm{thf})_{2}{ }^{d}$ & $1.20(0.93)$ & $|3.02|(2.81)$ & 0.866 \\
\hline$\left({ }^{2,6-\mathrm{Cl} 2 \mathrm{Ph}} \mathrm{PDP}^{\mathrm{Ph}}\right) \mathrm{Fe}(\mathrm{py})_{2}$ & $0.99(0.86)$ & $|3.12|(3.01)$ & 0.802 \\
\hline$\left({ }^{\mathrm{C} 6 \mathrm{~F} 5} \mathrm{PDP}^{\mathrm{Ph}}\right) \mathrm{Fe}(\mathrm{py})_{2}$ & $1.08(0.85)$ & $|2.91|(2.96)$ & 0.716 \\
\hline$\left(4-\mathrm{MeO}^{2,6-\mathrm{Cl} 2 \mathrm{Ph}} \mathrm{PDP}^{\mathrm{Ph}}\right) \mathrm{Fe}(\mathrm{thf})$ & $0.96(0.81)$ & $|2.00|(2.14)$ & 0.417 \\
\hline
\end{tabular}

${ }^{a}$ Sign not determined experimentally. ${ }^{b}$ Asymmetry parameter of the electronic field gradient.

${ }^{c}$ Not determined experimentally. ${ }^{d}$ Measured in frozen THF solution. 


\subsection{Conclusion}

A family of high-spin $\mathrm{Fe}^{\mathrm{II}}$ complexes carrying the new pyridine dipyrrolide ligands $\mathrm{H}_{2}{ }^{\mathrm{tBu}} \mathrm{PDP}{ }^{\mathrm{Ph}}, \mathrm{H}_{2}{ }^{2,6-\mathrm{Cl} 2 \mathrm{Ph}} \mathrm{PDP}^{\mathrm{Ph}}, \mathrm{H}_{2} 4-\mathrm{MeO}^{2,6-\mathrm{Cl} 2 \mathrm{Ph}} \mathrm{PDP}^{\mathrm{Ph}}$ and $\mathrm{H}_{2}{ }^{\mathrm{C} 6 \mathrm{~F} 5} \mathrm{PDP}^{\mathrm{Ph}}$ was synthesized and structurally characterized. The new PDP ligands $\mathrm{H}_{2}^{2,6-\mathrm{Cl} 2 \mathrm{Ph}} \mathrm{PDP}^{\mathrm{Ph}}$ and $\mathrm{H}_{2} 4-\mathrm{MeO}^{2,6-\mathrm{Cl} 2 \mathrm{Ph}} \mathrm{PDP}^{\mathrm{Ph}}$ were characterized via X-ray crystallography. $\mathrm{H}_{2}{ }^{2,6-C l 2 P h} \mathrm{PDP}^{\mathrm{Ph}}$ was found to exist as a discrete monomeric structure with a dimethyl sulfoxide solvent molecule acting as a hydrogen bond donor to the pyrrolide nitrogen protons. Alternatively, $\mathrm{H}_{2} 4-\mathrm{MeO}^{2,6-\mathrm{Cl} 2 \mathrm{Ph}} \mathrm{PDP}^{\mathrm{Ph}}$ was found to exist as a hydrogen bonded dimer in absence of coordinating solvent, akin to the previously reported analogue, $\mathrm{H}_{2}{ }^{\mathrm{Mes}} \mathrm{PDP}^{\mathrm{Ph}}$.

For $\mathrm{H}_{2}{ }^{\mathrm{tBu}} \mathrm{PDP}^{\mathrm{Ph}}$, it was discovered that four or five coordinate high-spin $\mathrm{Fe}^{\mathrm{II}}$ complexes could be isolated depending on the identity of the exogenous Lewis base employed during synthesis. The resulting compounds $\left({ }^{\mathrm{tBu}} \mathrm{PDP}^{\mathrm{Ph}}\right) \mathrm{Fe}\left(\mathrm{OEt}_{2}\right),\left({ }^{\mathrm{tBu}} \mathrm{PDP}^{\mathrm{Ph}}\right) \mathrm{Fe}(\text { thf })_{2}$, and $\left({ }^{\mathrm{tBu}} \mathrm{PDP}{ }^{\mathrm{Ph}}\right) \mathrm{Fe}(\mathrm{py})_{2}$ were characterized via a combination of ${ }^{1} \mathrm{H}$ NMR and Mössbauer spectroscopies as well as magnetic measurements. The solid-state structures of these new Fe $\mathrm{II}^{\mathrm{II}}$ synthons were unambiguously confirmed via single crystal X-ray diffraction. Four-coordinate $\left({ }^{\mathrm{tBu}} \mathrm{PDP}{ }^{\mathrm{Ph}}\right) \mathrm{Fe}\left(\mathrm{OEt}_{2}\right)$ was found to undergo loss of the diethyl ether solvento ligand in noncoordinating solvent, affording the diiron helical dimer $\mathrm{Fe}_{2}\left(\mu_{2}-\kappa^{2}{ }_{-}{ }^{\mathrm{Bu}} \mathrm{PDP}^{\mathrm{Ph}}\right)_{2}$, as evidenced ${ }^{1} \mathrm{H}$ NMR and ${ }^{57} \mathrm{Fe}$ Mössbauer spectroscopies. A preliminary X-ray crystallographic analysis of this complex has also been performed, confirming its atomic connectivity.

For $\mathrm{H}_{2}{ }^{2,6-\mathrm{Cl} 2 \mathrm{Ph}} \mathrm{PDP}^{\mathrm{Ph}}$ and $\mathrm{H}_{2} 4-\mathrm{MeO}^{2,6-\mathrm{Cl} 2 \mathrm{Ph}} \mathrm{PDP}^{\mathrm{Ph}}$, the four coordinate THF adducts ( $\left.{ }^{2,6-\mathrm{Cl} 2 \mathrm{Ph}} \mathrm{PDP} \mathrm{Ph}^{\mathrm{Ph}}\right) \mathrm{Fe}$ (thf) and (4- $\mathrm{MeO}^{2,6-\mathrm{Cl} 2 \mathrm{Ph}} \mathrm{PDP}^{\mathrm{Ph})} \mathrm{Fe}($ thf $)$ were synthesized and characterized crystallographically. $\left({ }^{2,6-\mathrm{Cl} 2 \mathrm{Ph}} \mathrm{PDP} \mathrm{P}^{\mathrm{Ph}}\right) \mathrm{Fe}(\mathrm{thf})$ was found to exhibit an equilibrium between fourand five-coordinate species in solution, which was supported by ${ }^{1} \mathrm{H}$ NMR and ${ }^{57} \mathrm{Fe}$ Mössbauer 
spectroscopies. A preliminary X-ray structural analysis of $\left({ }^{2,6-\mathrm{C} 2 \mathrm{Ph}} \mathrm{PDP}^{\mathrm{Ph}}\right) \mathrm{Fe}(\mathrm{thf})$ confirming atomic connectivity is also disclosed. For $\mathrm{H}_{2}^{2,6-C l 2 P h} \mathrm{PDP}^{\mathrm{Ph}}$ and $\mathrm{H}_{2}{ }^{\mathrm{C} 6 F 5} \mathrm{PDP}^{\mathrm{Ph}}$, the five coordinate bis-pyridine adducts $\left({ }^{2,6-\mathrm{Cl} 2 \mathrm{Ph}} \mathrm{PDP}^{\mathrm{Ph}}{ }^{\mathrm{Fe}}(\mathrm{py})_{2}\right.$ and $\left(\mathrm{H}_{2}{ }^{\mathrm{C} 6 \mathrm{~F} 5} \mathrm{PDP}^{\mathrm{Ph}}\right) \mathrm{Fe}(\mathrm{py})_{2}$ have been synthesized and structurally characterized. The derivation of the aryl substituent at the 5-position of the pyrrolide ring of the PDP ligand has been determined to have no impact upon the coordination environment and resulting electronic structure of the bis-THF and bis-pyridine adducts, relative to the previously reported analogue ( $\left.{ }^{\mathrm{Mes}} \mathrm{PDP} \mathrm{P}^{\mathrm{Ph}}\right) \mathrm{Fe}($ thf $)$.

In totality, these results reiterate the disparate electronic ground states operative in fourand five- coordinate high-spin $\mathrm{Fe}^{\mathrm{II}} \mathrm{PDP}$ complexes. Furthermore, the facile extension of the modular PDP ligand synthesis and iron metalation protocols to the new compounds presented here demonstrates that the synthesis of other new high-spin $\mathrm{Fe}^{\mathrm{II}}$ PDP derivatives with varying coordination numbers, geometries, and PDP ligand substitution patterns are synthetically accessible. Importantly, the development of these new high-spin $\mathrm{Fe}^{\mathrm{II}} \mathrm{PDP}$ synthons will allow for future exploration of their application in potential stoichiometric and catalytic group transfer reactions.

\subsection{Experimental Procedures}

All air- and moisture-sensitive manipulations were carried out using standard Schlenk line and cannula techniques or in an MBraun inert atmosphere drybox containing an atmosphere of purified nitrogen. Solvents for air- and moisture sensitive manipulations were dried and deoxygenated using a Glass Contour Solvent Purification System and stored over $4 \AA$ molecular sieves. All solids were dried under high vacuum; all liquids were dried over $\mathrm{CaH}_{2}$ and vacuum transferred into oven-dried glassware in order to bring into the glovebox. Deuterated benzene (benzene- $d_{6}$ ) and tetrahydrofuran (THF- $d_{8}$ ) for NMR spectroscopy were distilled from sodium 
metal and sodium benzophenone, respectively. Deuterated dichloromethane $\left(\mathrm{CD}_{2} \mathrm{Cl}_{2}\right)$ was distilled from calcium hydride. $\mathrm{CDCl}_{3}$ and DMSO- $d_{6}$ were obtained from Cambridge Isotopes and used as received. $\mathrm{Fe}\left[\mathrm{N}\left(\mathrm{SiMe}_{3}\right)_{2}\right]_{2},{ }^{15,16} \mathrm{Fe}(\mathrm{Cl})_{2}(\mathrm{py})_{4},{ }^{17}$ 4,4-dimethyl-1-phenyl-1-penten-3one, ${ }^{18} 1$-(2,3,4,5,6-pentafluorophenyl)-3-phenyl-2-propen-1-one, ${ }^{19}$ 1-(2,6-dichlorophenyl)-3phenyl-2-propen-1-one, ${ }^{19}$ 2,6-pyridinedicarboxaldehyde, ${ }^{20}$ and 4-methoxy-2,6pyridinedicarboxaldehyde ${ }^{21}$ were prepared according to literature procedures. $\mathrm{FeCl}_{2}, \mathrm{LiHMDS}$, trimethylsilylmethyl lithium, ammonium acetate, 3-benzyl-5-(2-hydroxyethyl)-4methylthiazolium chloride, sodium tert-butoxide, were purchased from commercial vendors and used as received. All solvents were purchased from commercial vendors and used as received. Preparation of 2,6-Bis(5-(tert-butyl)-3-phenyl-1H-pyrrol-2-yl)-pyridine, $\mathrm{H}_{2}{ }^{t B u} P D P^{P h}$.

In a Schlenk flask equipped with a magnetic stirrer was added $2.88 \mathrm{~g}(21.3 \mathrm{mmol})$ of 2,6pyridinecarboxaldehyde, 8.04 grams (42.7 mmol, 2.05 eq.) of 4,4-dimethyl-1-phenyl-1-penten-3one, 8.62 grams (32.0 mmol, 1.5 eq.) of 3-benzyl-5-(2-hydroxyethyl)-4-methylthiazolium chloride, and $150 \mathrm{~mL}$ of absolute ethanol. A condenser was affixed to the flask and the apparatus was attached to a Schlenk line. The system was purged with argon for five minutes, degassed, and the argon atmosphere was replenished. This procedure was repeated an additional four times. Under a heavy flow of argon, a $100 \mathrm{~mL}$ solution of absolute ethanol and 3.08 grams $(32.0 \mathrm{mmol}$, 1.5 eq.) of sodium tert-butoxide was added via syringe through the sidearm of the flask, resulting in an immediate color change of the solution from yellow to dark-brown. The solvent was brought to a reflux, which was maintained for $28 \mathrm{hrs}$. A yellow-orange precipitate was evident at this time, which was isolated via filtration and washed with three aliquots of cold ethanol. ${ }^{1} \mathrm{H}$ NMR analysis $\left(\mathrm{CDCl}_{3}\right)$ confirmed the identity of the solid as the desired 1,4-diketone intermediate, which was utilized in the next step without further purification. The diketone, $20 \mathrm{~g}$ 
(260 mmol, $12.2 \mathrm{eq}$ ) of ammonium acetate, and $100 \mathrm{~mL}$ of absolute ethanol were combined in a round bottom flask equipped with a magnetic stirrer. The solvent was brought to a reflux was maintained for 96 hours, at which time a yellow precipitate was evident in the reaction mixture. The precipitate was isolated via vacuum filtration and washed with copious amounts of cold ethanol. Drying under high vacuum for 48 hours afforded anhydrous $\mathrm{H}_{2}{ }^{\mathrm{tBu}} \mathrm{PDP}^{\mathrm{Ph}}$, a pale yellow solid which was stored in the glovebox for subsequent use. Yield: 6.50 grams, 13.7 mmol, 64\%. ${ }^{1} \mathrm{H}$ NMR (benzene- $\left.d_{6}, 400 \mathrm{MHz}, \delta, \mathrm{ppm}\right): 9.26$ (s, pyrrole-NH, 2H), 7.60 (d, J = 7.0 Hz, ortho$\mathrm{Ph} H, 4 \mathrm{H}), 7.20(\mathrm{t}, J=7.4 \mathrm{~Hz}$, meta $-\mathrm{Ph} H, 4 \mathrm{H}), 7.12(\mathrm{~d}, J=7.9 \mathrm{~Hz}, 3$-pyridine $H, 2 \mathrm{H}), 6.71(\mathrm{t}, J=$ $7.9 \mathrm{~Hz}, 4$-pyridine $H, 1 \mathrm{H}), 6.21(\mathrm{~d}, J=3.2 \mathrm{~Hz}$, pyrrole-CH, $2 \mathrm{H}), 1.24\left(\mathrm{~s}, t \mathrm{Bu}-\mathrm{CH}_{3}, 18 \mathrm{H}\right) .{ }^{1} \mathrm{H}$ NMR ( $\left.\mathrm{CDCl}_{3}, 400 \mathrm{MHz}, \delta, \mathrm{ppm}\right): 9.16$ (s, pyrrole-NH, 2H), 7.47 (d, J = 7.0 Hz, ortho-PhH, 4H), 7.35(t, $J=7.5 \mathrm{~Hz}$, meta $-\mathrm{PhH}, 4 \mathrm{H}) 7.27(\mathrm{t}, J=7.3$, para- $\mathrm{PhH}, 2 \mathrm{H}), 7.16(\mathrm{t}, J=7.8 \mathrm{~Hz}, 4-$ pyridine $H, 1 \mathrm{H}), 6.95$ (d, $J=7.9 \mathrm{~Hz}, 3$-pyridine $H, 2 \mathrm{H}), 6.08$ (d, $J=3.2 \mathrm{~Hz}$, pyrrole-CH, 2H), 1.40

$\left(\mathrm{s}, 18 \mathrm{H},{ }^{\mathrm{t}} \mathrm{Bu}-\mathrm{CH}_{3}\right) .{ }^{13} \mathrm{CNMR}\left(\mathrm{CDCl}_{3}, 600 \mathrm{MHz}, \delta, \mathrm{ppm}\right): 150.20,142.97,137.33,136.10,129.12$, 128.35, 126.34, 124.94, 124.67, 116.57, 107.40, 31.51, 30.46. HRMS (ESI) calcd for $\mathrm{C}_{33} \mathrm{H}_{36} \mathrm{~N}_{3}{ }^{+}$ $[\mathrm{M}+\mathrm{H}]^{+} 474.2904 \mathrm{~m} / \mathrm{z}$. Found 474.2900.

\section{Preparation of 2,6-Bis(5-(2,3,4,5,6-pentafluorophenyl)-3-phenyl-1H-pyrrol-2-yl)-pyridine, $\mathrm{H}_{2}{ }^{\mathrm{C} 65} \mathrm{PDP} \mathrm{P}^{\mathrm{Ph}}$.}

In a Schlenk tube equipped with a magnetic stirrer was added $332 \mathrm{mg}(2.46 \mathrm{mmols})$ of 2,6-pyridinecarboxaldehyde, 1.50 grams (5.03 mmol, 2.05 eq.) of 1-(2,3,4,5,6-

pentafluorophenyl)-3-phenyl-2-propen-1-one, and 131 milligrams (0.489 mmols, 0.20 eq.) of 3benzyl-5-(2-hydroxyethyl)-4-methylthiazolium chloride, and $15 \mathrm{~mL}$ of dry 1,4-dioxane. A condenser was affixed to the flask and the apparatus was attached to a Schlenk line. The system was purged with argon for five minutes, degassed, and replenished with a fresh argon 
atmosphere. This procedure was repeated an additional four times. Under a heavy flow of argon, $110 \mu \mathrm{L}$ of triethylamine ( $0.783 \mathrm{mmol}, 0.32$ eq.) dissolved in $1 \mathrm{~mL}$ of dry 1,4-dioxane was added via syringe, resulting in an immediate color change from yellow to dark-green. The solvent was brought to a reflux, which was maintained for $16 \mathrm{hrs}$. A yellow-orange precipitate was evident at this time. The entirely crude reaction mixture was transferred to a round bottom flask. Three five $-\mathrm{mL}$ aliquots of dichloromethane were used to rinse the Schlenk flask. The extracts were combined and the solvent was removed in vacuo, yielding an orange solid. ${ }^{1} \mathrm{H}$ and ${ }^{19} \mathrm{~F}$ NMR analysis $\left(\mathrm{CDCl}_{3}\right)$ confirmed the identity of the solid as the desired 1,4-diketone intermediate. The crude material was used without further purification for the second step. $10 \mathrm{~mL}$ of absolute ethanol was added to a round bottom flask containing the diketone, along with 4.00 grams (51.9 mmol, 21.1 eq.) of ammonium acetate. The mixture was stirred vigorously, and the solvent was brought to a reflux, which was maintained for $16 \mathrm{hrs}$. The resulting yellow precipitate was isolated via vacuum filtration on a medium porosity glass frit and washed with three $10 \mathrm{~mL}$ aliquots of $0^{\circ} \mathrm{C}$ ethanol. Drying the material under high vacuum at $100^{\circ} \mathrm{C}$ for 48 hours afforded the title compound as a pale yellow powder. Yield: 1.09 grams, $1.57 \mathrm{mmol}, 64 \% .{ }^{1} \mathrm{H}$ NMR (400 MHz, DMSO- $\left.d_{6}\right) \delta 11.68(\mathrm{~d}, J=2.3 \mathrm{~Hz}, 2 \mathrm{H}$, pyrrole-NH), $7.50-7.39(\mathrm{~m}, 9 \mathrm{H}$, ortho- and metaPh-H, and 4-pyH), $7.37-7.30$ (t, $J=7.0 \mathrm{~Hz}, 2 \mathrm{H}$, para-PhH), $7.00(\mathrm{~d}, J=7.9 \mathrm{~Hz}, 2 \mathrm{H}, 3-\mathrm{pyH})$, $6.67\left(\mathrm{~d}, J=2.4 \mathrm{~Hz}, 2 \mathrm{H}\right.$, pyrrole-CH). ${ }^{19} \mathrm{~F}$ NMR $\left(376 \mathrm{MHz}\right.$, DMSO- $\left.d_{6}\right) \delta-141.78(\mathrm{~d}, J=26.6 \mathrm{~Hz}$, 4F, ortho-F), $-156.89(\mathrm{t}, J=22.4 \mathrm{~Hz}, 2 \mathrm{~F}$, para $-\mathrm{F}),-162.85(\mathrm{td}, J=24.5,6.5 \mathrm{~Hz}, 4 \mathrm{~F}$, meta-F). HRMS (ESI) calcd for $\mathrm{C}_{37} \mathrm{H}_{18} \mathrm{~N}_{3} \mathrm{~F}_{10}{ }^{+}[\mathrm{M}+\mathrm{H}]^{+} 694.1336 \mathrm{~m} / \mathrm{z}$. Found 694.1339 .

Preparation of 1,1'-(2,6-pyridinediyl)bis[2-phenyl-4-(2,6-dichlorophenyl)]-1,4-butanedione.

In a $250 \mathrm{ml}$ Schlenk flask, $595 \mathrm{mg}$ (4.41 mmol) of 2,6-pyridinecarboxaldehyde, 2.5 grams (9.02 mmol) of 1-(2,6-dichlorophenyl)-3-phenyl-2-propen-1-one, and $890 \mathrm{mg}$ (3.30 mmol) of 3-benzyl-5-(2-hydroxyethyl)-4-methylthiazolium chloride were combined with a 
magnetic stirrer and $15 \mathrm{~mL}$ of absolute ethanol. A reflux condenser was affixed to the flask and the apparatus was attached to a Schlenk line and purged for 5 minutes with argon. The apparatus was then degassed, and again purged with argon. This procedure was repeated four additional times. In a separate flask, $317 \mathrm{mg}(3.30 \mathrm{mmol})$ of sodium tert-butoxide was dissolved in $5 \mathrm{~mL}$ of absolute ethanol. The sodium tert-butoxide solution was added to the Schlenk flask under a heavy flow of argon via the sidearm. An immediate color change to dark-brown was observed. The mixture was then brought to a gentle reflux, which was maintained for $12 \mathrm{hrs}$. The resulting tan precipitate was isolated on a medium porosity frit and washed with three $10 \mathrm{~mL}$ aliquots of cold ethanol. Yield: 2.28 grams (3.1 mmol), 75\%. ${ }^{1} \mathrm{H}$ NMR $\left(400 \mathrm{MHz}, \mathrm{CDCl}_{3}\right) \delta 8.21(\mathrm{~d}, J=7.8$ $\mathrm{Hz}, 2 \mathrm{H}), 7.95-7.87(\mathrm{~m}, 1 \mathrm{H}), 7.66-7.58(\mathrm{~d}, J=7.2 \mathrm{~Hz}, 4 \mathrm{H}), 7.36-7.27(\mathrm{~m}, 10 \mathrm{H}), 7.19(\mathrm{t}, J=$ $7.4 \mathrm{~Hz}, 2 \mathrm{H}), 6.34(\mathrm{dd}, J=10.1,3.7 \mathrm{~Hz}, 2 \mathrm{H}), 4.17(\mathrm{dd}, J=19.0,10.1 \mathrm{~Hz}, 2 \mathrm{H}), 3.46(\mathrm{dd}, J=19.0$, $3.7 \mathrm{~Hz}, 2 \mathrm{H}) .{ }^{13} \mathrm{C} \mathrm{NMR}\left(101 \mathrm{MHz}, \mathrm{CDCl}_{3}\right) \delta 45.46,47.27,126.46,127.64,128.26,129.13$, 129.20, 130.78, 137.08, 138.29, 139.21, 151.27, 198.24, 200.23, one resonance was not detected. HRMS (ESI) calcd for $\mathrm{C}_{37} \mathrm{H}_{26} \mathrm{~N}_{1} \mathrm{O}_{4} \mathrm{Cl}_{4}{ }^{+}[\mathrm{M}+\mathrm{H}]^{+}$688.0610 m/z. Found 688.0620. IR: $1699 \mathrm{~cm}^{-1}$ (broad, $\mathrm{C}=\mathrm{O}$ ).

\section{Preparation of 2,6-Bis(5-(2,6-dichlorophenyl)-3-phenyl-1H-pyrrol-2-yl)-pyridine,} $\mathrm{H}_{2}^{2,6-C l 2 P h} \mathrm{PDP}$.

A $250 \mathrm{~mL}$ round bottom flask was loaded with 2.28 grams $(3.31 \mathrm{mmol})$ of 1,1 '-(2,6pyridinediyl)bis[2-phenyl-4-(2,6-dichlorophenyl)]-1,4-butanedione, 3.00 grams (38.9 mmol, $11.75 \mathrm{eq}$ ) of ammonium acetate, and a magnetic stirrer. $25 \mathrm{~mL}$ of glacial acetic acid was added to the mixture. A condenser was affixed to the flask and the mixture was brought to a vigorous reflux, which was maintained for approximately $48 \mathrm{hrs}$. The resulting yellow powder was then isolated via vacuum filtration and washed with three $15 \mathrm{~mL}$ aliquots of cold ethanol. The solid was extracted into dichloromethane and purified via passage through a plug of basic alumina. 
Removal of the solvent in vacuo afforded a light yellow powder. Yield: $1.45 \mathrm{~g}$ (2.22 mmol), $67 \%$. Single crystals suitable for study via X-ray crystallographic analysis were obtained from a concentrated dimethyl sulfoxide solution of the compound. ${ }^{1} \mathrm{H}$ NMR (400 MHz, DMSO- $\left.d_{6}\right) \delta$ $11.54(\mathrm{~d}, J=2.5 \mathrm{~Hz}, 2 \mathrm{H}$, pyrrole-NH), $7.62(\mathrm{~d}, J=8.2 \mathrm{~Hz}, 4 \mathrm{H}), 7.43(\mathrm{~m}, 10 \mathrm{H}), 7.31(\mathrm{~m}, 3 \mathrm{H})$, $6.94(\mathrm{~d}, J=8.0 \mathrm{~Hz}, 2 \mathrm{H}), 6.30\left(\mathrm{~d}, J=2.9 \mathrm{~Hz}, 2 \mathrm{H}\right.$, pyrrole-CH). ${ }^{13} \mathrm{C}$ NMR $\left(101 \mathrm{MHz}, \mathrm{DMSO}-d_{6}\right)$ $\delta 113.55,116.43,124.45,126.20,126.64,127.16,128.60,128.66,129.03,130.83,131.44$, 135.84, 136.39, 136.76, 149.69. HRMS (ESI) calcd for $\mathrm{C}_{37} \mathrm{H}_{24} \mathrm{~N}_{3}{ }^{+}[\mathrm{M}+\mathrm{H}]^{+} 650.0719 \mathrm{~m} / \mathrm{z}$. Found 650.0767.

\section{Preparation of 1,1'-(4-methoxy-2,6-pyridinediyl)bis[2-phenyl-4-(2,6-dichlorophenyl)]-1,4- butanedione.}

In an oven dried Schlenk flask equipped with a magnetic stirrer was combined $291 \mathrm{mg}$ (1.76 mmol) of 4-methoxy-2,6-pyridinedicarboxaldehyde, $1.00 \mathrm{~g}$ (3.61 mmol, $2.05 \mathrm{eq})$ 1-(2,6dichlorophenyl)-3-phenyl-2-propen-1-one, $359 \mathrm{mg}$ (1.33 mmol, 0.75 eq.) of 3-benzyl-5-(2hydroxyethyl)-4-methylthiazolium chloride and $10 \mathrm{~mL}$ of absolute ethanol. A reflux condenser was equipped to the flask which was attached to a Schlenk line. The apparatus was purged with argon and then degassed, this procedure was repeated four subsequent times. In a separate flask was combined $128 \mathrm{mg}$ (1.33 mmol, 0.75 eq.) of sodium tert-butoxide and $4 \mathrm{~mL}$ absolute ethanol. Under a heavy argon flow, the sodium tert-butoxide solution was added via syringe to the Schlenk flask and the reaction mixture was brought to reflux. After 20 hrs. the reaction mixture was cooled to room temperature, and a yellow precipitate was observed. The precipitate was isolated via vacuum filtration on a medium porosity glass frit and washed three times with five $\mathrm{mL}$ aliquots of cold ethanol, dried in air, and used without further purification. Yield: $788 \mathrm{mg}$,

$1.1 \mathrm{mmol}, 62 \% .{ }^{1} \mathrm{H}$ NMR (400 MHz, DMSO-d6) $\delta 7.71$ (s, 2H, 3-pyridine $H$ ), $7.68-7.45$ (m, 9H, Ar), $7.37-7.03(\mathrm{~m}, 7 \mathrm{H}, \mathrm{Ar}), 6.20(\mathrm{dd}, J=10.5,3.3 \mathrm{~Hz}, 2 \mathrm{H}, \mathrm{CH}), 4.12(\mathrm{dd}, J=19.1,10.3 \mathrm{~Hz}$, 
2H, Ar), 3.94 (s, 3H, 4-pyridine-OCH $H_{3}$ ), 3.47 (dd, $J=18.8,3.2 \mathrm{~Hz}, 2 \mathrm{H}, \mathrm{CH}$ ). HRMS (ESI) calcd for $\mathrm{C}_{38} \mathrm{H}_{28} \mathrm{Cl}_{4} \mathrm{NO}_{5}{ }^{+}[\mathrm{M}+\mathrm{H}]^{+} 718.0716 \mathrm{~m} / \mathrm{z}$. Found 718.0732 .

Preparation of 2,6-Bis(5-(2,6-dichlorophenyl)-3-phenyl-1H-pyrrol-2-yl)-4-methoxy-pyridine $\mathrm{H}_{2} 4-\mathrm{MeO}^{2,6-\mathrm{Cl}^{2} \mathrm{Ph}} \mathrm{PDP} \mathrm{Ph}^{\mathrm{P}}$.

In a $100 \mathrm{~mL}$ round bottom flask equipped with a magnetic stirrer was added $788 \mathrm{mg}(1.1$ mmol) of 4-methoxy pyridine-2,6-(2,6-dichlorophenyl)-diketone and 1.71 grams (22 mmol, 20 eq.) of ammonium acetate. $10 \mathrm{~mL}$ of glacial acetic acid was added to the mixture and stirred vigorously. The solvent was brought to a gentle reflux, which was maintained for $24 \mathrm{hrs}$. Cooling to room temperature induced abundant precipitation of a yellow solid, which was isolated on a medium porosity frit and washed with three aliquots of cold ethanol. The crude solid was extracted into dichloromethane and washed through a plug of basic alumina to remove any residual acetic acid. Removal of the solvent in vacuo left an off-white/tan powder, identified as the title compound. Crystals suitable for study via X-ray diffraction were obtained from evaporation of a concentrated dichloromethane solution over 4 days. Yield: $324 \mathrm{mg}, 0.475$ mmol, 43\%. ${ }^{1} \mathrm{H}$ NMR $\left(600 \mathrm{MHz}\right.$, DMSO- $\left.d_{6}\right) \delta 11.48(\mathrm{~s}, 2 \mathrm{H}$, pyrrole-NH), $7.62(\mathrm{~d}, J=8.1 \mathrm{~Hz}$, 4H), $7.49-7.39(\mathrm{~m}, 11 \mathrm{H}), 7.28(\mathrm{t}, J=7.4 \mathrm{~Hz}, 2 \mathrm{H}), 6.53(\mathrm{~s}, 2 \mathrm{H}), 6.28(\mathrm{~d}, J=2.9 \mathrm{~Hz}, 2 \mathrm{H}$, pyrrole-CH), $3.32\left(\mathrm{~s}, 3 \mathrm{H}, 4\right.$-pyridine-OCH$\left.H_{3}\right) .{ }^{13} \mathrm{C}$ NMR (101 MHz, DMSO- $\left.d_{6}\right) \delta 54.36,102.51$, $113.44,124.52,126.01,126.71,127.04,128.59,129.24,130.85,131.44,135.85,136.75,150.89$, 165.09, one resonance was not detected. HRMS (ESI) calcd for $\mathrm{C}_{39} \mathrm{H}_{25} \mathrm{~N}_{3} \mathrm{Cl}_{4} \mathrm{O}^{+}[\mathrm{M}+\mathrm{H}]^{+}$ $680.0824 \mathrm{~m} / \mathrm{z}$. Found 680.0830 .

Preparation of $\left({ }^{(B u}{ }^{P D D P h}\right) \mathrm{Fe}\left(\mathrm{OEt}_{2}\right)$.

In the glovebox, a round bottom flask equipped with a magnetic stirrer, $239 \mathrm{mg}(0.635$ $\mathrm{mmol})$ of $\mathrm{Fe}\left[\mathrm{N}\left(\mathrm{SiMe}_{3}\right)_{2}\right]_{2}$ was dissolved in $10 \mathrm{~mL}$ of diethyl ether. In a separate $20 \mathrm{~mL}$ 
scintillation vial, $300 \mathrm{mg}$ of $\mathrm{H}_{2}{ }^{\mathrm{tBu}} \mathrm{PDP}^{\mathrm{Ph}}(0.633 \mathrm{mmol})$ was slurried in $10 \mathrm{~mL}$ of diethyl ether. The ligand slurry was added to the solution of $\mathrm{Fe}\left[\mathrm{N}\left(\mathrm{SiMe}_{3}\right)_{2}\right]_{2}$, resulting in an immediate color change to red. The reaction mixture was allowed to stir for $24 \mathrm{hrs}$. The resulting orange precipitate was isolated on a medium porosity glass frit, washed with three $1.5 \mathrm{~mL}$ aliquots of diethyl ether, and dried briefly in vacuo. Yield: $286 \mathrm{mg}, 0.475 \mathrm{mmol}, 75 \% . \mu_{\mathrm{eff}}=5.1 \mu_{\mathrm{B}}(295 \mathrm{~K}$, magnetic susceptibility balance). ${ }^{1} \mathrm{H}$ NMR (400 MHz, benzene- $d_{6}$ ) $\delta 111.47$ (singlet, $2 \mathrm{H}$ ), 86.61 (singlet, $2 \mathrm{H}$ ), 33.52 (singlet, ${ }^{\mathrm{t}} \mathrm{Bu}-\mathrm{CH}_{3}, 18 \mathrm{H}$ ), 25.87 (singlet, 4-pyridine- $H, 1 \mathrm{H}$ ), 22.60 (singlet, $\mathrm{Et}_{2} \mathrm{O}-\mathrm{CH}_{2}, 4 \mathrm{H}$ ), 11.13 (singlet, 4H), 7.47 (singlet, $4 \mathrm{H}$ ), 4.65 (singlet, $2 \mathrm{H}$ ), -1.63 (singlet, $\mathrm{Et}_{2} \mathrm{O}$ $\left.\mathrm{CH}_{3}, 6 \mathrm{H}\right)$. Anal. Calcd for $\left.{ }^{\mathrm{tBu}}{ }^{\mathrm{PDP}}{ }^{\mathrm{Ph}}\right) \mathrm{Fe}\left(\mathrm{OEt}_{2}\right) \mathrm{C}_{37} \mathrm{H}_{43} \mathrm{FeN}_{3} \mathrm{O}: \mathrm{C}, 73.87 ; \mathrm{H}, 7.20 ; \mathrm{N}, 6.98$. Found: C, 71.86; H, 6.95; N, 6.97.

\section{Preparation of $\mathrm{Fe}_{2}\left(\mu_{2}-\kappa^{2}-t B u P D P P h\right)_{2}$.}

In the glovebox, a round bottom flask equipped with a magnetic stirrer, $239 \mathrm{mg}(0.635$ mmol) of $\mathrm{Fe}\left[\mathrm{N}\left(\mathrm{SiMe}_{3}\right)_{2}\right]_{2}$ was dissolved in $10 \mathrm{~mL}$ of diethyl ether. In a separate $20 \mathrm{~mL}$ scintillation vial, $300 \mathrm{mg}$ of $\mathrm{H}_{2}{ }^{\mathrm{tBu}} \mathrm{PDP}^{\mathrm{Ph}}$ (0.633 mmol) was slurried in $10 \mathrm{~mL}$ of diethyl ether. The ligand slurry was added to the solution of $\mathrm{Fe}\left[\mathrm{N}\left(\mathrm{SiMe}_{3}\right)_{2}\right]_{2}$, resulting in an immediate color change to red. The reaction mixture was allowed to stir for $24 \mathrm{hrs}$. The resulting orange precipitate was isolated on a medium porosity glass frit, washed with three- $1.5 \mathrm{~mL}$ aliquots of diethyl ether, and dried briefly in vacuo. The resulting powder was combined in a round bottom flask equipped with a magnetic stirrer, and $15 \mathrm{~mL}$ of pentane was added. The suspension was stirred vigorously for four hours, at which time a color change from orange to dark-red/brown was noted. The mixture was then reduced to a solid in vacuo. The solid residue was extracted into the minimum amount of benzene and filtered through a pipette fitted with a celite column supported by a microfiber glass plug into a separate flask. The solvent was then removed in 
vacuo affording a dark powder. Yield: $240 \mathrm{mg}, 0.227 \mathrm{mmol}, 71 \% . \mu_{\mathrm{eff}}=7.0 \mu_{\mathrm{B}}(295 \mathrm{~K}$, magnetic susceptibility balance). ${ }^{1} \mathrm{H}$ NMR (400 MHz, benzene- $\left.d_{6}\right) \delta 78.99$ (singlet, 2H), 48.99 (singlet, 2H), 30.68 (singlet, $\left.{ }^{\mathrm{B}} \mathrm{BuCH} \mathrm{H}_{3}, 18 \mathrm{H}\right), 15.25$ (singlet, $4 \mathrm{H}$ ), 8.80 (singlet, $\left.4 \mathrm{H}\right), 2.08$ (singlet, $2 \mathrm{H}$ ), 0.91 (singlet, 4-py- $H, 1 \mathrm{H})$. Anal. Calcd for $\mathrm{Fe}_{2}\left(\mu_{2}-\kappa 2{ }^{\mathrm{tBu}}{ }^{\mathrm{PDP}}{ }^{\mathrm{Ph}}\right)_{2}, \mathrm{C}_{66} \mathrm{H}_{66} \mathrm{Fe}_{2} \mathrm{~N}_{6}$ : C, 75.14; H, 6.31; N, 7.97. Found: C, 74.37; H, 6.35; N, 7.42. Note, despite the low carbon content evidenced by $\mathrm{CHN}$ analysis, Mössbauer spectroscopy evidences $\mathrm{Fe}_{2}\left(\mu_{2}-\kappa^{2}{ }_{-}{ }^{\mathrm{Bu}} \mathrm{PDP}^{\mathrm{Ph}}\right)_{2}$ as the only iron containing species present within the sample.

\section{Preparation of $\left({ }^{t B u} P D P^{P h}\right) F e(t h f)_{2}$.}

In the glovebox, $300 \mathrm{mg}(0.633 \mathrm{mmol})$ of $\mathrm{H}_{2}{ }^{\mathrm{tBu}} \mathrm{PDP}^{\mathrm{Ph}}$ was dissolved in $10 \mathrm{~mL}$ of THF in a $20 \mathrm{~mL}$ scintillation vial equipped with a magnetic stirrer. Rapid stirring induced complete dissolution of $\mathrm{H}_{2}{ }^{\mathrm{tBu}} \mathrm{PDP} \mathrm{Ph}^{\mathrm{Ph}}$. In a separate round bottom flask, $280 \mathrm{mg}(0.743 \mathrm{mmol})$ of $\mathrm{Fe}\left[\mathrm{N}\left(\mathrm{SiMe}_{3}\right)_{2}\right]_{2}$ was dissolved in $10 \mathrm{~mL}$ of $\mathrm{THF}$, affording a homogeneous pale green solution.

With rapid stirring, the solution of the $\mathrm{H}_{2}{ }^{\mathrm{tBu}} \mathrm{PDP}^{\mathrm{Ph}}$ was added dropwise via pipette to the solution of $\mathrm{Fe}\left[\mathrm{N}\left(\mathrm{SiMe}_{3}\right)_{2}\right]_{2}$, resulting in an immediate color change to orange/red. The mixture was allowed to stir for $16 \mathrm{hrs}$. Subsequent removal of the solvent resulted in an orange film. The crude mixture was extracted into a minimum amount of THF and the resulting solution was filtered through a celite plug supported by a glass microfiber filter in a $20 \mathrm{~mL}$ scintillation vial. The solution was layered with $15 \mathrm{~mL}$ of pentane and stored at $-35^{\circ} \mathrm{C}$ for $48 \mathrm{hrs}$. The resulting red blocks were isolated on a medium porosity glass frit, washed with three-5 mL aliquots of pentane, and dried in vасио. The resulting filtrate was concentrated and a second crystallization was performed. The combined yield from two crops of crystallizations was $286 \mathrm{mg}, 0.426 \mathrm{mmol}$, $67 \% \cdot \mu_{\mathrm{eff}}=5.4 \mu_{\mathrm{B}}\left(295 \mathrm{~K}\right.$, magnetic susceptibility balance). ${ }^{1} \mathrm{H}$ NMR (400 MHz, benzene- $\left.d_{6}\right) \delta$ 110.80 (singlet, 2H), 89.17 (singlet, 2H), 36.27 (singlet, ${ }^{t} \mathrm{Bu}-\mathrm{CH}_{3}, 18 \mathrm{H}$ ), 26.82 (singlet, 4- 
pyridine- $H, 1 \mathrm{H}$ ), 11.01 (singlet, $4 \mathrm{H}$ ), 6.00-9.26 (overlapping singlets, $12 \mathrm{H}$ ), 4.64 (singlet, $2 \mathrm{H}$ ), 1.87 (singlet, THF-CH $\left.H_{2}, 8 \mathrm{H}\right)$. Anal. Calcd for $\left({ }^{\mathrm{tBu}} \mathrm{PDP}^{\mathrm{Ph}}\right) \mathrm{Fe}(\mathrm{thf})_{2}, \mathrm{C}_{41} \mathrm{H}_{49} \mathrm{FeN}_{3} \mathrm{O}_{2}: \mathrm{C}, 73.31 ; \mathrm{H}$, 7.35; N, 6.26. Found: C, 69.08; H, 6.46; N, 6.33. Single crystals suitable for study via X-ray crystallography were obtained from the aforementioned procedure.

\section{Preparation of $\left({ }^{t B u} P D P^{P h}\right) F e(p y)_{2}$.}

In the glovebox, $99 \mathrm{mg}(0.223 \mathrm{mmol})$ of $\mathrm{Fe}(\mathrm{Cl})_{2}(\mathrm{py})_{4}$ was suspended in $5 \mathrm{~mL}$ of pentane in a $20 \mathrm{~mL}$ scintillation vial equipped with a magnetic stirrer. In a separate vial, $43 \mathrm{mg}$ of neosilyl lithium ( $0.457 \mathrm{mmol}, 2.05 \mathrm{eq})$ was dissolved in $5 \mathrm{~mL}$ of pentane and added to the stirring yellow suspension, inducing a color change to purple. The reaction mixture was allowed to stir for $2 \mathrm{hrs}$. The resulting crude suspension was filtered through a plug of celite supported by a glass microfiber filter. The dark purple filtrate was concentrated to $1 \mathrm{~mL}$. In a separate vial was combined $107 \mathrm{mg}(0.226 \mathrm{mmol})$ of $\mathrm{H}_{2}{ }^{\mathrm{tBu}} \mathrm{PDP}^{\mathrm{Ph}}$ and $5 \mathrm{~mL}$ of toluene, yielding a homogeneous pale yellow solution. The solution of the proligand was added dropwise to the solution of the iron complex, affording a dark-red solution. The reaction mixture was allowed to stir for two hours, at which time $10 \mathrm{~mL}$ of pentane was added. Storage at $-35^{\circ} \mathrm{C}$ for $12 \mathrm{hrs}$ resulted in the formation of orange/red plates which were isolated via vacuum filtration over a medium porosity glass frit. The material was washed with three $5 \mathrm{~mL}$ aliquots of pentane, and dried in vacuo. Yield: $94 \mathrm{mg}, 0.137 \mathrm{mmol}, 61 \%$. A single crystal suitable for X-ray analysis was grown from slow diffusion of pentane into a concentrated solution of toluene at $-35^{\circ} \mathrm{C} . \mu_{\mathrm{eff}}=5.1 \mu_{\mathrm{B}}(295 \mathrm{~K}$, magnetic susceptibility balance). ${ }^{1} \mathrm{H}$ NMR (400 MHz, benzene- $\left.d_{6}\right) \delta 104.00$ (singlet, $2 \mathrm{H}$ ), 88.95 (singlet, 2H), 67.82 (broad singlet, 4H), 36.60 (singlet, ${ }^{\mathrm{t}} \mathrm{Bu}-\mathrm{CH}_{3}, 18 \mathrm{H}$ ), 30.33 (singlet, 4pyridine- $H, 1 \mathrm{H}$ ), 27.62 (singlet, 4H), 9.79-11.00 (overlapping singlets, $6 \mathrm{H}$ ), 6.68 (singlet, $4 \mathrm{H}$ ), 
4.43 (singlet, 2H). Anal. Calcd for $\left(^{\left({ }^{B u}\right.}{ }^{P D P}{ }^{\mathrm{Ph}}\right) \mathrm{Fe}(\mathrm{py})_{2}, \mathrm{C}_{43} \mathrm{H}_{43} \mathrm{FeN} \mathrm{N}_{5}$ : C, 75.32; H, 6.32; N, 10.21

Found: C, 75.49; H, 6.54; N, 8.49.

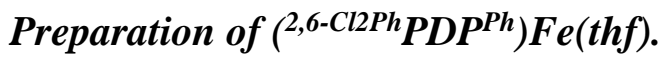

In the glovebox, $500 \mathrm{mg}(0.768 \mathrm{mmol})$ of $\left.\mathrm{H}_{2}{ }^{(2,6-\mathrm{Cl} 2 \mathrm{Ph}} \mathrm{PDP}^{\mathrm{Ph}}\right)$ and $10 \mathrm{~mL}$ of $\mathrm{THF}$ were loaded in a $100 \mathrm{~mL}$ flask equipped with a magnetic stirrer. In a separate vial, $265 \mathrm{mg}(1.58$ mmol) of LiHMDS was combined with $3 \mathrm{~mL}$ of THF. While vigorously stirring, the solution of LiHMDS was added to the solution of $\left.\mathrm{H}_{2}{ }^{(2,6-\mathrm{Cl} 2 \mathrm{Ph}} \mathrm{PDP}^{\mathrm{Ph}}\right)$, resulting in an immediate color change from tan to a brilliant luminescent yellow. The mixture was stirred for approximately two hours. In a separate $250 \mathrm{~mL}$ round bottom flask, $97 \mathrm{mg}(0.765 \mathrm{mmol})$ of $\mathrm{FeCl}_{2}, 20 \mathrm{~mL}$ of THF, and a magnetic stirrer were combined. While vigorously stirring, the solution of deprotonated ligand was added to the THF slurry of $\mathrm{FeCl}_{2}$, resulting in an immediate color change to an intense darkred. After 12 hours, the mixture was homogenous and the volume of solvent was reduced to approximately $3 \mathrm{~mL} .75 \mathrm{~mL}$ of diethyl ether was added, and immediate precipitation of a bright orange solid was observed. The resulting solid was isolated on a medium porosity glass frit and dried in vacuo. The solid was transferred to a $20 \mathrm{~mL}$ vial and combined with $5 \mathrm{~mL}$ of toluene, 10 $\mathrm{mL}$ of pentane, and a magnetic stirrer. Rapid stirring of the mixture induced precipitation of lithium chloride. The suspension was then filtered over a medium porosity frit containing a one inch pad of celite. The red compound was washed from the celite first with toluene, and then with dichloromethane, until all washings were clear. Removal of solvent in vacuo, followed by trituration with pentane afforded the title compound as an orange-red powder, which could be recrystallized from a concentrated dichloromethane solution layered with pentane at $-35^{\circ} \mathrm{C}$ for 48 hrs. Yield: $445 \mathrm{mg}(0.572 \mathrm{mmol}), 74 \% . \mu_{\mathrm{eff}}=5.1 \mu_{\mathrm{B}}(295 \mathrm{~K}$, magnetic susceptibility balance $) .{ }^{1} \mathrm{H}$ NMR (400 MHz, benzene- $d_{6}$ ) $\delta 106.09$ (singlet, 2H), 97.77 (singlet, 2H), 16.53 (broad singlet, 
4H), 13.45 (singlet, 4H), 12.23 (singlet, 4H), 11.91 (singlet, 4H), 9.76 (singlet, 2H), 7.99

(singlet, $4 \mathrm{H}), 0.33(1 \mathrm{H}, 4$-pyridine- $H)$. One resonance could not be located. Anal. Calcd for ${ }^{2,6-}$ $\left.{ }^{\mathrm{Cl} 2 \mathrm{Ph}} \mathrm{PDP}^{\mathrm{Ph}}\right) \mathrm{Fe}\left(\right.$ thf), $\mathrm{C}_{41} \mathrm{H}_{29} \mathrm{Cl}_{4} \mathrm{FeN}_{3} \mathrm{O}: \mathrm{C}, 63.35 ; \mathrm{H}, 3.76 ; \mathrm{N}$, 5.41. Found: $\mathrm{C}, 62.64 ; \mathrm{H}, 3.75 ; \mathrm{N}$, 5.23. The low carbon value observed in the $\mathrm{CHN}$ analysis suggests that despite multiple extractions of the compound via hydrocarbon solvents $1 / 3$ eq. of $\mathrm{LiCl}$ is still present in the sample. Anal. Calcd for $\left.{ }^{(2,6-\mathrm{Cl} 2 \mathrm{Ph}} \mathrm{PDP}^{\mathrm{Ph}}\right) \mathrm{Fe}(\mathrm{thf}) \cdot 1 / 3(\mathrm{LiCl}), \mathrm{C}_{41} \mathrm{H}_{29} \mathrm{Cl}_{4.33} \mathrm{FeLi}_{0.33} \mathrm{~N}_{3} \mathrm{O}: \mathrm{C}: 62.23 ; \mathrm{H}$ : 3.69; N: 5.31. Found: $62.64 ; \mathrm{H}, 3.75 ; \mathrm{N}, 5.23$. Single crystals suitable for an X-ray study were grown from diffusion of a pentane into a concentrated benzene solution of the title compound over $48 \mathrm{hrs}$.

\section{Preparation of $\left({ }^{2,6-C l 2 P h} P D P^{P h}\right) \mathrm{Fe}(\text { thf })_{2}$.}

$15 \mathrm{mg}$ of $\left.{ }^{(2,6-\mathrm{Cl} 2 \mathrm{Ph}} \mathrm{PDP}^{\mathrm{Ph}}\right) \mathrm{Fe}($ thf $)$ was weighed into a one dram vial. A $500 \mu \mathrm{L}$ aliquot of THF solvent was added, resulting in dissolution of the compound. The resulting mixture was filtered into a J. Young NMR tube, affording a homogeneous orange solution. On a high-vacuum line, the THF solvent was removed and the sample was evacuated for two hours. THF- $d_{8}$ was then vacuum transferred onto the sample, again affording a homogeneous orange solution. An ${ }^{1} \mathrm{H}$ NMR spectrum was acquired and demonstrated quantitative conversion of $\left({ }^{2,6-\mathrm{Cl} 2 \mathrm{Ph}} \mathrm{PDP}^{\mathrm{Ph}}\right) \mathrm{Fe}(\mathrm{thf})$ to $\left.{ }^{(2,6-\mathrm{Cl} 2 \mathrm{Ph}} \mathrm{PDP}^{\mathrm{Ph}}\right) \mathrm{Fe}(\text { thf })_{2}$, as demonstrated by the downfield shift of the resonance corresponding to the para-pyridine proton. The J. Young tube was returned to the glovebox and one drop of pentane was added to the sample as a secondary internal standard. A ${ }^{1} \mathrm{H}$ NMR spectrum was again acquired, with the resonances corresponding to $\left({ }^{2,6-\mathrm{Cl} 2 \mathrm{Ph}} \mathrm{PDP}{ }^{\mathrm{Ph}}\right) \mathrm{Fe}(\text { thf })_{2}$ unchanged. ${ }^{1} \mathrm{H}$ NMR (400 MHz, THF- $d_{8}$ ) $\delta 85.38$ (singlet, 2H), 65.88 (singlet, 2H), 22.15 (singlet, 4-pyridineH, 1H), 8.02 (singlet, 4H), 7.08 (singlet, 4H), 6.86 (singlet, 2H), 6.41 (singlet, 4H), 5.97 (singlet, 
$2 \mathrm{H})$. Note, resonances for the THF ligands were not observed due to rapid exchange with THF$d_{8}$

\section{Synthesis of $\left(^{2,6-C l 2 P h} P D P^{P h}\right) F e(p y)_{2}$.}

In a $20 \mathrm{~mL}$ vial equipped with a magnetic stirrer was added $153 \mathrm{mg}(0.345 \mathrm{mmol})$ of $\mathrm{Fe}(\mathrm{Cl})_{2}(\mathrm{py})_{4}$ and $15 \mathrm{~mL}$ of pentane. Vigorous stirring afforded a yellow suspension. In a separate vial $65 \mathrm{mg}$ ( $0.690 \mathrm{mmol}, 2.0$ eq.) of neosilyl lithium was dissolved in approximately $5 \mathrm{~mL}$ of pentane. The neosilyl lithium solution was added to the suspension of $\mathrm{Fe}(\mathrm{Cl})_{2}(\mathrm{py})_{4}$, inducing a rapid color change to dark-purple. The reaction mixture was allowed to stir for two hours, at which time it was filtered through a pad of celite supported on a glass microfiber filter into a round bottom flask. In a separate vial, $225 \mathrm{mg}(0.345 \mathrm{mmol})$ of $\mathrm{H}_{2}^{2,6-\mathrm{Cl} 2 \mathrm{Ph}} \mathrm{PDP}^{\mathrm{Ph}}$ was suspended in $5 \mathrm{~mL}$ of toluene and $10 \mathrm{~mL}$ of pentane. The ligand suspension was added dropwise to the stirring solution of $\mathrm{Fe}(\mathrm{Ns})_{2}(\mathrm{py})_{2}$, inducing a color change to yellow-orange within minutes accompanied by abundant precipitation of an orange solid. After one hour, the precipitate was collected on a medium porosity glass frit and washed with three $5 \mathrm{~mL}$ aliquots of pentane, and dried in vacuo. Yield: $167 \mathrm{mg}, 0.193 \mathrm{mmol}, 56 \%$. Single crystals of the compound were grown from slow evaporation of a dichloromethane solution over $36 \mathrm{hrs} . \mu_{\mathrm{eff}}=4.7 \mu_{\mathrm{B}}(295 \mathrm{~K}$, magnetic susceptibility balance). ${ }^{1} \mathrm{H}$ NMR (400 MHz, benzene- $\left.d_{6}\right) \delta 110.77$ (broad singlet, $4 \mathrm{H}$ ), 83.19 (singlet, 2H), 76.19 (singlet, 2H), 38.08 (singlet, 4H), 24.23 (singlet, 4-pyridine $H, 1 \mathrm{H}$ ), 9.41 (singlet, 4H), 7.48-8.08 (overlapping broad singlets, 6H), 7.25 (singlet, $2 \mathrm{H}$ ), 7.04 (singlet, $4 \mathrm{H}$ ), 5.31 (singlet, 2H). ${ }^{19} \mathrm{~F}$ NMR (376 MHz, benzene- $\left.d_{6}\right) \delta-162.59$ (broad singlet, $2 \mathrm{~F}$ ), -160.88 (broad singlet, 1F, paraPh-F), -71.52 (broad singlet, 2F). Anal. Calcd for ( $\left.{ }^{2,6-\mathrm{Cl} 2 \mathrm{Ph}} \mathrm{PDP}^{\mathrm{Ph}}\right) \mathrm{Fe}(\mathrm{py})_{2}$, $\mathrm{C}_{47} \mathrm{H}_{31} \mathrm{Cl}_{4} \mathrm{FeN}_{5}$ : C, 65.38; H, 3.62; N, 8.11. Found: C, 64.93; H, 3.98; N, 7.80. 


\section{Preparation of $\left(4-\mathrm{MeO}^{2,6-\mathrm{Cl} P \mathrm{Ph}} \mathrm{PDP} \mathrm{P}^{\mathrm{Ph}}\right) \mathrm{Fe}($ thf $)$.}

In a $20 \mathrm{~mL}$ scintillation vial $250 \mathrm{mg}(0.367 \mathrm{mmol})$ of $\mathrm{H}_{2} 4-\mathrm{MeO}^{2,6-\mathrm{Cl} 2 \mathrm{Ph}} \mathrm{PDP}^{\mathrm{Ph}}$ was

dissolved in $10 \mathrm{~mL}$ of THF, affording a colorless homogenous solution. In a separate vial 128 mg of LiHMDS (0.765 mmol, $2.08 \mathrm{eq})$ was dissolved in $5 \mathrm{~mL}$ of THF. The LiHMDS solution was added dropwise to the solution of $\mathrm{H}_{2} 4-\mathrm{MeO}^{2,6-\mathrm{Cl} 2 \mathrm{Ph}} \mathrm{PDP}^{\mathrm{Ph}}$, inducing an immediate color change to bright yellow. The reaction mixture was allowed to stir for two hours. In a separate 50 $\mathrm{mL}$ round bottom flask, $47 \mathrm{mg}$ of $\mathrm{FeCl}_{2}(0.371 \mathrm{mmol}, 1.01$ eq. $)$ was suspended in $10 \mathrm{~mL}$ of $\mathrm{THF}$ via vigorous stirring. Dropwise addition of the deprotonated ligand solution to the $\mathrm{FeCl}_{2}$ suspension induced an immediate color change to amber, accompanied via gradual dissolution of $\mathrm{FeCl}_{2}$. The reaction mixture was stirred for $16 \mathrm{hrs}$. The solvent was then concentrated in vacuo to approximately $2 \mathrm{~mL}$ and pentane $(25 \mathrm{~mL})$ was added. Vigorous stirring induced the precipitation of a bright orange microcrystalline solid. This solid was isolated on a fine porosity glass frit via vacuum filtration and subsequently transferred to a $20 \mathrm{~mL}$ scintillation vial. The solid was then extracted into $2 \mathrm{~mL}$ of toluene and pentane $(15 \mathrm{~mL})$ was added, resulting in precipitation of an orange microcrystalline powder. The suspended powder was passed over a medium porosity glass frit with a one inch pad of celite. The organic extracts were collected via vacuum filtration, and the celite pad was washed with three $25 \mathrm{~mL}$ aliquots of dichloromethane, or until the washings were clear. Removal of the solvent in vасиo and subsequent trituration with pentane afforded a bright orange powder. Yield $227 \mathrm{mg}, 0.281 \mathrm{mmol}, 77 \% .{ }^{1} \mathrm{H}$ NMR $(400 \mathrm{MHz}$, benzene- $d_{6}$ ) $\delta 101.94$ (singlet, 2H), 98.43 (singlet, 2H), 18.67 (broad singlet, 4H), 14.43 (singlet, 4H), 12.34 (singlet, 4H), 11.90 (singlet, 4H), 11.12 (singlet, 3H, 4-pyridine-OCH3), 10.34 (singlet, 2H), 8.76 (singlet, 4H). One resonance could not be located. Anal. Calcd for 
(4- $\mathrm{MeO}^{2,6-\mathrm{Cl} 2 \mathrm{Ph}} \mathrm{PDP}^{\mathrm{Ph}}$ )Fe(thf), $\mathrm{C}_{42} \mathrm{H}_{31} \mathrm{Cl}_{4} \mathrm{FeN}_{3} \mathrm{O}_{2}: \mathrm{C}, 62.48 ; \mathrm{H}, 3.87 ; \mathrm{N}, 5.20$. Found: $\mathrm{C}, 60.35 ; \mathrm{H}$, 3.76; N, 5.04. The low carbon value observed in the $\mathrm{CHN}$ analysis suggests that despite multiple extractions of the compound via hydrocarbon solvents $1 / 2$ eq. of $\mathrm{LiCl}$ is still present in the sample. Anal. Calcd for (4-MeO $\left.{ }^{2,6-\mathrm{Cl} 2 \mathrm{Ph}} \mathrm{PDP}^{\mathrm{Ph}}\right) \mathrm{Fe}(\mathrm{thf}) \cdot 1 / 2(\mathrm{LiCl}), \mathrm{C}_{42} \mathrm{H}_{31} \mathrm{Cl}_{4.5} \mathrm{FeLi}_{0.5} \mathrm{~N}_{3} \mathrm{O}_{2}$ : C:

60.88; H: 3.77; N: 5.07. Found: 60.35; H: 3.76; N: 5.04. Single crystals suitable for study via Xray crystallography were grown from diffusion of pentane into a concentrated benzene solution of the compound over $48 \mathrm{hrs}$.

\section{Synthesis of $\left({ }^{C 6 F 5} P D P P h\right) F e(p y)_{2}$.}

In a $20 \mathrm{~mL}$ vial equipped with a magnetic stirrer was added $64 \mathrm{mg}(0.144 \mathrm{mmol})$ of $\mathrm{Fe}(\mathrm{Cl})_{2}(\mathrm{py})_{4}$ and $10 \mathrm{~mL}$ of pentane. Vigorous stirring afforded a yellow suspension. In a separate vial $27 \mathrm{mg}$ ( $287 \mathrm{mmol}, 2.0$ eq.) of neosilyl lithium was dissolved in approximately $3 \mathrm{~mL}$ of pentane. The neosilyl lithium solution was added to the suspension of $\mathrm{Fe}(\mathrm{Cl})_{2}(\mathrm{py})_{4}$, inducing a rapid color change to dark-purple. The reaction mixture was allowed to stir for two hours, at which time it was filtered through a pad of celite supported on a glass microfiber filter into a 50 $\mathrm{mL}$ round bottom flask. In a separate vial, $100 \mathrm{mg}(0.144 \mathrm{mmol}, 1.0 \mathrm{eq})$ of $\mathrm{H}_{2}{ }^{\mathrm{C} 6 F 5} \mathrm{PDP}^{\mathrm{Ph}}$ was slurried in $1.5 \mathrm{~mL}$ of toluene and $5 \mathrm{~mL}$ of pentane. The ligand suspension was added dropwise to the stirring solution of $\mathrm{Fe}(\mathrm{Cl})_{2}(\mathrm{py})_{2}$, inducing a color change to yellow-orange and within minutes abundant precipitation of an orange solid was observed. After one hour, the precipitate was collected on a medium porosity glass frit and washed with three $1.5 \mathrm{~mL}$ aliquots of pentane, and dried in vacuo. Yield: $115 \mathrm{mg}, 127 \mathrm{mmol}, 88 \%$. Recrystallization was accomplished via layering a concentrated toluene solution of the title compound with excess pentane and storing the resulting solution at $-35^{\circ} \mathrm{C}$ for $36 \mathrm{hrs} .{ }^{1} \mathrm{H}$ NMR (400 MHz, benzene- $\left.d_{6}\right) \delta 83.08$ (broad singlet, 4H), 78.78 (singlet, 2H), 73.83 (singlet, 2H), 32.96 (singlet, 4H), 26.13 (singlet, 1H, 4- 
pyridine- $H$ ), 8.88 (singlet, $4 \mathrm{H}), 8.01$ (singlet, $2 \mathrm{H}), 7.59$ (singlet, $4 \mathrm{H}), 5.88$ (singlet, $2 \mathrm{H}) . \mu_{\mathrm{eff}}=5.3$ $\mu_{\mathrm{B}}\left(295 \mathrm{~K}\right.$, magnetic susceptibility balance) Anal. Calcd for $\left({ }^{\mathrm{C} 6 \mathrm{~F} 5} \mathrm{PDP}^{\mathrm{Ph}}\right) \mathrm{Fe}(\mathrm{py})_{2}, \mathrm{C}_{47} \mathrm{H}_{25} \mathrm{~F}_{10} \mathrm{FeN} 5$ : C, 62.34; H, 2.78; N, 7.73. Found: C, 62.19; H, 2.90; N, 7.84.

\section{Physical Measurements.}

${ }^{1} \mathrm{H}$ and ${ }^{13} \mathrm{C}\left\{{ }^{1} \mathrm{H}\right\}$ NMR spectra were recorded on an Agilent $400 \mathrm{MHz}$ spectrometer, JEOL 400 MHz YH spectrometer, or a Varian INOVA 600 MHz spectrometer. All chemical shifts are reported relative to $\mathrm{SiMe}_{4}$ using ${ }^{1} \mathrm{H}$ (residual) chemical shifts of the solvent as a secondary standard. Assignments of resonances for paramagnetic compounds are based on integration and only reported in the experimental procedures for conclusive cases. High resolution mass spectra were obtained on a Thermo Finnigan Linear Trapping Quadrupole mass spectrometer. Elemental analyses were performed at Robertson Microlit Laboratories, Inc., in

Ledgewood, NJ. Room temperature magnetic susceptibility measurements were performed with a Johnson Matthey Mark 1 instrument that was calibrated with $\mathrm{HgCo}(\mathrm{SCN})_{4}$. Zero field ${ }^{57} \mathrm{Fe}$ Mössbauer spectra were collected on a SEE Co. Mössbauer spectrometer (MS4) with a ${ }^{57} \mathrm{Co} / \mathrm{Rh}$ radiation source at $80 \mathrm{~K}$ in constant acceleration mode. The temperature in the sample chamber was controlled by a Janis Research Co. CCS- $850 \mathrm{He} / \mathrm{N}_{2}$ cryostat within an accuracy of $\pm 0.3 \mathrm{~K}$. The data were calibrated relative to $\alpha$-iron at $298 \mathrm{~K}$ with minimum experimental line widths of $0.23 \mathrm{~mm} / \mathrm{s}$. The fitting procedure to extract quantitative spectral parameters uses a least squares Lorentzian fitting method implemented in the WMOSS software developed by SEE Co.

\section{X-ray Crystallography.}

Single crystals suitable for X-ray diffraction were coated with polyisobutylene oil (Sigma-Aldrich) in a drybox, mounted on a nylon loop, and then quickly transferred to the goniometer head of a Bruker AXS D8 Venture fixed-chi X-ray diffractometer equipped with a 
Triumph monochromator, a Mo K $\alpha$ radiation source $(1=0.71073 \AA$ ), and a PHOTON 100

CMOS detector. The samples were cooled to $100 \mathrm{~K}$ with an Oxford Cryostream 700 system and optically aligned. The APEX3 software program (version 2016.9-0) ${ }^{22}$ was used for diffractometer control, preliminary frame scans, indexing, orientation matrix calculations, leastsquares refinement of cell parameters, and the data collection. Three sets of 12 frames each were collected using the omega scan method with a $10 \mathrm{~s}$ exposure time. Integration of these frames, followed by reflection indexing and least-squares refinement, produced a crystal orientation matrix for the crystal lattice that was used for the structural analysis. The data collection strategy was optimized for completeness and redundancy using the Bruker COSMO software suite. The space group was identified, and the data were processed using the Bruker SAINT+ program and corrected for absorption using SADABS. The structures were solved using direct methods (SHELXS) completed by subsequent Fourier synthesis and refined by full-matrix least-squares procedures using the programs provided by SHELXL-2014. ${ }^{23}$

\section{Density Functional Theory Calculations.}

All DFT calculations were performed with the ORCA program package. ${ }^{24}$ Geometry optimizations of the complexes and single-point calculations on the optimized geometries were carried out at the B3LYP level of DFT. ${ }^{25-27}$ The all-electron Gaussian basis sets were those developed by the Ahlrichs group. ${ }^{28-30}$ Triple- $\zeta$ quality basis sets def2-TZVP with one set of polarization functions on the metal and on the atoms directly coordinated to the metal center were used. For the carbon and hydrogen atoms, slightly smaller polarized split-valence def2-SVP basis sets were used that were of double- $\zeta$ quality in the valence region and contained a polarizing set of $\mathrm{d}$ functions on the nonhydrogen atoms. Auxiliary basis sets to expand the electron density in the resolution-of-the-identity (RIJCOSX) $)^{31-33}$ approach were chosen to match 
the orbital basis. ${ }^{34-36}$ Throughout this chapter computational results are described by using the broken-symmetry (BS) approach by Ginsberg ${ }^{37}$ and Noodleman. ${ }^{38}$ All molecular orbital and spin density plots were generated using the program Gabedit. ${ }^{39}$ Nonrelativistic single-point calculations on the optimized geometry were carried out to predict Mössbauer spectral parameters (isomer shifts and quadrupole splittings). These calculations employed the CP(PPP) basis set for iron. ${ }^{40}$ The Mössbauer isomer shifts were calculated from the computed electron densities at the iron centers as previously described. ${ }^{41,42}$ 


\section{References}

1. Hakey, B. M.; Darmon, J. M.; Zhang, Y.; Petersen, J. L.; Milsmann, C. Synthesis and Electronic Structure of Neutral Square-Planar High-Spin Iron(II) Complexes Supported by a Dianionic Pincer Ligand. Inorg. Chem. 2019, 58, 1252-1266.

2. Komine, N.; W. Buell, R.W.; Chen, C.; Hui, A. K.; Pink, M.; Caulton, K. G. Probing the Steric and Electronic Characteristics of a New Bis-Pyrrolide Pincer Ligand. Inorg. Chem. 2014, $53,3,1361-1369$.

3. Searles, K.; Fortier, S.; Khusniyarov, M. M.; Carroll, P. J.; Sutter, J.; Meyer, K.; Mindiola, D. J.; Caulton, K. G. A Cis-Divacant Octahedral and Mononuclear Iron(IV) Imide. Angew. Chem., Int. Ed. 2014, 53, 14139-14143.

4. Zhang, Y.; Petersen, J. L.; Milsmann, C. A Luminescent Zirconium(IV) Complex as a Molecular Photosensitizer for Visible Light Photoredox Catalysis. J. Am. Chem. Soc. 2016, 138, 13115-13118.

5. Zhang, Y. "Photoluminescent Zirconium Complexes for Visible Light Photoredox Catalysis" Ph.D. Dissertation, West Virginia University, Morgantown, West Virginia, 2019.

6. Gowda, A. S.; Petersen, J. L.; Milsmann, C. Redox Chemistry of Bis(Pyrrolyl)Pyridine Chromium and Molybdenum Complexes: An Experimental and Density Functional Theoretical Study. Inorg. Chem. 2018, 57, 1919-1934.

7. Hakey, B. M.; Darmon, J. M. Akhemedov, N. G.; Petersen, J. L. Milsmann, C. Reactivity of Pyridine Dipyrrolide Iron(II) Complexes with Organic Azides: $\mathrm{C}-\mathrm{H}$ Amination and Iron Tetrazene Formation. Inorg. Chem. 2019, 58, 11028-11042. 
8. Sorsche, D.; Miehlich, M. E.; Zolnhofer, E. M.; Carroll, P. J.; Meyer, K.; Mindiola, D. J. Metal-Ligand Cooperativity Promoting Sulfur Atom Transfer in Ferrous Complexes and Isolation of a Sulfurmethylenephosphorane Adduct. Inorg. Chem. 2018, 57, 11552-11559.

9. Grant, L. N.; Carroll, M. E.; Carroll, P. J.; Mindiola, D. J. An Unusual Cobalt Azide Adduct That Produces a Nitrene Species for Carbon-Hydrogen Insertion Chemistry. Inorg. Chem. 2016, $55,7997-8002$.

10. See Chapters 3 and 5 of this dissertation for further details.

11. Searles, K. Implementing New Ligand Platforms for Metal Ligand Multiple Bond and Dinitrogen Chemistry. Ph.D. Dissertation, Indiana University, Bloomington, Indiana, 2015.

12. Noodleman, L. J. Valence Bond Description of Antiferromagnetic Coupling in Transition Metal Dimers. Chem. Phys. 1981, 74, 5737-5743.

13. Noodleman, L.; Davidson, E. R. Ligand Spin Polarization and Antiferromagnetic Coupling in Transition Metal Dimers. Chem. Phys. 1986, 109, 131-143.

14. Iovan, D. A.; Betley, T. A. Characterization of Iron-Imido Species Relevant for N-Group Transfer Chemistry. J. Am. Chem. Soc. 2016, 138, 1983-1993.

15. Bürger, H.; Wannagat, U. Silylamido-Derivate von Eisen Und Kobalt. Monatshefte für Chemie und verwandte Teile anderer Wissenschaften 1963, 94, 1007-1012.

16. Andersen, R. A.; Faegri, K.; Haaland, A.; Rypdal, K.; Green, J. C.; Lappert, M. F.; Leung, W. P. Synthesis of Bis[Bis(Trimethylsilyl)Amido]Iron(II). Structure and Bonding in $\mathrm{M}\left[\mathrm{N}\left(\mathrm{SiMe}_{3}\right)_{2}\right]_{2}(\mathrm{M}=\mathrm{Mn}, \mathrm{Fe}, \mathrm{Co})$ : Two-Coordinate Transition-Metal Amides. Inorg. Chem. 1988, 27, 1782-1786. 
17. Cámpora, J.; Naz, A. M.; Palma, P.; Álvarez, E.; Reyes, M. L. 2,6-Diiminopyridine Iron(II) Dialkyl Complexes. Interaction with Aluminum Alkyls and Ethylene Polymerization Catalysis. Organometallics 2005, 24, 4878-4881.

18. Raoufmoghaddam, S.; Mannathan, S.; Minnaard, A. J.; de Vries, J. G.; de Bruin, B.; Reek, J. N. H. Importance of the Reducing Agent in Direct Reductive Heck Reactions. ChemCatChem 2018, 10, 266-272.

19. Robinson, T. P.; Hubbard, R. B.; Ehlers, T. J.; Arbiser, J. L.; Goldsmith, D. J.; Bowen, J. P. Synthesis and Biological Evaluation of Aromatic Enones Related to Curcumin. Bioorg. Med. Chem. 2005, 13, 4007-4013.

20. Peng, Y.; Li, Z.; Zeng, Y.; Xie, X.; Wang, H.; Li, L.; Liu, X. Solid Phase Extractors Derived by Functionalising Sub-Micro Silica Gel with Chelating Agents and Their pH-Tunable Adsorbing Capability towards $\mathrm{Pb}(\mathrm{II})$ and $\mathrm{Ag}(\mathrm{I})$. Microchim. Acta 2010, 170, 17-26.

21. Nakamura, Y.; Tetsuo, O.; Yohei, O. A Formal Anti-Markovnikov Hydroalkyoxylation of Allylic Alcohols with Ruthenium Catalyst. Chem. Lett. 2018, 47, 288-291.

22. APEX3: Crystallographic Software Package for Single Crystal Data Collection, Reduction and Preparation, Version 2016.9-0; Bruker AXS: Madison, WI, 2016.

23. Sheldrick, G. M. SHELXL-2014: Crystallographic Software Package; Bruker AXS, Inc.: Madison, WI, 2014.

24. Neese, F. The ORCA Program System. Wiley Interdiscip. Rev. Comput. Mol. Sci. 2012, 2 , 73-78.

25. Becke, A. D. Density Functional Calculations of Molecular Bond Energies. J. Chem. Phys. 1986, $84,4524-4529$. 
26. Becke, A. D. Density-Functional Thermochemistry. III. The Role of Exact Exchange. J. Chem. Phys. 1993, 98, 5648-5652.

27. Lee, C.; Yang, W.; Parr, R. G. Development of the Colle-Salvetti Correlation-Energy Formula into a Functional of the Electron Density. Phys. Rev. B: Condens. Matter Mater. Phys. 1988, $37,785-789$.

28. Schäfer, A.; Horn, H.; Ahlrichs, R. Fully Optimized Contracted Gaussian-Basis Sets for Atoms Li to Kr. J. Chem. Phys. 1992, 97, 2571-2577.

29. Schäfer, A.; Huber, C.; Ahlrichs, R. Fully Optimized Contracted Gaussian Basis Sets of Triple Zeta Valence Quality for Atoms Li to Kr. J. Chem. Phys. 1994, 100, 5829.

30. Weigend, F.; Ahlrichs, R. Balanced Basis Sets of Split Valence, Triple Zeta Valence and Quadruple Zeta Valence Quality for H to Rn: Design and Assessment of Accuracy. Phys. Chem. Chem. Phys. 2005, 7, 3297-3305.

31. Neese, F.; Wennmohs, F.; Hansen, A.; Becker, U. Efficient, Approximate and Parallel Hartree-Fock and Hybrid DFT Calculations. A "Chain-of-Spheres” Algorithm for the HartreeFock Exchange. Chem. Phys. 2009, 356, 98-109.

32. Kossmann, S.; Neese, F. Comparison of Two Efficient Approximate Hartee-Fock Approaches. Chem. Phys. Lett. 2009, 481, 240-243.

33. Neese, F. An Improvement of the Resolution of the Identity Approximation for the Formation of the Coulomb Matrix. J. Comput. Chem. 2003, 24, 1740-1747.

34. Eichkorn, K.; Treutler, O.; Öhm, H.; Häser, M.; Ahlrichs, R. Auxiliary Basis Sets to Approximate Coulomb Potentials. Chem. Phys. Lett. 1995, 240, 283-289. 
35. Eichkorn, K.; Treutler, O.; Öhm, H.; Häser, M.; Ahlrichs, R. Erratum: Auxiliary Basis Sets to Approximate Coulomb Potentials (Chem. Phys. Letters 240 (1995) 283). Chem. Phys. Lett. 1995, $242,652-660$.

36. Eichkorn, K.; Weigend, F.; Treutler, O.; Ahlrichs, R. Auxiliary Basis Sets for Main Row Atoms and Transition Metals and Their Use to Approximate Coulomb Potentials. Theor. Chem. Acc. 1997, 97, 119-124.

37. Ginsberg, A. P. Magnetic Exchange in Transition Metal Complexes 12. Calculation of Cluster Exchange Coupling Constants with the $\mathrm{X}_{a}$-Scattered Wave Method. J. Am. Chem. Soc. 1980, 102, 111-117.

38. Noodleman, L.; Peng, C. Y.; Case, D. A.; Mouesca, J.-M. Orbital Interactions, Electron Delocalization and Spin Coupling in Iron-Sulfur Clusters. Coord. Chem. Rev. 1995, 144, 199244.

39. Allouche, A.-R. Software News and Updates Gabedit-A Graphical User Interface for Computational Chemistry Softwares. J. Comput. Chem. 2011, 32, 174-182.

40. Neese, F. Prediction and Interpretation of the ${ }^{57} \mathrm{Fe}$ Isomer Shift in Mössbauer Spectra by Density Functional Theory. Inorg. Chim. Acta. 2002, 337, 181-192.

41. Römelt, M.; Ye, S.; Neese, F. Calibration of Modern Density Functional Theory Methods for the Prediction of ${ }^{57} \mathrm{Fe}$ Mössbauer Isomer Shifts : Meta-GGA and Double-Hybrid Functionals. Inorg. Chem. 2009, 48, 784-785.

42. Sinnecker, S.; Slep, L. D.; Bill, E.; Neese, F. Performance of Nonrelativistic and QuasiRelativistic Hybrid DFT for the Prediction of Electric and Magnetic Hyperfine Parameters in ${ }^{57}$ Fe Mössbauer Spectra. Inorg. Chem. 2005, 44, 2245-2254. 

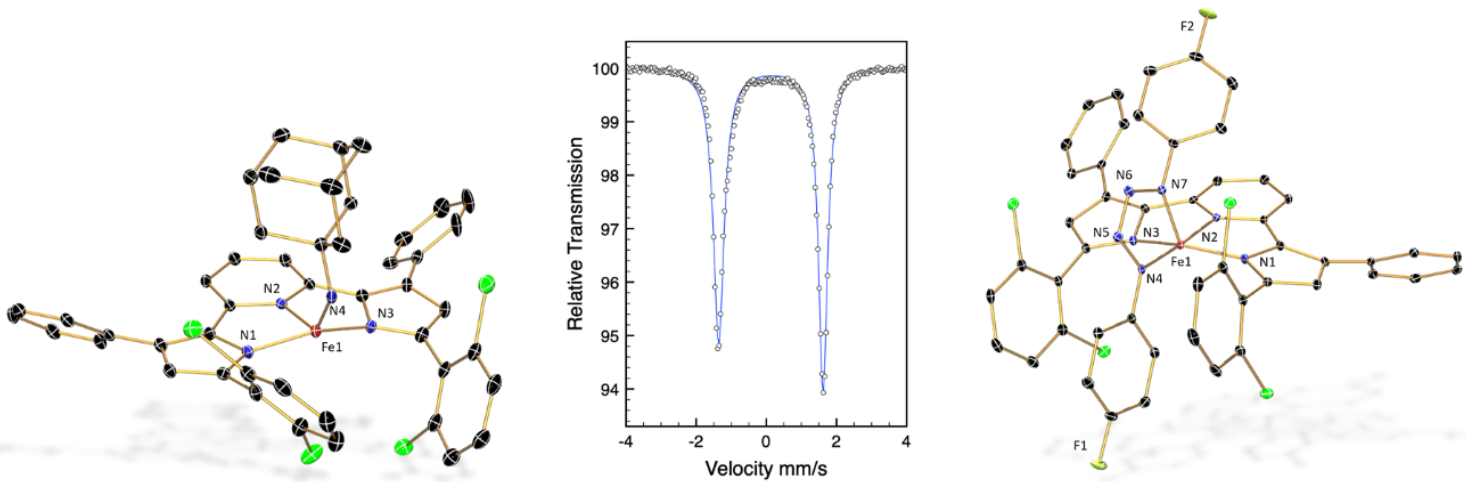

CHAPTER V: REACTIVITY OF A ROBUST HIGH-SPIN IRON(II) PYRIDINE BISPYRROLIDE COMPLEX WITH ORGANIC AZIDES

\subsection{Abstract}

Reaction of $\left.{ }^{2,6-\mathrm{Cl} 2 \mathrm{Ph}} \mathrm{PDP}^{\mathrm{Ph}}\right) \mathrm{Fe}(\mathrm{thf})\left(\mathrm{H}_{2}{ }^{2,6-\mathrm{Cl} 2 \mathrm{Ph}} \mathrm{PDP}^{\mathrm{Ph}}=2,6-\mathrm{Bis}(5-(2,6-\right.$ dichlorophenyl)-3phenyl-1H-pyrrol-2-yl)-pyridine) with various organic azides has been studied. The identity of the azide substituent has been found to have a profound impact on the transformation type and identity of the reaction products. Treatment of $\left({ }^{2,6-\mathrm{Cl} 2 \mathrm{Ph}} \mathrm{PDP}^{\mathrm{Ph}}\right) \mathrm{Fe}($ thf $)$ with bulky 1-adamantyl azide resulted in the formation of the cis-divacant octahedral diamagnetic low-spin $\mathrm{Fe}^{\mathrm{IV}}$ imide, $\left.{ }^{2,6-\mathrm{Cl} 2 \mathrm{Ph}} \mathrm{PDP}^{\mathrm{Ph}}\right) \mathrm{Fe}\left(\mathrm{N}^{1} \mathrm{Ad}\right)$. In a divergent manner, reaction with the bulky aryl azides, mesityl azide (mesityl = 2,4,6-trimethylphenyl), or xylyl azide (xylyl = 2,6-dimethylphenyl) resulted in the exclusive formation of the paramagnetic iron iminyl complexes $\left({ }^{2,6-\mathrm{Cl} 2 \mathrm{Ph}} \mathrm{PDP}{ }^{\mathrm{Ph}}\right) \mathrm{Fe}(\mathrm{NMes})$ and (2,6-Cl2Ph $\left.{ }^{2} P^{\mathrm{Ph}}\right) \mathrm{Fe}(\mathrm{NXyl})$. Reaction with the sterically unhindered aryl azides, parafluorophenylazide, $\mathrm{pFPhN}_{3}$, or 4-tertbutylphenyl azide, which lack sufficient steric protection of the intermediate iron nitrene, resulted in the exclusive formation of the corresponding Fe $\mathrm{e}^{\mathrm{III}}$ tetrazene complexes $\left({ }^{\mathrm{Mes}} \mathrm{PDP}{ }^{\mathrm{Ph}}\right) \mathrm{Fe}\left(\mathrm{N}_{4}(\mathrm{pFPh})_{2}\right)$ and $\left({ }^{\mathrm{Mes}} \mathrm{PDP}{ }^{\mathrm{Ph}}\right) \mathrm{Fe}\left(\mathrm{N}_{4}\left(\mathrm{p}^{\mathrm{t} B u P h}\right)_{2}\right)$. A reaction with 1-(4-azidobutyl)benzene was also explored and resulted in the isolation of 
(2,6-Cl2Ph $\left.\mathrm{PDP}^{\mathrm{Ph}}\right) \mathrm{Fe}\left(\mathrm{N}_{4}(\mathrm{nBuPh})_{2}\right)\left(\mathrm{HN}=\mathrm{CH}\left(\mathrm{CH}_{2}\right)_{3} \mathrm{Ph}\right)$, a low-spin $\mathrm{Fe}^{\mathrm{II}}$ complex carrying a neutral tetrazene and aldimine ligand. All complexes were characterized using a combination of X-ray crystallography, ${ }^{1} \mathrm{H}$ NMR, and ${ }^{57} \mathrm{Fe}$ Mössbauer spectroscopy. Complementary density functional theory (DFT) studies have been undertaken to explore potential electronic structures for the isolated iron(IV) imido and iron(III) iminyl radical complexes.

\subsection{Introduction}

Significant attention has recently been devoted to the renewed study of base metal catalyzed reactions. ${ }^{1}$ Specifically, researchers have identified iron as a potential surrogate for precious metals in a variety of valuable synthetic transformations, principally due to its ubiquity and benign nature. One specific class of reactions in which iron has shown significant promise is atom or group transfer reactions, such $\mathrm{C}-\mathrm{H}$ hydroxylation or amination. ${ }^{2}$ Decades ago, this field was pioneered by Breslow and coworkers, who disclosed the success of biomimetic iron porphyrin systems as catalysts in $\mathrm{C}-\mathrm{H}$ amination. ${ }^{3}$ Following this report, modern investigations from the Betley and Milsmann groups have included the development of similar pyrrole based ligand platforms that have demonstrated the capability to perform intramolecular $\mathrm{C}-\mathrm{H}$ amination of mesityl groups of the supporting ligands (Figure 5.1). ${ }^{4,5}$ The pyrrole based ligands utilized in these systems include the dipyrromethene and pyridine dipyrrolide classes of ligands, which can be viewed as porphyrin fragments. Despite the initial promise of the intramolecular reactivity observed in these reports, subsequent investigations have demonstrated that the high reactivity of the intermediate iron nitrenes responsible for the observed $\mathrm{C}-\mathrm{H}$ amination are susceptible to other competing degradation pathways, including tetrazene formation via [2+3] cycloaddition with a second equivalent of organic azide, or $\alpha$-hydrogen atom abstraction from the nitrene substituent. These challenges underscore the necessity for the careful development and steric 
attenuation of both the supporting ligand and the nitrene fragments in these systems in order to circumvent undesired reactivity.

In consideration of these necessities, the Betley group has demonstrated that the installation of inert and sterically encumbering 2,4,6-triphenylbenzene substitutions in place of mesityl groups on the dipyrromethene ligand render reactive iron nitrene complexes isolable and amenable to spectroscopic characterization. In depth spectroscopic and computational studies have elegantly demonstrated that these complexes do not contain canonical dianionic imidos, but instead feature high-spin $\mathrm{Fe}^{\mathrm{III}}$ ions antiferromagnetically coupled to iminyl radical ligands. The same group has subsequently invoked the participation of similar intermediates in their catalytic protocol to form $\mathrm{N}$-heterocycles via the decomposition of alkyl azides. The radical character imparted onto the iminyl ligand nitrogen is considered a critical component responsible for the success of this system. ${ }^{6}$ Mechanistically, this transformation is proposed to proceed via a C-H abstraction/radical rebound mechanism, invoking a direct comparison to the $\mathrm{C}-\mathrm{H}$ hydroxylation of hydrocarbons via iron oxo porphyrins in P450 enzymes. ${ }^{7}$ 

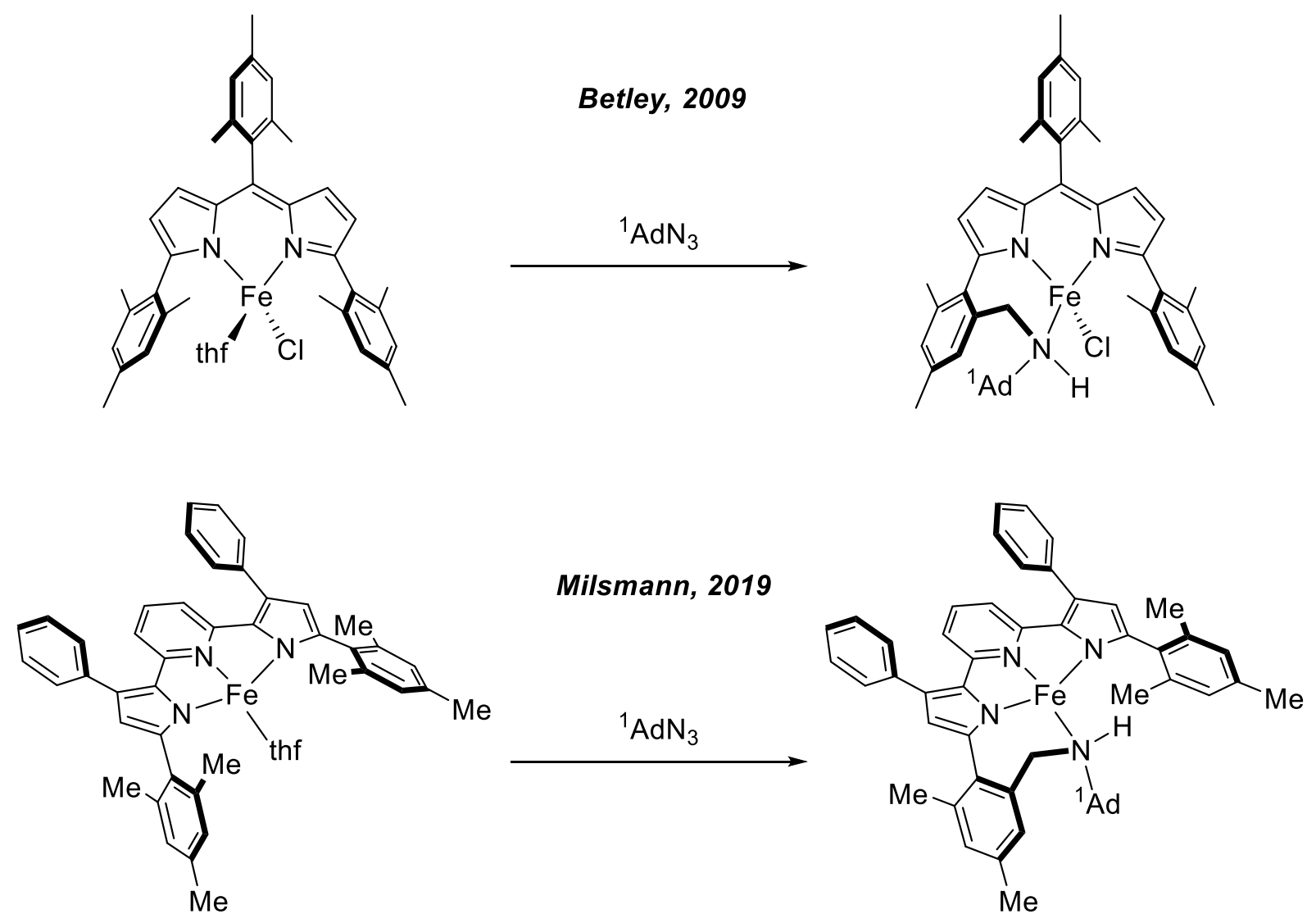

Figure 5.1. Examples of pyrrole based ligands susceptible to intramolecular $\mathrm{C}-\mathrm{H}$ amination.

Inspired by this success, it was envisioned that the installation of chemically robust aryl substituents at the 5-position of the PDP ligand pyrrolides may render the corresponding iron nitrene complexes amenable to isolation and spectroscopic study. The work presented in chapter 3 has demonstrated that by tailoring the nitrene source in reactions with ( $\left.{ }^{\mathrm{Mes}} \mathrm{PDP}^{\mathrm{Ph}}\right) \mathrm{Fe}($ thf $)$, the $\mathrm{Fe}^{\mathrm{III}}$ iminyl radical complex $\left({ }^{\mathrm{Mes}} \mathrm{PDP}{ }^{\mathrm{Ph}}\right) \mathrm{Fe}(\mathrm{NMes})$ could be spectroscopically characterized via ${ }^{1} \mathrm{H}$ NMR spectroscopy. ${ }^{8}$ This complex has been shown to engage in the direct C-H amination of the ${ }^{\mathrm{Mes}} \mathrm{PDP}^{\mathrm{Ph}}$ ligand, as it decomposes in solution to the corresponding nitrene group transfer product, $\mathrm{Fe}\left(\mathrm{MesNH}-{ }^{\mathrm{Mes}} \mathrm{PDP}^{\mathrm{Ph}}\right)$. Interestingly, despite the analogous reactivity to dipyrromethene complexes, calculations have suggested disparate ground states exist for $\left({ }^{\mathrm{Mes}} \mathrm{PDP}^{\mathrm{Ph}}\right) \mathrm{Fe}(\mathrm{NMes})$ 
and dipyrromethene iron iminyl complexes. Computational analysis suggests a square-planar intermediate-spin ferric ion engaged in antiferromagnetic coupling to an iminyl radical ligand may best describe the electronic structure of this complex. In hopes of developing analogous square-planar iron iminyl complexes, we turned to $\left({ }^{2,6-\mathrm{Cl} 2 \mathrm{Ph}} \mathrm{PDP}{ }^{\mathrm{Ph}}\right) \mathrm{Fe}($ thf $)$, presented in Chapter 4. The similar substitution pattern of this ligand was envisioned to closely emulate that of $\left({ }^{\mathrm{Mes}} \mathrm{PDP} \mathrm{Ph}^{\mathrm{Ph}}\right) \mathrm{Fe}(\mathrm{thf})$, used in the generation of $\left({ }^{\mathrm{Mes}} \mathrm{PDP}^{\mathrm{Ph}}\right) \mathrm{Fe}(\mathrm{NMes})$. Further, the replacement of the mesityl methyl groups with chloride substituents should prevent intramolecular C-H amination and possibly make the corresponding iron nitrene adducts more amenable to crystallization. Herein is described initial reactivity studies and computational analysis of a variety of products arising from the reactivity of $\left({ }^{2,6-\mathrm{ClPh}} \mathrm{PDP}{ }^{\mathrm{Ph}}\right) \mathrm{Fe}($ thf $)$ with organic azides, including iron imide complexes.

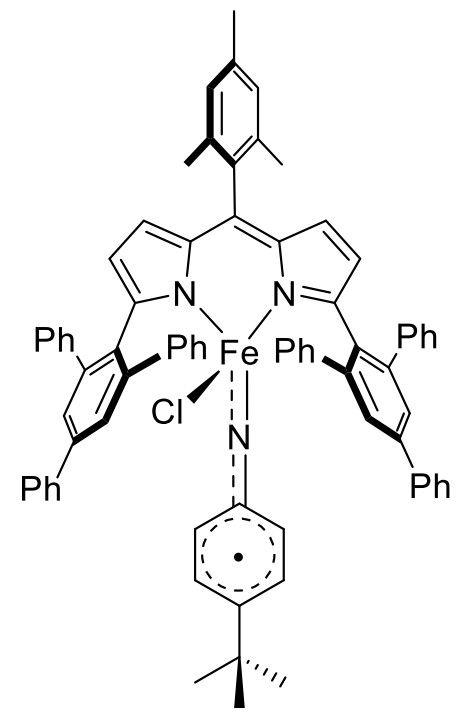

Betley, 2011

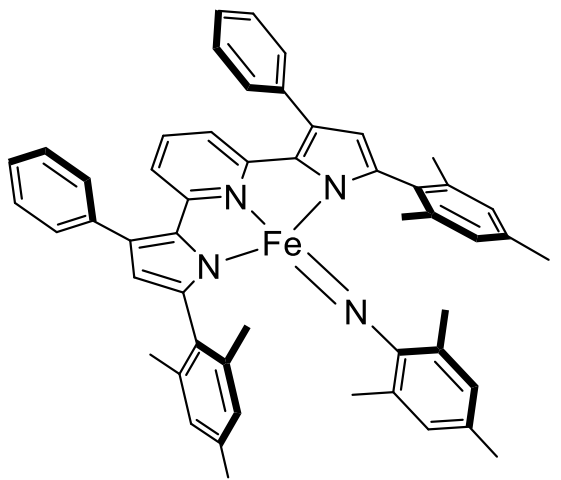

Chapter 3

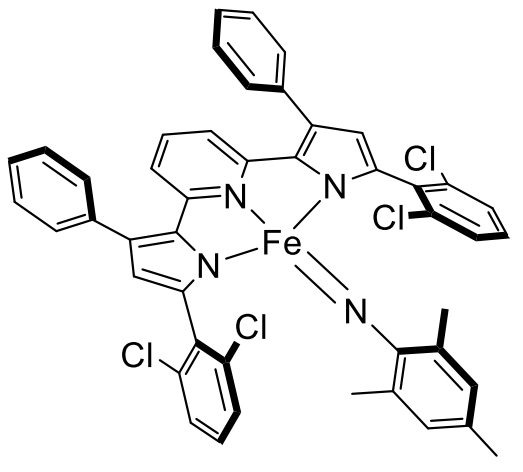

This Work

Figure 5.2. Dipyrromethene (left) and pyridine dipyrrolide (middle, right) iron nitrene complexes. 


\subsection{Reactivity of $\left.{ }^{(2,6-C 12 P h P D P P h}\right) \mathrm{Fe}($ thf $)$ with Adamantyl Azide}

Considering the propensity for the ${ }^{\mathrm{Mes}} \mathrm{PDP}^{\mathrm{Ph}}$ ligand framework to undergo facile $\mathrm{C}-\mathrm{H}$ amination of the mesityl substituent when treated with various organoazides, the complex $\left.{ }^{2,6-\mathrm{Cl} 2 \mathrm{Ph}} \mathrm{PDP}^{\mathrm{Ph}}\right) \mathrm{Fe}(\mathrm{thf})$ was chosen as an alternative synthon that led to the successful synthesis of $\left.{ }^{2,6-\mathrm{Cl} 2 \mathrm{Ph}} \mathrm{PDP}^{\mathrm{Ph}}\right) \mathrm{Fe}(\mathrm{NR})$ complexes. It was hypothesized that by maintaining an aryl substitution pattern at the five position of the pyrrolide would afford a ligand steric profile and corresponding electronic structure similar to that of ${ }^{\mathrm{Mes}} \mathrm{PDP}^{\mathrm{Ph}}$. Accordingly, treatment of a homogeneous red solution of $\left({ }^{2,6-\mathrm{Cl} 2 \mathrm{Ph}} \mathrm{PDP}{ }^{\mathrm{Ph}}\right) \mathrm{Fe}(\mathrm{thf})$ in benzene- $d_{6}$ with one equivalent of adamantyl azide at room temperature was found to induce no reaction, as determined by ${ }^{1} \mathrm{H}$ NMR spectroscopy. Heating the mixture at $60^{\circ} \mathrm{C}$ induced a color change of the solution to dark brown within minutes. Analysis of the crude reaction mixture via ${ }^{1} \mathrm{H}$ NMR spectroscopy demonstrated complete consumption of the starting material with concomitant appearance of a new $\mathrm{C}_{2 v}$ symmetric diamagnetic species, as indicated by relative integrations to the 4-pyridine triplet resonance (5.28 ppm). Removal of volatiles in vacuo and subsequent crystallization via slow evaporation of a diethyl ether solution afforded red single crystals suitable for analysis via X-ray diffraction. The X-ray analysis confirmed the identity of the reaction product as the iron imido complex, $\left.{ }^{2,6-\mathrm{Cl} 2 \mathrm{Ph}} \mathrm{PDP}^{\mathrm{Ph}}\right) \mathrm{Fe}\left(\mathrm{N}^{1} \mathrm{Ad}\right)$ (Scheme 5.1). An ORTEP of the molecular structure is depicted in Figure 5.4. 


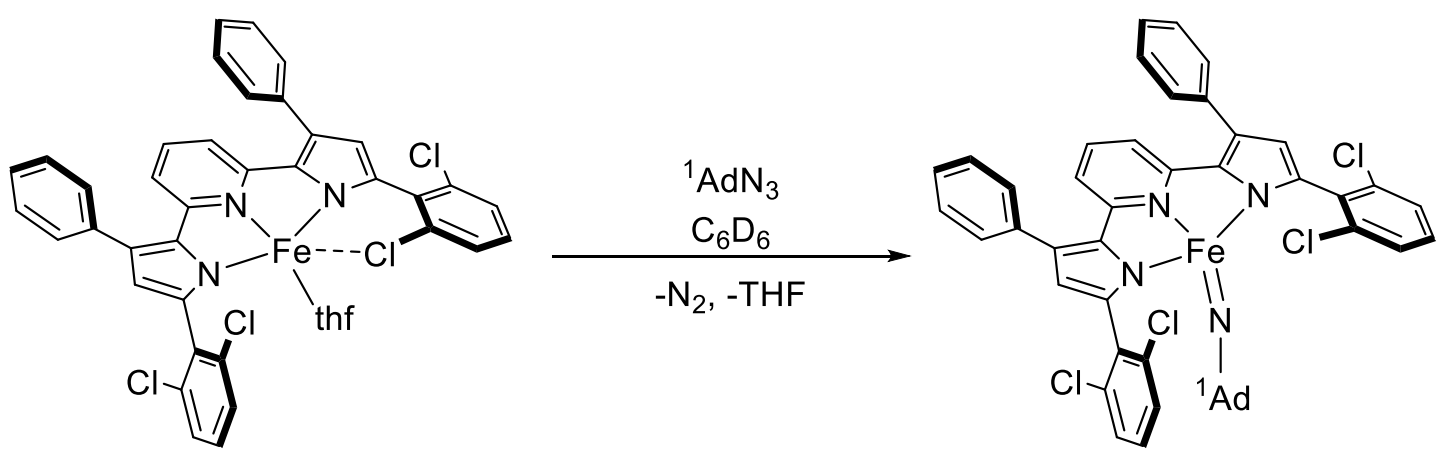

Scheme 5.1. Synthesis of $\left.{ }^{2,6-\mathrm{Cl} 2 \mathrm{Ph}} \mathrm{PDP} \mathrm{Ph}^{\mathrm{Ph}}\right) \mathrm{Fe}\left(\mathrm{N}^{1} \mathrm{Ad}\right)$.

The coordination geometry about the iron center is best described as a cis-divacant octahedron. The short iron-nitrogen bond lengths of are consistent with a low spin state, in agreement with the apparent diamagnetism observed via ${ }^{1} \mathrm{H}$ NMR spectroscopy. Distances of $1.887(4) \AA$ and $1.894(4) \AA$ to N1 and N3 of the pyrrolide N atoms, 1.898 (4) $\AA$ to N2, the pyridine nitrogen. The iron-imide nitrogen bond distance is $1.620(4) \AA$. In totality, the solid-state structure of $\left({ }^{2,6-\mathrm{C} 12 \mathrm{Ph}} \mathrm{PDP} \mathrm{Ph}^{\mathrm{Ph}}\right) \mathrm{Fe}\left(\mathrm{N}^{1} \mathrm{Ad}\right)$ is very similar to the previously studied analogue $\left({ }^{\mathrm{tBu}} \mathrm{PDP} \mathrm{tBu}^{\mathrm{tBu}}\right) \mathrm{Fe}\left(\mathrm{N}^{1} \mathrm{Ad}\right)$, reported by Caulton, Mindiola, et al. ${ }^{9}$ For comparison, important structural metrics determined via the $\mathrm{X}$-ray crystallographic analysis of $\left({ }^{2,6-\mathrm{Cl} 2 \mathrm{Ph}} \mathrm{PDP}^{\mathrm{Ph}}\right) \mathrm{Fe}\left(\mathrm{N}^{1} \mathrm{Ad}\right)$ and $\left({ }^{\mathrm{tBu}} \mathrm{PDP}{ }^{\mathrm{tBu}}\right) \mathrm{Fe}\left(\mathrm{N}^{1} \mathrm{Ad}\right)$ are provided in Table 5.2. Despite the similarity in the iron PDP nitrogen and iron imide bond lengths, a subtle but evident difference in the coordination geometry of the two complexes is present in the $\mathrm{N}_{\text {pyridine }}-\mathrm{Fe}-\mathrm{N}_{\text {imide }}$ bond angle. For cis-divacant octahedral $\left({ }^{\mathrm{tBu}} \mathrm{PDP} \mathrm{P}^{\mathrm{tBu}}\right) \mathrm{Fe}\left(\mathrm{N}^{1} \mathrm{Ad}\right)$ this angle was found to be $116.6(2),{ }^{9}$ while for $\left({ }^{2,6-\mathrm{Cl} 2 \mathrm{Ph}} \mathrm{PDP}{ }^{\mathrm{Ph}}\right) \mathrm{Fe}\left(\mathrm{N}^{1} \mathrm{Ad}\right)$ the imide fragment is more bent, with a $\mathrm{N}_{\text {pyridine }}-\mathrm{Fe}-\mathrm{N}_{\text {imide }}$ angle of $123.12(19)^{\circ}$. Despite the slight departure from cis-divacant octahedral geometry for $\left({ }^{2,6-\mathrm{C} 12 \mathrm{Ph}} \mathrm{PDP}^{\mathrm{Ph}}\right) \mathrm{Fe}\left(\mathrm{N}^{1} \mathrm{Ad}\right)$ relative to $\left({ }^{\mathrm{tBu} P D P}{ }^{\mathrm{tBu}}\right) \mathrm{Fe}\left(\mathrm{N}^{1} \mathrm{Ad}\right)$, the $\mathrm{Fe}-\mathrm{N}_{\text {imide }}-\mathrm{C}_{\text {imide }}$ bond angles are 139.94(4) and 140.5(3) degrees, respectively. 
Caulton, Mindiola, and coworkers have previously reported the density functional theory (DFT) characterization of $\left({ }^{\mathrm{tBu}} \mathrm{PDP}^{\mathrm{tBu}}\right) \mathrm{Fe}\left(\mathrm{N}^{1} \mathrm{Ad}\right)$ and cited an electronic and not steric preference for the imide to occupy an apical coordination site, resulting in a cis-divacant octahedral geometry. $\left.{ }^{2,6-\mathrm{Cl} 2 \mathrm{Ph}} \mathrm{PDP}^{\mathrm{Ph}}\right) \mathrm{Fe}\left(\mathrm{N}^{1} \mathrm{Ad}\right)$ offers the possibility of testing this proposal, as a planar geometry should be accessible for the complex due to the smaller steric profile of the 2,6dichlorophenyl substituents at the 5 position of the pyrrolides. Notably, the observed $\mathrm{C}_{2 v}$ symmetric ${ }^{1} \mathrm{H}$ NMR spectrum (Figure 5.3), suggests that the imido fragment is engaged in rapid equilibration above and below the plane of the ${ }^{2,6-\mathrm{Cl} 2 \mathrm{Ph}} \mathrm{PDP}^{\mathrm{Ph}}$ chelate faster than can be observed on the NMR timescale. This is in contrast to $\left.{ }^{\mathrm{tBu}}{ }^{\mathrm{PDP}}{ }^{\mathrm{tBu}}\right) \mathrm{Fe}\left(\mathrm{N}^{1} \mathrm{Ad}\right)$, which displays a $\mathrm{C}_{s}$ symmetric ${ }^{1} \mathrm{H}$ NMR spectrum due to its inability to access to a planar structure owing to the steric environment enforced by the tert-butyl groups at the 5 position of the pyrrolide heterocycles of the ${ }^{\mathrm{tBu}} \mathrm{PDP}^{\mathrm{tBu}}$ pincer. Interestingly, the chemical shifts of $\left.{ }^{(2,6-\mathrm{Cl} 2 \mathrm{Ph}} \mathrm{PDP}^{\mathrm{Ph}}\right) \mathrm{Fe}\left(\mathrm{N}^{1} \mathrm{Ad}\right)$ were found to be significantly deviated from those reported for $\left.{ }^{(\mathrm{BBu}} \mathrm{PDP}^{\mathrm{tBu}}\right) \mathrm{Fe}\left(\mathrm{N}^{1} \mathrm{Ad}\right)($ Table 5.1) and largely removed from their diamagnetic references values. For example, the 4-pyridine resonance in $\left(^{2,6-\mathrm{Cl} 2 \mathrm{Ph}} \mathrm{PDP}^{\mathrm{Ph}}\right) \mathrm{Fe}\left(\mathrm{N}^{1} \mathrm{Ad}\right)$ is observed at $5.28 \mathrm{ppm}$ vs. $6.28 \mathrm{ppm}$ in $\left({ }^{\mathrm{tBu}} \mathrm{PDP}{ }^{\mathrm{tBu}}\right) \mathrm{Fe}\left(\mathrm{N}^{1} \mathrm{Ad}\right)$. This behavior is similar to $\left({ }^{\mathrm{Mes}} \mathrm{PDP}^{\mathrm{Ph}}\right) \mathrm{Fe}\left(\mathrm{N}_{4} \mathrm{pTol} 2\right)$, discussed in Chapter 3, which features a 4-pyridine resonance at $5.75 \mathrm{ppm} .{ }^{5}$ Computational analysis and variable temperature NMR studies suggest that low-lying paramagnetic excited states may be accessible for $\left({ }^{\mathrm{Mes}} \mathrm{PDP}{ }^{\mathrm{Ph}}\right) \mathrm{Fe}\left(\mathrm{N}_{4} \mathrm{pTol}_{2}\right)$, resulting in the observed anomalous chemical shifts as a result of paramagnetic contributions to the chemical shifts. A similar situation may be operative for $\left({ }^{2,6 \mathrm{C} 12 \mathrm{Ph}} \mathrm{PDP}{ }^{\mathrm{Ph}}\right) \mathrm{Fe}\left(\mathrm{N}^{1} \mathrm{Ad}\right)$, as suggested by computational analysis (vide infra). 


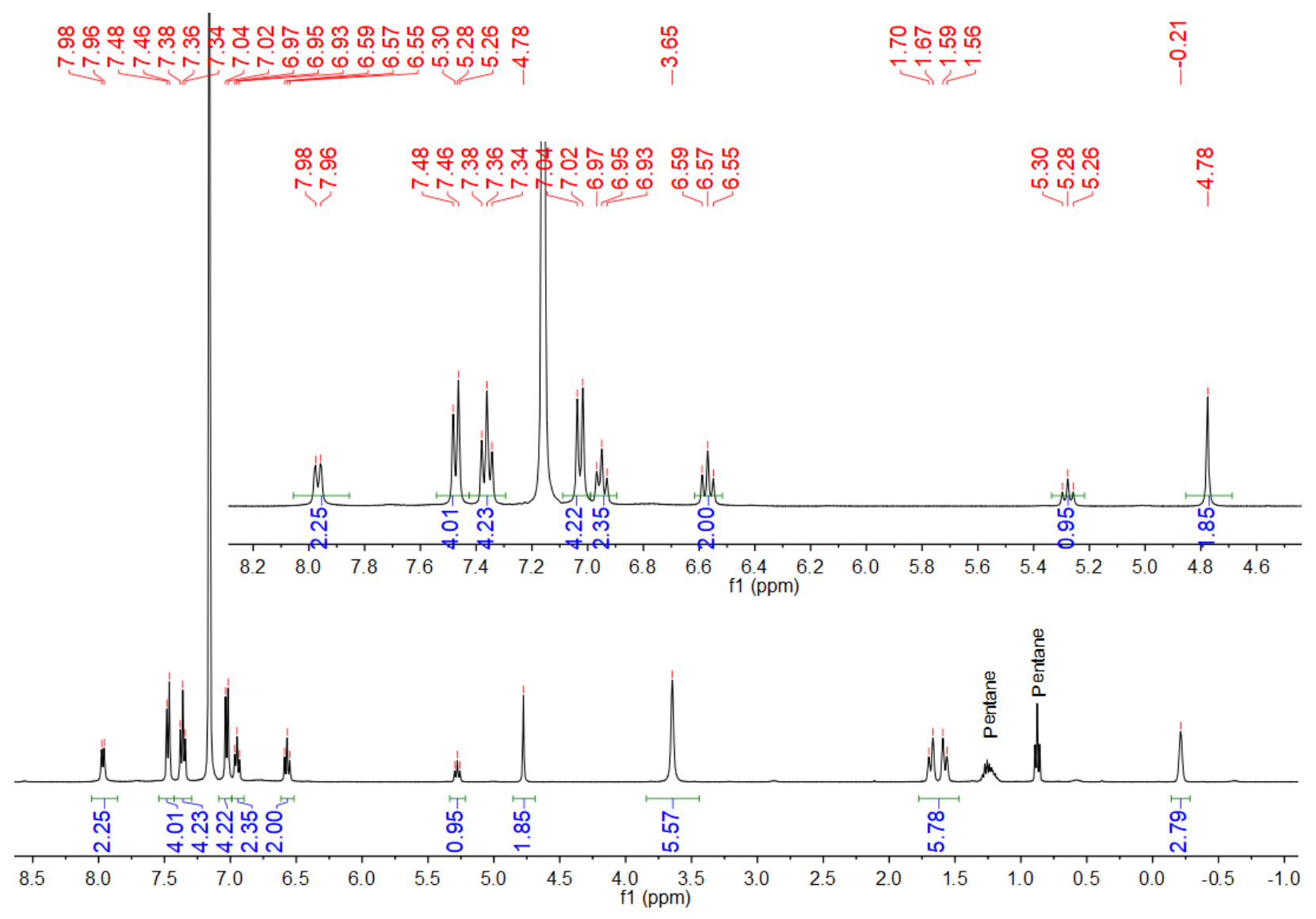

Figure 5.3. ${ }^{1} \mathrm{H}$ NMR spectrum of $\left({ }^{2,6-\mathrm{Cl} 2 \mathrm{Ph}} \mathrm{PDP}{ }^{\mathrm{Ph}}\right) \mathrm{Fe}\left(\mathrm{N}^{1} \mathrm{Ad}\right)$ at $400 \mathrm{MHz}$ in benzene- $d_{6}$.

Table 5.1. ${ }^{1} \mathrm{H}$ NMR chemical shifts (ppm) of $c i s$-divacant octahedral PDP iron imides.

\begin{tabular}{ccc}
\hline & $\left(^{\left({ }^{\mathrm{Bu}} \mathrm{PDP} \mathrm{BBu}^{\mathrm{tBu}}\right) \mathrm{Fe}\left(\mathrm{N}^{1} \mathrm{Ad}\right)^{a}}\right.$ & $\left(2,6-\mathrm{Cl} 2 \mathrm{Ph} \mathrm{PDP}^{\mathrm{Ph}}\right) \mathrm{Fe}\left(\mathrm{N}^{1} \mathrm{Ad}\right)$ \\
\hline 4-Pyridine $H$ & $6.28^{b}$ & 5.28 \\
3-Pyridine $H$ & $6.28^{b}$ & 7.97 \\
Pyrrole-CH & 6.64 & 4.78 \\
Adamantyl-CH$H_{2}$ & 2.23 & 3.65 \\
Adamantyl-CH & 1.46 & $1.70-1.56^{c}$ \\
Adamantyl-CH & 1.56 & -0.21
\end{tabular}

${ }^{a}$ Values obtained from reference $9 .{ }^{b}$ Overlapping resonances.

${ }^{c}$ multiplet resonance. 

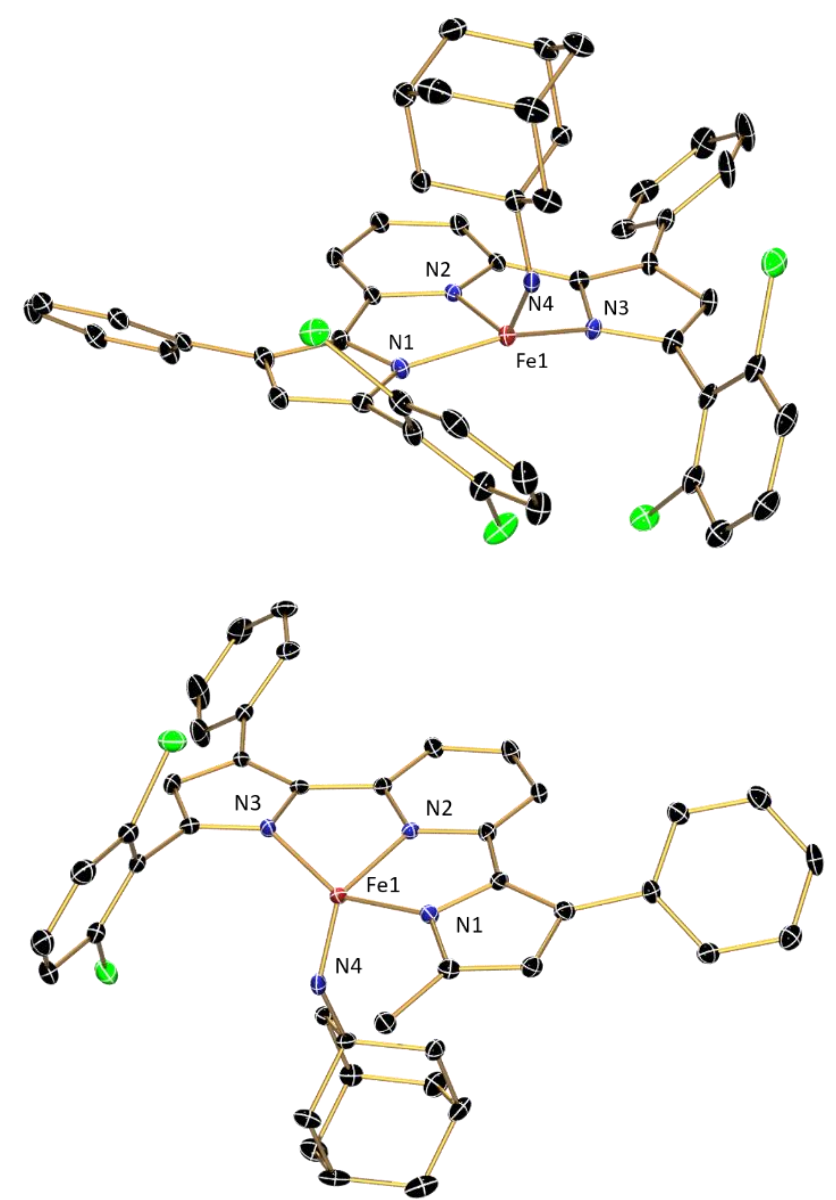

Figure 5.4. ORTEP depictions of (2,6-Cl2Ph $\left.\mathrm{PDP}{ }^{\mathrm{Ph}}\right) \mathrm{Fe}\left(\mathrm{N}^{1} \mathrm{Ad}\right)$ displayed at $30 \%$ probability ellipsoids. The bottom perspective view has one pyrrolide 2,6-dichlorophenyl substituent (with exception of the ipso carbon) and hydrogen atoms omitted for clarity. 
Table 5.2. Selected bond lengths $(\AA)$ and angles (deg) obtained from X-ray crystallography for $\left({ }^{\mathrm{tBu}} \mathrm{PDP} \mathrm{P}^{\mathrm{tBu}}\right) \mathrm{Fe}\left(\mathrm{N}^{1} \mathrm{Ad}\right)$ and $\left({ }^{2,6-\mathrm{Cl} 2 \mathrm{Ph}} \mathrm{PDP} \mathrm{P}^{\mathrm{Ph}}\right) \mathrm{Fe}\left(\mathrm{N}^{1} \mathrm{Ad}\right)$.

\begin{tabular}{|c|c|c|}
\hline & $\left({ }^{(\mathrm{Bu} u} \mathrm{PDP} \mathrm{P}^{\mathrm{tBu}}\right) \mathrm{Fe}\left(\mathrm{N}^{1} \mathrm{Ad}\right)^{a}$ & $\left({ }^{2,6-\mathrm{Cl} 2 \mathrm{Ph}} \mathrm{PDP} \mathrm{P}^{\mathrm{Ph}}\right) \mathrm{Fe}\left(\mathrm{N}^{1} \mathrm{Ad}\right)$ \\
\hline $\mathrm{Fe}(1)-\mathrm{N}(1)$ & $1.910(2)$ & $1.887(4)$ \\
\hline $\mathrm{Fe}(1)-\mathrm{N}(2)$ & $1.867(3)$ & $1.898(4)$ \\
\hline $\mathrm{Fe}(1)-\mathrm{N}(3)^{d}$ & - & $1.894(4)$ \\
\hline $\mathrm{Fe}(1)-\mathrm{N}(4)$ & $1.640(4)$ & $1.620(4)$ \\
\hline $\mathrm{Fe}(1)-\mathrm{C}(38)-(\mathrm{N} 4)$ & $140.5(3)$ & 139.94(4) \\
\hline $\mathrm{N}(1)-\mathrm{Fe}(1)-\mathrm{N}(2)$ & $82.13(7)$ & $81.21(17)$ \\
\hline $\mathrm{N}(1)-\mathrm{Fe}(1)-\mathrm{N}(3)^{d}$ & - & $151.59(18)$ \\
\hline $\mathrm{N}(1)-\mathrm{Fe}(1)-\mathrm{N}(4)$ & $106.21(7)$ & $100.82(19)$ \\
\hline $\mathrm{N}(2)-\mathrm{Fe}(1)-\mathrm{N}(3)^{d}$ & - & $80.67(17)$ \\
\hline $\mathrm{N}(2)-\mathrm{Fe}(1)-\mathrm{N}(4)$ & $116.6(2)$ & $123.12(19)$ \\
\hline $\mathrm{N}(3)-\mathrm{Fe}(1)-\mathrm{N}(4)^{d}$ & - & $107.38(19)$ \\
\hline
\end{tabular}

\subsection{Reactivity of (2,6-C22PhPDP $\left.{ }^{\mathrm{Ph}}\right) \mathrm{Fe}($ thf) with 4-Substituted Aryl Azides}

Considering the disparate outcome of the reaction of adamantyl azide with $\left({ }^{2,6-\mathrm{Cl} 2 \mathrm{Ph}} \mathrm{PDP}{ }^{\mathrm{Ph}}\right) \mathrm{Fe}($ thf $)$ relative to $\left({ }^{\mathrm{Mes}} \mathrm{PDP}{ }^{\mathrm{Ph}}\right) \mathrm{Fe}(\mathrm{thf})$, it was surmised that the possibility of isolating an iron nitrene with aryl substitution may exist within the framework of the 2,6-C12PhPDP ${ }^{\mathrm{Ph}}$ ligand. Accordingly, addition of a benzene- $d_{6}$ solution containing one equivalent of parafluorophenyl azide to a $\left({ }^{2,6-\mathrm{Cl} 2 \mathrm{Ph}} \mathrm{PDP}{ }^{\mathrm{Ph}}\right) \mathrm{Fe}($ thf $)$ solution in the same solvent led to an instantaneous color change from of the solution from red to dark brown. Analysis of the crude reaction mixture by ${ }^{1} \mathrm{H}$ NMR spectroscopy indicated an approximate 1:1 ratio of starting material to a new diamagnetic species based on integrations of the 4-pyridine proton resonances. Repetition of the experiment with two molar equivalents of para-fluorophenyl azide led to 
complete consumption of the starting material and clean formation of the new diamagnetic product, as ascertained by NMR. ${ }^{19} \mathrm{~F}$ NMR analysis confirmed the presence of one fluorine environment in the sample, as evidenced by a broad singlet resonance at $-121.86 \mathrm{ppm}$ (benzene- $d_{6}$, Figure 5.5). Performing the reaction on a preparative scale afforded a dark-brown powder after workup (vide infra), which was subjected to analysis via zero-field Mössbauer spectroscopy. The observed quadrupole doublet (Figure 5.4) gave a satisfactory fit with parameters $\delta=0.13 \mathrm{mms}^{-1}$ and $\left|\Delta \mathrm{E}_{\mathrm{Q}}\right|=2.97 \mathrm{mms}^{-1}$. These values are in good agreement with the Mössbauer parameters of $\delta=0.12 \mathrm{mms}^{-1}$ and $|\Delta \mathrm{EQ}|=3.12 \mathrm{mms}^{-1}$ for the related species $\left({ }^{\mathrm{Mes}} \mathrm{PDP} \mathrm{Ph}^{\mathrm{Ph}}\right) \mathrm{Fe}\left(\mathrm{N}_{4} \mathrm{pTol} 2\right)$, previously presented in Chapter $3 .{ }^{5}$

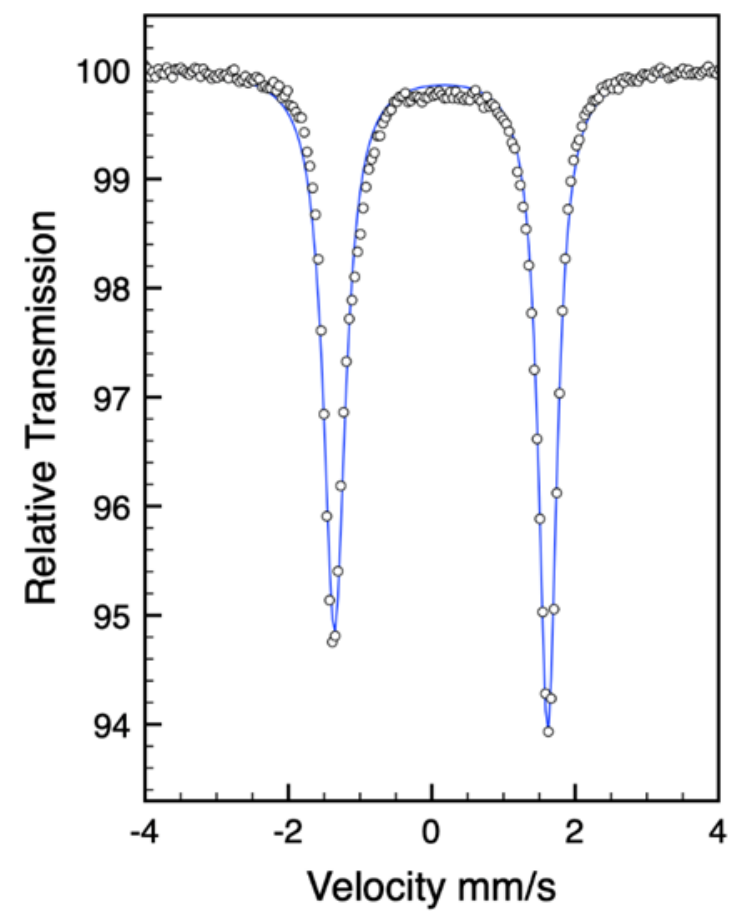

Figure 5.5. Zero-field Mössbauer spectrum of $\left({ }^{2,6-\mathrm{Cl} 2 \mathrm{Ph}} \mathrm{PDP}{ }^{\mathrm{Ph}}\right) \mathrm{Fe}\left(\mathrm{N}_{4}(\mathrm{pFPh})_{2}\right)$ acquired at $80 \mathrm{~K}$. The white circles indicate the experimental data and the blue line corresponds to the fit. 
Based on the available spectroscopic data, a tentative assignment of the species as the iron tetrazene complex $\left.{ }^{2,6-\mathrm{Cl} 2 \mathrm{Ph}} \mathrm{PDP}^{\mathrm{Ph}}\right) \mathrm{Fe}\left(\mathrm{N}_{4}(\mathrm{pFPh})_{2}\right)$ was made. Consistent with $\left({ }^{\mathrm{Mes}} \mathrm{PDP}{ }^{\mathrm{Ph}}\right) \mathrm{Fe}\left(\mathrm{N}_{4} \mathrm{pTol}_{2}\right),\left({ }^{2,6-\mathrm{Cl} 2 \mathrm{Ph}} \mathrm{PDP}^{\mathrm{Ph}}\right) \mathrm{Fe}\left(\mathrm{N}_{4}(\mathrm{pFPh})_{2}\right)$ is characterized by unusual chemical shifts for some resonances in the ${ }^{1} \mathrm{H}$ NMR spectrum (i.e.: $5.75 \mathrm{ppm}$ for 4-pyridine $H$ ), some of which are broadened and devoid of coupling (i.e.: $\mathrm{ArH}, 0.46 \mathrm{ppm}$ ), reminiscent of paramagnetically broadened and shifted resonances. This is further evidenced by the broad ${ }^{19} \mathrm{~F}$ resonance (Figure 5.6) that is entirely devoid of coupling to the protons on the phenyl ring of the tetrazene. For $\left({ }^{\mathrm{Mes}} \mathrm{PDP}{ }^{\mathrm{Ph}}\right) \mathrm{Fe}\left(\mathrm{N}_{4} \mathrm{pTol} 2\right)$ this behavior was ascribed to accessible paramagnetic excited states.

Evaporation of a concentrated dichloromethane solution of the pure material at room temperature afforded dark-brown single crystals suitable for study via X-ray crystallography. The solid-state structural analysis performed at $100 \mathrm{~K}$ confirmed the identity of the product as the iron tetrazene complex, $\left({ }^{2,6-\mathrm{Cl} 2 \mathrm{Ph}} \mathrm{PDP}^{\mathrm{Ph}}\right) \mathrm{Fe}\left(\mathrm{N}_{4}(\mathrm{pFPh})_{2}\right) .\left({ }^{2,6-\mathrm{Cl} 2 \mathrm{Ph}} \mathrm{PDP} \mathrm{Ph}^{\mathrm{Ph}}\right) \mathrm{Fe}\left(\mathrm{N}_{4}(\mathrm{pFPh})_{2}\right)$, which was crystallized in the triclinic space group P-1, was found to exist as a two-component nonmerohedral twin, featuring a major domain of $71.51(8) \%$. The coordination environment about the iron center is best described as a pseudo-square pyramidal in nature, and is isostructural with $\left({ }^{\mathrm{Mes}} \mathrm{PDP}{ }^{\mathrm{Ph}}\right) \mathrm{Fe}\left(\mathrm{N}_{4} \mathrm{pTol} 2\right)$. This result contrasts the apparent $\mathrm{C}_{2 \mathrm{v}}$ symmetry observed in the solution phase as determined by NMR spectroscopy. As previously discussed for ( $\left.{ }^{\mathrm{Mes} P D P}{ }^{\mathrm{Ph}}\right) \mathrm{Fe}\left(\mathrm{N}_{4} \mathrm{pTol} 2\right)$, this likely arises from rapid wagging of the tetrazene ligand above and below the plane of the PDP chelate on the timescale of the NMR experiment. The low energy barrier associated with this dynamic behavior in solution prevents the observation of discrete $\mathrm{C}_{s}$ symmetric isomers which are "frozen-out" under crystallography conditions at $100 \mathrm{~K} .{ }^{4}$ Relevant bond lengths and angles for $\left.{ }^{2,6-\mathrm{Cl} 2 \mathrm{Ph}} \mathrm{PDP}^{\mathrm{Ph}}\right) \mathrm{Fe}\left(\mathrm{N}_{4}(\mathrm{pFPh})_{2}\right)$ are summarized in Table 5.3. Notable bond distances include the nitrogen-nitrogen bonds within the tetrazene ligand, which were found to be 1.317(4) 
$\AA$ for $\mathrm{N}(4)-\mathrm{N}(5), 1.328(4) \AA$ for $\mathrm{N}(5)-\mathrm{N}(6)$, and 1.317(4) $\AA$ for N(6)-N(7), consistent with the retention of the radical monoanionic tetrazene formulation in this compound. Similarly, the iron PDP nitrogen distances were also found to be similar to those observed in

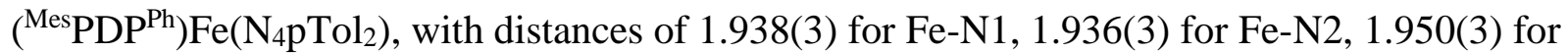
Fe-N3, 1.875(3) for Fe-N4, and 1.795(3) for Fe-N7. These bond lengths, which are consistent with a low-spin iron center, prompt an overall electronic structural assignment for the complex as containing a low-spin ferric center engaged in apparent antiferromagnetic coupling to a radical monoanionic tetrazene ligand.

In spite of the steric bulk of the para-substituted tert-butyl group, the reaction of $\left.{ }^{2,6-\mathrm{Cl} 2 \mathrm{Ph}} \mathrm{PDP}^{\mathrm{Ph}}\right) \mathrm{Fe}($ thf $)$ with para $^{\mathrm{t}}{ }^{\mathrm{Bu}} \mathrm{B}$-phenylazide proceeded with the formation of the tetrazene derivative, $\left({ }^{2,6-\mathrm{Cl} 2 \mathrm{Ph}} \mathrm{PDP}^{\mathrm{Ph}}\right) \mathrm{Fe}\left(\mathrm{N}_{4}\left(\mathrm{p}^{\mathrm{t}} \mathrm{BuPh}\right)_{2}\right)(\mathrm{Scheme} 5.2)$. The ${ }^{1} \mathrm{H}$ NMR spectrum of this compound (Figure 5.7, bottom) features NMR characteristics (broad resonances, unusual chemical shifts, etc.) similar to $\left({ }^{2,6-\mathrm{Cl} 2 \mathrm{Ph}} \mathrm{PDP}^{\mathrm{Ph}}\right) \mathrm{Fe}\left(\mathrm{N}_{4}(\mathrm{pFPh})_{2}\right)$ and $\left({ }^{\mathrm{Mes}} \mathrm{PDP}^{\mathrm{Ph}}\right) \mathrm{Fe}\left(\mathrm{N}_{4} \mathrm{pTol} 2\right) .{ }^{5}$ 

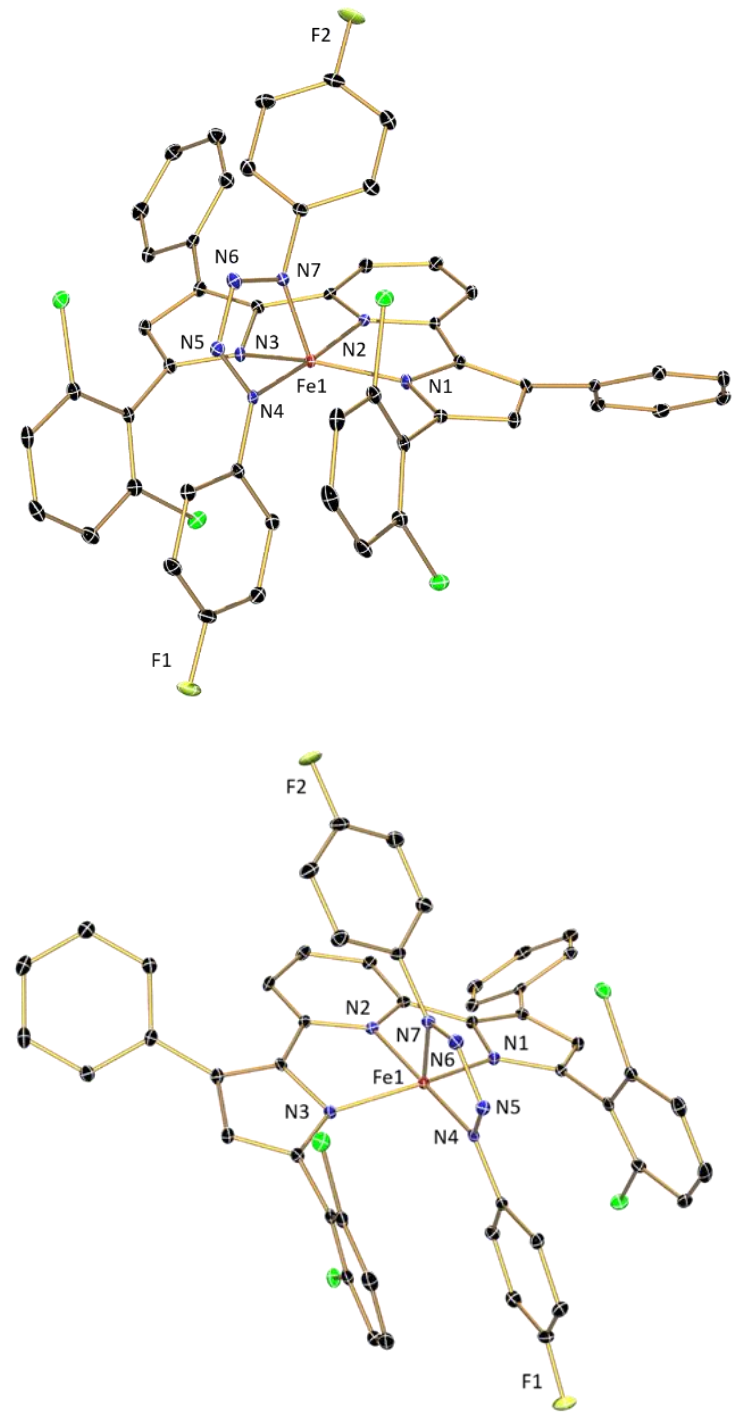

Figure 5.6. ORTEP depictions of two perspective views of $\left.{ }^{2,6-\mathrm{Cl} 2 \mathrm{Ph}} \mathrm{PDP}^{\mathrm{Ph}}\right) \mathrm{Fe}\left(\mathrm{N}_{4}(\mathrm{pFPh})_{2}\right)$ displayed at $30 \%$ probability ellipsoids. Hydrogen atoms and cocrystallized dichloromethane have been excluded for clarity. 


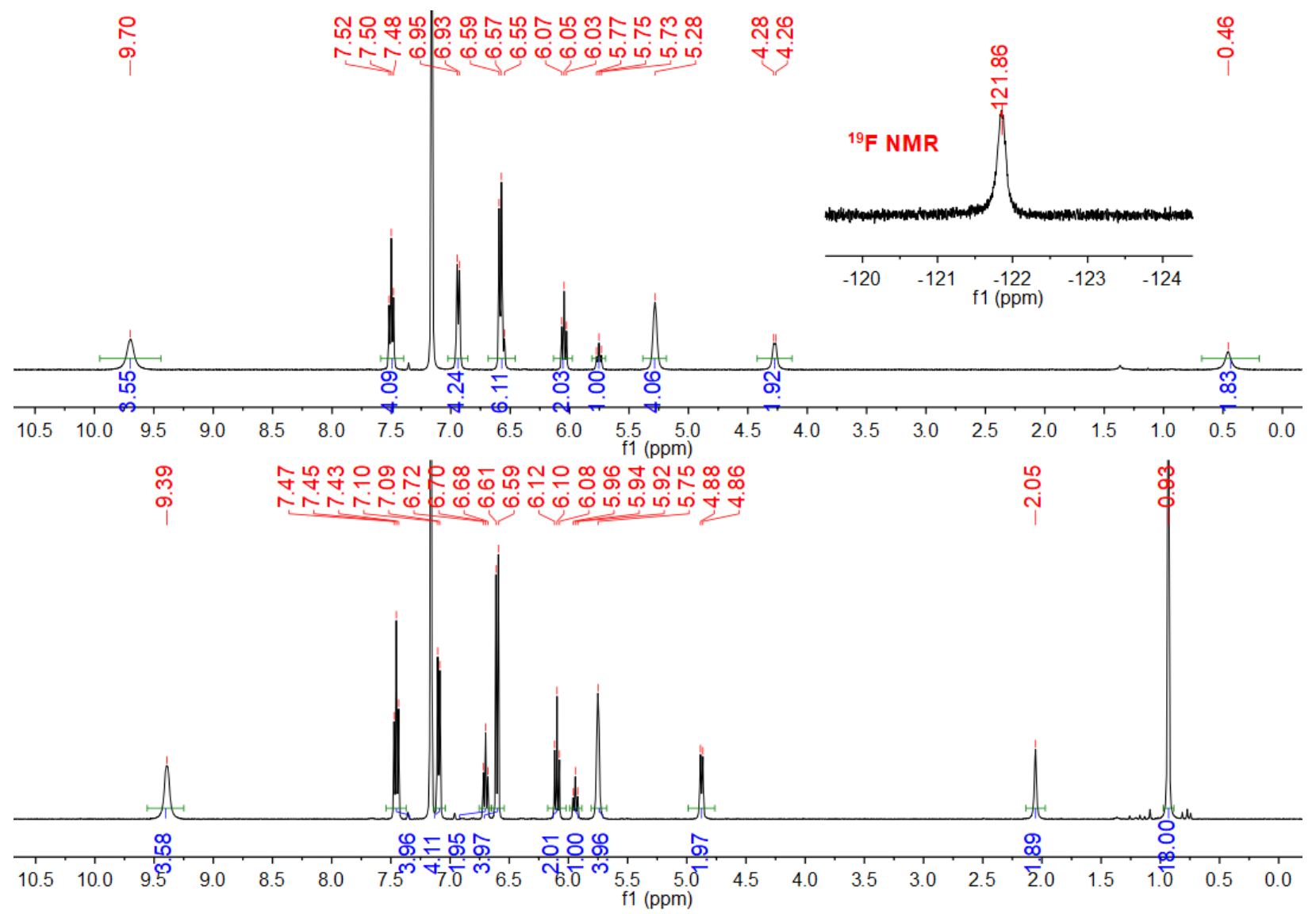

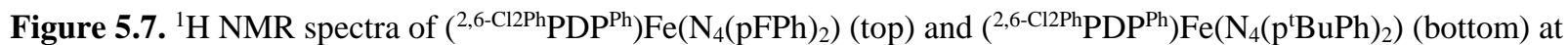
$400 \mathrm{MHz}$ in benzene- $d_{6}$. Top-right: ${ }^{19} \mathrm{~F}$ NMR spectra of $\left({ }^{2,6-\mathrm{Cl} 2 \mathrm{Ph}} \mathrm{PDP}{ }^{\mathrm{Ph}}\right) \mathrm{Fe}\left(\mathrm{N}_{4}(\mathrm{pFPh})_{2}\right)$ at $376 \mathrm{MHz}$ in benzene- $d_{6}$.
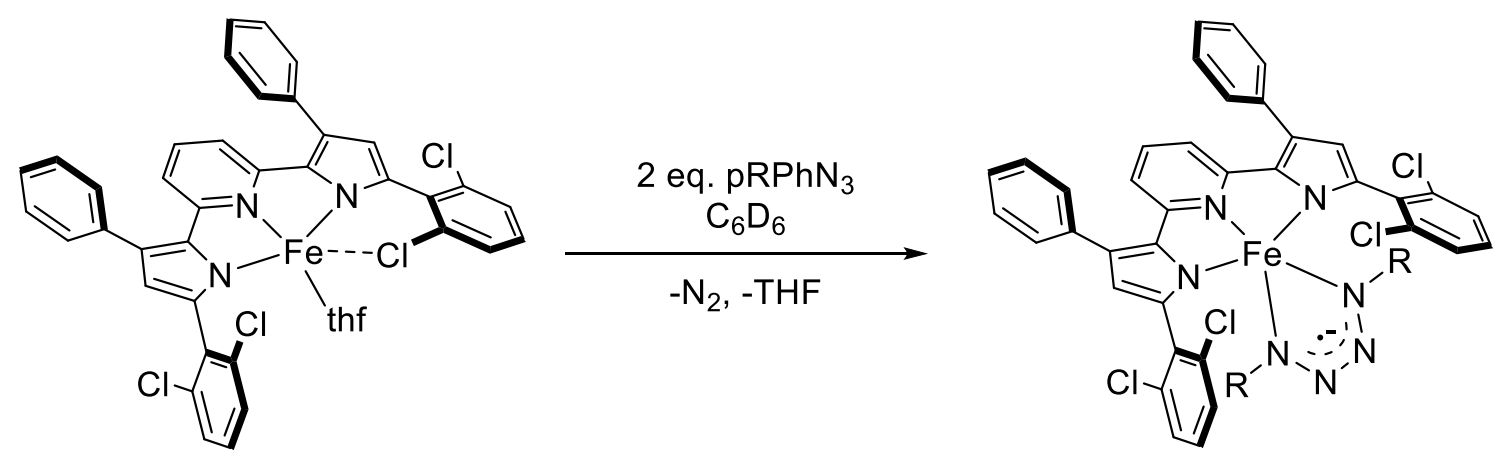

Scheme 5.2. Synthesis of $\left({ }^{2,6-\mathrm{Cl} 2 \mathrm{Ph}} \mathrm{PDP} \mathrm{Ph}^{\mathrm{Ph}}\right) \mathrm{Fe}\left(\mathrm{N}_{4}(\mathrm{pRPh})\right)_{2}$ complexes. $\mathrm{R}$ denotes fluoro or tert-butyl. 
Table 5.3. Selected bond lengths $(\AA)$ and angles $(\mathrm{deg})$ for $\left({ }^{\mathrm{Mes}} \mathrm{PDP}^{\mathrm{Ph}}\right) \mathrm{Fe}\left(\mathrm{N}_{4} \mathrm{Tol}_{2}\right)$ and $\left({ }^{2,6-\mathrm{Cl} 2 \mathrm{Ph} P D P}{ }^{\mathrm{Ph}}\right) \mathrm{Fe}\left(\mathrm{N}_{4}(\mathrm{pFPh})_{2}\right)$.

\begin{tabular}{ccc}
\hline & $\left({ }^{\mathrm{Mes} P D P h}\right) \mathrm{Fe}\left(\mathrm{N}_{4} \mathrm{Tol}_{2}\right)$ & $\left(2,6-\mathrm{Cl} 2 \mathrm{Ph} \mathrm{PDPh}^{\mathrm{Ph}}\right) \mathrm{Fe}\left(\mathrm{N}_{4}(\mathrm{pFPh})_{2}\right)$ \\
\hline $\mathrm{Fe}(1)-\mathrm{N}(1)$ & $1.946(3)$ & $1.938(3)$ \\
$\mathrm{Fe}(1)-\mathrm{N}(2)$ & $1.943(3)$ & $1.936(3)$ \\
$\mathrm{Fe}(1)-\mathrm{N}(3)$ & $1.955(3)$ & $1.950(3)$ \\
$\mathrm{Fe}(1)-\mathrm{N}(4)$ & $1.867(3)$ & $1.875(3)$ \\
$\mathrm{Fe}(1)-\mathrm{N}(7)$ & $1.803(3)$ & $1.795(3)$ \\
$\mathrm{N}(4)-\mathrm{N}(5)$ & $1.299(4)$ & $1.317(4)$ \\
$\mathrm{N}(5)-\mathrm{N}(6)$ & $1.336(4)$ & $1.328(4)$ \\
$\mathrm{N}(6)-\mathrm{N}(7)$ & $1.318(4)$ & $80.45(12)$ \\
$\mathrm{N}(1)-\mathrm{Fe}(1)-\mathrm{N}(2)$ & $79.87(11)$ & $152.95(12)$ \\
$\mathrm{N}(1)-\mathrm{Fe}(1)-\mathrm{N}(3)$ & $153.02(11)$ & $79.01(13)$ \\
$\mathrm{N}(2)-\mathrm{Fe}(1)-\mathrm{N}(3)$ & $79.80(11)$ & $176.88(13)$ \\
$\mathrm{N}(2)-\mathrm{Fe}(1)-\mathrm{N}(4)$ & $174.94(12)$ & $92.88(13)$ \\
$\mathrm{N}(2)-\mathrm{Fe}(1)-\mathrm{N}(7)$ & $96.34(12)$ & $78.75(12)$ \\
$\mathrm{N}(4)-\mathrm{Fe}(1)-\mathrm{N}(7)$ & $712)$ \\
\hline
\end{tabular}

In order to further support the electronic structure assignment of (2,6-Cl2Ph $\left.\mathrm{PDP}{ }^{\mathrm{Ph}}\right) \mathrm{Fe}\left(\mathrm{N}_{4}(\mathrm{pFPh})_{2}\right)$ made based upon ${ }^{1} \mathrm{H}$ NMR and X-ray crystallographic analysis, a full molecule DFT computational study was performed at the B3LYP level of theory using $\left({ }^{2,6-\mathrm{Cl} 2 \mathrm{Ph}} \mathrm{PDP}^{\mathrm{Ph}}\right) \mathrm{Fe}\left(\mathrm{N}_{4}(\mathrm{pFPh})_{2}\right)$ as a representative example. $\mathrm{BS}(1,1), \mathrm{BS}(2,2)$, and $\mathrm{RKS}$ approaches were employed, covering a gamut of potential electronic structures for the system. The BS(1,1) solution converged to the corresponding broken-symmetry solution, representing a low-spin $\mathrm{Fe}^{\mathrm{III}}$ center antiferromagnetically coupled to a tetrazene radical monoanion. The resulting optimized structure is in good agreement with the structural metrics obtained 
experimentally from X-ray crystallography. A high spatial overlap value of $S=0.67$ was computed, suggesting a highly covalent interaction between the metal and ligand fragments. Mössbauer parameters were computed from the optimized structure and were found to be in excellent agreement with the experimentally obtained values, $\delta=0.18 \mathrm{mms}^{-1}$ and $\Delta \mathrm{E}_{\mathrm{Q}}=-3.03$ $\mathrm{mms}^{-1}$. Analysis of the Mulliken population analysis obtained from the calculation obviated the presence of approximately one iron-centered spin as well as significant spin density of the opposite sign delocalized throughout the nitrogen atoms and aromatic system of one phenyl group of the tetrazene ligand, as demonstrated by the spin density plot depicted in Figure 5.7. The BS(2,2) computation converged spontaneously to the BS(1,1). Furthermore, the RKS calculation, accounting for either a low-spin $\mathrm{Fe}^{\mathrm{II}}$ center ligated by a neutral, fully oxidized tetrazene ligand, or low-spin $\mathrm{Fe}^{\mathrm{IV}}$ ion ligated by a dianionic tetrazene, was found to be only 1.9 $\mathrm{kcal} \mathrm{mol}^{-1}$ higher in energy than the $\mathrm{BS}(1,1)$ solution. The small energetic favorability observed by symmetry breaking in this context is identical to that observed in $\left({ }^{\mathrm{Mes}} \mathrm{PDP}{ }^{\mathrm{Ph}}\right) \mathrm{Fe}\left(\mathrm{N}_{4} \mathrm{pTol} 2\right)$, also displaying a calculated energy difference of $1.9 \mathrm{kcal} \mathrm{mol}^{-1}$ between the BS(1,1) and RKSoptimized structures. ${ }^{5}$ The computed Mössbauer parameters for the RKS calculation were found to have an identical isomer shift to the $\mathrm{BS}(3,1)$ computed structure, $\delta=0.18 \mathrm{mms}^{-1}$, while the calculated quadrupole splitting $\Delta \mathrm{E}_{\mathrm{Q}}=-2.73 \mathrm{mms}^{-1}$ for the RKS solution is slightly deviated from the experimentally observed value of $|2.97| \mathrm{mms}^{-1}$. Table 5.4 summarizes the experimental and calculated Mössbauer data for $\left(^{2,6-\mathrm{Cl} 2 \mathrm{Ph}} \mathrm{PDP}{ }^{\mathrm{Ph}}\right) \mathrm{Fe}\left(\mathrm{N}_{4}(\mathrm{pFPh})_{2}\right)$. Consistent with $\left({ }^{\mathrm{Mes}} \mathrm{PDP}^{\mathrm{Ph}}\right) \mathrm{Fe}\left(\mathrm{N}_{4} \mathrm{pTol}_{2}\right)$, a definitive assessment of the electronic structure of $\left.{ }^{2,6-\mathrm{Cl} 2 \mathrm{Ph}} \mathrm{PDP}^{\mathrm{Ph}}\right) \mathrm{Fe}\left(\mathrm{N}_{4}(\mathrm{pFPh})_{2}\right)$ cannot be made on the basis of computations alone, and the highresolution crystal structure coupled with the diamagnetism observed via NMR are the most telling pieces of information and are consistent with the assignment of a low-spin ferric ion 
ligated by a radical monoanionic tetrazene ligand in the ${ }^{2,6-\mathrm{Cl} 2 \mathrm{Ph}} \mathrm{PDP}^{\mathrm{Ph}} \mathrm{Fe}\left(\mathrm{N}_{4}(\mathrm{pRPh})_{2}\right)$ complexes presented here.

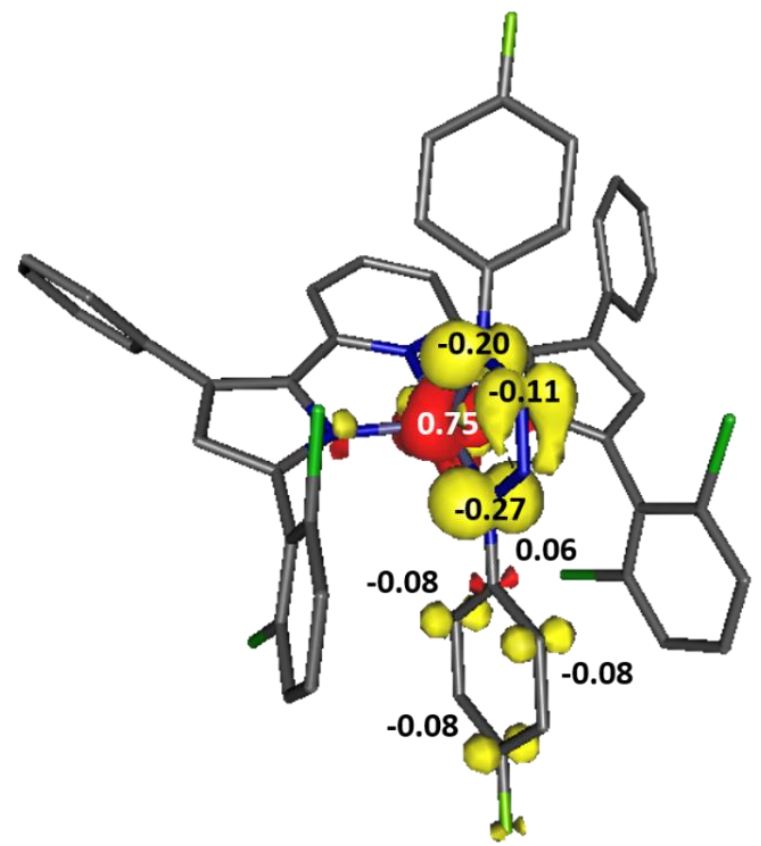

Figure 5.8. Spin density plot obtained from the Mulliken population analysis of a BS(1,1) calculation of $\left({ }^{2,6-\mathrm{Cl} 2 \mathrm{Ph}} \mathrm{PDP}{ }^{\mathrm{Ph}}\right) \mathrm{Fe}\left(\mathrm{N}_{4}(\mathrm{pFPh})_{2}\right)$.

Table 5.4. Experimental and calculated Mössbauer parameters for $\left({ }^{2,6-\mathrm{Cl} 2 \mathrm{Ph}} \mathrm{PDP}^{\mathrm{Ph}}\right) \mathrm{Fe}\left(\mathrm{N}_{4}(\mathrm{pFPh})_{2}\right)$.

\begin{tabular}{cccc}
\hline & $\delta / \mathrm{mms}^{-1}(\mathrm{calc})$ & $\Delta E_{Q} / \mathrm{mms}^{-1}$ & $\eta^{a}$ \\
\hline Experimental & 0.13 & $|2.97|^{b}$ & $-{ }^{c}$ \\
RKS & 0.18 & -2.73 & 0.683 \\
BS $(1,1)$ & 0.18 & -3.03 & 0.537
\end{tabular}

${ }^{a}$ Asymmetry parameter of the electronic field gradient. ${ }^{b}$ Sign not determined experimentally. ${ }^{c}$ Value not determined experimentally.

\subsection{Reactivity of (2,6-Cl2PhPDP $\left.{ }^{\mathrm{Ph}}\right) \mathrm{Fe}($ thf $)$ with Mesityl and Xylyl Azide}

Having isolated and characterized $\left({ }^{2,6-C 12 P h} \mathrm{PDP}^{\mathrm{Ph}}\right) \mathrm{Fe}\left(\mathrm{N}^{1} \mathrm{Ad}\right)$, it was anticipated that a sterically encumbered aryl nitrene congener may also be isolable. Hence, the bulky aryl azide mesityl azide $\left(\mathrm{MesN}_{3}\right)$ was selected as a suitable first candidate. To a red/orange benzene- $d_{6}$ 
solution of $\left.{ }^{2,6-\mathrm{Cl} 2 \mathrm{Ph}} \mathrm{PDP}^{\mathrm{Ph}}\right) \mathrm{Fe}(\mathrm{thf})$ was added a solution of one molar equivalence of $\mathrm{MesN}_{3}$ in the same solvent, inducing a rapid color change of the solution to dark brown. Analysis of the crude reaction mixture via ${ }^{1} \mathrm{H}$ NMR spectroscopy indicated complete consumption of the high-spin $\mathrm{Fe}^{\mathrm{II}}$ starting material and the appearance of eleven new paramagnetically shifted resonances spanning a chemical shift range of 23.45 to $-224.83 \mathrm{ppm}$. The 11 paramagnetically shifted broad singlet resonances is consistent with a $\mathrm{C}_{2 v}$ symmetric $\left({ }^{2,6-\mathrm{Cl} 2 \mathrm{Ph}} \mathrm{PDP} \mathrm{Ph}^{\mathrm{Ph}}\right)$ ligand environment and mesityl fragment. Integrations of the observed signals relative to the 4-pyridine resonance $(-4.41 \mathrm{ppm})$ were consistent with an initial assignment of the product as either an organoazide adduct, $\left({ }^{2,6-\mathrm{Cl} 2 \mathrm{Ph}} \mathrm{PDP}{ }^{\mathrm{Ph}}\right) \mathrm{Fe}\left(\mathrm{N}_{3} \mathrm{Mes}\right)$ or an iron nitrene $\left({ }^{2,6-\mathrm{Cl} 2 \mathrm{Ph}} \mathrm{PDP}^{\mathrm{Ph}}\right) \mathrm{Fe}(\mathrm{NMes})$. A comparison of the ${ }^{1} \mathrm{H}$ chemical shifts obtained from the NMR spectra of $\left({ }^{\mathrm{Mes}} \mathrm{PDP}{ }^{\mathrm{Ph}}\right) \mathrm{Fe}(\mathrm{NMes})$ and $\left.{ }^{2,6-\mathrm{Cl} 2 \mathrm{Ph}} \mathrm{PDP} \mathrm{Ph}^{\mathrm{Ph}}\right) \mathrm{Fe}(\mathrm{NMes})$ indicate that the two complexes are chemically similar, and prompts a tentative assignment of the product as the iron imide, as opposed to the plausible azide adduct.

In order to probe the generality of the ability to observe 2,6-disubstituted aryl nitrenes, an analogous reaction with 2,6-dimethyphenyl azide (xylyl azide) was performed in benzene- $d_{6}$ solution. Similar to the reaction with mesityl azide, an instantaneous color change of the solution to dark brown was observed. Analysis of a ${ }^{1} \mathrm{H}$ NMR spectrum (Figure 5.9) acquired of the crude reaction mixture demonstrated clean conversion to a new species featuring 11 paramagnetically shifted resonances spanning a range of 171.20 to $-133.78 \mathrm{ppm}$. The ${ }^{1} \mathrm{H}$ NMR spectra is consistent with a $\mathrm{C}_{2 v}$ symmetric complex and prompted an assignment of the product as (2,6-Cl2Ph $\left.\mathrm{PDP} \mathrm{Ph}^{\mathrm{Ph}}\right) \mathrm{Fe}(\mathrm{NXyl})$. Qualitatively, the ${ }^{1} \mathrm{H}$ NMR spectra of $\left({ }^{2,6-\mathrm{ClPh}} \mathrm{PDP}{ }^{\mathrm{Ph}}\right) \mathrm{Fe}(\mathrm{NMes})$ and (2,6-Cl2Ph $\left.\mathrm{PDP}{ }^{\mathrm{Ph}}\right) \mathrm{Fe}(\mathrm{NXyl})$ are very similar with the exception of two resonances. $\left.{ }^{2,6-\mathrm{Cl} 2 \mathrm{Ph}} \mathrm{PDP}{ }^{\mathrm{Ph}}\right) \mathrm{Fe}(\mathrm{NXyl})$ is characterized by one extremely downfield shifted resonance observed at $171.20 \mathrm{ppm}$. This resonance is absent in the ${ }^{1} \mathrm{H}$ NMR spectrum of $\left({ }^{2,6-\mathrm{Cl} 2 \mathrm{Ph}} \mathrm{PDP}^{\mathrm{Ph}}\right) \mathrm{Fe}(\mathrm{NMes})$. 
Integration of this resonance relative to the 4-pyridine resonance $(-5.07 \mathrm{ppm})$ demonstrated a 1:1 ratio, prompting an assignment as the para-phenyl proton of the 2,6-dimethylphenyl group of the nitrene unit. The absence of this resonance is consistent with the para-methyl substitution in the mesityl analogue, which has a corresponding chemical shift of $-224.83 \mathrm{ppm}$, a feature which is absent in spectrum of $\left({ }^{2,6-C l 2 P h} \mathrm{PDP}{ }^{\mathrm{Ph}}\right) \mathrm{Fe}(\mathrm{NXyl})$.
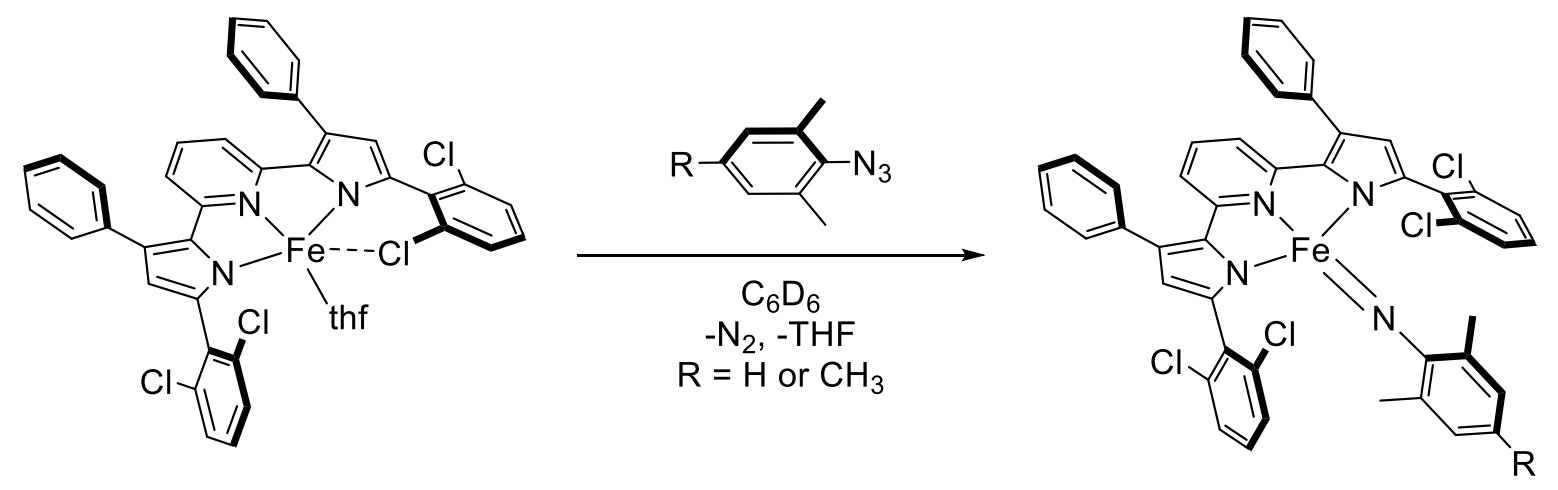

Scheme 5.3. Synthesis of (2,6-ClPh $\left.\mathrm{PDP}^{\mathrm{Ph}}\right) \mathrm{Fe}(\mathrm{NMes})$ and (2,6-Cl2Ph $\left.\mathrm{PDP} \mathrm{Ph}^{\mathrm{Ph}}\right) \mathrm{Fe}(\mathrm{NXyl})$. 


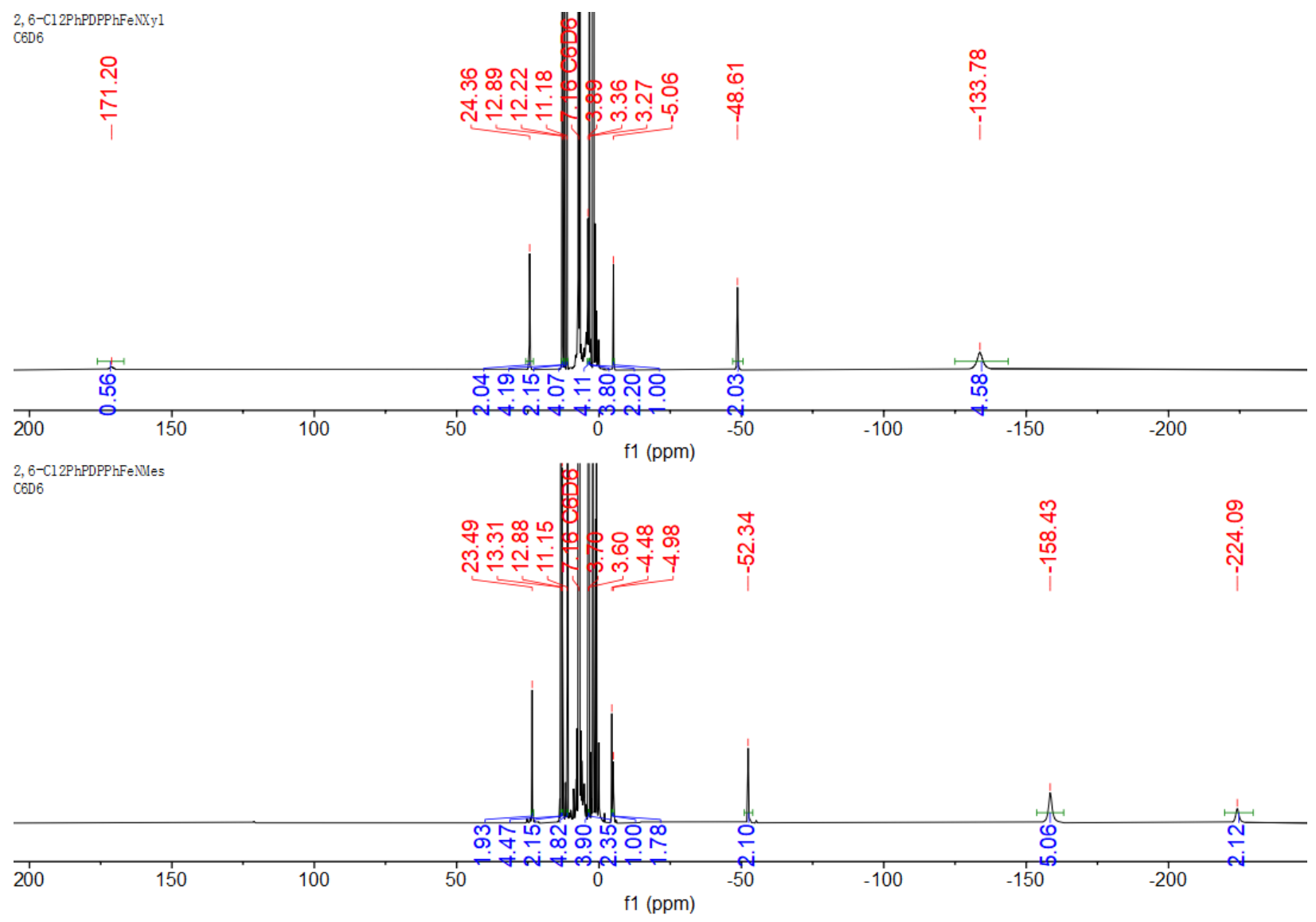

Figure 5.9. ${ }^{1} \mathrm{H}$ NMR spectra of $\left({ }^{2,6-C l P h} \mathrm{PDP}^{\mathrm{Ph}}\right) \mathrm{Fe}(\mathrm{NMes})\left(\right.$ bottom) and $\left({ }^{2,6-\mathrm{Cl} 2 \mathrm{Ph}} \mathrm{PDP}^{\mathrm{Ph}}\right) \mathrm{Fe}(\mathrm{NXyl})$ (top) in benzene- $d_{6}$.

\subsection{Reactivity of $\left(^{2,6-C l 2 P h} P D P^{P h}\right) \mathrm{Fe}($ thf $)$ with 1-(4-Azidobutyl)benzene}

With the observed propensity to form nitrene species via the decomposition of azides in the presence of $\left.{ }^{2,6-\mathrm{Cl} 2 \mathrm{Ph}} \mathrm{PDP}^{\mathrm{Ph}}\right) \mathrm{Fe}(\mathrm{thf})$, attempts were made to determine if productive $\mathrm{C}-\mathrm{H}$ amination could be leveraged in this system (Scheme 5.4). Accordingly, the substrate 1-(4-azidobutyl)benzene was chosen as a model substrate, as it has been demonstrated to undergo intramolecular $\mathrm{C}-\mathrm{H}$ amination at the benzylic position to form the corresponding 2-phenylpyrrolidine product following the generation of reactive nitrenes of iron. ${ }^{6}$ Reactions of this type have been proposed to occur via initial formation of the metal nitrene species followed by hydrogen atom abstraction from the benzylic position of the butylbenzene fragment to form a 
metal amido and a benzylic radical. Radical rebound of the carbon-based radical with the metal amido species gives rise to the phenyl pyrrolidine product.
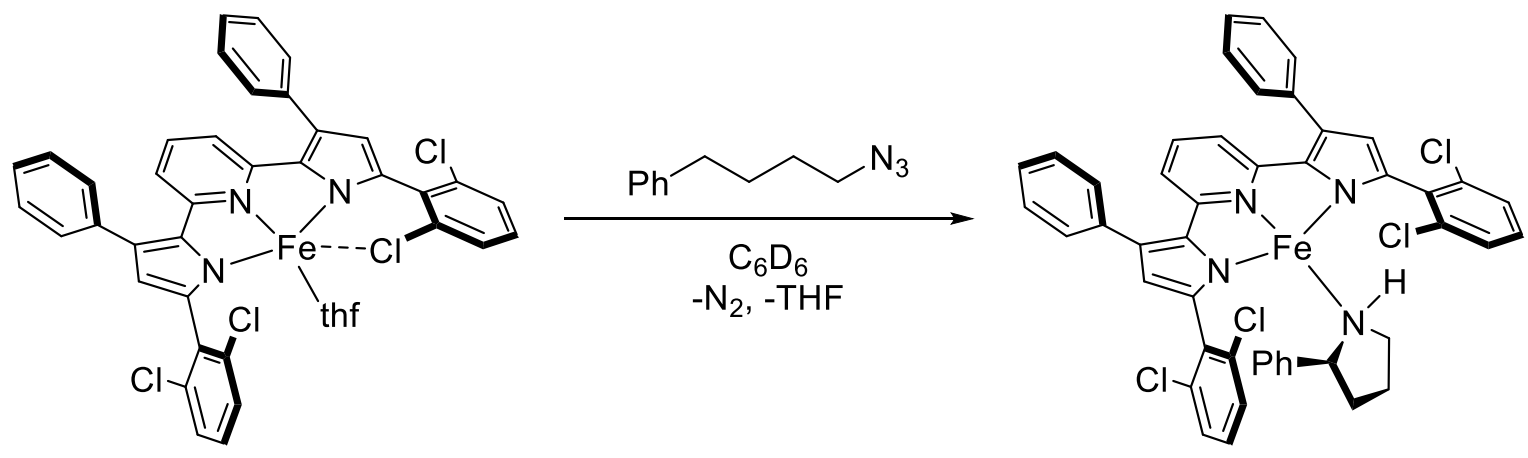

Scheme 5.4. Proposed synthesis of iron-bound 2-phenylpyrrolidine via decomposition of 1-(4-azidobutyl)benzene in the presence of $\left.{ }^{2,6-\mathrm{Cl} 2 \mathrm{Ph}} \mathrm{PDP}^{\mathrm{Ph}}\right) \mathrm{Fe}(\mathrm{thf})$.

Treatment of a benzene- $d_{6}$ solution of $\left({ }^{2,6-\mathrm{Cl} 2 \mathrm{Ph}} \mathrm{PDP}^{\mathrm{Ph}}\right) \mathrm{Fe}(\mathrm{thf})$ with a solution of one equivalent of 1-(4-azidobutyl)benzene in the same solvent yielded no discernable color change. Analysis of the crude reaction mixture via ${ }^{1} \mathrm{H}$ NMR spectroscopy indicated the generation of a new diamagnetic species as well as unreacted starting material. The new diamagnetic product was characterized via a distinct downfield doublet resonance at $9.62 \mathrm{ppm}$ with ${ }^{3} J_{\mathrm{H}-\mathrm{H}}$ of $21.6 \mathrm{~Hz}$, suggesting the incorporation of an imine functionality into the product. The experiment was repeated using three molar equivalents of the azide reagent, and full consumption of the starting materials was evidenced by ${ }^{1} \mathrm{H}$ NMR analysis. The volatiles were removed in vacuo, and crystallization of the crude product was accomplished by diffusion of pentane into a concentrated benzene solution of the new iron complex. Abundant crystallization of red plates suitable for analysis by X-ray crystallography were generated from this method. The structural analysis revealed the identity of the crystal as $\left({ }^{2,6-\mathrm{Cl} 2 \mathrm{Ph}} \mathrm{PDP}^{\mathrm{Ph}}\right) \mathrm{Fe}\left(\mathrm{N}_{4}(\mathrm{nBuPh})_{2}\right)\left(\mathrm{HN}=\mathrm{CH}\left(\mathrm{CH}_{2}\right)_{3} \mathrm{Ph}\right)$ carrying both tetrazene and imine ligands sourced from the azide starting material (Figure 5.10). This 
compound is an analogue of the low-spin $\mathrm{Fe}^{\mathrm{II}}$ species $\left({ }^{\mathrm{Mes}} \mathrm{PDP}^{\mathrm{Ph}}\right) \mathrm{Fe}\left(\mathrm{N}_{4} \mathrm{Bn}_{2}\right)(\mathrm{HN}=\mathrm{CHPh})$

presented in Chapter 3, which was obtained as one of the products in the reaction of

$\left({ }^{\mathrm{Mes}} \mathrm{PDP} \mathrm{Ph}^{\mathrm{Ph}}\right) \mathrm{Fe}(\mathrm{thf})$ with benzyl azide. The identity of the second product was determined to be the high-spin $\mathrm{Fe}^{\mathrm{II}}$ species $\mathrm{Fe}\left(\{\mathrm{NHBn}\}_{2^{-}}{ }^{\mathrm{Mes}} \mathrm{PDP}^{\mathrm{Ph}}\right)$, which arises from two consecutive C-H amination events of the MesPDP ${ }^{\mathrm{Ph}}$ ligand. ${ }^{5}$ Presumably, the lack of benzylic $\mathrm{C}-\mathrm{H}$ bonds on the PDP ligand in close proximity to an intermediate nitrene renders the formation of the tetrazene and imine-ligated product as the sole reaction outcome. At this time, the mechanistic pathway that accounts for the formation of this unusual compound is not entirely clear. However, the observation of a tetrazene ligand suggests that the initially generated iron nitrene intermediate undergoes a rapid $[2+3]$ cycloaddition to form the corresponding tetrazene. Subsequent capture and formation of another nitrene intermediate followed by hydrogen atom abstraction would account for the observed product (Scheme 5.5).

In regard to the details of the structural analysis of $\left({ }^{2,6-\mathrm{Cl} 2 \mathrm{Ph}} \mathrm{PDP}{ }^{\mathrm{Ph}}\right) \mathrm{Fe}\left(\mathrm{N}_{4}(\mathrm{nBuPh})_{2}\right)$ $\left(\mathrm{HN}=\mathrm{CH}\left(\mathrm{CH}_{2}\right)_{3} \mathrm{Ph}\right)$, the complex was found to crystallize in the triclinic space group $\mathrm{P}-1$. The iron-nitrogen bond distances of 1.9794(14) $\AA$ and 1.9941(14) $\AA$ to N1 and N3 (pyrrolide nitrogens), 1.9503(14) $\AA$ to N3 (pyridine nitrogen), 1.8526(14) $\AA$ and 1.8502(15) $\mathrm{A}$ to N4 and N7 (tetrazene nitrogens), and 2.0016(16) A to N8 (imine nitrogen) are in agreement with the low-spin state inferred from the diamagnetism of the compound observed via ${ }^{1} \mathrm{H}$ NMR. Analysis of the nitrogen-nitrogen bonds comprising the tetrazene ligand revealed distances of 1.299(2) $\AA$ for N4-N5, 1.351(2) $\AA$ for N5-N6, and 1.294(2) A for N6-N7, consistent with a fully oxidized neutral tetrazene ligand. ${ }^{10}$ The short $\mathrm{N}(8)-\mathrm{C}(58)$ distance of $1.272(2)$ confirms the presence of a double bond in the imine fragment and the imine hydrogen atom was successfully identified in 
the electron difference map. Additionally, analysis of the bond angles about the imine nitrogen and carbon are consistent with $\mathrm{sp}^{2}$ hybridization. In totality, the structural metrics for $\left({ }^{2,6-\mathrm{Cl} 2 \mathrm{Ph}} \mathrm{PDP}^{\mathrm{Ph}}\right) \mathrm{Fe}\left(\mathrm{N}_{4}(\mathrm{nBuPh})_{2}\right)\left(\mathrm{HN}=\mathrm{CH}\left(\mathrm{CH}_{2}\right)_{3} \mathrm{Ph}\right)$ are very similar to those of $\left({ }^{\mathrm{Mes}} \mathrm{PDP}{ }^{\mathrm{Ph}}\right) \mathrm{Fe}-$

$\left(\mathrm{N}_{4} \mathrm{Bn}_{2}\right)(\mathrm{HN}=\mathrm{CHPh})$. Pertinent bond lengths and angles for the two complexes are presented in Table 5.5 for direct comparison.

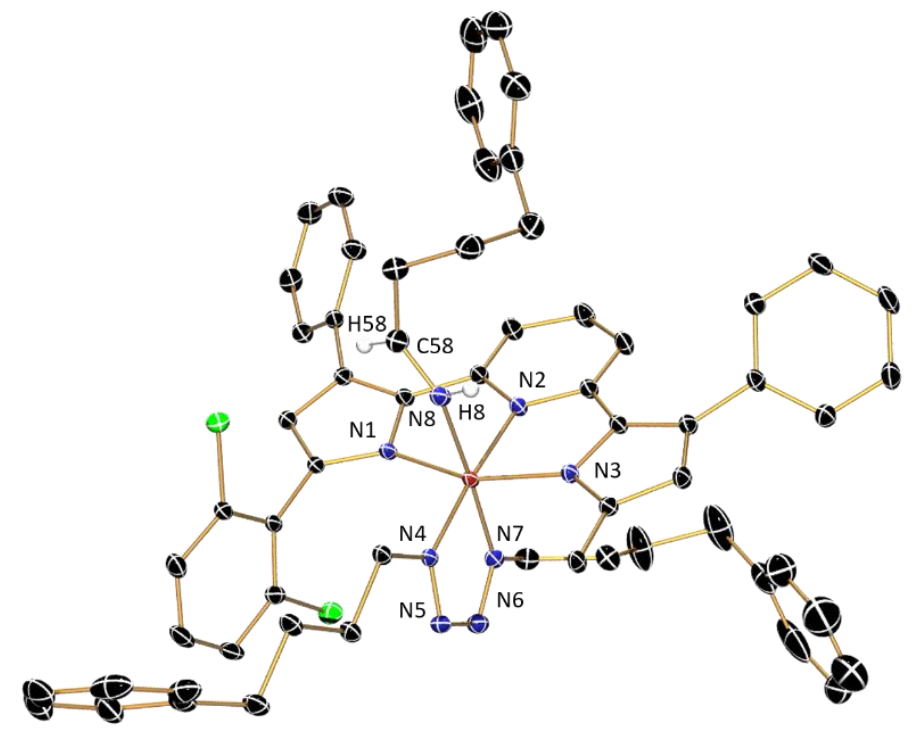

Figure 5.10. ORTEP of $\left({ }^{2,6-\mathrm{Cl} 2 \mathrm{Ph}} \mathrm{PDP}^{\mathrm{Ph}}\right) \mathrm{Fe}\left(\mathrm{N}_{4}(\mathrm{nBuPh})_{2}\right)\left(\mathrm{HN}=\mathrm{CH}\left(\mathrm{CH}_{2}\right)_{3} \mathrm{Ph}\right)$ depicted at $30 \%$ probability ellipsoids. Hydrogen atoms (with the exception of imine $\mathrm{NH}$ and $\mathrm{CH}$ ) and a pyrrole 2,6-dichlorophenyl substituent (with exception of the ipso carbon) have been excluded for clarity. 

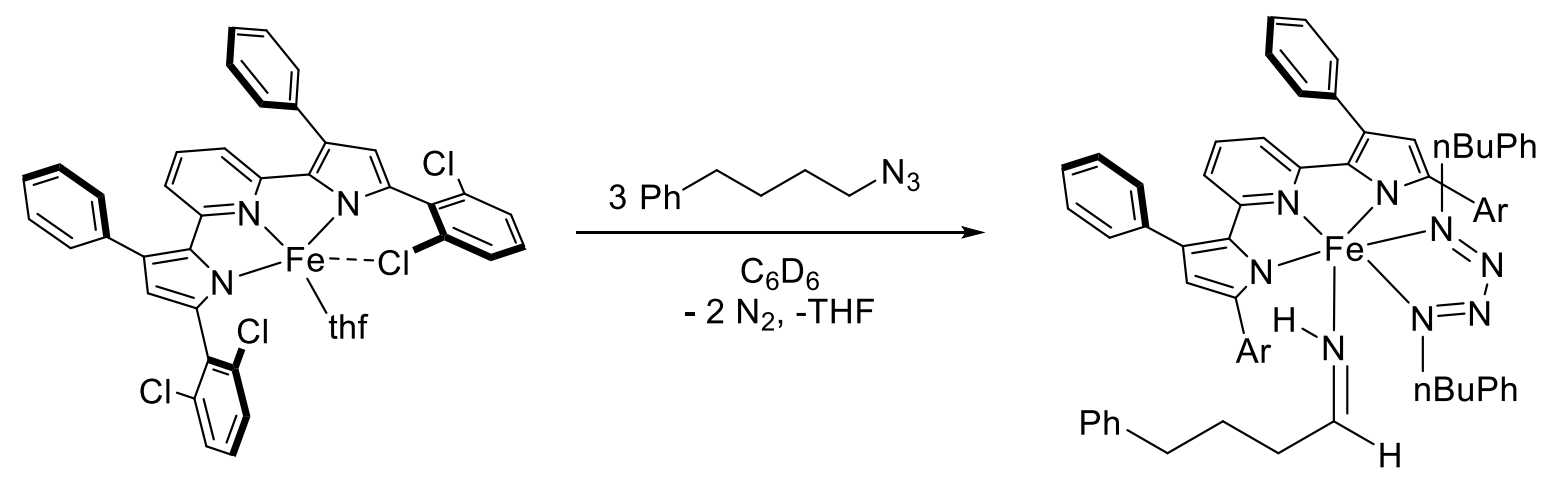

Scheme 5.5. Synthesis of $\left({ }^{2,6-\mathrm{Cl} 2 \mathrm{Ph}} \mathrm{PDP}^{\mathrm{Ph}}\right) \mathrm{Fe}\left(\mathrm{N}_{4}(\mathrm{nBuPh})_{2}\right)\left(\mathrm{HN}=\mathrm{CH}\left(\mathrm{CH}_{2}\right)_{3} \mathrm{Ph}\right)$.

Table 5.5. Selected bond lengths $(\AA)$ and angles $(\mathrm{deg})$ for $\left({ }^{\mathrm{Mes}} \mathrm{PDP}^{\mathrm{Ph}}\right) \mathrm{Fe}\left(\mathrm{N}_{4} \mathrm{Bn}_{2}\right)(\mathrm{HN}=\mathrm{CHPh})$ and $\left({ }^{2,6-\mathrm{Cl} 2 \mathrm{Ph}} \mathrm{PDP}^{\mathrm{Ph}}\right) \mathrm{Fe}\left(\mathrm{N}_{4}(\mathrm{nBuPh})_{2}\right)\left(\mathrm{HN}=\mathrm{CH}\left(\mathrm{CH}_{2}\right)_{3} \mathrm{Ph}\right)$.

\begin{tabular}{|c|c|c|}
\hline & $\begin{array}{c}\left({ }^{\text {Mes }} \mathrm{PDP}^{\mathrm{Ph}}\right) \mathrm{Fe}\left(\mathrm{N}_{4} \mathrm{Bn}_{2}\right)- \\
(\mathrm{HN}=\mathrm{CHPh})\end{array}$ & $\begin{array}{c}\left({ }^{2,6-\mathrm{Cl} 2 \mathrm{Ph}} \mathrm{PDP}^{\mathrm{Ph}}\right) \mathrm{Fe}- \\
\left(\mathrm{N}_{4}(\mathrm{nBuPh})_{2}\right)\left(\mathrm{HN}=\mathrm{CH}\left(\mathrm{CH}_{2}\right)_{3} \mathrm{Ph}\right)\end{array}$ \\
\hline $\mathrm{Fe}(1)-\mathrm{N}(1)$ & $1.996(1)$ & $1.9794(14)$ \\
\hline $\mathrm{Fe}(1)-\mathrm{N}(2)$ & $1.938(1)$ & $1.9503(14)$ \\
\hline $\mathrm{Fe}(1)-\mathrm{N}(3)$ & $1.995(1)$ & $1.9941(14)$ \\
\hline $\mathrm{Fe}(1)-\mathrm{N}(4)$ & $1.848(1)$ & $1.8526(14)$ \\
\hline $\mathrm{Fe}(1)-\mathrm{N}(7)$ & $1.855(1)$ & $1.8502(15)$ \\
\hline $\mathrm{Fe}(1)-\mathrm{N}(8)$ & $1.983(1)$ & $2.0016(16)$ \\
\hline $\mathrm{N}(4)-\mathrm{N}(5)$ & $1.3030(2)$ & $1.299(2)$ \\
\hline $\mathrm{N}(5)-\mathrm{N}(6)$ & $1.350(2)$ & $1.351(2)$ \\
\hline $\mathrm{N}(6)-\mathrm{N}(7)$ & $1.302(2)$ & $1.294(2)$ \\
\hline $\mathrm{N}(8)-\mathrm{C}(58)$ & $1.271(2)$ & $1.272(2)$ \\
\hline $\mathrm{N}(1)-\mathrm{Fe}(1)-\mathrm{N}(2)$ & $80.85(6)$ & $80.20(6)$ \\
\hline $\mathrm{N}(1)-\mathrm{Fe}(1)-\mathrm{N}(3)$ & $160.11(6)$ & $159.05(6)$ \\
\hline $\mathrm{N}(2)-\mathrm{Fe}(1)-\mathrm{N}(3)$ & $79.88(5)$ & $79.61(6)$ \\
\hline $\mathrm{N}(2)-\mathrm{Fe}(1)-\mathrm{N}(7)$ & $174.00(6)$ & $174.25(6)$ \\
\hline $\mathrm{N}(4)-\mathrm{Fe}(1)-\mathrm{N}(8)$ & $172.46(6)$ & $175.80(6)$ \\
\hline
\end{tabular}


The observation of iron tetrazene and imine formation in the product $\left({ }^{2,6-\mathrm{Cl} 2 \mathrm{Ph}} \mathrm{PDP}^{\mathrm{Ph}}\right) \mathrm{Fe}\left(\mathrm{N}_{4}(\mathrm{nBuPh})_{2}\right)\left(\mathrm{HN}=\mathrm{CH}\left(\mathrm{CH}_{2}\right)_{3} \mathrm{Ph}\right)$ is another example of the highly reactive nature of the nitrenoid intermediates formed within the context of the PDP Fe system.

Furthermore, the observation of the aldimine ligand formation demonstrates that an intermediate iron nitrene is competent for a $\mathrm{C}$-H functionalization reaction in the context of the new 2,6dichlorophenyl-substituted PDP supporting ligand. This result hints that the elimination of C-H bonds alpha to an intermediate iron nitrene fragment may allow for the systematic leveraging of a C-H functionalization reaction to occur in a controlled fashion. Studies involving the evaluation of $\alpha$-geminal dimethyl-substituted alkyl azides ${ }^{11}$ in reactions with $\left.{ }^{2,6-\mathrm{Cl} 2 \mathrm{Ph}} \mathrm{PDP}^{\mathrm{Ph}}\right) \mathrm{Fe}(\mathrm{thf})$ are currently underway in our laboratory (See Chapter 7 for future outlooks).

\subsection{Calculations of Isolated Iron Imides and Iminyl Radical Complexes}

In Chapter 3, computational evidence was presented that suggested the intermediacy of paramagnetic $\left({ }^{\mathrm{Mes}} \mathrm{PDP} \mathrm{Ph}^{\mathrm{Ph}}\right) \mathrm{Fe}(\mathrm{NR})$ complexes as potential intermediates in $\mathrm{C}-\mathrm{H}$ amination, tetrazene formation, and $\alpha$-hydrogen atom abstraction. The observation of paramagnetic complexes $\left({ }^{\mathrm{Ar} P D P}{ }^{\mathrm{Ph}}\right) \mathrm{Fe}(\mathrm{NR})$ (where $\mathrm{Ar}=2,6-\mathrm{Cl}_{2} \mathrm{Ph}$ or mesityl and $\mathrm{R}=$ Mesityl or Xylyl) by ${ }^{1} \mathrm{H}$ NMR spectroscopy has further solidified this claim. However, $\left({ }^{2,6-\mathrm{Cl} 2 \mathrm{Ph}} \mathrm{PDP} \mathrm{Ph}^{\mathrm{Ph}}\right) \mathrm{Fe}\left(\mathrm{N}^{1} \mathrm{Ad}\right)$ is apparently diamagnetic which is inconsistent with the paramagnetic description ascribed to the unobserved intermediate $\left({ }^{\mathrm{Mes}} \mathrm{PDP} \mathrm{P}^{\mathrm{Ph}}\right) \mathrm{Fe}\left(\mathrm{N}^{1} \mathrm{Ad}\right)$ probed computationally. Furthermore, the unusual ${ }^{1} \mathrm{H}$ NMR chemical shifts of $\left({ }^{2,6-\mathrm{Cl} 2 \mathrm{Ph}} \mathrm{PDP} \mathrm{Ph}^{\mathrm{Ph}}\right) \mathrm{Fe}\left(\mathrm{N}^{1} \mathrm{Ad}\right)$ suggested that low-lying paramagnetic excited states may be available to this complex. With these details in mind, a full molecule computational analysis of $\left({ }^{2,6-\mathrm{Cl} 2 \mathrm{Ph}} \mathrm{PDP}^{\mathrm{Ph}}\right) \mathrm{Fe}\left(\mathrm{N}^{1} \mathrm{Ad}\right)$ was undertaken to better understand what potential paramagnetic electronic structures may be available to this complex and determine their 
proximity in energy to the apparently diamagnetic ground state. With this in mind, RKS and $\mathrm{BS}(1,1)$ calculations were chosen to scan the singlet surface, UKS3 and BS(3,1) calculations on the triplet surface, and UKS5 and BS $(5,1)$ computations were performed on the pentet energy surface. For consistency, the same computational methods employed in the study presented in Chapter 3 were utilized in this work (ORCA 3.02/B3LYP functional).

The RKS calculation converged to an optimized solution in excellent agreement with the experimental structure obtained via X-ray crystallography. Notably the iron-imide bond length, Fe-N4, was calculated to be $1.598 \AA$, similar to the experimentally obtained value of $1.620(4) \AA$. Furthermore, the N2-Fe1-N4 bond angle, spanning the pyridine nitrogen, iron, and imide nitrogen, was accurately reproduced via DFT with a value of $120.42^{\circ}$, vs. an experimental value of $123.12(19)^{\circ}$, consistent with a cis-divacant octahedral geometry. The BS(1,1) calculation was found to converge on a $\mathrm{BS}(2,2)$ solution with $\mathrm{S}_{\mathrm{Fe}}=1$ and $\mathrm{S}_{\mathrm{L}}=1$ (of the opposite sign convention) for the imide fragment. The spin-density map illustrating this is presented in Figure 5.11. Analysis of the Fe- $\mathrm{N}_{\text {imide }}$ bond length revealed a distance of $1.920 \AA$, significantly deviated from the experimental value of $1.620(4) \AA$. The geometry of this structure trends away from cisdivacant octahedral and is best described as bent, as evidenced by a N2-Fe1-N4 bond angle of $141.37^{\circ}$. Despite the significant geometric discrepancies present between the RKS and BS(2,2) optimized structures, these solutions are only separated by only a mere $0.5 \mathrm{kcal} \mathrm{mol}^{-1}$. The UKS3 calculation spanning the triplet energy surface spontaneously converged to a $\mathrm{BS}(3,1)$ solution, which was found to be approximately $1.7 \mathrm{kcal} \mathrm{mol}^{-1}$ lower in energy than the RKS solution. The prevalence for this electronic structure seems to be pervasive in the PDP system when planarity is allowed for the nitrene fragment, as $\mathrm{BS}(3,1)$ solutions have also been observed to be energetically favored for the optimized triplet structures of all $\left({ }^{\mathrm{Mes}} \mathrm{PDP} \mathrm{Ph}^{\mathrm{Ph}}\right) \mathrm{Fe}(\mathrm{NR})$ fragments that 
have been analyzed computationally. Similarly, the BS(3,1) electronic structure in this context can be described as an intermediate spin ferric ion $\left(\mathrm{S}_{\mathrm{Fe}}=3 / 2\right)$ engaged in antiferromagnetic coupling with an iminyl based radical ligand, accounting for an overall $S=1$ state. A high spatial overlap value of 0.66 was computed for the non-orthogonal magnetic orbitals. Analysis of the structural metrics demonstrates that the iron-iminyl fragment adopts a bent structure, consistent with the aforementioned analogues of the ${ }^{\mathrm{Mes}} \mathrm{PDP}^{\mathrm{Ph}}$ ligand. The N2-Fe1-N4 angle of 138.20 deviates from the experimentally observed angle of $123.12(19)^{\circ}$, while the iron-imide/iminyl bond distance is significantly elongated from 1.620(4) $\AA$ in the X-ray structure to $1.709 \AA$. The $\mathrm{N}_{\mathrm{im}-\mathrm{C}} \mathrm{C}_{\mathrm{im}}$ bond length is reduced from 1.440(6) $\AA$ to $1.412 \AA$ in the optimized BS $(3,1)$ structure, indicating a trend towards a double bond and iminyl character. Mulliken population analysis confirmed the presence of approximately three spins located on the iron center, with significant radical character of the opposite sign present on the imide fragment, as depicted by the spin density plot in Figure 5.11.

UKS5 and BS(5,1) calculations also converged on the same solution, which was found to be the to be the lowest in energy and slightly favored over the $\mathrm{BS}(3,1)$ solution by $0.9 \mathrm{kcal} \mathrm{mol}^{-1}$. This is in contrast to the computational study of $\left({ }^{\mathrm{Mes}} \mathrm{PDP}^{\mathrm{Ph}}\right) \mathrm{Fe}\left(\mathrm{N}^{1} \mathrm{Ad}\right)$ and nitrene analogues, where $\mathrm{BS}(3,1)$ solutions were consistently identified to be the lowest energy solutions, albeit, modestly favored over other electronic structures. Despite this difference, all optimized geometries of $\left.{ }^{2,6-\mathrm{Cl} 2 \mathrm{Ph}} \mathrm{PDP}^{\mathrm{Ph}}\right) \mathrm{Fe}\left(\mathrm{N}^{1} \mathrm{Ad}\right)$ are computed to exist within $3.1 \mathrm{kcal} \mathrm{mol}^{-1}$ of one another. This result again underscores that it would be impossible to definitively identify the ground state of $\left({ }^{2,6-\mathrm{Cl} 2 \mathrm{Ph}} \mathrm{PDP}{ }^{\mathrm{Ph}}\right) \mathrm{Fe}\left(\mathrm{N}^{1} \mathrm{Ad}\right)$ solely via computational methods. ${ }^{12}$ The UKS5 solution is found to possess three iron centered spins $\left(\mathrm{S}_{\mathrm{Fe}}=3 / 2\right)$ and one imide centered $\operatorname{spin}\left(\mathrm{S}_{\mathrm{L}}=1 / 2\right)$ of the same sign (Figure 5.11). Formally, such as solution could be described as an intermediate 
spin $\mathrm{Fe}^{\mathrm{III}}$ ion $\left(\mathrm{S}_{\mathrm{Fe}}=3 / 2\right)$ engaged in ferromagnetic coupling with a monoanionic iminyl radical ligand $\left(S_{\mathrm{L}}=1 / 2\right)$ to account and overall $\mathrm{S}=2$ state. The Fe- $\mathrm{N}_{\mathrm{im}}$ bond length of $1.781 \AA$ is significantly elongated and relative to the experimentally determined value of $1.620(4) \AA$. A summary of the metrics obtained from this computational study is presented in Table 5.6.

Table 5.6. Calculated energies and selected structural parameters for different electronic structures of $\left.{ }^{2,6-\mathrm{Cl} P \mathrm{Ph}} \mathrm{PDP}{ }^{\mathrm{Ph}}\right) \mathrm{Fe}\left(\mathrm{N}^{1} \mathrm{Ad}\right)$ obtained from DFT calculations.

\begin{tabular}{|c|c|c|c|c|}
\hline & $\Delta$ Energy / $\mathrm{kcal} \mathrm{mol}^{-1}$ & $N_{p y}-\mathrm{Fe}-\mathrm{N}_{i m} /^{\circ}$ & $F e-N_{i m}-C_{i m} /^{\circ}$ & $\mathrm{Fe}-\mathrm{N}_{\mathrm{im}} / \AA$ \\
\hline RKS & +2.6 & 120.42 & 141.58 & 1.598 \\
\hline $\operatorname{BS}(2,2)^{a}$ & +3.1 & 141.37 & 146.86 & 1.920 \\
\hline $\mathrm{BS}(3,1) / \mathrm{UKS}^{b}$ & +0.9 & 138.23 & 159.23 & 1.709 \\
\hline $\mathrm{UKS}^{c}$ & 0 & 158.83 & 140.92 & 1.781 \\
\hline
\end{tabular}

${ }^{a}$ Antiferromagnetic coupling between i.s. $\mathrm{Fe}^{\mathrm{II}}(\mathrm{S}=1)$ and triplet nitrene $(\mathrm{S}=1) \cdot{ }^{b}$ Antiferromagnetic coupling between i.s. Fe ${ }^{\mathrm{III}}(\mathrm{S}=3 / 2)$ and iminyl radical $(\mathrm{S}=1 / 2)$. ${ }^{c}$ Ferromagnetic coupling ferromagnetic coupling between i.s. $\mathrm{Fe}^{\mathrm{III}}(\mathrm{S}=3 / 2)$ and iminyl radical $(1-)(\mathrm{S}=1 / 2)$. 

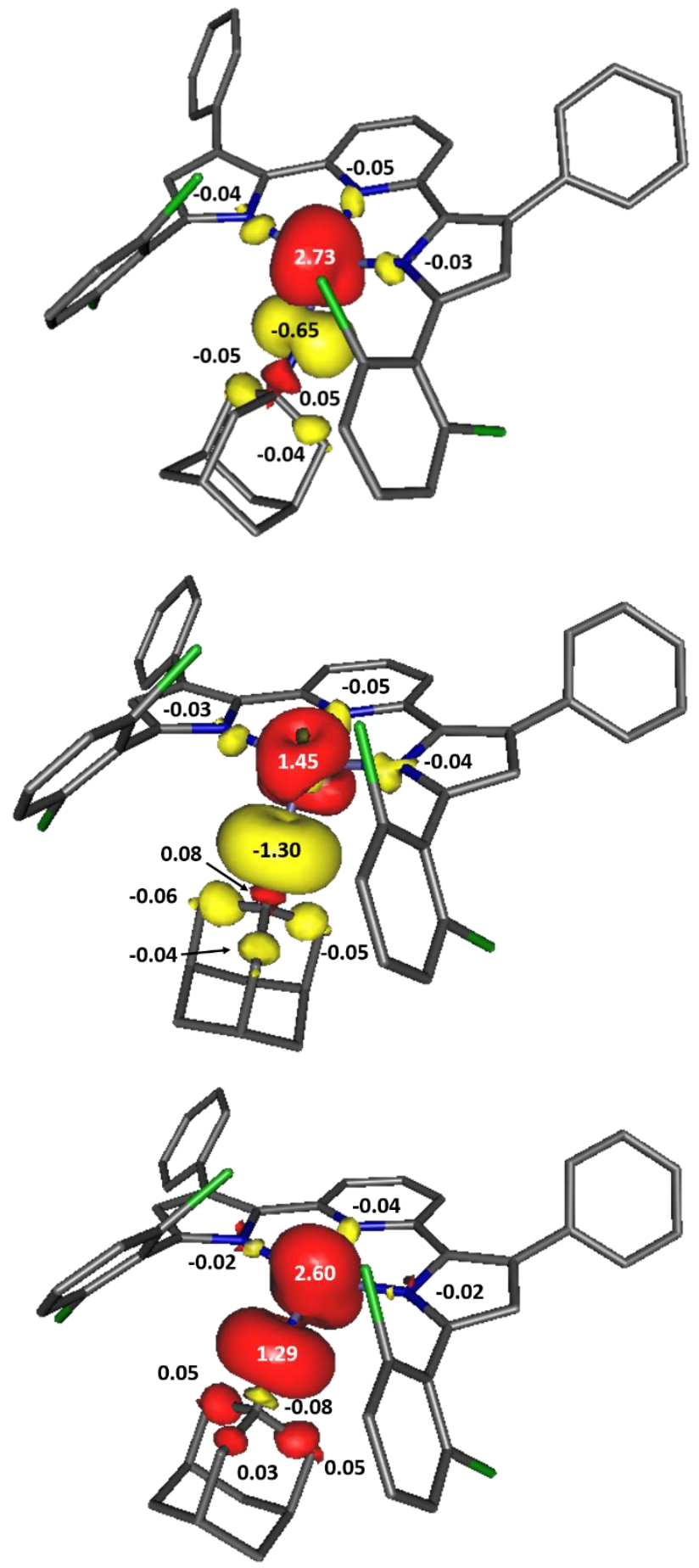

Figure 5.11. Spin density plots obtained from the Mulliken population analysis of BS(3,1)/UKS3 (top), BS(2,2) (middle), and UKS5 (bottom) calculations of $\left({ }^{2,6-\mathrm{Cl} 2 \mathrm{Ph}} \mathrm{PDP}^{\mathrm{Ph}}\right) \mathrm{Fe}\left(\mathrm{N}^{1} \mathrm{Ad}\right)$. 
Although these computational results may seem to disfavor the relevance or the contribution of a $\mathrm{BS}(3,1)$ electronic structure (or other paramagnetic electronic structures) to the ground state of $\left.{ }^{2,6-\mathrm{Cl} 2 \mathrm{Ph}} \mathrm{PDP}{ }^{\mathrm{Ph}}\right) \mathrm{Fe}\left(\mathrm{N}^{1} \mathrm{Ad}\right)$, attention is returned to the solution phase structure of the molecule, which possesses apparent $\mathrm{C}_{2 v}$ symmetry, as ascertained by ${ }^{1} \mathrm{H}$ NMR spectroscopy. This result suggests that on the timescale of the ${ }^{1} \mathrm{H}$ NMR experiment, $\left({ }^{2,6-C 12 P h} \mathrm{PDP} P{ }^{\mathrm{Ph}}\right) \mathrm{Fe}\left(\mathrm{N}^{1} \mathrm{Ad}\right)$ has access to a planar structure in solution, and thus, if the electronic structure departs from a diamagnetic state in a planar structure, the resulting paramagnetic states become highly relevant. The observed anomalous ${ }^{1} \mathrm{H}$ NMR shifts of the compound lend further credence to this argument, as occupation of the imide in a planar site between the two extremes of a cis-divacant octahedron may render spin-state changes. Complex electronic structures featuring multiconfigurational ground states have also recently been identified in other $3 \mathrm{~d}$ transition metal complexes carrying pyrrole and nitrene ligands that are competent in $\mathrm{C}-\mathrm{H}$ amination reactions. ${ }^{13-}$

In consideration of the results obtained from the computational study of $\left.{ }^{2,6-\mathrm{Cl} 2 \mathrm{Ph}} \mathrm{PDP}{ }^{\mathrm{Ph}}\right) \mathrm{Fe}\left(\mathrm{N}^{1} \mathrm{Ad}\right)$, aryl substituted PDP nitrene complexes were also investigated computationally using $\left({ }^{2,6-\mathrm{Cl} 2 \mathrm{Ph}} \mathrm{PDP}{ }^{\mathrm{Ph}}\right) \mathrm{Fe}(\mathrm{NMes})$ as a representative example to determine if they would be consistent with related $\left({ }^{\mathrm{Mes}} \mathrm{PDP}{ }^{\mathrm{Ph}}\right) \mathrm{Fe}(\mathrm{NR})$ analogues. The same computational approaches utilized for the study of $\left({ }^{2,6-\mathrm{Cl} 2 \mathrm{Ph}} \mathrm{PDP} \mathrm{Ph}^{\mathrm{Ph}}\right) \mathrm{Fe}\left(\mathrm{N}^{1} \mathrm{Ad}\right)$ and $\left({ }^{\mathrm{Mes}} \mathrm{PDP} \mathrm{Ph}^{\mathrm{Ph}}\right) \mathrm{Fe}(\mathrm{NR})$ complexes, with exclusion of RKS and BS(1,1) calculations, as both (2,6-C12PhPDP $\left.{ }^{\mathrm{Ph}}\right) \mathrm{Fe}(\mathrm{NMes})$ and $\left({ }^{2,6-C l 2 P h} \mathrm{PDP}^{\mathrm{Ph}}\right) \mathrm{Fe}(\mathrm{Xyl})$ were observed to be paramagnetic by ${ }^{1} \mathrm{H}$ NMR spectroscopy. With both complexes displaying similar NMR characteristics, and presumably possessing similar electronic structures, $\left({ }^{2,6-\mathrm{Cl} 2 \mathrm{Ph}} \mathrm{PDP}{ }^{\mathrm{Ph}}\right) \mathrm{Fe}(\mathrm{NMes})$ was chosen as a representative example for study, as the $\left({ }^{\mathrm{Mes}} \mathrm{PDP} \mathrm{Ph}^{\mathrm{Ph}} \mathrm{Fe}(\mathrm{NMes})\right.$ analogue has previously been computed. 
The UKS3 calculation spanning the triplet surface spontaneously converged to the corresponding BS(3,1) solution, consistent with $\left({ }^{2,6-\mathrm{Cl} 2 \mathrm{Ph}} \mathrm{PDP}^{\mathrm{Ph}}\right) \mathrm{Fe}\left(\mathrm{N}^{1} \mathrm{Ad}\right)$. Analysis of the optimized structure demonstrates excellent agreement with the previously investigated $\left({ }^{\mathrm{Mes}} \mathrm{PDP}^{\mathrm{Ph}}\right) \mathrm{Fe}(\mathrm{NR})$ complexes. ${ }^{5}$ The structure of $\left({ }^{2,6-\mathrm{Cl} 2 \mathrm{Ph}} \mathrm{PDP}^{\mathrm{Ph}}\right) \mathrm{Fe}(\mathrm{NMes})$ is best described as square planar, with a $\mathrm{N}_{\text {pyridine }}-\mathrm{Fe}-\mathrm{N}_{\text {imide }}$ bond angle of $176.39^{\circ}$. The short iron-nitrene bond length of $1.74 \AA$ implies significant multiple bond character. Further scrutiny of the bond distances in the computed structure demonstrate significant distortions throughout the nitrene aryl substituent. A Nimide- $\mathrm{C}_{i p s o}$ bond length of $1.33 \AA$ is computed, intermediate between carbonnitrogen double and single bond lengths. For reference, the high-spin $\mathrm{Fe}^{\mathrm{II}}$ aryl amine complex $\left({ }^{\mathrm{Mes}} \mathrm{PDP}^{\mathrm{Ph}}\right) \mathrm{Fe}\left(\mathrm{NH}_{2} \mathrm{Mes}\right)$ has an amine nitrogen to aryl ipso carbon bond length of $1.45 \AA$ (See Appendix A.2.8). This observation, coupled with the computed bond lengths of $1.45 \AA$ from the ipso carbon to the ortho carbon and $1.41 \AA$ for the meta to para carbon of the mesityl aryl ring (which depart from the $1.39 \AA$ bond lengths in benzene) ${ }^{16}$ suggest that as a whole nitrene fragment is best described as an iminyl radical ligand (Figure 5.13). This claim is supported by analysis of the spin density distribution (Figure 5.14) obtained from Mulliken population analysis. Spin density values of 2.64 on the iron center and -0.30 on the iminyl nitrogen are consistent with an intermediate spin ferric ion $\left(\mathrm{S}_{\mathrm{Fe}}=3 / 2\right)$ engaged in antiferromagnetic coupling with an iminyl radical ligand $\left(S_{L}=1 / 2\right)$. Notably, significant spin density is also found on the mesityl substituent, consistent with the significantly perturbed bond distances of the arene as well as the highly shifted ${ }^{1} \mathrm{H}$ NMR resonances of the protons of the mesityl group.

On the pentet surface the UKS5 calculation converged to an optimized structure best described as an intermediate-spin ferric ion $\left(\mathrm{S}_{\mathrm{Fe}}=3 / 2\right)$ engaged in ferromagnetic with and iminyl (1-) radical $\left(S_{L}=1 / 2\right)$, consistent with an alignment of the iron and iminyl radical spins. The spin 
density map (Figure 5.14) depicts approximately three iron centered spins along with significant spin present on the NMes fragment. Consistent with the $\mathrm{BS}(3,1)$ calculation, a nearly planar geometry is adopted by this structure with a $\mathrm{N}_{\mathrm{py}}-\mathrm{Fe}-\mathrm{N}_{\mathrm{im}}$ angle of $168.11^{\circ}$ and $\mathrm{Fe}-\mathrm{N}_{\mathrm{im}}$ bond length of $1.792 \AA$. It should be added that this structure is analogous to the UKS5 solution obtained for the ( $\left.{ }^{2,6-\mathrm{Cl} 2 \mathrm{Ph}} \mathrm{PDP} \mathrm{P}^{\mathrm{Ph}}\right) \mathrm{Fe}\left(\mathrm{N}^{1} \mathrm{Ad}\right)$.

The BS $(5,1)$ solution converged to an optimized structure that is similar to that for the $\mathrm{BS}(5,1)$ solution of $\left({ }^{2,6-\mathrm{Cl} 2 \mathrm{Ph}} \mathrm{PDP}^{\mathrm{Ph}}\right) \mathrm{Fe}\left(\mathrm{N}^{1} \mathrm{Ad}\right)$, with an $\mathrm{S}_{\mathrm{Fe}}=5 / 2$ center and one spin located on the nitrene fragment, $S_{L}=1 / 2$. Analysis of the bond metrics reveals a Fe-N distance of $1.81 \AA$, again, consistent with multiple bond character. Notably, the increase in the bond distance from $1.74 \AA$ in the $\mathrm{BS}(3,1)$ optimized structure to $1.81 \AA$ in the $\mathrm{BS}(5,1)$ structure is consistent with an increase of the iron spin-state from intermediate $\left(\mathrm{S}_{\mathrm{Fe}}=3 / 2\right)$ to high-spin $\left(\mathrm{S}_{\mathrm{Fe}}=5 / 2\right)$. Also consistent with the previously discussed structures is the observation that the mesityl fragment possesses a similarly contracted $\mathrm{N}_{\text {imide}}-\mathrm{C}_{\text {ipso }}$ bond length of $1.32 \AA$ and perturbed aryl carboncarbon bond distances (Figure 5.13). Additionally, the same contracted $\mathrm{N}_{\text {imide- }} \mathrm{C}_{i p s o}$ and perturbed aryl carbon-carbon bond distances within the nitrene mesityl substituent are present that are observed in the BS $(3,1)$ and UKS5 geometry optimized structures. Overall, this solution can be formally described as an intermediate spin $\mathrm{Fe}^{\mathrm{III}}$ center engaged in ferromagnetic coupling with an iminyl based radical ligand to account for an overall $\mathrm{S}=2$ state. An additional detail of interest in the optimized BS(5,1) structure is the presence of spin density $(0.04$, Figure 5.14$)$ on a $\mathrm{Cl}$ atom of the ${ }^{2,6-\mathrm{Cl} 2 \mathrm{Ph}} \mathrm{PDP}^{\mathrm{Ph}}$ supporting ligand. This chloride is presumably engaged in a weak Lewis-acid/base interaction, as evidenced by the $\mathrm{Fe}-\mathrm{Cl}$ distance of $2.734 \AA$, similar to $\left.{ }^{(2,6-\mathrm{Cl} 2 \mathrm{Ph}} \mathrm{PDP}^{\mathrm{Ph}}\right) \mathrm{Fe}($ thf $)$ where a similar chloride interaction is also present and measures 2.7161(5) $\AA$ (Figure 5.12). 

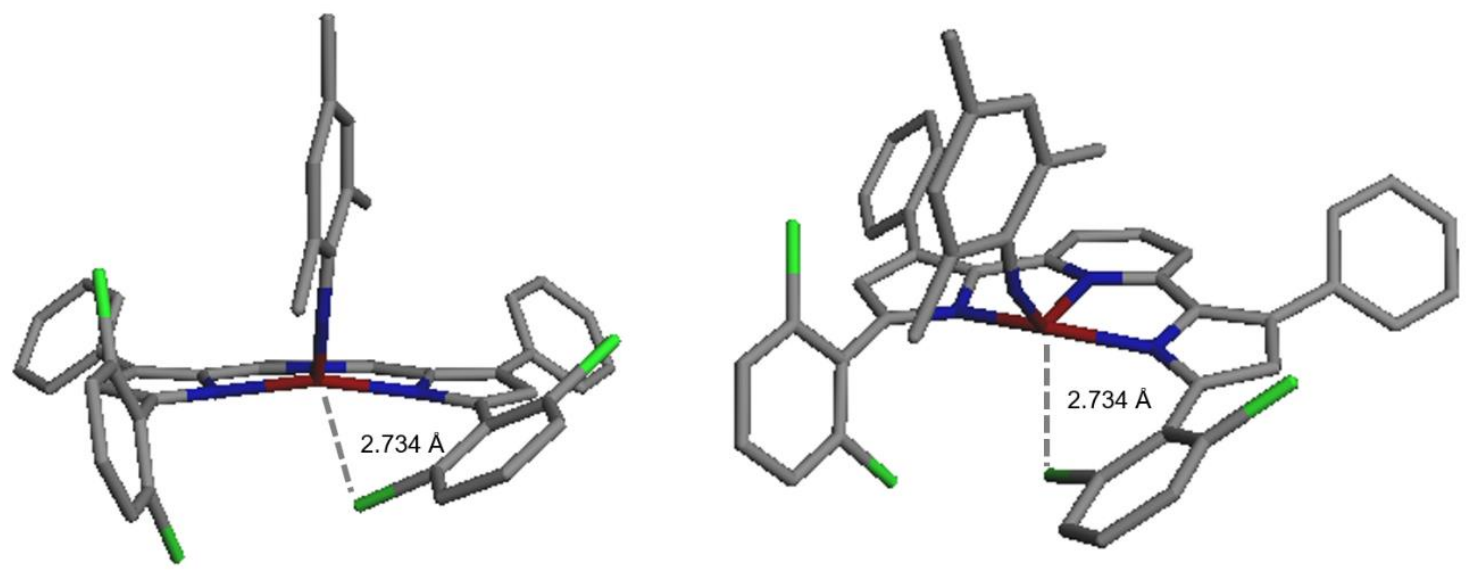

Figure 5.12. $\mathrm{BS}(5,1)$ optimized structure of $\left({ }^{2,6-\mathrm{Cl} 2 \mathrm{Ph}} \mathrm{PDP} \mathrm{Ph}^{\mathrm{Ph}}\right) \mathrm{Fe}(\mathrm{NMes})$ indicating $\mathrm{Fe}-\mathrm{Cl}$ interaction. Note, color scheme is as follows: red (iron), grey (carbon), blue (nitrogen), green (chlorine).

Although the solid-state structure has yet to be determined for $\left.{ }^{2,6-\mathrm{C} 12 \mathrm{Ph}} \mathrm{PDP}^{\mathrm{Ph}}\right) \mathrm{Fe}(\mathrm{NMes})$, these computational results, in combination with the observation of the paramagnetic ${ }^{1} \mathrm{H}$ NMR spectrum of $\left.{ }^{2,6-\mathrm{Cl} 2 \mathrm{Ph}} \mathrm{PDP}^{\mathrm{Ph}}\right) \mathrm{Fe}(\mathrm{NMes})$ sheds light on possible electronic structures for the compound. All three paramagnetic electronic structures study here suggest the presence of a destabilized iron-iminyl interaction, departing from a classical dianionic imido type ligand, although the ground state electronic configuration cannot be unambiguously assigned using DFT computational methods alone. This result is consistent with DFT calculations on isolable $\left.{ }^{2,6-\mathrm{Cl} 2 \mathrm{Ph}} \mathrm{PDP}{ }^{\mathrm{Ph}}\right) \mathrm{Fe}\left(\mathrm{N}^{1} \mathrm{Ad}\right)$ and $\left({ }^{\mathrm{Mes}} \mathrm{PDP}{ }^{\mathrm{Ph}}\right) \mathrm{Fe}(\mathrm{NMes})$, which are also predicted to have numerous electronic structure configurations within only a few kcal mol-1 (Table 5.8). 

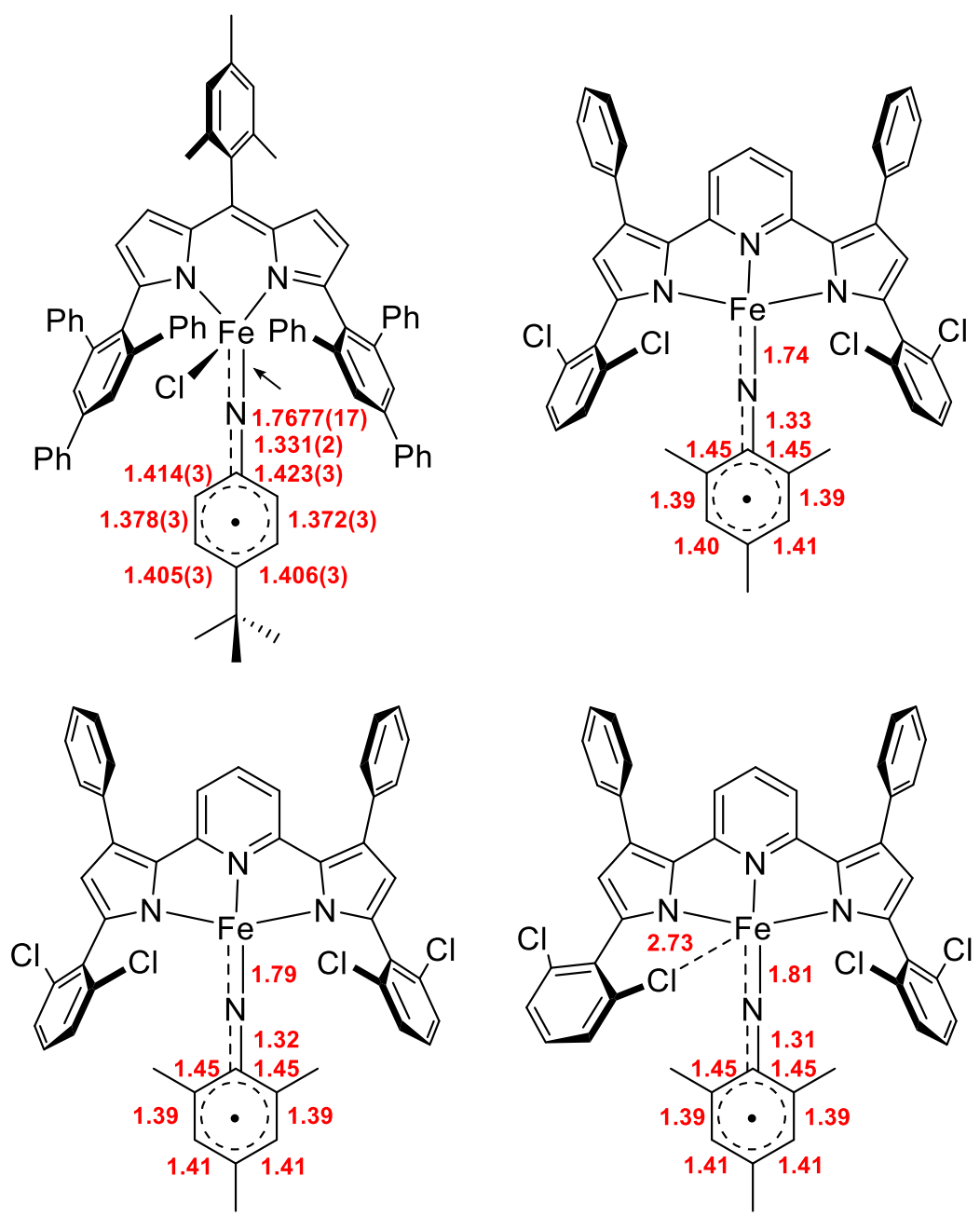

Figure 5.13. Comparison of bond lengths from the $\mathrm{X}$-ray crystal structure of $\left({ }^{\mathrm{Ar}} \mathrm{L}\right) \mathrm{FeCl}\left(\mathrm{N}\left(p-{ }^{\mathrm{t}} \mathrm{BuC}_{6} \mathrm{H}_{4}\right)\right)^{4}$ and the optimized structures obtained from UKS3/BS(3,1) (top-right), UKS5 (bottom-left), and BS(5,1) (bottom-right) DFT calculations of $\left({ }^{2,6-\mathrm{Cl} 2 \mathrm{Ph}} \mathrm{PDP}^{\mathrm{Ph}}\right) \mathrm{Fe}(\mathrm{NMes})$. Note: ${ }^{\mathrm{Ar}} \mathrm{L}=1,9-\left(2,4,6-\mathrm{Ph}_{3} \mathrm{C}_{6} \mathrm{H}_{2}\right)-5$-mesityldipyrromethene.

Table 5.7. Calculated energies and selected structural parameters for different electronic structures of $\left({ }^{2,6-\mathrm{Cl} 12 \mathrm{Ph}} \mathrm{PDP}^{\mathrm{Ph}}\right) \mathrm{Fe}(\mathrm{NMes})$ obtained from DFT calculations.

\begin{tabular}{ccccc}
\hline & $\Delta$ Energy $/ \mathrm{kcal} \mathrm{mol}^{-1}$ & $\mathrm{~N}_{\mathrm{py}}-\mathrm{Fe}-\mathrm{N}_{\mathrm{im}} /{ }^{\circ}$ & $\mathrm{Fe}-\mathrm{N}_{\mathrm{im}}-\mathrm{C}_{\mathrm{im}} /{ }^{\circ}$ & $\mathrm{Fe}-\mathrm{N}_{\mathrm{im}} / \AA$ \\
\hline $\mathrm{BS}(3,1) / \mathrm{UKS3}^{\mathrm{a}}$ & 0 & 176.39 & 141.76 & 1.738 \\
$\mathrm{UKS5}^{\mathrm{b}}$ & +1.4 & 168.11 & 143.57 & 1.792 \\
$\mathrm{BS}(5,1)^{\mathrm{c}}$ & +1.9 & 131.97 & 158.15 & 1.805
\end{tabular}

${ }^{a}$ antiferromagnetic coupling between i.s. Fe ${ }^{\mathrm{III}}(\mathrm{S}=3 / 2)$ and iminyl radical $(\mathrm{S}=1 / 2)$.

${ }^{b}$ ferromagnetic coupling between i.s. $\mathrm{Fe}^{\mathrm{III}}(\mathrm{S}=3 / 2)$ and iminyl $(1-)$ radical $(\mathrm{S}=1 / 2)$.

${ }^{c}$ antiferromagnetic coupling between h.s. $\mathrm{Fe}^{\mathrm{III}}(\mathrm{S}=5 / 2)$ and iminyl(1-) radical $(\mathrm{S}=1 / 2)$. 

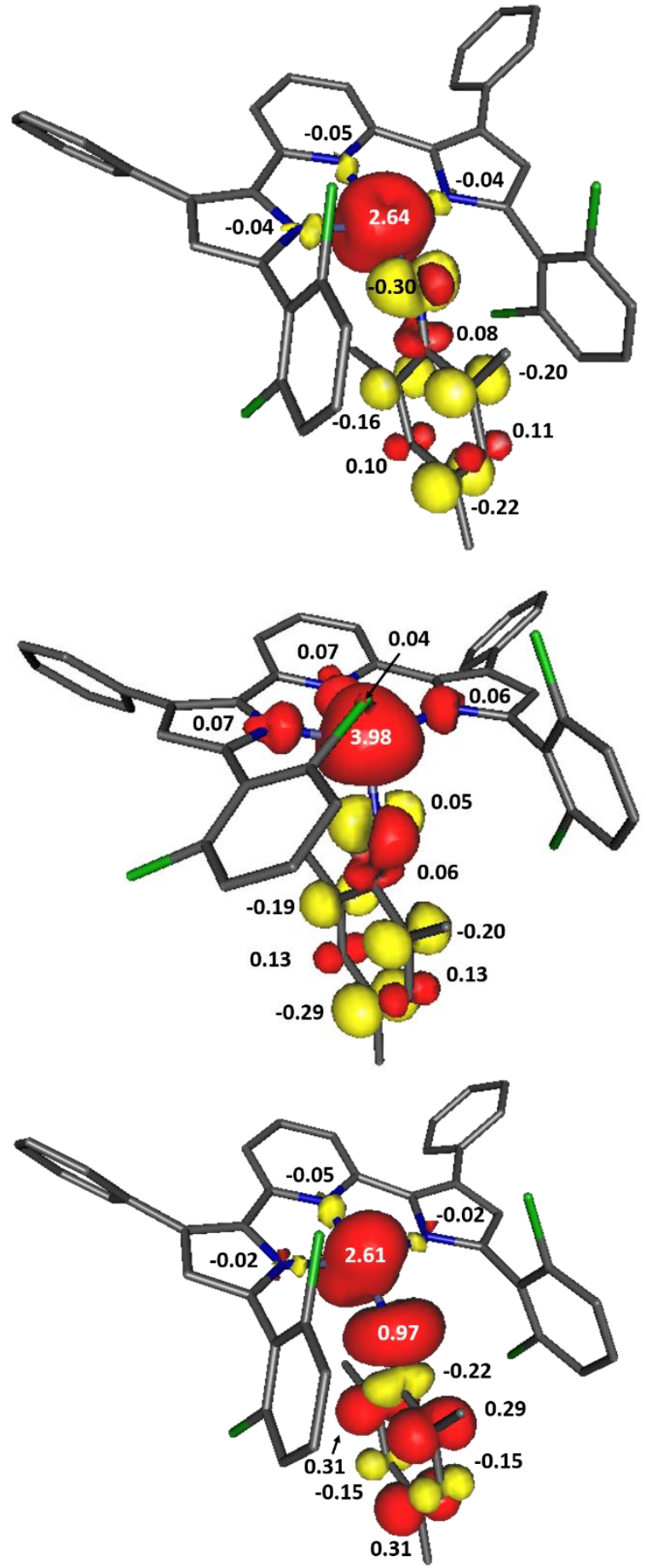

Figure 5.14. Spin density plots obtained from the Mulliken population analysis of BS(3,1)/UKS3 (top), BS(5,1) (middle), and UKS5 (bottom) calculations of ( $\left.{ }^{2,6-\mathrm{Cl} 2 \mathrm{Ph}} \mathrm{PDP}^{\mathrm{Ph}}\right) \mathrm{Fe}(\mathrm{NMes})$. 
Table 5.8. Calculated energies for different electronic structures of $\left({ }^{2,6-C 12 P h} \mathrm{PDP}^{\mathrm{Ph}}\right) \mathrm{Fe}\left(\mathrm{N}^{1} \mathrm{Ad}\right)$, $\left.{ }^{(2,6-\mathrm{Cl} 2 \mathrm{Ph}} \mathrm{PDP} \mathrm{Ph}^{\mathrm{Ph}}\right) \mathrm{Fe}(\mathrm{NMes})$, and $\left({ }^{\mathrm{Mes}} \mathrm{PDP}^{\mathrm{Ph}}\right) \mathrm{Fe}(\mathrm{NMes})$ obtained from DFT calculations.

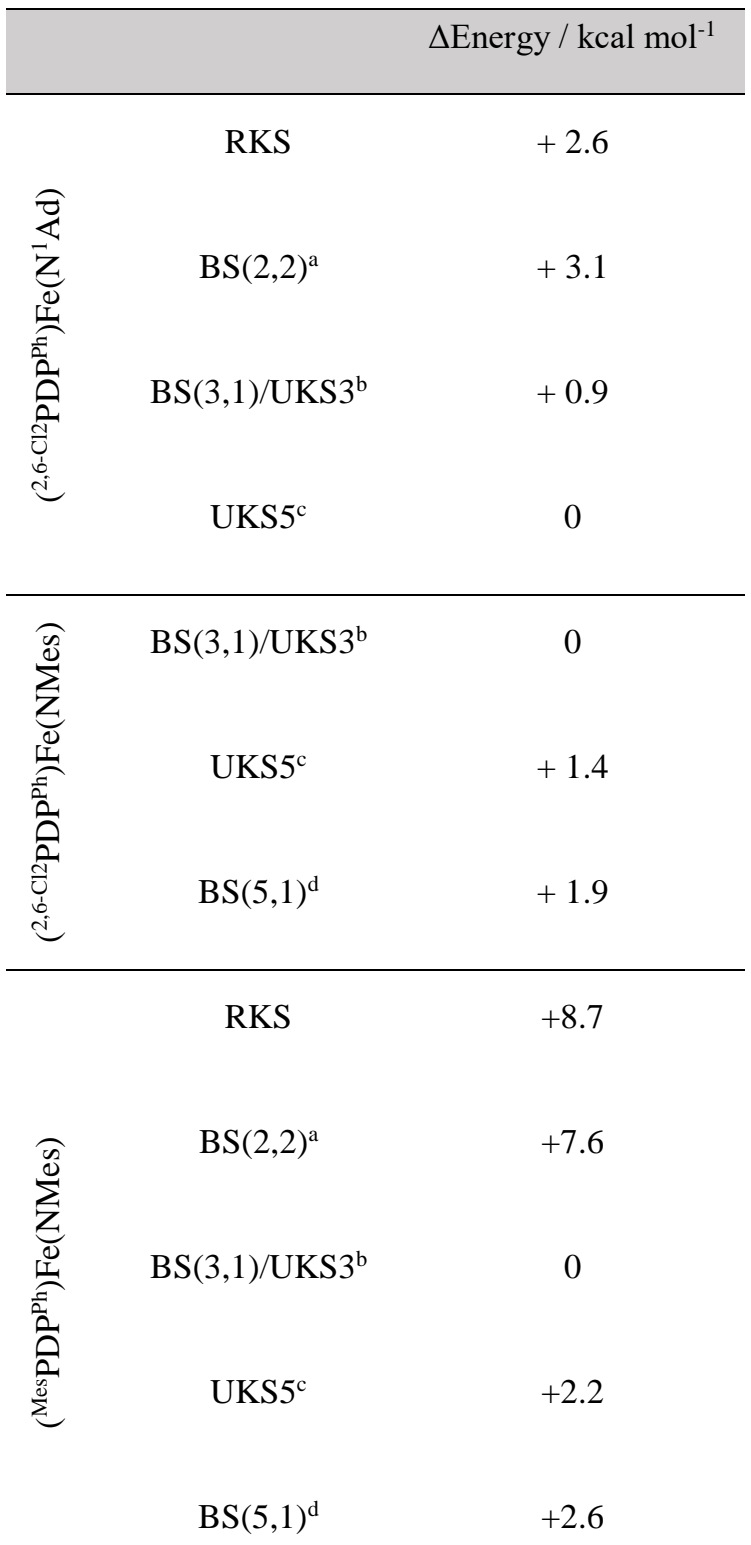

${ }^{a}$ Antiferromagnetic coupling between i.s. $\mathrm{Fe}^{\mathrm{II}}(\mathrm{S}=1)$ and triplet nitrene $(\mathrm{S}=1)$ or antiferromagnetic coupling between i.s. $\mathrm{Fe}^{\mathrm{IV}}(\mathrm{S}=1)$ and triplet nitrene $(\mathrm{S}=1) .{ }^{\mathrm{b}}$ Antiferromagnetic coupling between i.s. $\mathrm{Fe}^{\mathrm{III}}(\mathrm{S}=3 / 2)$ and iminyl radical $(S=1 / 2)$. ${ }^{c}$ Ferromagnetic coupling between i.s. $\mathrm{Fe}^{\mathrm{III}}(\mathrm{S}=3 / 2)$ and iminyl(1-) radical $(\mathrm{S}=1 / 2)$.

${ }^{\mathrm{d}}$ Antiferromagnetic coupling between h.s. $\mathrm{Fe}^{\mathrm{III}}(\mathrm{S}=5 / 2)$ and iminyl $(1-)$ radical $(\mathrm{S}=1 / 2)$. 


\subsection{Conclusion}

Reaction of (2,6-Cl2Ph $\left.\mathrm{PDP}{ }^{\mathrm{Ph}}\right) \mathrm{Fe}($ thf $)\left(\mathrm{H}_{2}{ }^{2,6-\mathrm{Cl} 2 \mathrm{Ph}} \mathrm{PDP}^{\mathrm{Ph}}=\right.$ 2,6-Bis(5-(2,6-dichlorophenyl)-3phenyl-1H-pyrrol-2-yl)-pyridine) with a variety of organic azides has been studied. The identity of the azide substituent has been found to have a substantial impact on the observed reaction products. Treatment of $\left({ }^{2,6-\mathrm{Cl} 2 \mathrm{Ph}} \mathrm{PDP} \mathrm{Ph}^{\mathrm{Ph}}\right) \mathrm{Fe}($ thf $)$ with the bulky aliphatic 1-adamantyl azide resulted in the formation of the cis-divacant octahedral diamagnetic low-spin $\mathrm{Fe}^{\mathrm{IV}}$ imide, ${ }^{2,6-\mathrm{Cl} 2 \mathrm{Ph}} \mathrm{PDP} \mathrm{Ph}^{\mathrm{Ph}} \mathrm{Fe}\left(\mathrm{N}^{1} \mathrm{Ad}\right)$. Alternatively, reaction with either para-fluorophenyl-azide or paratert-butylphenylazide, $\mathrm{pFPhN}_{3}$, which lacks steric protection of the nitrene, resulted in the exclusive formation of the corresponding $\mathrm{Fe}^{\mathrm{III}}$ tetrazene complexes $\left({ }^{2,6-\mathrm{Cl} 2 \mathrm{Ph}} \mathrm{PDP} \mathrm{Ph}^{\mathrm{Ph}}\right) \mathrm{Fe}-$ $\left(\mathrm{N}_{4}\left(\mathrm{pFPhN}_{3}\right)_{2}\right)$ and $\left({ }^{2,6-\mathrm{Cl} 2 \mathrm{Ph}} \mathrm{PDP}^{\mathrm{Ph}}\right) \mathrm{Fe}\left(\mathrm{N}_{4}\left(\mathrm{p}^{\mathrm{t}} \mathrm{BuPhN}_{3}\right)_{2}\right)$. In contrast, by using bulky aryl azide, such as mesityl azide, the paramagnetic iron iminyl complex $\left({ }^{2,6-\mathrm{Cl} 2 \mathrm{Ph}} \mathrm{PhPDP}{ }^{\mathrm{Ph}}\right) \mathrm{Fe}(\mathrm{NMes})$ has been characterized via ${ }^{1} \mathrm{H}$ NMR. Finally, the reaction of 4-azidobutylbenzene was also explored in attempt to leverage intramolecular $\mathrm{C}-\mathrm{H}$ amination to the corresponding cyclic pyrrolidine. Instead, a low-spin $\mathrm{Fe}^{\mathrm{II}}$ complex carrying a tetrazene and aldimine ligand $\left({ }^{2,6-\mathrm{Cl} 2 \mathrm{Ph}} \mathrm{PDP} \mathrm{Ph}^{\mathrm{Ph}} \mathrm{Fe}-\right.$ $\left(\mathrm{N}_{4}(\mathrm{nBuPh})_{2}\right)\left(\mathrm{HN}=\mathrm{CH}\left(\mathrm{CH}_{2}\right)_{3} \mathrm{Ph}\right)$ was isolated as the sole reaction product.

A complementary density functional theory (DFT) study has also been undertaken to explore potential paramagnetic electronic structures available to $\left.{ }^{2,6-\mathrm{Cl} 2 \mathrm{Ph}} \mathrm{PhPDP}{ }^{\mathrm{Ph}}\right) \mathrm{Fe}(\mathrm{NMes})$, which suggest this complex may feature an iminyl radical ligand. These results suggest that careful attention of the ancillary PDP ligand may allow for the isolation of iron nitrene complexes with discrete geometries and hence, electronic structures. Furthermore, it is anticipated that this will allow for the informed design of future systems leveraging discrete molecular iron complexes for nitrene group transfer. 


\subsection{Experimental Procedures}

All air- and moisture-sensitive manipulations were carried out using standard Schlenk line and cannula techniques or in an MBraun inert atmosphere drybox containing an atmosphere of purified nitrogen. Solvents for air- and moisture sensitive manipulations were dried and deoxygenated using a Glass Contour Solvent Purification System and stored over 4 Å molecular sieves. All solids were dried under high vacuum; all liquids were dried over $\mathrm{CaH}_{2}$ and vacuum transferred into oven-dried glassware in order to bring into the glovebox. Deuterated benzene (benzene- $d_{6}$ ) for NMR spectroscopy were distilled from sodium metal. Deuterated dichloromethane (dichloromethane- $d_{2}$ ) was distilled from calcium hydride. 1-Adamantyl azide was obtained from Sigma-Aldrich, dried under high vacuum, and recrystallized at $-35^{\circ} \mathrm{C}$ from pentane prior to use. Para-fluorophenyl azide,${ }^{17}$ para-tertbutylphenyl azide,,${ }^{17}$ mesityl azide, ${ }^{17}$ and 1-(4-azidobutyl)benzene ${ }^{6}$ were synthesized according to literature procedures.

\section{Preparation of (2,6-Cl2Ph PDP $\left.{ }^{P h}\right) \mathrm{Fe}\left(N^{I} \mathrm{Ad}\right)$.}

In the glovebox, $24 \mathrm{mg}(0.031 \mathrm{mmol})$ of $\left.{ }^{2,6-\mathrm{Cl} 2 \mathrm{Ph}} \mathrm{PDP}^{\mathrm{Ph}}\right) \mathrm{Fe}(\mathrm{thf})$ was suspended in $500 \mu \mathrm{L}$ of benzene- $d_{6}$ in a J. Young NMR Tube. In a separate dram vial, $6 \mathrm{mg}(0.034 \mathrm{mmol}, 1.1 \mathrm{eq}$.) of ${ }^{1} \mathrm{AdN}_{3}$ was dissolved in $500 \mu \mathrm{L}$ of benzene- $d_{6}$. The azide solution was added to the NMR tube and the tube was sealed. The mixture was shaken vigorously for thirty seconds and then the NMR tube was removed from the glovebox and placed in a $60^{\circ} \mathrm{C}$ oil bath. The tube was heated for 30 minutes and a ${ }^{1} \mathrm{H}$ NMR spectrum was acquired, which indicated the presence of $\left.{ }^{2,6-\mathrm{Cl} 2 \mathrm{Ph}} \mathrm{PDP}^{\mathrm{Ph}}\right) \mathrm{Fe}\left(\mathrm{N}^{1} \mathrm{Ad}\right)$. The tube was then returned to the glovebox and poured into a $20 \mathrm{~mL}$ vial. The J. Young tube was washed three times with $1.5 \mathrm{~mL}$ of benzene. The benzene solutions were combined and reduced to approximately $1 \mathrm{~mL}$. Addition of $5 \mathrm{~mL}$ of pentane induced the precipitation of a dark brown powder which was isolated via vacuum filtration on a medium 
porosity frit. The powder was washed three times with $1.5 \mathrm{~mL}$ of pentane and dried in vacuo. Yield: $11 \mathrm{mg}, 0.013 \mathrm{mmol}, 40 \% .{ }^{1} \mathrm{H}$ NMR $\left(400 \mathrm{MHz}\right.$, benzene- $\left.d_{6}\right) \delta 7.97(\mathrm{~d}, J=7.4 \mathrm{~Hz}, 2 \mathrm{H}, 3-$ pyridine $H), 7.47(\mathrm{~d}, J=7.5 \mathrm{~Hz}, 4 \mathrm{H}$, ortho- $\mathrm{Ph} H), 7.36(\mathrm{t}, J=7.5 \mathrm{~Hz}, 4 \mathrm{H}$, meta $-\mathrm{Ph} H), 7.03$ (d, $J=$ $8.0 \mathrm{~Hz}, 4 \mathrm{H}$, ortho $-\mathrm{Ph} H), 6.95(\mathrm{t}, J=7.2 \mathrm{~Hz}, 2 \mathrm{H}$, para $-\mathrm{Ph} H), 6.62-6.52(\mathrm{t}, J=8.0 \mathrm{~Hz}, 2 \mathrm{H}$, para$\mathrm{Ph} H$ ), 5.28 (t, $J=7.8 \mathrm{~Hz}, 1 \mathrm{H}, 4$-pyridine $H$ ), 4.78 (s, 2H, pyrrole-CH), 3.65 (s, 6H, adamantyl$\left.\mathrm{CH}_{2}\right), 1.80-1.46\left(\mathrm{~m}, 6 \mathrm{H}\right.$, adamantyl- $\left.\mathrm{CH}_{2}\right),-0.21$ (s, 3H, adamantyl-CH). ${ }^{13} \mathrm{C}$ NMR (101 MHz, benzene- $\left.d_{6}\right) \delta 27.52,36.99,107.35,117.86,128.59,128.80,128.94,130.54,130.84,133.74$, 135.10, 136.10, 138.15, 149.05, 155.95, 170.52 (three resonances were not located). Single crystals were grown via slow evaporation of a concentrated diethyl ether solution.

\section{Preparation of $\left(^{2,6-C l 2 P h} \mathrm{PDP}^{\mathrm{Ph}}\right) \mathrm{Fe}\left(\mathrm{N}_{4}(\mathrm{pFPh})_{2}\right)$.}

In a $20 \mathrm{~mL}$ scintillation vial equipped with a magnetic stirrer was combined $95 \mathrm{mg}(0.122$ $\mathrm{mmol})$ of $\left({ }^{2,6-\mathrm{Cl} 2 \mathrm{Ph}} \mathrm{PDP}^{\mathrm{Ph}}\right) \mathrm{Fe}(\mathrm{thf})$ and $10 \mathrm{~mL}$ of benzene. In a separate vial, $38 \mathrm{mg}(0.277 \mathrm{mmol}$, 2.27 eq.) of paraflurophenyl azide and $5 \mathrm{~mL}$ of benzene were combined. With vigorous stirring, the azide solution was added dropwise to the suspension of the iron compound. An immediate color change from red to dark-red/brown was observed upon addition, accompanied by effervescence of the solution. After $12 \mathrm{hrs}$ the solvent was removed, leaving a brown powder. The powder was transferred to a medium porosity glass frit and washed with three 5-mL aliquots of pentane and dried in vacuo. Single crystals suitable for study by X-ray diffraction were grown from slow evaporation of a concentrated dichloromethane solution of the compound. Yield: 95 mg, 82\%. ${ }^{1} \mathrm{H}$ NMR (400 MHz, dichloromethane- $\left.d_{2}\right) \delta 8.89(\mathrm{~s}, 4 \mathrm{H}), 7.63(\mathrm{t}, J=7.6 \mathrm{~Hz}, 4 \mathrm{H}), 7.07$ $(\mathrm{d}, J=7.4 \mathrm{~Hz}, 4 \mathrm{H}), 6.96(\mathrm{t}, J=7.6 \mathrm{~Hz}, 2 \mathrm{H}), 6.84(\mathrm{~d}, J=7.8 \mathrm{~Hz}, 4 \mathrm{H}), 6.79-6.71(\mathrm{t}, 2 \mathrm{H}), 6.66(\mathrm{t}$, $J=7.9 \mathrm{~Hz}, 1 \mathrm{H}), 6.04(\mathrm{~s}, 4 \mathrm{H}), 5.09(\mathrm{~d}, J=5.1 \mathrm{~Hz}, 2 \mathrm{H}), 2.28$ (s, $2 \mathrm{H})$. Satisfactory ${ }^{13} \mathrm{C}$ NMR data 
could not be acquired due to the extremely poor solubility of the compound in hydrocarbon solvents. ${ }^{19} \mathrm{~F}$ NMR $\left(376 \mathrm{MHz}\right.$, benzene- $\left.d_{6}\right) \delta-121.86$.

Preparation of $\left(^{2,6-C l 2 P h} P D P^{P h}\right) F e\left(N_{4} p^{t} B u P h_{2}\right)$.

In a $20 \mathrm{~mL}$ scintillation vial equipped with a magnetic stirrer was combined $102 \mathrm{mg}$ $(0.131 \mathrm{mmol})$ of $\left.{ }^{2,6-\mathrm{Cl} 2 \mathrm{Ph}} \mathrm{PDP}^{\mathrm{Ph}}\right) \mathrm{Fe}(\mathrm{thf})$ and $10 \mathrm{~mL}$ of benzene. In a separate vial, $50 \mathrm{mg}(0.285$ mmol, 2.18 eq.) of para tert-butylphenyl azide and $5 \mathrm{~mL}$ of benzene were combined. With vigorous stirring, the azide solution was added dropwise to the suspension of the iron compound. An immediate color change from red to dark-red/brown was observed upon addition, accompanied by effervescence of the solution. After $12 \mathrm{hrs}$ the solvent was removed, leaving a brown powder. The powder was transferred to a medium porosity glass frit and washed with three 5-mL aliquots of pentane and dried in vacuo. ${ }^{1} \mathrm{H}$ NMR $\left(400 \mathrm{MHz}\right.$, benzene- $\left.d_{6}\right) \delta 9.39(\mathrm{~s}$, 4H), $7.45(\mathrm{t}, J=7.6 \mathrm{~Hz}, 4 \mathrm{H}), 7.10(\mathrm{~d}, J=7.6 \mathrm{~Hz}, 4 \mathrm{H}), 6.70(\mathrm{t}, J=7.4 \mathrm{~Hz}, 2 \mathrm{H}), 6.60(\mathrm{~d}, J=8.1$ $\mathrm{Hz}, 4 \mathrm{H}), 6.10(\mathrm{t}, J=8.1 \mathrm{~Hz}, 2 \mathrm{H}), 5.94(\mathrm{t}, J=7.9 \mathrm{~Hz}, 1 \mathrm{H}, 4-\mathrm{py} H), 5.75(\mathrm{~s}, 4 \mathrm{H}), 4.87$ (d, $J=7.8$ $\mathrm{Hz}, 2 \mathrm{H}, 3-\mathrm{pyH}), 2.05(\mathrm{~s}, 2 \mathrm{H}), 0.93\left(\mathrm{~s}, 18 \mathrm{H}, p-\mathrm{Ph}\left(\mathrm{CH}_{3}\right)_{3}\right)$. Satisfactory ${ }^{13} \mathrm{C}$ NMR data could not be acquired due to the poor solubility of the compound in hydrocarbon solvents.

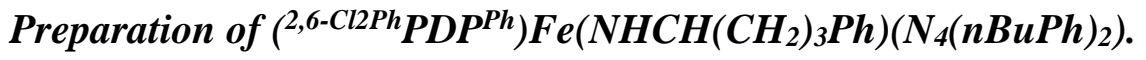

$50 \mathrm{mg}(0.064 \mathrm{mmol})$ of $\left({ }^{2,6-\mathrm{Cl} 2 \mathrm{Ph}} \mathrm{PDP}{ }^{\mathrm{Ph}}\right) \mathrm{Fe}(\mathrm{thf})$ was slurried in $5 \mathrm{~mL}$ of benzene in a 20 $\mathrm{mL}$ vial equipped with a magnetic stirrer. A $5 \mathrm{~mL}$ solution of $36 \mathrm{mg}$ (0.205 mmol, 3.2 eq.) of 1(4-azidobutyl)benzene was added to the vial. A color change from orange to red was noted accompanied by dissolution of all solids. The resulting homogeneous mixture was stirred for 24 hours. The solvent was then removed in vacuo, leaving a red residue which was washed three times with pentane. Yield: $32 \mathrm{mg}, 0.027 \mathrm{mmols}, 42 \% .{ }^{1} \mathrm{H}$ NMR (400 MHz, benzene- $d_{6} ; \delta$, ppm): $9.62(\mathrm{~d}, J=22.0 \mathrm{~Hz}, 1 \mathrm{H}$, aldimine-NH), $7.72(\mathrm{~d}, J=7.5 \mathrm{~Hz}, 4 \mathrm{H}, \operatorname{Ar} H), 7.41(\mathrm{~d}, J=7.9 \mathrm{~Hz}, 2 \mathrm{H}$, 
$\operatorname{Ar} H), 7.22(\mathrm{t}, J=7.7 \mathrm{~Hz}, 4 \mathrm{H}, \operatorname{Ar} H), 7.14-7.00(\mathrm{~m}, 13 \mathrm{H}, \operatorname{Ar} H), 6.97(\mathrm{t}, J=7.2 \mathrm{~Hz}, 4 \mathrm{H}, \operatorname{Ar} H)$, $6.90-6.73(\mathrm{~m}, 6 \mathrm{H}, \mathrm{ArH}), 6.30(\mathrm{t}, J=8.0 \mathrm{~Hz}, 2 \mathrm{H}, \mathrm{ArH}), 6.22(\mathrm{~s}, 2 \mathrm{H}$, pyrrole-CH), $3.59(\mathrm{~m}, 2 \mathrm{H},-$ $\left.\mathrm{CH}_{2}\right), 3.25\left(\mathrm{~m}, 2 \mathrm{H},-\mathrm{CH}_{2}\right), 2.50-2.47\left(\mathrm{~m}, 2 \mathrm{H},-\mathrm{CH}_{2}\right), 2.37-2.29\left(\mathrm{~m}, 2 \mathrm{H},-\mathrm{CH}_{2}\right), 1.98(\mathrm{t}, J=7.4$ $\left.\mathrm{Hz}, 2 \mathrm{H}, \mathrm{CH}_{2}\right), 1.82-1.65\left(\mathrm{~m}, 2 \mathrm{H},-\mathrm{CH}_{2}\right), 1.60-1.49\left(\mathrm{~m}, 2 \mathrm{H},-\mathrm{CH}_{2}\right) 1.48-1.19(\mathrm{~m}, 8 \mathrm{H},(4)-$ $\mathrm{CH}_{2}$ ). Red single crystals of the compound were grown from diffusion of pentane into a concentrated benzene solution at room temperature.

Preparation of $\left(^{2,6-C l 2 P h} P D P^{P h}\right) \mathrm{Fe}(\mathrm{NMes})$.

In the glovebox, $50 \mathrm{mg}(0.064 \mathrm{mmol})$ of $\left({ }^{2,6-\mathrm{Cl} 2 \mathrm{Ph}} \mathrm{PDP}^{\mathrm{Ph}}\right) \mathrm{Fe}($ thf $)$ was suspended in $500 \mu \mathrm{L}$ of benzene- $d_{6}$ in a J. Young NMR tube. In a separate dram vial, $12 \mathrm{mg}$ (0.074 mmol, 1.16 eq.) of mesityl azide was dissolved in $100 \mu \mathrm{L}$ of benzene- $d_{6}$. The azide solution was added to J. Young tube inducing an immediate color change of the suspension from red to dark brown. The tube was sealed and shaken vigorously for thirty seconds, and a ${ }^{1} \mathrm{H}$ NMR spectrum was acquired, indicating quantitative conversion of $\left.{ }^{2,6-\mathrm{Cl} 2 \mathrm{Ph}} \mathrm{PDP}{ }^{\mathrm{Ph}}\right) \mathrm{Fe}(\mathrm{thf})$. The NMR tube was returned to the glovebox and the solution was passed through a column of celite supported by a glass microfiber plug and collected in a $20 \mathrm{~mL}$ scintillation vial. The solvent was immediately removed in vacuo, affording a dark residue which was triturated with pentane. The resulting solid was transferred to a medium porosity glass frit and washed with three- $3 \mathrm{~mL}$ aliquots of pentane and dried in vacuo. Yield: $35 \mathrm{mg}, 0.042 \mathrm{mmol}, 65 \% .{ }^{1} \mathrm{H}$ NMR (400 MHz, benzene- $\left.d_{6}\right) \delta 23.45(\mathrm{~s}, 2 \mathrm{H}), 13.30(\mathrm{~s}, 4 \mathrm{H})$, $12.83(\mathrm{~s}, 2 \mathrm{H}), 11.17(\mathrm{~s}, 4 \mathrm{H}), 3.75(\mathrm{~s}, 4 \mathrm{H}), 3.62$ (s, 2H, para-phenylH), -4.41 (s, 1H, 4pyridine $H),-5.44(\mathrm{~s}, 2 \mathrm{H}),-52.54(\mathrm{~s}, 2 \mathrm{H}$, meta-mesityl $H),-159.03\left(\mathrm{~s}, 6 \mathrm{H}\right.$, ortho-mesityl-CH$\left.{ }_{3}\right),-$ 224.83 (s, 3H, para-mesityl- $\left.\mathrm{CH}_{3}\right)$. 


\section{Preparation of $\left.{ }^{2,6-C l 2 P h} P D P P h\right) F e(N m X y l)$.}

In a J. Young Tube $14 \mathrm{mg}(0.018 \mathrm{mmol})$ of $\left({ }^{2,6-\mathrm{Cl} 2 \mathrm{Ph}} \mathrm{PDP} \mathrm{Ph}^{\mathrm{Ph}}\right) \mathrm{Fe}(\mathrm{thf})$ was dissolved in $500 \mu \mathrm{L}$ of benzene- $d_{6}$. In a separate vial, $5 \mathrm{mg}$ (0.034 mmol, 1.9 eq.) of 2,6-dimethylphenyl azide was dissolved in $100 \mu \mathrm{L}$ of benzene- $d_{6}$. The azide solution was added to the NMR tube containing the solution of the iron complex. The tube was sealed and shaken rapidly for 30 seconds. A color change from red to brown as observed immediately. ${ }^{1} \mathrm{H}$ NMR spectroscopy indicated quantitative conversion to the product. ${ }^{1} \mathrm{H}$ NMR $\left(400 \mathrm{MHz}\right.$, benzene- $d_{6} ; \delta$, ppm): $133.78\left(6 \mathrm{H}\right.$, ortho- $\left.\mathrm{CH}_{3}\right),-48.61(2 \mathrm{H}$, meta- $\mathrm{Ph}),-5.07(1 \mathrm{H}, 4$-pyridine $H), 3.27(4 \mathrm{H}), 3.36(2 \mathrm{H})$, $3.90(4 \mathrm{H}), 11.18(4 \mathrm{H}), 12.22(2 \mathrm{H}), 12.88(4 \mathrm{H}), 24.36(2 \mathrm{H}), 171.20(1 \mathrm{H}$, para- $\mathrm{PhH})$. Note, resonances for free THF were not observed at 1.40 and $3.57 \mathrm{ppm}$, respectively, thus, complicating the unambiguous assignment of ${ }^{1} \mathrm{H}$ NMR resonances.

\section{Physical Measurements.}

${ }^{1} \mathrm{H}$ and ${ }^{13} \mathrm{C}\left\{{ }^{1} \mathrm{H}\right\}$ NMR spectra were acquired at $25{ }^{\circ} \mathrm{C}$ on a Varian Unity INOVA 600 $\mathrm{MHz}$ spectrometer equipped with a $5 \mathrm{~mm}$ inverse broadband PFG probe, on an Agilent $400 \mathrm{MHz}$ DD2 spectrometer equipped with a $5 \mathrm{~mm}$ One NMR probe, or a JNM-ECZ400S/L1 spectrometer equipped with a $5 \mathrm{~mm}$ ROYAL NMR probe. All chemical shifts are reported relative to $\mathrm{SiMe}_{4}$ using ${ }^{1} \mathrm{H}$ (residual) chemical shifts of the solvent as a secondary standard. Elemental analyses were performed at Robertson Microlit Laboratories, Inc., in Ledgewood, NJ. Room temperature magnetic susceptibility measurements were performed with a Johnson Matthey Mark 1 instrument that was calibrated with $\mathrm{HgCo}(\mathrm{SCN})_{4}$. Zero field ${ }^{57} \mathrm{Fe}$ Mössbauer spectra were collected on a SEE Co. Mössbauer spectrometer (MS4) with a ${ }^{57} \mathrm{Co} / \mathrm{Rh}$ radiation source at $80 \mathrm{~K}$ in constant acceleration mode. The temperature in the sample chamber was controlled by a Janis Research Co. CCS-850 He/ $\mathrm{N}_{2}$ cryostat within an accuracy of $\pm 0.3 \mathrm{~K}$. The data were calibrated 
relative to $\alpha$-iron at $298 \mathrm{~K}$. The fitting procedure to extract quantitative spectral parameters uses a least-squares Lorentzian fitting method implemented in the WMOSS software developed by SEE Co.

\section{X-ray Crystallography.}

Single crystals suitable for X-ray diffraction were coated with polyisobutylene oil (Sigma-Aldrich) in a drybox, mounted on a nylon loop, and then quickly transferred to the goniometer head of a Bruker AXS D8 Venture fixed-chi X-ray diffractometer equipped with a Triumph monochromator, a Mo K $\alpha$ radiation source $(\lambda=0.71073 \AA$ ), and a PHOTON 100 CMOS detector. The samples were cooled to $100 \mathrm{~K}$ with an Oxford Cryostream 700 system and optically aligned. The APEX3 software program (version 2016.9-0) ${ }^{18}$ was used for diffractometer control, preliminary frame scans, indexing, orientation matrix calculations, leastsquares refinement of cell parameters, and the data collection. Three sets of 12 frames each were collected using the omega scan method with a $10 \mathrm{~s}$ exposure time. Integration of these frames followed by reflection indexing and least-squares refinement produced a crystal orientation matrix for the crystal lattice that was used for the structural analysis. The data collection strategy was optimized for completeness and redundancy using the Bruker COSMO software suite. The space group was identified, and the data were processed using the Bruker SAINT+ program and corrected for absorption using SADABS. The structures were solved using direct methods (SHELXS) completed by subsequent Fourier synthesis and refined by full-matrix least-squares procedures using the programs provided by SHELXL-2014. ${ }^{19}$ 


\section{Density Functional Theory Calculations.}

All DFT calculations were performed with the ORCA program package. ${ }^{20}$ Geometry optimizations of the complexes and single-point calculations on the optimized geometries were carried out at the B3LYP level of DFT. ${ }^{21-23}$ The all-electron Gaussian basis sets were those developed by the Ahlrichs group. ${ }^{24-26}$ Triple- $\zeta$ quality basis sets def2-TZVP with one set of polarization functions on the metal and on the atoms directly coordinated to the metal center were used. For the carbon and hydrogen atoms, slightly smaller polarized split-valence def2-SVP basis sets were used that were of double- $\zeta$ quality in the valence region and contained a polarizing set of $d$ functions on the nonhydrogen atoms. Auxiliary basis sets to expand the electron density in the resolution-of-the-identity (RIJCOSX) ${ }^{27-29}$ approach were chosen to match the orbital basis. ${ }^{30-32}$ Throughout this chapter computational results are described by using the broken-symmetry (BS) approach by Ginsberg ${ }^{33}$ and Noodleman. ${ }^{34}$ Because several broken symmetry solutions to the spin-unrestricted Kohn-Sham equations may be obtained, the general notation $\mathrm{BS}(m, n)$ has been adopted, where $\mathrm{m}$ (n) denotes the number of spin-up (spin-down) electrons at the two interacting fragments. All molecular orbital and spin density plots were generated using the program Gabedit. ${ }^{35}$ Nonrelativistic single-point calculations on the optimized geometry were carried out to predict Mössbauer spectral parameters (isomer shifts and quadrupole splittings). These calculations employed the $\mathrm{CP}(\mathrm{PPP})$ basis set for iron.${ }^{36} \mathrm{Mössbauer}$ isomer shifts were calculated from the computed electron densities at the iron centers as previously described..$^{37,38}$ 


\section{References}

1. Chirik, P. J.; Weighardt, K. Radical Ligands Confer Nobility on Base-Metal Catalysts. Science 2010, 327, 794-795.

2. Park, Y.; Kim, Y.; Chang, S. Transition Metal-Catalyzed C-H Amination: Scope, Mechanism, and Applications. Chem. Rev. 2017, 117, 9247-9301.

3. Svastits, E. W.; Dawson, J. H.; Breslow, R.; Gellman, S. H. Functionalized Nitrogen Atom Transfer Catalyzed by Cytochrome P-450. J. Am. Chem. Soc. 1985, 107, 6427-6428.

4. King, E. R.; Betley, T. A. C-H Bond Amination from a Ferrous Dipyrromethene Complex. Inorg. Chem. 2009, 48, 2361-2363.

5. Hakey, B. M.; Darmon, J. M. Akhemedov, N. G.; Petersen, J. L. Milsmann, C. Reactivity of Pyridine Dipyrrolide Iron(II) Complexes with Organic Azides: C-H Amination and Iron Tetrazene Formation. Inorg. Chem. 2019, 58, 11028-11042.

6. Hennessy, E. T.; Betley, T. A. Complex N-Heterocycle Synthesis via Iron-Catalyzed, Direct C-H Bond Amination. Science 2013, 340, 591-595.

7. Meunier, B.; de Visser, S. P.; Shaik, S. Mechanism of Oxidation Reactions Catalyzed by Cytochrome P450 Enzymes. Chem. Rev. 2004, 104, 3947-3980.

8. See Chapter 3 of this dissertation for details.

9. Searles, K.; Fortier, S.; Khusniyarov, M. M.; Carroll, P. J.; Sutter, J.; Meyer, K.; Mindiola, D. J.; Caulton, K. G. A Cis-Divacant Octahedral and Mononuclear Iron(IV) Imide. Angew. Chem., Int. Ed. 2014, 53, 14139-14143.

10. Cowley, R. E.; Bill, E.; Neese, F.; Brenneseel, W. W.; Holland, P. L. Iron(II) Complexes with Redox-Active Tetrazene (RNNNNR) Ligands. Inorg. Chem. 2009, 48, 4828-4836. 
11. Baek, Y.; Betley, T. A. Catalytic C-H Amination Mediated by Dipyrrin Cobalt Imidos. J. Am. Chem. Soc. 2019, 141, 7797-7806.

12. Ye, S.; Neese, F. Accurate Modeling of Spin-State Energetics in Spin-Crossover Systems with Modern Density Functional Theory. Inorg. Chem. 2010, 49, 772-774.

13. Carsch, K. M.; DiMucci, I. M.; Iovan, D. A.; Li, A.; Zheng, S.; Titus, C. J.; Lee, S. J.; Irwin, K. D.; Nordlund, D.; Lancaster, K. M.; Betley, T. A. Synthesis of a Copper-Supported Triplet Nitrene Complex Pertinent to Copper-Catalyzed Amination. Science 2019, 365, 1138-1143.

14. Carsch, K. M.; Lukens, J. T.; DiMucci, I. M.; Iovan, D. A.; Zheng, S.; Lancaster, K. M.;

Betley, T. A. Electronic Structures and Reactivity Profiles of Aryl Nitrenoid-Bridged Dicopper Complexes. J. Am. Chem. Soc. 2020, 142, 2264-2276.

15. Dong, Y.; Lukens, J. T.; Clark, R. M.; Zheng, S.; Lancaster, K. M.; Betley, T. A. Synthesis, Characterization and C-H Amination Reactivity of Nickel Iminyl Complexes. Chem. Sci. 2020, $11,1260-1268$.

16. Cox, E. G.; Cruickshank, D. W. J.; Smith, J. A. S. The Crystal Structure of Benzene at $-3^{\circ}$ C. Proc. R. Soc. A 1958, 247, 1-21.

17. Peng, Y.; Fan, Y.; Li, S.; Li, B.; Xue, J.; Deng, Q. Iron-Catalyzed Nitrene Transfer Reaction of 4-Hydroxystilbenes with Aryl Azides: Synthesis of Imines via C=C Bond Cleavage. Org. Lett. 2019, 21, 8389-8394.

18. APEX3: Crystallographic Software Package for Single Crystal Data Collection, Reduction and Preparation, version 2016.9-0; Bruker AXS: Madison, WI, 2016.

19. Sheldrick, G. M. SHELXL-2014: Crystallographic Software Package; Bruker AXS, Inc.: Madison, WI, 2014. 
20. Neese, F. The ORCA Program System. Wiley Interdiscip. Rev. Comput. Mol. Sci. 2012, 2 , 73-78.

21. Becke, A. D. Density Functional Calculations of Molecular Bond Energies. J. Chem. Phys. 1986, $84,4524-4529$.

22. Becke, A. D. Density-Functional Thermochemistry. III. The Role of Exact Exchange. J. Chem. Phys. 1993, 98, 5648-5652.

23. Lee, C.; Yang, W.; Parr, R. G. Development of the Colle-Salvetti Correlation-Energy Formula into a Functional of the Electron Density. Phys. Rev. B: Condens. Matter Mater. Phys. 1988, 37, 785-789.

24. Schäfer, A.; Horn, H.; Ahlrichs, R. Fully Optimized Contracted Gaussian-Basis Sets for Atoms Li to Kr. J. Chem. Phys. 1992, 97, 2571-2577.

25. Schäfer, A.; Huber, C.; Ahlrichs, R. Fully Optimized Contracted Gaussian Basis Sets of Triple Zeta Valence Quality for Atoms Li to Kr. J. Chem. Phys. 1994, 100, 5829.

26. Weigend, F.; Ahlrichs, R. Balanced Basis Sets of Split Valence, Triple Zeta Valence and Quadruple Zeta Valence Quality for H to Rn: Design and Assessment of Accuracy. Phys. Chem. Chem. Phys. 2005, 7, 3297-3305.

27. Neese, F.; Wennmohs, F.; Hansen, A.; Becker, U. Efficient, Approximate and Parallel Hartree-Fock and Hybrid DFT Calculations. A "Chain-of-Spheres” Algorithm for the HartreeFock Exchange. Chem. Phys. 2009, 356, 98-109.

28. Kossmann, S.; Neese, F. Comparison of Two Efficient Approximate Hartee-Fock Approaches. Chem. Phys. Lett. 2009, 481, 240-243.

29. Neese, F. An Improvement of the Resolution of the Identity Approximation for the Formation of the Coulomb Matrix. J. Comput. Chem. 2003, 24, 1740-1747. 
30. Eichkorn, K.; Treutler, O.; Öhm, H.; Häser, M.; Ahlrichs, R. Auxiliary Basis Sets to Approximate Coulomb Potentials. Chem. Phys. Lett. 1995, 240, 283-289.

31. Eichkorn, K.; Treutler, O.; Öhm, H.; Häser, M.; Ahlrichs, R. Erratum: Auxiliary Basis Sets to Approximate Coulomb Potentials (Chem. Phys. Letters 240 (1995) 283). Chem. Phys. Lett. 1995, $242,652-660$.

32. Eichkorn, K.; Weigend, F.; Treutler, O.; Ahlrichs, R. Auxiliary Basis Sets for Main Row Atoms and Transition Metals and Their Use to Approximate Coulomb Potentials. Theor. Chem. Acc. 1997, 97, 119-24.

33. Ginsberg, A. P. Magnetic Exchange in Transition Metal Complexes 12. Calculation of Cluster Exchange Coupling Constants with the Xcu-Scattered Wave Method. J. Am. Chem. Soc. 1980, 102, 111-117.

34. Noodleman, L.; Peng, C. Y.; Case, D. A.; Mouesca, J.-M. Orbital Interactions, Electron Delocalization and Spin Coupling in Iron-Sulfur Clusters. Coord. Chem. Rev. 1995, 144, 199244.

35. Allouche, A.-R. Software News and Updates Gabedit-A Graphical User Interface for Computational Chemistry Softwares. J. Comput. Chem. 2011, 32, 174-182.

36. Neese, F. Prediction and Interpretation of the ${ }^{57} \mathrm{Fe}$ Isomer Shift in Mössbauer Spectra by Density Functional Theory. Inorg. Chim. Acta 2002, 337, 181-192.

37. Römelt, M.; Ye, S.; Neese, F. Calibration of Modern Density Functional Theory Methods for the Prediction of ${ }^{57} \mathrm{Fe}$ Mössbauer Isomer Shifts : Meta-GGA and Double-Hybrid Functionals. Inorg. Chem. 2009, 48, 784-785. 
38. Sinnecker, S.; Slep, L. D.; Bill, E.; Neese, F. Performance of Nonrelativistic and QuasiRelativistic Hybrid DFT for the Prediction of Electric and Magnetic Hyperfine Parameters in ${ }^{57}$ Fe Mössbauer Spectra. Inorg. Chem. 2005, 44, 2245-2254. 

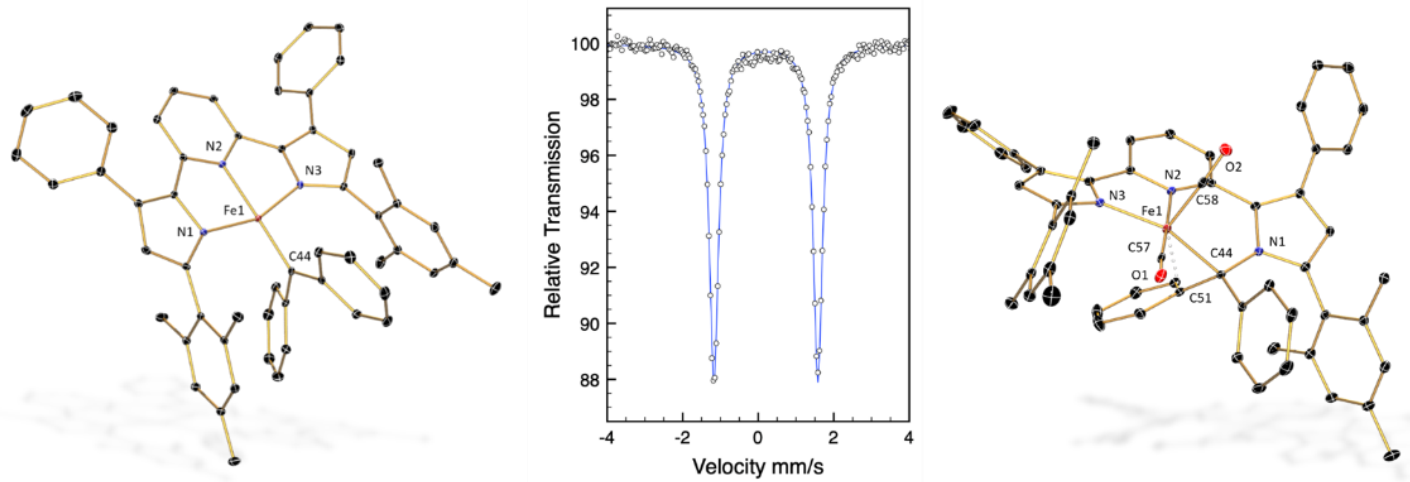

\section{CHAPTER VI: SYNTHESIS, CHARACTERIZATION, AND REACTIVITY OF A PYRIDINE DIPYRROLIDE IRON CARBENE COMPLEX}

\subsection{Abstract}

The paramagnetic iron carbene complexes $\left({ }^{\mathrm{Mes}} \mathrm{PDP}^{\mathrm{Ph}}\right) \mathrm{Fe}\left(\mathrm{CPh}_{2}\right)$ and $\left.{ }^{(2,6-\mathrm{Cl} 2 \mathrm{Ph}} \mathrm{PDP}^{\mathrm{Ph}}\right) \mathrm{Fe}\left(\mathrm{CPh}_{2}\right)$ have been prepared by the decomposition of diphenyldiazomethane in the presence of $\left({ }^{\mathrm{Mes}} \mathrm{PDP}^{\mathrm{Ph}}\right) \mathrm{Fe}($ thf $)$ and $\left({ }^{2,6-\mathrm{Cl} 2 \mathrm{Ph}} \mathrm{PDP}^{\mathrm{Ph}}\right) \mathrm{Fe}($ thf $)$, respectively. For $\left({ }^{\mathrm{Mes}} \mathrm{PDP}^{\mathrm{Ph}}\right) \mathrm{Fe}\left(\mathrm{CPh}_{2}\right)$ a thorough structural and spectroscopic study has been conducted, including $\mathrm{X}$-ray crystallographic characterization as well as ${ }^{1} \mathrm{H}$ NMR and variable-temperature and applied-field Mössbauer spectroscopies. A complementary density functional theory study has also been conducted to further elucidate the electronic structure of this complex, which may be described as containing an intermediate spin iron(III) ion engaged in antiferromagnetic coupling to a carbene radical monoanion, $\left(\mathrm{CR}_{2}{ }^{1-\bullet}\right)$.

Preliminary reactivity studies of $\left({ }^{\mathrm{Mes}} \mathrm{PDP}^{\mathrm{Ph}}\right) \mathrm{Fe}\left(\mathrm{CPh}_{2}\right)$ with carbon monoxide and isocyanides have also been investigated. Addition of carbon monoxide to $\left({ }^{\mathrm{Mes}} \mathrm{PDP}^{\mathrm{Ph}}\right) \mathrm{Fe}\left(\mathrm{CPh}_{2}\right)$ resulted in the insertion of the diphenylidene fragment, $\left(\mathrm{CPh}_{2}\right)$, into an iron pyrrolide nitrogen bond, forming a new carbon-nitrogen bond. This group transfer reaction is accompanied by ligation of two molecules of $\mathrm{CO}$ to the iron center. The resulting product, 
$\left(\mathrm{CPh}_{2}{ }^{\mathrm{Mes}} \mathrm{PDP}{ }^{\mathrm{Ph}}\right) \mathrm{Fe}(\mathrm{CO})_{2}$, has been characterized by X-ray crystallography, and NMR and

Mössbauer spectroscopies, confirming its structure and assigning its diamagnetic low-spin iron $\mathrm{Fe}^{\mathrm{II}}$ electronic ground state. Similarly, the reaction of $\left({ }^{\mathrm{Mes}} \mathrm{PDP}{ }^{\mathrm{Ph}}\right) \mathrm{Fe}\left(\mathrm{CPh}_{2}\right)$ with 2,6-

dimethylphenyl isocyanide results in an analogous carbene group transfer reaction, producing the isocyanide complex $\left(\mathrm{CPh}_{2}{ }^{\mathrm{Mes}} \mathrm{PDP}{ }^{\mathrm{Ph}}\right) \mathrm{Fe}\left(\mathrm{C} \equiv \mathrm{N}-2,6-\left(\mathrm{CH}_{3}\right)_{2} \mathrm{Ph}\right)_{2}$, which has also been thoroughly characterized. In benzene- $d_{6}$ solution, $\left(\mathrm{CPh}_{2}{ }^{\mathrm{Mes}} \mathrm{PDP}{ }^{\mathrm{Ph}}\right) \mathrm{Fe}\left(\mathrm{C} \equiv \mathrm{N}-2,6-\left(\mathrm{CH}_{3}\right)_{2} \mathrm{Ph}\right)_{2}$ is observed to undergo further carbene group transfer to an isocyanide ligand, resulting in the production of the corresponding ketenimine, $\mathrm{Ph}_{2} \mathrm{C}=\mathrm{C}=\mathrm{N}-\left(2,6-\left(\mathrm{CH}_{3}\right)_{2} \mathrm{Ph}\right)$ and $\left({ }^{\mathrm{Mes}} \mathrm{PDP}{ }^{\mathrm{Ph}}\right) \mathrm{Fe}\left(\mathrm{C} \equiv \mathrm{N}-2,6-\left(\mathrm{CH}_{3}\right)_{2} \mathrm{Ph}\right)_{3}$, as determined by ${ }^{1} \mathrm{H}$ NMR spectroscopy. The iron containing product of this reaction has been identified as the diamagnetic $\mathrm{Fe}^{\mathrm{II}}$ tris-isocyanide complex $\left({ }^{\mathrm{Mes}} \mathrm{PDP}^{\mathrm{Ph}}\right) \mathrm{Fe}\left(\mathrm{C} \equiv \mathrm{N}-2,6-\left(\mathrm{CH}_{3}\right)_{2} \mathrm{Ph}\right)_{3}$, arising from isocyanide ligand redistribution. Alternatively, when $\left({ }^{\mathrm{Mes}} \mathrm{PDP}{ }^{\mathrm{Ph}}\right) \mathrm{Fe}\left(\mathrm{CPh}_{2}\right)$ is treated with one equivalent of the sterically encumbered isocyanide, $\mathrm{C} \equiv \mathrm{N}-{ }^{1} \mathrm{Ad}$, the diamagnetic carbene isocyanide species $\left({ }^{\mathrm{Mes}} \mathrm{PDP}{ }^{\mathrm{Ph}}\right) \mathrm{Fe}\left(\mathrm{CPh}_{2}\right)\left(\mathrm{C} \equiv \mathrm{N}-{ }^{1} \mathrm{Ad}\right)$ is produced and has been characterized via ${ }^{1} \mathrm{H}$ NMR and X-ray crystallography. These results suggests the competency of isocyanide-ligated iron carbene species in carbene group transfer to isocyanides.

\subsection{Introduction}

Carbene complexes have become ubiquitous intermediates in the field of organometallic catalysis, having achieved widespread notoriety and recognition for their utility in a variety of synthetic methodologies. ${ }^{1-3}$ Of the many synthetic transformations that carbenes may facilitate, attractive examples include insertions into hydrogen-element (i.e. $\mathrm{C}-\mathrm{H}, \mathrm{N}-\mathrm{H}$, and $\mathrm{O}-\mathrm{H}$ ) bonds, cyclopropanation, and most notably, the olefin metathesis reaction. ${ }^{4-14}$ Historically, carbene complexes have been classified into two limiting classes depending on the nature of the electronic structure of the carbene fragment. Electrophilic carbenes are known as Fischer-type, 
while alternatively, Schrock-type carbenes are nucleophilic in nature. Fischer carbenes possess a bonding interaction between a lone pair with singlet carbene parentage and a vacant metal orbital of appropriate symmetry. The additional interaction of a filled metal d orbital with a vacant carbene $\mathrm{p}$ orbital results in a donor-acceptor bonding motif. Additional stabilization of the vacant p orbital of the Fischer-carbene is imparted by the presence of heteroatoms possessing lone pairs adjacent to the carbene, commonly oxygen and nitrogen atoms. ${ }^{15}$ In contrast, Schrock carbenes, which are comprised strictly of hydrocarbon structures, possess triplet ground states. The triplet carbene is engaged in highly covalent bonding with a triplet metal center, with the bonding being polarized towards the carbene, rendering it nucleophilic. ${ }^{15}$ More recently, the Grubbs family of catalysts, which features ruthenium (II) centers and an electrophilic carbene ligand distinct from the Fischer description has been recognized as a privileged class of catalysts in olefin metathesis chemistry. ${ }^{11}$ Schrock type carbenes are also highly active in olefin metathesis reactions and have received significant attention in their own right (Figure 6.1). ${ }^{9,10}$
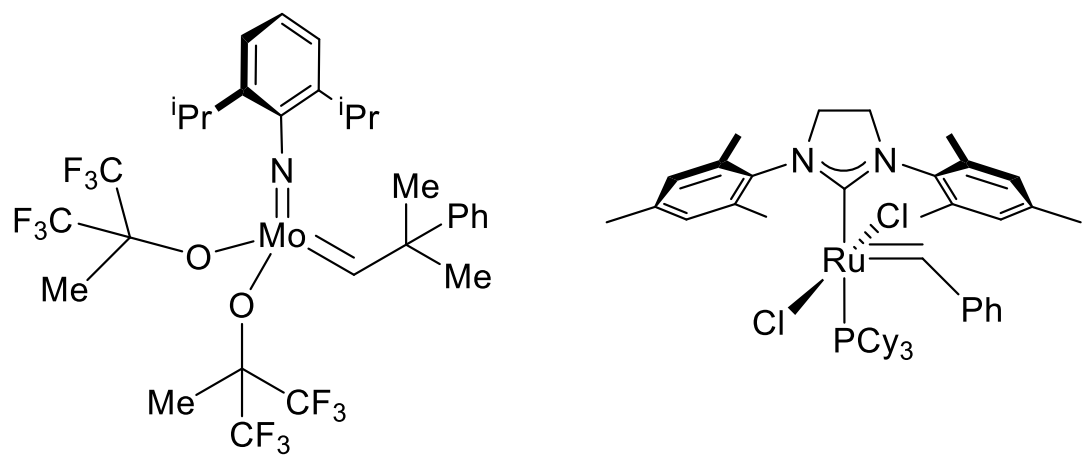

Figure 6.1. Examples of popular Schrock (left) and Grubbs (right) metathesis catalysts.

Although tremendous success has been realized by the Schrock and Grubbs catalyst systems over the past decades, each does possess inherent limitations. Notably, the Schrock type catalysts are air and moisture sensitive organometallic reagents, while the air-stable Grubbs catalyst systems employ precious ruthenium. In light of the latter, researchers have developed an 
interest in extending the olefin metathesis reaction to iron, the $3 \mathrm{~d}$ congener of ruthenium. The development of an iron-catalyzed olefin metathesis reaction is highly attractive in consideration of the cost reduction associated with the replacement of scarce ruthenium with a base metal alternative. In addition to iron being the most abundant of the transition metals, it also is recognized as benign. In consideration of the potential impact of an iron-catalyzed olefin metathesis reaction, researchers have sought to prepare iron complexes bearing carbene or alkylidene type ligands to explore their reactivity profiles. A host of examples are presented in Figure 6.2.

Despite the recent interest in the development of a molecular iron metathesis catalyst, evidence for iron carbene complexes actually predate Schrock's initial report of the first transition metal alkylidene complex. ${ }^{16}$ In early reports, Jolly and Green detailed suggested the production of the parent iron methylidene complex, $\left[\left(\eta^{5}-\mathrm{C}_{5} \mathrm{H}_{5}\right)\left(\eta^{1}-\mathrm{CH}_{2}\right) \mathrm{Fe}(\mathrm{CO})_{2}\right]\left[\mathrm{BF}_{4}\right]$, by treatment of $\left(\eta^{5}-\mathrm{C}_{5} \mathrm{H}_{5}\right) \mathrm{Fe}(\mathrm{CO})_{2}\left(\mathrm{CH}_{3}\right)$ with strong acids. ${ }^{17,18} \mathrm{~A}$ decade later, the first spectroscopic characterization of an iron carbene was accomplished by Brookhart and coworkers. ${ }^{13} \mathrm{C}$ NMR spectroscopy identified a doublet carbon resonance at $342.4 \mathrm{ppm}$ with ${ }^{1} J_{\mathrm{C}-\mathrm{H}}=146 \mathrm{~Hz}$, consistent with the iron benzylidene complex, $\left[\left(\eta^{5}-\mathrm{C}_{5} \mathrm{H}_{5}\right) \mathrm{Fe}(\mathrm{CO})_{2}(\mathrm{CHPh})\right] .{ }^{19}$ Subsequently, the research of iron carbenes has seen steady growth and now is a mature field with complexes characterized within a number of coordination environments.

The first examples of crystallographically characterized iron carbene complexes were reported, by Jones et al. Structural analysis of $\left[\left(\eta^{5}-\mathrm{C}_{5} \mathrm{H}_{5}\right)-\left(\eta^{1}-\mathrm{C}_{7} \mathrm{H}_{6}\right) \mathrm{Fe}(\mathrm{CO})_{2}\right]\left[\mathrm{PF}_{6}\right]$ and $\left[\left(\eta^{5}-\mathrm{C}_{5} \mathrm{H}_{5}\right)\left(\eta^{1}-\mathrm{C}_{11} \mathrm{H}_{8}\right) \mathrm{Fe}(\mathrm{CO})_{2}\right]\left[\mathrm{PF}_{6}\right]$ determined the iron carbene bond distances in these complexes to be 1.979(3) and 1.996(2) $\AA$, respectively. ${ }^{20,21}$ Lapinte then reported the structural characterization of the iron-ethylidene complex, $\left[\left(\eta^{5}-\mathrm{C}_{5} \mathrm{Me}_{5}\right) \mathrm{Fe}(\mathrm{dppe})(\mathrm{C}(\mathrm{H}) \mathrm{Me})\right][\mathrm{OTf}]$, where 
dppe $=$ ethylenebis $($ diphenylphosphine $)$, featuring an iron carbene bond distance of $1.787(8) \AA .^{22}$ Guerchais followed with the X-ray crystallographic analysis of related $\left[\left(\eta^{5}-\mathrm{C}_{5} \mathrm{Me}_{5}\right) \mathrm{Fe}(\mathrm{CO})-\right.$ $\left.\left\{\eta^{2}-\mathrm{C}(\mathrm{OMe}) \mathrm{C}_{6} \mathrm{H}_{4}-o-\mathrm{Cl}\right\}\right][\mathrm{OTf}]$ with an iron carbene bond length of $1.857(6) \AA{ }^{23}$

Complimentary synthetic investigations have included the exploration of macrocyclic ligands as supporting platforms for iron carbene fragments. Floriani and coworkers have reported the characterization of two diamagnetic $(\operatorname{tmtaa}) \mathrm{Fe}\left(\mathrm{CPh}_{2}\right)(\mathrm{tmtaa}=$ tetramethyldibenzotetraazaannulene) complexes. ${ }^{24,25}$ An additional report from the same group described the X-ray studies of the paramagnetic calixarene complexes $\left[\left\{p^{t} \mathrm{Bu}-\right.\right.$ calix $\left.\left.[4]-(\mathrm{O})_{2}(\mathrm{OR})_{2}\right\} \mathrm{Fe}\left(\mathrm{CPh}_{2}\right)\right]$, where $\mathrm{R}=\mathrm{Me}$ or $\mathrm{SiMe}_{3}$. The iron carbene bond lengths were found to be 1.943(8) $\AA$ and 1.958(5) $\AA$. SQUID magnetometry measurements are consistent with high-spin $\mathrm{Fe}^{\mathrm{II}}$ electronic structures for these species. ${ }^{26} \mathrm{~A}$ crystal structure of the diamagnetic porphyrin ligated-iron carbene $(\mathrm{TPFPP}) \mathrm{Fe}\left(\mathrm{CPh}_{2}\right)(\mathrm{TPFPP}=$ meso-tetrakis(pentafluorophenyl)porphyrinato dianion) with a short iron-carbon bond length of 1.794(3) $\AA$ has been reported by the Che group. ${ }^{27}$ An initial assignment of this compound as a low-spin $\mathrm{Fe}^{\mathrm{IV}}$ complex with a dianionic alkylidene ligand was made based on Mössbauer spectroscopic measurements. Li and coworkers have disclosed an in depth study revisiting the electronic structure of (TPFPP)Fe( $\left(\mathrm{CPh}_{2}\right)$ as well as the closely related dichlorocarbene analogues, (TPP)Fe( $\left(\mathrm{CCl}_{2}\right)$, and (TTP)Fe $\left(\mathrm{CCl}_{2}\right)$. A combination of X-ray crystallography, Fe K-edge X-ray absorption near edge spectroscopy (XANES), and variable temperature applied field Mössbauer spectroscopy has elucidated the electronic structure of these compounds as low-spin ferrous species with highly covalent iron carbene interactions. ${ }^{28}$ More recently, Che et al. have also recently reported a closely related family of diamagnetic iron porphyrin adamantylidene complexes, including structurally characterized (TPFPP)Fe(Ad). ${ }^{29} \mathrm{~A}$ combined theoretical and experimental study has concluded that these complexes also feature 
low-spin $\mathrm{Fe}^{\mathrm{II}}$ centers with ancillary neutral carbene donors. These electronic structural assignments for the iron porphyrin carbene derivatives are in agreement with extensive computational studies and other extensive experimental investigations that have been conducted by other groups. ${ }^{30-32}$

In contrast to the ever growing number of porphyrin based iron carbene complexes, Jenkins and coworkers have reported the synthesis and X-ray crystallographic characterization of a unique "all carbene" iron complex, featuring a tetra-N-heterocyclic carbene macrocycle and diphenylidene ligand. ${ }^{33}$ Akin to other macrocycle supported iron carbenes, $\left[\left({ }^{(S, S)-1,2-\mathrm{Cy}, \mathrm{BMe} 2} \mathrm{TC}^{H}\right) \mathrm{Fe}\left(\mathrm{CPh}_{2}\right)\right]$ is also diamagnetic and features a short iron-carbene bond length of 1.814(4) $\AA$. A preliminary assignment as a low-spin $\mathrm{Fe}^{\mathrm{IV}}$ complex has been made on the basis of electrochemical experiments and the diamagnetism of the complex observed by ${ }^{1} \mathrm{H} \mathrm{NMR}$ spectroscopy.

The first examples of pincer ligand iron alkylidene complexes were structurally characterized by Chirik. ${ }^{34}$ Paramagnetic ( $\left.{ }^{\mathrm{Et}} \mathrm{PDI}\right) \mathrm{Fe}\left(\mathrm{CPh}_{2}\right)$ and $\left({ }^{\mathrm{Me}} \mathrm{EtPDI}\right) \mathrm{Fe}\left(\mathrm{CPh}_{2}\right){ }^{\mathrm{Et}} \mathrm{PDI}=2,6$ $\left.\left(2,6-\mathrm{Et}_{2} \mathrm{C}_{6} \mathrm{H}_{3} \mathrm{~N}=\mathrm{CMe}\right)_{2} \mathrm{C}_{5} \mathrm{H}_{3} \mathrm{~N}\right)$ and $\left.\left.{ }^{\mathrm{Me}} \mathrm{EtPDI}=2,6-\left(2,6-\mathrm{Me}_{2} \mathrm{C}_{6} \mathrm{H}_{3} \mathrm{~N}=\mathrm{CEt}\right)_{2} \mathrm{C}_{5} \mathrm{H}_{3} \mathrm{~N}\right)\right)$ are the first examples of iron complexes featuring carbene radical ligands. A combined experimental and computational study of these compounds suggested the presence of high-spin $\mathrm{Fe}^{\mathrm{II}}$ centers engaged in antiferromagnetic coupling with redox-active bis(imino)pyridine and carbene radical ligands. Although these complexes are not active cyclopropanation catalysts, a reaction protocol has recently been designed that demonstrates related Fe PDI complexes as highly active carbene transfer catalysts. ${ }^{35}$ Additionally, carbene radical complexes have been identified as important intermediates in cobalt and iron catalyzed cyclopropanation catalysis. ${ }^{36-40}$ Other strategies for synthesizing iron carbene complexes have recently been disclosed by the Holland and 
Wolczanski groups, respectively. ${ }^{41-44}$ Table 6.1 summarizes a number of the notable iron carbene complexes that have been discussed and also includes their iron-carbene bond lengths, oxidation states, and spin states.
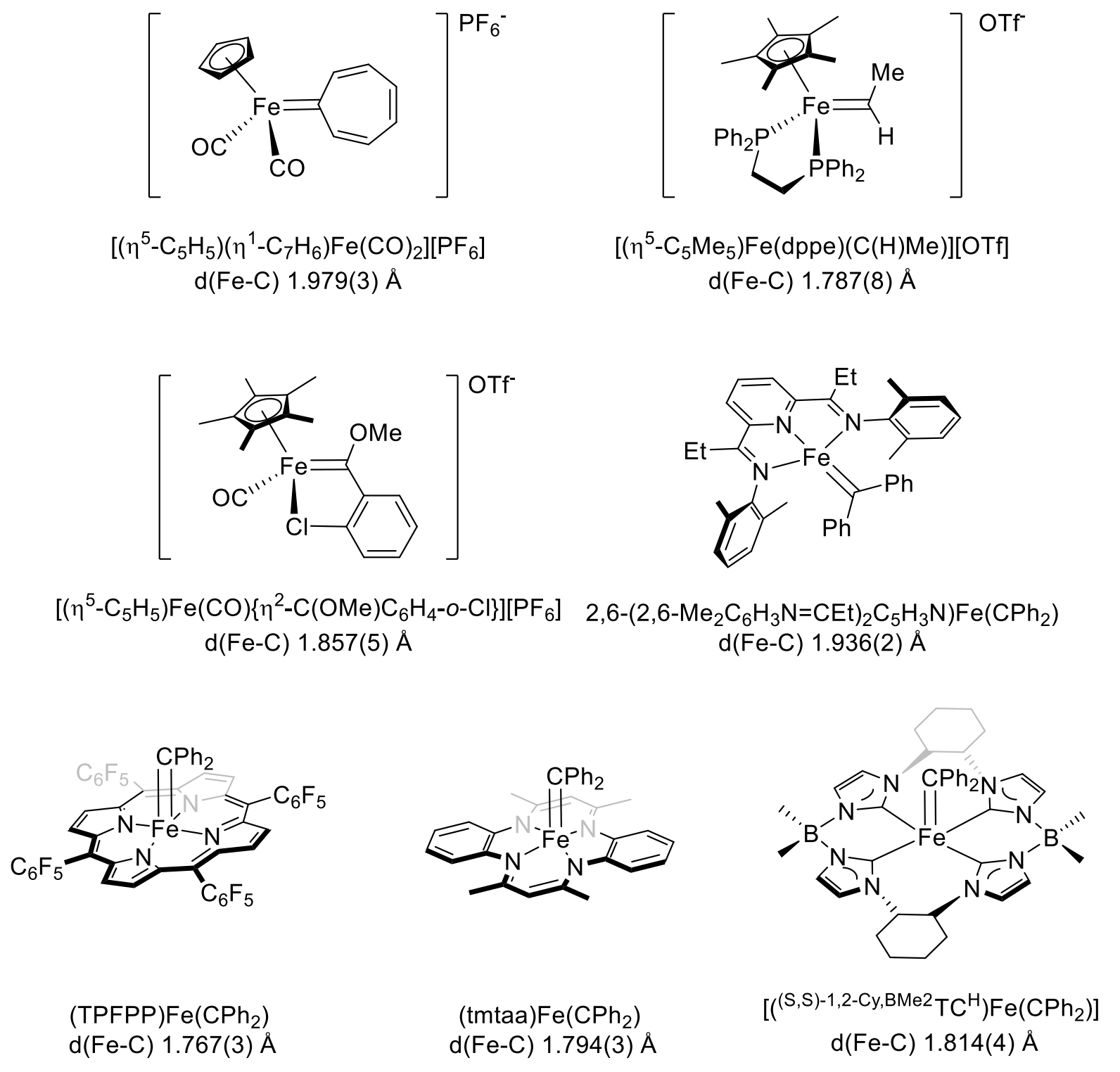

Figure 6.2. Examples of selected crystallographically characterized mononuclear iron carbene complexes and their corresponding iron carbene bond lengths. 
Table 6.1. Oxidation state, spin state, and iron carbene bond distances for selected crystallographically characterized iron carbene complexes.

\begin{tabular}{|c|c|c|c|c|}
\hline & $\begin{array}{l}\text { Oxidation } \\
\text { State }\end{array}$ & $\begin{array}{l}\text { Spin } \\
\text { State }^{a} \\
\end{array}$ & Fe-Carbene Bond Distance / $\AA$ & $\operatorname{Ref}$ \\
\hline$\left[\left(\eta^{5}-\mathrm{C}_{5} \mathrm{H}_{5}\right)\left(\eta^{1}-\mathrm{C}_{7} \mathrm{H}_{6}\right) \mathrm{Fe}(\mathrm{CO})_{2}\right]\left[\mathrm{PF}_{6}\right]$ & $\mathrm{Fe}^{\mathrm{II}}$ & 0 & $1.996(2)$ & 21 \\
\hline$\left[\left(\eta^{5}-\mathrm{C}_{5} \mathrm{Me}_{5}\right) \mathrm{Fe}(\mathrm{dppe})(\mathrm{C}(\mathrm{H}) \mathrm{Me})\right][\mathrm{OTf}]$ & $\mathrm{Fe}^{\mathrm{II}}$ & 0 & $1.787(8)$ & 22 \\
\hline $\begin{array}{c}{\left[\left(\eta^{5}-\mathrm{C}_{5} \mathrm{Me}_{5}\right)\right.} \\
\left.\mathrm{Fe}(\mathrm{CO})\left\{\eta^{2}-\mathrm{C}(\mathrm{OMe}) \mathrm{C}_{6} \mathrm{H}_{4}-o-\mathrm{Cl}\right\}\right][\mathrm{OTf}]\end{array}$ & $\mathrm{Fe}^{\mathrm{II}}$ & 0 & $1.857(6)$ & 23 \\
\hline (tmtaa) $\mathrm{Fe}\left(\mathrm{CPh}_{2}\right)$ & $\mathrm{Fe}^{\mathrm{II}}$ & 0 & $1.794(3)$ & 24 \\
\hline 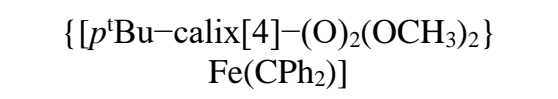 & $\mathrm{Fe}^{\mathrm{II}}$ & 2 & $1.943(8)$ & 26 \\
\hline (TPFPP)Fe( $\left(\mathrm{CPh}_{2}\right)$ & $\mathrm{Fe}^{\mathrm{II}}$ & 0 & $1.794(3)$ & 27 \\
\hline$\left[\left({ }^{(S, S)-1,2-\mathrm{Cy}, \mathrm{BMe} 2} \mathrm{TC}^{H}\right) \mathrm{Fe}\left(\mathrm{CPh}_{2}\right)\right]$ & $\mathrm{Fe}^{\mathrm{IV}}$ & 0 & $1.814(4)$ & 33 \\
\hline$\left({ }^{\mathrm{Me}} \mathrm{EtPDI}\right) \mathrm{Fe}\left(\mathrm{CPh}_{2}\right)$ & $\mathrm{Fe}^{\mathrm{II}}$ & 2 & $1.936(2)$ & 34 \\
\hline $\begin{array}{c}{\left[\text { mer- }\left\{\kappa-\mathrm{C}, \mathrm{N}, \mathrm{C}-\left(2-\mathrm{C}_{6} \mathrm{H}_{4}\right) \mathrm{CH}=\mathrm{N}\right.\right.} \\
\left.\left.\left(1,2-\mathrm{C}_{6} \mathrm{H}_{4}\right) \mathrm{C}\left({ }^{\mathrm{P}} \mathrm{Pr}\right)\right\} \mathrm{Fe}\left(\mathrm{PMe}_{3}\right)_{3}\right]\left[\mathrm{BAr}_{4}\right]\end{array}$ & $\mathrm{Fe}^{\mathrm{II}}$ & 0 & $1.899(3)$ & 41 \\
\hline $\begin{array}{c}{\left[\mathrm{MeC}\left[\mathrm{C}(\mathrm{Me}) \mathrm{N}-\left(2,6-\mathrm{Me}_{2} \mathrm{C}_{6} \mathrm{H}_{3}\right)\right]_{2}\right.} \\
\mathrm{Fe}_{2}\left(\mathrm{C}(\mathrm{H})\left(\mathrm{SiMe}_{3}\right)\right.\end{array}$ & $\mathrm{Fe}^{\mathrm{II}}$ & 2 & $1.956(6)-1.973(6)$ & 40 \\
\hline$\left({ }^{\mathrm{Mes}} \mathrm{PDP}^{\mathrm{Ph}}\right) \mathrm{Fe}\left(\mathrm{CPh}_{2}\right)$ & $\mathrm{Fe}^{\mathrm{III}}$ & 1 & $1.850(2)$ & This work \\
\hline$\left({ }^{\text {Mes }} \mathrm{PDP}^{\mathrm{Ph}}\right) \mathrm{Fe}\left(\mathrm{CPh}_{2}\right)\left(\mathrm{C} \equiv \mathrm{N}-{ }^{-1} \mathrm{Ad}\right)$ & $\mathrm{Fe}^{\mathrm{II}}$ & 0 & $1.801(3)$ & This work \\
\hline
\end{tabular}

${ }^{a}$ The spin-state equals $2 \mathrm{~S}$, where $\mathrm{S}$ is the total number of unpaired electrons in the compound.

Despite the growing number of iron carbene complexes which feature various ligands, oxidation states, and coordination motifs, to date none of these examples have demonstrated activity in the olefin metathesis reaction. Based on orbital analysis, Hoffman has suggested the necessity of an iron alkylidene complex in the +4 oxidation state for the realization of an active metathesis catalyst of iron. ${ }^{45}$ In consideration of this suggestion, the electronic rich, dianionic pyridine dipyrrolide (PDP) ligand framework was identified as a potential platform for the stabilization of formally $\mathrm{Fe}^{\mathrm{IV}}$ iron alkylidene species. Recently, Mindiola and coworkers have reported the first example of a pyridine dipyrrolide iron complex featuring a metal-ligand multiple bond. ${ }^{46}$ Spectroscopic and computational characterization of diamagnetic 
$\left.{ }^{(\mathrm{BBu}} \mathrm{PDP}^{\mathrm{tBu}}\right) \mathrm{Fe}\left(\mathrm{N}^{1} \mathrm{Ad}\right)$ confirmed its identity as a genuine $\mathrm{Fe}^{\mathrm{IV}}$ complex featuring a closed-shell dianionic imido ligand.

Following this report, the synthesis of the closely related analogues $\left({ }^{\mathrm{Mes}} \mathrm{PDP}{ }^{\mathrm{Ph}}\right) \mathrm{Fe}(\mathrm{NMes})$, $\left.{ }_{\left({ }^{2,6-C l 2 P h}\right.} \mathrm{PDP}^{\mathrm{Ph}}\right) \mathrm{Fe}\left(\mathrm{N}^{1} \mathrm{Ad}\right)$, and $\left.{ }^{2,6-\mathrm{Cl} 2 \mathrm{Ph}} \mathrm{PDP}^{\mathrm{Ph}}\right) \mathrm{Fe}(\mathrm{NMes})$ has been accomplished and presented in Chapters 3 and 5 of this dissertation, respectively. ${ }^{47}$ Crystallographically characterized $\left.{ }^{2,6-\mathrm{Cl} 2 \mathrm{Ph}} \mathrm{PDP}^{\mathrm{Ph}}\right) \mathrm{Fe}\left(\mathrm{N}^{1} \mathrm{Ad}\right)$ also possesses a low-spin $\mathrm{Fe}^{\mathrm{IV}}$ center and similar coordination environment to $\left.{ }^{(\mathrm{Bu}} \mathrm{PDP}^{\mathrm{tBu}}\right) \mathrm{Fe}\left(\mathrm{N}^{1} \mathrm{Ad}\right)$. The precedent provided by these complexes featuring metal-ligand multiple bonds suggests that access to an $\mathrm{Fe}^{\mathrm{IV}}$ alkylidene within the pyridine dipyrrolide ligand framework may also be possible. In contrast to $\left({ }^{\mathrm{R}} \mathrm{PDP} \mathrm{R}^{\mathrm{R}}\right) \mathrm{Fe}\left(\mathrm{N}^{1} \mathrm{Ad}\right)$ analogues, spectroscopically characterized $\left({ }^{\mathrm{Mes}} \mathrm{PDP}^{\mathrm{Ph}}\right) \mathrm{Fe}(\mathrm{NMes})$ and $\left({ }^{2,6-\mathrm{Cl} 2 \mathrm{Ph}} \mathrm{PDP}^{\mathrm{Ph}}\right) \mathrm{Fe}(\mathrm{NMes})$ are paramagnetic in nature. Computational analysis has suggested square-planar coordination geometries for these complexes and an electronic structure description of intermediate spin ferric centers $\left(\mathrm{S}_{\mathrm{Fe}}=3 / 2\right)$ engaged in antiferromagnetic coupling to iminyl radical ligands $\left(\mathrm{S}_{\mathrm{L}}=1 / 2\right)$, invoking assignment of an overall $\mathrm{S}=1$ ground state. The observed line broadening and paramagnetic shifts of the ${ }^{1} \mathrm{H}$ NMR resonances for these iron imide species is strong evidence of their paramagnetic ground state electronic structures.

With these details in mind, the question arose as to whether hypothetical $\left.{ }^{(\mathrm{Ar} P D P}{ }^{\mathrm{Ph}}\right) \mathrm{Fe}\left(\mathrm{CR}_{2}\right)$ complexes would adopt closed-shell diamagnetic $\mathrm{Fe}^{\mathrm{IV}}$ ground states with dianionic alkylidene ligands in a cis-divacant octahedral geometry, or alternatively, if the coordination environment available within $\left({ }^{\mathrm{Ar}} \mathrm{PDP}^{\mathrm{Ph}}\right)$ ligand motifs would afford square-planar carbene complexes featuring paramagnetic electronic structures with higher spin states. Herein is described the synthesis, characterization, and reactivity of iron carbene species synthesized from the reaction of high-spin $\left({ }^{\mathrm{Ar}} \mathrm{PDP}{ }^{\mathrm{Ph}}\right) \mathrm{Fe}(\mathrm{thf})$ complexes and diphenyldiazomethane. 


\subsection{Reactivity of $\left({ }^{\mathrm{Ar} P D P} \mathrm{Ph}^{\mathrm{Ph}}\right) \mathrm{Fe}($ thf $)$ Complexes with Diphenyldiazomethane}

Akin to the generation of iron imides in the context of pyridine dipyrrolide (PDP) iron complexes, it was reasoned that high-spin Fe(II) PDP solvento complexes would offer efficient access to potential high-valent Fe carbene complexes via the decomposition of diazo reagents and subsequent carbene capture at iron. ${ }^{47}$ Treatment of benzene- $d_{6}$ solutions of ( $\left.{ }^{\mathrm{Mes}} \mathrm{PDP}{ }^{\mathrm{Ph}}\right) \mathrm{Fe}(\mathrm{thf})$ or $\left.{ }^{2,6-\mathrm{Cl} 2 \mathrm{Ph}} \mathrm{PDP}^{\mathrm{Ph}}\right) \mathrm{Fe}(\mathrm{thf})$ with a diphenyldiazomethane solution of the same solvent at room temperature afforded a gradual color change from dark red to dark brown over $16 \mathrm{hrs} .{ }^{1} \mathrm{H}$ NMR spectroscopic analysis revealed the complete consumption of the high-spin $\mathrm{Fe}^{\mathrm{II}}$ starting materials with concomitant formation of new paramagnetic species, as evidenced by 12 and 10 resonances spanning a range of $-55.22 \mathrm{ppm}$ to $-91.41 \mathrm{ppm}$ and $-55.35 \mathrm{ppm}$ to $92.33 \mathrm{ppm}$ for the $\left({ }^{\mathrm{Mes}} \mathrm{PDP}{ }^{\mathrm{Ph}}\right) \mathrm{Fe}\left(\mathrm{CPh}_{2}\right)$ (Figure 6.3) and $\left.{ }^{2,6-\mathrm{Cl} 2 \mathrm{Ph}} \mathrm{PDP}^{\mathrm{Ph}}\right) \mathrm{Fe}\left(\mathrm{CPh}_{2}\right)$, respectively. The number of observed resonances suggested $\mathrm{C}_{2 v}$ symmetric products, and relative integrations of the resonances were consistent with either the diazoalkane adducts $\left({ }^{\mathrm{Ar} P D P}{ }^{\mathrm{Ph}}\right) \mathrm{Fe}\left(\mathrm{N}_{2} \mathrm{CPh}_{2}\right)$, or carbenes of the formulation $\left({ }^{\mathrm{Ar} P D P}{ }^{\mathrm{Ph}}\right) \mathrm{Fe}\left(\mathrm{CPh}_{2}\right)$. 


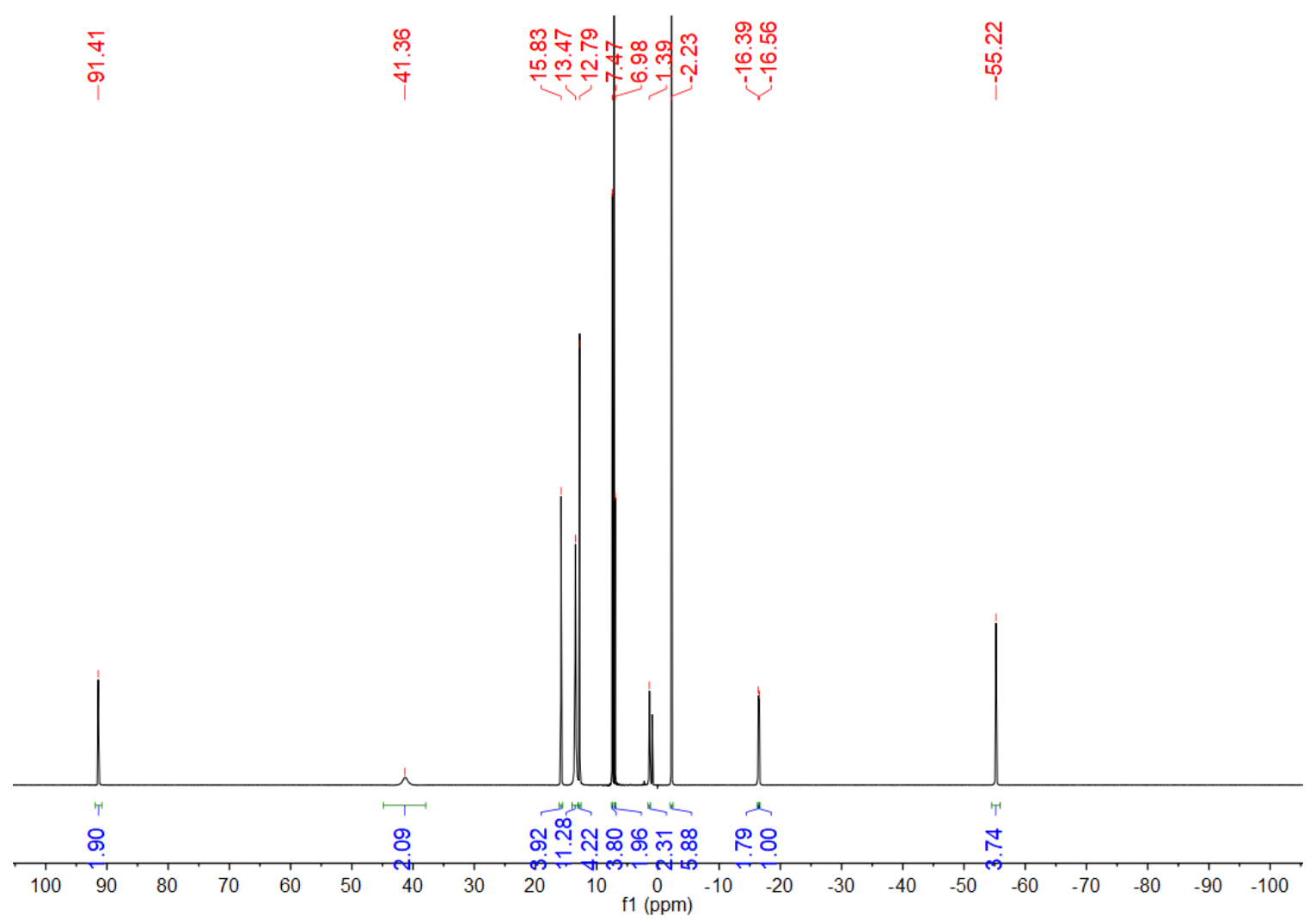

Figure 6.3. ${ }^{1} \mathrm{H}$ NMR spectrum of $\left({ }^{\mathrm{Mes}} \mathrm{PDP}{ }^{\mathrm{Ph}}\right) \mathrm{Fe}\left(\mathrm{CPh}_{2}\right)$ at $600 \mathrm{MHz}$ in benzene- $d_{6}$. The unmarked resonances corresponds to pentane present in the sample.

In consideration of these results, isolation of the product arising from the reaction of diphenyldiazomethane with $\left({ }^{\mathrm{Mes}} \mathrm{PDP}^{\mathrm{Ph}}\right) \mathrm{Fe}($ thf $)$ was pursued on a preparative scale. Accordingly, treatment of a diethyl ether slurry of $\left({ }^{\mathrm{Mes}} \mathrm{PDP} \mathrm{Ph}^{\mathrm{Ph}}\right) \mathrm{Fe}(\mathrm{thf})$ with a diphenyldiazomethane solution of the same solvent at room temperature afforded after a gradual color change from dark red to dark brown accompanied by a precipitate after $16 \mathrm{hrs}$. The solid was collected via vacuum filtration and after workup (vide infra) was isolated as a dark brown powder. An infrared spectrum of the product was acquired in $\mathrm{KBr}$ (Figure 6.4) and was devoid of any discernable $\mathrm{N}=\mathrm{N}$ diazo stretching mode $\left(2032 \mathrm{~cm}^{-1} \text { in } \mathrm{CPh}_{2} \mathrm{~N}_{2}\right)^{48}$, which suggested that the identity of the product was unlikely to be the diazoalkane adduct ( $\left.{ }^{\mathrm{Mes}} \mathrm{PDP}{ }^{\mathrm{Ph}}\right) \mathrm{Fe}\left(\mathrm{N}_{2} \mathrm{CPh}_{2}\right)$. 


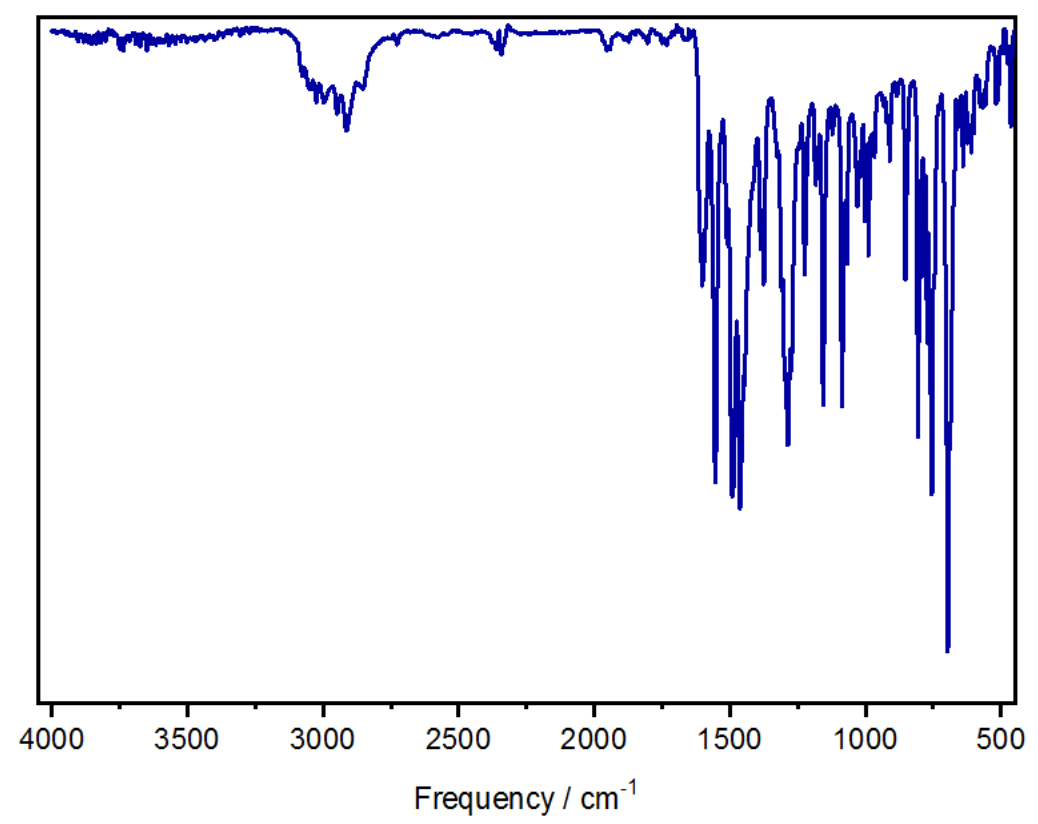

Figure 6.4. IR spectra of $\left({ }^{\mathrm{Mes}} \mathrm{PDP} \mathrm{Ph}^{\mathrm{Ph}}\right) \mathrm{Fe}\left(\mathrm{CPh}_{2}\right)(\mathrm{KBr})$.

Single crystals of the product suitable for X-ray crystallography were obtained by diffusion of pentane into a toluene solution of the purified material at $-35^{\circ} \mathrm{C}$. The $\mathrm{X}$-ray study identified the species as the iron carbene complex, $\left({ }^{\mathrm{Mes}} \mathrm{PDP}{ }^{\mathrm{Ph}}\right) \mathrm{Fe}\left(\mathrm{CPh}_{2}\right)(\mathrm{Scheme} 6.1)$. The compound was determined to be a toluene solvate and crystallized in the monoclinic space group $\mathrm{P} 21 / \mathrm{n}$. An ORTEP representation of $\left({ }^{\mathrm{Mes}} \mathrm{PDP} \mathrm{Ph}^{\mathrm{Ph}}\right) \mathrm{Fe}\left(\mathrm{CPh}_{2}\right)$ is depicted in Figure 6.5.

The geometry about the iron center is best described as square planar, as defined by the $\kappa^{3}$-PDP pincer and diphenylidene ligand $\left(\tau_{4}=0.17\right)$. It should be however be noted that an idealized square-planar structure cannot be realized for pyridine dipyrrolide ligand complexes as the geometric constraints imposed by the bite angles of the PDP chelate rigorously enforces distorted structures. In ( $\left.{ }^{\mathrm{Mes} P D P}{ }^{\mathrm{Ph}}\right) \mathrm{Fe}\left(\mathrm{CPh}_{2}\right)$, this is evidenced by the $\mathrm{N} 1-\mathrm{Fe} 1-\mathrm{N} 2, \mathrm{~N} 2-\mathrm{Fe} 1-\mathrm{N} 3$, and N1-Fe1-N3 bond angles of $80.27(8)^{\circ}, 159.35(8)^{\circ}$, and $79.58(8)^{\circ}$. The carbene fragment is nearly planar, as evidenced by the N2-Fe1-C44 angle of $176.20(9)^{\circ}$ and the overall $\mathrm{C}_{2 v}$ 
symmetric square planar geometry of $\left({ }^{\mathrm{Mes}} \mathrm{PDP}^{\mathrm{Ph}}\right) \mathrm{Fe}\left(\mathrm{CPh}_{2}\right)$ in the solid state is in agreement with the solution phase ${ }^{1} \mathrm{H}$ NMR spectrum. Furthermore, the bond angles about the carbene carbon, C44, are consistent with $\mathrm{sp}^{2}$ hybridization.

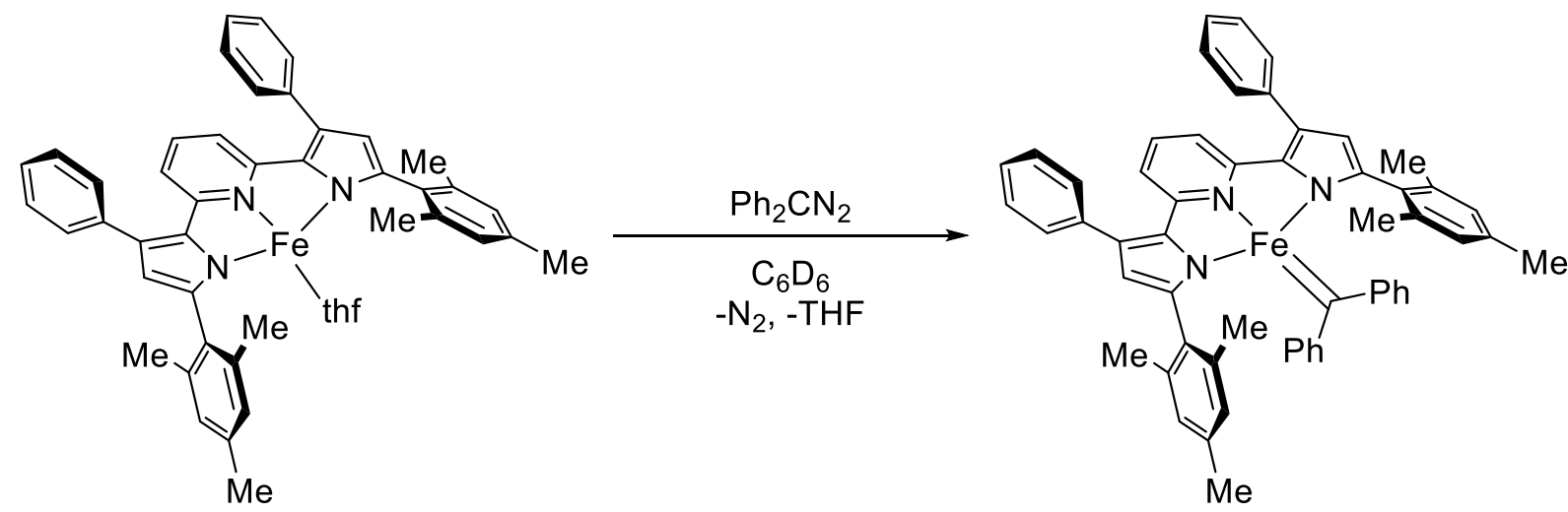

Scheme 6.1. Synthesis of $\left({ }^{\mathrm{Mes}} \mathrm{PDP}{ }^{\mathrm{Ph}}\right) \mathrm{Fe}\left(\mathrm{CPh}_{2}\right)$.

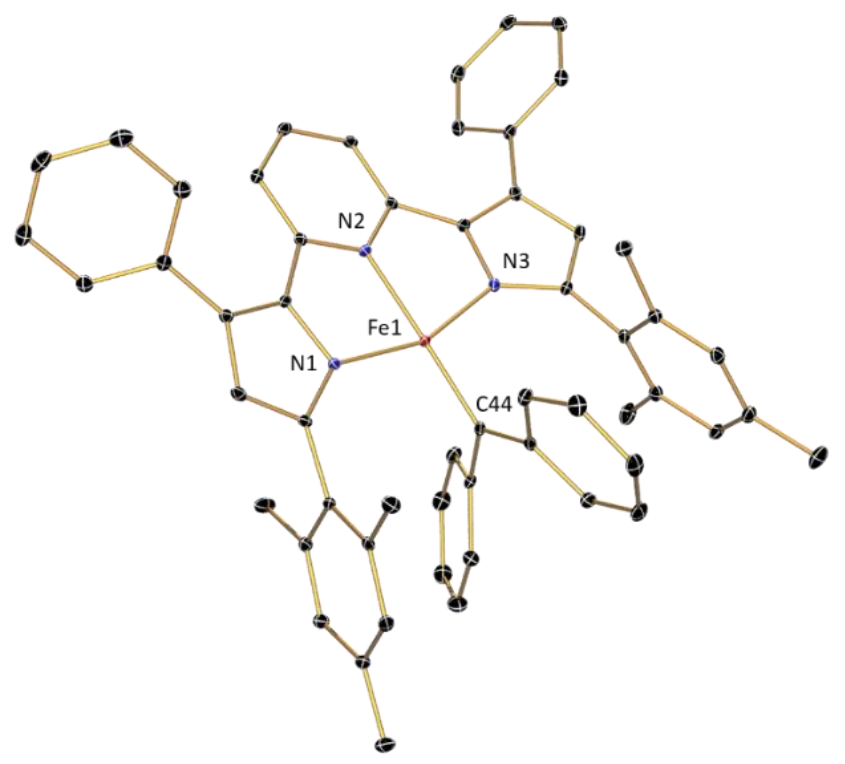

Figure 6.5. ORTEP of ( $\left.{ }^{\mathrm{Mes}} \mathrm{PDP}{ }^{\mathrm{Ph}}\right) \mathrm{Fe}\left(\mathrm{CPh}_{2}\right)$ depicted at $30 \%$ probability ellipsoids. Hydrogen atoms and a cocrystallized toluene solvent molecule are excluded for clarity. 
Notably, the square planar geometry of $\left({ }^{\mathrm{Mes}} \mathrm{PDP}^{\mathrm{Ph}}\right) \mathrm{Fe}\left(\mathrm{CPh}_{2}\right)$ is an unprecedented coordination motif for an iron carbene complex. Currently, the closest structural analogues to $\left({ }^{\text {Mes }} \mathrm{PDP}^{\mathrm{Ph}}\right) \mathrm{Fe}\left(\mathrm{CPh}_{2}\right)$ are the four-coordinate $\left({ }^{\mathrm{R}} \mathrm{PDI}\right) \mathrm{Fe}\left(\mathrm{CPh}_{2}\right)$ carbene radical species reported by Chirik. ${ }^{34}$ The X-ray structures for these pincer compounds feature carbene ligands positioned above the plane of the PDI chelate by $0.647 \AA$ and $0.706 \AA$ for $\left({ }^{\mathrm{Et} P D I}\right) \mathrm{Fe}\left(\mathrm{CPh}_{2}\right)$ and $\left({ }^{\mathrm{Me}} \mathrm{EtPDI}\right) \mathrm{Fe}\left(\mathrm{CPh}_{2}\right)$, respectively. This distortion, which is accompanied by bent $\mathrm{N}_{\text {pyridine-Fe- }}$ carbene bond angles of $147.82^{\circ}$ and $147.52^{\circ}$ for these two compounds is consistent with a trend away from square planarity towards a tetrahedral geometry. The Fe-C bond distance of 1.850(2) $\AA$ for $\left({ }^{\mathrm{Mes}} \mathrm{PDP}^{\mathrm{Ph}}\right) \mathrm{Fe}\left(\mathrm{CPh}_{2}\right)$ is indicative of multiple bond character. This distance is intermediate relative to the iron carbene bond distances of $1.979(3) \AA$ in $\left[\left(\eta^{5}-\mathrm{C}_{5} \mathrm{H}_{5}\right)\left(\eta^{1}-\mathrm{C}_{7} \mathrm{H}_{6}\right) \mathrm{Fe}(\mathrm{CO})_{2}\right]\left[\mathrm{PF}_{6}\right]$ and $1.787(8) \AA$ in $\left[\left(\eta^{5}-\mathrm{C}_{5} \mathrm{Me}_{5}\right) \mathrm{Fe}(\mathrm{dppe})(\mathrm{C}(\mathrm{H}) \mathrm{Me})\right][\mathrm{OTf}] .{ }^{21,22}$ Alternatively, the Chirik carbene radical complexes feature significantly longer iron carbene bond distances of 1.921(2) A and 1.936(2) $\AA$ for $\left({ }^{\mathrm{Et} P D I}\right) \mathrm{Fe}\left(\mathrm{CPh}_{2}\right)$ and $\left({ }^{\mathrm{Me}} \mathrm{EtPDI}\right) \mathrm{Fe}\left(\mathrm{CPh}_{2}\right)$, respectively. These observations are consistent with high-spin ferrous centers present in each of these compounds. ${ }^{34}$

Furthermore, the iron carbene bond distance in $\left({ }^{\mathrm{Mes}} \mathrm{PDP}^{\mathrm{Ph}}\right) \mathrm{Fe}\left(\mathrm{CPh}_{2}\right)$ is significantly elongated from the iron imido nitrogen bonds in the diamagnetic $\mathrm{Fe}^{\mathrm{IV}}$ PDP complexes $\left({ }^{\mathrm{tBu}}{ }^{\mathrm{PDP}}{ }^{\mathrm{tBu}}\right) \mathrm{Fe}\left(\mathrm{N}^{1} \mathrm{Ad}\right)$ and $\left({ }^{2,6-\mathrm{Cl} 2 \mathrm{Ph}} \mathrm{PDP}{ }^{\mathrm{Ph}}\right) \mathrm{Fe}\left(\mathrm{N}^{1} \mathrm{Ad}\right)$, which have crystallographically determined iron imide nitrogen bond lengths of 1.640(4) $\AA$ and 1.620(4) $\AA$, respectively. ${ }^{46,47}$ This is consistent with significantly more metal ligand multiple bond character in these complexes than in $\left({ }^{\mathrm{Mes}} \mathrm{PDP}{ }^{\mathrm{Ph}}\right) \mathrm{Fe}\left(\mathrm{CPh}_{2}\right)$. For $\left({ }^{\mathrm{Mes}} \mathrm{PDP}^{\mathrm{Ph}}\right) \mathrm{Fe}\left(\mathrm{CPh}_{2}\right)$, iron nitrogen contacts to the PDP pincer were found to be 1.9581(19) $\AA$ and 1.9455(19) $\AA$ for the pyrrolides N1 and N3, and 1.9779(19) $\AA$ for the central pyridine nitrogen, N2. For comparison, the Fe1-N1, Fe-N2, and Fe1-N3 distances for 
the iron pyrrolide and iron pyridine nitrogen bonds in $\left({ }^{\mathrm{tBu}} \mathrm{PDP} \mathrm{P}^{\mathrm{tBu}}\right) \mathrm{Fe}\left(\mathrm{N}^{1} \mathrm{Ad}\right)$ are $1.910(2) \AA$,

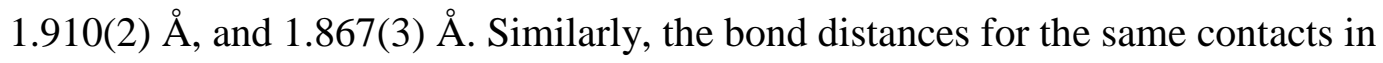
$\left({ }^{2,6-\mathrm{Cl} 2 \mathrm{Ph}} \mathrm{PDP} \mathrm{Ph}^{\mathrm{Ph}}\right) \mathrm{Fe}\left(\mathrm{N}^{1} \mathrm{Ad}\right)$ are 1.887(4) $\AA$, 1.894(4) $\AA$, and 1.898(4) $\AA$. It is clear that the iron nitrogen bond distances are significantly elongated in the formally $\mathrm{Fe}^{\mathrm{IV}}$ complex $\left({ }^{\mathrm{Mes}} \mathrm{PDP}{ }^{\mathrm{Ph}}\right) \mathrm{Fe}\left(\mathrm{CPh}_{2}\right)$ relative to authentic $\mathrm{Fe}^{\mathrm{IV}}$ complexes $\left({ }^{\mathrm{tBu}} \mathrm{PDP}^{\mathrm{tBu}}\right) \mathrm{Fe}\left(\mathrm{N}^{1} \mathrm{Ad}\right)$ and $\left({ }^{2,6-\mathrm{Cl} 2 \mathrm{Ph}} \mathrm{PDP}{ }^{\mathrm{Ph}}\right) \mathrm{Fe}\left(\mathrm{N}^{1} \mathrm{Ad}\right)$.

Finally, a comparison of the structural metrics of the square planar high-spin Fe ${ }^{\mathrm{II}} \mathrm{PDP}$ starting material, $\left({ }^{\mathrm{Mes}} \mathrm{PDP}{ }^{\mathrm{Ph}}\right) \mathrm{Fe}($ thf $)$, suggests that assignment of $\left({ }^{\mathrm{Mes}} \mathrm{PDP}{ }^{\mathrm{Ph}}\right) \mathrm{Fe}\left(\mathrm{CPh}_{2}\right)$ as a highspin ferrous ion with a weak field ancillary carbene ligand is unlikely. ( $\left.{ }^{\mathrm{Mes}} \mathrm{PDP}{ }^{\mathrm{Ph}}\right) \mathrm{Fe}(\mathrm{thf})$ is characterized by relatively long iron PDP nitrogen bond distances ranging from 2.0693(13)2.0419(14) $\AA$, inconsistent with the observed bond lengths to the nitrogens of the PDP pincer ligand in $\left({ }^{\mathrm{Mes}} \mathrm{PDP}{ }^{\mathrm{Ph}}\right) \mathrm{Fe}\left(\mathrm{CPh}_{2}\right) \cdot{ }^{49} \mathrm{~A}$ more complete summary of the structural metrics obtained for $\left({ }^{\mathrm{Mes}} \mathrm{PDP}{ }^{\mathrm{Ph}}\right) \mathrm{Fe}\left(\mathrm{CPh}_{2}\right)$ via $\mathrm{X}$-ray crystallography is provided later in Table 6.5.

The room-temperature magnetic moment of $\left({ }^{\mathrm{Mes}} \mathrm{PDP}{ }^{\mathrm{Ph}}\right) \mathrm{Fe}\left(\mathrm{CPh}_{2}\right)$ was found to be $3.8 \mu_{\mathrm{B}}$ (magnetic susceptibility balance), intermediate relative to the spin-only values expected for an $\mathrm{S}$ $=1\left(2.83 \mu_{\mathrm{B}}\right)$ or $\mathrm{S}=2$ system $\left(4.90 \mu_{\mathrm{B}}\right)$. In consideration of this ambiguity surrounding the oxidation state and spin-state of the iron center in $\left.{ }^{(\mathrm{Mes}} \mathrm{PDP}^{\mathrm{Ph}}\right) \mathrm{Fe}\left(\mathrm{CPh}_{2}\right)$, a zero-field Mössbauer spectrum was acquired on a powder sample of the complex at $80 \mathrm{~K}$. A single symmetric quadrupole doublet was fit satisfactorily with parameters of $\delta=0.20 \mathrm{mms}^{-1},\left|\Delta \mathrm{E}_{\mathrm{Q}}\right|=2.75 \mathrm{mms}^{-1}$, and $\Gamma_{\mathrm{L}}=\Gamma_{\mathrm{R}}=0.30 \mathrm{mms}^{-1}$ (Figure 6.6). The low isomer shift value is consistent with the short metal-ligand bond lengths observed crystallographically; however, it is significantly higher than the isomer shift value of $-0.09(1) \mathrm{mms}^{-1}$ reported for the diamagnetic $\mathrm{Fe}^{\mathrm{IV}}$ complex $\left({ }^{\mathrm{tBu}} \mathrm{PDP}{ }^{\mathrm{tBu}}\right) \mathrm{Fe}\left(\mathrm{N}^{1} \mathrm{Ad}\right) .{ }^{46}$ This result is consistent with the paramagnetism of the complex observed 
by ${ }^{1} \mathrm{H}$ NMR spectroscopy and is further evidence that the square-planar carbene complex

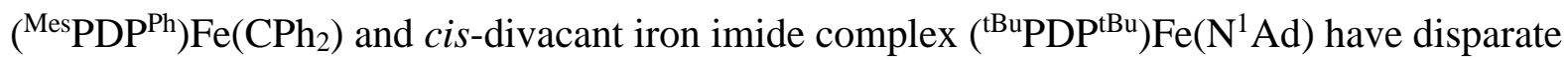
electronic structures, despite supporting isoelectronic carbene and nitrene fragments.

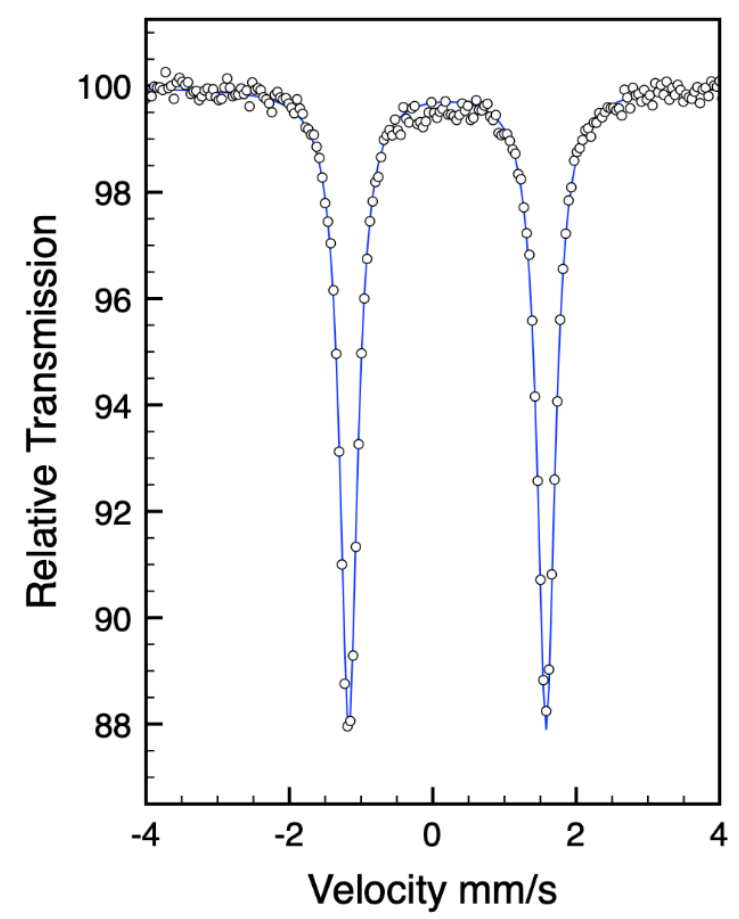

Figure 6.6. Zero-field ${ }^{57} \mathrm{Fe}$ Mössbauer spectrum of $\left({ }^{\mathrm{Mes}} \mathrm{PDP}^{\mathrm{Ph}}\right) \mathrm{Fe}\left(\mathrm{CPh}_{2}\right)$ acquired at $80 \mathrm{~K}$.

In order to further interrogate the electronic structure of $\left({ }^{\mathrm{Mes}} \mathrm{PDP}^{\mathrm{Ph}}\right) \mathrm{Fe}\left(\mathrm{CPh}_{2}\right)$, additional spectroscopic analysis was pursued via variable-temperature and variable-field Mössbauer spectroscopy. Two samples of $\left({ }^{\mathrm{Mes}} \mathrm{PDP}^{\mathrm{Ph}}\right) \mathrm{Fe}\left(\mathrm{CPh}_{2}\right)$ were prepared and analyzed, one in frozen toluene solution and a second powder sample frozen in mineral oil. The spectroscopic data for both samples was in good agreement, excluding the possibility of potential intermolecular magnetic interactions in the solid state. Thus, the data presented and described herein originates from the powder sample. The zero-field Mössbauer spectrum of $\left({ }^{\mathrm{Mes}} \mathrm{PDP}^{\mathrm{Ph}}\right) \mathrm{Fe}\left(\mathrm{CPh}_{2}\right)$ acquired at $4.2 \mathrm{~K}$ was consistent with the $80 \mathrm{~K}$ measurement, with $\delta=0.30 \mathrm{mms}^{-1}$ and $\Delta \mathrm{E}_{\mathrm{Q}}=2.86 \mathrm{mms}^{-1}$ (Figure 6.7). Subsequent measurements spanning applied fields of 0.1 to $7 \mathrm{~T}$ and temperatures of 
4.2 K to $100 \mathrm{~K}$ were performed (Figures 6.7 and 6.8). A negative sign for the quadrupole splitting $\left(-2.86 \mathrm{mms}^{-1}\right)$ and a value for the asymmetry parameter of the electronic field gradient $(\eta), 0.413$, were determined through the high temperature, high field measurement $(100 \mathrm{~K}, 7 \mathrm{~T})$. Satisfactory simulation of the data as an $\mathrm{S}=1$ system was achieved with $\mathrm{g}$ values of $4.80,2.50$, and $2.00 \mu_{\mathrm{B}}$ for $\mathrm{g}_{\mathrm{x}}, \mathrm{g}_{\mathrm{y}}$, and $\mathrm{g}_{\mathrm{z}}$. The overall magnetic splitting features exhibited under variablefield conditions were only successfully reproduced with a strong anisotropic ${ }^{57} \mathrm{Fe}$ hyperfine tensor, or internal field. The $A_{\mathrm{xx}}, A_{y y}$, and $A_{z z}$ values utilized in the fit were $+73.4,-5.9$, and -9.1 $\mathrm{T}$, respectively. The extremely large and atypical $A_{x x}$ value suggests a remarkably large unquenched angular momentum in this direction rendering the system unusually and largely anisotropic. ${ }^{50,51}$ Overall, the isomer shift and quadrupole splitting of $\left({ }^{\mathrm{Mes}} \mathrm{PDP}^{\mathrm{Ph}}\right) \mathrm{Fe}\left(\mathrm{CPh}_{2}\right)$ are more similar to reported intermediate spin $(\mathrm{S}=1) \mathrm{Fe}^{\mathrm{IV}}$ systems. ${ }^{52}$ The fit parameters utilized for simulation of the data are found in Table 6.2. 


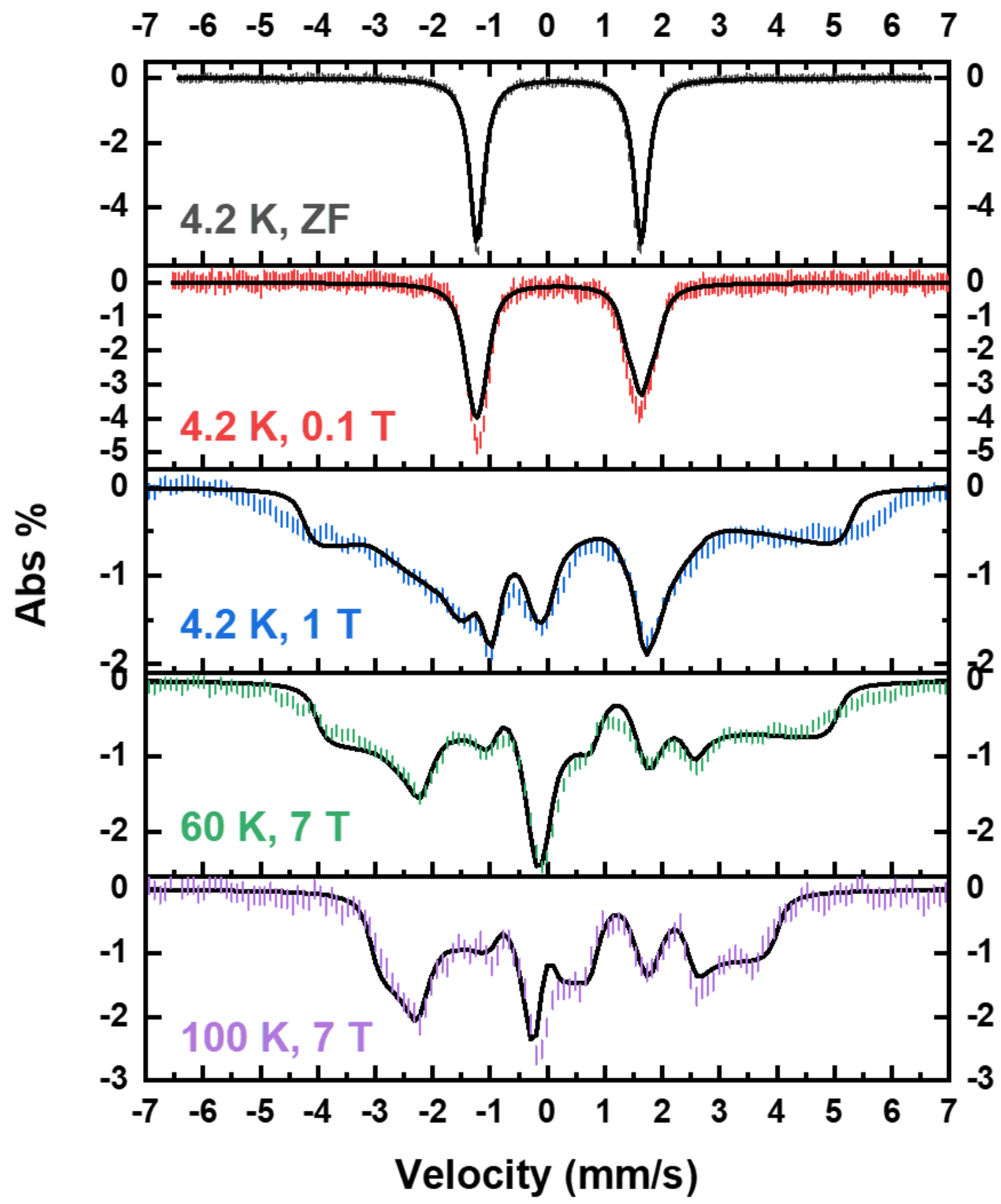

Figure 6.7. Zero-field and applied-field ${ }^{57} \mathrm{Fe}$ Mössbauer spectra of $\left({ }^{\mathrm{Mes}} \mathrm{PDP}{ }^{\mathrm{Ph}}\right) \mathrm{Fe}\left(\mathrm{CPh}_{2}\right)$ acquired at temperatures from $4.2 \mathrm{~K}$ to $100 \mathrm{~K}$ and field strengths of 0 to $7 \mathrm{~T}$. 


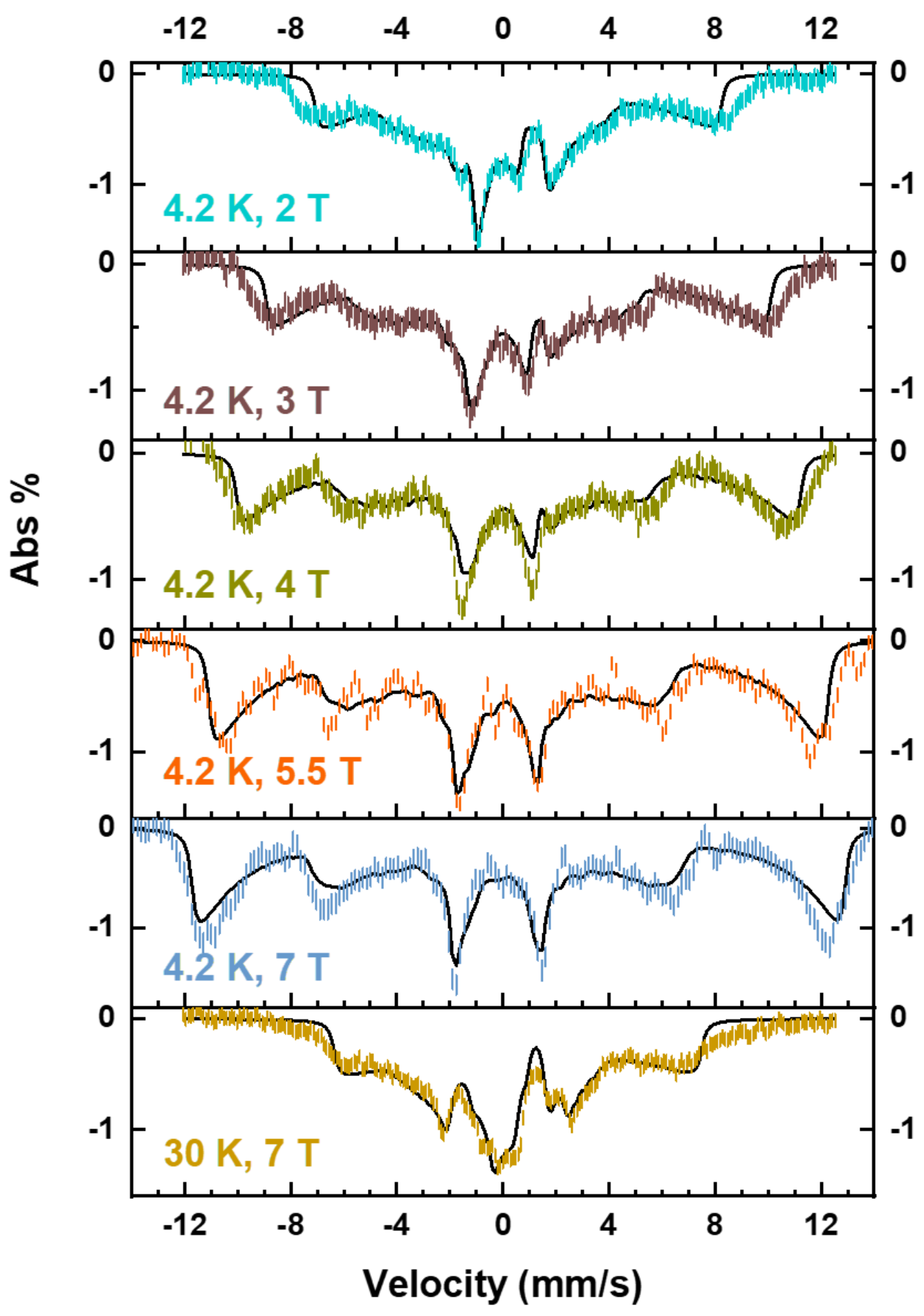

Figure 6.8. Zero-field and applied-field ${ }^{57} \mathrm{Fe}$ Mössbauer spectra of $\left({ }^{\mathrm{Mes}} \mathrm{PDP}{ }^{\mathrm{Ph}}\right) \mathrm{Fe}\left(\mathrm{CPh}_{2}\right)$ acquired at temperatures from $4.2 \mathrm{~K}$ to $30 \mathrm{~K}$ and fields strengths of 2 to $7 \mathrm{~T}$. 
Table 6.2. Fit parameters utilized in modeling experimental data obtained for $\left({ }^{\mathrm{Mes}} \mathrm{PDP}^{\mathrm{Ph}}\right) \mathrm{Fe}\left(\mathrm{CPh}_{2}\right)$ via variabletemperature applied-field Mössbauer spectroscopy.

\begin{tabular}{cc}
\hline Quantity & Value \\
\hline$S$ & 1 \\
$D$ & $10 \mathrm{~cm}^{-1}$ \\
$|\mathrm{E} / \mathrm{D}|$ & 0.2 \\
$\boldsymbol{g}$ & $4.80,2.50,2.00$ \\
$\delta$ & $0.20 \mathrm{mms}^{-1}$ \\
$\Delta E_{Q}$ & $-2.86 \mathrm{mms}^{-1}$ \\
$\eta$ & 0.413 \\
$A / \mathbf{g}_{\mathbf{n}} \boldsymbol{\beta}_{\mathbf{n}}$ & {$[+73.4,-5.9,-9.1] \mathrm{T}$} \\
$A r e a$ & 0.93 \\
$\Gamma$ & $0.300 \mathrm{mms}^{-1}$ \\
\hline
\end{tabular}

In consideration of the combined characterization obtained by means of ${ }^{1} \mathrm{H}$ NMR, zerofield Mössbauer spectroscopy, and X-ray crystallography, multiple possible electronic structures could be considered for $\left({ }^{\mathrm{Mes}} \mathrm{PDP}{ }^{\mathrm{Ph}}\right) \mathrm{Fe}\left(\mathrm{CPh}_{2}\right)$. However, the $\mathrm{S}=1$ state suggested by variabletemperature applied-field Mössbauer narrows the potential possibilities to two limiting electronic structure configurations for $\left({ }^{\mathrm{Mes}} \mathrm{PDP}{ }^{\mathrm{Ph}}\right) \mathrm{Fe}\left(\mathrm{CPh}_{2}\right)$. The first being an intermediate spin $\mathrm{Fe}^{\mathrm{IV}}$ center $\left(\mathrm{S}_{\mathrm{Fe}}=1\right)$ ligated by a closed-shell dianionic alkylidene ligand $\left(\mathrm{S}_{\mathrm{L}}=0\right)$. The second possibility is an intermediate-spin $\mathrm{Fe}^{\mathrm{III}}$ center $\left(\mathrm{S}_{\mathrm{Fe}}=3 / 2\right)$ engaged in antiferromagnetic coupling to a monoanionic carbene radical ligand $\left(S_{L}=1 / 2\right)$, which would afford an overall $S=1$ ground state. However, despite the wealth of physical characterization available for $\left({ }^{\mathrm{Mes}} \mathrm{PDP}{ }^{\mathrm{Ph}}\right) \mathrm{Fe}\left(\mathrm{CPh}_{2}\right)$, an unambiguous assignment of a limiting electronic structure for the complex is not possible from the currently available experimental data. 
Furthermore, due to the scarcity of paramagnetic iron carbene complexes, compounds suitable for close comparison do not exist in the literature at this time. Despite the lesser developed chemistry of paramagnetic iron carbenes, a number of paramagnetic iron imido complexes featuring non-innocent ligands have been recently synthesized and offer interesting comparisons within the context of iron ligand multiple bonding. One noteworthy complex is the intermediate-spin $\mathrm{Fe}(\mathrm{III})$ imido species $\left({ }^{\mathrm{i} P \mathrm{PD}} \mathrm{PD}\right) \mathrm{Fe}\left(\mathrm{N}\left(2,6-{ }^{\mathrm{i}} \mathrm{Pr}_{2}-\mathrm{C}_{6} \mathrm{H}_{3}\right)\right){ }^{\mathrm{i} \mathrm{Pr}} \mathrm{PDI}=(2,6-$ $\left.{ }^{i} \mathrm{Pr}_{2} \mathrm{C}_{6} \mathrm{H}_{3} \mathrm{~N}=\mathrm{CMe}\right)_{2} \mathrm{C}_{5} \mathrm{H}_{3} \mathrm{~N}$ ) reported by Chirik. ${ }^{53,54}$ This complex has a magnetic moment consistent with a $\mathrm{S}=1$ system $\left(2.8 \mu_{\mathrm{B}}\right.$ from 20 to $\left.300 \mathrm{~K}\right)$ and Mössbauer isomer shift, $\delta=0.302$ $\mathrm{mm} / \mathrm{s}$, similar to that of $\left({ }^{\mathrm{Mes}} \mathrm{PDP}^{\mathrm{Ph}}\right) \mathrm{Fe}\left(\mathrm{CPh}_{2}\right)$. X-ray crystallographic analysis of ( $\left.{ }^{\mathrm{PPr}} \mathrm{PDI}\right) \mathrm{Fe}\left(\mathrm{N}\left(2,6-{ }^{\mathrm{i}} \mathrm{Pr}_{2}-\mathrm{C}_{6} \mathrm{H}_{3}\right)\right.$ identified an iron imide nitrogen bond length of $1.7048(16) \AA$, consistent with a closed shell diamagnetic dianionic imide. Despite this metal ligand bonding interaction being consistent with double bond character, the PDI chelate in this complex exists as a monoreduced ligand radical engaged in antiferromagnetic coupling with the ferric center. This electronic structural motif offers precedent for a ligand radical bound to an intermediate spin $\mathrm{Fe}(\mathrm{III})$ ion in the context of a complex featuring a metal ligand multiple bond. Thus, the possibility of an intermediate-spin $\mathrm{Fe}^{\mathrm{III}}$ center $\left(\mathrm{S}_{\mathrm{Fe}}=3 / 2\right)$ engaged in antiferromagnetic coupling to a monoanionic carbene radical ligand $\left(\mathrm{S}_{\mathrm{L}}=1 / 2\right)$ in $\left({ }^{\mathrm{Mes}} \mathrm{PDP}^{\mathrm{Ph}}\right) \mathrm{Fe}\left(\mathrm{CPh}_{2}\right)$ should be carefully considered.

\subsection{Density Functional Theory Study of $\left({ }^{\mathrm{Mes}} \mathrm{PDP} \mathrm{Ph}^{\mathrm{Ph}}\right) \mathrm{Fe}\left(\mathrm{CPh}_{2}\right)$}

In light of the ambiguity surrounding the electronic structure of $\left({ }^{\mathrm{Mes}} \mathrm{PDP}^{\mathrm{Ph}}\right) \mathrm{Fe}\left(\mathrm{CPh}_{2}\right)$, we turned to density functional theory (DFT) calculations to gain further insight. Utilizing atomic coordinates obtained from X-ray crystallography, full molecule geometry optimizations were performed at the B3LYP level of theory for a variety of possible paramagnetic electronic 
structure descriptions. Unrestricted Kohn-Sham (UKS) calculations including UKS3 and UKS5 approaches, corresponding to triplet and quintet states, respectively, were utilized to account for possible $\mathrm{S}=1$ or $\mathrm{S}=2$ electronic structures. These include a $\mathrm{Fe}^{\mathrm{IV}}$ intermediate spin ion $\left(\mathrm{S}_{\mathrm{Fe}}=1\right)$ with a diamagnetic dianionic alkylidene ligand $\left(\mathrm{S}_{\mathrm{L}}=0\right)$ and a high spin $\mathrm{Fe}^{\mathrm{II}}$ ion with an ancillary carbene ligand $\left(\mathrm{S}_{\mathrm{L}}=0\right)$. Broken symmetry $(\mathrm{BS})$ calculations were employed to account for the possibility of intermediate-spin Fe(III) $\left(\mathrm{S}_{\mathrm{Fe}}=5 / 2\right)$ and high-spin $\mathrm{Fe}(\mathrm{III})\left(\mathrm{S}_{\mathrm{Fe}}=3 / 2\right)$ ions antiferromagnetically coupled to carbene radicals $\left(S_{L}=1 / 2\right)$, via $B S(3,1)$ and $B S(5,1)$ calculations, respectively.

Analysis of the results from the BS(3,1) and UKS calculations demonstrated convergence to identical electronic structures, consistent with an intermediate-spin $\mathrm{Fe}^{\mathrm{III}}$ ion antiferromagnetically coupled to a carbene radical ligand. This is supported by examination of the spin distribution obtained via Mulliken population analysis, which demonstrates a value of 2.68 on the iron center and -0.53 on the carbene carbon. Significant spin density is also present throughout the phenyl substituents of the carbene fragment (Figure 6.10). The high spatial overlap value of 0.80 is consistent with a highly covalent bonding interaction between the iron center and carbene ligand. Furthermore, the convergence of the UKS3 calculation to a BS $(3,1)$ solution is consistent with this optimized structure being the lowest energy on the triplet surface. Analysis of the BS $(5,1)$ calculation and the corresponding spin-density populations reveals a computed electronic structure consistent with a high-spin ferric ion antiferromagnetically coupled to a carbene-based radical. Spin density values of 3.96 and -0.24 were computed for the iron center and carbene carbon, respectively, while a significant portion of the remaining negative spin density is located throughout the phenyl substituents of the carbene (-0.29). The deviation of the spin density from the expected value of five for a high-spin 
$\mathrm{Fe}^{\mathrm{III}}$ center is rationalized by spin polarization that imparts spin density onto the nitrogens of the PDP ligand. Similar to the BS $(3,1)$ calculation, the spin density map of the Mulliken population analysis obtained from the $\mathrm{BS}(5,1)$ calculation also has significant spin density imparted onto the phenyl substituents of the carbene fragment. Importantly, upon examination of the structural metrics of the optimized BS(5,1) structure, it was observed that the calculated metrics were not in good agreement with the crystallographically determined structure of $\left({ }^{\mathrm{Mes}} \mathrm{PDP}{ }^{\mathrm{Ph}}\right) \mathrm{Fe}\left(\mathrm{CPh}_{2}\right)$. In the optimized BS(5,1) structure, the carbene fragment is drastically lifted out of the plane and the resulting geometry is most consistent with a bent structure intermediate to limiting planar and cis-divacant descriptions. This is obviated by the N2-Fe1-C44 bond angle of $120.26^{\circ}$. Furthermore, the Fe-carbene bond distance is drastically elongated to $2.001 \AA$, which is consistent with the high-spin state of the iron center. Although the optimized structure for the $\mathrm{BS}(5,1)$ calculation is only $3.1 \mathrm{kcal} \mathrm{mol}^{-1}$ higher in energy than the $\mathrm{BS}(3,1)$ calculation, this solution is currently disfavored in consideration of the inconsistency of the structural metrics with the experimentally determined structure from X-ray crystallography.

Interestingly, the UKS5 calculation did not converge to the corresponding BS $(5,1)$ solution, but instead converges to an electronic structure solution that is consistent with an intermediate-spin $\mathrm{Fe}^{\mathrm{III}}$ center ferromagnetically coupled to a carbene radical ligand. Spin-density values of 3.12 and 0.50 were computed for the iron center and the carbene carbon, consistent with an $S=2$ state. This electronic structure is consistent with a spin flip at the carbene carbon relative to the $\mathrm{BS}(3,1)$ solution. A stark energetic penalty is clear in consideration of this electronic structural change, as the optimized structure for the UKS5 solution lies $15.7 \mathrm{kcal} \mathrm{mol}^{-1}$ higher in energy than the corresponding BS(3,1)/UKS3 solution. Despite the excellent agreement of the structural metrics with those obtained by X-ray crystallography, the large energy 
difference between the computed structures suggests that this electronic structure is not a likely description of the electronic structure of $\left({ }^{\mathrm{Mes}} \mathrm{PDP}^{\mathrm{Ph}}\right) \mathrm{Fe}\left(\mathrm{CPh}_{2}\right) .{ }^{55}$ The spin-density plots obtained from each computational approach are depicted in Figure 6.10 and a summary of experimental and computation metrics obtained for $\left({ }^{\mathrm{Mes}} \mathrm{PDP}^{\mathrm{Ph}}\right) \mathrm{Fe}\left(\mathrm{CPh}_{2}\right)$ are compiled in Table 6.3.

Additionally, a qualitative molecular orbital diagram of $\left({ }^{\mathrm{Mes}} \mathrm{PDP}{ }^{\mathrm{Ph}}\right) \mathrm{Fe}\left(\mathrm{CPh}_{2}\right)$ developed from the results of the $\mathrm{BS}(3,1)$ calculation is depicted in Figure 6.9.

With these optimized structures in hand, Mössbauer parameters were calculated for all to use in comparison to the experimentally determined values. The computed isomer shift values are in excellent agreement with the experimental data, however, analysis of the quadrupole splitting values clearly favors the BS(3,1) electronic structure (Table 6.3). Although there is deviation between the computed (-4.04) and experimentally determined values (-2.86), DFT is able to correctly predict the negative sign associated with the quadrupole splitting of $\left.{ }^{\text {Mes }}{ }^{P D P}{ }^{\mathrm{Ph}}\right) \mathrm{Fe}\left(\mathrm{CPh}_{2}\right)$ determined by applied-field Mössbauer. In contrast, the BS(5,1) and UKS5 computed values predict an incorrect positive sign for the quadrupole splitting. Furthermore, the difference the experimental and computed quadrupole splittings, -2.86 vs. $-4.40 \mathrm{mms}^{-1}$, is rationalized on the basis of an inherent limitation to DFT, namely, the exclusion of unquenched orbital angular momentum. This leads to exclusion of spin orbit coupling and ultimately the observed inconsistency in computed $\Delta \mathrm{E}_{\mathrm{Q}}$ value. In consideration of the combined physical and computational characterization of $\left({ }^{\mathrm{Mes}} \mathrm{PDP}{ }^{\mathrm{Ph}}\right) \mathrm{Fe}\left(\mathrm{CPh}_{2}\right)$, an electronic structural assignment of the complex as an intermediate-spin ferric ion engaged in antiferromagnetic coupling to a carbene radical is favored at this time, in agreement with previously studied square-planar iron iminyl radical complexes of the PDP ligand. ${ }^{47}$ Notably, this makes $\left({ }^{\mathrm{Mes}} \mathrm{PDP}^{\mathrm{Ph}}\right) \mathrm{Fe}\left(\mathrm{CPh}_{2}\right)$ the first example 
of an iron carbene complex in the formal oxidation state of +3 , whereas previous examples have been limited to $\mathrm{Fe}(\mathrm{II})$ and $\mathrm{Fe}(\mathrm{IV})$ ions.

Table 6.3. Summary of physical and computational metrics for $\left({ }^{\mathrm{Mes}} \mathrm{PDP}^{\mathrm{Ph}}\right) \mathrm{Fe}\left(\mathrm{CPh}_{2}\right)$.

\begin{tabular}{ccccccc}
\hline & $\begin{array}{c}\Delta \text { Energy } \\
/ \text { cal mol }^{-1}\end{array}$ & $\begin{array}{c}F e-C_{\text {carbene }} \\
/ \AA\end{array}$ & $N_{\text {pyridine }}-F e-C_{\text {carbene }} /{ }^{\circ}$ & $\delta / \mathrm{mms}^{-1}$ & $\Delta E_{Q} / \mathrm{mms}^{-1}$ & $\eta^{a}$ \\
\hline Experimental & - & $1.850(2)$ & $176.20(9)$ & 0.20 & -2.86 & 0.413 \\
BS(3,1)/UKS3 & 0 & 1.881 & 179.94 & 0.24 & -4.04 & 0.208 \\
BS(5,1) & +15.7 & 1.996 & 120.26 & 0.27 & 3.15 & 0.856 \\
UKS5 & +3.14 & 2.001 & 179.98 & 0.22 & 4.36 & 0.624 \\
\hline
\end{tabular}



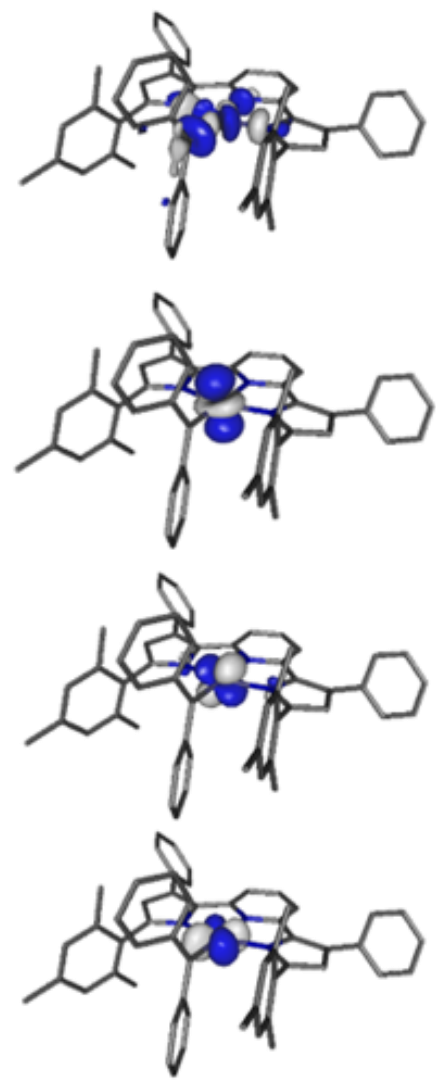

$S=0.80$
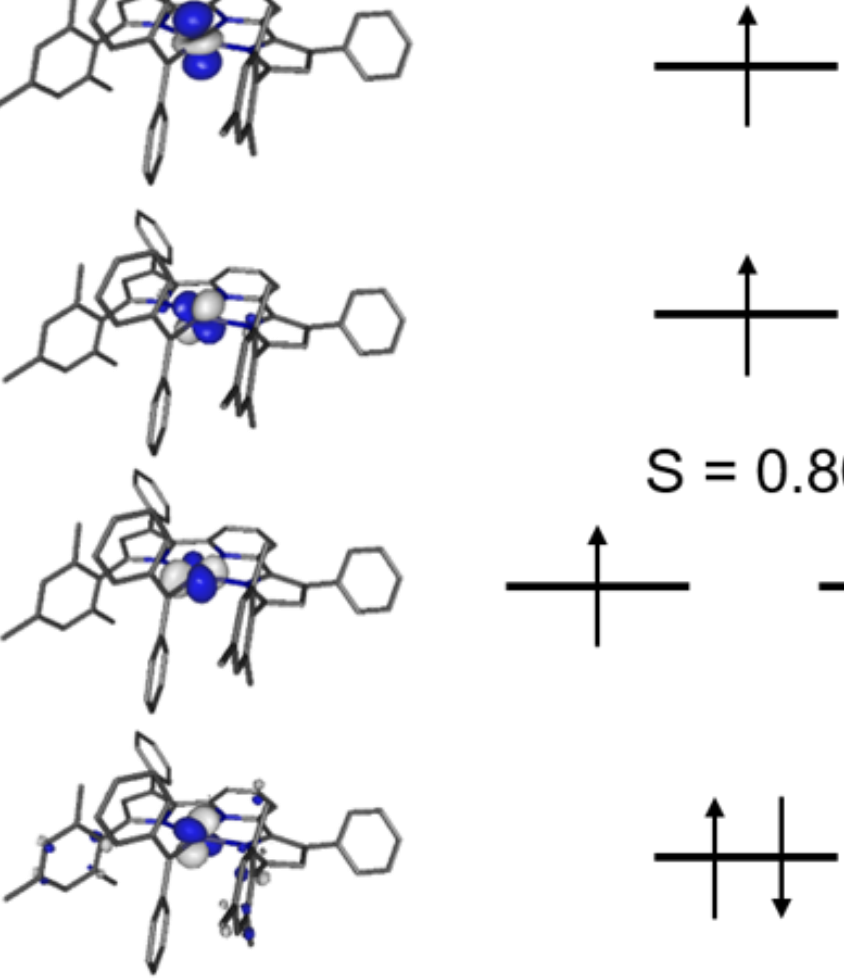
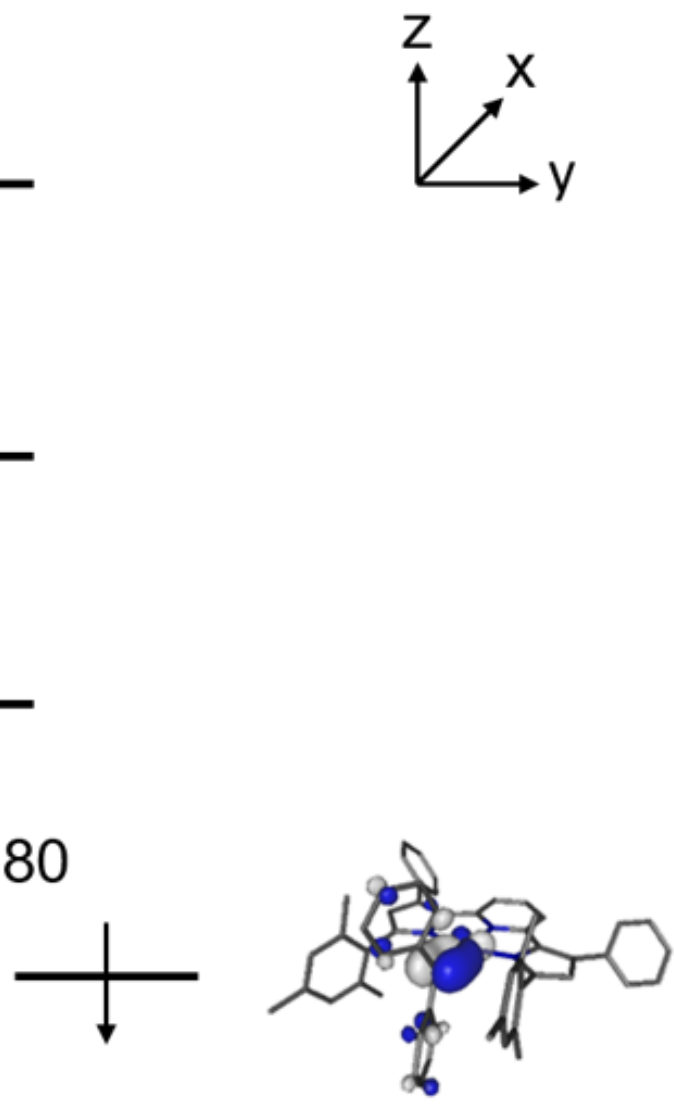

Figure 6.9. Qualitative molecular orbital diagram derived from the Unrestricted Corresponding Orbitals (UCO) obtained from BS(3,1)/UKS3 DFT calculations. 

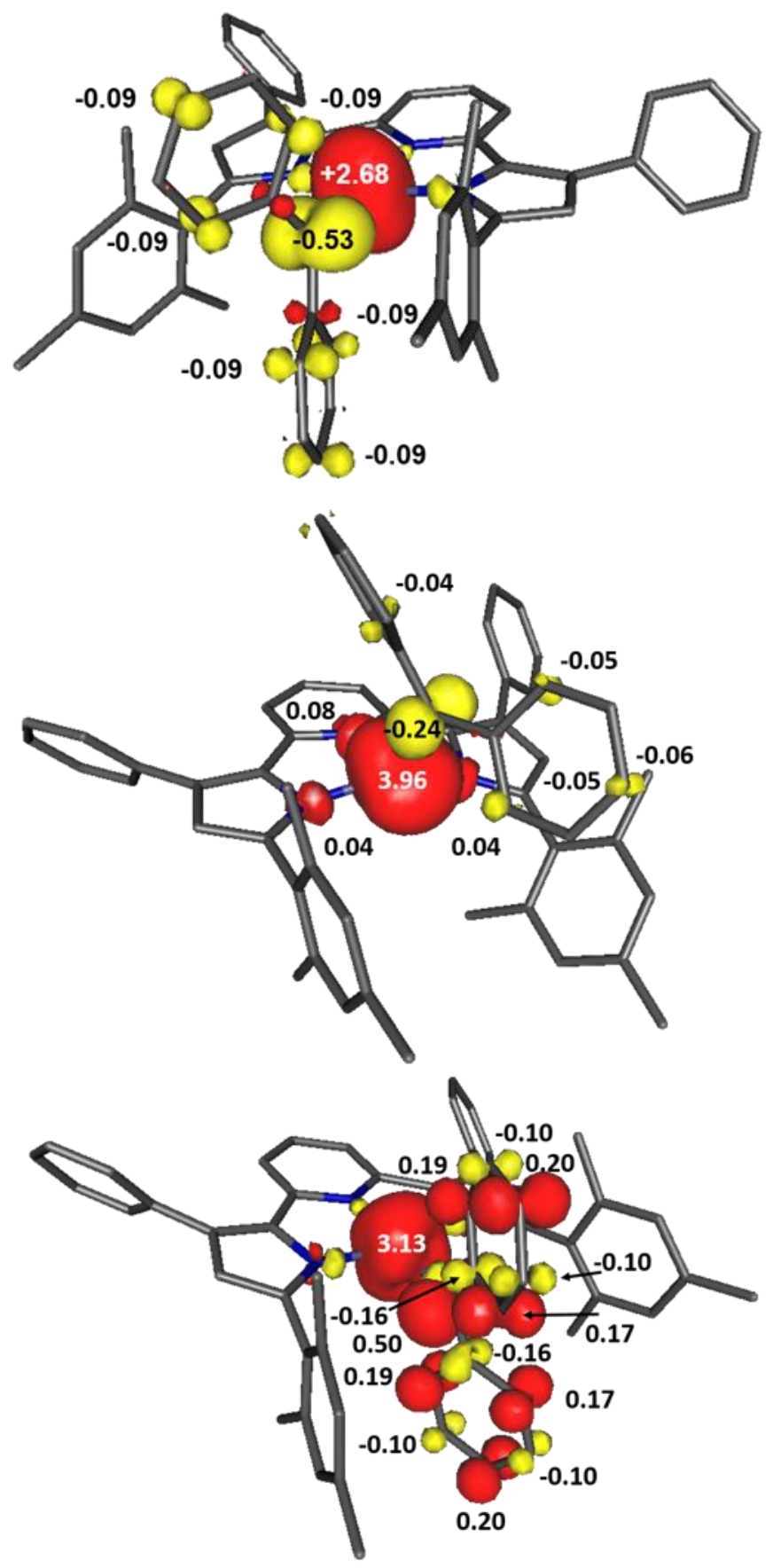

Figure 6.10. Spin-density plots obtained from Mulliken population analysis of UKS3/BS(3,1) (top), BS(5,1) (middle), and UKS5 (bottom) DFT calculations. 


\subsection{Reactivity Studies of ( $\left.{ }^{\mathrm{Mes}} \mathrm{PDP}{ }^{\mathrm{Ph}}\right) \mathrm{Fe}\left(\mathrm{CPh}_{2}\right)$}

With an established understanding of the electronic structure of $\left({ }^{\mathrm{Mes}} \mathrm{PDP}^{\mathrm{Ph}}\right) \mathrm{Fe}\left(\mathrm{CPh}_{2}\right)$, an evaluation of its utility in carbene group transfer was pursued. Previously, carbene group transfer reactions have been demonstrated by a variety of isolable late $3 \mathrm{~d}$ metal carbene complexes including those of iron ${ }^{34}$, cobalt ${ }^{56-58}$, nickel ${ }^{59-63}$, and copper ${ }^{64-66}$. In these instances, the ability to transfer the carbene ligand to organic substrates such as carbon monoxide, isocyanides, and organic azides is well documented. In particular, the carbene radical complex $\left({ }^{\mathrm{Me}} \mathrm{PDI}\right) \mathrm{Fe}\left(\mathrm{CPh}_{2}\right)$ reported by Chirik was found to facilitate carbene group transfer to $\mathrm{CO}, \mathrm{H}_{2}$, and organic azides. No cyclopropanation, C-H abstraction, or metathesis reactivity was observed for the compound, which was attributed to the lack of alkylidene or Schrock carbene character present in this complex, consistent with the presence of a high-spin $\mathrm{Fe}^{\mathrm{II}}$ ion. ${ }^{34}$

In order to assess the possibility of carbene group transfer from $\left({ }^{\mathrm{Mes}} \mathrm{PDP}^{\mathrm{Ph}}\right) \mathrm{Fe}\left(\mathrm{CPh}_{2}\right)$, reactions were first probed with carbon monoxide. The addition of $1 \mathrm{~atm}$ of $\mathrm{CO}$ to a benzene- $d_{6}$ solution of $\left({ }^{\mathrm{Mes}} \mathrm{PDP}^{\mathrm{Ph}}\right) \mathrm{Fe}\left(\mathrm{CPh}_{2}\right)$ at room temperature resulted in a rapid color change of the solution from dark green to red brown. Analysis of the crude reaction mixture by ${ }^{1} \mathrm{H}$ NMR spectroscopy demonstrated complete conversion of the starting material and quantitative formation of a new diamagnetic species. The ${ }^{1} \mathrm{H}$ NMR spectrum evidenced a diamagnetic product, with apparent $\mathrm{C}_{1}$ symmetry in solution. Six distinct singlets of equal intensity were identified within the range of $1.96 \mathrm{ppm}$ to $2.44 \mathrm{ppm}$, consistent with six chemically inequivalent methyl groups for the Mes ${ }^{\mathrm{PDP}}{ }^{\mathrm{Ph}}$ ligand. Furthermore, ${ }^{13} \mathrm{C}-\left\{{ }^{1} \mathrm{H}\right\}$ NMR in benzene- $d_{6}$ revealed two downfield resonances at $208.92 \mathrm{ppm}$ and $220.67 \mathrm{ppm}$, suggesting the incorporation of two unique carbonyl ligands in the product. Analysis by infrared spectroscopy $(\mathrm{KBr})$ confirmed the 
incorporation of terminal $\mathrm{CO}$ ligands into the product, with two strong $\mathrm{CO}$ stretches identified at $2023 \mathrm{~cm}^{-1}$ and $1954 \mathrm{~cm}^{-1}$ (Figure 6.11).

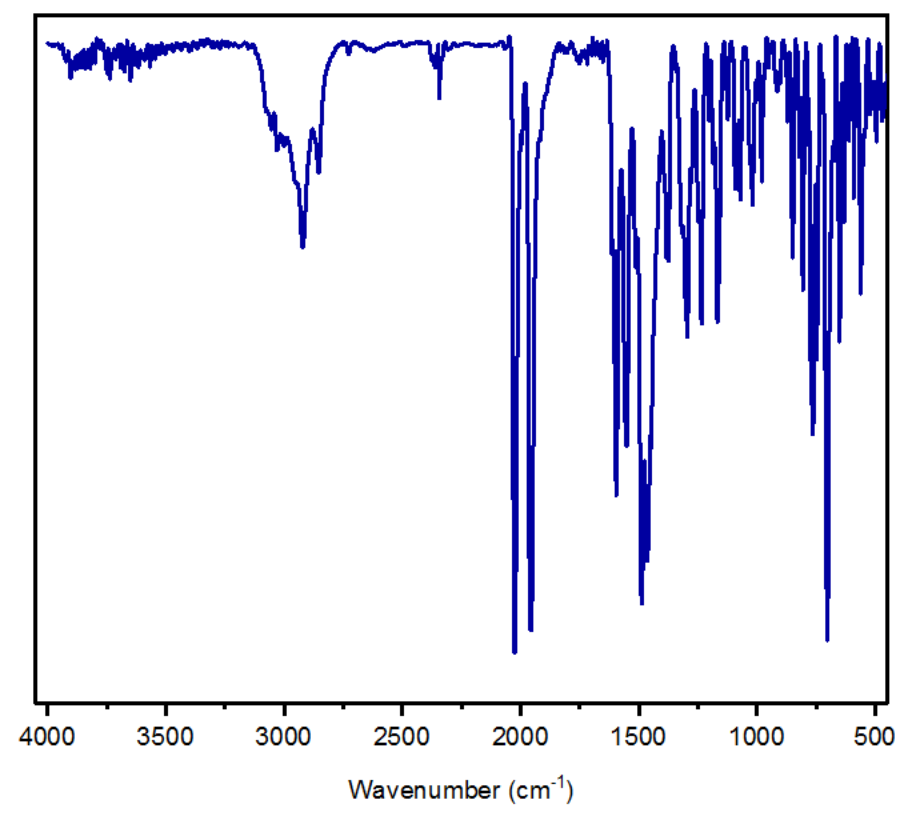

Figure 6.11. IR spectrum of $\left(\mathrm{CPh}_{2}{ }^{\mathrm{Mes}} \mathrm{PDP}{ }^{\mathrm{Ph}}\right) \mathrm{Fe}(\mathrm{CO})_{2}(\mathrm{KBr})$.

In consideration of the complex ${ }^{1} \mathrm{H}$ NMR spectrum, a zero-field Mössbauer spectrum was acquired of the product following workup (vide infra) and indicated clean transformation of the starting material to a single new iron-containing species with $\delta=0.13 \mathrm{mms}^{-1}$ and $\left|\Delta \mathrm{E}_{\mathrm{Q}}\right|=1.75$ $\mathrm{mms}^{-1}$. These Mössbauer parameters inferred a low-spin Fe(II) ground state for the new complex, consistent with the diamagnetism observed via ${ }^{1} \mathrm{H}$ NMR spectroscopy. The X-ray crystallographic analysis of single crystals obtained from the evaporation of a concentrated diethyl ether of solution of the compound revealed an iron complex having undergone insertion of the diphenylidene fragment into an iron-pyrrolide nitrogen bond (Scheme 6.2). Two carbonyl ligands were also bound to the iron center, in agreement with the ${ }^{13} \mathrm{C} N M R$ spectrum, as well as 
the modified PDP ligand, now a tridentate $\mathrm{C}, \mathrm{N}, \mathrm{N}$ chelate featuring an $\mathrm{N}$ alkylated pyrrole moiety. The modified PDP ligand maintains a dianionic charge, by way of one pyrrolide moiety and the newly formed alkyl ligand. The C44-N1 bond distance of $1.472(3) \AA$ is consistent with a C-N single bond. Overall, the solid-state structure of $\left(\mathrm{CPh}_{2}{ }^{\mathrm{Mes}} \mathrm{PDP}{ }^{\mathrm{Ph}}\right) \mathrm{Fe}(\mathrm{CO})_{2}$ is consistent with the apparent $\mathrm{C}_{1}$ symmetry observed by NMR spectroscopy. ORTEP depictions of $\left(\mathrm{CPh}_{2}{ }^{\mathrm{Mes}} \mathrm{PDP}{ }^{\mathrm{Ph}}\right) \mathrm{Fe}(\mathrm{CO})_{2}$ are presented in Figure 6.12, and important bond distances are summarized in Table 6.3. The metal-ligand bond distances are 1.9846(17), 1.9687(18), 2.076(2), 1.796(2), and 1.742(2) for the iron pyridine nitrogen (Fe-N2), pyrrolide nitrogen (Fe-N3), carbon (Fe-C51), and CO carbons (Fe-C57 and Fe-C58), respectively, are consistent with a low-spin Fe ion.

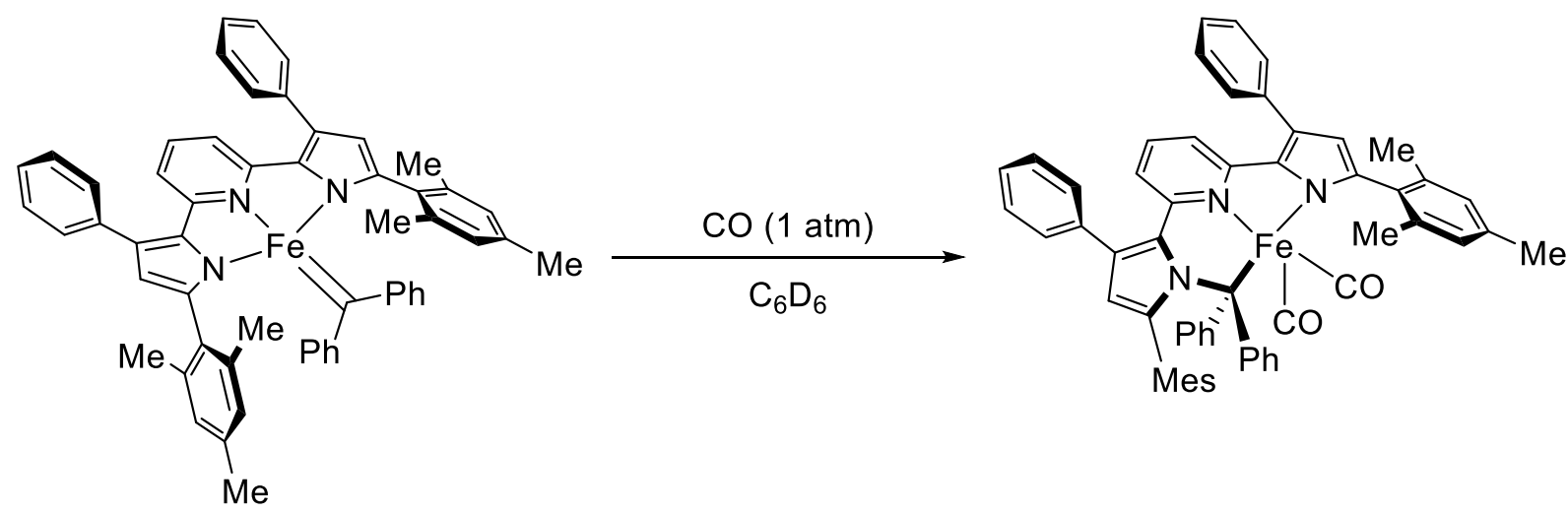

Scheme 6.2. Synthesis of $\left(\mathrm{CPh}_{2}{ }^{\mathrm{Mes}} \mathrm{PDP}{ }^{\mathrm{Ph}}\right) \mathrm{Fe}(\mathrm{CO})_{2}$. One mesityl PDP substituent in $\left(\mathrm{CPh}_{2}{ }^{\mathrm{Mes}} \mathrm{PDP}^{\mathrm{Ph}}\right) \mathrm{Fe}(\mathrm{CO})_{2}$ has been denoted "Mes".

The observation of the diphenylidene fragment in $\left(\mathrm{CPh}_{2}{ }^{\mathrm{Mes}} \mathrm{PDP}{ }^{\mathrm{Ph}}\right) \mathrm{Fe}(\mathrm{CO})_{2}$ bridging the iron center and a pyrrolide nitrogen is not an unprecedented coordination motif. Related examples of bridging carbene ligands have also been documented for porphyrin complexes and implicated as key intermediates in iron and cobalt catalyzed cyclopropanation. ${ }^{36,37,67-71}$ 


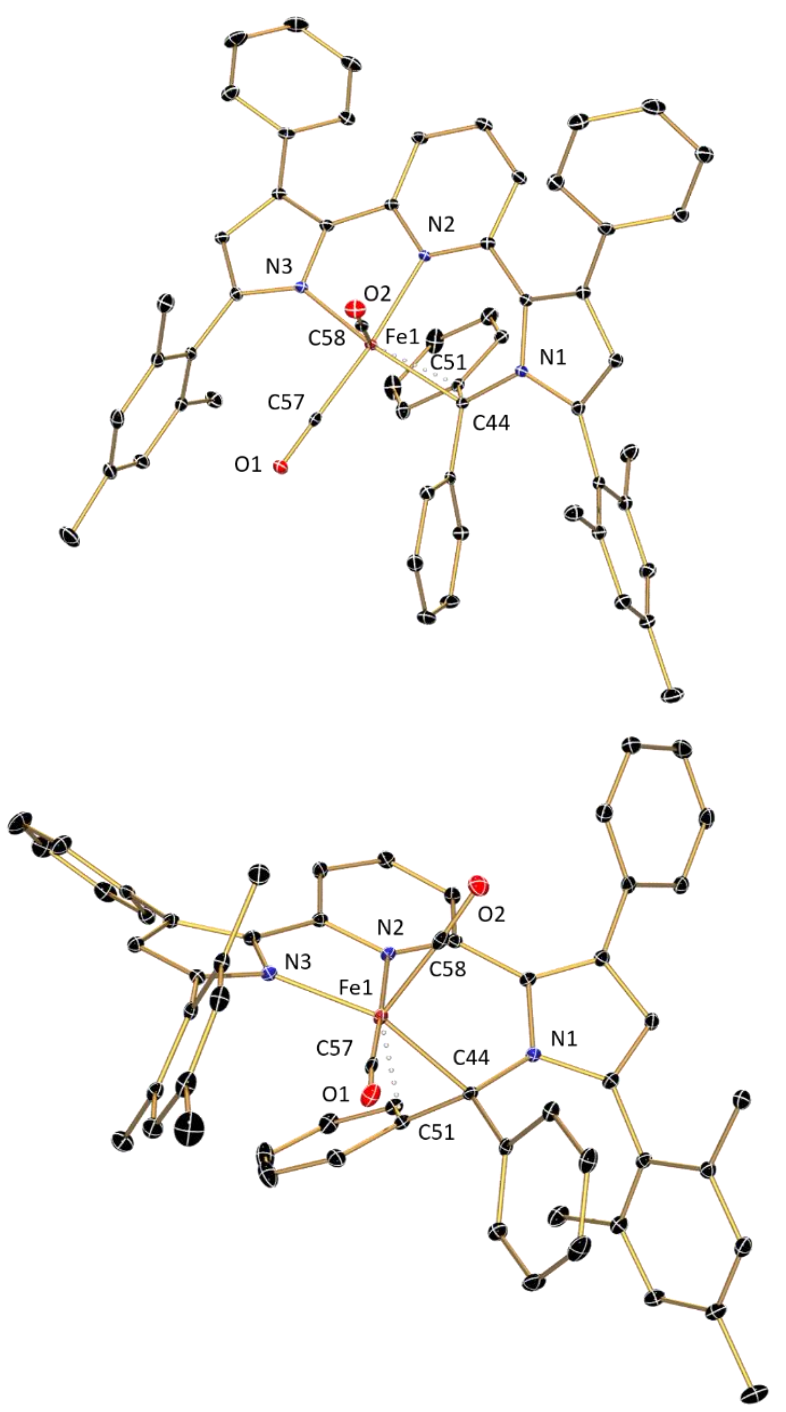

Figure 6.12. ORTEP depictions of two perspectives of $\left(\mathrm{CPh}_{2}{ }^{\mathrm{Mes}} \mathrm{PDP}{ }^{\mathrm{Ph}}\right) \mathrm{Fe}(\mathrm{CO})_{2}$ at $30 \%$ probability ellipsoids. Cocrystallized diethyl ether solvent and hydrogen atoms are omitted for clarity.

Having noted the carbene insertion chemistry upon reaction of $\left({ }^{\mathrm{Mes}} \mathrm{PDP}{ }^{\mathrm{Ph}}\right) \mathrm{Fe}\left(\mathrm{CPh}_{2}\right)$ with carbon monoxide, we sought out to explore the reactivity of this species with other organic substrates. Previously, catalytic carbene transfer to isocyanides has been demonstrated by cobalt and nickel systems to form the corresponding ketenimines. ${ }^{57,63}$ In consideration of this precedent, the reactivity of $\left({ }^{\mathrm{Mes}} \mathrm{PDP}{ }^{\mathrm{Ph}}\right) \mathrm{Fe}\left(\mathrm{CPh}_{2}\right)$ was explored with isocyanide reagents. The addition of two equivalents of 2,6-dimethylphenylisocyanide to a stirring benzene solution of 
$\left({ }^{\mathrm{Mes}} \mathrm{PDP}^{\mathrm{Ph}}\right) \mathrm{Fe}\left(\mathrm{CPh}_{2}\right)$ resulted in an immediate color change from dark green to red. ${ }^{1} \mathrm{H}$ NMR analysis of the crude reaction mixture in benzene- $d_{6}$ indicated complete consumption of $\left({ }^{\mathrm{Mes}} \mathrm{PDP}^{\mathrm{Ph}}\right) \mathrm{Fe}\left(\mathrm{CPh}_{2}\right)$ with concomitant formation of a new diamagnetic product. Eight singlet resonances were identified in the upfield region of the spectrum with relative integrations of 3 and a ninth singlet resonance with a relative integration of 6 . These resonances suggested a preliminary assignment of the product as a 2,6-dimethylphenylisocyanide analogue to $\left(\mathrm{CPh}_{2}{ }^{\mathrm{Mes}} \mathrm{PDP}^{\mathrm{Ph}}\right) \mathrm{Fe}(\mathrm{CO})_{2}$ with the six chemically distinct methyl groups corresponding to a $\mathrm{C}_{1}$ symmetric ${ }^{\mathrm{Mes}} \mathrm{PDP}^{\mathrm{Ph}}$ ligand environment. The three remaining singlet resonances, of 3:3:6 relative intensity, were assigned as two distinct 2,6-dimethylphenyl isocyanide ligands. An isocyanide ligand orthogonal to the PDP chelate plane undergoing fast rotation on the NMR timescale and consequently one methyl group signal accounting for the integration of six. A second isocyanide ligand in the plane of the PDP chelate was proposed to possess two chemically inequivalent methyl groups, resulting in the observation of the two additional singlet resonances with relative integrations of 3 and 3 , respectively. The observation of these two distinct signals on the timescale of the ${ }^{1} \mathrm{H}$ NMR experiment is attributed to restricted rotation of the isocyanide ligand, likely as a result of the sterically congested environment about the $\mathrm{Fe}$ center.

The IR spectrum $(\mathrm{KBr})$ of the product features two intense bands isocyanide $\mathrm{C} \equiv \mathrm{N}$ stretches at 2102 and $1999 \mathrm{~cm}^{-1}$, consistent with the incorporation of 2,6-dimethylphenyl isocyanide ligands into the observed product (Figure 6.13). 


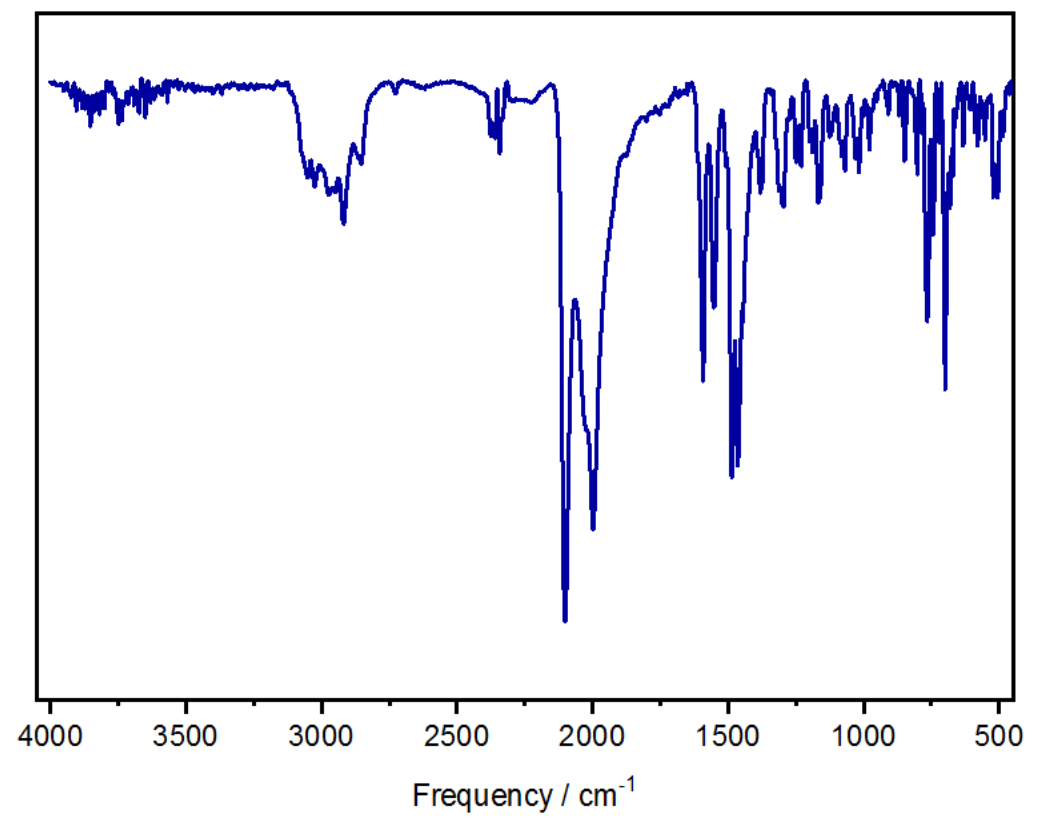

Figure 6.13. IR spectrum of $\left(\mathrm{CPh}_{2}{ }^{\mathrm{Mes}} \mathrm{PDP}{ }^{\mathrm{Ph}}\right) \mathrm{Fe}\left(\mathrm{C} \equiv \mathrm{N}-2,6-\left(\mathrm{CH}_{3}\right)_{2} \mathrm{Ph}\right)_{2}(\mathrm{KBr})$.

Furthermore, the ${ }^{13} \mathrm{C}-\left\{{ }^{1} \mathrm{H}\right\}$ NMR spectrum of the new species contains two ${ }^{13} \mathrm{C}$ resonances at 195.33 and $179.73 \mathrm{ppm}$, which provides further evidence of the presence of two chemically inequivalent isocyanide ligand environments. Gratifyingly, single crystals of the product suitable for analysis via X-ray crystallography were grown from a mixture of toluene and pentane at $-35^{\circ} \mathrm{C}$. The structural analysis confirmed the identity of the product as $\left(\mathrm{CPh}_{2}{ }^{\mathrm{Mes}} \mathrm{PDP}{ }^{\mathrm{Ph}}\right) \mathrm{Fe}\left(\mathrm{C} \equiv \mathrm{N}-2,6-\left(\mathrm{CH}_{3}\right)_{2} \mathrm{Ph}\right)_{2}$, consistent with the $\mathrm{C}_{1}$ symmetric NMR spectrum and other spectroscopic data (Scheme 6.3 and Figure 6.16). 


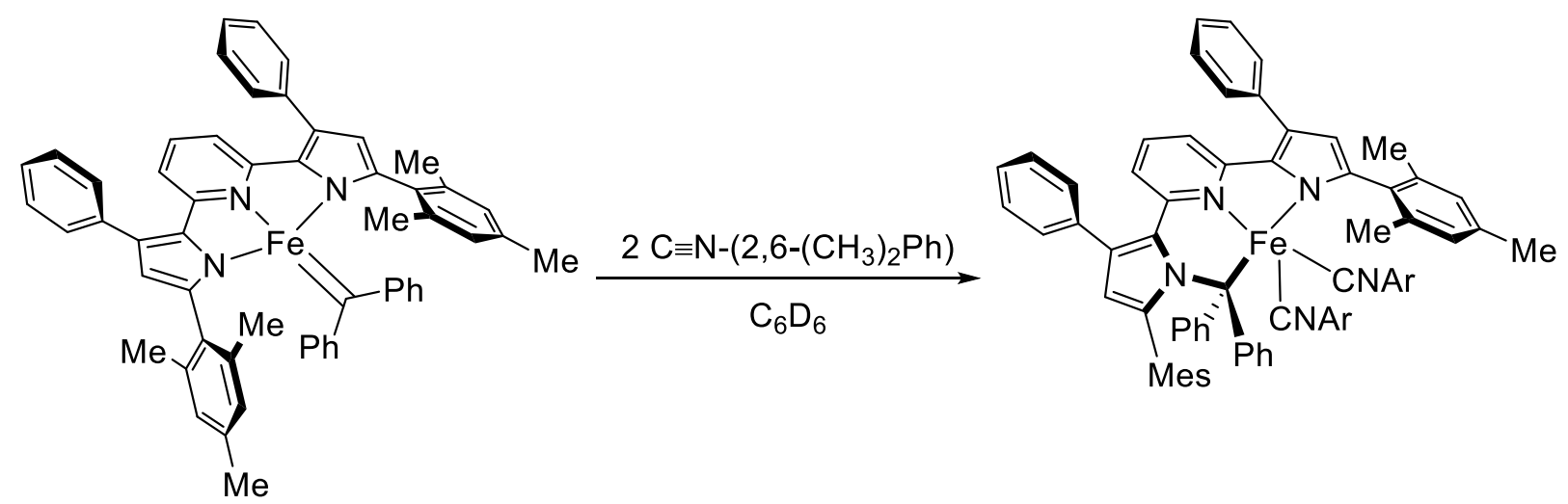

Scheme 6.3. Synthesis of $\left(\mathrm{CPh}_{2}{ }^{\mathrm{Mes}} \mathrm{PDP}{ }^{\mathrm{Ph}}\right) \mathrm{Fe}\left(\mathrm{C} \equiv \mathrm{N}-2,6-\left(\mathrm{CH}_{3}\right)_{2} \mathrm{Ph}\right)_{2}$. Note: For $\left(\mathrm{CPh}_{2}{ }^{\mathrm{Mes}} \mathrm{PDP}{ }^{\mathrm{Ph}}\right) \mathrm{Fe}\left(\mathrm{C} \equiv \mathrm{N}-2,6-\left(\mathrm{CH}_{3}\right)_{2} \mathrm{Ph}\right)_{2}$ one mesityl PDP substituent has been abbreviated "Mes" and the 2,6dimethylphenylisocyanide ligands have been abbreviated "CNAr".

Akin to $\left(\mathrm{CPh}_{2}{ }^{\mathrm{Mes}} \mathrm{PDP}{ }^{\mathrm{Ph}}\right) \mathrm{Fe}(\mathrm{CO})_{2}$, the formation of $\left(\mathrm{CPh}_{2}{ }^{\mathrm{Mes}} \mathrm{PDP}^{\mathrm{Ph}}\right) \mathrm{Fe}(\mathrm{C} \equiv \mathrm{N}-2,6$ -

$\left.\left(\mathrm{CH}_{3}\right)_{2} \mathrm{Ph}\right)_{2}$ is accounted for by insertion of the diphenylidene fragment into an iron pyrrolide bond, accompanied by ligation of two diphenyl isocyanide ligands. Interestingly, in accord with $\left(\mathrm{CPh}_{2}{ }^{\mathrm{Mes}} \mathrm{PDP}{ }^{\mathrm{Ph}}\right) \mathrm{Fe}(\mathrm{CO})_{2}$, the insertion of the diphenylidene fragment into an iron-pyrrolide nitrogen bond resulted in the formation of a new carbon-nitrogen single bond. The $\mathrm{sp}^{3}-$ hybridized alkyl carbon was detected in the ${ }^{13} \mathrm{C}-\left\{{ }^{1} \mathrm{H}\right\}$ NMR in dichloromethane- $d_{2}$ at 72.15 ppm. Unambiguous assignment of this resonance was accomplished via a combination of HSQC, HMBC, DEPT 135, and APT NMR experiments. HSQC analysis indicated a lack of correlation with any ${ }^{1} \mathrm{H}$ resonance, consistent with assignment as a quaternary carbon. A HMBC experiment indicated correlations between the ${ }^{13} \mathrm{C}$ resonance at $72.15 \mathrm{ppm}$ to ${ }^{1} \mathrm{H}$ resonances at $7.84,6.69$, and $6.25 \mathrm{ppm}$. These resonances were assigned as three of the four unique ortho-phenyl protons of the $\mathrm{CPh}_{2}$ fragment (Figure 6.13). The combination of DEPT 135 and APT experiments are also consistent with the assignment of this resonance as a quaternary carbon (Figure 6.14 and $6.15)$. 


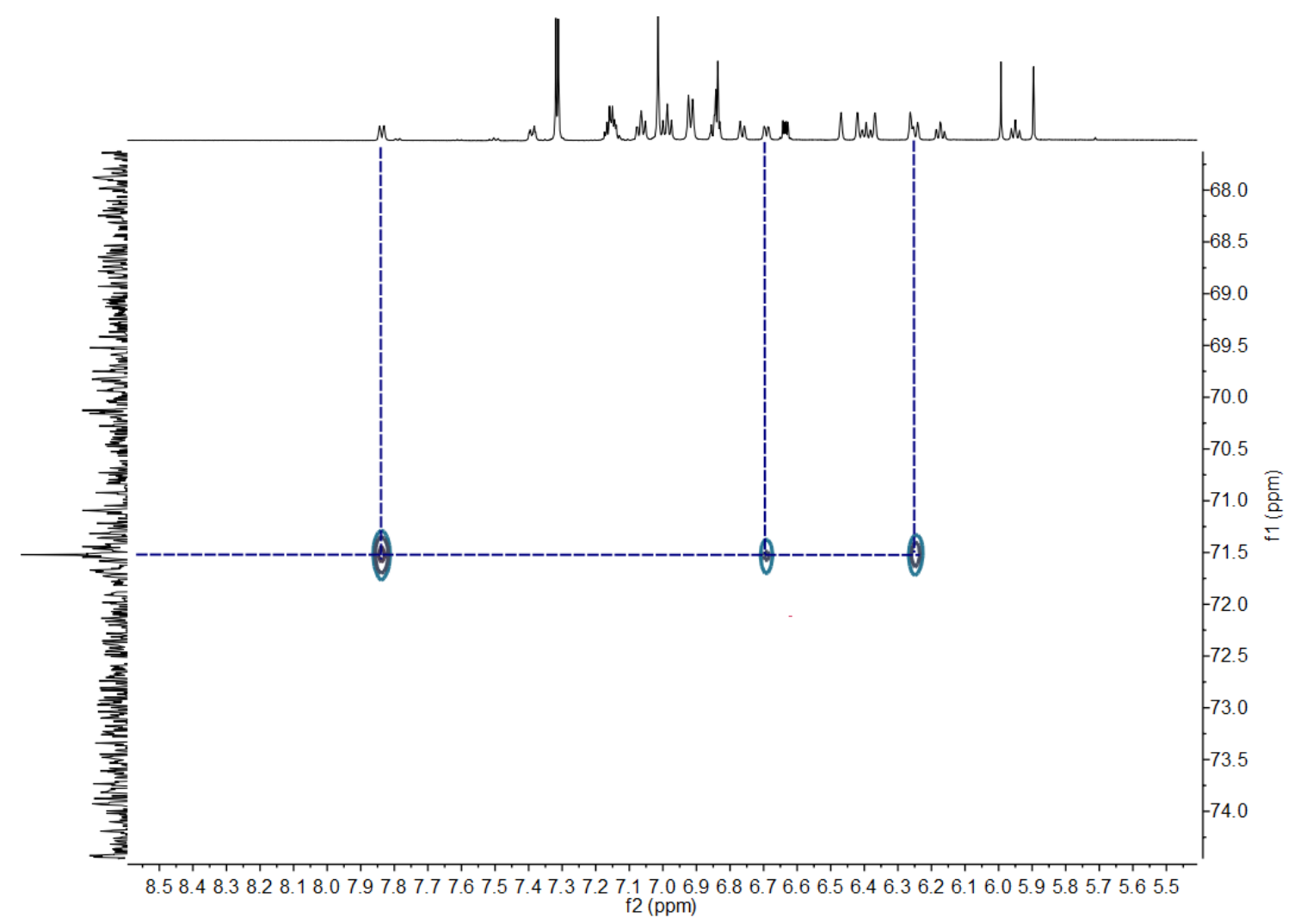

Figure 6.14. ${ }^{1} \mathrm{H}-{ }^{13} \mathrm{C}$ HMBC spectrum of $\left(\mathrm{CPh}_{2}{ }^{\mathrm{Mes}} \mathrm{PDP} \mathrm{Ph}^{\mathrm{Ph}}\right) \mathrm{Fe}\left(\mathrm{C} \equiv \mathrm{N}-2,6\left(\mathrm{CH}_{3}\right)_{2} \mathrm{Ph}\right)_{2}$ in dichloromethane- $d_{2}$. 

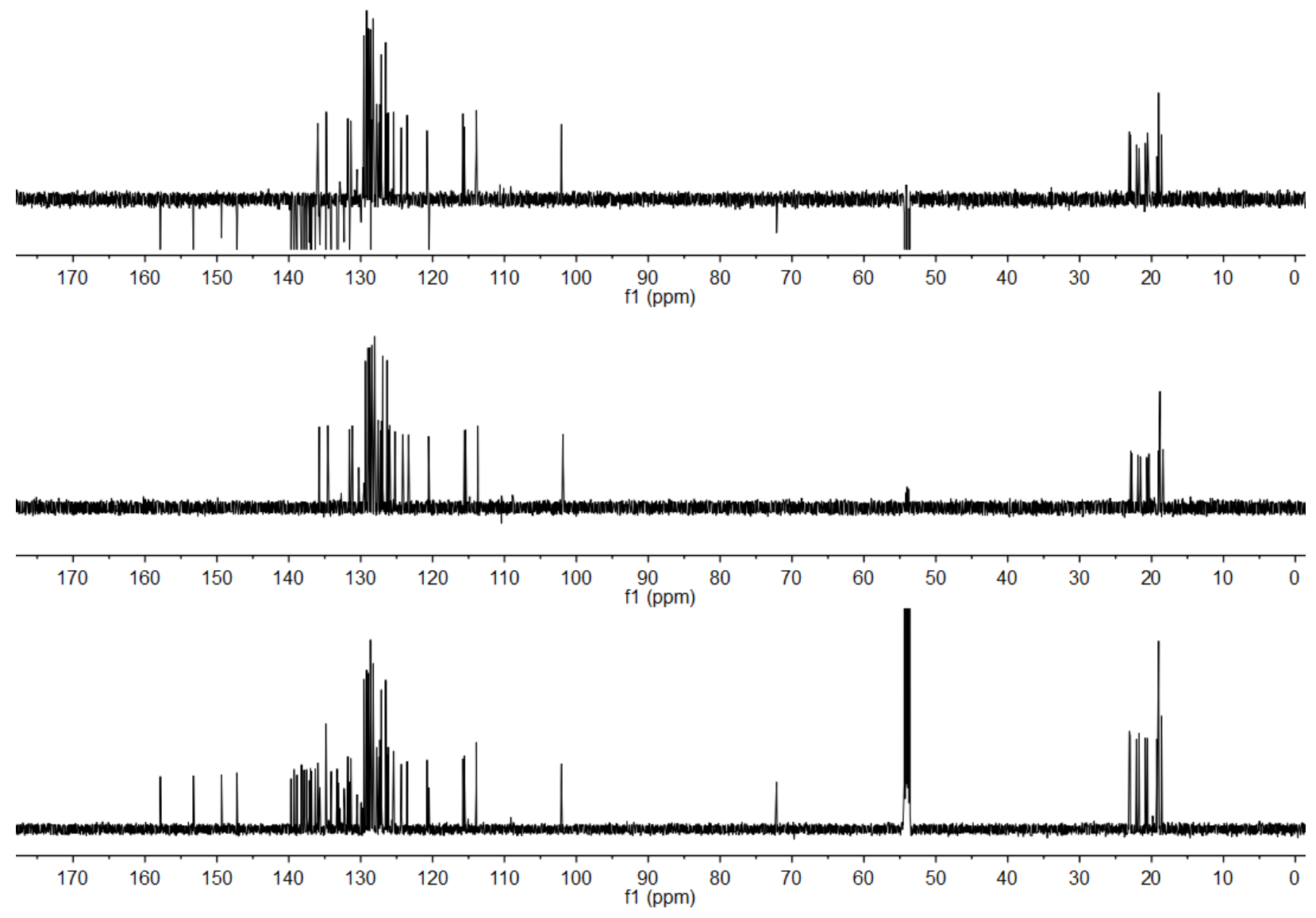

Figure 6.15. ${ }^{13} \mathrm{C}$ (bottom), DEPT 135 (middle), and APT (top) spectra of $\left(\mathrm{CPh}_{2}{ }^{\mathrm{Mes}} \mathrm{PDP}{ }^{\mathrm{Ph}}\right) \mathrm{Fe}\left(\mathrm{C} \equiv \mathrm{N}-2,6\left(\mathrm{CH}_{3}\right)_{2} \mathrm{Ph}\right)_{2}$ in dichloromethane- $d_{2}$.

In regard to the structural analysis of $\left(\mathrm{CPh}_{2}{ }^{\mathrm{Mes}} \mathrm{PDP}^{\mathrm{Ph}}\right) \mathrm{Fe}\left(\mathrm{C} \equiv \mathrm{N}-2,6\left(\mathrm{CH}_{3}\right)_{2} \mathrm{Ph}\right)_{2}$, notable bond lengths include 1.7570(15) $\AA$ (Fe1-C44) and 1.8461(14) $\AA$ (Fe1-C53) for the apical and inplane isocyanide carbons, 1.9837(12) $\AA$ (Fe1-N1) and 1.9776(12) $\AA$ (Fe1-N2) for the pyrrolide and pyridine nitrogens, and 2.0683(14) $\AA$ (Fe1-C62) for the alkyl carbon. The C62-N3 distance of 1.4773(17) $\AA$ is consistent with a carbon-nitrogen single bond. The structural data for $\left(\mathrm{CPh}_{2}{ }^{\mathrm{Mes}} \mathrm{PDP}^{\mathrm{Ph}}\right) \mathrm{Fe}\left(\mathrm{C} \equiv \mathrm{N}-2,6\left(\mathrm{CH}_{3}\right)_{2} \mathrm{Ph}\right)_{2}$ and $\left(\mathrm{CPh}_{2}{ }^{\mathrm{Mes}} \mathrm{PDP}^{\mathrm{Ph}}\right) \mathrm{Fe}(\mathrm{CO})_{2}$ is overall similar. Key bond distances and bond angles are summarized in Table 6.4 and an ORTEP of $\left(\mathrm{CPh}_{2}{ }^{\mathrm{Mes}} \mathrm{PDP} \mathrm{Ph}^{\mathrm{Ph}}\right) \mathrm{Fe}\left(\mathrm{C} \equiv \mathrm{N}-2,6\left(\mathrm{CH}_{3}\right)_{2} \mathrm{Ph}\right)_{2}$ is presented in Figure 6.16. 
Notably, $\left(\mathrm{CPh}_{2}{ }^{\mathrm{Mes}} \mathrm{PDP}{ }^{\mathrm{Ph}}\right) \mathrm{Fe}(\mathrm{CO})_{2}$ and $\left(\mathrm{CPh}_{2}{ }^{\mathrm{Mes}} \mathrm{PDP}{ }^{\mathrm{Ph}}\right) \mathrm{Fe}\left(\mathrm{C} \equiv \mathrm{N}-2,6-\left(\mathrm{CH}_{3}\right)_{2} \mathrm{Ph}\right)_{2}$ are the first examples of iron-alkyl complexes within the context of pyridine dipyrrolide iron chemistry. The iron alkyl bond distances are consistent with previously reported low-spin ferrous alkyls of related pyridine based pincer ligands. ${ }^{72}$ With $\left(\mathrm{CPh}_{2}{ }^{\mathrm{Mes}} \mathrm{PDP}^{\mathrm{Ph}}\right) \mathrm{Fe}(\mathrm{CO})_{2}$ and $\left(\mathrm{CPh}_{2}{ }^{\mathrm{Mes}} \mathrm{PDP}{ }^{\mathrm{Ph}}\right) \mathrm{Fe}-$ $\left(\mathrm{C} \equiv \mathrm{N}-2,6-\left(\mathrm{CH}_{3}\right)_{2} \mathrm{Ph}\right)_{2}$ being the first structurally characterized examples of low-spin $\mathrm{Fe}^{\mathrm{II}} \mathrm{PDP}$ compounds, zero-field Mössbauer spectra of each were acquired to further characterize the respective complexes. The spectra obtained from solid samples of each compound both revealed a single quadrupole doublet with $\delta=0.13 \mathrm{mms}^{-1}$ and $\left|\Delta \mathrm{E}_{\mathrm{Q}}\right|=1.75 \mathrm{mms}^{-1}$ for $\left(\mathrm{CPh}_{2}{ }^{\mathrm{Mes}} \mathrm{PDP}{ }^{\mathrm{Ph}}\right) \mathrm{Fe}-$ $(\mathrm{CO})_{2}$ and $\delta=0.18 \mathrm{mms}^{-1}$ and $|\Delta \mathrm{E} \mathrm{Q}|=1.51 \mathrm{mms}^{-1}$ for $\left(\mathrm{CPh}_{2}{ }^{\mathrm{Mes}} \mathrm{PDP}^{\mathrm{Ph}}\right) \mathrm{Fe}\left(\mathrm{C} \equiv \mathrm{N}-2,6-\left(\mathrm{CH}_{3}\right)_{2} \mathrm{Ph}\right)_{2}$ (Figure 6.17). These values are consistent with the low-spin Fe(II) electronic structure inferred from the diamagnetism of the complexes observed by NMR. The slightly lower isomer shift value for $\left(\mathrm{CPh}_{2}{ }^{\mathrm{Mes}} \mathrm{PDP}{ }^{\mathrm{Ph}}\right) \mathrm{Fe}(\mathrm{CO})_{2}$ is consistent with the contracted metal carbonyl bond distances in this complex relative to the isocyanides in $\left(\mathrm{CPh}_{2}{ }^{\mathrm{Mes}} \mathrm{PDP}^{\mathrm{Ph}}\right) \mathrm{Fe}\left(\mathrm{C} \equiv \mathrm{N}-2,6-\left(\mathrm{CH}_{3}\right)_{2} \mathrm{Ph}\right)_{2}$. This minor discrepancy between the two structures is likely a result of steric crowding about the iron center imparted by the bulkier isocyanide ligands. 

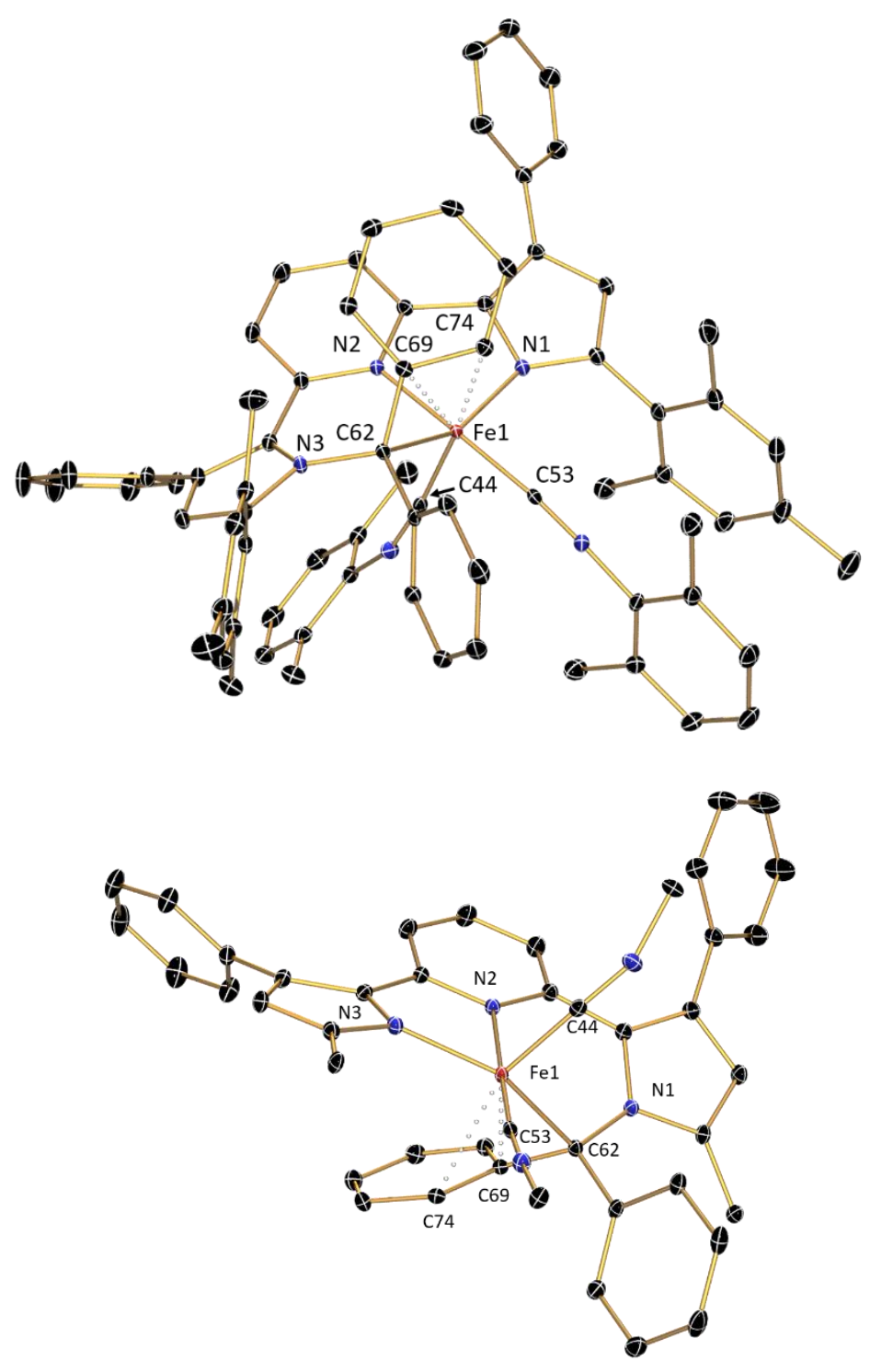

Figure 6.16. ORTEP depictions of two perspectives of $\left(\mathrm{CPh}_{2}{ }^{\mathrm{Mes}} \mathrm{PDP}{ }^{\mathrm{Ph}}\right) \mathrm{Fe}\left(\mathrm{C} \equiv \mathrm{N}-\left(\mathrm{CH}_{3}\right)_{2}(\mathrm{Ph})_{2}\right)_{2}$ at $30 \%$ probability ellipsoids. Note, in addition to hydrogen atoms and co-crystallized solvent, the bottom image has PDP mesityl substituents and 2,6-dimethylphenyl isocyanide substituents truncated to depict solely the ipso carbons. 
Table 6.4. Selected bond lengths $(\AA)$ and angles (deg) for $\left(\mathrm{CPh}_{2}{ }^{\mathrm{Mes}} \mathrm{PDP}^{\mathrm{Ph}}\right) \mathrm{Fe}(\mathrm{CO})_{2}$, $\left(\mathrm{CPh}_{2}{ }^{\mathrm{Mes}} \mathrm{PDP}{ }^{\mathrm{Ph}}\right) \mathrm{Fe}\left(\mathrm{C} \equiv \mathrm{N}-2,6-\left(\mathrm{CH}_{3}\right)_{2} \mathrm{Ph}\right)_{2}$, and $\left({ }^{\mathrm{Mes}} \mathrm{PDP}{ }^{\mathrm{Ph}}\right) \mathrm{Fe}\left(\mathrm{C} \equiv \mathrm{N}-2,6\left(\mathrm{CH}_{3}\right)_{2} \mathrm{Ph}\right)_{3}$.

\begin{tabular}{|c|c|c|c|c|c|}
\hline \multirow[b]{2}{*}{$\mathrm{Fe} 1-\mathrm{N} 2$} & \multirow{2}{*}{$\begin{array}{c}\left(\mathrm{CPh}_{2}^{\mathrm{Mes}}{ }^{\mathrm{PDP}}{ }^{\mathrm{Ph}}\right)- \\
\mathrm{Fe}(\mathrm{CO})_{2} \\
1.9846(17)\end{array}$} & \multicolumn{2}{|c|}{$\begin{array}{c}\left(\mathrm{CPh}_{2}{ }^{\mathrm{Mes}} \mathrm{PDP}^{\mathrm{Ph}}\right)_{-} \\
\mathrm{Fe}\left(\mathrm{C} \equiv \mathrm{N}-2,6-\left(\mathrm{CH}_{3}\right)_{2} \mathrm{Ph}\right)_{2}\end{array}$} & \multicolumn{2}{|c|}{$\begin{array}{c}\left({ }^{\mathrm{Mes}} \mathrm{PDP} \mathrm{P}^{\mathrm{Ph}}\right)- \\
\mathrm{Fe}\left(\mathrm{C} \equiv \mathrm{N}-2,6-\left(\mathrm{CH}_{3}\right)_{2} \mathrm{Ph}\right)_{3}\end{array}$} \\
\hline & & Fe1-N1 & $1.9837(12)$ & Fe1-N1 & $2.007(3)$ \\
\hline $\mathrm{Fe} 1-\mathrm{N} 3$ & $1.9687(18)$ & Fe1-N2 & $1.9776(12)$ & $\mathrm{Fe} 1-\mathrm{N} 2$ & $1.954(3)$ \\
\hline $\mathrm{Fe} 1-\mathrm{C} 44$ & $2.076(2)$ & $\mathrm{Fe} 1-\mathrm{C} 44$ & $1.7570(15)$ & Fe1-N3 & $1.999(3)$ \\
\hline Fe1-C57 & $1.796(2)$ & Fe1-C53 & $1.8461(14)$ & $\mathrm{Fe} 1-\mathrm{C} 44$ & $1.885(3)$ \\
\hline Fe1-C58 & $1.742(2)$ & Fe1-C62 & $2.0683(14)$ & Fe1-C53 & $1.845(4)$ \\
\hline N1-C44 & $1.472(3)$ & N3-C62 & $1.4733(17)$ & Fe1-C62 & $1.902(3)$ \\
\hline $\mathrm{N} 2-\mathrm{Fe} 1-\mathrm{N} 3$ & $81.44(7)$ & N1-Fe1-N2 & $81.54(5)$ & N1-Fe1-N2 & $80.14(11)$ \\
\hline $\mathrm{C} 44-\mathrm{Fe} 1-\mathrm{C} 58$ & $99.49(9)$ & $\mathrm{C} 44-\mathrm{Fe} 1-\mathrm{C} 62$ & $95.64(6)$ & N1-Fe1-N3 & $160.25(11)$ \\
\hline N1-C44-Fe1 & $115.06(13)$ & N3-C62-Fe1 & 115.37 & $\mathrm{~N} 2-\mathrm{Fe} 1-\mathrm{N} 3$ & $80.15(11)$ \\
\hline $\mathrm{N} 2-\mathrm{Fe} 1-\mathrm{C} 44$ & $91.46(8)$ & $\mathrm{N} 2-\mathrm{Fe} 1-\mathrm{C} 44$ & $86.32(6)$ & N1-Fe1-C44 & $87.52(13)$ \\
\hline N2-Fe1-C58 & $85.85(9)$ & N2-Fe1-C62 & $89.68(5)$ & N1-Fe1-C53 & $99.78(13)$ \\
\hline N3-Fe1-C44 & $153.23(8)$ & N1-Fe1-C44 & $108.63(6)$ & N1-Fe1-C62 & $86.40(13)$ \\
\hline $\mathrm{C} 44-\mathrm{Fe} 1-\mathrm{C} 57$ & $93.74(9)$ & C44-Fe1-C53 & $88.83(6)$ & N2-Fe1-C44 & $88.26(13)$ \\
\hline N2-Fe1-C57 & 173.14(9) & N2-Fe1-C53 & $172.84(6)$ & N2-Fe1-C53 & $179.44(14)$ \\
\hline N3-Fe1-C57 & $95.79(8)$ & N1-Fe1-C53 & $95.06(5)$ & N1-Fe1-C62 & $89.42(13)$ \\
\hline N3-Fe1-C58 & 105.64(9) & N1-Fe1-C62 & $153.46(5)$ & N3-Fe1-C44 & 90.72 \\
\hline- & - & - & - & N3-Fe1-C53 & $99.92(13)$ \\
\hline - & - & - & - & N3-Fe1-C62 & $94.56(13)$ \\
\hline
\end{tabular}



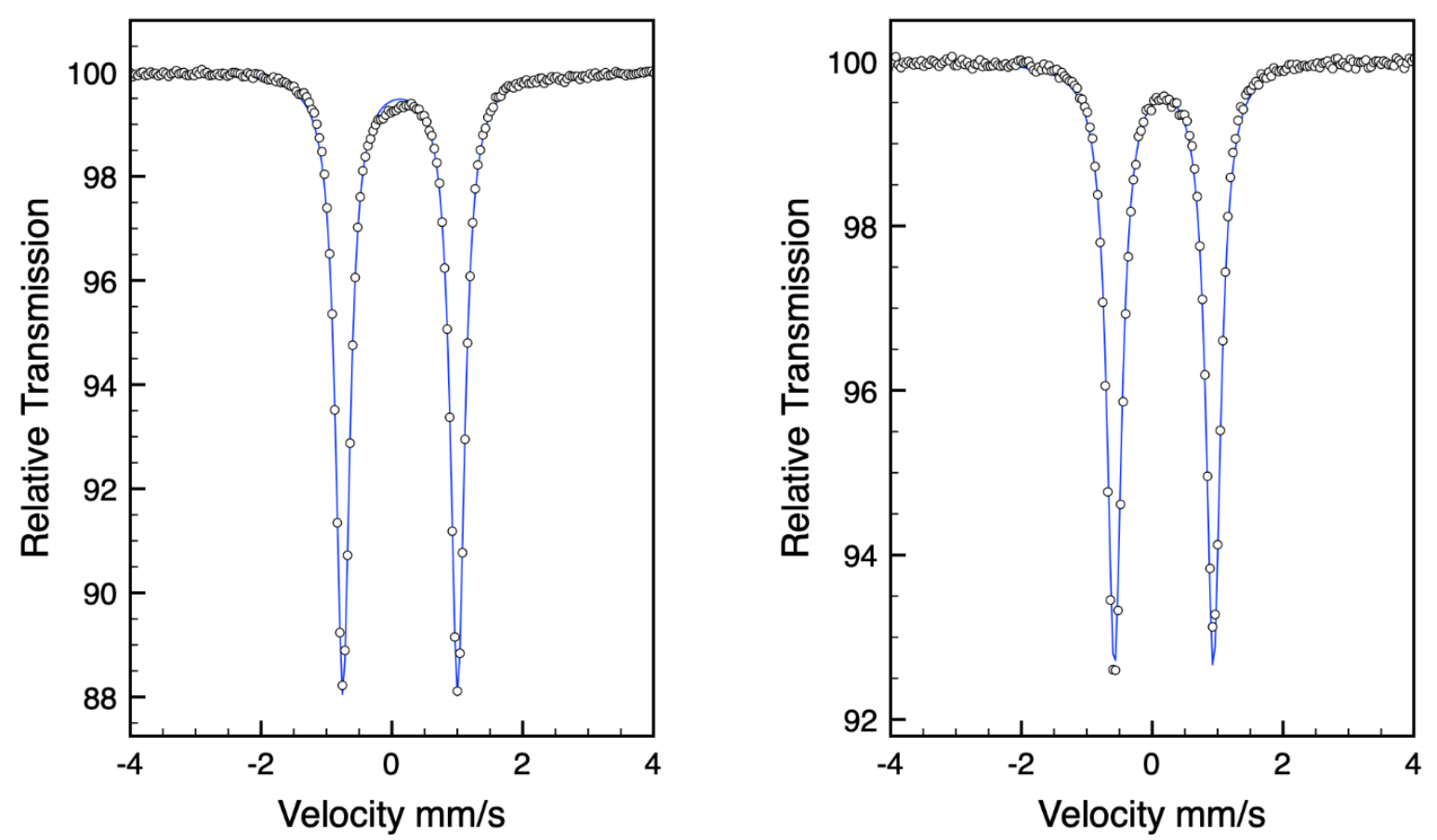

Figure 6.17. Zero-field ${ }^{57} \mathrm{Fe}$ Mössbauer spectra of $\left(\mathrm{CPh}_{2}{ }^{\mathrm{Mes}} \mathrm{PDP}{ }^{\mathrm{Ph}}\right) \mathrm{Fe}(\mathrm{CO})_{2}$ (left) and $\left(\mathrm{CPh}_{2}{ }^{\mathrm{Mes}} \mathrm{PDP}{ }^{\mathrm{Ph}}\right) \mathrm{Fe}\left(\mathrm{C} \equiv \mathrm{N}-2,6-\left(\mathrm{CH}_{3}\right)_{2} \mathrm{Ph}\right)_{2}$ (right) recorded at $80 \mathrm{~K}$.

\subsection{Reactivity Studies of $\left(\mathrm{CPh}_{2}{ }^{\mathrm{Mes}} \mathrm{PDP} \mathrm{Ph}^{\mathrm{Ph}}\right) \mathrm{Fe}\left(\mathrm{C} \equiv \mathrm{N}-2,6-\left(\mathrm{CH}_{3}\right)_{2} \mathrm{Ph}\right)_{2}$}

Based on the known propensity for $3 \mathrm{~d}$ transition metal carbene compounds to undergo carbene transfer group to isocyanides ${ }^{57,60,61,63}$, thermal decomposition studies of $\left(\mathrm{CPh}_{2}{ }^{\mathrm{Mes}} \mathrm{PDP}{ }^{\mathrm{Ph}}\right) \mathrm{Fe}\left(\mathrm{C} \equiv \mathrm{N}-2,6-\left(\mathrm{CH}_{3}\right)_{2} \mathrm{Ph}\right)_{2}$ were conducted. It was found that heating a benzene- $d_{6}$ solution of $\left(\mathrm{CPh}_{2}{ }^{\mathrm{Mes}} \mathrm{PDP} \mathrm{Ph}^{\mathrm{Ph}}\right) \mathrm{Fe}\left(\mathrm{C} \equiv \mathrm{N}-2,6-\left(\mathrm{CH}_{3}\right)_{2} \mathrm{Ph}\right)_{2}$ at $80^{\circ} \mathrm{C}$ for 48 hrs resulted in complete decomposition of the starting material to multiple diamagnetic and paramagnetic products, as determined by ${ }^{1} \mathrm{H}$ NMR spectroscopy. Anticipating an iron isocyanide complex as a likely reaction product, the independent synthesis and characterization of a $\left({ }^{\mathrm{Mes}} \mathrm{PDP}^{\mathrm{Ph}}\right) \mathrm{Fe}$ $\left(\mathrm{C} \equiv \mathrm{N}-2,6-\left(\mathrm{CH}_{3}\right)_{2} \mathrm{Ph}\right)$ species was pursued, in order to determine unambiguously the presence of such a species in the crude reaction mixture. 
The preparation of $\left({ }^{\mathrm{Mes}} \mathrm{PDP}{ }^{\mathrm{Ph}}\right) \mathrm{Fe}\left(\mathrm{C} \equiv \mathrm{N}-2,6\left(\mathrm{CH}_{3}\right)_{2} \mathrm{Ph}\right)_{3}$ and the related complex $\left({ }^{\mathrm{Mes}} \mathrm{PDP}{ }^{\mathrm{Ph}}\right) \mathrm{Fe}\left(\mathrm{C} \equiv \mathrm{N}-{ }^{1} \mathrm{Ad}\right)_{3}$ was accomplished by the addition of a benzene solution containing three molar equivalents of the corresponding isocyanide to a solution of ( $\left.{ }^{\mathrm{Mes}} \mathrm{PDP}{ }^{\mathrm{Ph}}\right) \mathrm{Fe}(\mathrm{thf})$ in the same solvent (Scheme 6.4). Both $\left({ }^{\mathrm{Mes}} \mathrm{PDP}{ }^{\mathrm{Ph}}\right) \mathrm{Fe}\left(\mathrm{C} \equiv \mathrm{N}-2,6\left(\mathrm{CH}_{3}\right)_{2} \mathrm{Ph}\right)_{3}$ and $\left({ }^{\mathrm{Mes}} \mathrm{PDP}{ }^{\mathrm{Ph}}\right) \mathrm{Fe}-$ $\left(\mathrm{C} \equiv \mathrm{N}-{ }^{1} \mathrm{Ad}\right)_{3}$ precipitated from the crude reaction mixture and were isolated as analytically pure yellow $\left(\mathrm{C} \equiv \mathrm{N}-2,6\left(\mathrm{CH}_{3}\right)_{2} \mathrm{Ph}\right)$ or orange $\left(\mathrm{C} \equiv \mathrm{N}-{ }^{1} \mathrm{Ad}\right)$ powders, following filtration and subsequent washing with pentane. Analysis by IR spectroscopy (KBr) indicated strong $\mathrm{C} \equiv \mathrm{N}$ stretches at $2103 \mathrm{~cm}^{-1}$ and $2150 \mathrm{~cm}^{-1}$ for $\left({ }^{\mathrm{Mes}} \mathrm{PDP}{ }^{\mathrm{Ph}}\right) \mathrm{Fe}\left(\mathrm{C} \equiv \mathrm{N}-2,6\left(\mathrm{CH}_{3}\right)_{2} \mathrm{Ph}\right)_{3}$, Figure 6.18, and $2123 \mathrm{~cm}^{-1}$ for $\left({ }^{\mathrm{Mes}} \mathrm{PDP}{ }^{\mathrm{Ph}}\right) \mathrm{Fe}\left(\mathrm{C} \equiv \mathrm{N}-{ }^{1} \mathrm{Ad}\right)_{3}$, Figure 6.19 .

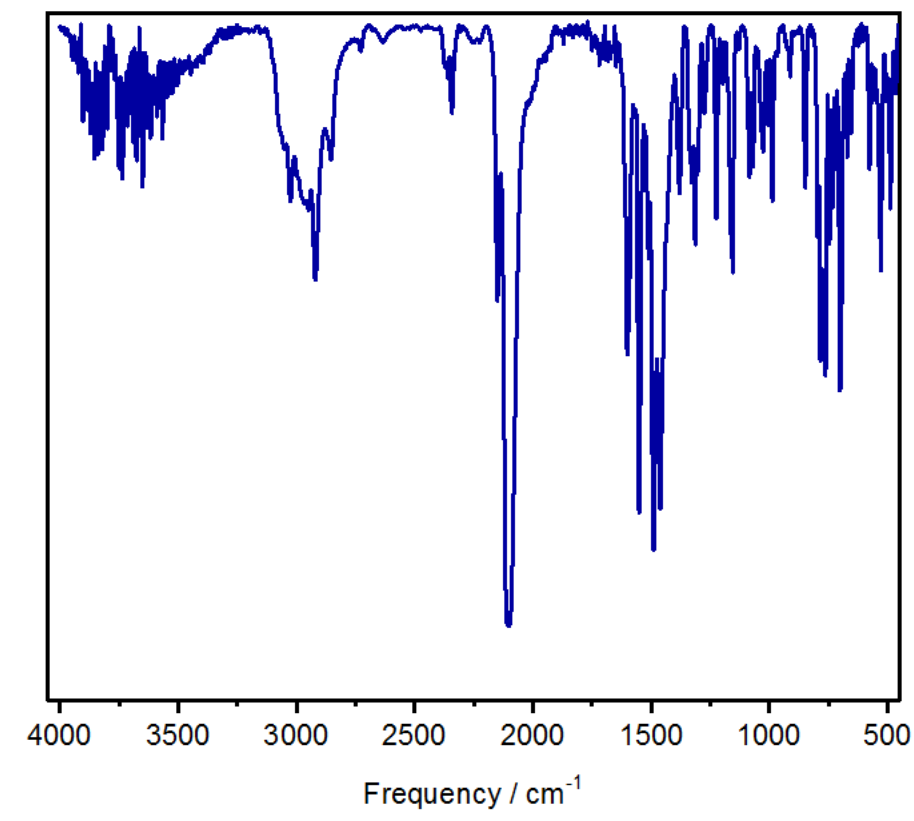

Figure 6.18. IR spectrum of $\left({ }^{\mathrm{Mes}} \mathrm{PDP}{ }^{\mathrm{Ph}}\right) \mathrm{Fe}\left(\mathrm{C} \equiv \mathrm{N}-\left(\mathrm{CH}_{3}\right)_{2} \mathrm{Ph}\right)_{3}(\mathrm{KBr})$. 


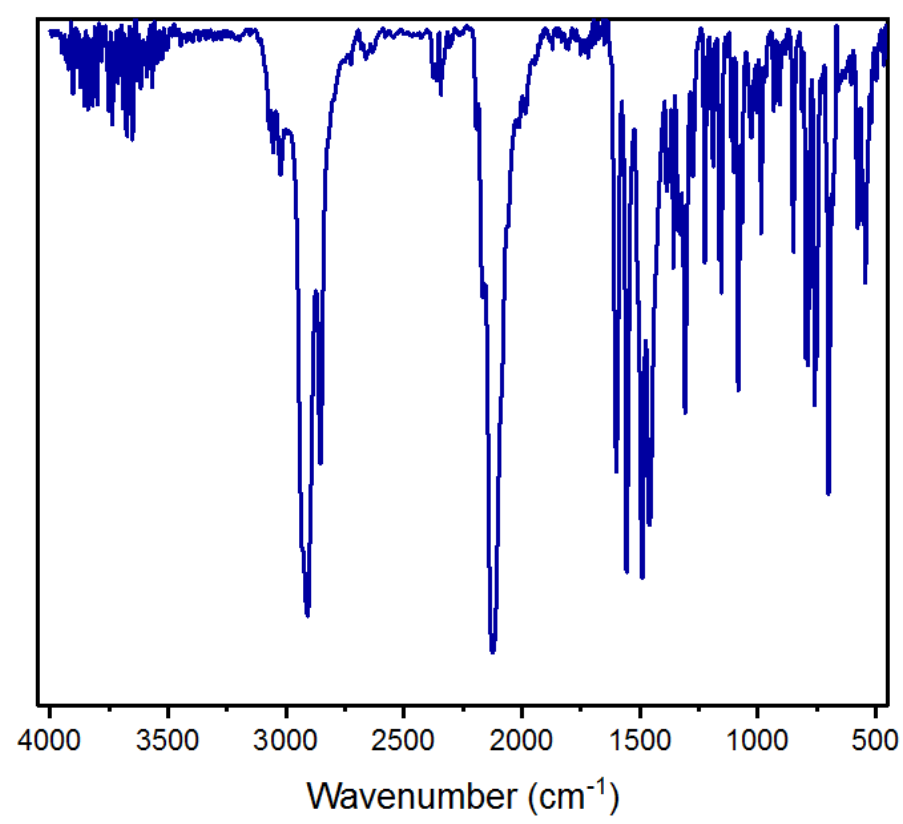

Figure 6.19. IR spectrum of $\left({ }^{\mathrm{Mes}} \mathrm{PDP} \mathrm{P}^{\mathrm{Ph}}\right) \mathrm{Fe}\left(\mathrm{C} \equiv \mathrm{N}-{ }^{1} \mathrm{Ad}\right)_{3}(\mathrm{KBr})$.

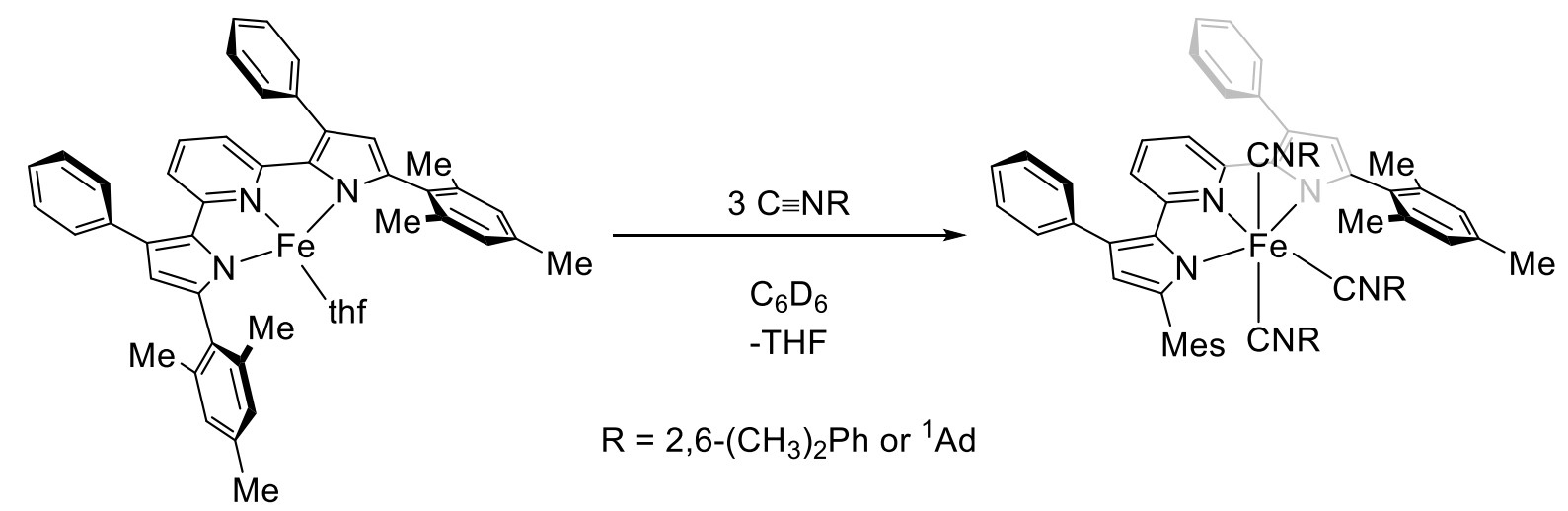

Scheme 6.4. Independent synthesis of $\left({ }^{\mathrm{Mes}} \mathrm{PDP} \mathrm{Ph}^{\mathrm{Ph}}\right) \mathrm{Fe}(\mathrm{C} \equiv \mathrm{NR})_{3}$ complexes. "Mes" denotes a mesityl substituent of the MesPDP ${ }^{\text {Ph }}$ ligand.

The ${ }^{1} \mathrm{H}$ NMR spectra of both species in benzene- $d_{6}$ or dichloromethane- $d_{2}$ are consistent with $\mathrm{C}_{2 v}$ symmetric structures in solution. X-ray studies performed on single crystals of both complexes and unambiguously confirmed their identities. Despite repeated efforts, only poorly 
diffracting crystals could be obtained for $\left({ }^{\mathrm{Mes}} \mathrm{PDP} \mathrm{P}^{\mathrm{Ph}}\right) \mathrm{Fe}\left(\mathrm{C} \equiv \mathrm{N}-{ }^{1} \mathrm{Ad}\right) 3$; thus, only the structure of $\left({ }^{\mathrm{Mes}} \mathrm{PDP}{ }^{\mathrm{Ph}}\right) \mathrm{Fe}\left(\mathrm{C} \equiv \mathrm{N}-2,6\left(\mathrm{CH}_{3}\right)_{2} \mathrm{Ph}\right)_{3}$ will be discussed in further detail. $\left({ }^{\mathrm{Mes}} \mathrm{PDP}{ }^{\mathrm{Ph}}\right) \mathrm{Fe}-$ $\left(\mathrm{C} \equiv \mathrm{N}-2,6\left(\mathrm{CH}_{3}\right)_{2} \mathrm{Ph}\right)_{3}$ was found to crystallize in the triclinic space group P-1 and an ORTEP of the solid-state structure is presented in Figure 6.20. The short iron PDP nitrogen bond lengths of

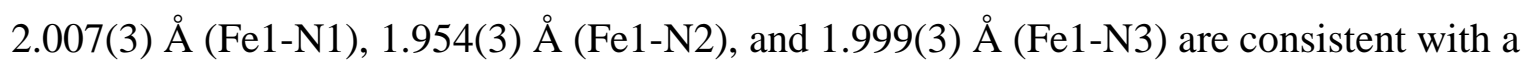
diamagnetic ferrous ground state. For example, comparison of these metrics to previously characterized high-spin $\mathrm{Fe}^{\mathrm{II}}(\mathrm{S}=2){ }^{\text {Mes }} \mathrm{PDP}^{\mathrm{Ph}}$ complexes is consistent with this assessment (see Table 6.5), as $\left({ }^{\mathrm{Mes}} \mathrm{PDP}{ }^{\mathrm{Ph}}\right) \mathrm{Fe}($ thf $)$ and $\left({ }^{\mathrm{Mes}} \mathrm{PDP}^{\mathrm{Ph}}\right) \mathrm{Fe}(\mathrm{py})_{2}$ both feature iron nitrogen bond lengths well in excess of $2 \AA$. Furthermore, the iron isocyanide carbon bond lengths of 1.885(3) $\mathrm{A}$ (FeC44), 1.845(4) $\AA$ (Fe1-C53), and 1.902(3) $\AA$ (Fe1-C62) for $\left({ }^{\mathrm{Mes}} \mathrm{PDP}^{\mathrm{Ph}}\right) \mathrm{Fe}\left(\mathrm{C} \equiv \mathrm{N}-2,6-\left(\mathrm{CH}_{3}\right)_{2} \mathrm{Ph}\right)_{3}$ are similar to the iron isocyanide carbon distances of $\left(\mathrm{CPh}_{2}{ }^{\mathrm{Mes}} \mathrm{PDP}^{\mathrm{Ph}}\right) \mathrm{Fe}\left(\mathrm{C} \equiv \mathrm{N}-2,6-\left(\mathrm{CH}_{3}\right)_{2} \mathrm{Ph}\right)_{2}$. A more complete presentation of the structural metrics obtained from crystallography is presented in Table 6.4 (vide supra). 


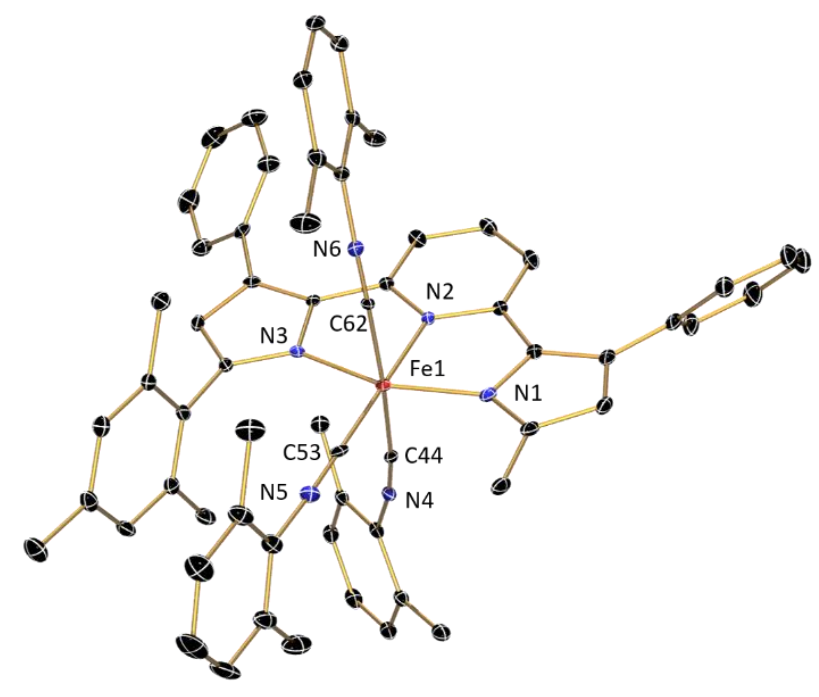

Figure 6.20. ORTEP of $\left({ }^{\mathrm{Mes}} \mathrm{PDP}{ }^{\mathrm{Ph}}\right) \mathrm{Fe}\left(\mathrm{C} \equiv \mathrm{N}-2,6-\left(\mathrm{CH}_{3}\right)_{2} \mathrm{Ph}\right)_{3}$ depicted at $30 \%$ probability ellipsoids. Note only one of the two independent molecules in the unit cell is depicted. Additionally, co-crystallized benzene, hydrogen atoms, and a mesityl substituent of the PDP ligand (with exception of the ipso carbon) are excluded for clarity.

Table 6.5. Iron-PDP nitrogen bond lengths $(\AA)$ in high- and low-spin $\mathrm{Fe}^{\mathrm{II}}{ }^{\mathrm{Mes}} \mathrm{PDP}^{\mathrm{Ph}}$ complexes.

\begin{tabular}{|c|c|c|c|c|}
\hline & Spin-State & $F e-N_{P y r i d i n d} / \AA$ & $F e-N_{\text {pyrrole }} / \AA$ & $F e-N_{\text {pyrrole }} / \AA$ \\
\hline$\left({ }^{\text {Mes }} \mathrm{PDP}^{\mathrm{Ph}}\right) \mathrm{Fe}(\mathrm{thf})$ & 2 & $2.0693(14)$ & $2.0596(14)$ & $2.0419(14)$ \\
\hline$\left({ }^{\text {Mes }} \mathrm{PDP}^{\mathrm{Ph}}\right) \mathrm{Fe}(\mathrm{py})_{2}$ & 2 & $2.1126(13)$ & $2.0968(13)$ & $2.0863(13)$ \\
\hline$\left(\mathrm{CPh}_{2}{ }^{\mathrm{Mes}} \mathrm{PDP}^{\mathrm{Ph}}\right) \mathrm{Fe}(\mathrm{CO})_{2}$ & 0 & $1.9846(17)$ & $1.9687(18)$ & - \\
\hline$\left(\mathrm{CPh}_{2}{ }^{\mathrm{Mes}} \mathrm{PDP}^{\mathrm{Ph}} \mathrm{Fe}\left(\mathrm{C} \equiv \mathrm{N}-2,6-\left(\mathrm{CH}_{3}\right)_{2} \mathrm{Ph}\right)_{2}\right.$ & 0 & $1.9776(12)$ & $1.9837(12)$ & - \\
\hline$\left({ }^{\text {Mes }} \mathrm{PDP} P \mathrm{Ph}\right) \mathrm{Fe}\left(\mathrm{C} \equiv \mathrm{N}-2,6-\left(\mathrm{CH}_{3}\right)_{2} \mathrm{Ph}\right)_{3}$ & 0 & $1.954(3)$ & $2.007(3)$ & $1.999(3)$ \\
\hline
\end{tabular}

Zero-field ${ }^{57} \mathrm{Fe}$ Mössbauer spectra of $\left({ }^{\mathrm{Mes}} \mathrm{PDP}{ }^{\mathrm{Ph}}\right) \mathrm{Fe}\left(\mathrm{C} \equiv \mathrm{N}-2,6\left(\mathrm{CH}_{3}\right)_{2} \mathrm{Ph}\right)_{3}$ and $\left({ }^{\mathrm{Mes}} \mathrm{PDP}{ }^{\mathrm{Ph}}\right) \mathrm{Fe}\left(\mathrm{C} \equiv \mathrm{N}-{ }^{1} \mathrm{Ad}\right)_{3}$ acquired at $80 \mathrm{~K}$ revealed quadrupole doublets with $\delta=0.11 \mathrm{mms}^{-1}$ and $\left|\Delta \mathrm{E}_{\mathrm{Q}}\right|=0.48 \mathrm{mms}^{-1}$ for $\left({ }^{\mathrm{Mes}} \mathrm{PDP}{ }^{\mathrm{Ph}}\right) \mathrm{Fe}\left(\mathrm{C} \equiv \mathrm{N}-2,6\left(\mathrm{CH}_{3}\right)_{2} \mathrm{Ph}\right)_{3}$ and $\delta=0.15 \mathrm{mms}^{-1}$ and $\left|\Delta \mathrm{E}_{\mathrm{Q}}\right|=0.76$ $\mathrm{mms}^{-1}$ for $\left({ }^{\mathrm{Mes}} \mathrm{PDP}{ }^{\mathrm{Ph}}\right) \mathrm{Fe}\left(\mathrm{C} \equiv \mathrm{N}-{ }^{1} \mathrm{Ad}\right)_{3}($ Figure 6.21). The isomer shift values are consistent with a 
low-spin $\mathrm{Fe}^{\mathrm{II}}$ ion present in both species and in good agreement with $\left(\mathrm{CPh}_{2}{ }^{\mathrm{Mes}} \mathrm{PDP}^{\mathrm{Ph}}\right) \mathrm{Fe}(\mathrm{CO})_{2}$ and $\left(\mathrm{CPh}_{2}{ }^{\mathrm{Mes}} \mathrm{PDP}{ }^{\mathrm{Ph}}\right) \mathrm{Fe}\left(\mathrm{C} \equiv \mathrm{N}-2,6-\left(\mathrm{CH}_{3}\right)_{2} \mathrm{Ph}\right)_{2}$, while the small quadrupole splitting values are consistent with symmetric charge distributions at the iron centers. A summary of all experimentally and computationally determined Mössbauer parameters for the compounds studied in this chapter is presented in Table 6.7.
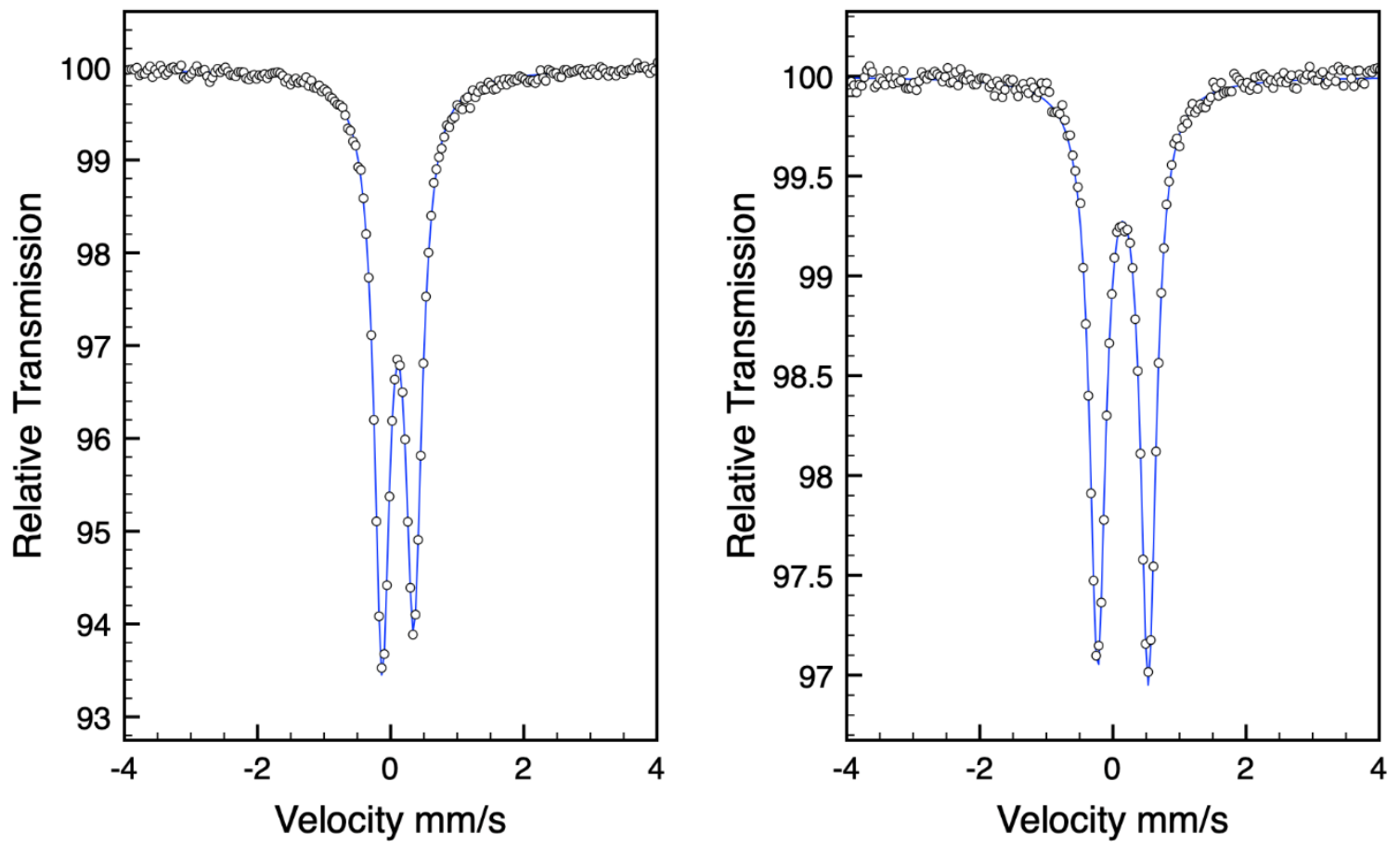

Figure 6.21. Zero-field ${ }^{57} \mathrm{Fe}$ Mössbauer spectra of $\left({ }^{\mathrm{Mes}} \mathrm{PDP}{ }^{\mathrm{Ph}}\right) \mathrm{Fe}\left(\mathrm{C} \equiv \mathrm{N}-2,6-\left(\mathrm{CH}_{3}\right)_{2} \mathrm{Ph}\right)_{3}(\mathrm{left})\left({ }^{\mathrm{Mes}} \mathrm{PDP}{ }^{\mathrm{Ph}}\right) \mathrm{Fe}\left(\mathrm{C} \equiv \mathrm{N}-{ }^{1} \mathrm{Ad}\right)_{3}$ (right) recorded at $80 \mathrm{~K}$. 
Table 6.6. Experimental and calculated Mössbauer parameters for ${ }^{\mathrm{Mes}} \mathrm{PDP}^{\mathrm{Ph}}$ complexes in this chapter.

\begin{tabular}{|c|c|c|c|}
\hline & $\delta / \mathrm{mms}^{-1}($ calc $)$ & $\Delta E_{Q} / m^{\prime} s^{-1}($ calc $)$ & $\eta^{a, b}$ \\
\hline$\left({ }^{\mathrm{Mes}} \mathrm{PDP}^{\mathrm{Ph}}\right) \mathrm{Fe}\left(\mathrm{CPh}_{2}\right)$ & $0.20(0.24)^{c}$ & $-2.86 \mid(-4.04)^{c}$ & $0.208^{c}$ \\
\hline$\left(\mathrm{CPh}_{2}{ }^{\mathrm{Mes}} \mathrm{PDP} \mathrm{Ph}^{\mathrm{Ph}}\right) \mathrm{Fe}(\mathrm{CO})_{2}$ & $0.13(0.11)$ & $|1.75|(2.00)$ & 0.672 \\
\hline$\left(\mathrm{CPh}_{2}{ }^{\mathrm{Mes}} \mathrm{PDP} \mathrm{Ph}^{\mathrm{Ph}}\right) \mathrm{Fe}\left(\mathrm{C} \equiv \mathrm{N}-2,6-\left(\mathrm{CH}_{3}\right)_{2} \mathrm{Ph}\right)_{2}$ & $0.18(0.22)$ & $|1.51|(1.72)$ & 0.224 \\
\hline$\left({ }^{\mathrm{Mes}} \mathrm{PDP} \mathrm{Ph}^{\mathrm{Ph}}\right) \mathrm{Fe}\left(\mathrm{C} \equiv \mathrm{N}-{ }^{1} \mathrm{Ad}\right)_{3}$ & $0.15(0.20)$ & $|0.76|(1.15)$ & 0.089 \\
\hline$\left({ }^{\text {Mes }} \mathrm{PDP} P \mathrm{Ph}\right) \mathrm{Fe}\left(\mathrm{C} \equiv \mathrm{N}-2,6-\left(\mathrm{CH}_{3}\right)_{2} \mathrm{Ph}\right)_{3}$ & 0.11 & $|0.48|$ & - \\
\hline
\end{tabular}

${ }^{a}$ Asymmetry parameter of the electronic field gradient. ${ }^{b}$ Not determined experimentally. ${ }^{c}$ Obtained from $\mathrm{BS}(3,1) / \mathrm{UKS} 3$ calculation.

With established spectroscopic markers in hand for $\left({ }^{\mathrm{Mes}} \mathrm{PDP}{ }^{\mathrm{Ph}}\right) \mathrm{Fe}\left(\mathrm{C} \equiv \mathrm{N}-2,6-\left(\mathrm{CH}_{3}\right)_{2} \mathrm{Ph}\right)_{3}$, a comparison of its ${ }^{1} \mathrm{H}$ NMR chemical shifts was made to the mixture of decomposition products produced from the thermal decomposition of $\left(\mathrm{CPh}_{2}{ }^{\mathrm{Mes}} \mathrm{PDP}{ }^{\mathrm{Ph}}\right) \mathrm{Fe}\left(\mathrm{C} \equiv \mathrm{N}-2,6-\left(\mathrm{CH}_{3}\right)_{2} \mathrm{Ph}\right)_{2}$. The presence of $\left({ }^{\mathrm{Mes}} \mathrm{PDP}{ }^{\mathrm{Ph}}\right) \mathrm{Fe}\left(\mathrm{C} \equiv \mathrm{N}-2,6-\left(\mathrm{CH}_{3}\right)_{2} \mathrm{Ph}\right)_{3}$ in the mixture was confirmed by diagnostic singlet resonances at $2.14 \mathrm{ppm}$ and $2.27 \mathrm{ppm}$ each with relative integration of 12 , albeit, as a minor component of the mixture. These resonances correspond to the mesityl ortho methyl groups of the Mes ${ }^{\mathrm{PDP}} \mathrm{Ph}^{\mathrm{Ph}}$ chelate and the apical 2,6-dimethylphenylisocyanide ligands. The second diamagnetic decomposition product was determined to be the ketenimine, $N-(2,2-$ diphenylethenylidene)-2,6-dimethyl-benzenamine $\left(\mathrm{Ph}_{2} \mathrm{C}=\mathrm{C}=\mathrm{N}-\left(\mathrm{CH}_{3}\right)_{2} \mathrm{Ph}\right)$, based on comparison of the ${ }^{1} \mathrm{H}$ chemical shifts and relative integrations to the literature reported values (Figure 6.22 and 6.23) ${ }^{57}$ Furthermore, $\left({ }^{\mathrm{Mes}} \mathrm{PDP}{ }^{\mathrm{Ph}}\right) \mathrm{Fe}\left(\mathrm{CPh}_{2}\right)$ was also identified in the ${ }^{1} \mathrm{H}$ NMR spectrum, also in low concentration, as determined by relative integration to the two diamagnetic species. Lastly, the second paramagnetic compound present in the mixture was determined to be the majority iron containing species, based on integration relative $\left({ }^{\mathrm{Mes}} \mathrm{PDP} P \mathrm{Ph}\right) \mathrm{Fe}\left(\mathrm{C} \equiv \mathrm{N}-2,6-\left(\mathrm{CH}_{3}\right)_{2} \mathrm{Ph}\right)_{3}$ and $\left({ }^{\mathrm{Mes}} \mathrm{PDP}{ }^{\mathrm{Ph}}\right) \mathrm{Fe}\left(\mathrm{CPh}_{2}\right)$. The integration relative to the ketenimine product was determined to be approximately $1: 1$. The 11 paramagnetically shifted and broadened resonances of the new 
paramagnetic complex are consistent with a PDP iron species possessing apparent $\mathrm{C}_{2 \mathrm{v}}$ symmetry in solution. The number of resonances and their relative integrations (Figure 6.24) are consistent a tentative assignment of this species as a mono isocyanide adduct, $\left({ }^{\mathrm{Mes}} \mathrm{PDP}{ }^{\mathrm{Ph}}\right) \mathrm{Fe}-$ $\left(\mathrm{C} \equiv \mathrm{N}-2,6-\left(\mathrm{CH}_{3}\right)_{2} \mathrm{Ph}\right)$. Diagnostic resonances at $12.27,-1.01$, and $-23.69 \mathrm{ppm}$ were determined to have relative integrations of 12:6:6 and are anticipated to correspond to the ortho and para mesityl methyl groups of the ${ }^{\mathrm{Mes}} \mathrm{PDP}^{\mathrm{Ph}}$ pincer and the ortho methyl groups of the isocyanide ligand. Scheme 6.5 summarizes the products of thermal decomposition of $\left(\mathrm{CPh}_{2}{ }^{\mathrm{Mes}} \mathrm{PDP}^{\mathrm{Ph}}\right) \mathrm{Fe}$ $\left(\mathrm{C} \equiv \mathrm{N}-2,6-\left(\mathrm{CH}_{3}\right)_{2} \mathrm{Ph}\right)_{2}$.

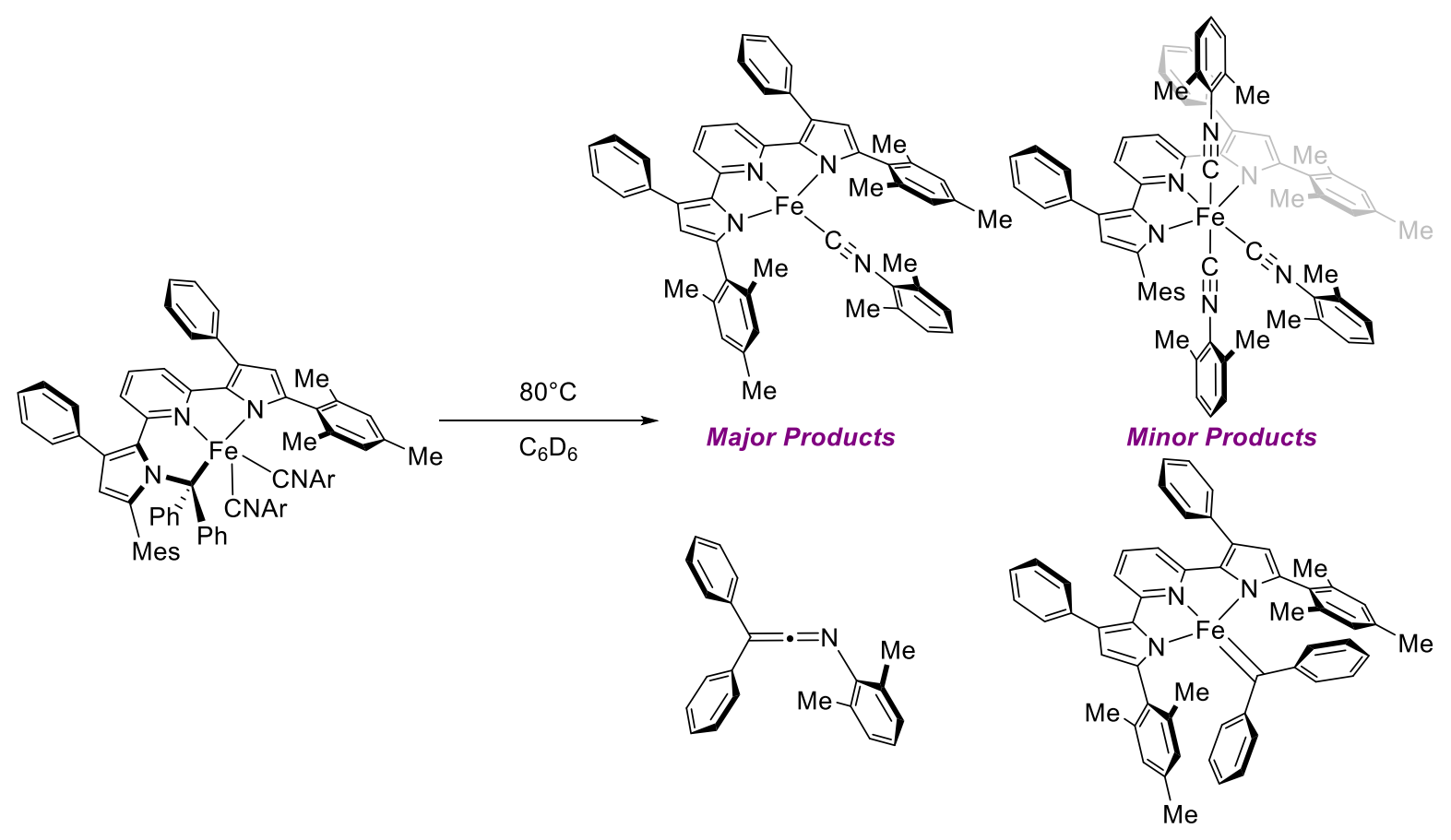

Scheme 6.5. Thermal decomposition of $\left(\mathrm{CPh}_{2}{ }^{\mathrm{Mes}} \mathrm{PDP}{ }^{\mathrm{Ph}}\right) \mathrm{Fe}\left(\mathrm{C} \equiv \mathrm{N}-2,6-\left(\mathrm{CH}_{3}\right)_{2} \mathrm{Ph}\right)_{2}$. 


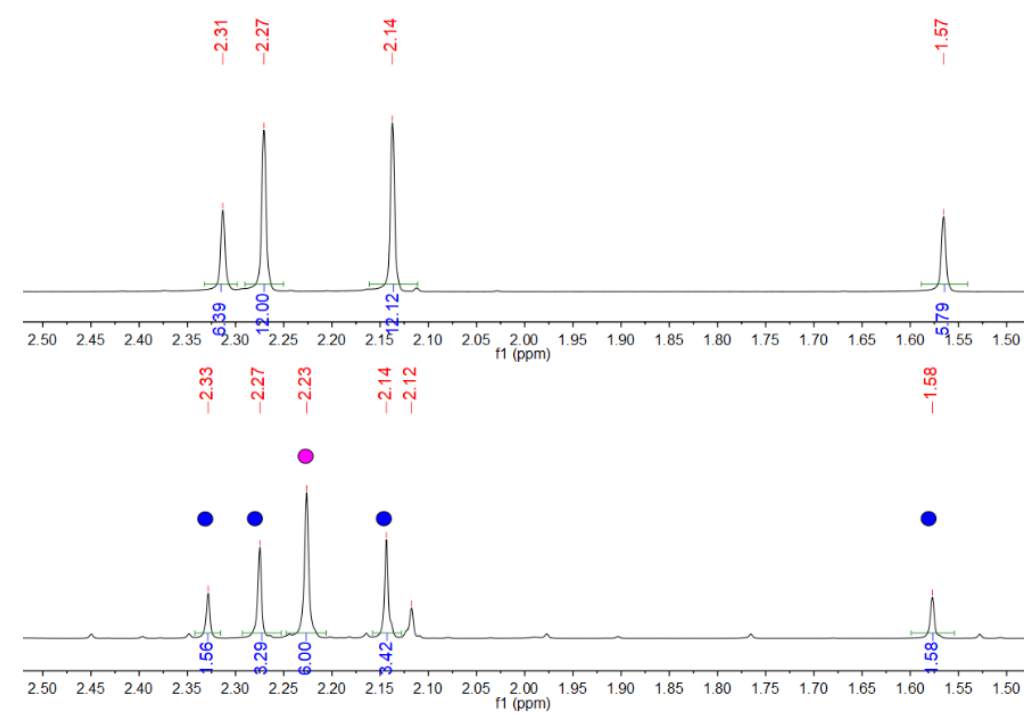

Figure 6.22. ${ }^{1} \mathrm{H}$ NMR spectra $(600 \mathrm{MHz})$ in benzene- $d_{6}$ of upfield aliphatic resonances of an independently prepared sample of $\left({ }^{\mathrm{Mes}} \mathrm{PDP}{ }^{\mathrm{Ph}}\right) \mathrm{Fe}\left(\mathrm{C} \equiv \mathrm{N}-2,6-\left(\mathrm{CH}_{3}\right)_{2} \mathrm{Ph}\right)_{3}$ (top) and the crude reaction mixture obtained from heating $\left(\mathrm{CPh}_{2}{ }^{\mathrm{Mes}} \mathrm{PDP}{ }^{\mathrm{Ph}}\right) \mathrm{Fe}\left(\mathrm{C} \equiv \mathrm{N}-2,6-\left(\mathrm{CH}_{3}\right)_{2} \mathrm{Ph}\right)_{2}$ to $80^{\circ} \mathrm{C}$ for approximately $48 \mathrm{hrs}$ (bottom). Blue circles indicate peaks assigned as $\left({ }^{\mathrm{Mes}} \mathrm{PDP}{ }^{\mathrm{Ph}}\right) \mathrm{Fe}\left(\mathrm{C} \equiv \mathrm{N}-2,6-\left(\mathrm{CH}_{3}\right)_{2} \mathrm{Ph}\right)_{3}$ and pink circles indicated peaks assigned as $\mathrm{Ph}_{2} \mathrm{C}=\mathrm{C}=\mathrm{N}-2,6-$

$\left(\mathrm{CH}_{3}\right)_{2} \mathrm{Ph}$.

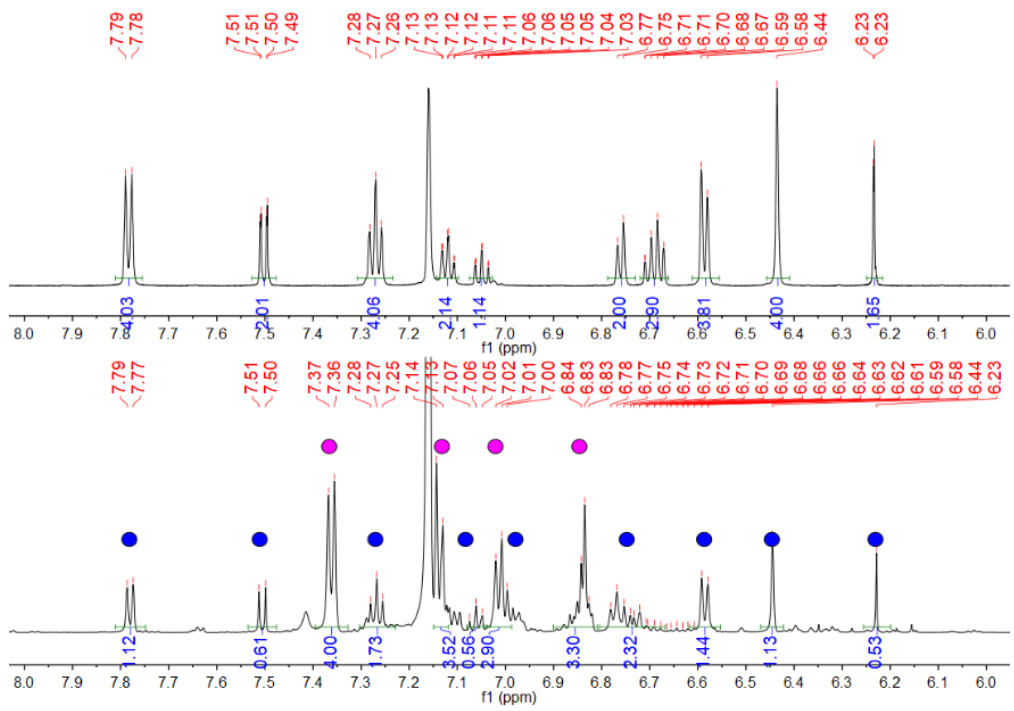

Figure 6.23. ${ }^{1} \mathrm{H}$ NMR spectra $(600 \mathrm{MHz})$ in benzene- $d_{6}$ of downfield aryl resonances of an independently prepared sample of $\left({ }^{\mathrm{Mes}} \mathrm{PDP}{ }^{\mathrm{Ph}}\right) \mathrm{Fe}\left(\mathrm{C} \equiv \mathrm{N}-2,6-\left(\mathrm{CH}_{3}\right)_{2} \mathrm{Ph}\right)_{3}$ (top) and the crude reaction mixture obtained from heating $\left(\mathrm{CPh}_{2}{ }^{\text {Mes }} \mathrm{PDP}{ }^{\mathrm{Ph}}\right) \mathrm{Fe}\left(\mathrm{C} \equiv \mathrm{N}-2,6-\left(\mathrm{CH}_{3}\right)_{2} \mathrm{Ph}\right)_{2}$ to $80^{\circ} \mathrm{C}$ for approximately $48 \mathrm{hrs}$ (bottom). Blue circles indicate peaks assigned as $\left({ }^{\mathrm{Mes}} \mathrm{PDP}{ }^{\mathrm{Ph}}\right) \mathrm{Fe}\left(\mathrm{C} \equiv \mathrm{N}-2,6-\left(\mathrm{CH}_{3}\right)_{2} \mathrm{Ph}\right)_{3}$ and pink circles indicated peaks assigned as $\mathrm{Ph}_{2} \mathrm{C}=\mathrm{C}=\mathrm{N}-2,6-$

$\left(\mathrm{CH}_{3}\right)_{2} \mathrm{Ph}$. 

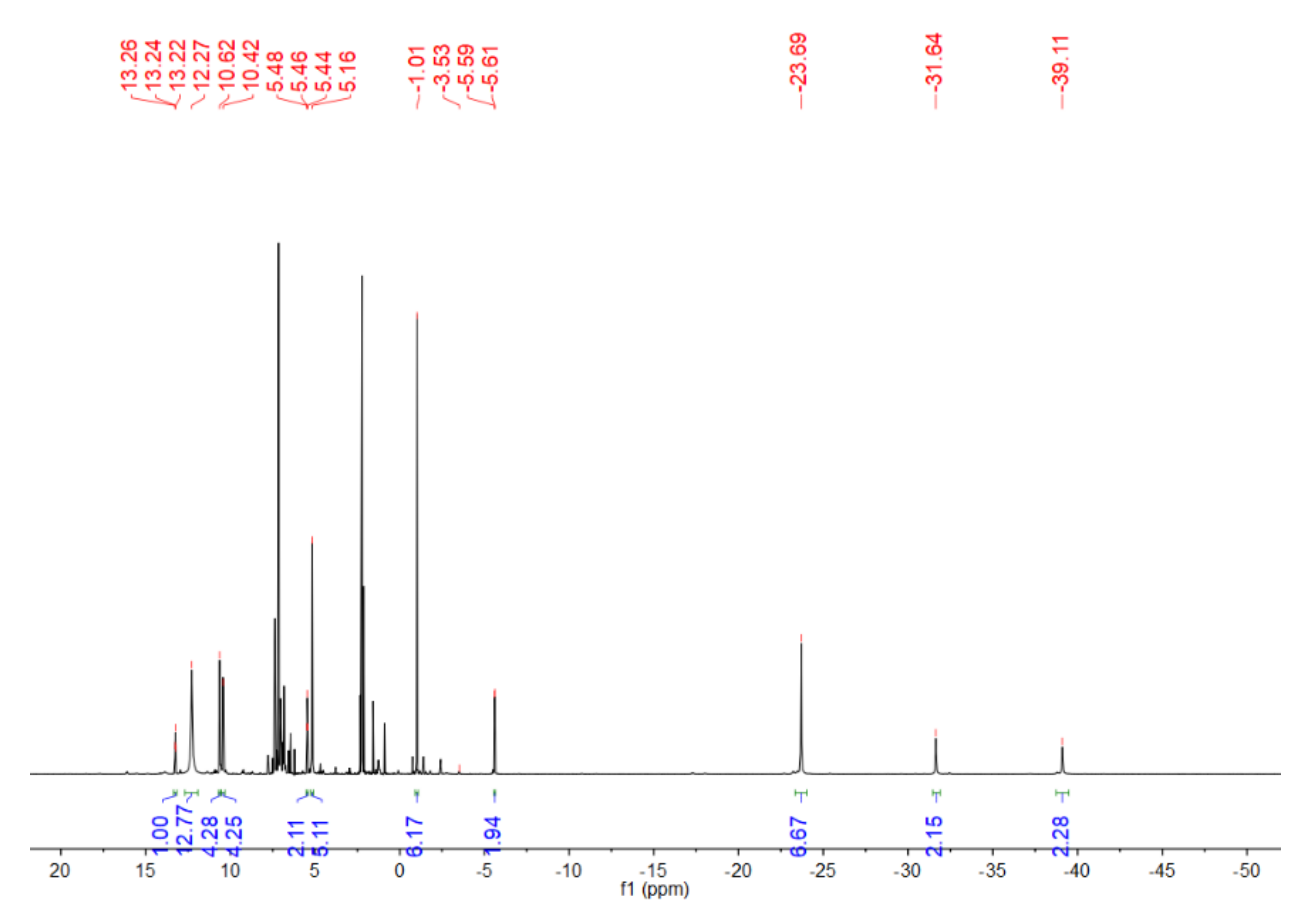

Figure 6.24. ${ }^{1} \mathrm{H}$ NMR spectrum $(400 \mathrm{MHz})$ in benzene- $d_{6}$ from -50 to $20 \mathrm{ppm}$ of crude reaction mixture obtained from heating $\left(\mathrm{CPh}_{2}{ }^{\mathrm{Mes}} \mathrm{PDP}{ }^{\mathrm{Ph}}\right) \mathrm{Fe}\left(\mathrm{C} \equiv \mathrm{N}-2,6-\left(\mathrm{CH}_{3}\right)_{2} \mathrm{Ph}\right)_{2}$ to $80^{\circ} \mathrm{C}$ for approximately $48 \mathrm{hrs}$. Note: The resonances and relative integrations for $\left({ }^{\mathrm{Mes}} \mathrm{PD}{ }^{\mathrm{Ph}}\right) \mathrm{Fe}\left(\mathrm{CPh}_{2}\right),\left({ }^{\mathrm{Mes}} \mathrm{PDP}{ }^{\mathrm{Ph}}\right) \mathrm{Fe}\left(\mathrm{C} \equiv \mathrm{N}-2,6-\left(\mathrm{CH}_{3}\right)_{2} \mathrm{Ph}\right)_{3}$, and $\mathrm{Ph}{ }_{2} \mathrm{C}=\mathrm{C}=\mathrm{N}-2,6-\left(\mathrm{CH}_{3}\right)_{2} \mathrm{Ph}$ have been omitted for clarity.

\subsection{Synthesis of a Monoisocyanide Carbene Adduct}

Intrigued by the observed reactivity with carbon monoxide and 2,6-dimethylphenyl isocyanide, the question of mechanistic formation of the observed products arose. It was postulated that multiple disparate reaction pathways could account for the observation of $\left(\mathrm{CPh}_{2}{ }^{\mathrm{Mes}} \mathrm{PDP}^{\mathrm{Ph}}\right) \mathrm{Fe}(\mathrm{CO})_{2}$ and $\left.\left(\mathrm{CPh}_{2}{ }^{\mathrm{Mes}} \mathrm{PDP}{ }^{\mathrm{Ph}}\right) \mathrm{Fe}\left(\mathrm{C} \equiv \mathrm{N}-2,6-\left(\mathrm{CH}_{3}\right)_{2} \mathrm{Ph}\right)_{2}: 1\right)$ Ligation of one $\mathrm{CO} /$ isocyanide ligand to the $\left({ }^{\mathrm{Mes}} \mathrm{PDP}^{\mathrm{Ph}}\right) \mathrm{Fe}\left(\mathrm{CPh}_{2}\right)$, forming a mixed species $\left({ }^{\mathrm{Mes}} \mathrm{PDP}^{\mathrm{Ph}}\right) \mathrm{Fe}$ $\left(\mathrm{CPh}_{2}\right)(\mathrm{CE})\left(\right.$ where $\mathrm{E}=\mathrm{O}$, or $\mathrm{NR}$, and $\left.\left.\mathrm{R}=2,6-\left(\mathrm{CH}_{3}\right)_{2} \mathrm{Ph}\right)\right)$, followed by carbene insertion into an iron-pyrrolide bond and subsequent ligation of a second equivalent of $\mathrm{CO} /$ isocyanide, or 2) ligation of two $\mathrm{CO} /$ isocyanide ligands, forming a $\left({ }^{\mathrm{Mes}} \mathrm{PDP}^{\mathrm{Ph}}\right) \mathrm{Fe}\left(\mathrm{CPh}_{2}\right)(\mathrm{CR})_{2}$ species, followed by subsequent carbene insertion into an iron-pyrrolide bond. These two mechanistic possibilities are depicted in Figure 6.25. 
Proposed pathway 1:
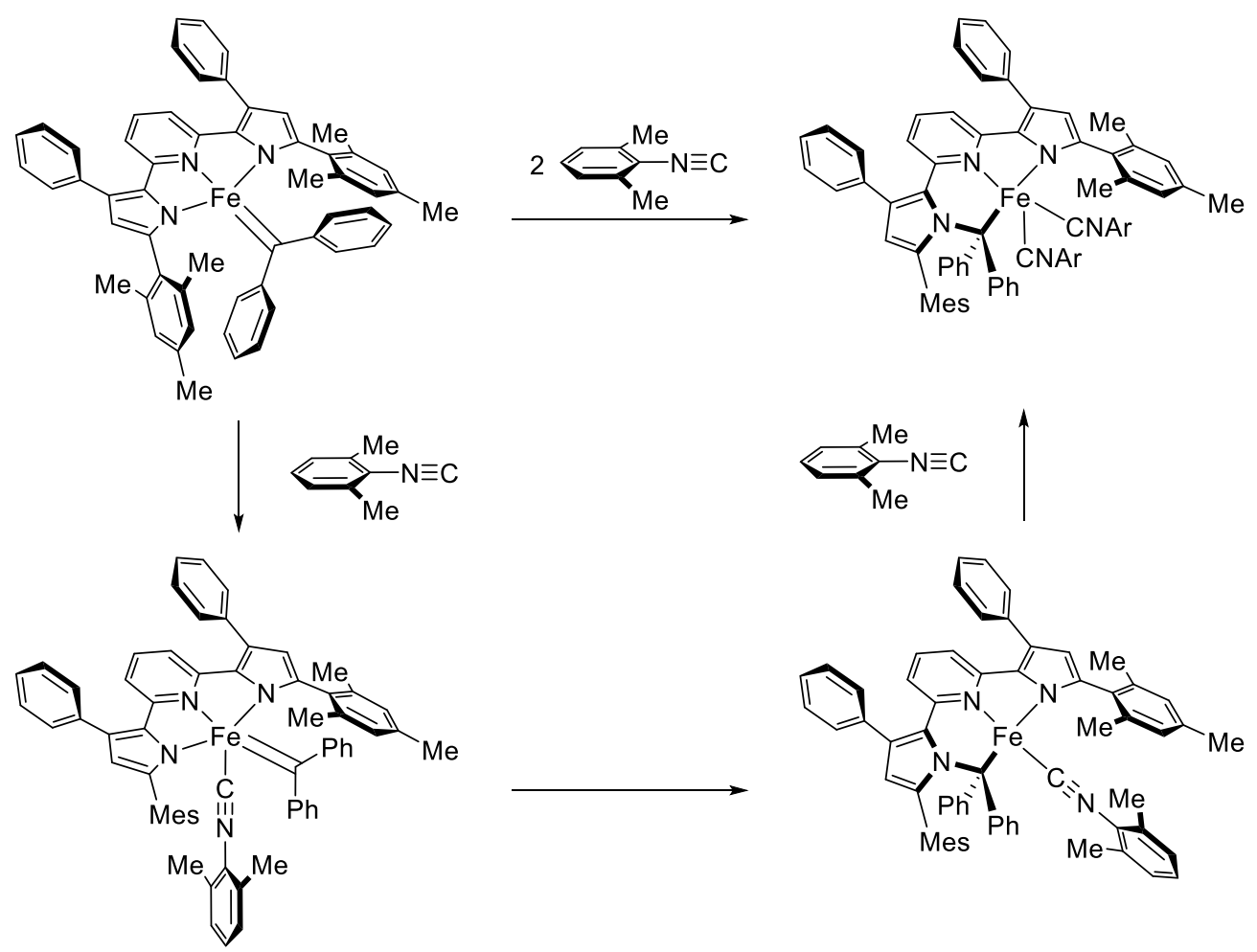

proposed intermediate

proposed intermediate

Proposed pathway 2:

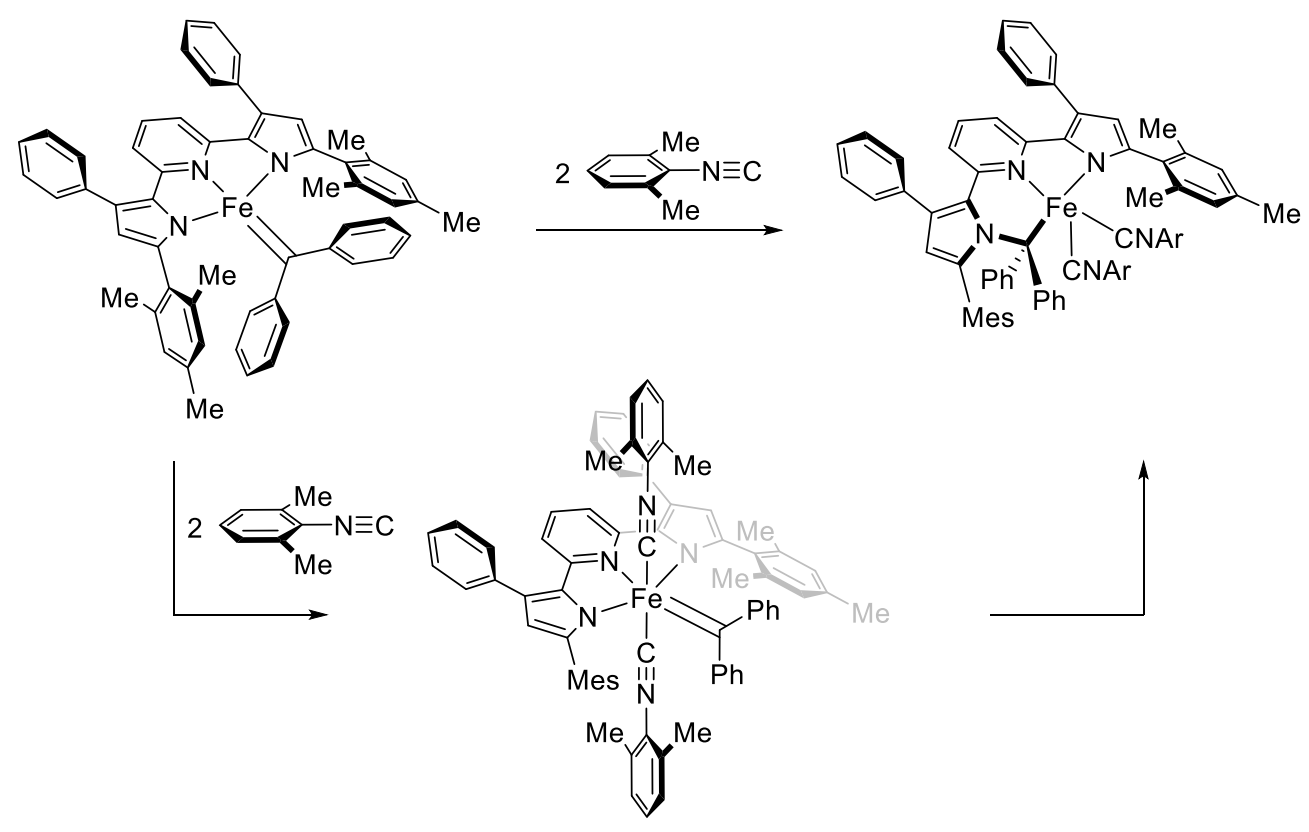

proposed intermediate

Figure 6.25. Possible mechanisms for the formation of $\left(\mathrm{CPh}_{2}{ }^{\mathrm{Mes}} \mathrm{PDP} \mathrm{Ph}^{\mathrm{Ph}}\right) \mathrm{Fe}\left(\mathrm{C} \equiv \mathrm{N}-2,6-\left(\mathrm{CH}_{3}\right)_{2} \mathrm{Ph}\right)_{2}$ from $\left({ }^{\mathrm{Mes}} \mathrm{PDP}^{\mathrm{Ph}}\right) \mathrm{Fe}\left(\mathrm{CPh}_{2}\right)$. 
In lieu of this mechanistic ambiguity, reactions with the bulky isocyanide $\mathrm{C} \equiv \mathrm{N}-{ }^{1} \mathrm{Ad}$ were explored to see if a kinetically more stable mono- or bis-isocyanide carbene complex could be isolated and characterized. Accordingly, it was found that careful addition of a dilute benzene solution of one equivalent of $\mathrm{C} \equiv \mathrm{N}-{ }^{1}$ Ad to a solution of $\left({ }^{\mathrm{Mes}} \mathrm{PDP}{ }^{\mathrm{Ph}}\right) \mathrm{Fe}\left(\mathrm{CPh}_{2}\right)$ in the same solvent resulted in an instantaneous color change of the solution from green to red brown. After removal of volatiles, crystallization of the product via slow evaporation of a diethyl ether solution afforded single crystals suitable for analysis via X-ray crystallography. The resulting structure was found to be the carbene mono isocyanide complex, $\left({ }^{\mathrm{Mes}} \mathrm{PDP}{ }^{\mathrm{Ph}}\right) \mathrm{Fe}\left(\mathrm{CPh}_{2}\right)\left(\mathrm{C} \equiv \mathrm{N}-{ }^{1} \mathrm{Ad}\right)(\mathrm{Figure}$ 6.24 and Scheme 6.6.). In the solid state $\left({ }^{\mathrm{Mes}} \mathrm{PDP}{ }^{\mathrm{Ph}}\right) \mathrm{Fe}\left(\mathrm{CPh}_{2}\right)\left(\mathrm{C} \equiv \mathrm{N}-{ }^{1} \mathrm{Ad}\right)$ adopts a distorted square pyramidal geometry. This distorted geometry is enforced by the bite angle of the PDP ligand and results in a $\tau_{5}$ value of $0.46 .^{73,74}$ Analysis of the bond metrics obtained from the X-ray analysis realized a significant contraction of the iron-carbene bond distance from $1.850(2) \AA$ in $\left({ }^{\mathrm{Mes}} \mathrm{PDP}{ }^{\mathrm{Ph}}\right) \mathrm{Fe}\left(\mathrm{CPh}_{2}\right)$ to $1.801(3) \AA$ in $\left({ }^{\mathrm{Mes}} \mathrm{PDP}{ }^{\mathrm{Ph}}\right) \mathrm{Fe}\left(\mathrm{CPh}_{2}\right)\left(\mathrm{C} \equiv \mathrm{N}-{ }^{1} \mathrm{Ad}\right)$. This value is similar to the highly contracted iron-carbene bond distances previously reported for diamagnetic cyclopentadienyl-ligated iron carbenes and various macrocyclic iron diphenylidene complexes (Table 6.1). Furthermore, the significantly contracted Fe- $\mathrm{C}_{\text {carbene }}$ bond distance in $\left({ }^{\mathrm{Mes}} \mathrm{PDP}{ }^{\mathrm{Ph}}\right) \mathrm{Fe}\left(\mathrm{CPh}_{2}\right)\left(\mathrm{C} \equiv \mathrm{N}-{ }^{1} \mathrm{Ad}\right)$ relative to $\left({ }^{\mathrm{Mes}} \mathrm{PDP}^{\mathrm{Ph}}\right) \mathrm{Fe}\left(\mathrm{CPh}_{2}\right)$ is consistent with the likelihood of alternative electronic structures for the two species. ${ }^{22,24,27,33}$ 

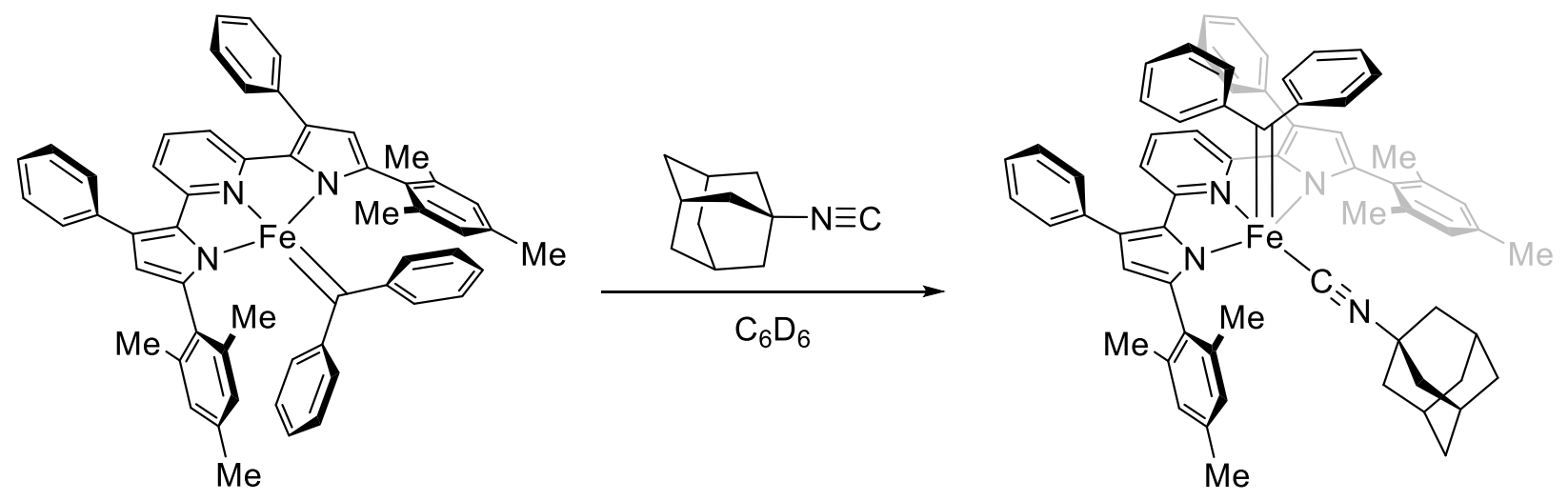

Scheme 6.6. Synthesis of $\left({ }^{\mathrm{Mes}} \mathrm{PDP}{ }^{\mathrm{Ph}}\right) \mathrm{Fe}\left(\mathrm{CPh}_{2}\right)\left(\mathrm{C} \equiv \mathrm{N}-{ }^{-1} \mathrm{Ad}\right)$.

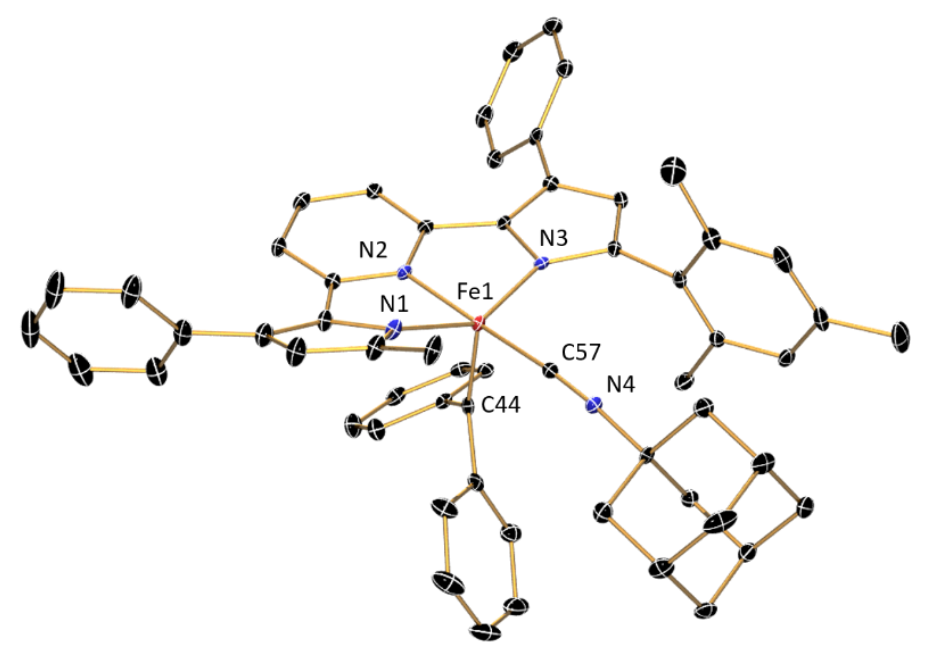

Figure 6.26. ORTEP of $\left({ }^{\mathrm{Mes}} \mathrm{PDP} \mathrm{Ph}^{\mathrm{Ph}}\right) \mathrm{Fe}\left(\mathrm{CPh}_{2}\right)\left(\mathrm{C} \equiv \mathrm{N}-{ }^{-1} \mathrm{Ad}\right)$ depicted at $30 \%$ probability ellipsoids. Co-crystallized solvent molecules, hydrogen atoms, and a PDP mesityl substituent (with exception of the ipso carbon) are omitted for clarity.

Analysis of the remaining crystalline material by ${ }^{1} \mathrm{H}$ NMR spectroscopy in benzene- $d_{6}$ solution revealed the diamagnetic nature of $\left({ }^{\mathrm{Mes}} \mathrm{PDP}{ }^{\mathrm{Ph}}\right) \mathrm{Fe}\left(\mathrm{CPh}_{2}\right)\left(\mathrm{C} \equiv \mathrm{N}-{ }^{1} \mathrm{Ad}\right)($ Figure 6.25). The identification of three distinct upfield singlet resonances at 2.78, 2.53, and 2.14 ppm, respectively, is consistent with inequivalent mesityl methyl groups, suggesting a $\mathrm{C}_{s}$ symmetric ${ }^{\mathrm{Mes}} \mathrm{PDP}^{\mathrm{Ph}}$ ligand environment. The observation of three additional aliphatic resonances at 1.60 , 1.25 , and $0.76 \mathrm{ppm}$, in a relative 3:6:6 ratio, were attributed to the symmetric $\mathrm{C} \equiv \mathrm{N}-{ }^{1} \mathrm{Ad}$ ligand. 
Overall, the solution phase ${ }^{1} \mathrm{H}$ NMR spectrum is consistent with the structure obtained by X-ray crystallography (Figure 6.19).

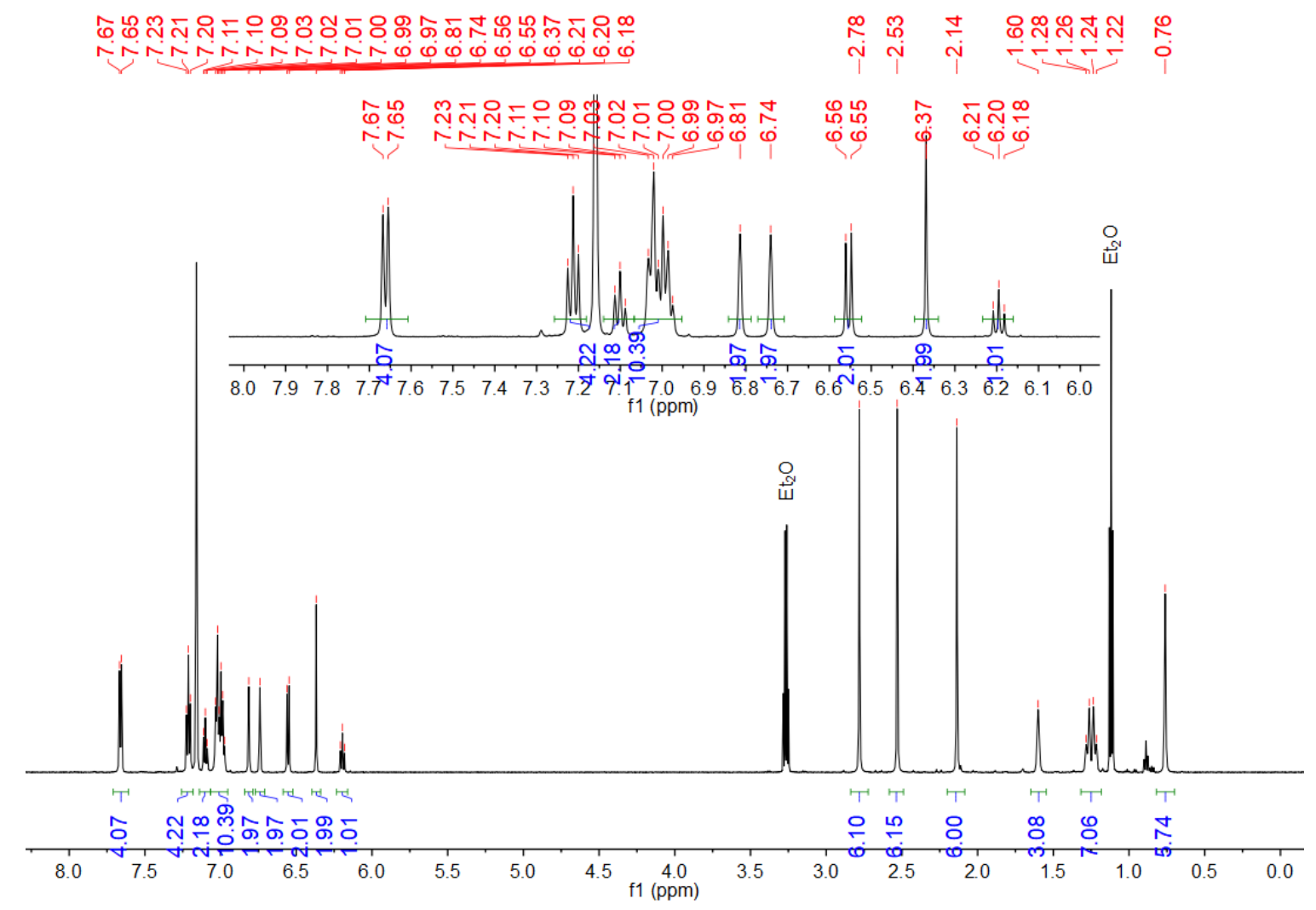

Figure 6.27. ${ }^{1} \mathrm{H}$ NMR spectrum of $\left({ }^{\mathrm{Mes}} \mathrm{PDP} \mathrm{Ph}^{\mathrm{Ph}}\right) \mathrm{Fe}\left(\mathrm{CPh}_{2}\right)\left(\mathrm{C} \equiv \mathrm{N}-{ }^{-1} \mathrm{Ad}\right)$ at $600 \mathrm{MHz}$ in benzene- $d_{6}$. The inset depicts a range of 6-8 ppm for closer examination of the aryl proton resonances. 
Table 6.7. Selected bond lengths $(\AA)$ and angles $(\mathrm{deg})$ for $\left({ }^{\mathrm{Mes}} \mathrm{PDP} \mathrm{Ph}^{\mathrm{Ph}}\right) \mathrm{Fe}\left(\mathrm{CPh}_{2}\right)$ and $\left({ }^{\mathrm{Mes} P D P} \mathrm{Ph}^{\mathrm{Ph}}\right) \mathrm{Fe}\left(\mathrm{CPh}_{2}\right)\left(\mathrm{C} \equiv \mathrm{N}-{ }^{-} \mathrm{Ad}\right)$.

\begin{tabular}{ccc}
\hline & $\left({ }^{\mathrm{Mes} P D P \mathrm{Ph}}\right) \mathrm{Fe}\left(\mathrm{CPh}_{2}\right)$ & $\left({ }^{\mathrm{Mes} P D P}{ }^{\mathrm{Ph}}\right) \mathrm{Fe}\left(\mathrm{CPh}_{2}\right)\left(\mathrm{C} \equiv \mathrm{N}-{ }^{1} \mathrm{Ad}\right)$ \\
\hline $\mathrm{Fe} 1-\mathrm{N} 1$ & $1.9581(19)$ & $1.955(2)$ \\
$\mathrm{Fe} 1-\mathrm{N} 2$ & $1.9779(19)$ & $1.930(2)$ \\
$\mathrm{Fe} 1-\mathrm{N} 3$ & $1.9455(19)$ & $1.949(2)$ \\
$\mathrm{Fe} 1-\mathrm{C} 44$ & $1.850(2)$ & $1.801(3)$ \\
$\mathrm{Fe} 1-\mathrm{C} 57$ & - & $1.886(3)$ \\
$\mathrm{N} 1-\mathrm{Fe} 1-\mathrm{N} 2$ & $80.27(8)$ & $79.58(10)$ \\
$\mathrm{N} 1-\mathrm{Fe} 1-\mathrm{N} 3$ & $159.35(8)$ & $148.31(10)$ \\
$\mathrm{N} 2-\mathrm{Fe} 1-\mathrm{N} 3$ & $79.58(8)$ & $80.75(9)$ \\
$\mathrm{C} 44-\mathrm{Fe} 1-\mathrm{N} 1$ & $100.88(9)$ & $102.51(11)$ \\
$\mathrm{N} 2-\mathrm{Fe} 1-\mathrm{C} 44$ & $176.20(9)$ & $92.88(11)$ \\
$\mathrm{C} 44-\mathrm{Fe} 1-\mathrm{N} 3$ & $99.52(9)$ & $103.06(11)$ \\
$\mathrm{C} 44-\mathrm{Fe} 1-\mathrm{C} 57$ & - & $90.61(12)$ \\
$\mathrm{C} 57-\mathrm{Fe} 1-\mathrm{N} 1$ & - & $97.60(11)$ \\
$\mathrm{C} 57-\mathrm{Fe} 1-\mathrm{N} 2$ & - & $175.92(11)$ \\
$\mathrm{C} 57-\mathrm{Fe} 1-\mathrm{N} 3$ & $-53(11)$ \\
\hline
\end{tabular}

In regard to the electronic structure of $\left({ }^{\mathrm{Mes}} \mathrm{PDP}^{\mathrm{Ph}}\right) \mathrm{Fe}\left(\mathrm{CPh}_{2}\right)\left(\mathrm{C} \equiv \mathrm{N}-{ }^{1} \mathrm{Ad}\right)$, the highly contracted iron-carbene bond distance suggests significant multiple-bond character. Assignment of the carbene fragment as a dianionic alkylidene ligand would infer a low-spin $\mathrm{Fe}^{\mathrm{IV}}$ formal oxidation state, in agreement with the diamagnetism of the complex indicated by ${ }^{1} \mathrm{H}$ NMR spectroscopy. Alternatively, if assigned as an ancillary carbene ligand, a diamagnetic low-spin $\mathrm{Fe}^{\mathrm{II}}$ assignment would be appropriate. It should be noted that the previously reported diamagnetic macrocyclic iron carbene complexes have withstood longstanding debate about their 
electronic structures due to similar ambiguity in the assignment of a formal oxidation state for the iron center. It is anticipated that future spectroscopic and theoretical studies may offer further insight into the uncertainty surrounding the formal oxidation state of the iron center in $\left({ }^{\mathrm{Mes}} \mathrm{PDP}^{\mathrm{Ph}}\right) \mathrm{Fe}\left(\mathrm{CPh}_{2}\right)\left(\mathrm{C} \equiv \mathrm{N}-{ }^{1} \mathrm{Ad}\right)$.

\subsection{Conclusion}

The paramagnetic iron carbene complexes $\left({ }^{\mathrm{Mes}} \mathrm{PDP}^{\mathrm{Ph}}\right) \mathrm{Fe}\left(\mathrm{CPh}_{2}\right)$ and $\left.{ }^{2,6-\mathrm{Cl} 2 \mathrm{Ph}} \mathrm{PDP}^{\mathrm{Ph}}\right) \mathrm{Fe}\left(\mathrm{CPh}_{2}\right)$ have been prepared via the decomposition of diphenyldiazomethane and in the presence of $\left({ }^{\mathrm{Mes}} \mathrm{PDP}^{\mathrm{Ph}}\right) \mathrm{Fe}($ thf $)$ and $\left({ }^{2,6-\mathrm{Cl} 2 \mathrm{Ph}} \mathrm{PDP}^{\mathrm{Ph}}\right) \mathrm{Fe}($ thf $)$. For $\left({ }^{\mathrm{Mes}} \mathrm{PDP}^{\mathrm{Ph}}\right) \mathrm{Fe}\left(\mathrm{CPh}_{2}\right)$, a combination of ${ }^{1} \mathrm{H} \mathrm{NMR}$, variable-temperature and applied-field ${ }^{57} \mathrm{Fe}$ Mössbauer, and X-ray crystallography has unambiguously assigned the solution- and solid-state structures of the complex. A complementary density functional theory study of $\left({ }^{\mathrm{Mes}} \mathrm{PDP}{ }^{\mathrm{Ph}}\right) \mathrm{Fe}\left(\mathrm{CPh}_{2}\right)$ has also been performed, which suggests this compound may be described as an intermediate spin iron(III) ion engaged in antiferromagnetic coupling to a monoanionic carbene radical ligand $\left(\mathrm{CR}_{2}{ }^{1-\bullet}\right)$.

Preliminary reactivity studies of $\left({ }^{\mathrm{Mes}} \mathrm{PDP}{ }^{\mathrm{Ph}}\right) \mathrm{Fe}\left(\mathrm{CPh}_{2}\right)$ with carbon monoxide and isocyanides have also been performed. It has been found that $\left({ }^{\mathrm{Mes}} \mathrm{PDP}^{\mathrm{Ph}}\right) \mathrm{Fe}\left(\mathrm{CPh}_{2}\right)$ reacts rapidly with carbon monoxide to form the diamagnetic complex $\left(\mathrm{CPh}_{2}{ }^{\mathrm{Mes}} \mathrm{PDP}{ }^{\mathrm{Ph}}\right) \mathrm{Fe}(\mathrm{CO})_{2}$. This product is accounted for by insertion of the diphenylidene fragment into an iron-pyrrolide nitrogen bond, accompanied by ligation of two molecules of $\mathrm{CO}$ to the iron center. Excitingly, $\left(\mathrm{CPh}_{2}{ }^{\mathrm{Mes}} \mathrm{PDP}^{\mathrm{Ph}}\right) \mathrm{Fe}(\mathrm{CO})_{2}$ constitutes $\mathrm{CPh}_{2}$ group transfer by the formation of a new carbonnitrogen bond, forming a modified N-alkylated PDP ligand. Similarly, addition of 2,6dimethylphenyl isocyanide to $\left({ }^{\mathrm{Mes}} \mathrm{PDP}^{\mathrm{Ph}}\right) \mathrm{Fe}\left(\mathrm{CPh}_{2}\right)$ results in an analogous carbene insertion, carbon-nitrogen bond formation, and PDP ligand modification. Notably, no reaction intermediates are observed in either of these contexts. 
Heating benzene- $d_{6}$ solutions of $\left(\mathrm{CPh}_{2}{ }^{\mathrm{Mes}} \mathrm{PDP}^{\mathrm{Ph}}\right) \mathrm{Fe}\left(\mathrm{C} \equiv \mathrm{N}-2,6-\left(\mathrm{CH}_{3}\right)_{2} \mathrm{Ph}\right)_{2}$ induces further carbene group transfer to an isocyanide ligand, resulting in the production of the corresponding ketenimine $\mathrm{Ph}_{2} \mathrm{C}=\mathrm{C}=\left(2,6-\left(\mathrm{CH}_{3}\right)_{2} \mathrm{Ph}\right.$, the isocyanide complex $\left({ }^{\mathrm{Mes}} \mathrm{PDP}{ }^{\mathrm{Ph}}\right) \mathrm{Fe}\left(\mathrm{C} \equiv \mathrm{N}-2,6-\left(\mathrm{CH}_{3}\right)_{2} \mathrm{Ph}\right)_{3}$, and the parent carbene $\left({ }^{\mathrm{Mes}} \mathrm{PDP}{ }^{\mathrm{Ph}}\right) \mathrm{Fe}\left(\mathrm{CPh}_{2}\right)$, as determined by ${ }^{1} \mathrm{H}$ NMR spectroscopy. This result suggests that carbene group transfer to the nitrogen of a pyrrolide ligand is a reversible process, consistent with previously investigated iron porphyrin systems.

Lastly, when $\left({ }^{\mathrm{Mes}} \mathrm{PDP}{ }^{\mathrm{Ph}}\right) \mathrm{Fe}\left(\mathrm{CPh}_{2}\right)$ is treated with one equivalent of the sterically encumbered isocyanide, $\mathrm{C} \equiv \mathrm{N}-{ }^{1} \mathrm{Ad}$, the diamagnetic carbene isocyanide species, $\left({ }^{\text {Mes }} \mathrm{PDP}^{\mathrm{Ph}}\right) \mathrm{Fe}\left(\mathrm{CPh}_{2}\right)\left(\mathrm{C} \equiv \mathrm{N}-{ }^{1} \mathrm{Ad}\right)$, is produced. This complex, which has been characterized by ${ }^{1} \mathrm{H}$ NMR and X-ray crystallography, offers valuable information concerning the identity of transition metal complexes that are mechanistically relevant to carbene group transfer to isocyanides. Furthermore, the existence of this complex suggests that PDP iron carbene complexes may find future utility in other stoichiometric or catalytic carbene group transfer reactions by tuning of the electronic structure of the iron center by the addition of ancillary ligands.

\subsection{Experimental Procedures}

\section{General Considerations}

All air- and moisture-sensitive manipulations were carried out using standard Schlenk line and cannula techniques or in an MBraun inert atmosphere drybox containing an atmosphere of purified nitrogen. Solvents for air- and moisture-sensitive manipulations were dried and deoxygenated using a Glass Contour Solvent Purification System and stored over 4 A molecular sieves. All solids were dried under high vacuum; all liquids were dried over $\mathrm{CaH}_{2}$ and vacuum transferred into oven-dried glassware in order to bring into the glovebox. Carbon monoxide was 
purchased from Matheson and used as received. 2,6-dimethylphenylisocyanide was purchased from Fluka. 1-Adamantyl isocyanide was obtained from TCI and sublimed under high-vacuum prior to use. Deuterated benzene (benzene- $d_{6}$ ) and dichloromethane (dichloromethane- $d_{2}$ ) for NMR spectroscopy were distilled from sodium metal and calcium hydride, respectively. $\mathrm{H}_{2}{ }^{\mathrm{Mes}} \mathrm{PDP}^{\mathrm{Ph}}$ and $\left({ }^{\mathrm{Mes}} \mathrm{PDP}{ }^{\mathrm{Ph}}\right) \mathrm{Fe}(\mathrm{thf})$ were prepared according to previously reported procedures. ${ }^{49}$

\section{Safety Considerations.}

Diazo reagents are known energetic materials that may decompose violently via explosion upon input of energy from external sources (heat, light, pressure). While we did not encounter any problems or dangerous situations during the course of this study, all experiments involving diazo reagents were performed on small scale with $1 \mathrm{~g}$ or less of material. All manipulations outside of the glovebox were performed behind a blast shield in a fumehood. The diazo reagents were stored in the dark at $-35^{\circ} \mathrm{C}$ in the glovebox.

\section{Preparation of diphenyldiazomethane.}

Diphenyldiazomethane was prepared according to a modified literature procedure. ${ }^{75}$ Note: diazo reagents are known to be potentially energetic materials. Thus, all synthetic manipulations outside of the glovebox were performed behind a blast shield in a fumehood. In a round bottom flask equipped with a magnetic stirrer was combined $1.00 \mathrm{~g}(5.1 \mathrm{mmol})$ of benzophenone hydrazone and $12 \mathrm{~mL}$ of dichloromethane, affording a colorless homogeneous solution. The flask was immersed in an ice bath and cooled to $0^{\circ} \mathrm{C}$. Subsequently, $1.15 \mathrm{~g}(13.1$ mmol, 2.6 eq.) of activated $\mathrm{MnO}_{2}$ was added slowly, inducing an immediate color change of the solution to dark purple. The flask was wrapped in aluminum foil and allowed to stir overnight. After $16 \mathrm{hr}$ the crude reaction mixture was passed through a plug of basic alumina. The resulting purple solution was removed, affording a viscous dark-purple oil. The crude 
diphenyldiazomethane was transferred to an oven dried flask and freeze/pump/thaw degassed three times on a high-vacuum line. The material was transferred to the glovebox where it was stored over $4 \AA$ molecular sieves for 24 hrs. Extraction into $10 \mathrm{~mL}$ of pentane, subsequent passage through a pipette column of basic alumina, and removal of solvent in vacuo afforded pure diphenyldiazomethane (devoid of solvent and water), as discerned by ${ }^{1} \mathrm{H}$ NMR spectroscopy. Yield: $561 \mathrm{mg}, 2.89 \mathrm{mmol}, 57 \%$. The ${ }^{1} \mathrm{H}$ NMR data were consistent with previously reported literature values.

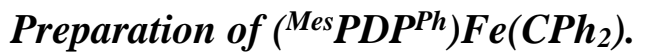

To a $20 \mathrm{~mL}$ scintillation vial equipped with a magnetic stirrer was added $500 \mathrm{mg}(0.691$ mmol) of ( $\left.{ }^{\mathrm{Mes}} \mathrm{PDP}^{\mathrm{Ph}}\right) \mathrm{Fe}(\mathrm{thf})$ and $5 \mathrm{~mL}$ of diethyl ether. Vigorous stirring of the mixture afforded a maroon suspension. In a separate vial, $175 \mathrm{mg}(1.3 \mathrm{eq}, 0.902 \mathrm{mmol})$ of diphenyldiazomethane was dissolved in $5 \mathrm{~mL}$ of diethyl ether. The solution of diphenyldiazomethane was added dropwise to the suspension containing the iron compound. After $16 \mathrm{hrs}$, a dark precipitate was evident. The material was isolated on a medium porosity glass frit and dried in vacuo. The resulting dark solid was transferred to a separate vial and extracted into a minimum amount of benzene, resulting in an olive green solution. The benzene extracts were then passed through a plug of celite and collected in a tared flask. Additional benzene $(10 \mathrm{~mL})$ was utilized to completely wash the celite plug until washings were completely clear. Removal of volatiles and subsequent trituration with pentane afforded a dark brown solid identified as $\left({ }^{\mathrm{Mes}} \mathrm{PDP}{ }^{\mathrm{Ph}}\right) \mathrm{Fe}\left(\mathrm{CPh}_{2}\right)$. Yield: $362 \mathrm{mg}(0.443 \mathrm{mmol}, 64 \%) . \mu_{\mathrm{eff}}=3.8(2) \mu_{\mathrm{B}}(295 \mathrm{~K}$, magnetic susceptibility balance), $\mu_{\mathrm{eff}}=3.4(3) \mu_{\mathrm{B}} .{ }^{1} \mathrm{H}$ NMR (600 MHz, benzene- $\left.d_{6} ; \delta, \mathrm{ppm}\right): 91.41(\mathrm{~s}, 2 \mathrm{H})$, 41.22 (s, 4H), 15.83 (s, 4H), 13.47 (s, 12H, ortho-mesityl- $\left.\mathrm{CH}_{3}\right), 12.78$ (s, 4H), 7.47 (s, 4H),

6.98 (apparent triplet, $J=7.0 \mathrm{~Hz},{ }^{\mathrm{Mes}} \mathrm{PDP}^{\mathrm{Ph}} 4-\mathrm{Ph} H$ ), 1.39 (s, 2H), -2.23 (s, 6H, para-mesityl- 
$\mathrm{CH}_{3}$ ), -16.39 (s, 2H), -16.56 (s, 1H, 4-pyridine $H$ ), -55.22 (s, 4H).Anal. Calcd for

$\left({ }^{\text {Mes }} \mathrm{PDP}^{\mathrm{Ph}}\right) \mathrm{Fe}\left(\mathrm{CPh}_{2}\right), \mathrm{C}_{56} \mathrm{H}_{47} \mathrm{FeN}_{3}: \mathrm{C}, 82.24 ; \mathrm{H}, 5.79 ; \mathrm{N}$, 5.14. Found: C, 82.24; H, 5.90; N, 5.06.

Slow evaporation of a diethyl ether solution at $-35^{\circ} \mathrm{C}$ provided dark single crystals of

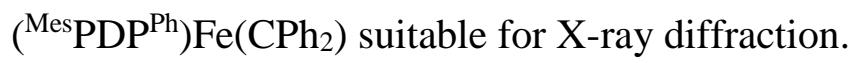

Preparation of $\left(^{(2,6-C l 2 P h} \mathrm{PDP}^{\mathrm{Ph}}\right) \mathrm{Fe}\left(\mathrm{CPh}_{2}\right)$.

To a J. Young NMR tube was added $25 \mathrm{mg}(0.032 \mathrm{mmol})$ of $\left({ }^{2,6-\mathrm{Cl} 2 \mathrm{Ph}} \mathrm{PDP}^{\mathrm{Ph}}\right) \mathrm{Fe}(\mathrm{thf})$ and $500 \mu \mathrm{L}$ of benzene- $d_{6}$ affording a turbid red/orange suspension. In a dram vial $12 \mathrm{mg}(0.062$ mmol, 0.94 eq.) of diphenyldiazomethane was dissolved in $100 \mu \mathrm{L}$ of benzene- $d 6$. The solution of diphenyldiazomethane was added to the J. Young tube containing the iron complex, resulting in an immediate color change of the solution to dark brown. The tube was sealed, shaken for thirty seconds, and a ${ }^{1} \mathrm{H}$ NMR spectrum was acquired which demonstrated quantitative conversion to the title compound. ${ }^{1} \mathrm{H}$ NMR (600 MHz, benzene- $d_{6} ; \delta$, ppm): $-55.35(4 \mathrm{H}),-20.56$ $(2 \mathrm{H}),-12.73(1 \mathrm{H}),-2.57(2 \mathrm{H}), 3.63(4 \mathrm{H}), 12.19(4 \mathrm{H}), 15.71(4 \mathrm{H}), 53.43(4 \mathrm{H}), 92.33(2 \mathrm{H}), 2$ resonances not located.

\section{Preparation of $\left(\mathrm{CPh}_{2}{ }^{\mathrm{Mes}} \mathrm{PDP} \mathrm{Ph}^{\mathrm{Ph}}\right) \mathrm{Fe}(\mathrm{CO})_{2}$.}

In the glovebox, a $50 \mathrm{~mL}$ thick walled glass vessel was loaded with a magnetic stirrer, $190 \mathrm{mg}(0.232 \mathrm{mmol})$ of $\left({ }^{\mathrm{Mes}} \mathrm{PDP}^{\mathrm{Ph}}\right) \mathrm{Fe}\left(\mathrm{CPh}_{2}\right)$, and $15 \mathrm{~mL}$ of toluene. The vessel was sealed and removed from the glovebox, attached to a high-vacuum line, and degassed. To the vessel was added $1 \mathrm{~atm}$ of $\mathrm{CO}$, inducing an immediate color change of the solution from olive green to dark red/brown. The vessel was sealed and the reaction mixture was allowed to stir for $12 \mathrm{hrs}$. Removal of CO and solvent on the high-vacuum line afforded a dark brown residue. The vessel was returned to the glovebox and the resulting material was extracted into a minimum amount of diethyl ether. The resulting extract was filtered through a plug of celite into a $20 \mathrm{~mL}$ scintillation 
vial. Complete removal of volatiles afforded a dark brown residue which was triturated with pentane to afford the title compound as a brown solid. Yield: $150 \mathrm{mg}(0.172 \mathrm{mmol}, 74 \%) .{ }^{1} \mathrm{H}$ NMR (400 MHz, benzene- $d_{6} ; \delta$, ppm) $\delta 7.87(\mathrm{~d}, J=8.0 \mathrm{~Hz}, 1 \mathrm{H}), 7.65(\mathrm{~d}, J=7.2 \mathrm{~Hz}, 2 \mathrm{H}), 7.48$ (d, $J=7.0 \mathrm{~Hz}, 2 \mathrm{H}), 7.37(\mathrm{~d}, J=8.6 \mathrm{~Hz}, 1 \mathrm{H}), 7.25(\mathrm{t}, J=7.6 \mathrm{~Hz}, 2 \mathrm{H}), 7.21-7.17(\mathrm{~m}, 2 \mathrm{H}), 7.14-$ $7.02(\mathrm{~m}, 3 \mathrm{H}), 7.02-6.92(\mathrm{~m}, 2 \mathrm{H}), 6.88-6.81(\mathrm{~m}, 5 \mathrm{H}), 6.73(\mathrm{t}, J=7.6 \mathrm{~Hz}, 1 \mathrm{H}), 6.44(\mathrm{t}, J=7.4$ Hz, 1H), $6.38-6.26$ (m, 5H), 6.24 (s, 1H), 6.21 (t, $J=7.6 \mathrm{~Hz}, 1 \mathrm{H}), 2.44$ (s, 3H, Mesityl-CH $\mathrm{CH}_{3}$, 2.40 (s, 3H, Mesityl- $\mathrm{CH}_{3}$ ), 2.17 (s, 3H, Mesityl- $\mathrm{CH}_{3}$ ), 2.02 (overlapping singlets, 6H, Mesityl$\left.\mathrm{CH}_{3}\right), 1.96$ (s, 3H, Mesityl- $\left.\mathrm{CH}_{3}\right) .{ }^{13} \mathrm{C}$ NMR (101 MHz, benzene- $\left.d_{6}\right) \delta 20.79$ (Mesityl- $\mathrm{CH}_{3}$ ), 21.03 (Mesityl- $\mathrm{CH}_{3}$ ), 21.32 (Mesityl- $\mathrm{CH}_{3}$ ), 21.33 (Mesityl- $\mathrm{CH}_{3}$ ), 22.68 (Mesityl- $\mathrm{CH}_{3}$ ), 22.69 (Mesityl$\left.\mathrm{CH}_{3}\right), 76.01\left(\mathrm{CPh}_{2}\right), 104.58,114.67,116.26,116.66,120.31,121.07,123.58,126.16,126.75$, $126.94,127.20,127.23,128.59,128.65,128.92,129.26,129.44,129.54,129.80,129.83,130.00$, $131.18,131.35,131.81,132.30,132.66,134.67,135.91,136.02,136.29,136.40,137.14,137.21$, $137.33,137.45,137.89,139.23,139.29,139.85,145.69,149.71,152.60,157.27,208.93(C O)$, $220.67(\mathrm{CO})$. IR ( $\mathrm{KBr}$ pellet): $1954 \mathrm{~cm}^{-1}(\mathrm{C} \equiv \mathrm{O})$ and $2023 \mathrm{~cm}^{-1}(\mathrm{C} \equiv \mathrm{O})$. Single crystals of $\left(\mathrm{CPh}_{2}{ }^{\mathrm{Mes}} \mathrm{PDP}^{\mathrm{Ph}}\right) \mathrm{Fe}(\mathrm{CO})_{2}$ suitable for study via $\mathrm{X}$-ray were grown from slow evaporation of a diethyl ether solution at $-35^{\circ} \mathrm{C}$. Anal. Calcd for $\left(\mathrm{CPh}_{2}{ }^{\mathrm{Mes}} \mathrm{PDP}^{\mathrm{Ph}}\right) \mathrm{Fe}(\mathrm{CO})_{2}, \mathrm{C}_{58} \mathrm{H}_{47} \mathrm{FeN}_{4} \mathrm{O}_{2}$ : C, 79.72; H, 5.42; N, 4.81. Found: C, 79.22; H, 5.94; N, 4.56.

\section{Preparation of $\left(\mathrm{CPh}_{2}{ }^{\mathrm{Mes} P D P}{ }^{\mathrm{Ph}}\right) \mathrm{Fe}\left(\mathrm{C} \equiv \mathrm{N}-2,6-\left(\mathrm{CH}_{3}\right)_{2} \mathrm{Ph}\right)_{2}$.}

To a $20 \mathrm{~mL}$ scintillation vial equipped with a magnetic stirrer was added $250 \mathrm{mg}(0.306$ $\mathrm{mmol})$ of $\left({ }^{\mathrm{Mes}} \mathrm{PDP}^{\mathrm{Ph}}\right) \mathrm{Fe}\left(\mathrm{CPh}_{2}\right)$ and $10 \mathrm{~mL}$ of benzene. In a separate vial, $86 \mathrm{mg}(0.656 \mathrm{mmol}$, 2.14 eq.) of 2,6-dimethylphenylisocyanide was dissolved in $5 \mathrm{~mL}$ of benzene. The isocyanide solution was added dropwise to the solution containing the iron complex, resulting in an immediate color change from olive green to dark red. The reaction mixture was stirred for $12 \mathrm{hrs}$ 
at room temperature. The solvent was then removed in vacuo, affording a red/brown powder. The powder was extracted into benzene and filtered through a plug of celite into a round bottom flask. The celite plug was washed with additional aliquots of benzene until the washings were completely clear. Removal of the solvent in vacuo afforded the title compound as a red/brown solid. Yield: $318 \mathrm{mg}(0.294 \mathrm{mmol}, 96 \%) .{ }^{1} \mathrm{H}$ NMR (600 MHz, dichloromethane- $\left.d_{2} ; \delta, \mathrm{ppm}\right)$ : $7.84(\mathrm{~d}, o-\mathrm{Ph} H, 1 \mathrm{H}), 7.38(\mathrm{~m}, o-\mathrm{Ph} H, 1 \mathrm{H}), 7.32\left(\mathrm{~d}, o-\mathrm{PhCH}_{3}, 4 \mathrm{H}\right), 7.32\left(m-\mathrm{PhCH}_{3}, 2 \mathrm{H}\right), 7.16(p-$ $\left.\mathrm{PhCH}_{3}, 2 \mathrm{H}\right), 7.16(m-\mathrm{Ph} H, 1 \mathrm{H}), 7.15(m-\mathrm{Ph} H, 1 \mathrm{H}), 7.06(m-\mathrm{Ph} H, 1 \mathrm{H}), 7.06(p-\mathrm{Ph} H, 1 \mathrm{H}), 7.01$ $(m-\mathrm{Ph} H, 2 \mathrm{H}), 7.01(p-\mathrm{Ph} H, 1 \mathrm{H}), 6.99(m-\mathrm{Ph} H, 2 \mathrm{H}), 6.92(o-\mathrm{Ph} H, 2 \mathrm{H}), 6.92(m-\mathrm{ArH}, \mathrm{H}), 6.85(3-$ pyH, 1H), 6.84 (3-pyH, 1H), 6.84 (p-ArH, H), 6.75 (m-ArH, H), 6.69 (o-PhH, 1H), 6.63 (m, 4py $H, 1 \mathrm{H}), 6.47$ (s, $m$-MesCH, 1H), 6.42 (s, $m$-MesCH, 1H), $6.39(m-\mathrm{Ph} H, 1 \mathrm{H}), 6.37$ (s, $m$ MesCH, 1H), $6.27(\mathrm{~s}, m-\mathrm{Mes} C H, 1 \mathrm{H}), 6.25(m-\mathrm{Ph} H, 1 \mathrm{H}), 6.17(m-\mathrm{Ph} H, 1 \mathrm{H}), 5.99$ (s, pyrroleCH, 1H), $5.95(\mathrm{t}, p-\mathrm{Ph} H, 1 \mathrm{H}), 5.90(\mathrm{~s}$, pyrroleCH, $1 \mathrm{H}), 2.42\left(\mathrm{~s}, o-\mathrm{MesCH}_{3}, 3 \mathrm{H}\right), 2.35\left(\mathrm{~s}, o-\mathrm{CH}_{3}, 3 \mathrm{H}\right)$, 2.12 (s, o-MesCH$H_{3}, 3 \mathrm{H}$ ), 2.07 (s, o-MesCH$H_{3}, 6 \mathrm{H}$ ), 2.06 (s, o-MesCH$H_{3}, 3 \mathrm{H}$ ), 2.01 (s, $o-\mathrm{MesCH}_{3}$, 3H), 1.98 (s, $p$ - $\left.\mathrm{MesCH}_{3}, 3 \mathrm{H}\right), 1.73$ (s, $\left.o-\mathrm{CH}_{3}, 3 \mathrm{H}\right), 1.39$ (s, $p$-MesCH$\left.H_{3}, 3 \mathrm{H}\right) .{ }^{13} \mathrm{C}$ NMR $(151 \mathrm{MHz}$, dichloromethane- $d_{2} ; \delta$, ppm): 195.33 (C53/C62), 179.73 (C53/C62), 157.86 (C3), 153.27 (C22), 149.36 (C11), 147.23 (C41), 139.68 (C6), 139.26 (C25), 138.86 (C13), 138.22 (C30), 137.87 (C32), 137.52 (C15), 137.17 (C12), 136.98 (C36), 136.84 (C17), 136.32 (C34), 135.96 (C46), 135.67 (C4), 134.83 (C64), 134.78 (C57), 134.09 (C55), 133.28 (C59), 133.12 (C31), 132.31 (C63), 131.77 (C51), 131.54 (C23), 131.36 (C49), 129.94 (C54), 129.55 (C26), 129.17 (C7), 129.10 (C48), 128.92 (C27), 128.64 (C8), 128.59 (C5), 128.59 (C24), 128.54 (C35), 128.27 (C65), 127.78 (C16), 127.76 (C14), 127.45 (C50), 127.32 (C58), 127.27 (C56), 127.13 (C33), 127.13 (C45), 126.53 (C43), 126.53 (C66), 126.37 (C28), 126.17 (C21), 125.42 (C9), 124.35 (C44), 123.54 (C42), 120.76 (C1), 120.76 (C2) 120.50 (C47), 115.77 (C10), 115.58 (C29), 
102.06 (C52), 72.15 (C40), 23.08 (C38), 22.98 (C37), 22.98 (C60), 22.08 (C19), 21.74 (C18), 20.87 (C39), 20.56 (C20), 19.03 (C67), 18.61 (C61). IR (KBr pellet): $1999 \mathrm{~cm}^{-1}(\mathrm{C} \equiv \mathrm{N})$ and 2102 $\mathrm{cm}^{-1}(\mathrm{C} \equiv N)$. Single crystals suitable for study via $X$-ray were grown via diffusion of pentane into a concentrated toluene at $-35^{\circ} \mathrm{C}$. Anal. Calcd for $\left(\mathrm{CPh}_{2}{ }^{\mathrm{Mes}} \mathrm{PDP}^{\mathrm{Ph}}\right) \mathrm{Fe}\left(\mathrm{C} \equiv \mathrm{N}-\left(2,6-\left(\mathrm{CH}_{3}\right)_{2} \mathrm{Ph}\right)_{2}\right.$, $\mathrm{C}_{74} \mathrm{H}_{65} \mathrm{FeN}_{5}: \mathrm{C}, 82.28 ; \mathrm{H}, 6.07 ; \mathrm{N}, 6.48$. Found: $\mathrm{C}, 82.43 ; \mathrm{H}, 6.06 ; \mathrm{N}, 6.40$.

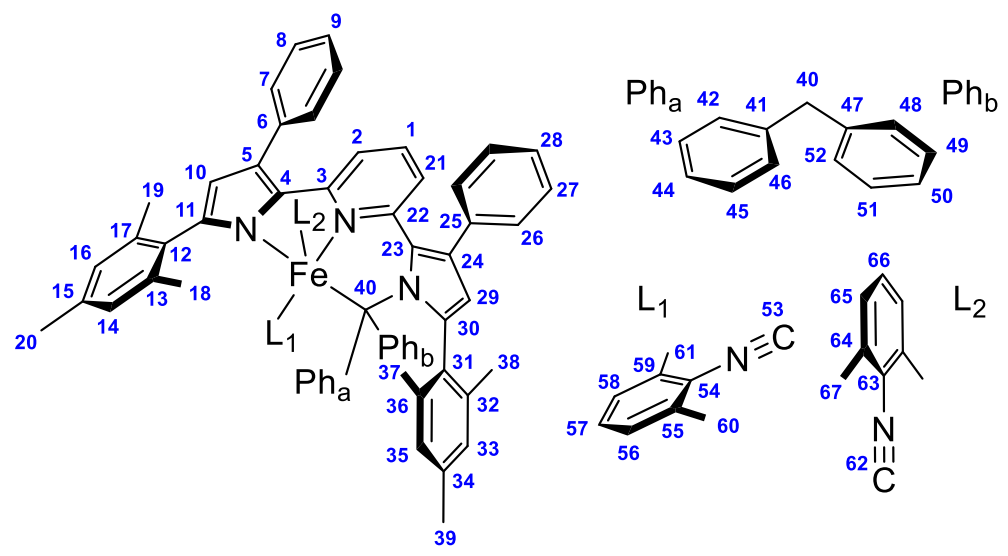

Figure 6.28. ${ }^{13} \mathrm{C}$ NMR labeling scheme for $\left({ }^{\mathrm{Mes}} \mathrm{PDP}{ }^{\mathrm{Ph}}\right) \mathrm{Fe}\left(\mathrm{C} \equiv \mathrm{N}-2,6-\left(\mathrm{CH}_{3}\right)_{2} \mathrm{Ph}\right)_{2}$.

\section{Preparation of $\left({ }^{\text {Mes }} \mathrm{PDP}^{\mathrm{Ph}}\right) \mathrm{Fe}\left(\mathrm{C} \equiv \mathrm{N}-2,6-\left(\mathrm{CH}_{3}\right)_{2} \mathrm{Ph}\right)_{3}$.}

A $20 \mathrm{~mL}$ scintillation vial was loaded with a magnetic stirrer, $250 \mathrm{mg}(0.345 \mathrm{mmol})$ of $\left({ }^{\mathrm{Mes}} \mathrm{PDP}^{\mathrm{Ph}}\right) \mathrm{Fe}($ thf), and $5 \mathrm{~mL}$ of benzene, affording a homogenous dark red solution. In a separate vial, $140 \mathrm{mg}$ ( $1.07 \mathrm{mmol}, 3.1 \mathrm{eq}$.) of 2,6-dimethylphenylisocyanide was dissolved in $5 \mathrm{~mL}$ of benzene. The isocyanide solution was added to slowly, dropwise, to the solution of the iron compound, resulting in an immediate color change of the solution from dark red to orange. Within minutes, an abundant yellow/orange precipitate was evident. The reaction mixture was allowed to stir for 12 hours. The resulting precipitate was isolated on a medium porosity glass frit and washed with three $5 \mathrm{~mL}$ aliquots of pentane. Drying in vacuo afforded the title compound as an analytically pure yellow powder. Yield: $322 \mathrm{mg}(0.308 \mathrm{mmol}, 89 \%) .{ }^{1} \mathrm{H}$ NMR $\left(600 \mathrm{MHz}\right.$, dichloromethane- $\left.d_{2} ; \delta, \mathrm{ppm}\right): 7.49\left(\mathrm{AA}^{\prime} \mathrm{BB}^{\prime} \mathrm{C}, J_{\mathrm{AB}}=7.64 \mathrm{~Hz}, J_{\mathrm{AB}^{\prime}}=0.51 \mathrm{~Hz}, J_{\mathrm{AA}^{\prime}}=\right.$ 
$\left.1.94 \mathrm{~Hz}, J_{\mathrm{AC}}=1.31 \mathrm{~Hz}, o-\mathrm{Ph} H, 4 \mathrm{H}\right), 7.35\left(\mathrm{AA}^{\prime} \mathbf{B B}^{\prime} \mathrm{C}, J_{\mathrm{AB}}=7.64 \mathrm{~Hz}, J_{\mathrm{AB}}{ }^{\prime}=0.51, J_{\mathrm{BB}}{ }^{\prime}=1.44 \mathrm{~Hz}\right.$, $\left.J_{\mathrm{BC}}=7.43 \mathrm{~Hz}, m-\mathrm{Ph} H, 4 \mathrm{H}\right), 7.22\left(\mathrm{AB}_{2}, J_{\mathrm{AB}}=8.0 \mathrm{~Hz}, 4-\mathrm{py} H, 4 \mathrm{H}\right), 7.20\left(\mathrm{AA}^{\prime} \mathrm{BB}^{\prime} \mathrm{C}, J_{\mathrm{BC}}=7.43\right.$ $\left.\mathrm{Hz}, J_{\mathrm{AC}}=1.31 \mathrm{~Hz}, p-\mathrm{Ph} H, 1 \mathrm{H}\right), 7.11\left(\mathrm{AB} \mathbf{B}_{2}, J_{\mathrm{AB}}=8.0 \mathrm{~Hz}, 3-\mathrm{py} H, 2 \mathrm{H}\right), 7.09\left(\mathrm{AB}_{2}, J_{\mathrm{AB}}=7.80 \mathrm{~Hz}\right.$, $p-\mathrm{Ph} H, 2 \mathrm{H}$ (apical isocyanides)), 2H), $7.03\left(\mathrm{AB}_{2}, J_{\mathrm{AB}}=7.50 \mathrm{~Hz}, p-\mathrm{Ph} H\right.$ (equatorial isocyanide)), $7.02\left(\mathrm{AB}_{2}, J_{\mathrm{AB}}=7.8 \mathrm{~Hz}, m-\mathrm{Ph} H, 4 \mathrm{H}\right.$ (apical isocyanides) $), 6.95\left(\mathrm{AB}_{2}, J_{\mathrm{AB}}=7.5 \mathrm{~Hz}, p-\mathrm{Ph} H, 1 \mathrm{H}\right.$ (apical isocyanide)), 6.40 (s, $m$-Mes $H, 4 \mathrm{H}), 5.71$ (s, pyrrole $H, 2 \mathrm{H}), 2.37$ (s, $m$ - $\mathrm{CH}_{3}, 6 \mathrm{H}$ (equatorial isocyanide)), 2.19 (s, $m$ - $\mathrm{CH}_{3}, 12 \mathrm{H}$ (apical isocyanides)), 2.03 (s, $\left.o-\mathrm{MesCH}_{3}, 12 \mathrm{H}\right), 1.46$ (s, $p$ $\left.\mathrm{MesCH}_{3}, 6 \mathrm{H}\right) .{ }^{13} \mathrm{C} \mathrm{NMR}\left(151 \mathrm{MHz}\right.$, dichloromethane-d $\left.d_{2} ; \delta, \mathrm{ppm}\right): 178.15(\mathrm{C} 24), 176.68$ (C18), 157.58 (C3), 147.35 (C11), 139.89 (C6), 137.85 (C13), 137.63 (C15), 136.69 (C12), 136.59 (C4), 136.05 (C1), 135.86 (C20), 134.47 (C26), 130.05 (C5), 130.01 (25), 129.70 (C7), 128.69 (C8), 128.51 (C22), 128.42 (C19), 128.35 (C21), 127.54 (C27), 127.36 (C14), 127.20 (C28), 125.66 (C9), 115.05 (C10), 109.12 (C2), 21.79 (C16), 20.86 (C17), 19.84 (C29), 19.07 (C23). IR (KBr pellet): $2103 \mathrm{~cm}^{-1}(\mathrm{C} \equiv \mathrm{N})$ and $2150 \mathrm{~cm}^{-1}(\mathrm{C} \equiv \mathrm{N})$. Anal. Calcd for $\left({ }^{\mathrm{Mes}} \mathrm{PDP}{ }^{\mathrm{Ph}}\right) \mathrm{Fe}(\mathrm{CN}-(2,6-$ $\left.\left(\mathrm{CH}_{3}\right)_{2} \mathrm{Ph}\right)_{3}, \mathrm{C}_{70} \mathrm{H}_{64} \mathrm{FeN}_{6}$ : C, 80.44; H, 6.17; N, 8.04. Found: C, 80.17; H, 6.07; N, 7.99. Single crystals suitable for analysis via X-ray were grown from diffusion of pentane into a concentrated benzene solution of $\left({ }^{\mathrm{Mes}} \mathrm{PDP}{ }^{\mathrm{Ph}}\right) \mathrm{Fe}\left(\mathrm{C} \equiv \mathrm{N}-\left(2,6-\left(\mathrm{CH}_{3}\right)_{2} \mathrm{Ph}\right)_{3}\right.$ at room temperature.

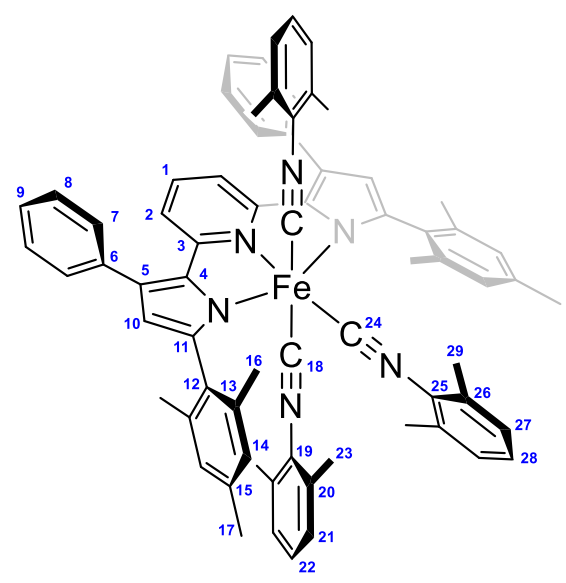

Figure 6.29. ${ }^{13} \mathrm{C}$ NMR labeling scheme for $\left({ }^{\mathrm{Mes}} \mathrm{PDP} \mathrm{P}^{\mathrm{Ph}}\right) \mathrm{Fe}\left(\mathrm{C} \equiv \mathrm{N}-2,6-\left(\mathrm{CH}_{3}\right)_{2} \mathrm{Ph}\right)_{3}$. 


\section{Preparation of $\left({ }^{M e s} P D P P h\right) F e\left(C \equiv N-{ }^{1} A d\right)_{3}$.}

A $20 \mathrm{~mL}$ scintillation vial was loaded with a magnetic stirrer, $250 \mathrm{mg}(0.345 \mathrm{mmol})$ of $\left({ }^{\mathrm{Mes}} \mathrm{PDP}^{\mathrm{Ph}}\right) \mathrm{Fe}(\mathrm{thf})$, and $5 \mathrm{~mL}$ of benzene. Vigorous stirring of the mixture resulted in a homogenous dark red solution. In a separate vial, $173 \mathrm{mg}$ (1.07 mmol, 3.1 eq.) of 1-adamantylisocyanide $\left(\mathrm{C} \equiv \mathrm{N}-{ }^{1} \mathrm{Ad}\right)$ was dissolved in $5 \mathrm{~mL}$ of benzene. The isocyanide solution was added dropwise, to the solution of the iron compound, resulting in an immediate color change of the solution from dark red to red/brown. The reaction mixture was allowed to stir for 12 hours. To the resulting suspension was added $5 \mathrm{~mL}$ of pentane, which induced precipitation of yellow/orange microcrystalline material. The precipitate was isolated on a medium porosity glass frit and washed with three 5 aliquots of pentane, affording the title compound as an analytically pure yellow powder. Yield: $316 \mathrm{mg}(0.278 \mathrm{mmol}, 81 \%) .{ }^{1} \mathrm{H}$ NMR $(600 \mathrm{MHz}$, dichloromethane$\left.d_{2} ; \delta, \mathrm{ppm}\right): 7.48\left(\mathrm{AA}^{\prime} \mathrm{BB}^{\prime} \mathrm{C}, J_{\mathrm{AB}}=7.79 \mathrm{~Hz}, J_{\mathrm{AA}}{ }^{\prime}=1.91 \mathrm{~Hz}, J_{\mathrm{AC}}=1.29 \mathrm{~Hz}, J_{\mathrm{AB}}{ }^{\prime}=0.55 \mathrm{~Hz}, o-\right.$ $\mathrm{Ph} H, 4 \mathrm{H}), 7.33\left(\mathrm{AA}^{\prime} \mathbf{B B}^{\prime} \mathrm{C}, J_{\mathrm{AB}}=7.79 \mathrm{~Hz}, J_{\mathrm{BC}}=7.42 \mathrm{~Hz}, J_{\mathrm{BB}}{ }^{\prime}=1.48 \mathrm{~Hz}, J_{\mathrm{AB}}{ }^{\prime}=0.55 \mathrm{~Hz}, m-\right.$ $\mathrm{Ph} H, 4 \mathrm{H}), 7.17\left(\mathrm{AA}^{\prime} \mathrm{BB}^{\prime} \mathbf{C}, J_{\mathrm{BC}}=7.42 \mathrm{~Hz}, J_{\mathrm{AC}}=1.29 \mathrm{~Hz}, m-\mathrm{Ph} H, 2 \mathrm{H}\right), 7.13\left(\mathrm{AB}_{2}, 4-\mathrm{py} H, 1 \mathrm{H}\right)$, $6.97\left(\mathrm{AB}_{2}, J=7.9 \mathrm{~Hz}, 3-\mathrm{py} H, 2 \mathrm{H}\right), 6.79$ (s, $\left.m-\mathrm{Mes} H, 4 \mathrm{H}\right), 5.51$ (s, pyrrole $\left.H, 2 \mathrm{H}\right), 2.24$ (s, $p$ $\left.\mathrm{MesCH}_{3}, 6 \mathrm{H}\right), 2.18\left(\mathrm{~s}, \mathrm{o}-\mathrm{MesCH}_{3}, 12 \mathrm{H}\right), 1.98(\mathrm{~s}, 6 \mathrm{H}), 1.83(\mathrm{~s}, 3 \mathrm{H}), 1.80(\mathrm{~s}, 12 \mathrm{H}), 1.59(\mathrm{~J}=12.4$ Hz, 6H), $1.54(\mathrm{~m}, J=12.4 \mathrm{~Hz}, 6 \mathrm{H}), 1.52(\mathrm{~m}, J=12.4 \mathrm{~Hz} 3 \mathrm{H}), 1.45(\mathrm{~m}, J=12.4,3 \mathrm{H}), 1.04(\mathrm{~s}$, 6H). ${ }^{13} \mathrm{C}$ NMR (151 MHz, dichloromethane- $\left.d_{2} ; \delta, \mathrm{ppm}\right): 163.75$ (C23), 163.55 (C18), 157.00 (C3), 147.79 (C4), 140.17 (C6), 138.78 (C13), 137.97 (C12), 136.83 (C11), 135.91 (C15), 134.70 (C1), 129.52 (C7), 128.77 (C5), 128.50 (C8), 127.97 (C14), 125.30 (C9), 116.36 (C10), 108.54 (C2), 57.07 (C24), 56.82 (C19), 43.98 (C25), 42.29 (C20), 35.87 (C27), 35.79 (C22), 29.55 (C21), 29.46 (C26), 21.90 (C16), 21.32 (C17). IR (KBr pellet): $2123 \mathrm{~cm}^{-1}$ (C $\equiv \mathrm{N}$, broad). 
Anal. Calcd for $\left({ }^{\mathrm{Mes}} \mathrm{PDP}{ }^{\mathrm{Ph}}\right) \mathrm{Fe}\left(\mathrm{C} \equiv \mathrm{N}-{ }^{1} \mathrm{Ad}\right)_{3}, \mathrm{C}_{76} \mathrm{H}_{82} \mathrm{FeN}$ : $\mathrm{C}, 80.40 ; \mathrm{H}, 7.28 ; \mathrm{N}, 7.40$. Found: $\mathrm{C}$, $80.00 ; \mathrm{H}, 7.29 ; \mathrm{N}, 7.08$.

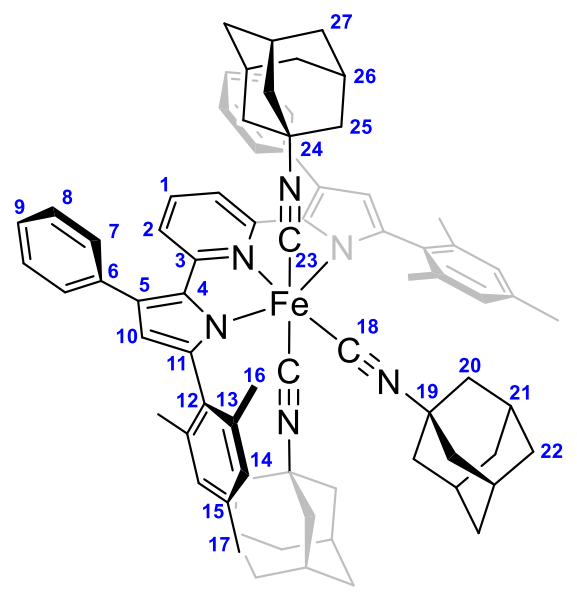

Figure 6.30. ${ }^{13} \mathrm{C}$ NMR labeling scheme for $\left({ }^{\mathrm{Mes}} \mathrm{PDP} \mathrm{P}^{\mathrm{Ph}}\right) \mathrm{Fe}\left(\mathrm{C} \equiv \mathrm{N}-{ }^{1} \mathrm{Ad}\right)_{3}$.

\section{Preparation of $\left({ }^{\text {Mes } P D P P h}\right) \mathrm{Fe}\left(\mathrm{CPh}_{2}\right)\left(C \equiv \mathrm{N}^{1} \mathrm{Ad}\right)$.}

To a $20 \mathrm{~mL}$ scintillation vial equipped with a magnetic stirrer was added $100 \mathrm{mg}(0.122$ mmol) of $\left({ }^{\mathrm{Mes}} \mathrm{PDP}^{\mathrm{Ph}}\right) \mathrm{Fe}\left(\mathrm{CPh}_{2}\right)$ and $2 \mathrm{~mL}$ of benzene. Vigorous stirring of the mixture afforded a dark green solution. In a separate vial, $20 \mathrm{mg}(0.124 \mathrm{mmol}, 1.02 \mathrm{eq}$, $)$ of 1-adamantylisocyanide was dissolved in $1 \mathrm{~mL}$ of pentane. The solution of 1-adamantylisocyanide was added dropwise to the stirring solution of $\left({ }^{\mathrm{Mes}} \mathrm{PDP}{ }^{\mathrm{Ph}}\right) \mathrm{Fe}\left(\mathrm{CPh}_{2}\right)$, resulting in an immediate color change from olive green to dark red/brown. The solvent was immediately removed in vacuo affording a dark solid. Crystallization of the product was accomplished via evaporation of a diethyl ether solution at $35^{\circ} \mathrm{C}$. Yield: $19 \mathrm{mg}, 0.019 \mathrm{mmols}, 16 \% .{ }^{1} \mathrm{H}$ NMR (600 MHz, benzene- $d_{6} ; \delta$, ppm): 7.66 (d, $J=$ $7.4 \mathrm{~Hz}, 4 \mathrm{H}$, ortho-Ph), 7.21 (t, $J=7.6 \mathrm{~Hz}, 4 \mathrm{H}$, meta- $\mathrm{Ph}), 7.10$ (t, $J=7.4 \mathrm{~Hz}, 2 \mathrm{H}$, para- $\mathrm{Ph}), 7.00$ (m, 10H, Ar), 6.81 (s, 2H, meta-Mesityl), 6.74 (s, 2H, meta-Mesityl), 6.55 (d, J = 7.9 Hz, 2H, 3pyridine), 6.37 (s, 2H, pyrrole-H), 6.20 (t, $J=7.9 \mathrm{~Hz}, 1 \mathrm{H}, 4$-pyridine), 2.78 (s, 6H, Mesityl- 
$\mathrm{CH}_{3}$ ), 2.53 (s, 6H, Mesityl- $\mathrm{CH}_{3}$ ), 2.14 (s, 6H, Mesityl- $\mathrm{CH}_{3}$ ), 1.60 (s, $\left.3 \mathrm{H},{ }^{1} \mathrm{Ad}\right), 1.25$ (m, $J=12.3$ $\left.\mathrm{Hz}, 6 \mathrm{H},{ }^{1} \mathrm{Ad}\right), 0.76\left(\mathrm{~s}, 6 \mathrm{H},{ }^{1} \mathrm{Ad}\right) .{ }^{13} \mathrm{C}$ NMR $\left(151 \mathrm{MHz}\right.$, benzene- $\left.d_{6} ; \delta, \mathrm{ppm}\right): 354.13\left(\mathrm{CPh}_{2}\right) . \operatorname{Red}$ single crystals suitable for X-ray crystallography were grown from slow evaporation of a diethyl ether solution of $\left({ }^{\mathrm{Mes}} \mathrm{PDP}^{\mathrm{Ph}}\right) \mathrm{Fe}\left(\mathrm{CPh}_{2}\right)\left(\mathrm{C} \equiv \mathrm{N}-{ }^{1} \mathrm{Ad}\right)$ at $-35^{\circ} \mathrm{C}$.

\section{Physical Measurements.}

${ }^{1} \mathrm{H}$ and ${ }^{13} \mathrm{C}\left\{{ }^{1} \mathrm{H}\right\}$ NMR spectra were acquired at $25^{\circ} \mathrm{C}$ on a Varian Unity INOVA 600 $\mathrm{MHz}$ spectrometer equipped with a $5 \mathrm{~mm}$ inverse broadband $\mathrm{PFG}$ probe, on an Agilent $400 \mathrm{MHz}$ DD2 spectrometer equipped with a $5 \mathrm{~mm}$ One NMR probe, or a JNM-ECZ400S/L1 spectrometer equipped with a $5 \mathrm{~mm}$ ROYAL NMR probe. All chemical shifts are reported relative to $\mathrm{SiMe}_{4}$ using ${ }^{1} \mathrm{H}$ (residual) chemical shifts of the solvent as a secondary standard. Elemental analyses were performed at Robertson Microlit Laboratories, Inc., in Ledgewood, NJ. Room temperature magnetic susceptibility measurements were performed with a Johnson Matthey Mark 1 instrument that was calibrated with $\mathrm{HgCo}(\mathrm{SCN})_{4}$. Zero-field ${ }^{57} \mathrm{Fe}$ Mössbauer spectra were collected on a SEE Co. Mössbauer spectrometer (MS4) with a ${ }^{57} \mathrm{Co} / \mathrm{Rh}$ radiation source at $80 \mathrm{~K}$ in constant acceleration mode. The temperature in the sample chamber was controlled by a Janis Research Co. CCS-850 He/ $\mathrm{N}_{2}$ cryostat within an accuracy of $\pm 0.3 \mathrm{~K}$. The data were calibrated relative to $\alpha$-iron at $298 \mathrm{~K}$. The fitting procedure to extract quantitative spectral parameters uses a least-squares Lorentzian fitting method implemented in the WMOSS software developed by SEE Co. Variable-temperature applied-field ${ }^{57} \mathrm{Fe}$ Mössbauer spectra were performed on samples prepared by mixing a powder sample with mineral oil and then frozen in liquid nitrogen. A second sample was prepared in dilute frozen toluene solution. The spectroscopic results measured on the powder sample and frozen solution sample were consistent, suggesting that potential "powder effects" (such as intermolecular magnetic interactions) could be excluded 
from consideration in spectral analysis. The data presented in this chapter is that of the spectroscopic analysis of the sample of solid powder frozen mineral oil.

\section{X-ray Crystallography.}

Single crystals suitable for X-ray diffraction were coated with polyisobutylene oil (Sigma-Aldrich) in a drybox, mounted on a nylon loop, and then quickly transferred to the goniometer head of a Bruker AXS D8 Venture fixed-chi X-ray diffractometer equipped with a Triumph monochromator, a Mo K $\alpha$ radiation source $(\lambda=0.71073 \AA)$, and a PHOTON 100 CMOS detector. The samples were cooled to $100 \mathrm{~K}$ with an Oxford Cryostream 700 system and optically aligned. The APEX3 software program (version 2016.9-0) ${ }^{76}$ was used for diffractometer control, preliminary frame scans, indexing, orientation matrix calculations, leastsquares refinement of cell parameters, and the data collection. Three sets of 12 frames each were collected using the omega scan method with a $10 \mathrm{~s}$ exposure time. Integration of these frames followed by reflection indexing and least-squares refinement produced a crystal orientation matrix for the crystal lattice that was used for the structural analysis. The data collection strategy was optimized for completeness and redundancy using the Bruker COSMO software suite. The space group was identified, and the data were processed using the Bruker SAINT+ program and corrected for absorption using SADABS. The structures were solved using direct methods (SHELXS) completed by subsequent Fourier synthesis and refined by full-matrix least-squares procedures using the programs provided by SHELXL-2014. ${ }^{77}$

\section{Density Functional Theory Calculations.}

All DFT calculations were performed with the ORCA program package. ${ }^{78}$ Geometry optimizations of the complexes and single-point calculations on the optimized geometries were carried out at the B3LYP level of DFT. ${ }^{79-81}$ The all-electron Gaussian basis sets were those 
developed by the Ahlrichs group. ${ }^{82-84}$ Triple- $\zeta$ quality basis sets def2-TZVP with one set of polarization functions on the metal and on the atoms directly coordinated to the metal center were used. For the carbon and hydrogen atoms, slightly smaller polarized split-valence def2-SVP basis sets were used that were of double- $\zeta$ quality in the valence region and contained a polarizing set of $d$ functions on the nonhydrogen atoms. Auxiliary basis sets to expand the electron density in the resolution-of-the-identity (RIJCOSX) $)^{85-87}$ approach were chosen to match the orbital basis. ${ }^{88-90}$ Throughout this chapter computational results are described by using the broken-symmetry (BS) approach by Ginsberg ${ }^{91}$ and Noodleman. ${ }^{92}$ Because several broken symmetry solutions to the spin-unrestricted Kohn-Sham equations may be obtained, the general notation $\mathrm{BS}(\mathrm{m}, \mathrm{n})$ has been adopted, where $\mathrm{m}(\mathrm{n})$ denotes the number of spin-up (spin-down) electrons at the two interacting fragments. All molecular orbital and spin density plots were generated using the program Gabedit. ${ }^{93}$ Nonrelativistic single-point calculations on the optimized geometry were carried out to predict Mössbauer spectral parameters (isomer shifts and quadrupole splittings). These calculations employed the $\mathrm{CP}(\mathrm{PPP})$ basis set for iron. ${ }^{94}$ Mössbauer isomer shifts were calculated from the computed electron densities at the iron centers as previously described. ${ }^{95,96}$ 


\section{References}

1. Schrock, R. R. Multiple Metal-Carbon Bonds for Catalytic Metathesis Reactions (Nobel Lecture). Angew. Chem. Int. Ed. 2006, 45, 3748-3759.

2. Grubbs, R. H. Olefin-Metathesis Catalysts for the Preparation of Molecules and Materials (Nobel Lecture). Angew. Chem. Int. Ed. 2006, 45, 3760-3765.

3. Chauvin, Y. Olefin Metathesis: The Early Days (Nobel Lecture). Angew. Chem. Int. Ed. 2006, $45,3740-3747$.

4. Dörwald, F. Z. Metal Carbenes in Organic Synthesis; Wiley-VCH: Weinheim, 1999.

5. Doyle, M. P. Catalytic Methods for Metal Carbene Transformations. Chem. Rev. 1986, 86, 919-939.

6. Davies, H. M. L.; Manning, J. R. Catalytic C-H Functionalization by Metal Carbenoid and Nitrenoid Insertion. Nature, 2008, 451, 417-424.

7. Catalytic Iron-Carbene Intermediate Revealed in a Cytochrome $C$ Carbene Transferase. Lewis, R. D.; Garcia-Borràs, M.; Chalkley, M. J.; Buller, A. R.; Houk, K. N.; Arnold, F. H. Proc. Natl. Acad. Sci. U.S.A 2018, 115, 7308-7313.

8. Coelho, P. S.; Brustad, E. M.; Kannan, A.; Arnold, F. H. Olefin Cyclopropanation via Carbene Transfer Catalyzed by Engineered Cytochrome P450 Enzymes. Science 2013, 339, 307-310.

9. Schrock, R. R. In Topics in Organometallic Chemistry. Alkene Metathesis in Organic Synthesis; Fürstner, A., Ed.; Springer: Berlin, 1998; Vol. 1, p 1.

10. Schrock, R. R. The Alkoxide Ligand in Alkene and Acetylene Olefin Metathesis Reactions. Polyhedron 1995, 14, 3177.

11. Vougioukalakis, G. C.; Grubbs, R. H. Ruthenium-Based Heterocyclic Carbene-Coordinated Olefin Metathesis Catalysts. Chem. Rev. 2010, 110, 1746-1787. 
12. Brookhart, M.; Studabaker, W. B. Cyclopropanes From Reactions of Transition Metal Carbene Complexes with Olefins. Chem. Rev. 1987, 87, 411-432.

13. J. R. Wolf , C. G. Hamaker , J.-P. Djukic , T. Kodadek and L. K. Woo. Shape and Stereoselective Cyclopropanation of Alkenes Catalyzed by Iron Porphyrins. J. Am. Chem. Soc. 1995, 117, 9194-9199.

14. Holzwarth, M. S.; Alt, I.; Plietker, B. Catalytic Activation of Diazo Compounds Using ElectronRich Defined Iron Complexes for Carbene-Transfer Reactions. Angew. Chem. Int. Ed. 2012, 51, $5351-5354$.

15. Crabtree, R. H. Wiley. The Organometallic Chemistry of the Transition Metals, $4^{\text {th }}$ ed.; Wiley-Interscience: Hoboken, NJ, 2005.

16. R. R. Schrock. An “Alkylcarbene” Complex of Tantalum by Intramolecular $\alpha$-Hydrogen Abstraction. J. Am. Chem. Soc. 1974, 96, 6796-6797.

17. Jolly, P. W.; Pettit, R. Evidence for a Novel Metal-Carbene System. J. Am. Chem. Soc. 1966, $88,5044-5045$.

18. Green, M. L. H.; M. Ishaq, M., Whiteley, R. N. Studies on Some Substituted Methyl Derivatives of Iron, Molybdenum, and Tungsten. J. Chem. Soc. A, 1967, 0, 1508-1515.

19. Brookhart, M.; Tucker, J. R.; Flood, T. C.; Jensen, J. Spectroscopic Characterization of an Electrophilic Transition-Metal-Methylene Complex, $\eta^{5}-\mathrm{C}_{5} \mathrm{H}_{5}\left[\left(\mathrm{C}_{6} \mathrm{H}_{5}\right)_{2} \mathrm{PCH}_{2} \mathrm{CH}_{2} \mathrm{P}\left(\mathrm{C}_{6} \mathrm{H}_{5}\right)_{2}\right]-$ $\mathrm{Fe}=\mathrm{CH}_{2}{ }^{+} . J$. Am. Chem. Soc. 1980, 102, 3, 1203-1205.

20. Allison, N. T.; Kawada,Y.; Jones, W. M. Synthesis of Transition Metal Complexes of Cycloheptatrienylidene. J. Am. Chem. Soc. 1978, 100, 5224-5226.

21. Riley, P. E.; Davies, R. E.; Allison, N. T.; Jones, W. M. Structures of and Bonding in $\eta^{1}$ Cycloheptatrienylidene Complexes of Iron. Inorg. Chem. 1982, 21, 1321. 
22. Mahias, V.; Cron, S.; Toupet, L.; Lapinte, C. Synthesis of Bis(methoxycarbene) and Bis(alkylidene) Ligands Bridging Two Iron Centers in the $\mathrm{Cp} * \mathrm{Fe}(\mathrm{L} 1)(\mathrm{L} 2)$ Series. X-ray Crystal Structure of the Iron Alkylidene $[\mathrm{Cp} * \mathrm{Fe}(\mathrm{dppe})(=\mathrm{C}(\mathrm{H}) \mathrm{Me})]\left[\mathrm{PF}_{6}\right]$. Organometallics 1996, 15, 5399-5408.

23. Poigant, G.; Nlate, S.; Guerchais, V.; Edwards, A. J.; Raithby, P. R. Synthesis and Properties of $\left(\eta^{2}-\mathrm{C}, \mathrm{X}\right)$ Chelate Arylcarbene Complexes $\left[\mathrm{Fe}\left(\mathrm{C}_{5} \mathrm{Me}_{5}\right)(\mathrm{L})\left\{\eta^{2}-\mathrm{C}(\mathrm{OMe}) \mathrm{C}_{6} \mathrm{H}_{4}-o-\mathrm{X}\right\}\right][\mathrm{OTf}](\mathrm{L}=$ $\left.\mathrm{CO}, \mathrm{PMe}_{3} ; \mathrm{X}=\mathrm{OMe}, \mathrm{Cl}\right)$. Organometallics 1997, 16, 1, 124-132.

24. Klose, A.; Solari, E.; Floriani, C.; Re, N.; Chiesi-Villa, A.; Rizzoli, C. Iron-Carbene Functionalities Supported by a Macrocyclic Ligand: Iron-Carbon Double Bond Stabilized by Tetramethyldibenzotetraazaannulene. Chem. Commun., 1997, 23, 2297-2298.

25. Klose, A.; Hesschenbrouck, J.; Solari, E.; Latronico, M.; Floriani, C.; Re, N.; Chiesi-Villa, A.; Rizzoli, C. The Metal-Carbon Multiple Bond in Iron(I)- and Iron(II) Dibenzotetramethyltetra[14]azaannulene: Carbene, Carbonyl, and Isocyanide Derivatives. $J$. Organomet. Chem. 1999, 591, 45-62.

26. Giusti, M.; Solari, E.; Giannini, L.; Floriani, C.; Chiesi-Villa, A.; Rizzoli, C. Iron-Carbene Bonded to a Planar Tetraoxo Surface Defined by Dimethoxy-p-tert-butylcalix[4]arene Dianion. Organometallics 1997, 16, 5610-5612.

27. Li, Y.; Huang, J. S.; Zhou, Z. Y.; Che, C.; You, X. Z. Remarkably Stable Iron Porphyrins Bearing Nonheteroatom-Stabilized Carbene or (Alkoxycarbonyl)carbenes: Isolation, X-ray Crystal Structures, and Carbon Atom Transfer Reactions with Hydrocarbons. J. Am. Chem. Soc. 2002, 124, 13185-13193. 
28. Liu, Y.; Xu, W.; Zhang, J.; Fuller, W.; Schulz, C. E.; Li, J. Electronic Configuration and Ligand Nature of Five-Coordinate Iron Porphyrin Carbene Complexes: An Experimental Study. J. Am. Chem. Soc., 2017, 139, 5023-5026.

29. Wang, H.; Wan, Q.; Low, K.; Zhou, C.; Huang, J.; Zhang, J.; Che, C. Stable Group 8 Metal Porphyrin Mono- and Bis(dialkylcarbene) Complexes: Synthesis, Characterization, and Catalytic Activity. Chem. Sci., 2020, 11, 2243-2259.

30. Iron Porphyrin Carbenes as Catalytic Intermediates: Structures, Mössbauer and NMR Spectroscopic Properties, and Bonding. Angew. Chem. Int. Ed. 2014, 53, 7574-7578.

31. Zhang, Y. Computational Investigations of Heme Carbenes and Heme Carbene Transfer Reactions. Chem. Euro. J. 2019, 25, 13231-13247.

32. New Insights into the Ligand Nature of Carbene: Synthesis and Characterizations of SixCoordinate Iron(II) Carbene Porphyrin Complexes. Haimang Wang, Charles E. Schulz, Xuehong Wei, and Jianfeng Li. Inorg. Chem. 2019, 58, 143-151.

33. DeJesus, J. F.; Jenkins, D. M. A Chiral Macrocyclic Tetra- $N$-Heterocyclic Carbene Yields an “All Carbene” Iron Alkylidene Complex. Chem. Eur. J. 2020, 26, 1425-1439.

34. Russell, S. K.; Hoyt, J. M.; Bart, S. C.; Milsmann, C.; Stieber, S. C. E.; Semproni, S. P.; DeBeer, S.; Chirik, P. J. Synthesis, Electronic Structure and Reactivity of Bis(imino)pyridine Iron Carbene Complexes: Evidence for a Carbene Radical. Chem. Sci., 2014, 5, 1168-1174.

35. Wang, B.; Howard, I. G.; Pope, J. W.; Conte, E. D.; Deng, Y. Bis(imino)pyridine Iron Complexes for Catalytic Carbene Transfer Reactions. Chem. Sci., 2019, 10, 7958-7963.

36. Dzik, W.I.; Xu, X.; Reek, J. N. H.; de Bruin, B. 'Carbene Radicals' in Co ${ }^{\mathrm{II}}$ (por)-Catalyzed Olefin Cyclopropanation. J. Am. Chem. Soc., 2010, 132, 10891-10902. 
37. Dzik, W.I.; Xu, X.; Reek, J. N. H.; de Bruin, B. Correction to “'Carbene Radicals' in Co (por)Catalyzed Olefin Cyclopropanation.” J. Am. Chem. Soc., 2010, 132, 18429-18429.

38. Dzik, W. I.; Zhang, P. X.; de Bruin, B. Redox Noninnocence of Carbene Ligands: Carbene Radicals in (Catalytic) C-C Bond Formation. Inorg. Chem., 2011, 50, 9896-9903.

39. Lu, H.; Dzik, W. I.; Xue, X.; Wojtas, L.; de Bruin, B.; Zhang, X. P. Experimental Evidence for Cobalt(III)-Carbene Radicals: Key Intermediates in Cobalt(II)-Based Metalloradical Cyclopropanation. J. Am. Chem. Soc. 2011, 133, 8518-8521.

40. Liu, J.; Hu, L.; Wang, L.; Chen, H.; Deng, L. An Iron(II) Ylide Complex as a Masked OpenShell Iron Alkylidene Species in Its Alkylidene-Transfer Reactions with Alkenes. J. Am. Chem. Soc. 2017, 139, 3876-3888.

41. Reesbeck, M. E.; Grubel, K.; Kim, D.; Brennessel, W. W.; Mercado, B. Q.; Holland, P. L. Diazoalkanes in Low-Coordinate Iron Chemistry: Bimetallic Diazoalkyl and Alkylidene Complexes of Iron(II) Inorg. Chem. 2017, 56, 1019-1022.

42. Lindley, B. M.; Swidan, A.; Lobkovsky, E. B.; Wolczanski, P. T.; Adelhardt, M.; Sutter, J.;

Meyer, K. Fe(IV) Alkylidenes via Protonation of Fe(II) Vinyl Chelates and a Comparative Mössbauer Spectroscopic Study. Chem. Sci., 2015, 6, 4730-4736.

43. Lindley, B. M.; Jacobs, B. P.; MacMillan, S. N.; Wolczanski, P. T. Neutral Fe(IV)

Alkylidenes, Including Some That Bind Dinitrogen. Chem. Commun. 2016, 52, 3891-3894.

44. Jacobs, B. P.; Agarwal, R. G.; Wolczanski, P. T.; Cundari, T. R.; MacMillan, S. N. Fe(IV) Alkylidenes are Actually Fe(II), and a Related Octahedral Fe(II) "Alkylidene" is a Conjugated Vinyl Complex. Polyhedron 2016, 116, 47-56.

45. Eisenstein, O.; Hoffmann, R.; Rossi, A. R. Some Geometrical and Electronic Features of the Intermediate Stages of Olefin Metathesis. J. Am. Chem. Soc. 1981, 103, 5582-5584. 
46. Searles, K.; Fortier, S.; Khusniyarov, M. M.; Carroll, P. J.; Sutter, J.; Meyer, K.; Mindiola, D. J.; Caulton, K. G. A Cis-Divacant Octahedral and Mononuclear Iron(IV) Imide. Angew. Chem., Int. Ed. 2014, 53, 14139-14143.

47. See Chapter 3 and Chapter 5 of this dissertation for details.

48. Javed, M. I.; Brewer, M. Diphenyldiazomethane. Org. Synth. 2008, 85, 189.

49. Hakey, B. M.; Darmon, J. M.; Zhang, Y.; Petersen, L.; Milsmann, C. Synthesis and Electronic Structure of Neutral Square-Planar High-Spin Iron(II) Complexes Supported by a Dianionic Pincer Ligand. Inorg. Chem. 2019, 58, 1252-1266.

50. Zadrozny, J. M.; Xiao, D. J.; Atanasov, M.; Long, G. R.; Grandjean, F.; Neese, F.; Long, J. R. Magnetic Blocking in a Linear Iron(I) Complex. Nat. Chem. 2013, 5, 577-581.

51. Bunting, P. C.; Atanasov, M.; Damgaard-Meller, E.; Perfetti, M.; Crassee, I.; Orlita, M.; Overgaard, J.; van Slageren, J.; Neese, F.; Long, J. R. A Linear Cobalt(II) Complex with Maximal Orbital Angular Momentum from a non-Aufbau Ground State. Science 2018, 362, 7319-7327.

52. Rohde, J.-U.; In, J.-H.; Lim, M. H.; Brennessel, W. W.; Bukowski, M. R.; Stubna, A.; Münck, E.; Nam, W.; Que, L., Jr. Science 2003, 299, 1037-1039.

53. Bart, S.C.; Lobkovsky, E.; Bill, E.; Chirik, P. J. Synthesis and Hydrogenation of Bis(imino)pyridine Iron Imides. J. Am. Chem. Soc. 2006, 128, 5302-5303.

54. Bowman, A. C.; Milsmann, C.; Bill, E.; Turner, Z. R.; Lobvosky, E.; DeBeer, S.; Wieghardt, K.; Chirik, P. J. Synthesis and Electronic Structure Determination of N-Alkyl-Substituted Bis(imino)pyridine Iron Imides Exhibiting Spin Crossover Behavior. J. Am. Chem. Soc. 2011, $133,17353-17369$. 
55. Ye, S.; Neese, F. Accurate Modeling of Spin-State Energetics in Spin-Crossover Systems with Modern Density Functional Theory. Inorg. Chem. 2010, 49, 772-774.

56. Bellow, J. A.; Stoian, S. A.; Van Tol, J.; Ozarowski, A.; Lord, R. L.; Groysman, S. Synthesis and Characterization of a Stable High-Valent Cobalt Carbene Complex. J. Am. Chem. Soc. 2016, $138,5531-5534$.

57. Grass, A.; Dewey, N. S.; Lord, R. L.; Groysman, S. Ketenimine Formation Catalyzed by a High-Valent Cobalt Carbene in Bulky Alkoxide Ligand Environment. Organometallics 2019, 38, 962-972.

58. Grass, A.; Wannipurage, D.; Lord, R. L.; Groysman, S. Group-Transfer Chemistry at Transition Metal Centers in Bulky Alkoxide Ligand Environments. Coord. Chem. Rev. 2019, $400,1-16$.

59. Mindiola, D. J.; Hillhouse, G. L. Synthesis, Structure, and Reactions of a Three-Coordinate Nickel-Carbene Complex, \{1,2-Bis(di-tert-butylphosphino)ethane $\} \mathrm{NiCPh}_{2}$. J. Am. Chem. Soc. 2002, 124, 9976-9977.

60. Waterman, R.; Hillhouse, G. L. Group Transfer from Nickel Imido, Phosphinidene, and Carbene Complexes to Ethylene with Formation of Aziridine, Phosphirane, and Cyclopropane Products. J. Am. Chem. Soc. 2003, 125, 13350-13351.

61. Laskowski, C. A.; Hillhouse, G. L. Synthesis and Carbene-Transfer Reactivity of Dimeric Nickel Carbene Cations Supported by N-Heterocyclic Carbene Ligands. Chem. Sci. 2011, 2, $321-325$.

62. Iluc, V. M.; Hillhouse, G. L. Three-Coordinate Nickel Carbene Complexes and Their OneElectron Oxidation Products. J. Am. Chem. Soc. 2014, 136, 6479-6488. 
63. Maity, A. K.; Zeller, M.; Uyeda, C. Carbene Formation and Transfer at a Dinickel Active Site. Organometallics 2018, 37, 2437-2441.

64. Dai, X.; Warren, T. H. Discrete Bridging and Terminal Copper Carbenes in CopperCatalyzed Cyclopropanation. J. Am. Chem. Soc. 2004, 126, 10085-10094.

65. Badiei, Y. M.; Warren, T. H. Electronic Structure and Electrophilic Reactivity of Discrete Copper Diphenylcarbenes. J. Organomet. Chem. 2005, 690, 5989-6000.

66. Hofmann, P.; Shishkov, I. V.; Rominger, F. Synthesis, Molecular Structures, and Reactivity of Mono- and Binuclear Neutral Copper(I) Carbenes. Inorg. Chem. 2008, 47, 11755-11762. 67. Mansuy, D.; Morgenstern-Badaru, I.; Lange, M.; Gans, P. An Intermediate-Spin Iron(III) Porphyrin Complex with a Vinylidene Group Inserted into an Iron-Nitrogen Bond: Paramagnetic Susceptibility, EPR, and Moessbauer Properties. Inorg. Chem. 1982, 21, 1427-1430.

68. Balch, A. L.; Cheng, R. J.; La Mar, G. N.; Latos-Grazynski, L. Proton Nuclear Magnetic Resonance Studies of Iron Porphyrin Complexes with a Vinyl Carbene Inserted Between Iron and a Pyrrole Nitrogen. Inorg. Chem. 1985, 24, 2651-2656.

69. Artaud, I.; Gregoire, N.; Battioni, J. P.; Dupre, D.; Mansuy, D. Heme Model Studies Related to Cytochrome P-450 Reactions: Preparation of Iron Porphyrin Complexes with Carbenes Bearing a $\beta$-Oxygen Atom and Their Transformation into Iron- $N$-Alkylporphyrins and IronMetallacyclic Complexes. J. Am. Chem. Soc. 1988, 8714-8716.

70. Formation and Fate of Iron-Carbene Complexes in Reactions Between a Diazoalkane and Iron-Porphyrins: Relevance to the Mechanism of Formation of $N$-Substituted Hemes in Cytochrome P-450-Dependent Oxidation of Sydnones. J. Am. Chem. Soc. 1990, 112, 6899-6905. 
71. Torrent-Sucarrat, M.; Arrastia, I.; Arrieta, A.; Cossío, F. P. Stereoselectivity, Different Oxidation States, and Multiple Spin States in the Cyclopropanation of Olefins Catalyzed by FePorphyrin Complexes. ACS Catal. 2018, 8, 11140-11153.

72. Rummelt, S. M.; Darmon, J. M.; Yu, R. P.; Viereck, P; Pabst, T. P.; Turner, Z. R.;

Margulieux, G. W.; G., Shunlin; Chirik, P. J. Synthesis, Structure, and Hydrogenolysis of Pyridine Dicarbene Iron Dialkyl Complexes. Organometallics 2019, 38, 3159-3168.

73. See Chapter 2 of this dissertation for details regarding the coordination environment enforced by PDP ligands in a $\kappa^{3}$ coordination mode.

74. Addison, A. W.; Rao, T. N.; Reedjik, J.; van Rijn, J.; Verschoor, G. C. Synthesis, Structure, and Spectroscopic Properties of Copper(II) Compounds Containing Nitrogen-Sulphur Donor Ligands; the Crystal and Molecular Structure of Aqua[1,7-bis( $N$-methylbenzimidazol-2'-yl)-2,6dithiaheptane]Copper(II) Perchlorate. J. Chem. Soc., Dalton Trans., 1984, 1349-1356.

75. Friscourt, F,; Christoph J. Fahrni, C. J.; Boons, G. J. Fluorogenic Strain-Promoted AlkyneDiazo Cycloadditions. Chem. Eur. J. 2015, 40, 13996-14001.

76. APEX3: Crystallographic Software Package for Single Crystal Data Collection, Reduction and Preparation, version 2016.9-0; Bruker AXS: Madison, WI, 2016.

77. Sheldrick, G. M. SHELXL-2014: Crystallographic Software Package; Bruker AXS, Inc.: Madison, WI, 2014.

78. Neese, F. The ORCA Program System. Wiley Interdiscip. Rev. Comput. Mol. Sci. 2012, 2 , 73-78.

79. Becke, A. D. Density Functional Calculations of Molecular Bond Energies. J. Chem. Phys. 1986, 84, 4524-4529. 
80. Becke, A. D. Density-Functional Thermochemistry. III. The Role of Exact Exchange. J. Chem. Phys. 1993, 98, 5648-5652.

81. Lee, C.; Yang, W.; Parr, R. G. Development of the Colle-Salvetti Correlation-Energy Formula into a Functional of the Electron Density. Phys. Rev. B: Condens. Matter Mater. Phys. 1988, 37, 785-789.

82. Schäfer, A.; Horn, H.; Ahlrichs, R. Fully Optimized Contracted Gaussian-Basis Sets for Atoms Li to Kr. J. Chem. Phys. 1992, 97, 2571-2577.

83. Schäfer, A.; Huber, C.; Ahlrichs, R. Fully Optimized Contracted Gaussian Basis Sets of Triple Zeta Valence Quality for Atoms Li to Kr. J. Chem. Phys. 1994, 100, 5829.

84. Weigend, F.; Ahlrichs, R. Balanced Basis Sets of Split Valence, Triple Zeta Valence and Quadruple Zeta Valence Quality for H to Rn: Design and Assessment of Accuracy. Phys. Chem. Chem. Phys. 2005, 7, 3297-3305.

85. Neese, F.; Wennmohs, F.; Hansen, A.; Becker, U. Efficient, Approximate and Parallel Hartree-Fock and Hybrid DFT Calculations. A “Chain-of-Spheres” Algorithm for the HartreeFock Exchange. Chem. Phys. 2009, 356, 98-109.

86. Kossmann, S.; Neese, F. Comparison of Two Efficient Approximate Hartee-Fock Approaches. Chem. Phys. Lett. 2009, 481, 240-243.

87. Neese, F. An Improvement of the Resolution of the Identity Approximation for the Formation of the Coulomb Matrix. J. Comput. Chem. 2003, 24, 1740-1747.

88. Eichkorn, K.; Treutler, O.; Öhm, H.; Häser, M.; Ahlrichs, R. Auxiliary Basis Sets to Approximate Coulomb Potentials. Chem. Phys. Lett. 1995, 240, 283-289.

89. Eichkorn, K.; Treutler, O.; Öhm, H.; Häser, M.; Ahlrichs, R. Erratum: Auxiliary Basis Sets to Approximate Coulomb Potentials. Chem. Phys. Lett. 1995, 242, 652-660. 
90. Eichkorn, K.; Weigend, F.; Treutler, O.; Ahlrichs, R. Auxiliary Basis Sets for Main Row Atoms and Transition Metals and Their Use to Approximate Coulomb Potentials. Theor. Chem. Acc. 1997, 97, 119-124.

91. Ginsberg, A. P. Magnetic Exchange in Transition Metal Complexes 12. Calculation of Cluster Exchange Coupling Constants with the X $\alpha$-Scattered Wave Method. J. Am. Chem. Soc. 1980, 102, 111-117.

92. Noodleman, L.; Peng, C. Y.; Case, D. A.; Mouesca, J. M. Orbital Interactions, Electron Delocalization and Spin Coupling in Iron-Sulfur Clusters. Coord. Chem. Rev. 1995, 144, 199244.

93. Allouche, A.-R. Gabedit-A Graphical User Interface for Computational Chemistry Softwares. J. Comput. Chem. 2011, 32, 174-182.

94. Neese, F. Prediction and Interpretation of the ${ }^{57}$ Fe Isomer Shift in Mössbauer Spectra by Density Functional Theory. Inorg. Chim. Acta 2002, 337, 181-192.

95. Sinnecker, S.; Slep, L. D.; Bill, E.; Neese, F. Performance of Nonrelativistic and QuasiRelativistic Hybrid DFT for the Prediction of Electric and Magnetic Hyperfine Parameters in ${ }^{57}$ Fe Mössbauer Spectra. Inorg. Chem. 2005, 44, 2245-2254.

96. Römelt, M.; Ye, S.; Neese, F. Calibration of Modern Density Functional Theory Methods for the Prediction of ${ }^{57} \mathrm{Fe}$ Mössbauer Isomer Shifts: Meta-GGA and Double-Hybrid Functionals. Inorg. Chem. 2009, 48, 784-785. 


\section{CHAPTER VII: CONCLUDING REMARKS AND FUTURE OUTLOOKS}

This dissertation has presented the synthesis, characterization, and reactivity studies of a variety of homogenous pyridine dipyrrolide (PDP) ligated iron complexes. An emerging theme in this area is the propensity for the ${ }^{\mathrm{Mes}} \mathrm{PDP}^{\mathrm{Ph}}$ ligand to support iron complexes with unusual coordination environments and electronic structures, which arise from the planarity enforced by the meridional ${ }^{\mathrm{Mes}} \mathrm{PDP}^{\mathrm{Ph}}$ pincer ligand. Notable advances include the first examples of neutral square-planar high-spin $\mathrm{Fe}^{\mathrm{II}}$ complexes, $\left({ }^{\mathrm{Mes}} \mathrm{PDP}^{\mathrm{Ph}}\right) \mathrm{Fe}(\mathrm{thf})$ and $\left({ }^{\mathrm{Mes}} \mathrm{PDP}^{\mathrm{Ph}}\right) \mathrm{Fe}\left(\mathrm{OEt}_{2}\right)$ (Figure 7.1 and Chapter 2), reactive paramagnetic PDP Fe nitrene adducts such as ( $\left.{ }^{\mathrm{Mes}} \mathrm{PDP}^{\mathrm{Ph}}\right) \mathrm{Fe}(\mathrm{NMes})$ and $\left({ }^{\mathrm{Cl} 2 \mathrm{Ph}} \mathrm{PDP}{ }^{\mathrm{Ph}}\right) \mathrm{Fe}(\mathrm{NMes})$ (Figure 7.2 and Chapters 3 and 5), and the first example of a squareplanar iron carbene complex, $\left({ }^{\mathrm{Mes}} \mathrm{PDP}{ }^{\mathrm{Ph}}\right) \mathrm{Fe}\left(\mathrm{CPh}_{2}\right)$ (Figure 7.2 and Chapter 6).
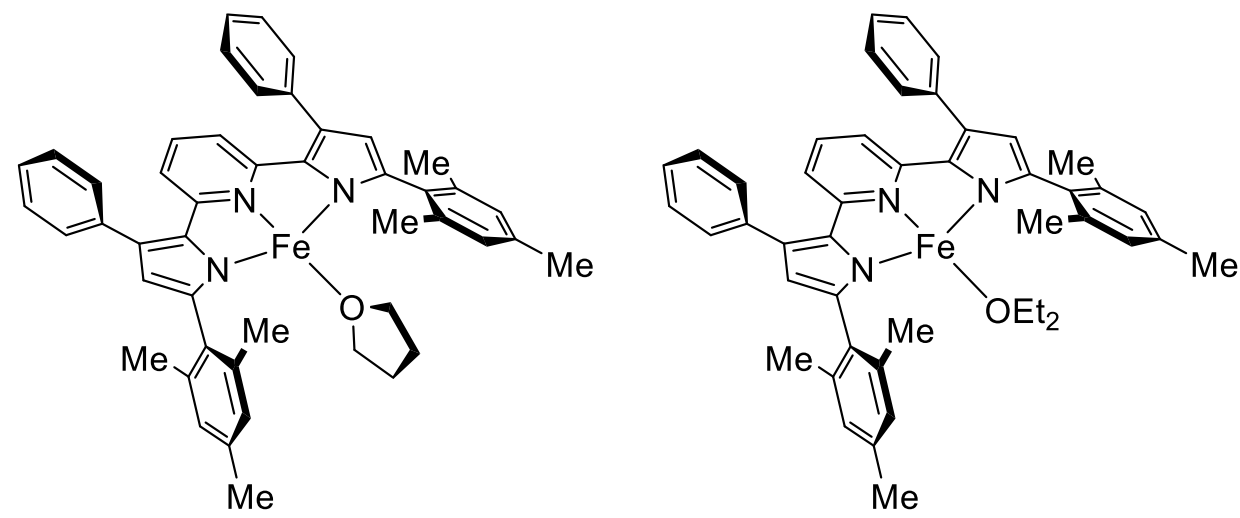

Figure 7.1. Neutral square-planar high-spin $\mathrm{Fe}^{\mathrm{II}}$ complexes $\left({ }^{\mathrm{Mes}} \mathrm{PDP}{ }^{\mathrm{Ph}}\right) \mathrm{Fe}(\mathrm{thf})(\mathrm{left})$ and $\left({ }^{\mathrm{Mes}} \mathrm{PDP}^{\mathrm{Ph}}\right) \mathrm{Fe}\left(\mathrm{OEt}_{2}\right)$ (right). 

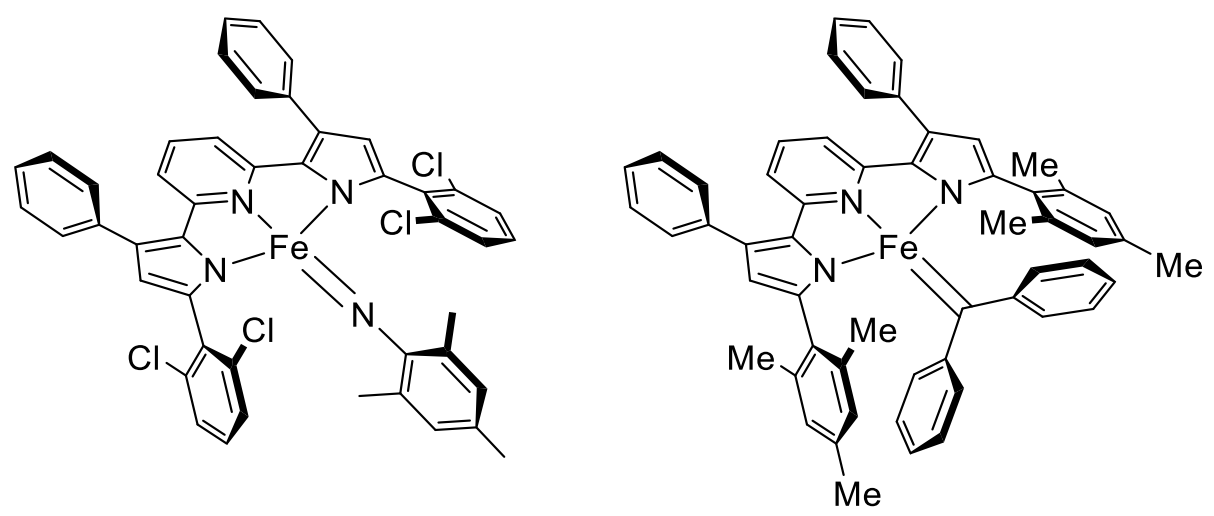

Figure 7.2. Paramagnetic PDP Fe nitrene complex $\left({ }^{\mathrm{Cl} 2 \mathrm{Ph}} \mathrm{PDP}{ }^{\mathrm{Ph}}\right) \mathrm{Fe}(\mathrm{NMes})(\mathrm{left})$ and square-planar iron carbene complex $\left({ }^{\mathrm{Mes}} \mathrm{PDP}{ }^{\mathrm{Ph}}\right) \mathrm{Fe}\left(\mathrm{CPh}_{2}\right)$ (right).

Chapter 2 has presented a thorough electronic structure study of $\left({ }^{\mathrm{Mes}} \mathrm{PDP}^{\mathrm{Ph}}\right) \mathrm{Fe}\left(\mathrm{OEt}_{2}\right)$ and $\left({ }^{\mathrm{Mes}} \mathrm{PDP}^{\mathrm{Ph}}\right) \mathrm{Fe}(\mathrm{thf})$. These species are the first reported examples of neutral square-planar highspin $\mathrm{Fe}^{\mathrm{II}}$ coordination compounds. Both complexes feature a doubly occupied $\mathrm{d}_{\mathrm{z} 2}$ orbital, accompanied by four singly occupied d orbitals, which account for the observed $\mathrm{S}=2$ ground states. Key consequences of the planar coordination environment imposed by the dianionic ${ }^{\text {Mes }} \mathrm{PDP}^{\mathrm{Ph}}$ ligand are the stabilization of the $\mathrm{d}_{\mathrm{x} 2-\mathrm{y} 2}$ orbital via geometric distortion, destabilization of the $\mathrm{d}_{\mathrm{xy}}$ orbital via $\sigma$ donation, and stabilization of the $\mathrm{d}_{\mathrm{xy}} / \mathrm{d}_{\mathrm{yz}}$ orbitals via $\pi$ donation. In combination, these elements result in a compressed ligand field with an energetically accessible $\mathrm{d}_{\mathrm{x} 2-\mathrm{y} 2}$ orbital. This phenomena is in contrast to canonical square-planar coordination compounds which are characterized by a significantly destabilized $\mathrm{d}_{\mathrm{x} 2-\mathrm{y} 2}$ orbital and consequently, intermediate-spin $\mathrm{S}=1$ ground states for $\mathrm{Fe}^{\mathrm{II}}$ ions.

$\left({ }^{\mathrm{Mes}} \mathrm{PDP}^{\mathrm{Ph}}\right) \mathrm{Fe}(\mathrm{NMes})$ and other related PDP iron nitrene adducts have been implicated as reactive intermediates in the stoichiometric intramolecular $\mathrm{C}-\mathrm{H}$ amination of the supporting ligand scaffold (Chapter 3). These observations serve as a foundation for future investigations concerning productive intramolecular or intermolecular $\mathrm{C}-\mathrm{H}$ amination reactivity, or furthermore, the development of catalytic methodologies for $\mathrm{C}-\mathrm{N}$ bond formation. It is 
anticipated that judicious selection of appropriate azides as nitrene sources in conjunction with robust PDP iron complexes lacking weak $\mathrm{C}-\mathrm{H}$ bonds on the ligand periphery will be key design elements of such systems. Furthermore, successful development of these methodologies may perhaps find application in the synthesis of elaborate $\mathrm{N}$-heterocycles, which are ubiquitous in biologically relevant molecules. For example, Figure 7.3 demonstrates a possible stoichiometric synthesis of iron-bound 2,2-dimethyl-5-phenyl-pyrrolidine, from (4-azido-4methylpentyl)benzene via a proposed intermediate $\left({ }^{\mathrm{C} 2 \mathrm{Ph}} \mathrm{PDP}^{\mathrm{Ph}}\right)$ iron nitrene complex.

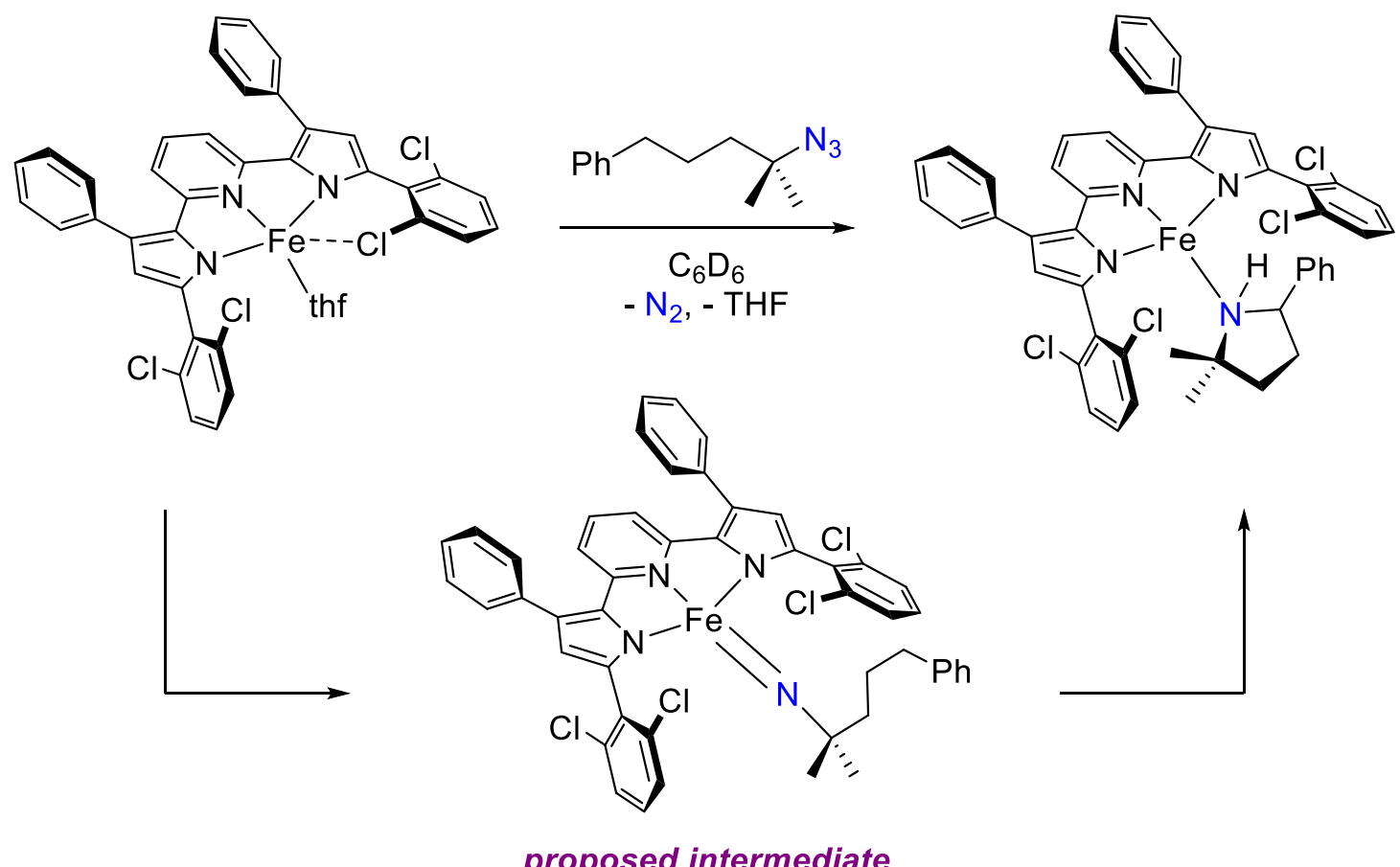

Figure 7.3. Stoichiometric synthesis of iron-bound 2,2-dimethyl-5-phenyl-pyrrolidine from 4-azido-4-methylpentylbenzene via a proposed intermediate $\left({ }^{\mathrm{Cl} 2 \mathrm{Ph}} \mathrm{PDP}{ }^{\mathrm{Ph}}\right)$ iron nitrene intermediate.

The synthesis of a coordinatively unsaturated four-coordinate pincer ligand supported iron carbene complex, $\left({ }^{\mathrm{Mes}} \mathrm{PDP}^{\mathrm{Ph}}\right) \mathrm{Fe}\left(\mathrm{CPh}_{2}\right)$, is an important advancement in the chemistry of iron carbenes. Despite decades of study, previously reported examples of iron carbene complexes have largely been limited to systems featuring saturated coordination spheres, or macrocyclic 
supporting ligands. Importantly, these coordination motifs disallow the cis-coordination of substrate molecules, a necessity for many catalytic mechanisms. Despite the known stability of iron carbenes supporting the diphenyl carbene fragment, it is anticipated that elaboration of the identity of the carbene substituents in other PDP iron carbene complexes will lead to increased activity in carbene transfer reactions. Moreover, the existence of discrete PDP iron carbene complexes suggests that high-spin $\mathrm{Fe}^{\mathrm{II}} \mathrm{PDP}$ complexes may be utilized as precatalysts in conjunction with diazo reagents to generate PDP iron carbene intermediates in a catalytic fashion. Leveraging such intermediates in cyclopropanation or $\mathrm{C}-\mathrm{H}$ insertion reactions would offer attractive alternatives to popular precious metal catalyst based methodologies. A proposed catalytic cyclopropanation of styrene using methyl phenyldiazoacetate and $\left({ }^{\mathrm{Mes}} \mathrm{PDP}^{\mathrm{Ph}}\right) \mathrm{Fe}(\mathrm{thf})$ as precatalyst is depicted below in Figure 7.4.

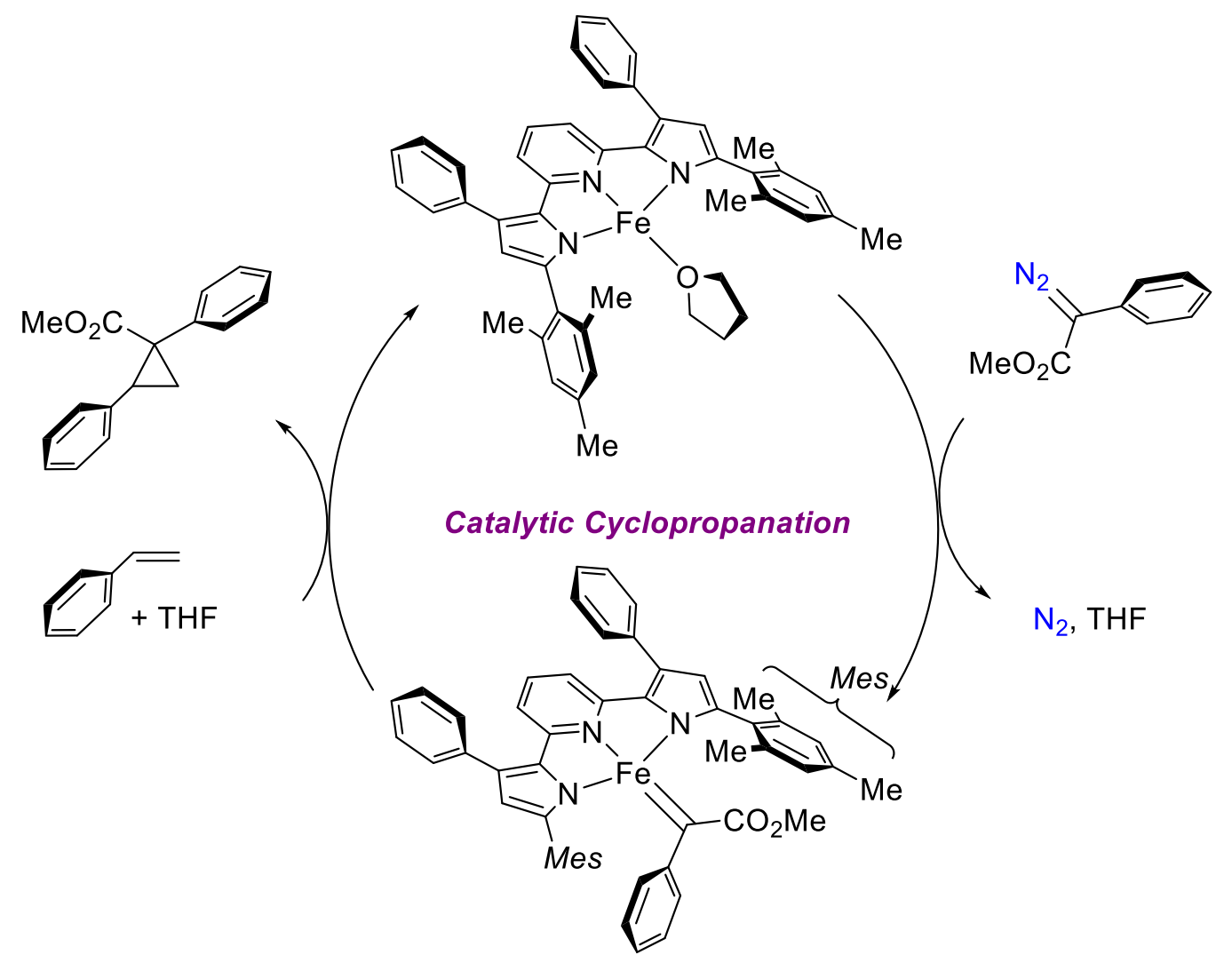

Figure 7.4. Proposed $\left({ }^{\mathrm{Mes}} \mathrm{PDP}^{\mathrm{Ph}}\right) \mathrm{Fe}(\mathrm{thf})$ catalyzed cyclopropanation of styrene using methyl phenyldiazoacetate Note, stereochemistry of the cyclopropane product is ambiguous. 
Note that a 4-methoxyphenyl substituted analogue to the carbene intermediate in this proposed catalytic cycle has been synthesized by the reaction of $\left({ }^{\mathrm{Mes}} \mathrm{PDP}{ }^{\mathrm{Ph}}\right) \mathrm{Fe}(\mathrm{thf})$ with the corresponding diazo reagent, methyl 4-methoxyphenyldiazoacetate (Scheme 7.1). This species, $\left({ }^{\mathrm{Mes}} \mathrm{PDP}{ }^{\mathrm{Ph}}\right) \mathrm{Fe}\left(\mathrm{C}\left(\mathrm{CO}_{2} \mathrm{Me}\right)(4-\mathrm{MeOPh})\right)$, was characterized by X-ray crystallography and an ORTEP diagram is presented in Figure A.2.11. (Appendix II). This result offers an exciting entry into future carbene group transfer reactivity studies of PDP iron complexes carrying donoracceptor carbene fragments, of which, $\left({ }^{\mathrm{Mes}} \mathrm{PDP}{ }^{\mathrm{Ph}}\right) \mathrm{Fe}\left(\mathrm{C}\left(\mathrm{CO}_{2} \mathrm{Me}\right)(4-\mathrm{MeOPh})\right)$ is the first known crystallographically characterized example.

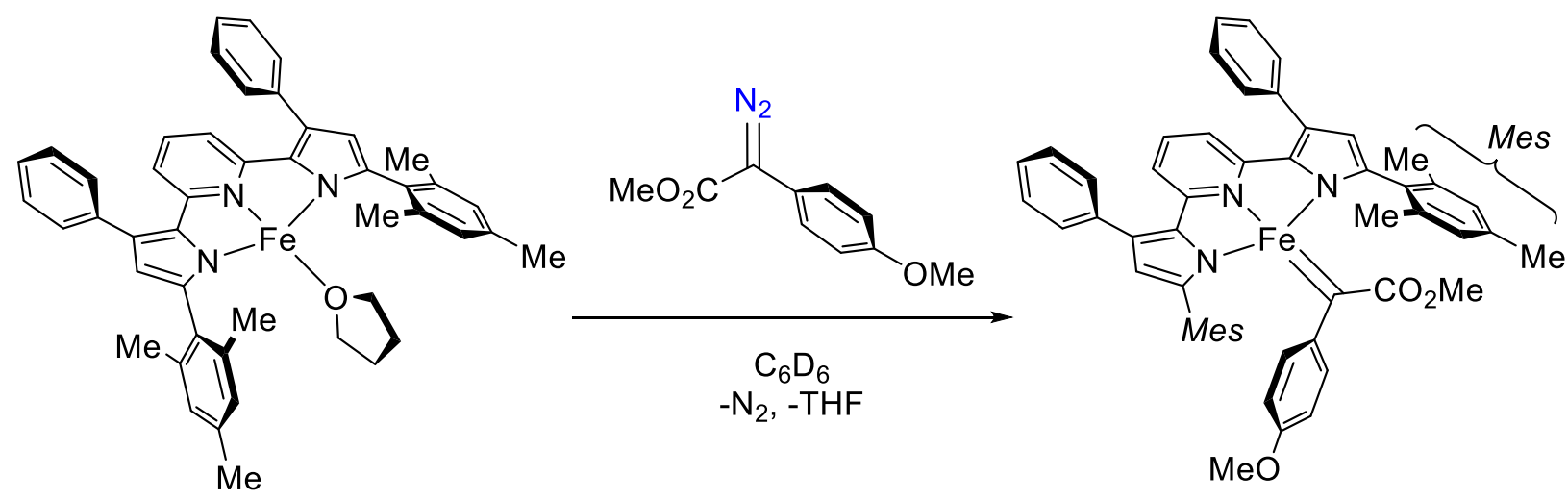

Scheme 7.1. Synthesis of $\left({ }^{\mathrm{Mes}} \mathrm{PDP}{ }^{\mathrm{Ph}}\right) \mathrm{Fe}\left(\mathrm{C}\left(\mathrm{CO}_{2} \mathrm{Me}\right)(4-\mathrm{MeOPh})\right)$ from $\left({ }^{\mathrm{Mes}} \mathrm{PDP}{ }^{\mathrm{Ph}}\right) \mathrm{Fe}($ thf $)$ and methyl 4-methoxyphenyldiazoacetate. 


\section{APPENDIX I: SYNTHESIS AND CHARACTERIZATION OF A REDUCED PYRIDINE DIPYRROLIDE IRON TETRAZENE COMPLEX}

\section{A.1.1 Abstract}

The pyridine bispyrrolide iron tetrazene complexes, of general formula $\left({ }^{\mathrm{Mes}} \mathrm{PDP}^{\mathrm{Ph}}\right) \mathrm{Fe}\left(\mathrm{N}_{4} \mathrm{Ar} \mathrm{r}_{2}\right)$ or $\left({ }^{2,6 \mathrm{Cl} 2 \mathrm{Ph}} \mathrm{PDP}{ }^{\mathrm{Ph}}\right) \mathrm{Fe}\left(\mathrm{N}_{4} \mathrm{Ar}_{2}\right)$ obtained from the reaction of $\left({ }^{\mathrm{R}} \mathrm{PDP}{ }^{\mathrm{Ph}}\right) \mathrm{Fe}(\mathrm{L})$, where $\mathrm{L}$ is a diethyl ether or tetrahydrofuran ligand and $\mathrm{R}^{\prime}$ is $2,6-\mathrm{Cl}_{2} \mathrm{Ph}$ or $2,4,6$-trimethylphenyl (Mes), with two equivalents of an aryl azide, have been found to possess a complex electronic structure. The proposed ground state configuration of a low-spin iron (III) iron antiferromagnetically coupled to a tetrazene based radical monoanion, $\left(\mathrm{N}_{4} \mathrm{Ar}^{-*}\right)$, has been adopted based on high resolution X-ray crystallographic analysis, ${ }^{57} \mathrm{Fe}$ Mössbauer spectroscopy, and a density functional theory study performed on the representative complex $\left({ }^{\mathrm{Mes}} \mathrm{PDP}^{\mathrm{Ph}}\right) \mathrm{Fe}\left(\mathrm{N}_{4} \mathrm{Tol}_{2}\right)$. Access to a representative reduced pyridine dipyrrolide iron tetrazene species was permitted via chemical reduction of $\left({ }^{\mathrm{Mes}} \mathrm{PDP}^{\mathrm{Ph}}\right) \mathrm{Fe}\left(\mathrm{N}_{4} \mathrm{Tol}_{2}\right)$ with cobaltocene, yielding the separated ion-pair $\left[\mathrm{CoCp}_{2}\right]\left[\left({ }^{\mathrm{Mes}} \mathrm{PDP}{ }^{\mathrm{Ph}}\right) \mathrm{Fe}\left(\mathrm{N}_{4} \mathrm{Tol}_{2}\right)\right] .{ }^{1} \mathrm{H}$ NMR obviated the paramagnetic ground state of this complex, while a combination of magnetic measurements, X-ray crystallography, and ${ }^{57} \mathrm{Fe}$ Mössbauer spectroscopy suggest an electronic structure formulation of a high-spin iron(III) ion and closed-shell dianionic tetrazene ligand, $\left(\mathrm{N}_{4} \mathrm{Tol}_{2}{ }^{2-}\right)$.

\section{A.1.2 Introduction}

Iron tetrazene complexes, once rare, have become more frequently encountered due to the surge of research in the area of iron imido chemistry. This type of compound is believed to arise from the $[2+3]$ cycloaddition of an iron imide intermediate with an organic azide. Recently, iron tetrazene complexes have become an attractive target of synthetic chemists, due to their complex 
electronic structures and applications in catalysis. ${ }^{1-7}$ Similar to the alpha-diimine class of ligands, tetrazenes possess an extended pi system, and thus have been identified as potentially redoxactive. Accordingly, to date, iron complexes have been isolated carrying neutral, radical anionic, and dianionic forms of tetrazene ligands (Scheme Scheme A.1.1. and Figure A.1.1.).

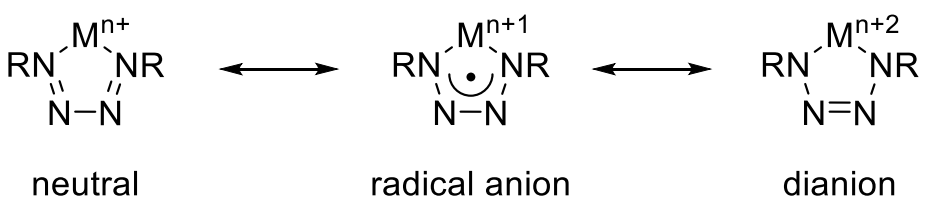

Scheme A.1.1. Possible formal electronic configurations of a tetrazene ligand complexed to a metal center.

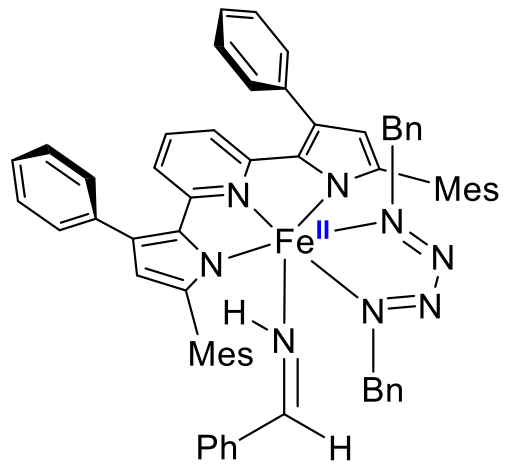

neutral

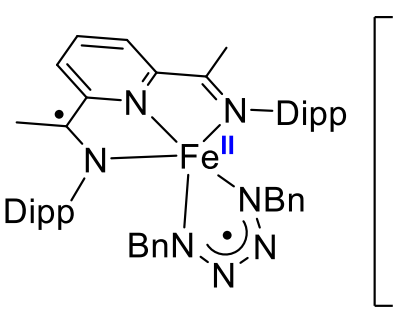

$\left[\begin{array}{r}\text { Dipp } \\ \text { AdN }\end{array}\right.$

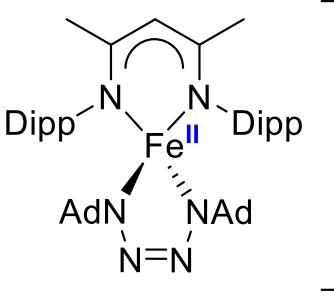

dianion

Figure A.1.1. Examples of $\mathrm{Fe}^{\mathrm{II}}$ complexes carrying neutral, radical anion, and dianionic tetrazene ligands. Note: Mes = mesityl, $\mathrm{Bn}=$ benzyl, $\mathrm{Dipp}=2,6$-diisopropylphenyl, $\mathrm{Ad}=1$-adamantyl .

In chapters 3 and 5 of this dissertation, the synthesis and characterization of $\left.\left({ }^{\mathrm{Mes}} \mathrm{PDP}^{\mathrm{Ph}}\right) \mathrm{Fe}\left(\mathrm{N}_{4} \mathrm{pTol} \mathrm{T}_{2}\right),{ }^{2,6-\mathrm{Cl} 2 \mathrm{Ph}} \mathrm{PDP}^{\mathrm{Ph}}\right) \mathrm{Fe}\left(\mathrm{N}_{4}(\mathrm{pFPh})_{2}\right)$, and $\left({ }^{2,6-\mathrm{Cl} 2 \mathrm{Ph}} \mathrm{PDP}^{\mathrm{Ph}}\right) \mathrm{Fe}\left(\mathrm{N}_{4}\left(\mathrm{p}^{\mathrm{t} B u P h}\right)_{2}\right)$, has been described. A combination of X-ray crystallography, ${ }^{1} \mathrm{H}$ NMR, ${ }^{57} \mathrm{Fe}$ Mössbauer spectroscopy, and density functional theory calculations have elucidated the electronic structures of these complexes, best described as low-spin ferric ions antiferromagnetically coupled to 
tetrazene radical monoanions. Such an electronic structure has previously been unknown within the context of iron tetrazene coordination chemistry. In an effort to probe the redox-chemistry of $\left({ }^{\mathrm{Mes}} \mathrm{PDP}{ }^{\mathrm{Ph}}\right) \mathrm{Fe}\left(\mathrm{N}_{4} \mathrm{Tol}_{2}\right)$, its reductive chemistry was explored, resulting in the isolation of $\left[\mathrm{Co}(\mathrm{Cp})_{2}\right]\left[\left({ }^{\mathrm{Mes}} \mathrm{PDP}{ }^{\mathrm{Ph}}\right) \mathrm{Fe}\left(\mathrm{N}_{4} \mathrm{Tol}_{2}\right)\right]\left[\mathrm{Co}(\mathrm{Cp})_{2}\right]$. This appendix describes the synthesis and characterization of $\left[\mathrm{Co}(\mathrm{Cp})_{2}\right]\left[\left({ }^{\mathrm{Mes}} \mathrm{PDP}{ }^{\mathrm{Ph}}\right) \mathrm{Fe}\left(\mathrm{N}_{4} \mathrm{Tol}_{2}\right)\right]$.

\section{A.1.3 Synthesis and Characterization of $\left[\mathrm{CoCp}_{2}\right]\left[\left({ }^{\mathrm{Mes}} \mathrm{PDP}{ }^{\mathrm{Ph}}\right) \mathrm{Fe}\left(\mathrm{N}_{4} \mathrm{Tol}_{2}\right)\right]$}

The addition of one equivalent of cobaltocene to stirring solutions of $\left({ }^{\mathrm{Mes}} \mathrm{PDP}{ }^{\mathrm{Ph}}\right) \mathrm{Fe}\left(\mathrm{N}_{4} \mathrm{Tol}_{2}\right)$ in dichloromethane solvent was found to immediately induce a color change from dark red/brown to dark brown/green with concomitant precipitation of a black powder. Removal of volatiles in vacuo and subsequent washing of the resulting solid material with benzene and hexanes affording a black powder. Despite poor solubility in hydrocarbon solvents, low-quality ${ }^{1} \mathrm{H}$ NMR spectra in dichloromethane- $d_{2}$ clearly established the paramagnetic nature of the product. Single crystals suitable for X-ray diffraction were obtained from the same solvent and established the identity of the product as the separated ion pair $\left[\mathrm{CoCp}_{2}\right]\left[\left({ }^{\mathrm{Mes} P D P}{ }^{\mathrm{Ph}}\right) \mathrm{Fe}\left(\mathrm{N}_{4} \mathrm{Tol}_{2}\right)\right]$.

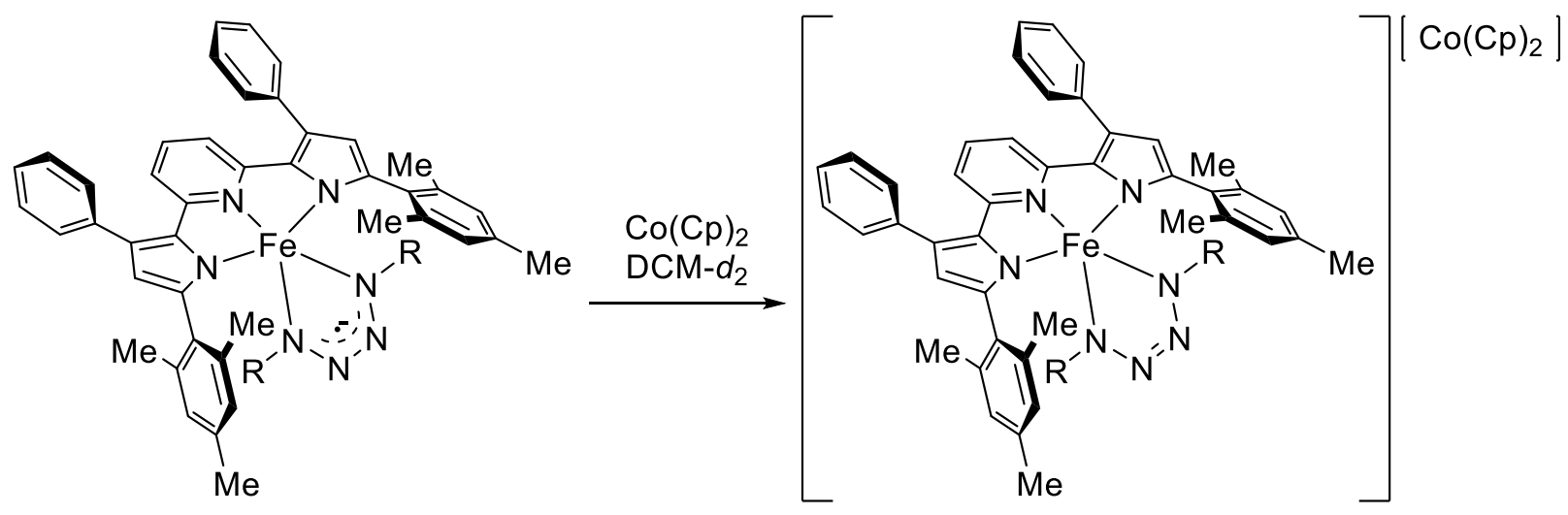

\footnotetext{
Scheme A.1.2. Synthesis of $\left.\left[\mathrm{Co}(\mathrm{Cp})_{2}\right]\left[{ }^{\mathrm{Mes}} \mathrm{PDP}^{\mathrm{Ph}}\right) \mathrm{Fe}\left(\mathrm{N}_{4} \mathrm{Tol}_{2}\right)\right]$. R denotes para-tolyl.
} 


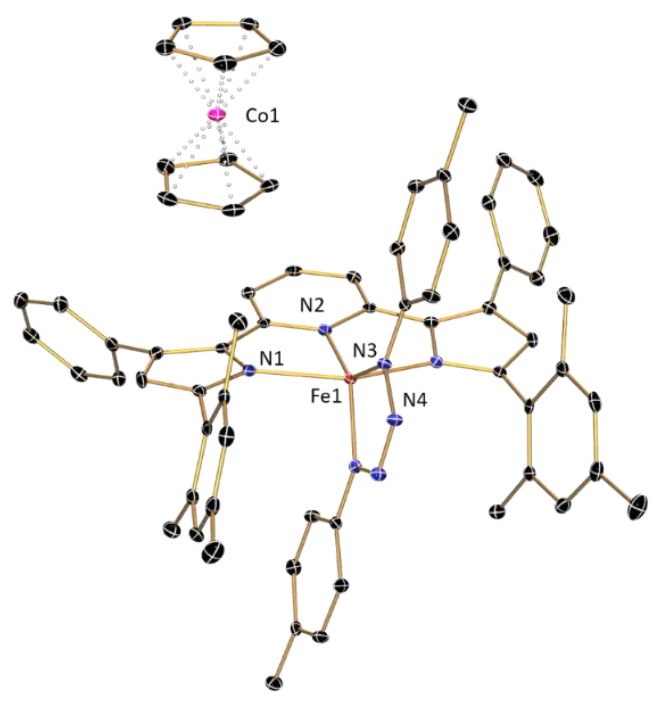

Figure A.1.2. ORTEP of $\left[\mathrm{Co}(\mathrm{Cp})_{2}\right]\left[\left({ }^{\mathrm{Mes}} \mathrm{PDP}^{\mathrm{Ph}}\right) \mathrm{Fe}\left(\mathrm{N}_{4} \mathrm{Tol}_{2}\right)\right]$ depicted at $30 \%$ probability ellipsoids. Hydrogen atoms were removed for clarity.

$\left[\mathrm{CoCp}_{2}\right]\left[\left({ }^{\mathrm{Mes}} \mathrm{PDP}{ }^{\mathrm{Ph}}\right) \mathrm{Fe}\left(\mathrm{N}_{4} \mathrm{Tol}_{2}\right)\right]$ crystallizes in the monoclinic space group $\mathrm{C} 2 / \mathrm{c}$ and adopts a trigonal bipyramidal structure in the solid state, with the $\left[\left({ }^{\mathrm{Mes}} \mathrm{PDP}{ }^{\mathrm{Ph}}\right) \mathrm{Fe}\left(\mathrm{N}_{4} \mathrm{Tol}_{2}\right)\right]$ anion lying on a two-fold rotation axis that passes through the Fe(1), N(2), and C(7) atoms. Similarly, the $\left[\mathrm{Co}(\mathrm{Cp})_{2}\right]$ cation is constrained by a two-fold rotation axis that passes through the $\mathrm{Co}(1)$ atom. Notable bond lengths include 2.119 (2) $\AA$ and 2.111 (3) $\AA$ to the pyrrolide and pyridine nitrogens from the iron center and 1.962 (2) A to the apical tetrazene nitrogen, N4. The relatively long iron pyridine and iron pyrrole bonds are consistent with a high-spin state for the iron center. Importantly, the N3-N4 bond length of 1.375 (3) $\AA$ and N4-N4' bond length of 1.283 (5) $\AA$. The N3-N4 bond length is consistent with the N-N single bond in 1,2-diphenylhydrazine (1.394 (7) $\AA)^{8}$, while the N4-N4' bond length is similar to the $\mathrm{N}=\mathrm{N}$ bond in cis azobenzene $(1.251 \AA)^{9}$ and is consistent with a double bond. These structural metrics are consistent with a description of the tetrazene ligand as a dianion, as evidenced by the alternating long, short, and long N-N bonds 
within the $\mathrm{N}_{4}$ chelate ligand. ${ }^{2}$ The combination of a dianionic tetrazene and dianionic pyridine dipyrrolide ligand infers a formal oxidation state of +3 for the iron center. The room-temperature solid-state magnetic moment of $6.1 \mu_{\mathrm{B}}$ is consistent with a high-spin ferric center $(\mathrm{S}=5 / 2)$.

Table A.1.1. Selected bond lengths $(\AA)$ and angles $(\mathrm{deg})$ for $\left[\mathrm{CoCp}_{2}\right]\left[\left({ }^{\mathrm{Mes}} \mathrm{PDP}^{\mathrm{Ph}}\right) \mathrm{Fe}\left(\mathrm{N}_{4} \mathrm{Tol}_{2}\right)\right]$

\begin{tabular}{cc}
\hline $\left.\mathrm{CoCp}_{2}\right]\left[\left({ }^{\mathrm{Mes} P D P}{ }^{\mathrm{Ph}}\right) \mathrm{Fe}\left(\mathrm{N}_{4} \mathrm{Tol}_{2}\right)\right]$ \\
\hline $\mathrm{Fe} 1-\mathrm{N} 1$ & $2.119(2)$ \\
$\mathrm{Fe} 1-\mathrm{N} 2$ & $2.111(3)$ \\
$\mathrm{N} 3-\mathrm{N} 4$ & $1.962(2)$ \\
$\mathrm{N} 4-\mathrm{N} 4{ }^{\prime}$ & $1.375(3)$ \\
$\mathrm{N} 1-\mathrm{Fe} 1-\mathrm{N} 2$ & $1.283(5)$ \\
$\mathrm{N} 1-\mathrm{Fe} 1-\mathrm{N} 3$ & $106.60(9)$ \\
$\mathrm{N} 2-\mathrm{Fe} 1-\mathrm{N} 3$ & $141.35(7)$ \\
$\mathrm{Fe} 1-\mathrm{N} 3-\mathrm{N} 4$ & $116.23(17)$ \\
$\mathrm{N} 3-\mathrm{N} 4-\mathrm{N} 4$ & $115.12(14)$
\end{tabular}

To further interrogate the electronic structure of $\left[\mathrm{Co}(\mathrm{Cp})_{2}\right]\left[\left({ }^{\mathrm{Mes}} \mathrm{PDP}^{\mathrm{Ph}}\right) \mathrm{Fe}\left(\mathrm{N}_{4} \mathrm{Tol}_{2}\right)\right]$ a zerofield Mössbauer spectrum (Figure A.1.3.) was acquired of a powder sample of at $80 \mathrm{~K}$. The resulting spectrum is contains a broad asymmetric feature which was fitted with $\delta=0.45 \mathrm{mms}^{-1}$ and $\left|\Delta \mathrm{E}_{\mathrm{Q}}\right|=2.83 \mathrm{mms}^{-1}$. The isomer shift of $0.45 \mathrm{mms}^{-1}$ is consistent with the isomer shift value of $0.39(1) \mathrm{mms}^{-1}$ for $\left.{ }^{(\mathrm{Bu}} \mathrm{PDP}^{\mathrm{tBu}}\right) \mathrm{Fe}(\mathrm{Cl})$, the only previously reported example of a high-spin $\mathrm{Fe}^{\mathrm{III}}$ PDP iron complex. Notably, $\left.{ }^{\mathrm{tBu}} \mathrm{PDP}^{\mathrm{tBu}}\right) \mathrm{Fe}(\mathrm{Cl})$ also displays an asymmetric Mossbauer spectrum at $77 \mathrm{~K}$, as indicated by linewidths ( $\left.\Gamma_{\mathrm{FWHM}}\right)$ of $0.74(1)$ and $1.24(1) \mathrm{mms}^{-1}$, however, these linewidths are not nearly as extreme as the linewidths of $\Gamma_{\mathrm{L}}=1.86 \mathrm{mms}^{-1}$ and $\Gamma_{\mathrm{R}}=3.95 \mathrm{mms}^{-1}$ 
obtained from the fit of the $80 \mathrm{~K}$ spectrum of $\left[\mathrm{Co}(\mathrm{Cp})_{2}\right]\left[\left({ }^{\mathrm{Mes}} \mathrm{PDP}^{\mathrm{Ph}}\right) \mathrm{Fe}\left(\mathrm{N}_{4} \mathrm{Tol}_{2}\right)\right] \cdot{ }^{10}$ Furthermore, asymmetric Mössbauer spectra have been well documented within the context of similar highspin $\mathrm{Fe}^{\mathrm{III}}(\mathrm{S}=5 / 2)$ porphyrin complexes. The manifestation of asymmetry in the Mössbauer spectra of these species has been explained theoretically as resulting from a slowing of temperature dependent spin-spin relaxation times. ${ }^{11-14}$ Thus, the appearance of a broad and asymmetric feature in the Mössbauer spectrum of $\left[\mathrm{Co}(\mathrm{Cp})_{2}\right]\left[\left(^{\mathrm{Mes}} \mathrm{PDP}^{\mathrm{Ph}}\right) \mathrm{Fe}\left(\mathrm{N}_{4} \mathrm{Tol}_{2}\right)\right]$ provides additional evidence for the assignment of a high-spin ferric state for the iron center of this complex.

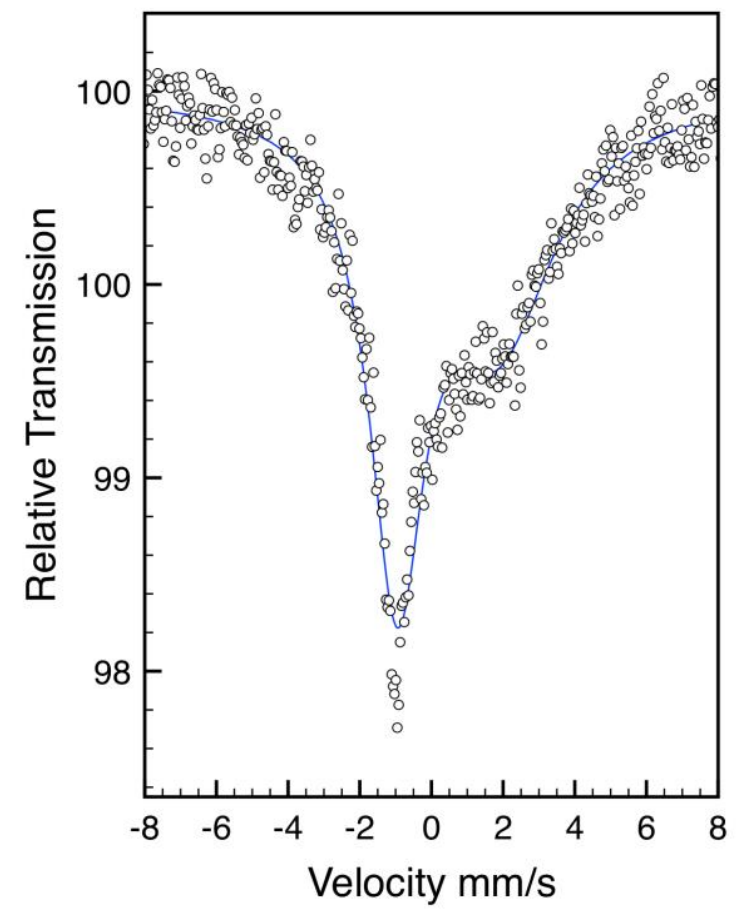

Figure A.1.3. Zero-field ${ }^{57} \mathrm{Fe}$ Mössbauer spectrum of $\left[\mathrm{Co}(\mathrm{Cp})_{2}\right]\left[\left({ }^{\mathrm{Mes}} \mathrm{PDP}{ }^{\mathrm{Ph}}\right) \mathrm{Fe}\left(\mathrm{N}_{4} \mathrm{Tol}_{2}\right)\right]$ acquired at $80 \mathrm{~K}$. 


\section{A.1.4 Experimental Procedures}

\section{General Considerations}

All air- and moisture-sensitive manipulations were carried out using standard Schlenk line and cannula techniques or in an MBraun inert atmosphere drybox containing an atmosphere of purified nitrogen. Solvents for air- and moisture-sensitive manipulations were dried and deoxygenated using a Glass Contour Solvent Purification System and stored over 4 A molecular sieves. All solids were dried under high vacuum; all liquids were dried over $\mathrm{CaH}_{2}$ and vacuum transferred into oven-dried glassware in order to bring into the glovebox. $\operatorname{Co}(\mathrm{Cp})_{2}$ was obtained from commercial sources and used as received. Deuterated benzene (benzene- $d_{6}$ ) and dichloromethane (dichloromethane- $d_{2}$ ) for NMR spectroscopy were distilled from sodium metal and calcium hydride, respectively. $\left({ }^{\mathrm{Mes}} \mathrm{PDP}{ }^{\mathrm{Ph}}\right) \mathrm{Fe}\left(\mathrm{N}_{4} \mathrm{Tol}_{2}\right)$ was prepared according to the previously reported procedure. ${ }^{15}$

\section{Preparation of $\left[\mathrm{Co}(\mathrm{Cp})_{2}\right]\left[\left({ }^{\mathrm{Mes}} \mathrm{PDP} \mathrm{Ph}^{\mathrm{Ph}}\right) \mathrm{Fe}\left(\mathrm{N}_{4} \mathrm{Tol}_{2}\right)\right]$.}

In the glovebox, $100 \mathrm{mg}(0.112 \mathrm{mmol})$ of $\left({ }^{\mathrm{Mes}} \mathrm{PDP}^{\mathrm{Ph}}\right) \mathrm{Fe}\left(\mathrm{N}_{4} \mathrm{Tol}_{2}\right)$ was dissolved in $5 \mathrm{~mL}$ of dichloromethane in a $20 \mathrm{~mL}$ scintillation vial equipped with a magnetic stirrer. In a separate via, $21 \mathrm{mg}(0.111 \mathrm{mmol})$ of cobaltocene was dissolved in $1 \mathrm{~mL}$ of dichloromethane. The cobaltocene solution was added dropwise to the stirring solution of ( $\left.{ }^{\mathrm{Mes}} \mathrm{PDP}^{\mathrm{Ph}}\right) \mathrm{Fe}\left(\mathrm{N}_{4} \mathrm{Tol}_{2}\right)$, inducing an immediate color change from dark red/brown to brown/green. The reaction mixture was stirred for one hour and the solvent was then removed in vacuo, affording a dark powder. The resulting powder was transferred to a medium porosity glass frit and washed with $20 \mathrm{~mL}$ of benzene and $20 \mathrm{~mL}$ of hexanes and dried in vacuo. Yield: $91 \mathrm{mg}, 0.084 \mathrm{mmol}, 76 \% . \mu_{\mathrm{eff}}=6.1 \mu_{\mathrm{B}}$ (298 K, magnetic susceptibility balance). A crystal suitable for study via X-ray diffraction was obtained from a concentrated solution of dichloromethane. 


\section{Physical Measurements.}

${ }^{1} \mathrm{H}$ and ${ }^{13} \mathrm{C}\left\{{ }^{1} \mathrm{H}\right\}$ NMR spectra were acquired at $25{ }^{\circ} \mathrm{C}$ on a Varian Unity INOVA 600 $\mathrm{MHz}$ spectrometer equipped with a $5 \mathrm{~mm}$ inverse broadband PFG probe, on an Agilent $400 \mathrm{MHz}$ DD2 spectrometer equipped with a $5 \mathrm{~mm}$ One NMR probe, or a JNM-ECZ400S/L1 spectrometer equipped with a $5 \mathrm{~mm}$ ROYAL NMR probe. All chemical shifts are reported relative to $\mathrm{SiMe}_{4}$ using ${ }^{1} \mathrm{H}$ (residual) chemical shifts of the solvent as a secondary standard. Room temperature magnetic susceptibility measurements were performed with a Johnson Matthey Mark 1 instrument that was calibrated with $\mathrm{HgCo}(\mathrm{SCN})_{4}$. Zero-field ${ }^{57} \mathrm{Fe}$ Mössbauer spectra were collected on a SEE Co. Mössbauer spectrometer (MS4) with a ${ }^{57} \mathrm{Co} / \mathrm{Rh}$ radiation source at $80 \mathrm{~K}$ in constant acceleration mode. The temperature in the sample chamber was controlled by a Janis Research Co. CCS-850 He/ $\mathrm{N}_{2}$ cryostat within an accuracy of $\pm 0.3 \mathrm{~K}$. The data were calibrated relative to $\alpha$-iron at $298 \mathrm{~K}$. The fitting procedure to extract quantitative spectral parameters uses a least-squares Lorentzian fitting method implemented in the WMOSS software developed by SEE Co.

\section{X-ray Crystallography.}

Single crystals suitable for X-ray diffraction were coated with polyisobutylene oil (Sigma-Aldrich) in a drybox, mounted on a nylon loop, and then quickly transferred to the goniometer head of a Bruker AXS D8 Venture fixed-chi X-ray diffractometer equipped with a Triumph monochromator, a Mo K $\alpha$ radiation source $(\lambda=0.71073 \AA)$, and a PHOTON 100 CMOS detector. The samples were cooled to $100 \mathrm{~K}$ with an Oxford Cryostream 700 system and optically aligned. The APEX3 software program (version 2016.9-0) ${ }^{16}$ was used for diffractometer control, preliminary frame scans, indexing, orientation matrix calculations, leastsquares refinement of cell parameters, and the data collection. Three sets of 12 frames each were 
collected using the omega scan method with a $10 \mathrm{~s}$ exposure time. Integration of these frames followed by reflection indexing and least-squares refinement produced a crystal orientation matrix for the crystal lattice that was used for the structural analysis. The data collection strategy was optimized for completeness and redundancy using the Bruker COSMO software suite. The space group was identified, and the data were processed using the Bruker SAINT+ program and corrected for absorption using SADABS. The structures were solved using direct methods (SHELXS) completed by subsequent Fourier synthesis and refined by full-matrix least-squares procedures using the programs provided by SHELXL-2014. ${ }^{17}$ 


\section{References}

1. Mock, M. T.; Popescu, C. V.; Yap, G. P. A.; Dougherty, W. G.; Riordan, C. G. Monovalent Iron in a Sulfur Rich Environment. Inorg. Chem. 2008, 47, 1889-1891.

2. Cowley, R. E.; Bill, E.; Neese, F.; Brennessel, W. W.; Holland, P. L. Iron(II) Complexes with Redox-Active Tetrazene (RNNNNR) Ligands. Inorg. Chem., 2009, 48, 4828-4836.

3. Bowman, A. C.; Tondreau, A. M.; Lobkovsky, E.; Margulieux, G. W.; Chirik, P. J. Synthesis and Electronic Structure Diversity of Pyridine(diimine)iron Tetrazene Complexes. Inorg. Chem. 2018, 57, 9634-9643.

4. Cramer, S. A.; Sanchez, R. H.; Brakhage, D. F.; Jenkins, D. M. Probing the Role of an Fe ${ }^{\mathrm{IV}}$ Tetrazene in Catalytic Aziridination. Chem. Comm., 2014, 50, 13967-13970.

5. Chandrachud, Preeti P.; Bass, Heather M; Jenkins, David M. Synthesis of Fully Aliphatic Aziridines with a Macrocyclic Tetracarbene Iron Catalyst. Organometallics, 2016, 35, 16521657.

6. Isbill, Sara B.; Chandrachud, Preeti P.; Kern, Jesse L.; Jenkins, David M.; Roy, Sharani. Elucidation of the Reaction Mechanism of $\mathrm{C}_{2}+\mathrm{N}_{1}$ Aziridination from Tetracarbene Iron Catalysts. ACS Catal. 2019, 9, 6223-6233.

7. Yousif, M.; Wannipurage, D.; Huizenga, C. D.; Washnock-Schmid, E.; Peraino, N. J.;

Ozarowski, A.; Stoian S. A.; Lord, R. L.; Groysman, S. Catalytic Nitrene Homocoupling by an Iron(II) Bisalkoxide Complex: Bulking up the Alkoxide Enables a Wider Range of Substrates and Provides Insight into the Reaction Mechanism. Inorg. Chem. 2018, 57, 9425-9438.

8. Synthesis and Structure of Diarylboryl-Substituted Hydrazines and Diphosphanes: Role of $\sigma$ Orbital Hybridization and $\pi$-Orbital Overlap in N-N and P-P Multiple-Bond Lengths Inorg.

Chem. 1991, 30, 528-535. 
9. Mostad, A.; Rømming, C. A Refinement of the Crystal Structure of cis-Azobenzene. Acta Chem. Scand. 1971, 25, 3561-3568.

10. Searles, K.; Fortier, S.; Khusniyarov, M. M.; Carroll, P. J.; Sutter, J.; Meyer, K.; Mindiola, D. J.; Caulton, K. G. A Cis-Divacant Octahedral and Mononuclear Iron(IV) Imide. Angew. Chem., Int. Ed. 2014, 53, 14139-14143.

11. Kaczmarzyk, T.; Jackowski, T.; Dziliński, K.; Sinyakov, G. N. Asymmetry in Mössbauer Spectra of Fe $\mathrm{III}^{\mathrm{III}}$ Azaporphyrin Complexes. Nukleonika 2007, 52, 93-98.

12. Kaczmarzyk, T.; Dziedzic-Kocurek, K.; Rutkowska, I.; Dziliński, K. Mössbauer Study of a Tetrakis (Pentafluorophenyl) Porphyrin Iron (III) Chloride in Comparison with the Fluorine Unsubstituted Analogue. Nukleonika 2015, 60, 57-61.

13. Blume, M. Temperature-Dependent Spin-Spin Relaxation Times: Application to the Mössbauer Spectra of Ferric Hemin. Phys. Rev. Lett. 1967, 18, 305-308.

14. Clauser, M. J.; Mössbauer, R. L. Pseudoquadrupole Shift and Asymmetric Line Broadening of Recoilless Nuclear Resonance Spectra. Phys. Rev. 1969, 178, 559-567.

15. Hakey, B. M.; Darmon, J. M.; Akhmedov, N. G.; Petersen, J. L.; Milsmann, C. Inorg. Chem. 2019, 58, 16, 110282-11042.

16. APEX3: Crystallographic Software Package for Single Crystal Data Collection, Reduction and Preparation, version 2016.9-0; Bruker AXS: Madison, WI, 2016.

17. Sheldrick, G. M. SHELXL-2014: Crystallographic Software Package; Bruker AXS, Inc.: Madison, WI, 2014. 


\section{CRYSTALLOGRAPHIC ANALYSIS}

cm31cms: $\left[\left({ }^{\mathrm{Me}} \mathrm{PDP}{ }^{\mathrm{Ph}}\right) \mathrm{Fe}\left(\mathrm{OEt}_{2}\right)\right]_{2}$
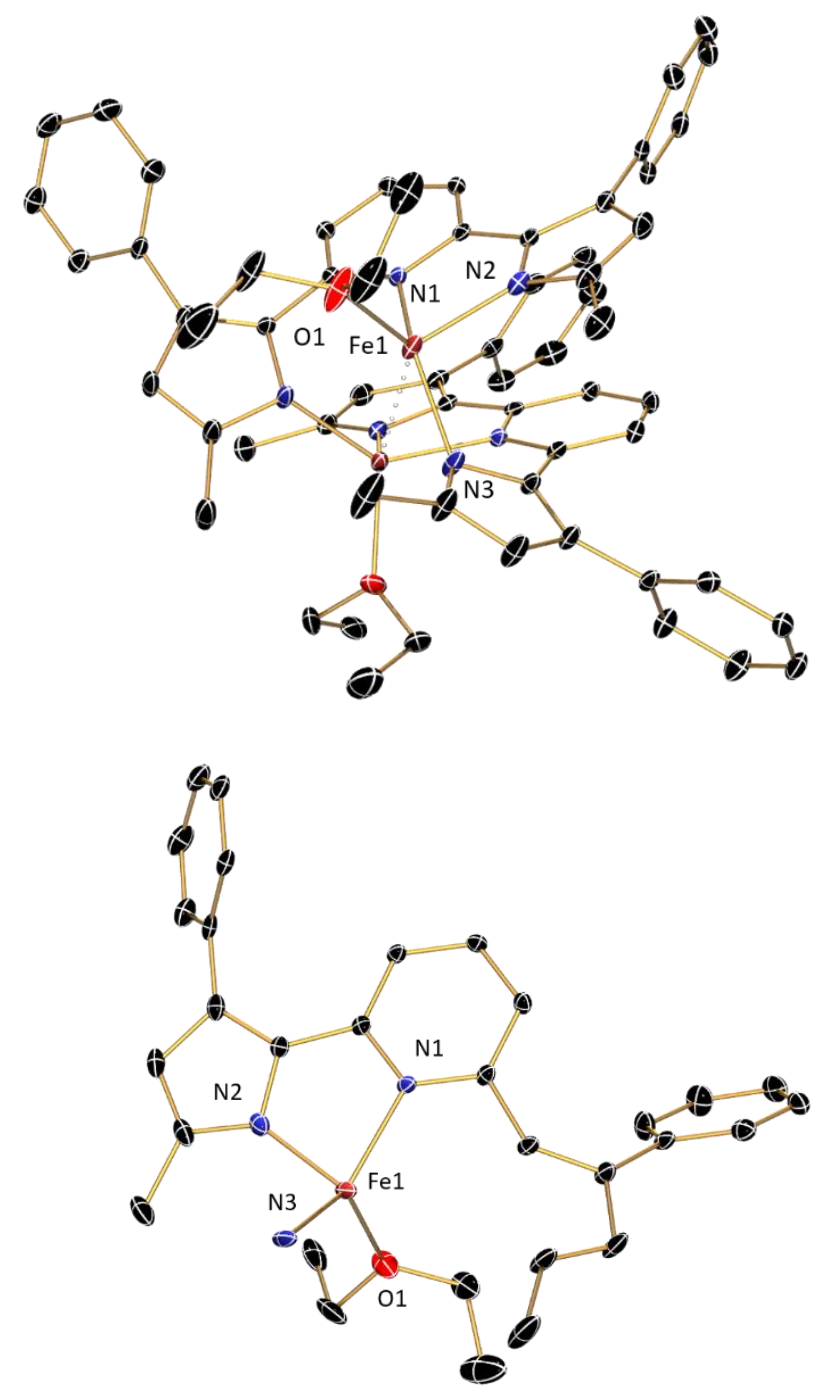

Figure A.2.1. ORTEP depictions of $\left[\left({ }^{\mathrm{Me}} \mathrm{PDP}{ }^{\mathrm{Ph}}\right) \mathrm{Fe}\left(\mathrm{OEt}_{2}\right)\right]_{2}$ and the asymmetric unit of $\left[\left({ }^{\mathrm{Me}} \mathrm{PDP}{ }^{\mathrm{Ph}}\right) \mathrm{Fe}\left(\mathrm{OEt}_{2}\right)\right]_{2}$ displayed at $30 \%$ probability ellipsoids. Hydrogen atoms are omitted for clarity. 
cm40cms: $\left({ }^{\mathrm{Me}} \mathrm{PDP}{ }^{\mathrm{Ph}}\right) \mathrm{Fe}(\mathrm{py})_{3}$

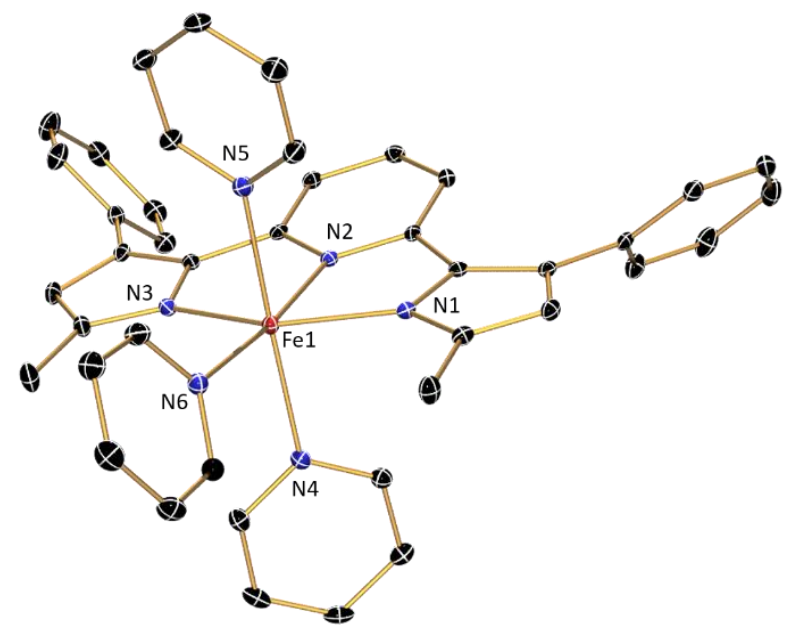

Figure A.2.2. ORTEP of $\left({ }^{\mathrm{Me}} \mathrm{PDP}{ }^{\mathrm{Ph}}\right) \mathrm{Fe}(\mathrm{py})_{3}$ displayed at $30 \%$ probability ellipsoids. Hydrogen atoms and cocrystallized fluorobenzene are omitted for clarity.

cm114cms: $\left({ }^{\mathrm{Mes}} \mathrm{PDP}{ }^{\mathrm{Ph}}\right) \mathrm{Fe}\left(\mathrm{NH}_{2} \mathrm{Bn}\right)_{3}$

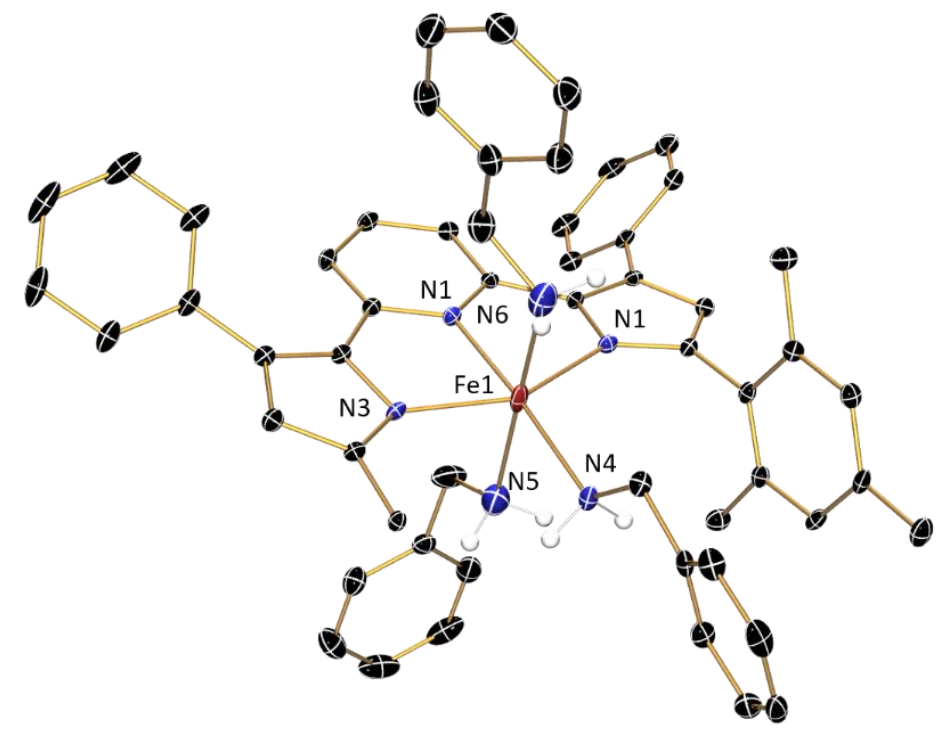

Figure A.2.3. ORTEP of $\left({ }^{\mathrm{Mes}} \mathrm{PDP}{ }^{\mathrm{Ph}}\right) \mathrm{Fe}\left(\mathrm{NH}_{2} \mathrm{Bn}\right)_{3}$ displayed at $30 \%$ probability ellipsoids. Hydrogen atoms, excluding amine protons are excluded for clarity. Only the ipso carbon of one mesityl substituent of the ${ }^{\mathrm{Mes}} \mathrm{PDP}^{\mathrm{Ph}}$ is depicted. 
cm141cms: $\left({ }^{\mathrm{Ph} P D P}{ }^{\mathrm{Ph}}\right) \mathrm{Fe}(\mathrm{thf})_{3}$

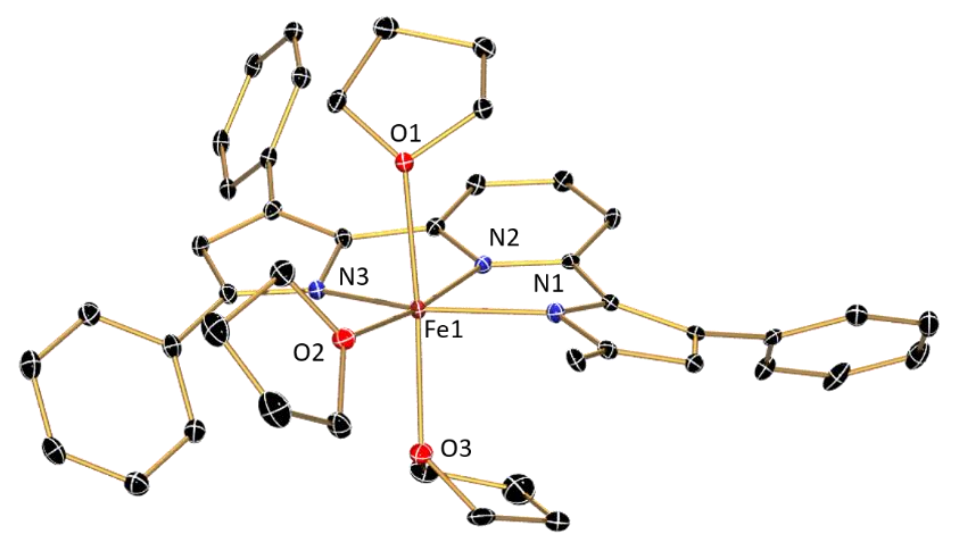

Figure A.2.4. ORTEP of $\left({ }^{\mathrm{Ph} P D P} \mathrm{Ph}^{\mathrm{P}}\right) \mathrm{Fe}(\mathrm{thf})_{3}$ displayed at $30 \%$ probability ellipsoids. Hydrogen atoms and cocrystallized THF solvent are omitted for clarity. Only the ipso carbon of one ${ }^{\mathrm{Ph} P D P}{ }^{\mathrm{Ph}}$ phenyl substituent is depicted.

cm158cms: $\left({ }^{\mathrm{Mes}} \mathrm{PDP}{ }^{\mathrm{Ph}}\right) \mathrm{Fe}(\mathrm{Cl})(\mathrm{py})$

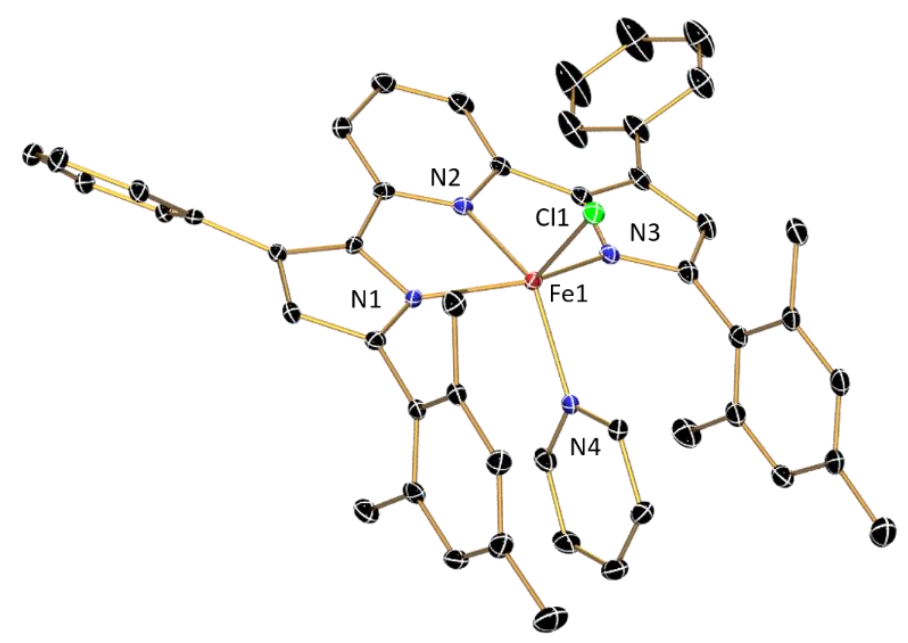

Figure A.2.5. ORTEP of $\left({ }^{\mathrm{Mes}} \mathrm{PDP}^{\mathrm{Ph}}\right) \mathrm{Fe}(\mathrm{Cl})($ py) displayed at $30 \%$ probability ellipsoids. Hydrogen atoms and cocrystallized THF are omitted for clarity. 


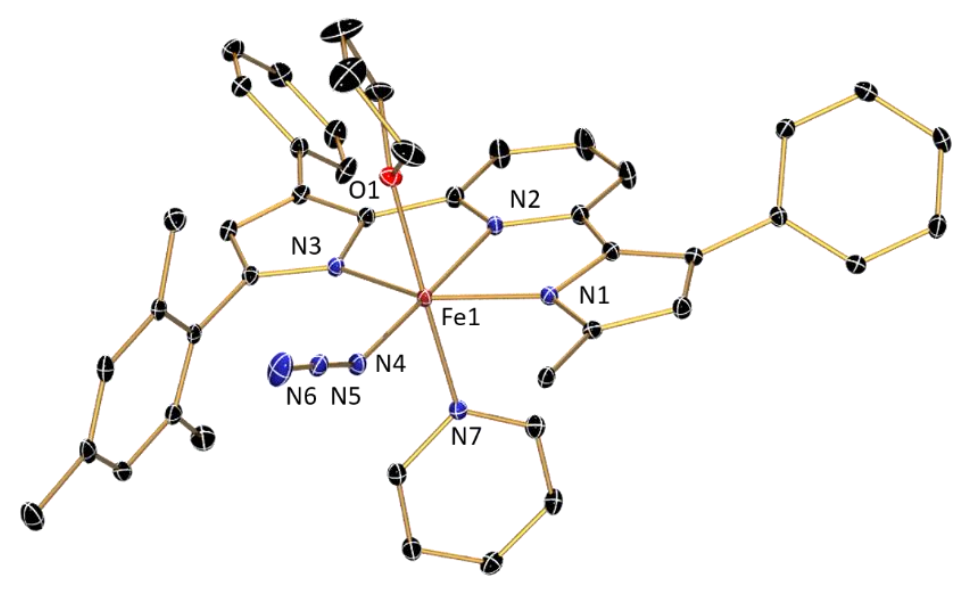

Figure A.2.6. ORTEP of $\left({ }^{\mathrm{Mes}} \mathrm{PDP}^{\mathrm{Ph}}\right) \mathrm{Fe}\left(\mathrm{N}_{3}\right)(\mathrm{py})($ thf $)$ displayed at $30 \%$ probability ellipsoids. A cocrystallized molecule of pentane and hydrogen atoms have been omitted for clarity. Only the ipso carbon of one mesityl substituent of the ${ }^{\mathrm{Mes}} \mathrm{PDP}^{\mathrm{Ph}}$ ligand has been depicted.

cm188cms: $\left({ }^{\mathrm{Mes}} \mathrm{PDP}^{\mathrm{Ph}}\right) \mathrm{Fe}(\mathrm{pyrr})(\mathrm{py})$

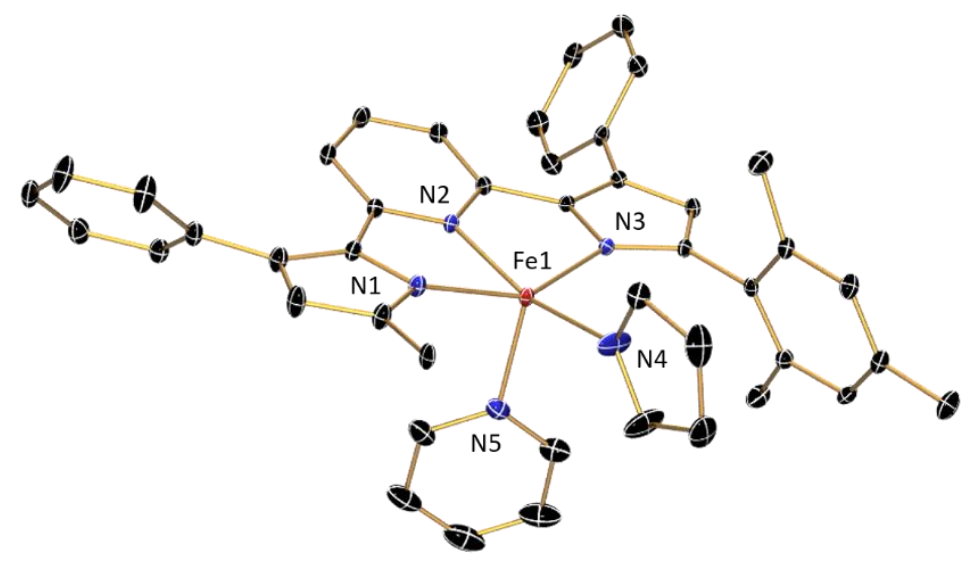

Figure A.2.7. ORTEP of $\left({ }^{\mathrm{Mes}} \mathrm{PDP}^{\mathrm{Ph}}\right) \mathrm{Fe}(\mathrm{pyyr})(\mathrm{py})$ displayed at $30 \%$ probability ellipsoids. Hydrogen atoms and cocrystallized diethyl ether have been omitted for clarity. Only the ipso carbon of one mesityl group of the ${ }^{\mathrm{Mes}} \mathrm{PDP}^{\mathrm{Ph}}$ has been depicted. 
cm189cms: $\left({ }^{\mathrm{Mes}} \mathrm{PDP}{ }^{\mathrm{Ph}}\right) \mathrm{Fe}\left(\mathrm{NH}_{2} \mathrm{Mes}\right)$

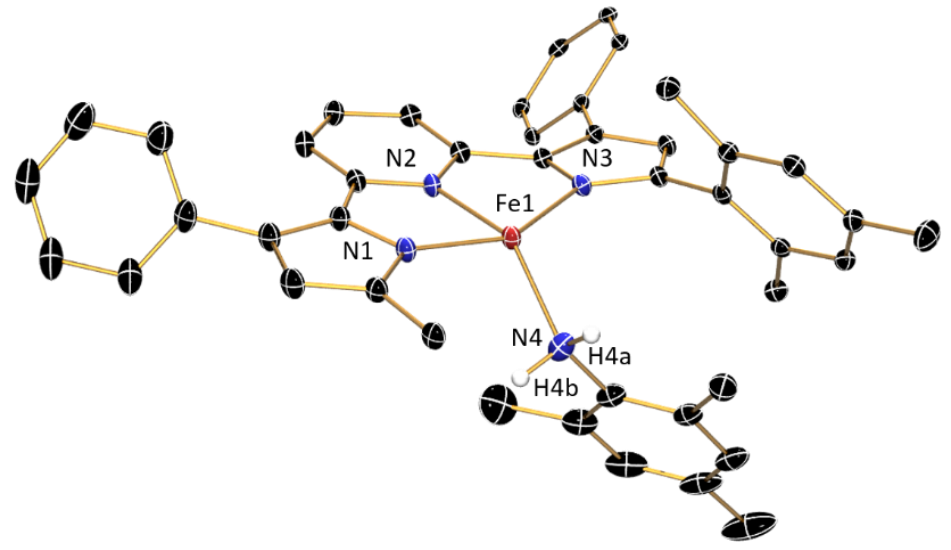

Figure A.2.8. ORTEP of $\left({ }^{\mathrm{Mes}} \mathrm{PDP}{ }^{\mathrm{Ph}}\right) \mathrm{Fe}\left(\mathrm{NH}_{2} \mathrm{Mes}\right)$ displayed at $30 \%$ probability ellipsoids. Hydrogen atoms (excluding amine protons) and cocrystallized $\left({ }^{\mathrm{Mes}} \mathrm{PDP}{ }^{\mathrm{Ph}}\right) \mathrm{Fe}\left(\mathrm{NH}_{2} \mathrm{Mes}\right)_{2}$ and toluene are removed for clarity. Only the ipso carbon of one ${ }^{\mathrm{Mes}} \mathrm{PDP}^{\mathrm{Ph}}$ mesityl group is depicted.

cm189cms: $\left({ }^{\mathrm{Mes}} \mathrm{PDP}{ }^{\mathrm{Ph}}\right) \mathrm{Fe}\left(\mathrm{NH}_{2} \mathrm{Mes}\right)_{2}$

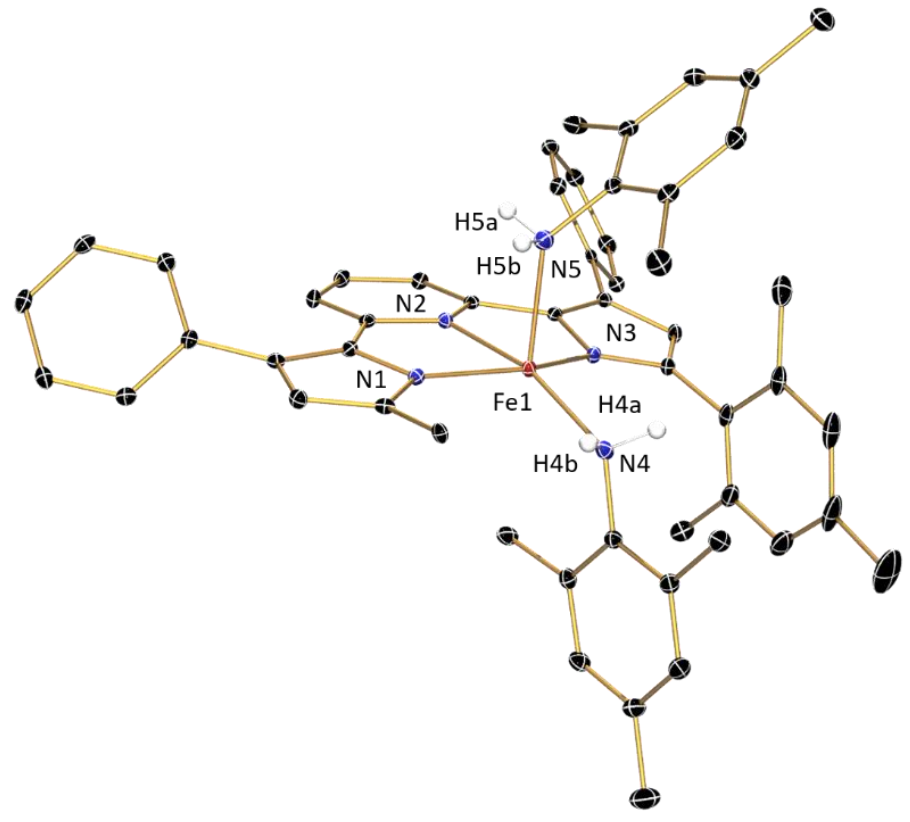

Figure A.2.9. ORTEP of $\left({ }^{\mathrm{Mes}} \mathrm{PDP}^{\mathrm{Ph}}\right) \mathrm{Fe}\left(\mathrm{NH}_{2} \mathrm{Mes}\right)_{2}$ displayed at $30 \%$ probability ellipsoids. Hydrogen atoms (excluding amine protons) and cocrystallized $\left({ }^{\mathrm{Mes}} \mathrm{PDP} \mathrm{Ph}^{\mathrm{Ph}}\right) \mathrm{Fe}\left(\mathrm{NH}_{2} \mathrm{Mes}\right)$ and toluene are removed for clarity. Only the ipso carbon of one ${ }^{\mathrm{Mes}} \mathrm{PDP} \mathrm{Ph}^{\mathrm{Ph}}$ mesityl group is depicted. 
cm239cms: $\left({ }^{2,6-C 12 P h} \mathrm{PDP}^{\mathrm{Ph}}\right) \mathrm{Fe}\left(\mathrm{OEt}_{2}\right)$

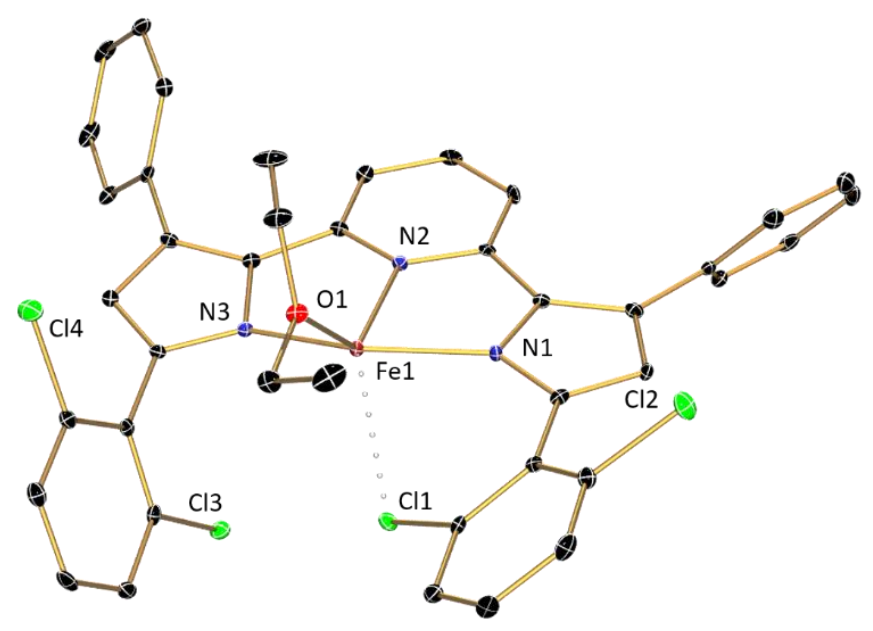

Figure A.2.10. ORTEP of (2,6-Cl2Ph $\left.\mathrm{PDP}^{\mathrm{Ph}}\right) \mathrm{Fe}\left(\mathrm{OEt}_{2}\right)$ displayed at $30 \%$ probability ellipsoids. Hydrogen atoms and cocrystallized toluene are removed for clarity.

cm254cms: $\left({ }^{\mathrm{Mes}} \mathrm{PDP}{ }^{\mathrm{Ph}}\right) \mathrm{Fe}\left(\mathrm{C}\left(\mathrm{CO}_{2} \mathrm{Me}\right)(4-\mathrm{MeOPh})\right)$

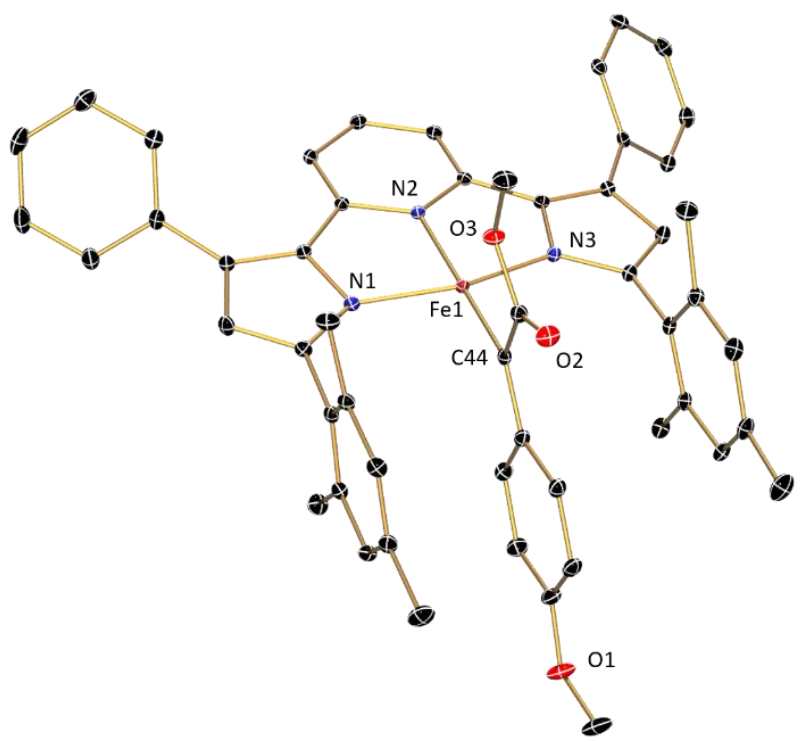

Figure A.2.11. ORTEP of $\left({ }^{\mathrm{Mes}} \mathrm{PDP}^{\mathrm{Ph}}\right) \mathrm{Fe}\left(\mathrm{C}\left(\mathrm{CO}_{2} \mathrm{Me}\right)(4-\mathrm{MeOPh})\right)$ displayed at $30 \%$ probability ellipsoids. Hydrogen atoms are omitted for clarity. 
cm272cms: $\left.\mathrm{Co}^{(2,6-\mathrm{Cl} 2 \mathrm{Ph}} \mathrm{PDP}^{\mathrm{Ph}}\right)$

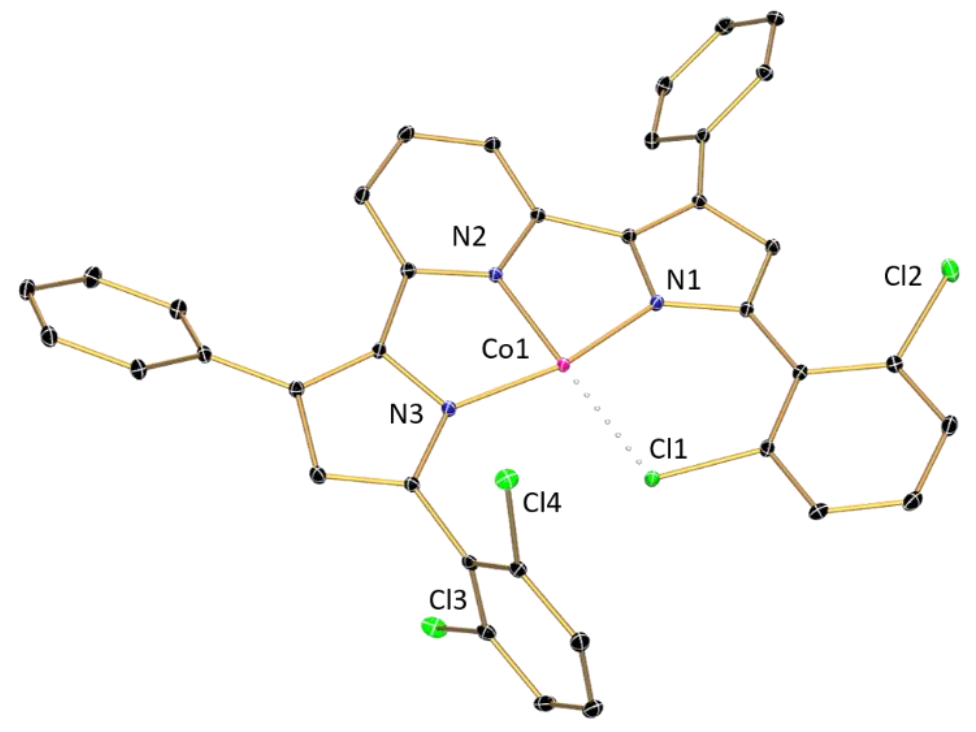

Figure A.2.12. ORTEP of $\left.\mathrm{Co}^{2,6-\mathrm{Cl} 2 \mathrm{Ph}} \mathrm{PDP} \mathrm{Ph}^{\mathrm{Ph}}\right)$ displayed at $30 \%$ probability ellipsoids. Hydrogen atoms omitted for clarity.

cm281cms: $\left({ }^{\mathrm{C} 6 \mathrm{~F} 5} \mathrm{PDP}^{\mathrm{Ph}}\right) \mathrm{Fe}\left(\mathrm{OEt}_{2}\right)_{2}$

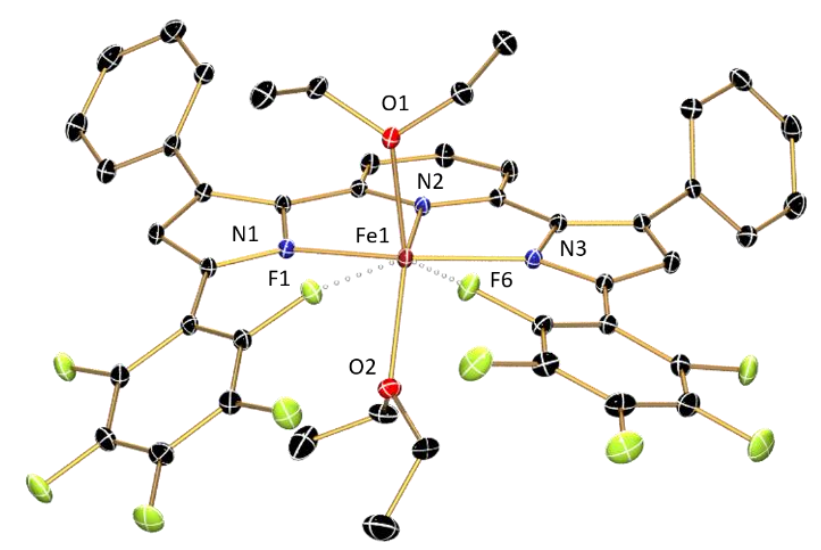

Figure A.2.13. ORTEP of $\left({ }^{\mathrm{C} 6 \mathrm{~F} 5} \mathrm{PDP}^{\mathrm{Ph}}\right) \mathrm{Fe}\left(\mathrm{OEt}_{2}\right)_{2}$ displayed at 30\% probability ellipsoids. Hydrogen atoms omitted for clarity. 
cm260cms: $\left(\mathrm{H}_{2}{ }^{\mathrm{pTol}} \mathrm{PDP}^{\mathrm{Ph}}\right) \cdot \mathrm{DMSO}$

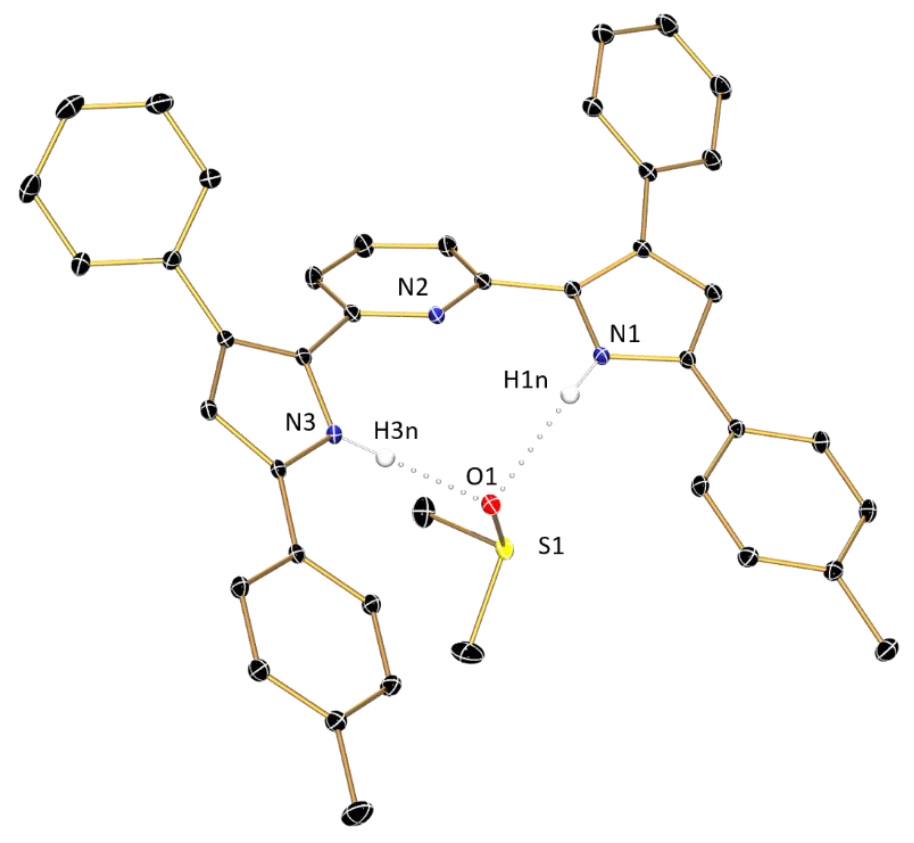

Figure A.2.14. ORTEP of $\mathrm{H}_{2}{ }^{\mathrm{pTol}} \mathrm{PDP}^{\mathrm{Ph}} \cdot \mathrm{DMSO}$ displayed at $30 \%$ probability ellipsoids. Hydrogen atoms (with exception of pyrrole $\mathrm{N} H$ hydrogens) and a second cocrystallized molecule of DMSO is excluded for clarity.

cm298cms: $\left({ }^{\mathrm{C} 6 \mathrm{~F} 5} \mathrm{PDP}^{\mathrm{Ph}}\right) \mathrm{Fe}(\mathrm{py}) 2_{2}(\mathrm{py})$

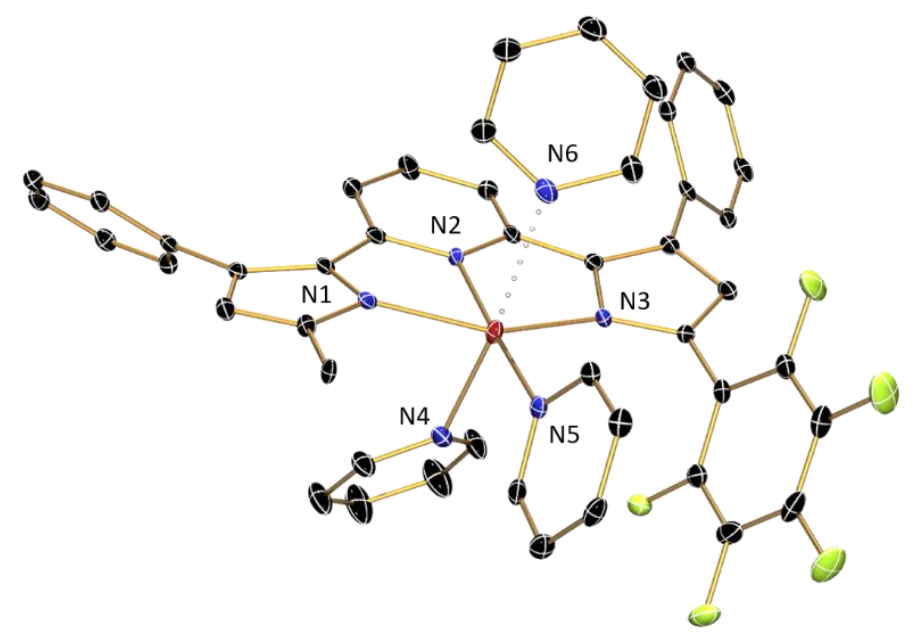

Figure A.2.15. ORTEP of ( $\left.{ }^{\mathrm{C} 6 \mathrm{~F} 5} \mathrm{PDP}^{\mathrm{Ph}}\right) \mathrm{Fe}(\mathrm{py})_{2} \cdot\left(\mathrm{C}_{6} \mathrm{H}_{5} \mathrm{~N}\right)$ displayed at $30 \%$ probability ellipsoids. Hydrogen atoms and one $\mathrm{C}_{6} \mathrm{~F}_{5}$ pyrrole substituent (with exception of the ipso carbon) have been excluded for clarity. 